Raphael Grazziano

\title{
VIRTUALIDADES E CONTRADIÇÕES NO ESPAÇO SOB PADRÕES GLOBAIS: LEED® E ARQUITETURA CORPORATIVA EM SÃO PAULO
}

\author{
Versão corrigida \\ Tese apresentada à \\ Faculdade de Arquitetura e Urbanismo da \\ Universidade de São Paulo \\ para a obtenção do título de \\ Doutor em Arquitetura e Urbanismo
}

Área de Concentração:

História e Fundamentos da Arquitetura e do Urbanismo

Orientador: Prof. Dr. Luiz Antonio Recamán Barros

São Paulo 
Autorizo a reprodução e divulgação total ou parcial deste trabalho, por qualquer meio convencional ou eletrônico, para fins de estudo e pesquisa, desde que citada a fonte.

Todos os esforços foram feitos para reconhecer as fontes autorais e de imagem neste trabalho.

raphael.grazziano@usp.br

Exemplar revisado e alterado em relação à versão original, sob responsabilidade do autor e anuência do orientador. A versão original, em formato digital, ficará arquivada na Biblioteca da Faculdade.

São Paulo, 8 de dezembro de 2019

Esta tese contou com apoio da Coordenação de Aperfeiçoamento de Pessoal de Nível Superior (CAPES) nos níveis de Mestrado (01/09/2014 a 31/11/2015) e de Doutorado (01/02/2016 a 28/02/2017) e da Fundação de Amparo à Pesquisa do Estado de São Paulo (FAPESP) nas linhas de fomento Doutorado Direto (processo n. 2016/21407-0) e Bolsa Estágio de Pesquisa no Exterior (processo n. 2017/16322-8).

Catalogação na Publicação

Serviço Técnico de Biblioteca

Faculdade de Arquitetura e Urbanismo da Universidade de São Paulo

Grazziano, Raphael

Virtualidades e contradições no espaço sob padrões globais: LEED ${ }^{\circledR}$ e arquitetura corporativa em São Paulo / Raphael Grazziano; orientador Luiz Antonio Recamán Barros. - Versão corrigida - São Paulo, 2019.

440 .

Tese (Doutorado) - Faculdade de Arquitetura e Urbanismo da Universidade de São Paulo. Área de concentração: História e Fundamentos da Arquitetura e do Urbanismo.

1. História da Arquitetura - Século XXI. 2. Arquitetura Sustentável. 3. Edifícios Comerciais. 4. Desenho Urbano. 5. Certificados de Sustentabilidade Ambiental. 6. Tecnologia (Arquitetura).

7. Teoria da Arquitetura.

I. Barros, Luiz Antonio Recamán, orient. II. Título.

Elaborada eletronicamente através do formulário disponível em: <http://www.fau.usp.br/fichacatalografica/> 
GRAZZIANO, Raphael. Virtualidades e contradições no espaço sob padrões globais: LEED ${ }^{\infty}$ e arquitetura corporativa em São Paulo. Tese de Doutorado, Faculdade de Arquitetura e Urbanismo da Universidade de São Paulo. São Paulo, 2019.

Aprovado em

Banca Examinadora

$\operatorname{Prof}(\mathrm{a}) . \operatorname{Dr}(\mathrm{a})$

Instituição

Julgamento

Assinatura

Prof(a). Dr(a)

Instituição

Julgamento

Assinatura

$\operatorname{Prof}(a) . \operatorname{Dr}(a)$

Instituição

Julgamento

Assinatura

Prof(a). Dr(a)

Instituição

Julgamento

Assinatura

$\operatorname{Prof}(a) . \operatorname{Dr}(a)$

Instituição

Julgamento

Assinatura 



\section{AGRADECIMENTOS}

Agradeço a meu orientador Luiz Recamán, que me acompanhou durante boa parte da vida acadêmica, com quem aprendo a cada conversa e que me incentivou a um olhar rente ao objeto; a Leandro Medrano e aos colegas do grupo de pesquisa PC3, que tanto compartilharam esse percurso; aos professores presentes nas bancas de passagem e de qualificação, com suas críticas e incentivos fundamentais no decorrer da pesquisa: Francisco Comaru, Joana Gonçalves, Maria Lúcia Refinetti Martins e Paulo Sinisgalli; a Keller Easterling, que atenciosamente me recebeu e supervisionou durante a pesquisa no exterior; a Hugo Segawa e Nader Vossoughian, pelos debates a respeito da pesquisa.

Agradeço aos entrevistados, cuja generosidade dos relatos trouxe um ponto de vista privilegiado para a pesquisa: Adriano Sartori, Arathi Gowda, Chris Chatto, David Gottfried, Felipe Faria, Flávia Marcondes, Guido Petinelli, Jan Beyea, José Goldemberg, José Moulin, Kristin Hopkins-Klegg, Luciana Maki, Luiz Gonzaga Nogueira Jr., Marcos Casado, Peter Templeton, Robert Berkebile, Shanta Tucker, Siegbert Zanettini, Takuji Nakashima, Tania Yang e Thassanee Wanick. Fiz todos os esforços para me manter fiel a seus pontos de vista na transposição ao texto.

Agradeço a Hannah Machado e Miguel Jacob pela produção de dois mapas a partir dos dados que haviam organizado sobre o preço médio do solo em São Paulo; a Cristina Wehba pela gentil cessão de parte de seu material de pesquisa; a Alessandro Muzi, Frederico Costa, Guilherme Pianca, Leonardo Musumeci, Marcela Ferreira, Mariana Strassacapa, Rafael Urano e Victor Próspero, que me ajudaram com inúmeras referências ao longo desses anos; a Gabriel Kogan, pela cuidadosa edição que realizou em materiais prévios desta pesquisa; a Marcos Silva e Alfonso Simelio Jurado por me auxiliarem com importantes trâmites relacionados ao estágio no exterior.

Agradeço aos amigos Ana e Otávio Monteiro Nagano, Tiago Martinelli, Ivan Souto e Luiz Paulo Vital Bueno, com quem dividi a pesquisa incontáveis vezes e que viram muitos dos caminhos tomados ao longo do tempo; à companhia de Alexandre Sato, Bruno Uehara, Caio Yuzo, Lucas Colebrusco, Priscyla Gomes e Renata Mori; a meu pai Paulo e à Eliane, pelo apoio e estímulo; a minha mãe Lúcia e meu irmão Gustavo, que me amparam cotidianamente nos mais variados graus de relação com o trabalho; a Daiana Buffulin, com amor, pela torcida e carinho, sempre. 


\section{RESUMO}

GRAZZIANO, Raphael. Virtualidades e contradições no espaço sob padrões globais: LEED ${ }^{\circledR}$ e arquitetura corporativa em São Paulo. 2019. 440p. Tese (Doutorado) - Faculdade de Arquitetura e Urbanismo, Universidade de São Paulo. São Paulo, 2019.

O Leadership in Energy and Environmental Design (LEED ${ }^{\circledR}$ ) é um sistema norte-americano criado em 1998 para avaliar parâmetros de sustentabilidade em edifícios. Ele é gerido por uma organização não governamental, o US Green Building Council (USGBC ${ }^{\circledR}$ ), fundado no início dos anos 1990. Em razão da relevância alcançada pelo sistema, há diversos autores que discutem seu desempenho técnico e seu impacto para a sustentabilidade. A realização desta pesquisa no campo de história e fundamentos da arquitetura e do urbanismo coloca, entretanto, outros debates e instrumentos de trabalho. Os aspectos técnicos do sistema LEED ${ }^{\circledR}$ são examinados com o objetivo de explicitar suas premissas de operação, por meio da hipótese de que elas teriam impacto nas disciplinas da arquitetura e do urbanismo, sobretudo nas estratégias de projeto. Para tanto, o trabalho inquire o sistema LEED $^{\circledR}$ ao longo de cinco partes. Na primeira parte, sua história é construída pela identificação dos agentes envolvidos em sua criação e das posições ali em disputa. Na segunda, é realizado um esclarecimento conceitual do sistema $\mathrm{LEED}^{\circledR}$ pelo estabelecimento do campo de referências com que seus criadores trabalham, incluindo-o dentro do âmbito da modernização ecológica e do ecocapitalismo. Na terceira, são elaborados seus impactos arquitetônico-urbanísticos, tanto em sentido virtual - de seu horizonte de potencialidades projetuais implícito -, quanto empírico, este detalhado com escopo em dois conjuntos de edifícios localizados na marginal Pinheiros, em São Paulo, certificados pelo sistema LEED ${ }^{\oplus}$ Core \& Shell. Na quarta parte, igual procedimento é realizado, mas agora a respeito do sistema LEED ${ }^{\circledR}$ for Neighborhood Development. Por fim, na quinta parte, são elaborados os nexos entre os diversos padrões em circulação no mercado e a produção arquitetônico-urbanística das cidades globais. Como resultado, pôde-se explicitar como o LEED ${ }^{\circledR}$ Core \& Shell reafirma determinadas características da torre corporativa norte-americana, como o LEED ${ }^{\circledast}$ for Neighborhood Development configura o New Urbanism dentro de um padrão técnico e como o mercado tensiona as questões arquitetônico-urbanísticas para cumprir preceitos não ambientais de projeto. O LEED ${ }^{\circledR}$ é interpretado como uma tecnologia do neoliberalismo, por dar lastro às trocas financeiras globais ao oferecer parâmetros de comparabilidade de projetos e de mensuração de seus atributos.

Palavras-chave: História da Arquitetura - Século XXI. Arquitetura Sustentável. Edifícios Comerciais. Desenho Urbano. Certificados de Sustentabilidade Ambiental. Tecnologia (Arquitetura). Teoria da Arquitetura. 


\section{ABSTRACT}

GRAZZIANO, Raphael. Virtualities and contradictions in the space under global patterns: LEED ${ }^{\circ}$ and corporate architecture in São Paulo. 2019. 440p. Doctoral thesis - Faculdade de Arquitetura e Urbanismo, Universidade de São Paulo. São Paulo, 2019.

Leadership in Energy and Environmental Design $\left(\right.$ LEED $\left.^{\circ}\right)$ is a North American system launched in 1998 to assess sustainability parameters in buildings. It is managed by a non-governmental organization, the US Green Building Council $\left(\mathrm{USGBC}^{\circledR}\right)$, that was formed in the early 1990s. The system has obtained global relevance, and for this reason it has been a case study for several authors, who discuss the system's technical performance and sustainability impact. Nevertheless, as this research is developed in the field of history and tenets of architecture and urbanism, other debates and scientific instruments arise. LEED ${ }^{\otimes}$ 's technical aspects are examined in order to clarify its operation premises, following the research hypothesis that these premises would have impact in the disciplines of architecture and urbanism, especially in their design strategies. Therefore, the thesis inquires the system in five parts. In the first part, it is reported the system's history by means of identifying the agents involved in its formation and the positions disputed at that time. In the second part, it is carried out a conceptual elucidation of LEED ${ }^{\circledR}$ by means of establishing the references used by its founders, including it in the discussion of ecological modernization and ecocapitalism. In the third part, LEED $^{\otimes}$ 's architectural and urbanistic impacts are formulated. On the one hand, the impacts are virtual - that is to say, they are related to the horizon of design potentialities implicit to LEED $^{\circledR}$-, while on the other hand they are empirical, an aspect that is detailed using two clusters of buildings located in marginal Pinheiros, in São Paulo, certified by $\mathrm{LEED}^{\circledR}$ Core \& Shell. In the fourth part, the same methodology is applied, but this time to LEED ${ }^{\circledR}$ for Neighborhood Development. At last, in the fifth part, the connections between patterns and the architectural and urbanistic production of global cities are formulated. The research findings revealed how LEED $^{\circledR}$ Core \& Shell may support certain features of the North American corporate tower, how LEED ${ }^{\circledR}$ for Neighborhood Development sets the New Urbanism in a technical pattern and how the market may stress architectural and urbanistic questions in order to fulfill non-environmental design criteria. LEED $^{\circ}$ is read as a technology of neoliberalism, as it underlies global financial exchanges by offering parameters for the comparability between projects and mensuration of their features.

Keywords: History of Architecture - 21st century. Sustainable Architecture. Commercial Buildings. Urban Design. Green Certifications. Technology (Architecture). Theory of Architecture. 


\section{LISTA DE FIGURAS}

1.1 Estrutura típica de um crédito do sistema LEED ${ }^{\circledR}$. Fonte: LEED $^{\circledR} \mathrm{NC}$ v.3, revisão de 2011. Inclui intervenções do autor. empreendimentos. Fonte: LEED Project Directory, 4 jan 2019. Elaborado pelo autor. Certificados LEED $^{\circledR}$ nos Estados Unidos, organizados por sistema. Amostra de 61.777 empreendimentos. Fonte: LEED Project Directory, 4 jan 2019. Elaborado pelo autor. empreendimentos. Fonte: LEED Project Directory, 4 jan 2019. Elaborado pelo autor.

3. Elaborado e classificado pelo autor. Regeneration, via Flickr, 5 out 2008. Godamanna. Direitos de Aitken Spence. Fonte: http://plus.usgbc.org/in-the-leed/. Acesso em 6 nov 2018. "Building green: the emerging geography of LEED-certified buildings and professionals". Austrália, Áustria, Bolívia, Brasil, Bulgária, Canadá, Cazaquistão, Chile, China, Colômbia, Costa Rica, Croácia, Egito, El Salvador, Emirados Árabes Unidos, Eslovênia, Espanha, Estados Unidos, Filipinas, Finlândia, França, Gana, Grécia, Guatemala, Holanda, Hong Kong, Hungria, Ilhas Maurício, Islândia, Índia, Indonésia, Irlanda, Itália, Jordânia, Kuwait, Líbano, Luxemburgo, Malásia, Marrocos, México, Montenegro, Namíbia, Nova Zelândia, Nicarágua, Noruega, Palestina, Panamá, Paquistão, Paraguai, Peru, Polônia, Qatar, Quênia, Reino Unido, Ruanda, Sérvia, Singapura, Sri Lanka, Suécia, Suíça, Taiwan, Tanzânia, Turquia, Uruguai e Vietnã. Ao fim da lista, consta ainda o logotipo do World GBC. Levantamento realizado em 4 jan 2019. empreendimentos. Fonte: LEED Project Directory, 4 jan 2019. Elaborado pelo autor. 

empreendimentos. Fonte: LEED Project Directory, 4 jan 2019. Elaborado pelo autor. empreendimentos. Fonte: LEED Project Directory, 4 jan 2019. Elaborado pelo autor. empreendimentos. Fonte: LEED Project Directory, 4 jan 2019. Elaborado pelo autor.

3.1 Membros-fundadores do GBC Brasil, organizados por nível de contribuição. \& Wakefield em São Paulo. Fonte: "10 anos fazendo história", Revista GBC Brasil, n. 14, p. 54. Identificação pelo autor. 4 jan 2019. Elaborado pelo autor.

3.4 Registros brasileiros no LEED ${ }^{\circledR}$, organizados por sistema. Amostra de 1342 empreendimentos. Fonte: LEED Project Directory (USGBC), com correções pelo autor em Empreendimentos LEED (GBC Brasil), 4 jan 2019. Elaborado pelo autor.

3.5 Certificados LEED ${ }^{\circledR}$ no Brasil, organizados por sistema. Amostra de 533 empreendimentos. Fonte: LEED Project Directory (USGBC), com correções pelo autor a partir de Empreendimentos LEED (GBC Brasil), 4 jan 2019. Elaborado pelo autor. empreendimentos. Fonte: LEED Project Directory (USGBC), com correções pelo autor a partir de Empreendimentos LEED (GBC Brasil), 4 jan 2019. Elaborado pelo autor. Brasil, 4 jan 2019. Classificação realizada pelo GBC Brasil. Gráfico elaborado pelo autor. Desempenho dos países com mais certificados LEED ${ }^{\circledR}$, fora dos Estados Unidos, por quantidade de empreendimentos. Na legenda, países organizados por ordem de classificação em 2018. Entre parênteses, a quantidade de empreendimentos certificados até 2018. Fonte: LEED Project Directory (USGBC), 4 jan 2019. Elaborado pelo autor. Global Green Building Entrepreneurship Award, concedida pelo World GBC, em 13 nov 2012. Fonte: Pitanga Comunicação, via Flickr.

3.10 Fernando Henrique Cardoso inaugura a conferência e feira Greenbuilding de 2014. À direita, o cofundador do GBC Brasil, José Moulin. Fonte: Revista GBC, n. 2, dez 2014, p. 24. 
3.11 Thassanee Wanick, fundadora do GBC Brasil, na campanha One Degree Less. Fonte: "Green Building Council incentiva o uso de telhado branco", Casa, 22 abr 2010.

3.12 Agência do banco Real-ABN AMRO na Granja Viana, primeiro edifício certificado no Brasil. Projeto do corpo técnico do banco. Fonte: "Sustentável desde o canteiro", Téchne, n. 125, ago 2007.

3.13 aflalo/gasperini arquitetos, Rochaverá Corporate Towers (1999/2008-2012). Primeiro conjunto corporativo de grande porte certificado no Brasil, em foto com apenas as duas primeiras torres inauguradas (2008). Fonte: Nelson Kon, acervo online.

3.14 aflalo/gasperini arquitetos e KPF, Ventura Corporate Towers (2005/2008-2010). Fonte: Tishman Speyer, acervo online.

3.15 aflalo/gasperini arquitetos, Eldorado Business Tower (1998/2007). Primeiro edifício nível Platinum da América Latina. Fonte: Daniel Ducci, via Galeria de Arquitetura.

3.16 Bairro Ilha Pura, primeiro LEED ND no Brasil (c2011/2016). Fonte: Luciano Pádua, "Vila Olímpica: encalhe monumental", Exame, 8 jul 2016. Fernando Henrique Cardoso recebe certificado de Thassanee Wanick durante evento de inauguração da primeira fase do Rochaverá Corporate Towers (6 fev 2009). Fonte: Weber, via Flickr. Marina Silva na 6 ${ }^{a}$ Greenbuilding, em 2015. Da esquerda para a direita, a segunda pessoa é Thassanee Wanick; ao centro, Marina Silva; logo a seguir da palestrante, José Moulin Netto. Fonte: Revista GBC, n. 6, out-nov 2015, p26. Sérgio Moro na 9a Greenbuilding, em seu primeiro evento público após sua nomeação como ministro (5 nov 2018). Fonte: Geraldo Bubniak/AGB, via Katna Baran, "Não pretendo jamais disputar uma eleição, diz Moro", Folha de S. Paulo. LEED Project Directory, 4 jun 2019. Elaborado pelo autor.

5.2 Al Waseel Hills, em Riad, capital da Arábia Saudita, onde se encontram 615 certificados LEED ${ }^{\circledR}$ Homes. Fonte: Joannou \& Paraskevaides Group, 23 jan 2017. 191 residências em sua fase final. O projeto é do escritório HOK e também se situa em Riad. Em suas imediações, encontra-se o Centro de Estudos e Pesquisas de Petróleo Rei Abdullah, do Zaha Hadid Architects. Fonte: HOK, 31 out 2012, acervo online.

5.4 Comparação da proporção de aumento do valor médio de locação de edifícios de escritório certificados pelo LEED ${ }^{\circledR}$, segundo dados disponíveis na literatura. Elaborado pelo autor. Fonte: Desempenho LEED, 2016. Redesenhado pelo autor. 

Janeiro. Fonte: Desempenho LEED, 2016. Redesenhado pelo autor. pelo LEED $^{\circledR}$, segundo dados disponíveis na literatura. Elaborado pelo autor. pelo LEED ${ }^{\circledR}$. Redesenhado pelo autor. certificados pelo LEED ${ }^{\circ}$. Redesenhado pelo autor.

5.10 Comparação de estimativas de custos de edifícios certificados pelo LEED ${ }^{\circledR}$, segundo dados disponíveis na literatura. O gráfico indica os aumentos médios inferiores e superiores estimados nas referências. Elaborado pelo autor.

5.11 Participação de edifícios certificados LEED $^{\oplus}$ no mercado corporativo de alto padrão, em São Paulo e Rio de Janeiro. Fonte: Desempenho LEED, 2016. Editado e redesenhado pelo autor.

5.12 Distribuição de edifícios certificados com LEED ${ }^{\bullet}$ CS v3, no mundo, de acordo com sua pontuação. Amostra de 3.088 projetos. Fonte: LEED Project Directory, 4 jan 2019. Elaborado pelo autor.

5.13 Distribuição de edifícios certificados com LEED ${ }^{\circ} \mathrm{NC}$ v3, no mundo, de acordo com sua pontuação. Amostra de 9.139 projetos. Fonte: LEED Project Directory, 4 jan 2019. Elaborado pelo autor.

5.14 Distribuição de edifícios certificados com LEED ${ }^{\circledR}$ CS v3, no Brasil, de acordo com sua pontuação. Amostra de 193 projetos. Fonte: LEED Project Directory, 4 jan 2019. Elaborado pelo autor.

5.15 Distribuição de edifícios certificados com LEED $^{\circledR} \mathrm{NC}$ v3, no Brasil, de acordo com sua pontuação. Amostra de 144 projetos. Fonte: LEED Project Directory, 4 jan 2019.

Elaborado pelo autor.

5.16 Gráfico com quantidade de empreendimentos por capitais brasileiras. Fonte: LEED Project Directory, 4 jan 2019.

5.17 Mancha urbana da Região Metropolitana de São Paulo com empreendimentos certificados. Amostra de 197 empreendimentos. Fonte: Google Earth, LEED Project Directory (4 jun 2019).

Elaborado pelo autor.

5.18 Mancha urbana de Rio de Janeiro com empreendimentos certificados. Amostra de 67 empreendimentos. Fonte: Google Earth, LEED Project Directory (4 jun 2019). Elaborado pelo autor.

5.19 Mancha urbana da Região Metropolitana de Curitiba com empreendimentos certificados. Amostra de 24 empreendimentos. Fonte: Google Earth, LEED Project Directory (4 jun 2019). Elaborado pelo autor. 
5.20 Empreendimentos $\mathrm{LEED}^{\oplus}$ e preço médio do $\mathrm{m}^{2}$ dos terrenos por quadra fiscal no município de São Paulo. Divisão em decis. Fonte: Dados IPTU/PMSP 2016; LEED Project Directory, 4 jun 2019. Base cartográfica: MDC/SMDU; Emplasa 2007. Elaborado por Hannah Machado e Miguel Jacob. Organização dos ativos de FIIs por Isabel Pinto Alvarez com elaboração de Alex da Silva Dias Américo, via Alvarez, "A produção de espaços financeirizados na metrópole de São Paulo", 260. Edição final e levantamento de empreendimentos LEED $^{\circledR}$ pelo autor.

5.21 Empreendimentos $\mathrm{LEED}^{\circ}$ e preço médio do $\mathrm{m}^{2}$ dos terrenos por quadra fiscal no município de São Paulo. Divisão em Natural Breaks (Jenks). Fonte: Dados IPTU/PMSP 2016; LEED Project Directory, 4 jun 2019. Base cartográfica: MDC/SMDU; Emplasa 2007. Elaborado por Hannah Machado e Miguel Jacob. Organização dos ativos de FIIs por Isabel Pinto Alvarez com elaboração de Alex da Silva Dias Américo, via Alvarez, "A produção de espaços financeirizados na metrópole de São Paulo", 260. Edição final e levantamento de empreendimentos $\mathrm{LEED}^{\circledR}$ pelo autor.

7.1 Área construída bruta certificada pelo LEED ${ }^{\circledR}$ fora dos Estados Unidos, divisão por sistema. Fonte: LEED Project Directory (USGBC), com correções pelo autor a partir de Empreendimentos LEED (GBC Brasil), 4 jan 2019. Elaborado pelo autor. Directory (USGBC), com correções pelo autor a partir de Empreendimentos LEED (GBC Brasil), 4 jan 2019. Elaborado pelo autor. Distribuição das áreas dos edifícios certificados no sistema LEED ${ }^{\circledR}$ CS. Fonte: LEED Project Directory (USGBC), com correções pelo autor a partir de Empreendimentos LEED (GBC Brasil), 4 jan 2019. Elaborado pelo autor. Buckminster Fuller, 4D Lightful Tower (1928). Fonte: Foster e Fernández-Galiano, AV Monografias, n. 143, 5. Archive. n. 143,112 . edible city. Fonte: Cuthbert, Understanding cities, 182. world, 10 . 
7.11 Kenneth Yeang, torre Mesiniaga (c1989/1992). Vista geral. Fonte: NG KL/Aga Khan Trust for Culture, 231 via Archdaily.

7.12 Kenneth Yeang, torre Mesiniaga (c1989/1992). Elevação sudoeste. Sem escala. Fonte: Acervo do arquiteto, via Archdaily.

7.13 Kenneth Yeang, torre Mesiniaga (c1989/1992). Planta de um pavimento de escritórios. Sem escala. Fonte: Acervo do arquiteto, via Archdaily.

7.14 Foster + Partners, Commerzbank (1991/1997). Corte. Sem escala. Fonte: Foster + Partners, acervo online.

7.15 Foster + Partners, Commerzbank (1991/1997). Planta de pavimentos dos escritórios. Sem escala. Fonte: Foster + Partners, acervo online.

7.16 Foster + Partners, Commerzbank (1991/1997). Planta do pavimento térreo da torre. Sem escala. Fonte: Foster + Partners, acervo online.

7.17 Foster + Partners, 30 St Mary Axe (1997/2004). Corte. Sem escala. Fonte: Foster + Partners, acervo online.

7.18 Foster + Partners, 30 St Mary Axe (1997/2004) Planta do pavimento térreo da torre. Sem escala. Fonte: Foster + Partners, acervo online.

7.19 Foster + Partners, 30 St Mary Axe (1997/2004). Planta dos pavimentos de escritório, do topo ao térreo. Sem escala. Fonte: Foster + Partners, acervo online.

7.20 BNIM, MSU EPICenter (1997). Fonte: BNIM, acervo online.

7.21 Fox \& Fowle, 4 Times Square (1995/1999). Fonte: FX Collaborative, acervo online. março 2000 . março 2000.

7.25 Fox \& Fowle, 4 Times Square (1995/1999). Plantas do térreo, oitavo e quadragésimo oitavo pavimentos. Sem escala. Fonte: Architectural Record, março 2000. cleaning up Times Square", The New York Times, 16 out 2015. Burgee (s/d). Fonte: The Skyscraper Museum via Urban Omnibus. Architecture Week. 

dos arquitetos via Architecture Week.

7.30 Cook Fox, One Bryant Park (2004/2009). Croqui do empreendimento, incluindo o 4 Times Square. Fonte: Acervo dos arquitetos via Archdaily.

7.31 Cook Fox, One Bryant Park (2004/2009). Esquema de captação e reaproveitamento de água. Sem escala. Fonte: Detail, mai 2009.

7.32 Cook Fox, One Bryant Park (2004/2009). Esquema de iluminação e controle térmico. Sen escala. Fonte: Detail, mai 2009.

7.33 Cook Fox, One Bryant Park (2004/2009). Vista a partir da 42nd East St. Fonte: Cook Fox, acervo online.

7.34 Cook Fox, One Bryant Park (2004/2009). Detalhe da fachada. Fonte: Acervo dos arquitetos, via Archdaily.

7.35 SOM, One World Trade Center (2005/2014). Fonte: SOM, acervo online.

7.36 Foster + Partners, torre Hearst (2000/2006). Fonte: Acervo do autor, 2018.

7.37 KPF, 10 Hudson Yards (2010/2016). Fonte: Dan Howarth/Dezeen.

7.38 Renzo Piano Building Workshop e FXCollaborative, The New York Times (2000/2007). Fonte: John W. Cahill, via Council of Tall Buildings and Urban Habitat (CTBUH).

8.1 Imagem aérea do setor Chucri Zaidan. Fonte: Geosampa, 1954. Fonte: Geosampa, implantações dos empreendimentos. preliminar. Sem escala. Fonte: Fonte: Corbioli, "Fachadas inclinadas atendem à estética e à lógica do mercado", Projeto Design, abr 2009, 52. preliminar. Sem escala. Fonte: Fonte: Corbioli, "Fachadas inclinadas atendem à estética e à lógica do mercado", Projeto Design, abr 2009, 52. preliminar. Sem escala. Fonte: Fonte: Corbioli, "Fachadas inclinadas atendem à estética e à lógica do mercado", Projeto Design, abr 2009, 52. 
8.11 aflalo/gasperini arquitetos, Rochaverá Corporate Towers (1999/2008-2012). Implantação, versão preliminar. Sem escala. Fonte: Fonte: Corbioli, "Fachadas inclinadas atendem à estética e à lógica do mercado", Projeto Design, abr 2009, 53.

8.12 aflalo/gasperini arquitetos, Rochaverá Corporate Towers (1999/2008-2012). Implantação, versão preliminar. Sem escala. Fonte: Fonte: Corbioli, "Fachadas inclinadas atendem à estética e à lógica do mercado", Projeto Design, abr 2009, 53.

8.13 aflalo/gasperini arquitetos, Rochaverá Corporate Towers (1999/2008-2012). Implantação, versão preliminar. Sem escala. Fonte: Fonte: Corbioli, "Fachadas inclinadas atendem à estética e à lógica do mercado", Projeto Design, abr 2009, 53.

8.14 Diagrama do Rochaverá Corporate Towers. Elaborado pelo autor.

8.15 aflalo/gasperini arquitetos, Rochaverá Corporate Towers (1999/2008-2012). Implantação. Sem escala. Fonte: Pura Arquitetura, acervo online.

8.16 aflalo/gasperini arquitetos, Rochaverá Corporate Towers (1999/2008-2012). $1^{\circ}$ subsolo. Sem escala. Fonte: Pura Arquitetura, acervo online.

8.17 aflalo/gasperini arquitetos, Rochaverá Corporate Towers (1999/2008-2012). Pavimento-tipo. Sem escala. Fonte: aflalo/gasperini arquitetos, acervo online.

8.18 aflalo/gasperini arquitetos, Rochaverá Corporate Towers (1999/2008-2012). Corte da implantação. Sem escala. Fonte: Pura Arquitetura, acervo online.

8.19 aflalo/gasperini arquitetos, Rochaverá Corporate Towers (1999/2008-2012). Elevação das torres A e B. 269 Sem escala. Fonte: Pura Arquitetura, acervo online.

8.20 aflalo/gasperini arquitetos, Rochaverá Corporate Towers (1999/2008-2012). Planta do $18^{\circ}$ pavimento das torres A e B. Sem escala. Fonte: Pura Arquitetura, acervo online.

8.21 aflalo/gasperini arquitetos, Rochaverá Corporate Towers (1999/2008-2012). Detalhes de fachadas das torres A e B. Sem escala. Fonte: Pura Arquitetura, acervo online. aflalo/gasperini arquitetos, Rochaverá Corporate Towers (1999/2008-2012). Vista a partir da marginal Pinheiros. Fonte: aflalo/gasperini arquitetos, acervo online.

8.23 aflalo/gasperini arquitetos, Rochaverá Corporate Towers (1999/2008-2012). Vista a partir do cruzamento das avenidas João Dória e Dr. Chucri Zaidan. Fonte: aflalo/gasperini arquitetos, acervo online.

8.24 aflalo/gasperini arquitetos, Rochaverá Corporate Towers (1999/2008-2012). Vista a partir da praça interior. Fonte: aflalo/gasperini arquitetos, acervo online.

8.25 aflalo/gasperini arquitetos, Rochaverá Corporate Towers (1999/2008-2012). Vista a partir dos fundos do empreendimento. Fonte: Acervo do autor, 12 nov 2015.

8.26 aflalo/gasperini arquitetos, Rochaverá Corporate Towers (1999/2008-2012). Vista da lateral. Fonte: Acervo do autor, 6 set 2018 . 

garagem. Fonte: Acervo do autor, 16 ago 2019.

8.28 Diagrama do Morumbi Corporate. Elaborado pelo autor.

8.29 aflalo/gasperini arquitetos, Morumbi Corporate (2008/2013). Implantação. Sem escala. Fonte: Corbioli, "Supremacia do espaço público", Projeto Design, n.409.

8.30 aflalo/gasperini arquitetos, Morumbi Corporate (2008/2013). Mezanino de serviços. Sem escala. Fonte: Archdaily.

8.31 aflalo/gasperini arquitetos, Morumbi Corporate (2008/2013). Pavimento-tipo das torres. Sem escala. Fonte: Corbioli, “Supremacia do espaço público”, Projeto Design, n.409.

8.32 aflalo/gasperini arquitetos, Morumbi Corporate (2008/2013). Corte longitudinal. Sem escala. Fonte: Archdaily.

8.33 aflalo/gasperini arquitetos, Morumbi Corporate (2008/2013). Elevação frontal. Sem escala. Fonte: Archdaily.

8.34 aflalo/gasperini arquitetos, Morumbi Corporate (2008/2013). Vista frontal, com Rochaverá Corporate Towers à direita. Fonte: Ana Mello, jul 2014, acervo online.

8.35 aflalo/gasperini arquitetos, Morumbi Corporate (2008/2013). Vista do edifício-garagem. Fonte: Acervo do autor, 16 ago 2019.

8.36 aflalo/gasperini arquitetos, Morumbi Corporate (2008/2013). Croqui de possível integração com o Rochaverá, pela leitura dos arquitetos. Fonte: Archdaily.

8.37 Diagrama do WT Morumbi. Elaborado pelo autor.

8.38 aflalo/gasperini arquitetos, WT Morumbi (2009/2016). Implantação. Sem escala. Fonte: Acervo dos arquitetos, via Archdaily.

8.39 aflalo/gasperini arquitetos, WT Morumbi (2009/2016). Planta do décimo pavimento. Sem escala. Fonte: Acervo dos arquitetos, via Archdaily.

8.40 aflalo/gasperini arquitetos, WT Morumbi (2009/2016). Corte longitudinal. Sem escala. Fonte: Acervo dos arquitetos, via Archdaily.

8.41 aflalo/gasperini arquitetos, WT Morumbi (2009/2016). Vista a partir da marginal Pinheiros. Fonte: Leonardo Finotti, acervo online.

8.42 aflalo/gasperini arquitetos, WT Morumbi (2009/2016). Fosso paisagístico. Fonte: Acervo do autor, 27 ago 2016.

8.43 Alteração em andamento da entrada do WT Morumbi, em razão de desapropriação. Elaborado pelo autor a partir de Wehba, "Novas relações de produção imobiliária na metrópole do século XXI", 140. Imagem: Google Earth, 10 mai 2018. 
8.46 Imagem aérea do setor Juscelino Kubitschek. Fonte: Geosampa, 2000.

8.47 Imagem aérea do setor Juscelino Kubitschek. Fonte: Geosampa, 2004.

8.48 Imagem aérea do setor Juscelino Kubitschek. Fonte: Google Earth, 14 dez 2008.

8.49 Imagem aérea do setor Juscelino Kubitschek. Fonte: Google Earth, 10 mai 2018.

8.50 Vista geral do setor Juscelino Kubitschek. Fonte: Acervo do autor, 6 set 2018.

8.51 Implantação dos empreendimentos no setor Juscelino Kubitschek. Escala 1:5000. Elaborado pelo autor.

8.52 Edifício Eletropaulo, com construção embargada. Fonte: Serapião, "Esqueletos no armário", Projeto Design, out 2010, 74.

8.53 Complexo em versão do aflalo/gasperini para a Tishman Speyer, não construído. Fonte: Serapião, “Esqueletos no armário", Projeto Design, out 2010, 76.

8.54 Complexo em versão do KPF para a Tishman Speyer, não construído. Fonte: Serapião, "Esqueletos no armário", Projeto Design, out 2010, 76.

8.55 Complexo em versão do aflalo/gasperini para a Ergi, não construído. Fonte: Serapião, "Esqueletos no armário", Projeto Design, out 2010, 78.

8.56 Complexo em versão de Botti Rubin para a Ergi, não construído. Fonte: Serapião, "Esqueletos no armário", Projeto Design, out 2010, 77.

8.57 Complexo em versão de Botti Rubin para a WTorre, não construído. Fonte: Serapião, "Esqueletos no armário", Projeto Design, out 2010, 79.

8.58 Complexo em versão de Edo Rocha para a WTorre, não construído. Fonte: Serapião, "Esqueletos no armário", Projeto Design, out 2010, 80.

8.59 Diagrama do complexo WTJK. Elaborado pelo autor.

8.60 Arquitectonica, complexo WTJK (2007-2014). Implantação. Sem escala. Fonte: Gelinski, "Recortes suavizam fachada monolítica", Finestra, n. 66.

8.61 Arquitectonica, complexo WTJK (2007-2014). Pavimentos da torre São Paulo. Sem escala. Fonte: Gelinski, "Recortes suavizam fachada monolítica”, Finestra, n. 66.

8.62 Arquitectonica, complexo WTJK (2007-2014). Corte da torre São Paulo. Sem escala. Fonte: Gelinski,

"Recortes suavizam fachada monolítica", Finestra, n. 66.

8.63 Arquitectonica, complexo WTJK (2007-2014). Elevação da rua Chedid Jafet. Sem escala. Fonte:

Gelinski, "Megacomplexo abriga torres e shopping”, Finestra, n. 79. 
Fonte: Gelinski, “Megacomplexo abriga torres e shopping”, Finestra, n. 79.

8.65 Arquitectonica, complexo WTJK (2007-2014). Vista a partir da esquina entre a avenida Juscelino Kubitschek e a rua Chedid Jafet. Fonte: Gelinski, "Megacomplexo abriga torres e shopping”, Finestra, n. 79 . 2016. autor, 16 ago 2019 . arquitetura de Croce, Aflalo e Gasperini, 295. arquitetura de Croce, Aflalo e Gasperini, 295. Sem escala. Fonte: Archdaily. tipo. Sem escala. Fonte: Archdaily. escala. Fonte: Archdaily. Sem escala. Fonte: Gelinski, “Torres de Cesar Pelli na Vila Olímpia”, Finestra, n. 103. fachada. Sem escala. Fonte: Gelinski, “Torres de Cesar Pelli na Vila Olímpia”, Finestra, n. 103. do cruzamento entre as avenidas Juscelino Kubitschek e Chedid Jafet. Fonte: Acervo do autor, 6 set 2018. calçada elevada da avenida Juscelino Kubitschek e do cercamento do conjunto ao fundo. Fonte: Pelli Clarke Pelli via Balmori Associates, acervo online. cercamento e do paisagismo. Fonte: Acervo do autor, 27 set 2016. fundos do empreendimento a partir da passarela Marcelo Fromer. Fonte: Acervo do autor, 16 ago 2019. 

térreo das torres. Fonte: Pelli Clarke Pelli via Balmori Associates, acervo online.

8.81 Pelli Clarke Pelli e aflalo/gasperini arquitetos, São Paulo Corporate Towers (2008/2015). Vista a partir do térreo superior em direção ao complexo WTJK. Fonte: Acervo do autor, 6 set 2018. térreo superior. Ao fundo, edifício Atrium VII, de aflalo/gasperini arquitetos. Fonte: Acervo do autor, 6 set 2018

8.83 Pelli Clarke Pelli e aflalo/gasperini arquitetos, São Paulo Corporate Towers (2008/2015). Detalhe da fachada. Fonte: Acervo do autor, 6 set 2018.

8.84 Pelli Clarke Pelli e aflalo/gasperini arquitetos, São Paulo Corporate Towers (2008/2015). Vista do interior do pavimento-tipo. Fonte: Archdaily.

8.85 Distribuição de pontos nos estudos de caso certificados pelo LEED ${ }^{\circledR}$ CS v2. Fonte: LEED ${ }^{\circledR}$ Project Directory.

8.86 Distribuição de pontos nos estudos de caso certificados pelo LEED ${ }^{\circledR}$ CS v3. Fonte: LEED $^{\star}$ Project Directory.

8.88 aflalo/gasperini arquitetos, Edifícios Atrium I e II (1986/- e 1990/-). Fonte: Serapião, A arquitetura de Croce, Aflalo e Gasperini, 163.

8.89 aflalo/gasperini arquitetos, Eco Berrini (2007/2011). Fonte: Daniel Ducci via aflalo/gasperini arquitetos, acervo online.

8.90 aflalo/gasperini arquitetos, edifício Odebrecht (2008/2014). Fonte: Daniel Ducci, acervo online.

8.91 KPF e aflalo/gasperini arquitetos, Infinity Tower (2008/2012). Fonte: Daniel Ducci, acervo online.

8.93 Esquema de vidros do Eldorado Business Tower. Fonte: Éride Moura, "Fachada inteligente", Téchne, 2010. Redesenhado pelo autor.

8.94 Comparativo de pavimentos-tipo de edifícios corporativos, ordenados por ano de inauguração. Escala $1: 1000$.

8.95 aflalo/gasperini arquitetos, Os Bandeirantes (1992/c1995). Fonte: Serapião, A arquitetura de Croce, Aflalo e Gasperini, 308.

8.96 Botti Rubin, CENU (1989/2000). Fonte: Acervo do autor, 6 set 2018. Juscelino Kubitschek e CENU e WTC. Escala 1:7500. Elaborado pelo autor. Fontes: Geosampa, Google Earth, implantações dos empreendimentos. 
Gasperini, 355.

9.1 Seleção de esquemas de projeto publicados no LEED ${ }^{\circledR}$ ND, versão 2009.

Fonte: Paul Grover/REX via Oliver Wainwright, "A royal revolution: is Prince Charles's model village having the last laugh?", The Guardian, 27 out 2016.

9.10 Distribuição de empreendimentos certificados LEED ${ }^{\circledR}$ ND nos Estados Unidos. Fonte: Smith, "Planning for urban sustainability".

9.11 Distribuição de edifícios certificados com LEED $^{\circledast}$ ND v3, Estágio 2, no mundo, de acordo com sua pontuação. Amostra de 56 projetos. Fonte: LEED Project Directory, 4 jan 2019. Elaborado pelo autor.

9.12 Plano do The Brewery. Fonte: Farr, Sustainable nation, 56.

9.13 Plano de redesenvolvimento da cidade de Mueller. Fonte: Farr, Sustainable nation, 52.

10.1 Vista da região do rio Pinheiros (1968). Fonte: Ivo Justino via Mariana Rosario, “Os desafios da Berrini para dar a volta por cima”, Veja SP, 21 jan 2019.

10.2 Vista da região do rio Pinheiros, na altura da ponte Eusébio Matoso (29 jan 1997). Fonte: Juca Martins/Acervo IMS.

10.3 Vista da região do rio Pinheiros (10 fev 1997). Fonte: Juca Martins/Acervo IMS.

10.4 Carlos Bratke, Edifício Oswaldo Bratke (-/1982). Fonte: Centre Pompidou.

10.5 Avenida Engenheiro Luís Carlos Berrini (1975). Fonte: Bratke-Collet, acervo online.

10.6 Edifícios certificados e sua localização dentro das áreas de operações urbanas. Elaborado pelo autor. Fontes: LEED Project Directory, SMDU, Geosampa.

10.7 aflalo/gasperini arquitetos, Parque da Cidade. Implantação, versões preliminares (s/d). Fonte: Serapião, Monolito, 18 . 
Serapião, Monolito, 20.

10.9 aflalo/gasperini arquitetos, Parque da Cidade. Implantação, versões preliminares (s/d). Fonte:

Serapião, Monolito, 21.

10.10 aflalo/gasperini arquitetos, Parque da Cidade. Implantação, versões preliminares (s/d). Fonte:

Serapião, Monolito, 24.

10.11 aflalo/gasperini arquitetos, Parque da Cidade. Implantação, versões preliminares (s/d). Fonte: Serapião, Monolito, 29.

10.12 aflalo/gasperini arquitetos, Parque da Cidade. Implantação, versão preliminar (2011). Fonte: Serapião, A arquitetura de Croce, Aflalo e Gasperini, 299.

10.13 aflalo/gasperini arquitetos, Parque da Cidade. Vista, versão preliminar (2011). Fonte: Serapião, A arquitetura de Croce, Aflalo e Gasperini, 299.

10.14 Diagrama do Parque da Cidade. Elaborado pelo autor.

10.15 aflalo/gasperini arquitetos, Parque da Cidade (2010/-). Implantação. Sem escala. Fonte: aflalo/ gasperini arquitetos, acervo online.

10.16 aflalo/gasperini arquitetos, Parque da Cidade (2010/-). Simulação vista a partir da marginal Pinheiros. Fonte: aflalo/gasperini arquitetos, acervo online.

10.17 aflalo/gasperini arquitetos, Parque da Cidade (2010/-). Simulação do parque interno. Fonte: aflalo/ gasperini arquitetos, acervo online.

10.18 aflalo/gasperini arquitetos, Parque da Cidade (2010/-). Vista do conjunto, com obra em andamento. Fonte: Ana Mello via Fernanda Strazzacappa, "Parque da Cidade: complexo multiuso", Galeria da Arquitetura.

10.19 aflalo/gasperini arquitetos, Parque da Cidade (2010/-). Vista da primeira etapa de torres inauguradas. Fonte: Ana Mello via Fernanda Strazzacappa, "Parque da Cidade: complexo multiuso”, Galeria da Arquitetura.

10.20 aflalo/gasperini arquitetos, Parque da Cidade (2010/-). Vista do eixo de circulação. Fonte: Ana Mello via Fernanda Strazzacappa, "Parque da Cidade: complexo multiuso”, Galeria da Arquitetura.

10.21 aflalo/gasperini arquitetos, Parque da Cidade (2010/-). Vista da segunda etapa, a partir da marginal 386 Pinheiros, com torre Jequitibá e hotel Four Seasons. Fonte: Daniel Ducci via Archdaily.

10.22 Vista da construção do Parque da Cidade, a partir do shopping. Fonte: Acervo do autor, 16 ago 2019.386

10.23 Distribuição de pontos nos empreendimentos brasileiros certificados no LEED ND v3. Fonte: LEED 389 Project Directory, 4 jan 2019. Elaborado pelo autor. 
11.1 ONGs internacionais ambientalistas segundo sua classificação em agendas "sentimentais", de preservação de recursos e de ecossistemas. Fonte: Frank et al., “The rationalization and organization of nature in world culture", 93.

11.2 Expansão global de organizações no século XX. Fonte: Drori, Meyer e Hwang, Globalization and organization, 5 .

11.3 Taxa de risco suavizada de formação de ONGs internacionais ambientalistas de 1880 a 1990. Fonte: Frank et al., "The rationalization and organization of nature in world culture", 85.

11.4 Contagem cumulativa de adoção e taxa de risco de fundação de cursos de negócios, 1880-1999. Fonte: Moon e Wotipka, "The worldwide diffusion of business education, 1881-1999: historical trajectory and mechanisms of expansion", 123.

11.5 Número de periódicos com artigos sobre negócios e administração de empresas. Amostra de 217 periódicos. Fonte: Moon e Wotipka, “The worldwide diffusion of business education, 1881-1999: historical trajectory and mechanisms of expansion", 126.

11.6 Quantidade cumulativa de sistemas de avaliação ambiental. Elaborado pelo autor. Dados: ATHENA ${ }^{\bullet}$ (2002), BEAT ${ }^{\circledast}$ (2000), BREEAM ${ }^{\circledR}$ (1990), $\operatorname{CASBEE}^{\circledast}$ (2001), DGNB (2009), EcoEffect ${ }^{\oplus}$ (1999), Ecoprofile (1999), Eco-Quantum (1997), EDGE ${ }^{\circledast}$ (2015), Energy Star (1992), Miljøstatus (1997), Green Globes ${ }^{\circledast}$ (2007), Green Star ${ }^{\circledast}$ (2003), HQE ${ }^{\circledR}$ (2004), ISO 14000 (1996), LBC ${ }^{\circledast}$ (2006), LEED (1998), MINERGIE (1998), Parksmart ${ }^{\oplus}$ (2014), Passivhaus (1996), PEER ${ }^{\circledR}$ (2015), Procel Edifica (2003), SBTool (2007), Selo Azul (2010), SITES ${ }^{\circledast}$ (2007), TRUE ${ }^{\bullet}$ (2013), Well ${ }^{\circledR}$ (2014), What Works Cities (2015). 


\section{LISTA DE TABELAS}

1.1 Projetos certificados pelo LEED New Construction v. 1 Pilot. Fonte: USGBC, 1 ago 2018.

$\begin{array}{lll}2.1 & \text { Sistemas administrados pelo } \mathrm{GBCI}^{\bullet} \text {. Elaborado pelo autor. } & 74\end{array}$

7.1 Créditos do LEED $^{\circledR}$ New Construction, versão 3. Porcentagens pelo autor. 202

7.2 Créditos do $\mathrm{LEED}^{\star}$ Core \& Shell, versão 3. Porcentagens pelo autor. 204

7.3 Taxas de certificação para o sistema LEED ${ }^{\circledR}$ BD+C v4. Fonte: USGBC, fevereiro 2014 via material 218 didático GBC Brasil, “Como se tornar um LEED BD+C”, 2015.

7.4 Taxas de certificação para o sistema LEED BD+C v4. Fonte: GBCI, 14 março 2019, tradução nossa.

8.1 Dados dos empreendimentos estudados. Elaborado pelo autor. 256

8.2 Pontuação dos estudos de caso certificados no LEED ${ }^{\circledR}$ CS v2. Fonte: LEED ${ }^{\bullet}$ Project Directory, 4 jan 308 2019. Elaborado pelo autor.

8.3 Distribuição de pontos no $\mathrm{LEED}^{\circ} \mathrm{CS}$ v2, projetos corporativos certificados não confidenciais no Brasil. 310 Fonte: LEED ${ }^{\circledR}$ Project Directory, 4 jan 2019. Elaborado pelo autor. Amostra de 29 empreendimentos. Baseado em metodologia de Garde, "Sustainable by design".

8.4 Pontuação dos estudos de caso certificados no LEED ${ }^{\circledR}$ CS v3. Fonte: LEED ${ }^{\circledR}$ Project Directory, 4 jan 2019. Elaborado pelo autor.

8.5 Distribuição de pontos no LEED ${ }^{\circledR}$ CS v3, projetos corporativos certificados não confidenciais no Brasil. 314 Fonte: LEED ${ }^{\circledR}$ Project Directory, 4 jan 2019, com correções e elaboração do autor. Amostra de 113 empreendimentos. Baseado em metodologia de Garde, "Sustainable by design".

9.1 Créditos do LEED ${ }^{\circledR}$ for Neighborhood Development, versão 2009. Porcentagens pelo autor.

9.2 Distribuição de pontos no LEED ${ }^{\circledR}$ ND Piloto. Amostra de 73 empreendimentos nos Estados Unidos. Cores e listagem dos créditos organizados segundo o grau de cumprimento. Fonte: Garde, "Sustainable by design?". Redesenhado pelo autor.

9.3 Distribuição de pontos no LEED ${ }^{\circledR}$ ND 2009, projetos não confidenciais. Amostra de 29 empreendimentos nos Estados Unidos. Cores e listagem dos créditos organizados segundo o grau de cumprimento. Fonte: LEED ${ }^{\circledR}$ Project Directory, 4 jan 2019. Elaborado pelo autor a partir de metodologia de Garde, "Sustainable by design?".

10.1 Pontuação dos empreendimentos brasileiros certificados no LEED ${ }^{\circledR}$ ND v3. O Ilha Pura já foi certificado no Estágio 3, com 43 pontos, mas o detalhamento do desempenho ainda não está disponível publicamente. Fonte: LEED ${ }^{\circledR}$ Project Directory, 4 jan 2019. Elaborado pelo autor. 


\section{LISTA DE ABREVIATURAS}

ABEEólica Associação Brasileira de Energia Eólica

ABNT Associação Brasileira de Normas Técnicas

ABRAGEL Associação Brasileira de Geração de Energia Limpa

ABRAVA Associação Brasileira de Refrigeração, Ar Condicionado, Ventilação e Aquecimento

ACHR News Air Conditioning, Heating \& Refrigeration News

ACP Alternative Compliance Paths For Projects Outside the US [instrumento do LEED ${ }^{\circledR}$ ]

AIA American Institute of Architects

AMCHAM American Chamber of Commerce

ANSI American National Standards Institute

AP ver $L E E D^{\circ} A P$

Aqua Alta Qualidade Ambiental

AsBEA Associação Brasileira dos Escritórios de Arquitetura

ASHRAE American Society of Heating, Refrigerating, and Air-Conditioning Engineers

ASTM American Society for Testing and Materials

$\mathrm{BD}+\mathrm{C} \quad$ ver $L E E D^{\oplus} B D+C$

BEAT $^{\bullet} \quad$ Building Environmental Assessment Tool

BNDES Banco Nacional de Desenvolvimento Econômico e Social

BNIM Berkebile Nelson Immenschuh McDowell [escritório de arquitetura]

BRE Building Research Establishment

BREEAM Building Research Establishment Environmental Assessment Method

BRS Building Research Station

CA Coeficiente de Aproveitamento

CaGBC Canada Green Building Council

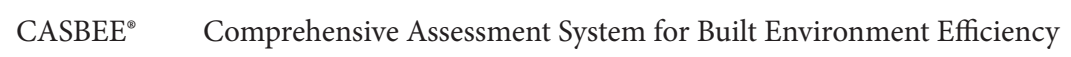

CBCS Conselho Brasileiro de Construção Sustentável

CDHU Companhia de Desenvolvimento Habitacional e Urbano

CEO Chief Executive Officer

CENESP Centro Empresarial São Paulo

CENU Centro Empresarial Nações Unidas

CEPAC Certificado de Potencial Adicional de Construção

CFC Clorofluorcarboneto

CI ver LEED ${ }^{\circledR} \mathrm{CI}$

CNPJ Cadastro Nacional da Pessoa Jurídica

CNU Congress for the New Urbanism

COTE Committee on the Environment

COTE-AIA ver COTE, ver AIA 


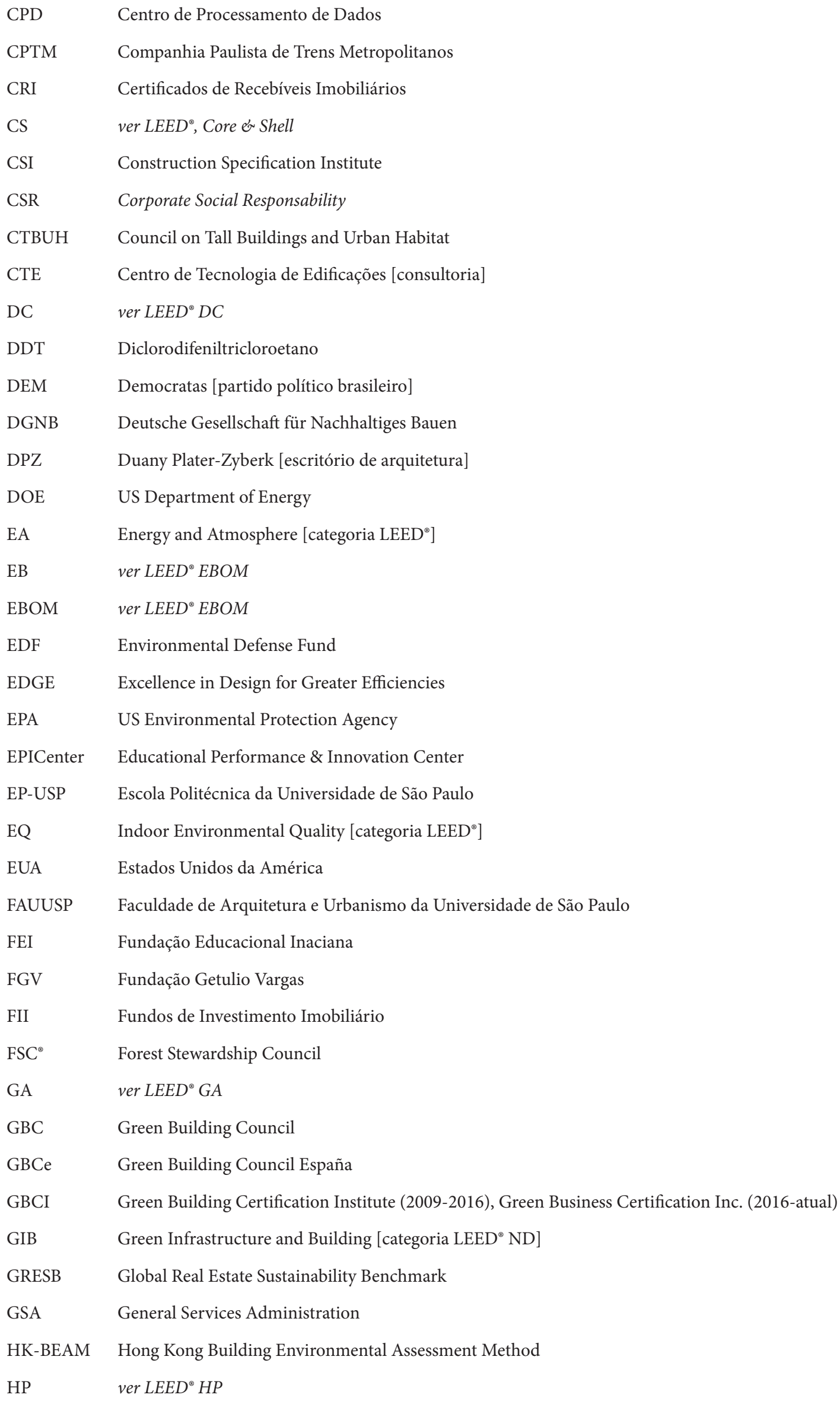




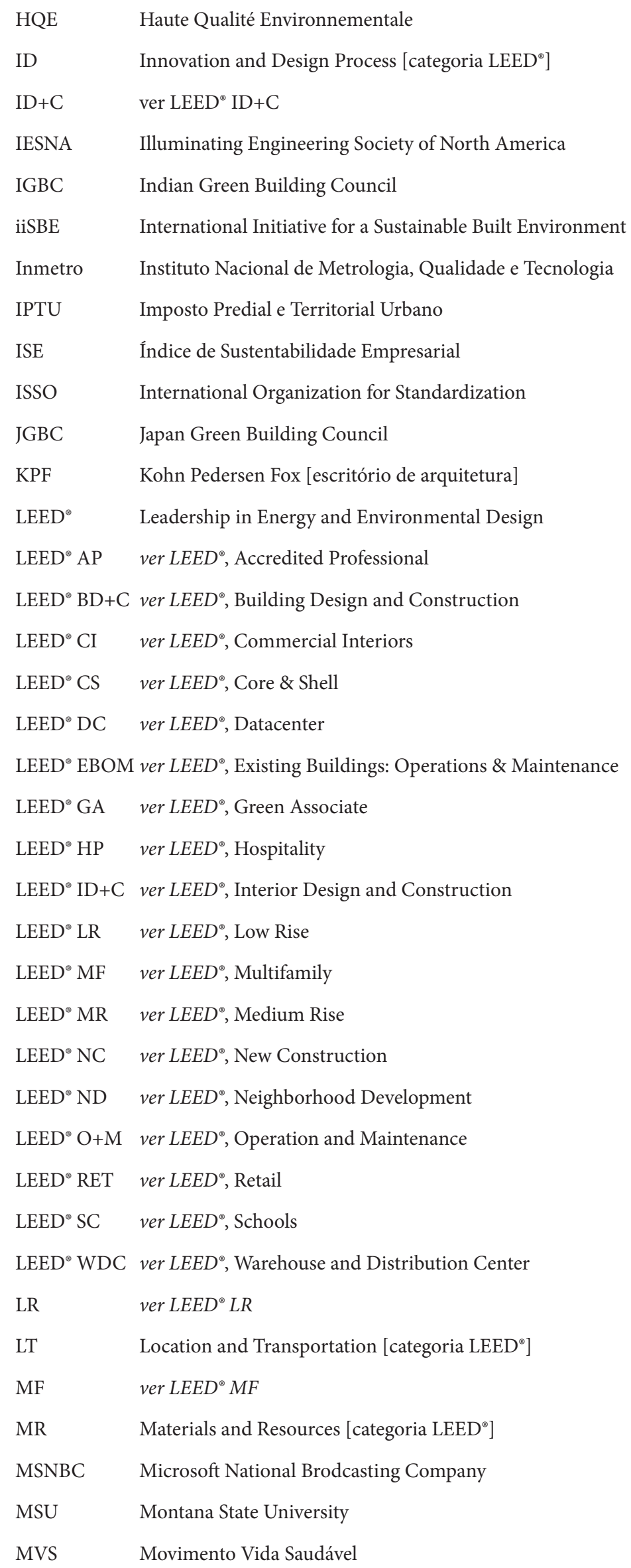




\begin{tabular}{|c|c|}
\hline NC & ver $L E E D^{\infty} N C$ \\
\hline ND & $\operatorname{ver} L E E D^{\circ} N D$ \\
\hline NIST & National Institute of Standards and Technology \\
\hline NJDEP & New Jersey Department of Environmental Protection \\
\hline NPD & Neighborhood Pattern and Design [categoria LEED ${ }^{\circledR}$ ND] \\
\hline NRDC & Natural Resources Defense Council \\
\hline $\mathrm{O}+\mathrm{M}$ & ver $L E E D^{\circ} O+M$ \\
\hline OLEM & Office of Land and Emergency Management, anterior: OSWER \\
\hline ONG & Organização Não Governamental \\
\hline OSHA & Occupational Safety and Health Administration - US Department of Labor \\
\hline OSWER & Office of Solid Waste and Emergency Response, atual: OLEM \\
\hline OUCAE & Operação Urbana Consorciada Água Espraiada \\
\hline OUCFL & Operação Urbana Consorciada Faria Lima \\
\hline PDE & Plano Diretor Estratégico \\
\hline PEER $^{\oplus}$ & Performance Excellence in Electricity Renewal \\
\hline PGE & Pacific Gas and Electric Company \\
\hline PIB & Produto Interno Bruto \\
\hline PL & Projeto de Lei \\
\hline Procel & Programa Nacional de Conservação de Energia Elétrica \\
\hline PSDB & Partido da Social Democracia Brasileira \\
\hline RET & ver $L E E D^{\circledR} R E T$ \\
\hline RMI & Rocky Mountain Institute \\
\hline $\mathrm{RP}$ & Regional Priority [categoria LEED ${ }^{\circledR}$ ] \\
\hline RPBW & Renzo Piano Building Workshop [escritório de arquitetura] \\
\hline SPOP & São Paulo Office Park \\
\hline SC & ver $L E E D^{\circledR} S C$ \\
\hline SDG\&E & San Diego Gas and Electric \\
\hline SITES $^{\circ}$ & Sustainable Sites Initiative \\
\hline SLL & Smart Location and Linkage [categoria LEED ${ }^{\bullet} \mathrm{ND}$ ] \\
\hline SMACNA & Sheet Metal and Air Conditioning Contractors National Association \\
\hline SOM & Skidmore, Owings \& Merrill [escritório de arquitetura] \\
\hline SRI & Socially Responsible Investment \\
\hline SS & Sustainable Sites [categoria LEED ${ }^{\circledR}$ ] \\
\hline TRUE $^{\oplus}$ & Total Resource Use and Efficiency \\
\hline UFSC & Universidade Federal de Santa Catarina \\
\hline UFSCar & Universidade Federal de São Carlos \\
\hline UKGBC & United Kingdom Green Building Council \\
\hline USGBC $^{\bullet}$ & United States Green Building Council \\
\hline
\end{tabular}


USZWBC US Zero Waste Business Council

VOC Volatile Organic Compound

WDC $\quad$ ver LEED $^{\circ}$ WDC

WE Water Efficiency [categoria LEED ${ }^{\circledR}$ ]

WTC World Trade Center

WWF World Wide Fund for Nature

WWR Window-to-Wall Ratio

ZGF Zimmer Gunsul Frasca [escritório de arquitetura] 


\section{SUMÁRIO}

Agradecimentos 5

Resumo 6

Abstract 7

Lista de figuras 8

Lista de tabelas 23

Lista de abreviaturas 24

Introdução 33

Materiais e métodos 40

\section{PARTE I}

A BUSCA DO CONSENSO: REDES DE AGENTES NA CRIAÇÃO DO LEED®

\section{Capítulo 1}

A formação do United States Green Building Council 43

Prospecção 43

Um presidente para o USGBC ${ }^{\oplus} \quad 50$

Construindo o consenso 53

LEED $^{\circledR}$, produto de sustentabilidade financeira 56

LEED $^{\circledR}$ no território norte-americano 67

\section{Capítulo 2}

'Velocidade é qualidade': a expansão de mercado 71

Um sistema para cada programa arquitetônico 71

Ecossistema de padrões 73

LEED $^{\circledR}$ para o urbano 78

World GBC e os embates da internacionalização $\quad 79$

\section{Capítulo 3}

O modelo brasileiro de conselho verde 89

Networking 89

Disputa da marca 94

Cisão no consenso 96

Os 'pilares' do GBC Brasil 101

As certificações de grande repercussão 117 


\section{PARTE II}

O EFICIENTE MOTOR DO STATUS QUO: FUNDAMENTOS AMBIENTALISTAS NO SISTEMA DE AVALIAÇÃO 125

\section{Capítulo 4}

'Dólares também são verdes' 127

Negócios sustentáveis 127

Teorias no LEED ${ }^{\circledR} 133$

Eficiência e inovação tecnológica 141

Autonomia política e espectro partidário $\quad 145$

LEED $^{\circledR}$, um produto de modernização ecológica 151

O malogro da equivalência integral do par economia-ecologia 156

\section{Capítulo 5}

Triple A como vanguarda do mercado 159

'Subindo a barra' 159

Benefícios financeiros do edifício verde 164

Produtividade do colarinho branco 171

Gestão de risco e imagem corporativa 172

LEED $^{\oplus}$, elemento distintivo em mercado especializado 177

\section{Capítulo 6}

Além do LEED ${ }^{\circledR} 185$

Fissuras no Triple A 185

Eficiência em paradoxo 189

PARTE III

TORRE AMBIENTAL: OS PADRÕES ARQUITETÔNICOS DO LEED® 197

\section{Capítulo 7}

Triple A como arquitetura de vanguarda 199

Os sistemas LEED ${ }^{\circledR}$ New Construction e Core \& Shell 199

Mecanização do ambiente 208

A arquitetura do envelope 212

Implantação e áreas verdes 216

Grande porte 221

Experimentações formais na arquitetura ambiental corporativa 222

Viabilização do modelo de mercado norte-americano 237

Virtualidade da exceção 246 


\title{
Capítulo 8
}

A tensão com o capital simbólico 255

Setor Chucri Zaidan: edifícios de aflalo/gasperini arquitetos 261

Setor Juscelino Kubitschek: parcerias internacionais 289

O uso empírico dos sistemas LEED ${ }^{\circledR}$ New Construction e Core \& Shell 306

\section{PARTE IV}

\section{NEW URBANISM NA MARGINAL PINHEIROS 337}

\author{
Capítulo 9 \\ LEED $^{\circledR}$ e a revisão do subúrbio norte-americano 339 \\ O sistema LEED ${ }^{\circledR}$ for Neighborhood Development 339 \\ New Urbanism 343 \\ O tecido urbano para o LEED ${ }^{\circledR}$ for Neighborhood Development 355
}

\section{Capítulo 10}

Obstáculos do pacto disciplinar brasileiro 367

Marginal Pinheiros, centro financeiro de uma cidade global periférica 367

Parque da Cidade 379

Limites disciplinares 387

Evasivas ao LEED ${ }^{\circledast}$ for Neighborhood Development 391

\section{PARTE V}

O ESPAÇO SOB PADRÕES GLOBAIS 393

\section{Capítulo 11}

O lastro dos produtos espaciais na certificação 395

Disposição 395

Produtos espaciais 404

Arquitetura auditada 410

Considerações finais 419

Referências 425

Versões preliminares $\quad 440$ 


\section{INTRODUÇÃO}

Qual o impacto dos padrões técnicos na arquitetura e no urbanismo contemporâneos? As últimas décadas foram palco do aparecimento de uma profusão de padrões que incidem nas mais variadas atividades, como o projeto. Os diversos termos com que esses padrões se autodefinem - códigos, normas, selos, guias, protocolos, programas, processos, sistemas, certificados etc. indicam ligeiras diferenças, discursivas ou efetivas, de como eles se comportam em relação ao ambiente construído. Surgem demandas antes inexistentes: no padrão ISO 9000, o escritório deve documentar cada etapa do projeto a fim de assegurar a qualidade do seu serviço. Também se estabelecem métodos para lidar com questões antes sem definição: na certificação What Works Cities, criada pela Bloomberg Philantropies, o antes difuso termo smart city é demarcado por critérios de levantamento e tratamento de dados estatísticos a respeito da população e das políticas públicas de uma cidade. Do fluxograma de um escritório à gestão municipal, da morfologia urbana à extração de madeira, do consumo energético em estacionamentos às pressões hídricas do paisagismo, inúmeros aspectos da arquitetura e do urbanismo tornam-se passíveis de mensuração, comparação, avaliação, pontuação e certificação.

ABNT, ANSI, BRE, RMI, SDGE\&E, COTE-AIA, ABRAVA, ABRAGEL, ASTM, IESNA, OSWER, ASHRAE, USZWBC... Os agentes envolvidos com padrões são associações, autarquias, departamentos públicos, organizações não governamentais e institutos com variados graus de proximidade ao mercado, à sociedade civil e ao Estado. É uma rede de interesses e perspectivas variados do que deve ser padronizado e de como isso deve ser feito. Os acrônimos abundantes ao longo desta tese refletem o objeto que é tratado e podem ser desnorteantes mesmo aos habituados. Mais do que um dever protocolar, a lista de abreviaturas inserida no início deve então ser entendida como o mapa de navegação no estudo dos padrões.

Dentre essas diversas siglas, o objeto principal é o sistema de avaliação LEED ${ }^{\circledR}$, Leadership 
in Energy and Environmental Design, "Liderança em Energia e Projeto Ambiental". Esse sistema foi criado no início da década de 1990 pelo USGBC ${ }^{\circledast}$, United States Green Building Council, uma organização não governamental e sem fins lucrativos. Um dos fundadores do USGBC ${ }^{\circledast}$ formou

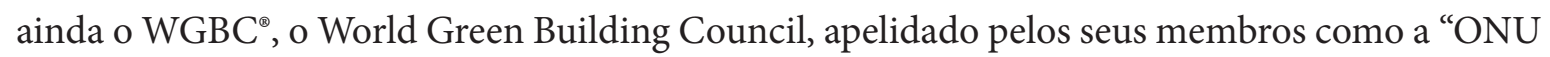
dos conselhos verdes", ao qual estavam associados, até meados de 2019, 68 conselhos nacionais. Dentre eles está o GBC Brasil, um conselho com protagonismo no debate de arquitetura ambiental na América Latina, que organizou o mercado nacional a ponto de o país ocupar em 2018 o proeminente quinto lugar no ranking mundial de certificados LEED ${ }^{\odot}$.

A grande maioria desses certificados foi atribuída a novos edifícios. Logo, o LEED $^{\circledR}$ acompanhou a transformação da paisagem urbana, sobretudo porque, como se verá ao longo do trabalho, as certificações têm alta tendência de concentração em determinadas cidades e endereços. Em São Paulo, essa transformação é marcante nos arredores do rio Pinheiros, majoritariamente em sua margem direita, em uma faixa de algumas quadras de largura percorrendo a região entre a rua Verbo Divino e a ponte Eusébio Matoso. Certamente, o LEED $^{\circledR}$ não é a causa dessa transformação, decorrente da construção de edifícios de escritório para abrigar o setor de serviços em ascensão durante o crescimento econômico da década de 2000. Mas o sistema é uma das demandas a serem cumpridas pelos novos projetos, em alguma medida neles interferindo.

São dois os motivos para a eleição do LEED $^{\star}$ como objeto principal, em detrimento de outros padrões. O primeiro motivo é a sua forte disseminação. No Brasil, é a maior entre os diversos sistemas de avaliação ambiental: o LEED $^{\circledR}$ possui 550 empreendimentos certificados no país, contra 313 de seu concorrente Aqua, um sistema autóctone gerido pela Fundação Vanzolini. ${ }^{1}$ Mundialmente, também é o sistema de avaliação ambiental de maior alcance, atingindo quase 140.000 registros e 72.000 certificados. O sistema britânico BREEAM ${ }^{\circledR}$ é maior em números absolutos, mas os registros são fortemente limitados ao seu reino de origem; no Brasil, as poucas tentativas de implantação foram abandonadas.

O segundo motivo é a objetividade dos parâmetros de avaliação. O LEED ${ }^{\circledR}$ avalia os empreendimentos por um conjunto de créditos, atribuindo mais ou menos pontos de acordo com a per-

1. Há uma pequena discrepância nos períodos de levantamento, mas que não contradiz o argumento: para o LEED ${ }^{\circledR}$, os dados foram obtidos até o fim de 2018; para o Processo Aqua, até o início de maio de 2019. 
formance do projeto avaliada por pareceristas credenciados, de modo que um empreendimento pode ser comparado aos seus concorrentes ou ser destacado pelo seu desempenho singular. Essa avaliação não é subjetiva: para realizá-la, o sistema baseia-se em parâmetros técnicos que lhe garantem neutralidade e objetividade em um processo autocelebrado como científico e up to date. Essa característica é acompanhada pela transparência do sistema: o USGBC ${ }^{\circledast}$ é a única organização a divulgar em seu site oficial a maior parte dos dados de localização, tipologia, avaliação, pontuação e sua distribuição nos diferentes créditos, datas de registro e certificação, tipos de proprietário, entre outros, excetuada uma parcela de empreendimentos confidenciais. Desse modo, a objetividade de avaliação do LEED $^{\circledR}$ - feita por parâmetros quantitativos e a documentação de "boas práticas" em um checklist - facilita a identificação de como os créditos são cumpridos, assim como daqueles que são evitados. Diferentemente, por exemplo, do Processo Aqua, que nem sempre avalia o cumprimento por parâmetros de projeto, mas por justificativas em textos dissertativos. Quanto à transparência, a abrangência de dados disponibilizada supera em muito qualquer um de seus concorrentes, embora ainda não seja possível acessar os relatórios de avaliação específicos para que a completa transparência seja alcançada, uma premissa em qualquer procedimento científico.

A confidencialidade dos dados e os símbolos de marca registrada dos acrônimos são indícios do desígnio desses sistemas: não são apenas padrões técnicos, mas produtos comercializados e que buscam sobressair no mercado. Por esse motivo, os padrões lidam com as mesmas imposições de qualquer mercadoria: carecem de se mostrar atrativos para seus consumidores e de oferecer benefícios mais relevantes do que os de seus concorrentes. Eles precisam fornecer uma guia pela qual o mercado se orientará, mas também o convencer de que o seu rumo é melhor do que os demais.

Esses modos de operar estão presentes desde o início da formação do USGBC ${ }^{\oplus}$, antes mesmo do lançamento do LEED ${ }^{\circ}$, embora naquele momento não fossem necessariamente hegemônicos no conselho verde. André Micoud, conforme lido pelo urbanista Henri Acselrad, descreve o movimento ambientalista francês como uma "nebulosa associativa": ao mesmo tempo um corpo institucional multiforme e um conjunto turvo e indeterminado de práticas. ${ }^{2} \mathrm{~A}$ expressão pode ser diretamente aplicada ao USGBC ${ }^{\oplus}$ e aos conselhos verdes associados ao WGBC ${ }^{\circledast}$. De um lado,

2. Henri Acselrad, "Ambientalização das lutas sociais - o caso do movimento por justiça ambiental", Estudos avançados 24, $\mathrm{n}^{\circ} 68$ (2010): 104, http://dx.doi.org/10.1590/S0103-40142010000100010. 
eles possuem filiação variada, com representantes de toda cadeia produtiva da construção civil e de movimentos ambientalistas, além de contarem com apoio do Estado. De outro lado, sua atuação se dá na tensão entre atrair os agentes de mercado e promover mudanças produtivas, entre criticar corporações poluentes e se associar a elas por edifícios sustentáveis, entre buscar o apoio estatal e alegar independência de ação.

Em razão da objetividade de seu caráter técnico, os padrões são resistentes à interpretação histórica: eles aparentam ser resultado de um desenrolar sem conflitos e deixam poucas pistas de quais dissensos enfrentaram. $\mathrm{O}$ sistema $\mathrm{LEED}^{\circledR}$ não detalha seu próprio processo de constituição: nas quatro versões em que foi lançado, é apenas a terceira que possui uma página indicando datas básicas de formação do USGBC ${ }^{\circledast}$ e de lançamento das diferentes versões. Quando a contextualização histórica se faz necessária, a quase totalidade dos trabalhos sobre o LEED ${ }^{\circledR}$ cita as informações encontradas nessa mesma página do sistema, o que deixava grande parte de sua história obscura. A reconstrução do percurso entre a formação do USGBC ${ }^{\oplus}$, o lançamento do LEED $^{\circledR}$ e sua rápida disseminação global exigiu o levantamento de informações esparsas em jornais, revistas setoriais, autobiografias de CEOs, atas, estatutos, currículos, missões corporativas e sobretudo depoimentos, sempre que fossem possíveis. Essa história foi contada na primeira parte deste trabalho, "A busca do consenso: redes de agentes na criação do LEED", por sua vez dividida em três capítulos, referentes ao $\mathrm{USGBC}^{\circledast}$ (capítulo 1), ao WGBC ${ }^{\circledast}$ (capítulo 2) e ao GBC Brasil (capítulo 3). Como em todo esforço formativo, a fundação desses conselhos foi marcada pelo embate e seleção dos modos de operação, de modo que as decisões de gestão tomadas nos estágios iniciais ainda reverberam nas estratégias de atuação atuais.

Se a primeira parte examina os agentes, a segunda parte trata justamente desses modos de operação privilegiados em sua história. Eles confluem para a gestão do USGBC ${ }^{\circledast}$ como um negócio, em que o $\mathrm{LEED}^{\circ}$ se torna a principal fonte de receita do conselho. Isso já podia ser induzido no capítulo 2 pela atuação do conselho, que sempre esteve interessado em rapidamente expandir tanto a sua quantidade de sistemas quanto a sua abrangência espacial, de modo que o LEED $^{\circledR}$ tem aplicação internacional logo na sua primeira versão. Mas isso também pode ser observado pelo exame das autobiografias dos fundadores do USGBC ${ }^{\circledR}$. No capítulo 4, essas ideias são organizadas como um modelo de atuação ambientalista cuja origem pode ser recuperada por meio das referências que esses fundadores usam em seus textos. Desse modo, é argumentado que o USGBC ${ }^{\oplus}$ 
e os diversos conselhos verdes do WGBC ${ }^{\circledast}$ estão alinhados à chamada "modernização ecológica", uma corrente da sociologia ambiental que busca suprimir as contradições entre ecologia e economia ao ver o ambientalismo como uma nova fronteira possível de acumulação capitalista. $\mathrm{O}$ argumento do capítulo acompanha esse discurso tendencialmente conflitante: o avanço ambiental das corporações acaba sempre por esbarrar no aumento de custos e na lógica antimercantil do controle ambiental.

Nesse ponto, convém esclarecer a terminologia apresentada no capítulo 4 e utilizada ao longo de todo o trabalho. Seguindo Manuel Castells, "ecologia" será empregada apenas quando se referir a aspectos teóricos; “ambiental” ou "ambientalista”, por outro lado, trata dos aspectos práticos. ${ }^{3}$ Desse modo, "ambientalismo" é a prática do movimento social, e arquitetura "ambiental" é a ecologia colocada em prática pelos arquitetos. O termo "sustentabilidade", usado amiúde sem definição clara, será utilizado aqui apenas quando remeter a uma tentativa de conciliação entre economia, ecologia e sociedade, um projeto político expresso no fim dos anos 1980 no relatório Our common future das Nações Unidas. Assim, nem todo movimento ambientalista e nem toda arquitetura ambiental são "sustentáveis", pois há aqueles que tratam desse tripé como conflito, e não como conciliação, caso dos movimentos sociais ligados à justiça ambiental e ao ecomarxismo. Por fim, o termo "verde", comum na literatura anglo-saxã, só será empregado no sentido utilizado por dois dos fundadores do USGBC ${ }^{\oplus}$, David Gottfried e Rick Fedrizzi: a conjugação dos termos economia e ecologia, em que o tripé da sustentabilidade se torna um binômio. Por mais que ambos os autores ainda mencionem questões sociais, a ênfase é de tal grau que justifica uma mudança qualitativa do termo.

Em sua estratégia de convencimento, a certificação apresenta vantagens competitivas aos empreendedores interessados. O capítulo 5, "Triple A como vanguarda do mercado", trata justamente de que ordem são essas vantagens, e de como elas se tornaram um elemento de distinção no estrato mais valorizado dos edifícios de escritórios, os chamados “Triple A". Valores maiores para o metro quadrado locado ou vendido, custos menores de operação do edifício, maior produtividade no trabalho dos seus ocupantes, diminuição da percepção de risco quando atrelado a

3. Manuel Castells, “O 'verdejar' do ser: o movimento ambientalista”, in A era da informação, Trad. de Klauss Brandini Gerhardt [1996], vol. 2, O poder da identidade, 3 vols. (São Paulo: Paz e Terra, 1999), 141-68. 
fundos imobiliários, evidência de sustentabilidade em relatórios corporativos, menor volatilidade de preço, ganhos de imagem, acesso a mercados de nicho e distinção em mercados já especializados são as diversas vantagens competitivas encontradas na certificação dos empreendimentos.

Poucas dessas vantagens, entretanto, interessam a proprietários residenciais ou de empreendimentos de menor porte, razão pela qual o uso do LEED ${ }^{\circ}$ fora dos Estados Unidos converge para as grandes torres de escritório para locação. Os limites desse modelo de negócio, tanto por dificuldades práticas quanto aporias teóricas, são o tema do capítulo 6. A crítica ao LEED $^{\circledR}$ é propriamente realizada a partir desse capítulo, sendo os capítulos anteriores desenvolvimentos históricos e teóricos em que a dimensão dos impasses não surge de modo central. No diagnóstico elaborado desse capítulo em diante, o modelo do sistema LEED ${ }^{\circledR}$ se encontra esgotado pouco mais de vinte anos após seu lançamento.

Esgotado ou não, entretanto, o LEED $^{\circledR}$ certificou grande quantidade de empreendimentos, e seu possível papel de projeto foi tratado apenas marginalmente pela literatura a seu respeito. Há então um padrão espacial no padrão técnico? Se os padrões técnicos são resistentes à história, igualmente o são à estética. Isso porque a flexibilidade do $\mathrm{LEED}^{\circledR}$, a prevalência dos créditos em critérios de especificação técnica e sua ênfase burocrática na documentação de processos dificulta a leitura de sugestões arquitetônicas e urbanísticas. Ainda assim, será argumentado que elas existem, e o método de análise segue o título da tese, em busca das "virtualidades" e "contradições" do LEED ${ }^{\oplus}$. Por um lado, isso será feito pela virtualidade do LEED $^{\oplus}$, isto é, pelo exame imanente das tendências espaciais em germe no sistema. Para tal, o sistema é analisado isoladamente, em que são considerados os objetos de pontuação, o seu peso no conjunto e as "estratégias potenciais" sugeridas explicitamente pelo sistema. Nesse momento, o sistema é considerado sem as injunções de seu uso efetivo, portanto com cumprimento integral. Em seguida, por outro lado, as descobertas são contrapostas à análise empírica. Essa análise é primordialmente qualitativa: embora dados quantitativos sejam mencionados, os edifícios entendidos como objetos culturais não podem ser tomados como uma massa indistinta de performances, e sim em como cada caso resolve as contradições entre as exigências do LEED ${ }^{\circledR}$ e as inúmeras demandas incidentes em um projeto. Surgem por essa análise os modos como cada projeto transforma essas exigências em um atributo central, ou, pelo contrário, como cria artifícios para evitá-las.

Esses dois aspectos do sistema LEED $^{\oplus}$, os virtuais e os empíricos, são explorados nas partes 
III e IV. Na parte III, eles são vistos nos sistemas LEED ${ }^{\circledR}$ New Construction e Core \& Shell, os mais comuns em edifícios de escritórios. ${ }^{4}$ Assim, a ênfase é dos padrões arquitetônicos sugeridos e de como eles confluem para um determinado desenho urbano. Já na parte IV, a análise é do sistema LEED ${ }^{\circledR}$ for Neighborhood Development, dedicado a bairros, e por isso o ponto de vista é inverso: o das sugestões urbanísticas presentes no sistema, e de como elas confluem para certas soluções arquitetônicas. Nesse sentido, serão exploradas não só as contradições entre a virtualidade dos sistemas e as demandas empíricas, mas também aquelas entre os diversos sistemas sob a marca LEED ${ }^{\circledR}$, nem sempre coincidentes em sua visão de sustentabilidade.

Para informar a análise, foram escolhidos empreendimentos localizados nos arredores da marginal Pinheiros, projetos não só de grande divulgação pelo GBC Brasil à época de seu lançamento, mas que também estão espacialmente agrupados, reforçando o argumento de mudança da paisagem urbana. A concentração de grande quantidade de empreendimentos certificados levaria, assim, a uma mudança qualitativa do espaço urbano. Foram selecionados quatro empreendimentos na avenida Chucri Zaidan: Rochaverá Corporate Towers, Morumbi Corporate, WT Morumbi e Parque da Cidade, todos do escritório aflalo/gasperini arquitetos; ${ }^{5}$ além disso, também foram escolhidos dois complexos na confluência entre as avenidas Chedid Jafet e Juscelino Kubitschek: o WTJK, do escritório peruano-estadunidense Arquitectonica, e o São Paulo Corporate Towers, do argentino-estadunidense Pelli Clarke Pelli.

Esses certificados têm uma consequência dupla, explorada por fim na quinta e última parte do trabalho. De um lado, sua flexibilidade não autoriza leituras estritamente tipológicas. A teoria da interferência espacial dos certificados deve, no seu lugar, utilizar-se da noção de disposição, isto é, das características de projeto "dispostas" ao mesmo tipo de relações espaciais, e não propriamente da recorrência de formas arquitetônicas e urbanísticas, embora a tensão entre essas duas linhas de análise seja também elaborada no texto. De outro lado, os empreendimentos certificados dão forma às cidades globais ao mesmo tempo em que facilitam o fluxo de capitais que

\footnotetext{
4. Ao longo da tese, as citações em outras línguas foram traduzidas, mas não o foram os nomes dos sistemas LEED ${ }^{\bullet}$ e de seus diversos créditos. A utilização do LEED ${ }^{\circledR}$ pelo GBC Brasil foi acompanhada, segundo depoimentos, por debates a respeito da tradução dos termos, que muitas vezes não encontravam consenso. Em razão dessa disputa, foi preferida a citação no original.

5. A grafia em letras minúsculas segue o mais recente padrão de branding do escritório e será respeitada ao longo de todo o trabalho.
} 
lhes é próprio. Azeitam, com isso, não só as transações financeiras, como também a reprodução global das disposições de projeto.

O LEED ${ }^{\circledR}$, portanto, está vinculado a uma história corporativa, a uma posição sobre a ecologia e a sua relação com a economia política contemporânea, a estratégias projetuais, a processos de remodelação de espaços privilegiados das metrópoles e a técnicas de viabilização da globalização.

\section{MATERIAIS E MÉTODOS}

Devido à ausência de bibliografia sobre a história dos diversos conselhos ligados ao LEED ${ }^{\circledR}$, o material de pesquisa centrou-se, especialmente nos capítulos 1 a 3, em entrevistas com profissionais que participaram da fundação dos conselhos e de sua gestão. Como modo de verificação, as informações levantadas foram cruzadas entre os diversos relatos, mas outras fontes foram buscadas para a checagem. Desse modo, foram levantados atas, estatutos e postagens nos sites do USGBC ${ }^{\circledast}$ e do GBC Brasil, materiais que muitas vezes já não estavam mais online quando este trabalho foi concluído. Nesse mesmo sentido, ainda foi examinada toda a publicação disponível na Revista GBC, além de notícias publicadas em jornais de grande circulação e palestras gravadas e disponíveis online. Buscou-se, assim, suplantar a ausência de material para a verificação das informações obtidas, já que a documentação interna dos conselhos não pôde ser disponibilizada e foi muitas vezes tida por perdida. Entrevistas e levantamento em jornais foram ainda as principais fontes para estabelecer o processo de projeto nos casos elencados nos capítulos 8 e 10 .

Os dados disponíveis no LEED ${ }^{\circledR}$ Project Directory também foram largamente utilizados na pesquisa. O portal online concentra as informações de todos os empreendimentos registrados nas certificações do $\mathrm{GBCI}^{\oplus}$, e o faz com planilhas abertas, permitindo sua análise após tratamento e correções. Os dados disponíveis nesse site do $\mathrm{GBCI}^{\circledR}$ foram ainda cruzados com aqueles disponíveis no site do GBC Brasil, o que revelou algumas discrepâncias que foram corrigidas, garantindo entradas mais completas. A maior parte dos gráficos disponíveis na tese resulta desse trabalho com dados primários. No caso brasileiro, esses registros foram ainda georreferenciados, o que permitiu ver a distribuição espacial de registros e certificados no país. 


\section{PARTE I}

\section{A BUSCA DO CONSENSO: REDES DE AGENTES NA CRIAÇÃO DO LEED®}

Nós estamos rapidamente construindo um ecossistema de ferramentas de avaliação, tecnologias e plataformas interconectadas que ampliam a influência e alcance geográfico do USGBC, trazendo novos interessados ao nosso trabalho.

Rick Fedrizzi ${ }^{1}$

1. No original: "we're rapidly building an ecosystem of linked rating tools, technologies and platforms that broaden USGBC's influence and geographic reach, bringing new stakeholders to our work." Rick Fedrizzi, "Rick Fedrizzi to join the International WELL Building Institute as Chairman”, USGBC, 6 de julho de 2016, https://www.usgbc.org/articles/rick-fedrizzi-join-international-well-building-institute-chairman, tradução nossa. 



\section{CAPÍTULO 1}

\section{A FORMAÇÃO DO UNITED STATES GREEN BUILDING COUNCIL}

\section{PROSPECÇÃO}

A história do $\mathrm{LEED}^{\circledR}$ não começa no seu lançamento em 1998, e sim na fundação do USGBC ${ }^{\circledast}$ cinco anos antes. É por meio das políticas desse último, a organização sem fins lucrativos United States Green Building Council, que são melhor entendidos os objetivos do primeiro, o sistema de avaliação Leadership in Energy and Environmental Design. O sistema é o produto mais bem-sucedido da ONG criada pelo incorporador imobiliário David Gottfried, pelo advogado Mike Italiano e pelo executivo Rick Fedrizzi.

David Gottfried é o principal membro desse grupo de fundadores. Ele conta sua trajetória em três livros de memórias: Greed to green, ${ }^{1}$ Greening my life ${ }^{2}$ e Explosion green. ${ }^{3} \mathrm{O}$ argumento é comum aos três: como "o poder do indivíduo", para usar o título de um ciclo de palestras de que participa, estaria na origem de um novo mercado, não mais obstinado ao ganho de curto prazo, mas de maior responsabilidade ambiental e que receberia, além de tudo, ainda mais lucros. Também comum aos três livros é a intimidade do relato: desilusões amorosas, pai exigente, desejos de consumo, construção sustentável e a gestão do $\mathrm{USGBC}^{\circledast}$ se sucedem com igual valor narrativo. O segundo e o terceiro livro são na verdade revisões do primeiro, omitindo indiscrições e detalhes excessivamente privados ao mesmo tempo em que desenrolam os novos acontecimentos entre

1. David Gottfried, Greed to green: the transformation of an industry and a life, Prefácio de Paul Hawken (Berkeley, CA: WorldBuild Publishing, 2004).

2. David Gottfried, Greening my life: a green building pioneer takes on his most challenging project (Berkeley, CA: Regenerative Publishing, 2010).

3. David Gottfried, Explosion green: one man's journey to green the world's largest industry, Prefácio de Paul Hawken. Introdução de Rick Fedrizzi. (Nova York: Morgan James, 2014).

4. No original, "The power of one"; Gottfried, 134, tradução nossa. 
as edições. Desse modo, tanto pelo maior arco temporal, quanto pela maior objetividade, aqui a análise dará preferência ao último volume, Explosion green, como relato principal dos eventos salvo quando o cotejamento tenha revelado informações relevantes nas versões anteriores.

Gottfried formou-se na Universidade Stanford, em 1982, em um curso por ele batizado de "gestão de engenharia" [engineering management] ao combinar livremente disciplinas de engenharias civil e industrial e administração de empresas. ${ }^{5}$ Aos vinte e dois anos e recém-graduado, mudou-se para a costa leste dos Estados Unidos, em Washington DC, como assistente de sua prima Diane, então proprietária de uma próspera incorporadora imobiliária. No ano seguinte tornou-se supervisor de projeto, auxiliando na indicação de terrenos e edifícios em área urbana consolidada [urban infill] para desenvolvimento imobiliário e reformas, com foco na locação de escritórios e apartamentos residenciais. ${ }^{6} \mathrm{O}$ crescimento dentro da empresa foi rápido, tanto em termos de deveres na sua administração quanto em retornos financeiros. Após quatro anos, com a ligação da prima dando credibilidade para seus negócios, abriu sua própria incorporadora, a Gottfried Development, Inc.?

Depois de alguns anos em sua própria firma e de outras colaborações, voltou a trabalhar com sua prima em 1991, agora como empreiteiro. Ao perceber Gottfried “pouco entusiasmado” com seu novo cargo, sua prima lhe atribuiu a tarefa de prospectar outros mercados com o objetivo de diversificar a atuação da companhia. Naquele momento, os Estados Unidos se encontravam em recessão econômica durante os últimos anos da presidência de George H.W. Bush (1989-1993), caracterizada pelo aumento de desemprego e desaquecimento do mercado imobiliário. Contra as expectativas dos leitores de seu livro, a relação com a sustentabilidade é a princípio fortuita: Gottfried narra ter encontrado nela muito casualmente uma resposta à estagnação no setor imobiliário, depois de ler uma matéria na revista Time sobre oportunidades em negócios sustentáveis. Nessa mesma época, teve notícias sobre o novo edifício do Environmental Defense Fund (EDF), projetado por William McDonough - arquiteto que cerca de dez anos depois seria coautor de Cradle to cradle, livro que defende a circularidade do uso de materiais, sem rejeitos inaproveitáveis na cadeia produtiva. ${ }^{8}$

\footnotetext{
5. Gottfried, Greed to green, 11.

6. Gottfried, Explosion green, 6, 11-12.

7. Gottfried, Greed to green, 31-32. A criação da própria empresa é omitida em Explosion green.

8. Gottfried, Explosion green, 21; Gottfried, Greed to green, 4; William McDonough e Michael Braungart, Cradle to cradle:
} 
Ao conseguir uma visita à construção do EDF, Gottfried notou como as especificações técnicas privilegiavam a eficiência das luminárias e materiais naturais ou reciclados, vistas por ele como completamente diferentes do então habitual, pois "Alguns dos princípios de eficiência energética e reciclagem de lixo eram conhecidos [no escritório de sua prima], mas os conceitos de materiais sustentáveis e qualidade do ar interno eram totalmente novos." Assim, a visita lhe revelou uma nova forma de conceber um projeto pela orquestração de diversos aspectos de sustentabilidade, entendidos então como eficiência no uso de recursos e bem-estar dos ocupantes internos.

A bem dizer, e apesar da surpresa de Gottfried, a sustentabilidade já vinha sendo discutida na arquitetura ao menos desde a década de 1960, contando inclusive com diferentes vertentes, muitas vezes conflitantes, de abordagem - seja do ponto de vista técnico, morfológico ou político. ${ }^{10}$ Entretanto, a experiência de Gottfried com arquitetura sustentável era naquele momento escassa, e se limitava à aprendizagem em uma disciplina de Gil Masters na faculdade, em que Gottfried montou a maquete de uma mansão sustentável:

O que não se podia dizer em um olhar casual é que seu projeto estava corretamente orientado para o sol com aquecimento e resfriamento passivos, assim como para gerar eletricidade solar e água quente, com a ajuda de um telhado repleto de painéis na direção sul e sudoeste. Lá em cima havia painéis fotovoltaicos recebendo raios o bastante para a casa gerar toda a sua eletricidade - o que nós hoje chamamos de "net-zero". Além disso, na cobertura havia uma horta orgânica - o que nós hoje chamamos de "cobertura verde". A casa tinha quatro quartos... A casa tinha até mesmo uma quadra de basquete subterrânea com uma parede de aquecimento passivo (parede trombe) que era enchida com água: um dos melhores retentores de calor. ${ }^{11}$

remaking the way we make things (Nova York: North Point Press, 2002).

9. No original: "Some of the principles of energy efficiency and waste recycling were known, but the concepts of sustainable materials and indoor air quality were brand new." Gottfried, Explosion green, 22, tradução nossa.

10. Para aspectos dessa história, ver Phillip James Tabb e A. Senem Deviren, The greening of architecture: a critical history and survey of contemporary sustainable architecture and urban design (Surrey, Inglaterra; Burlington, EUA: Ashgate Publishing, 2013); Luis Fernández-Galiano, "iLa economía, ecologistas!: la construcción sostenible ante la crisis del petróleo", Arquitectura viva, $\mathrm{n}^{\circ}$ 105: Etiquetas verdes (2005): 23-25; ou nosso Raphael Grazziano, "A perspectiva tecnológica da sustentabilidade ambiental: Buckminster Fuller e a arquitetura dos anos 2000", Oculum Ensaios 15, no 1 (2018): 111-28, https:// doi. org/10.24220/2318-0919v15n1a3374 onde é discutido o percurso que levou à hegemonia da sustentabilidade high tech tal como experenciada - e, como será visto adiante, proposta - por Gottfried.

11. No original: "What you couldn't tell in a casual glance was that its design was properly oriented to the sun for passive solar heating and cooling, as well as for generating solar electricity and hot water, with the help of a roof full of south- and 
Adiantando o argumento, a passagem é aqui transcrita porque a arquitetura sustentável de Gottfried, presente na sua referência de faculdade, se dava não só pela incorporação de estratégias passivas de controle térmico, mas também enfaticamente pelo emprego de soluções tecnológicas de alto custo e dependência, em especial quando propostas no início dos anos 1980. A história é contada igualmente nas diferentes edições do livro, onde o par formado pelo programa residencial requintado e dispendioso e a agenda sustentável de sua casa nunca é tratado como um problema. Pelo contrário, sua junção é vista como um "idealismo" perdido ao iniciar sua vida profissional e como um modelo a ser retomado ao entrar no mercado da sustentabilidade. Essa posição foi recorrente na história do USGBC ${ }^{\oplus}$, onde a eficiência energética dos sistemas mecânicos teve protagonismo sobre outras propostas de ambientalismo.

Tendo como ponto de partida a notícia da revista, a visita técnica e a disciplina de faculdade, Gottfried passou a pesquisar iniciativas de sustentabilidade em órgãos do governo federal como o US Department of Energy (DOE) e a US Environmental Protection Agency (EPA), além de frequentar um comitê de sustentabilidade (COTE) no American Institute of Architects (AIA), então formado por Joel Ann Todd, William Browning, Randolph Croxton, Gail Lindsey, Gregory Franta e William McDonough, e liderado por Bob Berkebile. ${ }^{12}$ Seguindo a referência desse grupo, Gottfried participou da conferência anual do AIA de 1992 em Boston, onde se impressionou pelas apresentações de William McDonough e Randolph Croxton e conheceu o estado da arte da construção sustentável nos Estados Unidos.

Em meio à pesquisa que se estendia por meses, Gottfried enfrentava o ceticismo de sua prima em incorporar as descobertas nos projetos da empresa, mesmo depois de apresentações de portfólio por McDonough e Croxton. Entrementes, continuava a estudar o tema, quando então recebeu a indicação de Mike Italiano, um dos sócios do escritório Bell, Boyd \& Loyd, especializado em direito ambiental e também de Washington DC. Italiano era especializado em litígios ambientais, sobretudo de Superfundos, um programa federal norte-americano criado em

southwest-facing panels. There were enough solar photovoltaic panels catching rays up there for the house to generate all of its own electricity - what we know call 'net-zero'. Also on the roof was an organic vegetable garden - now known as a 'vegetated roof'. The house had four bedrooms... The house had a sunken basketball court with a passive heating wall (Trombe wall) that was filled with water: one of the best heat retainers." Gottfried, Explosion green, 26-27, tradução nossa.

12. Gottfried, 24-25. 
1980 para a descontaminação de solo, como em casos de vazamento de óleo, chumbo, amianto ou radiação. Segundo Gottfried, Italiano "havia escrito um livro sobre vazamentos em tanques subterrâneos de combustível" e "aconselhava fabricantes no desenvolvimento de produtos e na proteção contra riscos legais, e tinha feito alguns trabalhos com proprietários de edifícios."13 Com a ajuda de Italiano, Gottfried conseguiu apoio da prima para abrir a Katz Environmental Consulting, uma subsidiária que ofereceria consultoria em sustentabilidade para os clientes da incorporadora principal.

Apesar da baixa concorrência em uma época onde esse tipo de serviço era incomum, Gottfried não encontrava clientes, mesmo quando se apresentava a ONGs ambientalistas como o Worldwatch Institute. Italiano convidou-o então para presidir um recém-criado subcomitê de construção sustentável na American Society for Testing and Materials (ASTM), uma das mais antigas associações responsáveis pela criação de normas técnicas voluntárias no mundo e na qual Italiano havia liderado o Comitê de Avaliação Ambiental e Gestão de Risco. ${ }^{14}$ Esse foi, portanto, o primeiro contato de Gottfried com a criação de uma norma ambiental, o que reverberou posteriormente na criação do LEED ${ }^{\oplus}$. Por um lado, a chefia do subcomitê colocava Gottfried na prática da construção sustentável pela qual vinha se interessando. Por outro, ele seguia o conselho de Italiano de que esse seria mais um elemento de negociação com sua prima, pois "isso vai colocar sua empresa [Katz Environmental Consulting] no mapa... presidir um subcomitê da ASTM é coisa importante."15

Gottfried formou o subcomitê com a vice-presidência de William Browning, da COTE-AIA, e mais de cem membros inscritos. Após algumas reuniões, Gottfried escreveu a primeira síntese do que poderia ser uma norma de projeto, construção e operação de edifícios sustentáveis, cobrindo práticas de eficiência no uso de recursos naturais, qualidade ambiental interna e redução da produção de lixo: foi chamada Standard E-50.06.1, Standard practice for green building. Entretanto, essa versão recebeu diversos comentários negativos, os quais, segundo as regras da ASTM, deveriam ser todos resolvidos ou descartados por votação. Esse seria um "método de

13. No original: "[ha]d written a book on leaky underground fuel tanks" e "advised manufacturers on product development and defense against liability, and had done some work with building owners." Gottfried, 37, tradução nossa.

14. Gottfried, 36, 39.

15. No original: "this will put your company on the map" e "Being chair of an ASTM subcommittee is a big deal." Gottfried, 39, tradução nossa. 
consenso", que aumentaria a força do conjunto de membros do subcomitê, mas também podia obstruir o andamento da norma. Foi o que aconteceu: dentre as inúmeras críticas, que não são descritas no relato, Gottfried destaca as de um grupo de membros que insistia na possibilidade de construção de uma área de fumantes ventilada mecanicamente como alternativa à proibição de fumar em áreas internas. ${ }^{16}$ Segundo ele, a insistência do grupo, financiado pelo Tobacco Institute, inviabilizou na prática a norma de sustentabilidade da ASTM, ${ }^{17}$ até hoje não publicada. ${ }^{18}$ Apesar dessa experiência, Gottfried ainda via virtudes no método e posteriormente empregou-o, adaptado, no desenvolvimento do LEED ${ }^{\oplus}$.

A Katz Environmental Consulting, o subcomitê da ASTM e ainda uma tentativa de criar sua própria consultoria em mercado mais propício em São Francisco emperraram. Novamente por intermédio de Italiano, Gottfried recebeu uma oferta de trabalho de Terry Bevels - um advogado ligado ao escritório de lobistas de Anne Wexler, a qual tivera papel de destaque na articulação política do democrata Jimmy Carter (1977-1981), o primeiro presidente com políticas ambientalistas nos Estados Unidos. Segundo Gottfried,

Mike [Italiano] disse que Terry [Bevels] tinha clientes querendo que ele conseguisse dinheiro do Congresso para novos projetos de edifícios. A ideia de Terry era inventar um programa de edifícios-modelo sustentáveis e incluir os edifícios de seus clientes nele.

"Isso parece ilegal", eu [David Gottfried] disse.

"É feito o tempo inteiro. Perfeitamente legítimo." Mike me assegurou. ${ }^{19}$

Se é na norma malograda da ASTM que está a primeira pista do que viria a ser o LEED ${ }^{\circledast}$, então é nesses edifícios-modelo [demonstrations] feitos no arranjo norte-americano entre mer-

16. Gottfried, 40-41.

17. Gottfried, 41; David Gottfried, (Fundador do USGBC e do World GBC), Entrevista para o autor, Email, 7 de junho de 2018.

18. A ASTM possui normas relacionadas a questões específicas da construção, mas nenhuma que coordene o conjunto de práticas. Cf. "Sustainability standards", ASTM, acessado 11 de setembro de 2018, https://www.astm.org/Standards/sustainability-standards.html.

19. No original: "Mike said Terry had clients who wanted him to get money from Congress for new building projects. Terry's idea was to invent a demonstration green building program and include his clients' buildings in it. 'That sounds illegal', I said. 'It's done all the time. Perfectly legit.' Mike assured me." Gottfried, Explosion green, 55, tradução nossa. 
cado e Estado, extravagante até para um nativo, como revela a desconfiança de Gottfried, que é encontrado o prenúncio do USGBC ${ }^{\oplus}$. Nesse programa de edifícios-modelo, a tarefa de Gottfried, Italiano e Bevels era criar uma ONG para dar apoio a cinco projetos que buscavam financiamento do Congresso: o Iowa Wildlife Center, a Montana State University, o National Institute of Standards and Technology (NIST), o New England Aquarium e o Lamont-Doherty Earth Observatory da Universidade de Columbia, sendo os dois últimos clientes diretos do lobby de Bevels. Havia um montante disponível de um milhão de dólares, a ser repartido igualmente para cada projeto. A ONG foi chamada US Green Manufacturers Council, por meio da qual Gottfried buscava fabricantes que poderiam se tornar membros do conselho e fornecer materiais sustentáveis para o programa de edifícios-modelo. Ao mesmo tempo, como fundamento para os projetos, utilizariam no programa do Congresso a norma da ASTM, naquilo que Gottfried havia elaborado antes do dissenso interno do subcomitê..$^{20}$

Os projetos representados por Bevels conquistaram o financiamento congressual, mas ele se retirou logo em seguida do US Green Manufacturers Council em formação, alegando conflito de interesses: ele não poderia ao mesmo tempo representar seus clientes e ser funcionário de uma organização que facilitaria a venda de produtos para a construção de seus próprios projetos. Face à saída oportunista de Bevels e subitamente sem o impulso inicial do elo com o Congresso, Italiano e Gottfried precisavam decidir qual rumo seguir. Ao invés de cancelarem a entidade, propuseram aos potenciais membros a criação não de um conselho exclusivo de fabricantes, mas de toda a cadeia produtiva da construção civil. Com isso, mediariam os conflitos entre as diversas partes, definiriam o que seria um edifício sustentável e poderiam elaborar seu próprio programa de avaliação, tendo em vista o lançamento então recente do primeiro certificado de construção sustentável, o Building Research Establishment Environmental Assessment Method (BREEAM ${ }^{\circledR}$ ), na Inglaterra. Gottfried e Italiano procuraram Robert Berkebile, presidente do COTE-AIA, para propor que as atividades do comitê fossem financiadas por CEOs interessados, ao invés de convênios com o EPA. Berkebile, entretanto, estava publicando relatórios com sua equipe indicando a toxicidade de materiais de construção, e por isso considerava que havia um potencial de conflito de interesse. ${ }^{21} \mathrm{Na}$

20. Gottfried, 55-59.

21. Robert Berkebile, (Diretor em BNIM), Entrevista para o autor, Telefone, 29 de junho de 2018; Brian Barth, "Is LEED tough enough for the climate-change era?", Citylab, 5 de junho de 2018, https:/www.citylab.com/environment/2018/06/is- 
mesma época, Gottfried e Italiano começaram a realizar reuniões com empresários, e conseguiram apoio da Milliken \& Company, do setor de carpetes; Herman Miller, de móveis de escritório; e Carrier Corporation, de sistemas de climatização. ${ }^{22}$ Com o novo escopo, a entidade foi fundada em 6 de abril de 1993 com o nome de US Green Building Council. ${ }^{23}$

\section{UM PRESIDENTE PARA 0 USGBC@}

Naquela reunião inicial com representantes da Carrier, Rick Fedrizzi foi sugerido para o posto de presidente do USGBC ${ }^{\circledast}$. Convidado em seguida por Gottfried, manteve-se no cargo até o fim de 1999, e como CEO de 2004 a 2016. ${ }^{24}$ Como principal porta-voz do USGBC ${ }^{\circledR}$ nesse período, Fedrizzi é talvez aquele que com mais entusiasmo defendeu a tese de união entre mercado e sustentabilidade ambiental: o "lucro pode salvar o planeta" é o subtítulo de seu livro. ${ }^{25}$ Com Fedrizzi, o USGBC ${ }^{\oplus}$ passou a ser gerido como um negócio, de modo que a sustentabilidade econômica da entidade, e também do certificado, é tão relevante quanto a sua "missão" ambiental. ${ }^{26}$

O convite a Fedrizzi foi feito no início de $1993 .{ }^{27}$ Naquele momento, enquanto trabalhava na empresa que inventou o ar condicionado no início do século XX sob a liderança de Willis Carrier, ${ }^{28}$ Fedrizzi era diretor de marketing ambiental. Respondendo à demanda de um novo CEO, foi encarregado de criar uma linha de ar condicionados ecológicos. Após reunir-se com David Gottfried, Amory Lovins e William Browning, em abril do mesmo ano, Fedrizzi propôs a criação

-leed-tough-enough-for-the-climate-change-era/559478/?utm_source=citylab-daily\&silverid=NDA0MDc4ODA2Nzk4S0.

22. Gottfried, Explosion green, 64-69.

23. Gottfried, 69, 79; Robert Cassidy et al., "White paper on sustainability: A report on the green building movement. Supplement to Building Design \& Construction”, Building Design \& Construction, novembro de 2013, 19.

24. Gottfried, Explosion green, 138; Rick Fedrizzi, Greenthink: how profit can save the planet, Prefácio de Leonardo DiCaprio (Charleston, SC: Disruption Books, 2015), 209; Rick Fedrizzi, "Rick Fedrizzi to join the International WELL Building Institute as Chairman", USGBC, 6 de julho de 2016, https://www.usgbc.org/articles/rick-fedrizzi-join-international-well-building-institute-chairman.

25. Fedrizzi, Greenthink.

26. Essa interpretação é recorrente nas referências. Além do próprio livro de Fedrizzi, também Peter Templeton, (Vice-diretor de Desenvolvimento de Mercado Global do USGBC), Entrevista para o autor, 20 de abril de 2018.

27. Gottfried, Explosion green, 76.

28. Cf. Reyner Banham, The architecture of the well-tempered environment (Londres, Reino Unido; Chicago, EUA: The Architectural Press; The University of Chicago Press, 1969). 
de um selo ecológico para os produtos da Carrier. ${ }^{29} \mathrm{~A}$ tarefa de aperfeiçoar os equipamentos coube aos engenheiros; Fedrizzi, como diretor de marketing, desenvolveu os selos:

Enquanto os engenheiros trabalhavam, eu me dirigi para minha própria especialidade. Eu decidi criar um sistema de avaliação para exibir as novas propriedades dos nossos novos produtos. Eu pedi para um dos melhores designers gráficos que eu conhecia que propusesse logos para as diferentes maneiras com que nós estávamos fazendo nossos ar condicionados mais responsáveis ambientalmente. Eu queria que esses logos fossem descolados, icônicos e rapidamente reconhecíveis. Havia ao todo seis deles: qualidade do ar interno, redução de ruído, distribuição de ar, fluidos refrigerantes, eficiência energética e redução no uso de materiais/conteúdo reciclável.

[...] Se um dos nossos ar condicionados tinha aperfeiçoado seus fluidos refrigerantes, eu colava um adesivo de refrigerantes. Se outro tinha um novo compressor mais eficiente e tinha reduzido seu nível de decibéis, lá iam adesivos de eficiência energética e redução de ruído. [...]

Eu devo assinalar que isso não era um sistema de avaliação chique, consensual, revisado por pares, rigorosamente testado. Eu só estava premiando com adesivos baseado na minha melhor sensação da direção para que os produtos estavam (e deviam estar) apontando. Esse era todo o plano - colocar adesivos em ar condicionados. ${ }^{30}$

Logo, o sistema ainda estava muito longe do que viria a ser o LEED $^{\oplus}$, operando de modo largamente subjetivo. Os selos foram apresentados em janeiro de 1994, em uma feira de fabri-

29. Os relatos são ligeiramente diferentes aqui. No livro de Gottfried, Fedrizzi já tinha criado a linha de equipamentos ecológicos quando os dois se conheceram em um evento em Squaw Valley, CA, no fim de janeiro de 1993; já no de Fedrizzi, a linha é posterior em quase um ano, e os dois teriam se conhecido em abril de 1993. Cf. Gottfried, Explosion green, 76-77; Fedrizzi, Greenthink, 18.

30. No original: "As the engineers worked, I turned to my own area of expertise. I decided to create a rating system to showcase the new features of our new products. I asked one of the best graphic designers I knew to come up with logos for the different ways in which we were making air conditioners more environmentally responsible. I wanted these logos to be cool, iconic, and instantly recognizable. There were six of them in all: indoor air quality, sound reduction, air distribution, refrigerants, energy efficiency, and material reduction/recycled content. [...] If one of our air conditioners had improved its refrigerants, I slapped on a refrigerants sticker. If another had a new, more efficient compressor and had reduced its decibel level, on went the stickers for energy efficiency and sound reduction. [...] I should point out that this was not some fancy, consensus-based, peer-reviewed, rigorously tested rating system. I was just awarding stickers based on my best guess of the direction the products were (and should have been) heading. That was the whole plan - put stickers on air conditioners." Fedrizzi, Greenthink, 19-20, tradução nossa. 
cantes vinculada a American Society of Heating, Refrigerating, and Air-Conditiong Engineers (ASHRAE).${ }^{31}$ Segundo Fedrizzi, apesar da simplicidade do plano, já que a entrega dos adesivos era inteiramente intuitiva, houve grande rebuliço entre fabricantes e jornalistas. "Eu tinha começado a criar uma marca", e em contraste ao plano simples, o marketing teria causado efeitos profundos nos novos equipamentos. ${ }^{32}$ Para justificar a estratégia, Fedrizzi defende uma terceira via além das duas posições ambientalistas que identifica como prevalecentes. Por um lado, havia aquela da literatura clássica do ambientalismo, como a militância contra o pesticida DDT por Rachel Carson em seu conhecido livro Primavera silenciosa, ou o conservacionismo de áreas naturais por Aldo Leopold: por melhor que fossem, os textos estavam muito distantes do plano industrial em que Fedrizzi se encontrava, e das metas de vendas que precisava garantir como diretor de marketing. Por outro, Fedrizzi diz se diferenciar do costumeiro greenwashing, onde os mesmos produtos continuavam a ser comercializados, mas apenas com embalagens dirigidas a um público-alvo preocupado com o impacto de seu consumo sobre o meio ambiente. A terceira via seria aquela do então recém-lançado livro de Paul Hawken, The ecology of commerce: a incorporação da ecologia nas decisões corporativas, como incentivo aos negócios; a harmonização entre restauração da natureza e técnicas de livre mercado. ${ }^{33}$ Os selos de Fedrizzi prestigiariam os equipamentos, incentivariam sua virada ambiental e facilitariam a transmissão da mensagem aos usuários; se alinhariam, desse modo, ao proposto por Hawken.

Entretanto, está ausente das duas fontes autobiográficas até aqui esmiuçadas que assim como a entrada de Gottfried no setor da sustentabilidade se deu em momento de estagnação do setor imobiliário, assim também os sistemas de climatização se encontravam naquele momento em dificuldades. Em 1987, o Protocolo de Montreal havia coibido o uso de CFC, o principal refrigerante existente no mercado, devido a seus efeitos nocivos à camada de ozônio. ${ }^{34}$ Empresas

\footnotetext{
31. Fedrizzi, cap. 1. A data da feira não pôde ser localizada e não é citada diretamente no texto. Foi induzida a partir dos relatos de Gottfried (2014) e Fedrizzi (2015), além de Fedrizzi mencionar que, um ano antes da feira, havia lido o recém-lançado The ecology of commerce.

32. No original: "I had begun to create a brand." Fedrizzi, 21, grifo no original, tradução nossa.

33. Paul Hawken, The ecology of commerce: a declaration of sustainability (Nova York: HarperCollins Publishers, 1993). Para mais detalhes, ver capítulo 4 .

34. Mark Skaer, “The 1990s: the decade of refrigerant chaos - and change", ACHR News, 25 de abril de 2001, https://www. achrnews.com/articles/84856-the-1990s-the-decade-of-refrigerant-chaos-8212-and-change; Organização das Nações Unidas, "Montreal Protocol on Substances that Deplete the Ozone Layer", 1987, http://www.un-documents.net/mpsdol.htm. 
como a Carrier precisavam então não só construir uma alternativa aos equipamentos baseados no CFC, pois vinham sofrendo pressão do EPA para que fossem drasticamente reduzidos e controlados, mas também reabilitar a imagem danificada do setor de climatização.

\section{CONSTRUINDO 0 CONSENSO}

O lançamento do USGBC ${ }^{\circledast}$ foi oficializado em um evento no AIA de Washington DC. Estavam presentes os três membro-fundadores físicos, além de cerca de sessenta empresas que aceitaram dar apoio, dentre as quais são diretamente citadas: no setor de energia, a Pacific Gas and Electric Company (PGE) e a San Diego Gas and Electric (SDG\&E); em consultoria de engenharia, a atual WSP; entre organizações ambientais, o Rocky Mountain Institute (RMI) e o Natural Resources Defense Council (NRDC). ${ }^{35}$ Para as filiações iniciais, foram procurados representantes das mais diversas fases da cadeia produtiva da construção civil, por um lado, e por outro excluídas as associações comerciais. Para Gottfried, ao defenderem os interesses de categorias empresariais específicas, as associações comerciais poderiam paralisar as discussões do USGBC ${ }^{\circledast}$, como ocorrera no subcomitê da ASTM. As associações comerciais seriam em muitos casos formadas por lobistas, para quem "uma organização sem fins lucrativos poderia servir como um escudo para seus membros assumirem questões controversas sem expor sua marca corporativa pessoal." ${ }^{36} \mathrm{O}$ $\mathrm{USGBC}^{\circledast}$ aderia, assim, "mais ao espírito do que à letra do ANSI" ${ }^{37}$ - Quando o conselho ficou melhor estabelecido, a posição foi revista e essas associações passaram a ser aceitas também. ${ }^{38}$

Com a credibilidade trazida pela presidência de Fedrizzi, as empresas tornaram-se membros do $\mathrm{USGBC}^{\circledast}$ mediante o pagamento de uma taxa de inscrição que permitiu a contratação do primeiro grupo de funcionários e a estabilização financeira de Gottfried, naquele momento

35. Gottfried, Explosion green, 70-74, 79.

36. No original: "A nonprofit organization could serve as a shield for its members to take on controversial issues without exposing their personal corporate brand." Gottfried, 75, tradução nossa.

37. No original: "to the spirit rather than the letter of ANSI." Informação obtida a partir de entrevistas com David Gottfried e Kevin Hydes. Cf. David M. Hart, "Don't worry about the government? LEED Green Building Rating System and Energy Efficiency in US Commercial Buildings", MIT Industrial Performance Center. Energy Innovation Working Paper, $\mathrm{n}^{\circ}$ 09-001 (março de 2009): 8, tradução nossa.

38. Gottfried, Explosion green, 87. 
o único desempregado e integralmente comprometido com a organização. Os valores eram relativamente baixos: em uma ponta, empresas com faturamento anual superior a US\$ 1 bilhão pagavam US\$ 10.000 por ano, mais uma taxa de inscrição de US\$15.000; na outra ponta, ONGs pagavam anualmente US\$ 300; os demais casos distribuíam-se entre esses dois extremos. Naquele momento, a ênfase de filiação era corporativa. Por um lado, as empresas tinham maior peso estratégico. Por outro, em argumento mais pragmático, tanto empresas quanto indivíduos representam os mesmos custos fixos, como correio e carga de trabalho, mas os indivíduos têm menor escala de influência e normalmente pagam menores taxas de inscrição. ${ }^{39}$

No evento, foram apresentadas as medidas inaugurais do USGBC ${ }^{\circledR}$. A primeira era a aceleração das normas ASTM a respeito da construção sustentável, já que a configuração da ONG reduzia o poder de dissenso por grupos de lobistas. A segunda era a elaboração de normas para produtos sustentáveis que pudessem guiar os fabricantes. A terceira medida inaugural era a criação de uma versão local do já existente sistema de avaliação britânico, o BREEAM ${ }^{\oplus}$. A quarta, por fim, era a fundação de um centro de informações que reunisse dados sobre construção sustentável..$^{40}$ Entretanto, pelos relatos, a relação com a ASTM continuou sendo apenas um ponto de referência para as próprias práticas internas do USGBC; ${ }^{\bullet}$ e as normas para fabricantes, segundo Gottfried, se mostraram complexas demais para serem realizadas. Dessas medidas, são as duas últimas que ganharam maior protagonismo.

Naqueles momentos iniciais do USGBC ${ }^{\circledast}$, algumas estratégias ainda não estavam delineadas. Não estava tão clara, por exemplo, a sua "gestão como um negócio". Ou ainda, o modelo da cenoura contra o chicote, para usar uma fórmula gasta de manuais de gestão, segundo a qual, ao invés de punir as piores práticas do empresariado, se deveria incentivar as melhores. Um exemplo dessa indefinição inicial, logo no primeiro ano do USGBC ${ }^{\oplus}$, é Italiano propondo a estratégia do chicote:

Os produtos seriam taxados baseados no seu nível de poluição, como na quantidade de dióxido de carbono produzido no processo de fabricação. Se duas placas de carpete, por exemplo, eram produzidas por dois processos diferentes, o carpete "mais verde" teria uma redução fiscal. Sua determinação "verde"

\footnotetext{
39. Gottfried, 82-83.

40. Gottfried, 81-82. 
viria de um processo mais aperfeiçoado ambientalmente: o uso de materiais com conteúdo reciclável, plantas industriais com energia limpa derivada de painéis solares ou hidrelétricas, ou outros atributos verdes. Diversos grupos ambientalistas, tais como o World Resources Institute e Redefining Progress, estavam estudando o potencial impacto no mercado dessa taxa. Mike [Italiano] estava fascinado pelo conceito e, uma vez que o conselho [USGBC ${ }^{\circledR}$ ] era uma realidade, juntou um grupo, composto por alguns arquitetos, nossos membros de organizações ambientais e outros, incluindo a Herman Miller, para estudar sua aplicabilidade para a indústria da construção civil. Teoricamente, essa redução de taxas poderia tornar a alternativa verde mais barata, encorajando então as pessoas a comprá-la. ${ }^{41}$

Gottfried concordava com a proposta, mas ela foi mal recebida pelos fabricantes. O vice-presidente do USGBC ${ }^{\circledR}$ à época, William King da Armstrong World Industries - uma fabricante de forros, divisórias e coberturas -, teria afirmado que "Ainda está muito cedo para estudarmos isso... Nós ainda nem definimos a construção sustentável, e muito menos desenvolvemos procedimentos e políticas", ${ }^{42}$ ecoando uma posição comum a diversos membros. O diagnóstico era compartilhado pelo conselho diretor, formado por doze representantes de diferentes setores da construção civil, incluindo membros de organizações ambientais, como William Browning do Rocky Mountain Institute e Robert Watson do NRDC..$^{43}$ Em uma reunião, Jan Beyea, representante da National Audubon Society, defendeu a taxa; sendo voto vencido dentro do conselho, renunciou

\footnotetext{
41. No original: "Products would be taxed based on their level of pollution, such as the amount of carbon dioxide produced in the manufacturing process. If two carpet tiles, for example, were produced by different processes, the 'greener' carpet would get a tax break. Its 'green' determination would come from a more environmentally enhanced process: use of recycled-content materials, 'clean' manufacturing plant energy derived from solar panels or hydroeletric, or other green features. Many environmental groups, such as World Resources Institute and Redefining Progress, had been studying the potential market impact for such a tax. Mike was enthralled by the concept and, once the council was a reality, had put together a group, made up of some architects, our environamental organization members, and a few others, including Herman Miller, to study its applicability to the building industry. Theoretically, such a tax break could make a green alternative cheaper, thus encouraging people to buy it." Gottfried, 89-90, tradução nossa.

42. No original: "It's just too early for us to study this... We haven't even defined green building, much less developed policies and procedures". Gottfried, 90, tradução nossa.

43. Entre os membros do conselho diretor, além de Gottfried, King, Browning, Beyea e Watson, constam ainda: Chuck Angyal, arquiteto e responsável pela equipe do programa de eficiência energética da San Diego Gas \& Electric; Ross Spiegel, funcionário do Construction Specifications Institute; Steve Piguet; Robert Bell, da fabricante de drywalls US Gypsum; Kath Williams, da Montana State University. Não foram encontradas informações sobre o período exato de participação de cada membro. Gottfried, Greed to green, 132-33, 158; Gottfried, Explosion green, 103.
} 
irritado ao cargo, enquanto acusava os restantes de greenwashing. ${ }^{44}$ Passados mais de vinte anos, Beyea hoje contemporiza, e acredita que sua interpretação à época não se mostrou correta:

Eu acho que o processo LEED tornou-se uma valiosa ferramenta de educação. Embora os ganhos ambientais reais sejam pequenos e provavelmente superestimados, é necessária a educação a partir de numerosas direções para mudar uma sociedade, eu acredito. O LEED tem um papel a desempenhar. Na época, eu não sabia quão difícil era para os arquitetos adotarem novas tecnologias. As margens são pequenas e não há tempo para a maior parte dos arquitetos de se afastar do convencional. O sistema LEED deixa isso mais fácil para os arquitetos, eu acho. Se eu soubesse dessa dificuldade na época, eu provavelmente teria trabalhado para obter os fundamentos para tornar mais fácil e menos arriscado para arquitetos que não se especializaram no campo da arquitetura sustentável trabalharem com novas abordagens sustentáveis em sua prática. ${ }^{45}$

\section{LEED®, PRODUTO DE SUSTENTABILIDADE FINANCEIRA}

Pelos relatos, revelam-se dois encargos centrais para a sobrevivência da organização que nascia. Primeiro, a credibilidade no mercado. Como visto, a presidência de Fedrizzi cumpria esse papel nas relações públicas, garantindo que o USGBC ${ }^{\circledR}$ não fosse visto como um grupo ambientalista antimercado. Cada nova grande empresa a garantir apoio aumentava a força para angariar novos membros. Também o comprometimento de outras instituições favorecia o USGBC . É o caso do

\footnotetext{
44. Gottfried, Greed to green, 128-29; Gottfried, Explosion green, 92-93; Fedrizzi, Greenthink, 28. O nome do cientista só é citado no primeiro livro de Gottfried. Não fica claro quando essa reunião exatamente aconteceu. No relato de Gottfried, entende-se que teria ocorrido no fim de 1993 ou início de 1994. Já em entrevista concedida para essa pesquisa, Beyea afirma que resignou do conselho em novembro de 1996, tendo emails como evidência. Jan Beyea, (Representante da National Audubon Society no primeiro conselho diretor do USGBC), Entrevista para o autor, Email, 7 a 24 de junho de 2018.

45. No original: "I think the LEED process has turned out to be a valuable educational tool. Although the actual environmental gains are small and likely overstated, it takes education from a large numbers of directions to change a society, I think. LEED has a role to play. At the time, I was not aware how tough it is for architects to take on new technologies. Margins are small and there is not time for most architects to stray from conventionality. The LEED system makes it easier for architects, I think. Had I known this difficulty at the time, I would probably have worked to get foundations to make it easier and less risky for architects who do not specialize in the green architecture field to work new green approaches into their practice." Beyea, (Representante da National Audubon Society no primeiro conselho diretor do USGBC), Entrevista para o autor, tradução nossa.
} 
NIST, ligado ao Departamento de Comércio dos Estados Unidos, ao auxiliar na promoção de eventos; e do Construction Specification Institute (CSI), formado por profissionais da construção civil. ${ }^{46} \mathrm{O}$ acúmulo de filiações garantia o aumento da capilaridade do USGBC ${ }^{\bullet}$ dentro do setor da construção.

O segundo encargo central era a estabilidade financeira da organização, que depois do primeiro ano já enfrentava problemas para cobrir suas despesas. Durante certo período, as atividades só foram mantidas graças aos recursos pessoais de Gottfried. ${ }^{47}$ Entre indas e vindas, entre distanciamento e reaproximação de Gottfried ao USGBC ${ }^{\circledast}$, o que de fato estabilizou as finanças foi outro suporte governamental, somado ao programa de edifícios-modelo do Congresso e à assistência do NIST. Dessa vez, uma subvenção do DOE de 800 mil dólares, liberados entre 1997 e 1999 diretamente para criação de um sistema de avaliação - o LEED ${ }^{\circledR}$. O incentivo foi conquistado por Robert Watson, que naquele momento presidia o comitê de desenvolvimento do sistema. ${ }^{48} \mathrm{O}$ sistema foi desenvolvido por um comitê formado por voluntários, muitos anteriormente envolvidos em trabalhos como o EPICenter em Montana, um laboratório de alta eficiência com projeto liderado por Bob Berkebile, ou profissionais oriundos de outros programas, como aqueles de sustentabilidade da Casa Branca e do Pentágono. ${ }^{49}$

Como já dito, o LEED ${ }^{\circledR}$ espelhava-se no certificado britânico BREEAM ${ }^{\circledR}$. Robert Watson, na liderança da equipe de organização de um sistema para o USGBC ${ }^{\oplus}$, chegou a considerar a apropriação do certificado britânico. Mas descartou-o por considera-lo excessivamente dependente de uma assessoria para o processo de certificação e demasiadamente centrado em emissões de dióxido de carbono, sem tratar de temas mais amplos da energia. ${ }^{50} \mathrm{~A}$ influência chegou a ser direta na na segunda versão do LEED $^{\circ}$, com membros da equipe tendo trabalhado no certificado pioneiro. ${ }^{51}$ De fato, o BREEAM ${ }^{\circledR}$ é o primeiro do gênero de certificados ambien-

\footnotetext{
46. Gottfried, Explosion green, 94-96.

47. Gottfried, 97-98.

48. Gottfried, 127. A importância desse financiamento foi enfatizada em Templeton, (Vice-diretor de Desenvolvimento de Mercado Global do USGBC), Entrevista para o autor.

49. Berkebile, (Diretor em BNIM), Entrevista para o autor; ver também Barth, "Is LEED tough enough for the climate-change era?"

50. Cassidy et al., "White paper on sustainability", 7.

51. Jerry Yudelson, Reinventing green building: why certification systems aren't working and what we can do about it, Prefácio de Pamela Lippe (Gabriola Land, Canada: New Society Publishers, 2016), 29.
} 
tais, criado pelo Building Research Establishment (BRE) em $1990^{52}$ - oito anos antes do LEED ${ }^{\circ}$. A criação do BRE remonta a 1921, quando o órgão foi fundado para a pesquisa de materiais e processos que pudessem aprimorar a construção britânica após a Primeira Guerra Mundial. Naquele momento, chamava-se Building Research Station (BRS) e se encontrava sob os auspícios do Departament of Scientific and Industrial Research. As metas do BRS se expandiram progressivamente e seu vínculo estatal revezou-se entre diversos departamentos e ministérios: absorveu pesquisas em combate ao incêndio, conforto ambiental, planejamento urbano, geotecnia e fatores humanos na construção; colaborou com a reconstrução no pós-guerras, com a reabilitação de conjuntos habitacionais e com o ensino universitário; associou-se ao desenvolvimento industrial e a políticas públicas. A partir de 1986, o agora BRE foi distanciado do governo e passou a ser gerido como um negócio, atraindo investimento privado. Em 1990, tornou-se uma agência governamental. Por fim, em 1997, foi vendido como fundação sem fins lucrativos para um conjunto de cem organizações. ${ }^{53}$

Um estudo interno realizado em 1993 mostrou que a aquisição de novas informações através da realização de pesquisas ocupava menos de metade do esforço técnico do BRE; a maior parte estava devotada ao uso do conhecimento e experiência que o BRE e o resto da comunidade internacional de pesquisa haviam acumulado por 75 anos. Isso refletiu-se nas contribuições do BRE para padrões, sua promoção de eficiência energética, seu aconselhamento a departamentos governamentais, atividades de consultoria e o desenvolvimento de ferramentas de aplicação tais como o BREEAM. ${ }^{54}$

52. BRE (Building Research Establishment), BREEAM International New Construction. Technical Manual (Watford: BRE, 2014).

53. Sintetizada aqui, a história do BRE é longa e relacionou-se aos mais diversos aspectos do ambiente construído, desde a provisão de saneamento básico a países africanos até o controle da inclinação da Torre de Pisa. Para mais detalhes, consultar Roger Courtney, "Building Research Establishment - past, present and future”, Building Research \& Information 25, n 5 (1997): 285-91, https://doi.org/10.1080/096132197370264.

54. No original: "An internal study carried out in 1993 showed that acquiring new information through carrying out research occupied less than half of BRE's technical effort; the greater part was devoted to using the knowledge and experience that the BRE and the rest of the international research community had built up over 75 years. This was reflected in BRE's contributions to standards, its promotion of energy efficiency, its advice to Government Departments, consultancy activities and the development of application tools such as BREEAM." Courtney, 288, tradução nossa. 
O BREEAM ${ }^{\odot}$ fez parte da transformação do BRE em agente de mercado. De fato, o primeiro sistema era eminentemente comercial, direcionado a edifícios de escritórios. Seguindo a análise dos pesquisadores Faulconbridge e Yalciner, ressalte-se que esse sistema de avaliação se apoia em critérios de desempenho relacionados ao consumo de energia e de água, à produção de lixo e poluição; gratifica "melhores práticas" de sustentabilidade, como em infraestrutura predial para ciclistas; e classifica o projeto em diferentes níveis, de acordo com a pontuação obtida.$^{55} \mathrm{O}$ potencial do BREEAM ${ }^{\circledR}$ como produto comercial foi aumentado com a privatização do BRE: ele ficava então desimpedido para expandir transnacionalmente, adaptar-se a novas tendências e conquistar mercados emergentes. ${ }^{56}$

Pari passu, a criação do $\mathrm{LEED}^{\circledR}$ colocava um sistema a mais no mercado global, em competição com o BREEAM ${ }^{\circledR}$.

Na versão piloto de agosto de $1998,{ }^{57}$ havia apenas um sistema LEED ${ }^{\oplus}$, referente a Novas Construções (NC). Ele possuía 69 pontos, distribuídos em seis categorias: Sustainable Sites (SS), Water Efficiency (WE), Energy and Atmosphere (EA), Materials and Resources (MS), Indoor Environmental Quality (EQ) e Innovation and Design Process (ID). Naquele momento, o próprio $\mathrm{USGBC}^{\circledast}$ avaliava o cumprimento dos créditos e, dependendo de seu desempenho, o projeto era classificado como Certificado (26 a 32 pontos), Silver (33 a 38 pontos), Gold (39 a 51 pontos) ou Platinum (a partir de 52 pontos) - uma distinção mais enfática do que no sistema britânico, cujos níveis são Pass, Good, Very Good, Excellent e Outstanding. ${ }^{58}$

Os créditos em geral estabelecem parâmetros que precisam ser atingidos, mas também há pontuação para "melhores práticas". Alguns exemplos: no LEED ${ }^{\circledR}$ NC v2.1, o crédito 4.1 da categoria Sustainable Sites confere um ponto quando o projeto está localizado a até meia milha de uma estação de transporte coletivo sobre trilhos; o crédito 1.2 da categoria Water Efficiency

\footnotetext{
55. James Faulconbridge e Sercan Yalciner, "Local variants of mobile sustainable building assessment models: the marketization and constrained mutation of BREEAM ES”, Global networks 15 (2015): 364, https://doi.org/10.1111/glob.12083.

56. Courtney, "Building Research Establishment - past, present and future”, 291.

57. USGBC (United States Green Building Council), "LEED 2009 for new construction and major renovations with alternative compliance paths for projects outside the US; v. 3 reference guide" (USGBC, 2011), xi.

58. A primeira versão do sistema $\mathrm{BREEAM}^{\circledR}$ não pôde ser localizada, e assim a comparação foi realizada com base no disponível na literatura. A organização foi contatada, mas negou o envio do sistema piloto. USGBC (United States Green Building Council), LEED green building rating system 1.0 (Washington DC: USGBC, 1999); BRE (Building Research Establishment), BREEAM International New Construction. Technical Manual.
} 


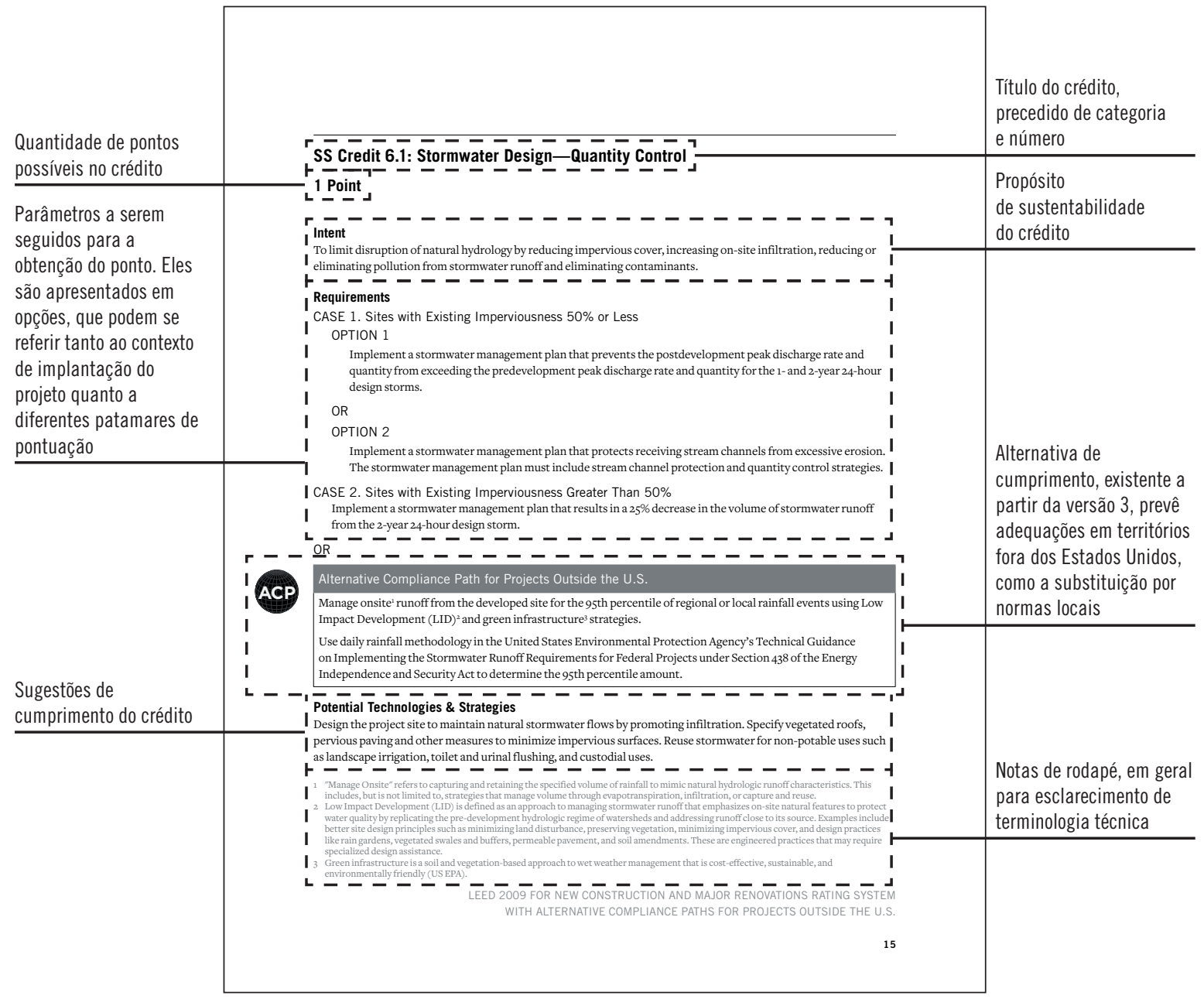

Fig 1.1. Estrutura típica de um crédito do sistema LEED ${ }^{\circledR}$.

Fonte: LEED ${ }^{\circledR}$ NC v.3, revisão de 2011. Inclui intervenções do autor. 
concede outro ponto caso não seja usada água potável na irrigação do paisagismo; mais um ponto caso a obra construída passe por comissionamento, verificando se as especificações projetadas foram adequadamente construídas e reguladas, no crédito 3 de Energy and Atmosphere; a redução em $50 \%$ do rejeito de entulho de obra enviado para aterros confere um ponto no crédito 2.1 de Materials and Resources; carpetes com colas de baixo teor de compostos orgânicos voláteis, os quais são prejudiciais à saúde, representam outro ponto no crédito 4.3 de Indoor Environmental Quality. Além dos créditos livremente escolhidos, cada categoria ainda apresenta certos pré-requisitos para a certificação, como equipamentos de ar condicionado sem uso de CFC (EA. Prereq.3)..$^{59}$

Segundo Gottfried, a segunda versão do $\mathrm{LEED}^{\circledR}$, lançada em março de $2000,{ }^{60}$ avançava em relação à piloto ao estabelecer templates que agilizavam a entrega de documentação. ${ }^{61}$ Já na terceira, de 2009, houve uma tentativa de maior adequação do LEED ${ }^{\circledR}$ a especificidades geográficas. Por um lado, surgiu mais uma categoria, a Regional Priority (RP). Nela são concedidos pontos extras de acordo com o que o USGBC ${ }^{\oplus}$ considera como mais urgente na área do projeto, pontos esses conferidos dentro do conjunto de créditos já existente no sistema. Por outro lado, a especificidade geográfica também estaria presente nos Alternative Compliance Paths For Projects Outside the US (ACP), nos quais são indicadas possibilidades de cumprimento do crédito quando o projeto está fora do território norte-americano e, portanto, sem o jugo de suas normas e leis. Além disso, a versão 3 ainda apresenta um aumento considerável na quantidade pontos disponíveis, de 69 para 110 pontos, flexibilizando o cumprimento do sistema. ${ }^{62}$ Ainda do ponto de vista da estrutura do sistema, a quarta versão, mais recente e de novembro de 2013, tem como principal diferença a criação de uma nova categoria, Location and Transportation (LT), isolando pontos antes alocados em Sustainable Sites. Seu peso dentro do sistema, entretanto, continuou o mesmo. ${ }^{63}$ A cada ver-

59. USGBC (United States Green Building Council), Green building rating system for new construction \& major renovations (LEED NC). Version 2.1 (Washington, DC: USGBC, 2003).

60. USGBC (United States Green Building Council), "LEED 2009 for new construction and major renovations with alternative compliance paths for projects outside the US; v. 3 reference guide", xi.

61. Gottfried, Explosion green, 130.

62. USGBC (United States Green Building Council), "LEED 2009 for new construction and major renovations with alternative compliance paths for projects outside the US; v. 3 reference guide”. As estratégias de adequação geográfica foram destacadas por Templeton, (Vice-diretor de Desenvolvimento de Mercado Global do USGBC), Entrevista para o autor. 63. USGBC (United States Green Building Council), "LEED v4 for building design and construction” (USGBC, 5 de abril de 2016). 


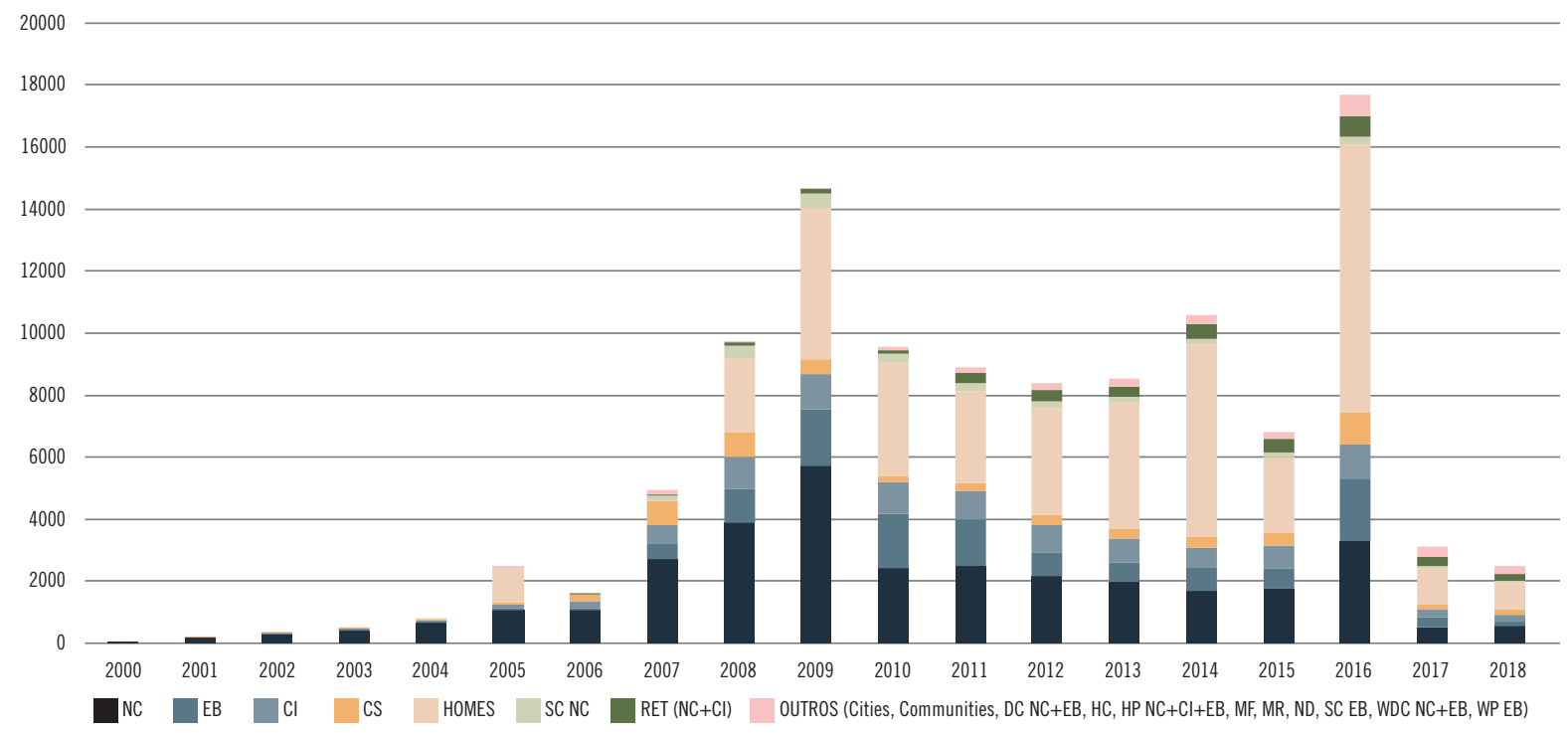

Fig 1.2. Registros LEED ${ }^{\circledR}$ nos Estados Unidos, organizados por sistema. Amostra de 111.236 empreendimentos. Fonte: LEED Project Directory, 4 jan 2019. Elaborado pelo autor.

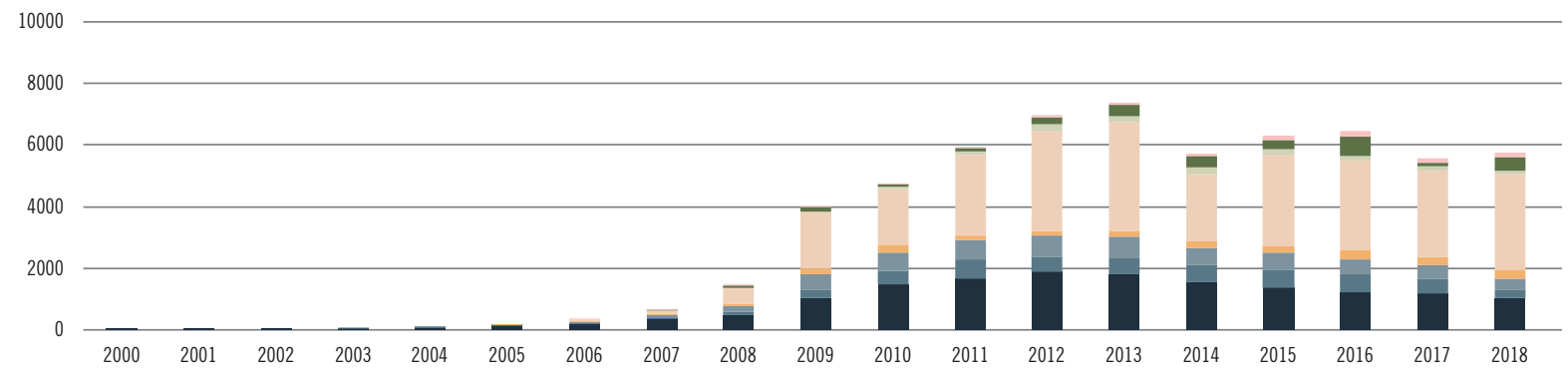

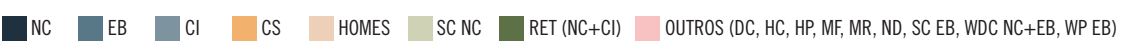

Fig 1.3. Certificados LEED nos Estados Unidos,

organizados por sistema. Amostra de 61.777

empreendimentos. Fonte: LEED Project Directory, 4 jan

2019. Elaborado pelo autor. 
são, somam-se ainda atualizações periódicas (2.1 em 2002, 2.2 em 2005, 4.1 em 2018), embora não com tanta regularidade como o $\mathrm{BREEAM}^{\circ}$, que as faz anualmente desde 2002.

Encontra-se na figura 1.1 a aparência típica de um crédito do sistema LEED ${ }^{\circledR}$. Para efeito de análise, a versão 3 foi usada como base. Em primeiro lugar, porque a versão 3 é a mais comum no Brasil e entre os projetos analisados nesta tese. Em segundo lugar, porque, contraintuitivamente, é a que possui estrutura gráfica mais clara entre todas as versões, incluindo a mais recente v4. O conteúdo do sistema será analisado no próximo capítulo.

Ao longo do tempo, foram criados sistemas específicos para diferentes programas. A versão piloto só possuía o sistema de novas construções (LEED ${ }^{\circledR} \mathrm{NC}$ ). Em seguida, a versão 2 incluiu sistemas de edifícios para locação [speculative buildings] (LEED ${ }^{\circledR}$ Core \& Shell - CS), interiores $\left(\mathrm{LEED}^{\oplus}\right.$ Commercial Interiors - CI), edifícios existentes (LEED ${ }^{\circledast}$ Existing Buildings Operations and Maintenance - EBOM) e escolas (LEED ${ }^{\circledR}$ Schools). Na versão 3 houve profusão de sistemas, adicionando varejo, em novas construções ou renovações (LEED ${ }^{\circledR}$ Retail NC ou EBOM); equipamentos de saúde (LEED ${ }^{\circledR}$ Healthcare); casas unifamiliares (LEED ${ }^{\curvearrowleft}$ Homes); edifícios residenciais multifamiliares (LEED ${ }^{\circledR}$ Midrise); e bairros (LEED $\left.{ }^{\circledR} \mathrm{ND}\right)$. Na última versão, a quarta, os sistemas se reorganizam sob os grupos entre construção e projeto de novas estruturas (LEED ${ }^{\oplus}$ Building Construction and Design $-\mathrm{BD}+\mathrm{C}$ ), operação de edifícios existentes (LEED ${ }^{\oplus}$ Operation and Maintenance $-\mathrm{O}+\mathrm{M}$ ), interiores (LEED ${ }^{\odot}$ Interior Design and Construction - ID +C), além dos já existentes LEED ${ }^{\oplus}$ Homes e LEED ${ }^{\oplus}$ ND. Dentro de cada um desses grupos, além dos programas já existentes, ainda se somam sistemas específicos para data centers, armazéns e centros logísticos e hotéis.

Desses sistemas, o LEED ${ }^{\circledR} \mathrm{NC}$ - pela variedade de programas que abrange - e o LEED ${ }^{\curvearrowleft}$ Homes são os de maior presença no mercado norte-americano [fig 1.2 a 1.4].

Os sistemas foram concebidos a partir de comitês técnicos reunindo voluntários da cadeia da indústria da construção, principalmente projetistas - sejam eles ligados à arquitetura, à engenharia ou ao paisagismo - e consultores de conforto ambiental e eficiência energética [fig 1.5].

Ao redor do LEED ${ }^{\circ}$ foi ainda concebida uma rede de atividades para fortalecer o sistema e o USGBC ${ }^{\circledast}$. Desde 2002, o evento Greenbuild International Conference and Expo é organizado anualmente, contando com "keynote speakers" como Bill Clinton (2007 e 2017), Hillary Clinton (2013), Colin Powell (2010) e Michael Bloomberg (2011). O evento é itinerante pelos Estados 


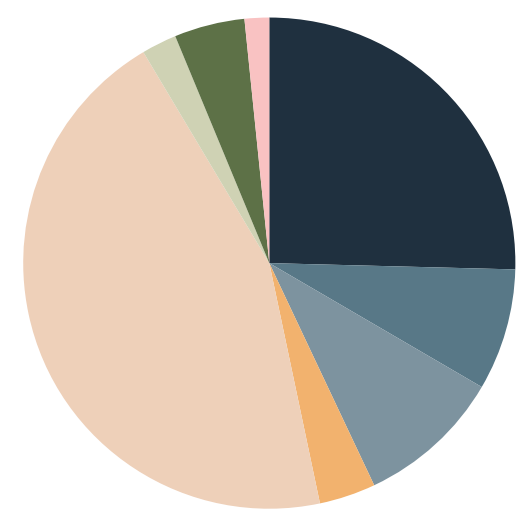

$\square$ NC $\square$ EB $\square \mathrm{Cl} \square \mathrm{CS} \quad$ hOMES SC NC $\square$ REt (NC+Cl) $\square$ OUTROS (DC, HC, HP, MF, MR, ND, SC EB, WDC NC+EB, WP EB)

Fig 1.4. Total de certificados LEED ${ }^{\circ}$ nos Estados

Unidos, organizados por sistema. Amostra de 61.777

empreendimentos. Fonte: LEED Project Directory, 4 jan

2019. Elaborado pelo autor.

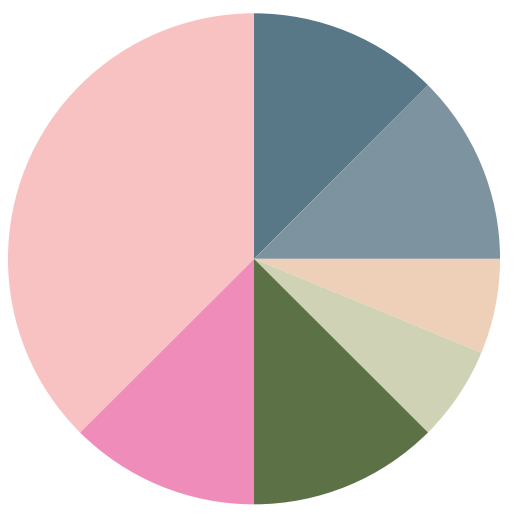

NC v2.2

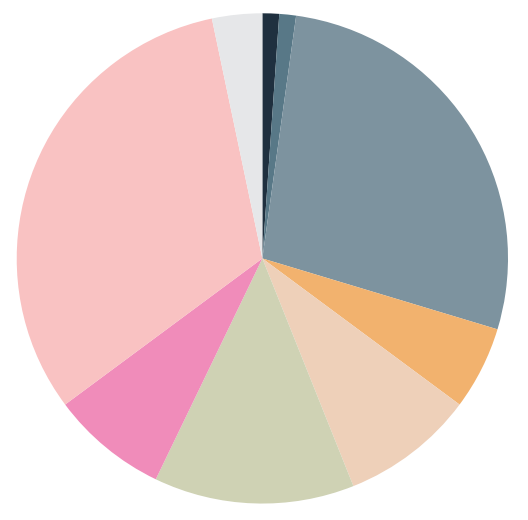

NC V3
Associação comercial
Construtora
Consultoria
Educação
Estado
Fabricante
Incorporadora
ONG
Projetista Serviços

Fig 1.5. Origem profissional de membros do comitê técnico do LEED ${ }^{\circledR}$ NC v. 2.2 e 3. Fonte: LEED $^{\circledR}$ NC v. 2.2 e

3. Elaborado e classificado pelo autor.

Na organização dos comitês técnicos das duas versões, nota-se a considerável redução de construtoras na versão 3, em que tampouco há incorporadoras. Em contrapartida, há substancial crescimento da proporção de consultores e fabricantes - que começam a constituir um campo próprio de sustentação e reprodução do LEED ${ }^{\circledR}$. 
Unidos e conta com palestras sobre edifícios certificados pelo LEED ${ }^{\circledR}$ e mesmo outros sistemas, além de feira de fabricantes [fig 1.6].

Ainda no sentido de formar profissionais para o uso da ferramenta, o USGBC ${ }^{ø}$ vende cursos sobre os diferentes sistemas. Assim preparado, o interessado pode fazer uma prova para LEED $^{\circledR}$ Green Associate (LEED ${ }^{\circledR}$ GA), que certifica seus conhecimentos sobre o sistema. Em seguida, ele também pode prestar exame para LEED $^{\circledR}$ Accredited Professional (LEED ${ }^{\curvearrowleft}$ AP), o que lhe confere não só a certificação de maior treinamento, mas permite também a obtenção de um ponto extra em todo projeto de que participa, dentro da categoria Innovation and Design Process (crédito ID.2). Nenhuma dessas qualificações é, entretanto, imprescindível para o envio da documentação para avaliação.

Essa avaliação dos empreendimentos, inicialmente realizada pelo próprio USGBC ${ }^{\circledast}$, foi transferida a partir da terceira versão para uma instituição específica, o Green Building Certification Institute (GBCI) - renomeado como Green Business Certification Inc. em abril de 2016, devido ao aumento de seu escopo de atuação. ${ }^{64}$ A pontuação no LEED ${ }^{\circledR}$ é aferida primordialmente pela documentação. Uma vistoria da obra é possível, mas opcional segundo a decisão do avaliador, e dificultada em projetos fora dos Estados Unidos - diferentemente do BREEAM ${ }^{\curvearrowleft}$ e sua filiada HK-BEAM ou do canadense Green Globes ${ }^{\oplus}$, os quais, ao invés da checagem documental, fazem a aferição direta do espaço construído. ${ }^{65}$

Em vista da situação periclitante no início do USGBC ${ }^{\circledast}$, pode-se dizer que foi o LEED ${ }^{\circledR}$ que lhe deu estabilidade financeira, não só pelo próprio processo de certificação, mas também pelos diversos produtos associados. É o que afirma o pesquisador David Hart:

O USGBC passou por uma série de crises de gestão enquanto o LEED estava sendo esboçado, quase falindo em mais de uma ocasião. O lançamento da versão piloto do LEED em 1998 pareceu estabilizar a organização. Sua rápida aceitação gerou uma receita muito necessária por meio do registro de projetos

64. USGBC (United States Green Building Council), "LEED 2009 for new construction and major renovations with alternative compliance paths for projects outside the US; v. 3 reference guide", xi.

65. Julie Cidell, "A political ecology of the built environment: LEED certification for green buildings", Local Environment 14, n. 7 (ago de 2009): 627, https://doi.org/10.1080/13549830903089275; John Burnett, "City buildings — Eco-labels and shades of green!", Landscape and Urban Planning, no 83 (2007): 33, https://doi.org/10.1016/j.landurbplan.2007.09.003. 


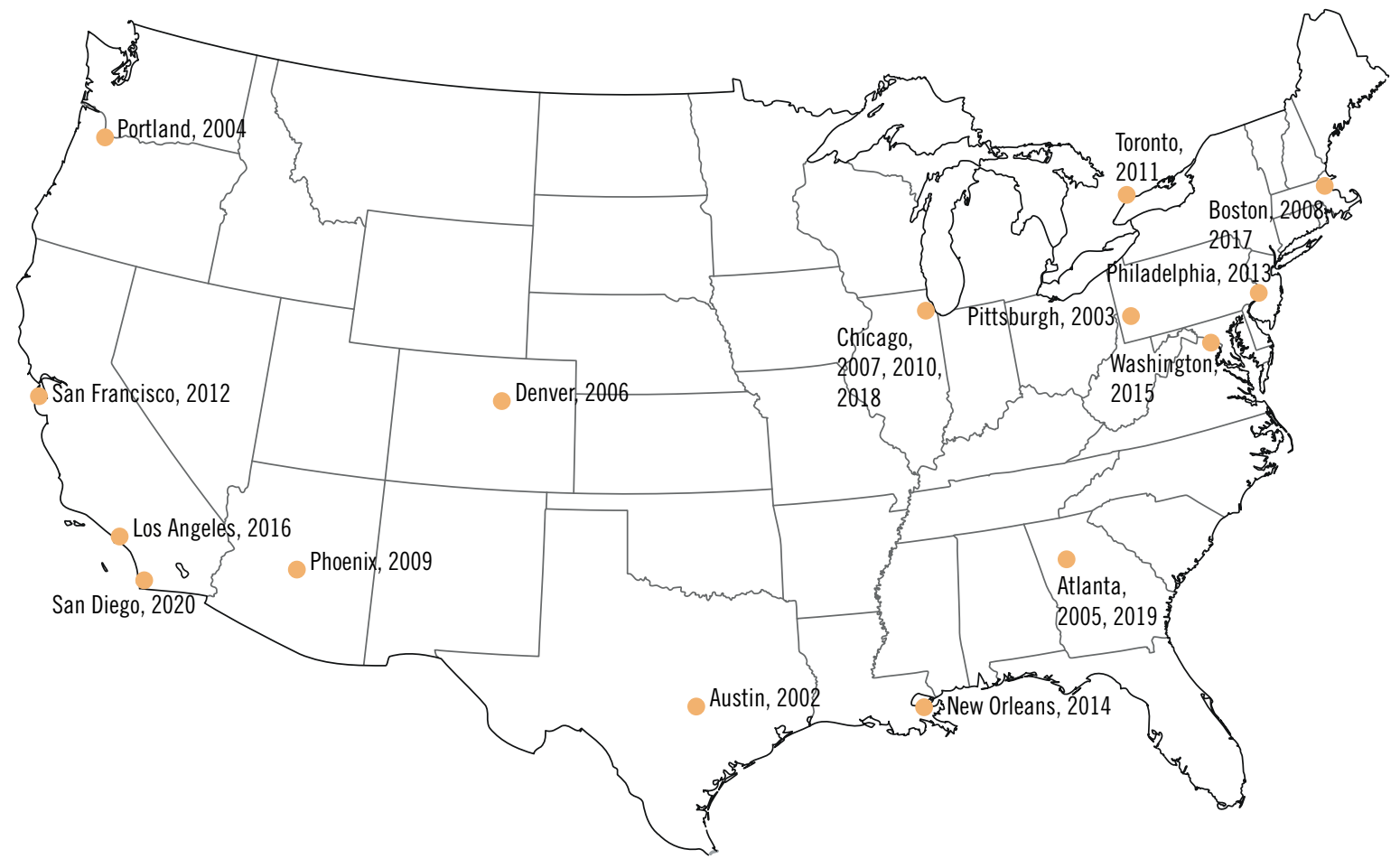

Fig 1.6. Local e ano das feiras Greenbuild nos Estados Unidos. Fonte: Vecteezy. Elaborado pelo autor.
A localização da feira Greenbuild varia ano a ano. Em geral, ela é realizada em cidades com grande número de certificações per capita, como pode ser induzido pela comparação com a fig 1.9, elaborada em artigo de Julie Cidell. Também pode ser percebida a capilaridade do $\mathrm{USGBC}^{\oplus}$ nos Estados Unidos, ainda que os eventos se concentrem em regiões metropolitanas nas costas do país. Sobretudo se essa espacialização for comparada com a versão brasileira do evento: aqui, a feira Greenbuilding aconteceu em São Paulo entre 2011 e 2017, saindo apenas em 2018, quando foi realizada em Curitiba. 
para serem classificados, a venda de publicações e taxas de treinamento. [...] Por volta do começo de 2000, quando foi publicada a versão 2.0 revisada, o USGBC estava finalmente a caminho de realizar a visão de Gottfried de ser uma organização sem fins lucrativos que era "construída como um negócio" e oferecia um "pacote completo de produtos". ${ }^{66}$

\section{LEED® NO TERRITÓRIO NORTE-AMERICANO}

A história do LEED ${ }^{\circledast}$ está em seus agentes, mas também nos edifícios certificados. Por maior que seja o marketing do sistema, os edifícios são aqueles que ao mesmo tempo realizaram todo o processo e estabelecem os modelos a serem superados pela competição de mercado.

Há apenas onze projetos certificados na versão piloto [tab 1.1]. Dois são centros ambientais. Tratam-se, portanto, de casos de exceção, áreas de teste, ensaios do uso do certificado e de estratégias de sustentabilidade. Outros quatro são edifícios governamentais: dois centros de treinamento militar, um tribunal, um laboratório. Dois edifícios compartilham o pioneirismo da certificação, obtida em 30 de março de 2000. É o caso do Phillip Merrill Environmental Center, no nível Platinum, localizado na cidade de Annapolis, próxima a Washington DC [fig 1.7]. Foi construído para a Chesapeake Bay Foundation, entidade ligada à despoluição da baía da qual leva o nome. E também do Kandalama Hotel, no nível Certificado, localizado no Sri Lanka [fig 1.8].

Quando essas certificações ocorreram, a versão 2 já estava no mercado, com expansão muito mais rápida do que na versão piloto. A segunda versão, mais estruturada e com mais sistemas disponíveis, representou a expansão do LEED $^{\circledR}$ pelo território norte-americano. A partir de estudo de Julie Cidell, nota-se como já em 2007 os edifícios certificados estavam distribuídos pelos Estados Unidos, mesmo se algumas áreas apresentassem concentração maior [fig 1.9]. A capilaridade deveu-se a três frentes. Em primeiro lugar, empresas incorporaram o LEED $^{\circledR}$ como prática habitual, certificando seus novos edifícios. Foi o caso de montadoras de automóveis como

66. No original: "USGBC went through a series of management crises while LEED was being drafted, nearly going under on more than one occasion. The launch of the LEED pilot version in 1998 seems to have stabilized the organization. Its rapid uptake generated much-needed revenue through registration for projects to be rated, sale of publications, and training fees. [...] By early 2000, when it published the revised LEED version 2.0, USGBC was finally on its way to fulfilling Gottfried's vision of being a non-profit that was "built like a business" that offered a "full suite of products"' Hart, "Don't worry about the government? LEED Green Building Rating System and Energy Efficiency in US Commercial Buildings”, 9, tradução nossa. 


\begin{tabular}{llll}
\hline Projeto & Certificação & País & Nível \\
\hline CBF Phillip Merrill Environmental Center & 30 março 2000 & Estados Unidos & Platinum \\
\hline Kandalama Hotel & 30 março 2000 & Sri Lanka & Certificado \\
\hline BEQ, Great Lakes Naval Training Center & 28 agosto 2001 & Estados Unidos & Certificado \\
\hline Steelcase Wood Furniture Manufacturing Plant & 28 setembro 2001 & Estados Unidos & Silver \\
\hline Q Building Lab & 7 fevereiro 2002 & Estados Unidos & Gold \\
\hline Donald Bren School of Environment & 18 abril 2002 & Estados Unidos & Platinum \\
\hline Marion Courthouse & 26 agosto 2002 & Estados Unidos & Certificado \\
\hline Plaza Building, Desert Vista Campus & 28 outubro 2002 & Estados Unidos & Certificado \\
\hline Barksdale Air Force Base Physical Fitness & 13 dezembro 2002 & Estados Unidos & Certificado \\
\hline US EPA, New England Regional Laboratory & 2 fevereiro 2003 & Estados Unidos & Gold \\
\hline The Chicago Center for Green Technology & 17 junho 2003 & Estados Unidos & Platinum \\
\hline
\end{tabular}

Tab 1.1. Projetos certificados pelo LEED New

Construction v. 1 Pilot. Fonte: USGBC, 1 ago 2018.

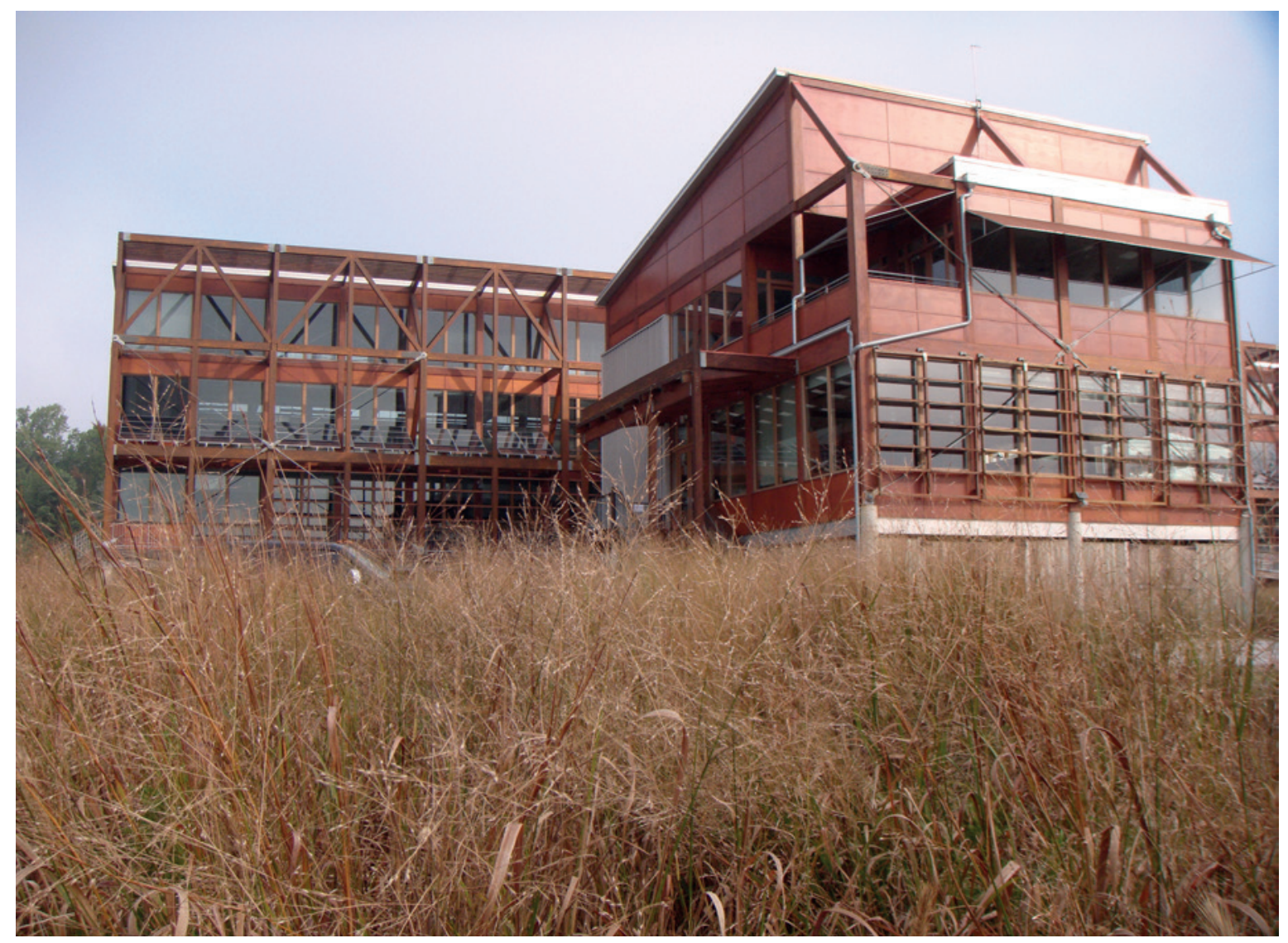

Fig 1.7. Philip Merrill Environmental Center, sede para a

Chesapeake Bay Foundation. Fonte: The Regeneration, via

Flickr, 5 out 2008. 
a Ford e a Toyota, bancos como o PNC, e lojas de móveis como a Steelcase ou de serviços de telefonia como a Sprint. Em segundo, campi universitários usaram o certificado para modernizar suas estruturas, o que permitiu a presença do LEED $^{\circledR}$ mesmo longe de regiões metropolitanas. Em terceiro lugar, a capilaridade do $\mathrm{LEED}^{\circledR}$ se deu também por municípios, ao tornarem compulsória a certificação de edifícios públicos - o que é especialmente significativo nos Estados Unidos, onde as capitais dos estados muitas vezes não coincidem com os centros econômicos e populacionais. ${ }^{67}$ Além da certificação dos seus próprios edifícios, ações governamentais também incentivaram projetos sustentáveis na iniciativa privada. As medidas para tanto foram de diversas ordens: reconhecimento oficial do LEED ${ }^{\circledR}$ como ferramenta de avaliação da sustentabilidade, incentivos fiscais e estímulo da oferta de produtos sustentáveis pela compra governamental dirigida. ${ }^{68}$ Ainda outra vez, o Estado teve papel central na promoção do LEED ${ }^{\circledR}$.

\footnotetext{
67. Julie Cidell, "Building green: the emerging geography of LEED-certified buildings and professionals", The Professional Geographer 61, n. 2 (abr de 2009): 200-215, https://doi.org/10.1080/00330120902735932. Ver também o prefácio de Rick Fedrizzi em livro de Jerry Yudelson, que indica a adoção do LEED ${ }^{\circledR}$ por diversos estados e municípios norte-americanos, o apoio da GSA e a utilização pelos empreendedores do Ground Zero. Cf. Jerry Yudelson, The green building revolution, Prefácio de Rick Fedrizzi (Washington, DC; Covelo, CA; Londres: Island Press, 2008), xv, 9, 11, 26, 32-33, 60 e cap. 8.

68. Julie Cidell e Miriam A. Cope, "Factors explaining the adoption and impact of LEED-based green building policies at the municipal level", Journal of Environmental Planning and Management 57, $\mathrm{n}^{\circ} 12$ (2014): 1763-81, https://doi.org/10.1080/09 640568.2013.835714; Timothy Simcoe e Michael W. Toffel, "Government green procurement spillovers: evidence from municipal building policies in California", Journal of Environmental Economics and Management, $\mathrm{n}^{\circ} 68$ (2014): 411-34, https:// doi.org/10.1016/j.jeem.2014.09.001 Este último artigo foi indicado, em versão de esboço, por Peter Templeton durante a entrevista concedida para a tese. Ver ainda Gottfried, Explosion green, 128-30; Hart, "Don’t worry about the government? LEED Green Building Rating System and Energy Efficiency in US Commercial Buildings".
} 


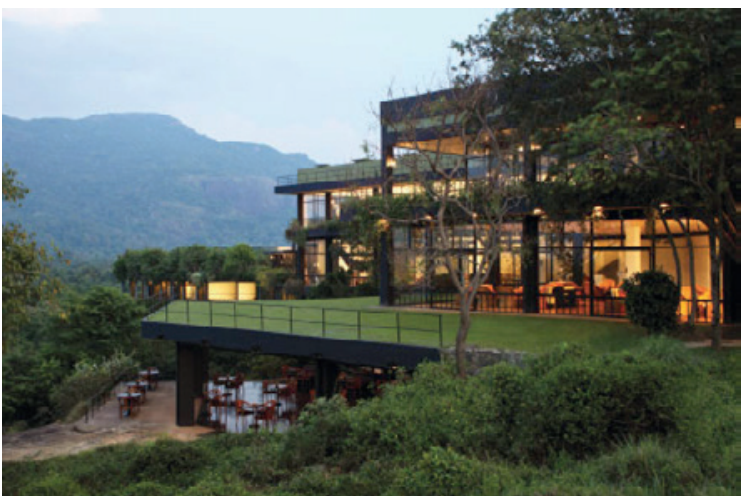

Fig 1.8. Heritance Kandalama Hotel. Projeto de Geoffrey Bawa. Dambulla, Sri Lanka. Foto: Samitha Godamanna. Direitos de Aitken Spence. Fonte: Kiley Jacques, "In the LEED”, USGBC+, acervo online. Acesso em 25 ago 2019. O hotel, implantado entre duas áreas de patrimônio mundial, foi certificado em 2000 no LEED ${ }^{\circ}$ NC piloto, com 24 pontos. Sua certificação ainda na primeira versão do LEED ${ }^{\circledR}$ é vista como evidência do impulso internacionalizante do sistema desde sua concepção.

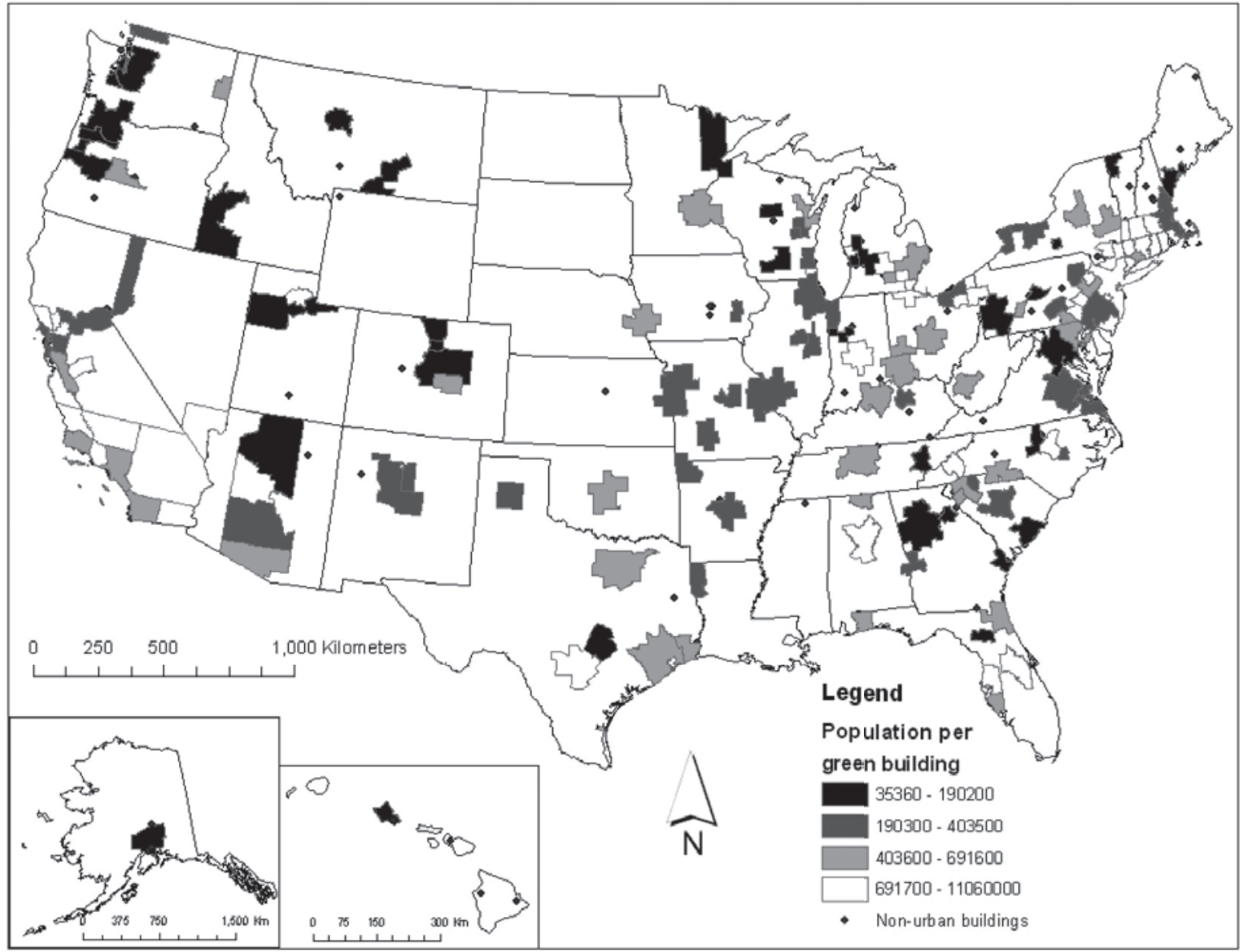

Fig 1.9. Edifícios certificados pelo LEED ${ }^{\circledR}$, per capita, nos Estados Unidos, até 1 out 2007. Fonte: Cidell, “Building green: the emerging geography of LEED-certified buildings and professionals".
O mapa de Julie Cidell indica a concentração de empreendimentos certificados seguindo o que já era sua hipótese: a de maior quantidade certificados em capitais, cidades universitárias e no noroeste dos Estados Unidos. Nessa distribuição per capita, destacam-se, na costa leste, as regiões em torno das cidades de Washington DC, Pittsburgh e Atlanta; na costa oeste, as de Seattle e Portland. 


\section{CAPÍTULO 2}

\section{'VELOCIDADE É QUALIDADE': A EXPANSÃO DE MERCADO}

"Velocidade é qualidade". ${ }^{1}$ É por esse bordão de Mike Italiano que o USGBC ${ }^{\circledast}$ foi guiado. Sua operação deveria ser uma combinação de expansão de uso e aprofundamento de suas ferramentas. A consolidação da entidade só seria possível por conquistas consecutivas nessas frentes de trabalho. Para Gottfried, a estratégia era autodeclaradamente agressiva [scrappy] e em consonância com práticas de mercado posteriormente comuns em big techs como o Google. ${ }^{2}$ Assim, como será exposto, o USGBC ${ }^{\circledast}$ sempre trabalhou em sua própria expansão antes mesmo de ter estabelecidas suas ferramentas. É paradigmático, por exemplo, que a criação do seu braço global, o World Green Building Council, tenha ocorrido apenas um dia antes do lançamento da versão 2 do LEED ${ }^{\circledR}$ - e vale enfatizar que a primeira versão, piloto, teve apenas onze edifícios certificados. Nesse sentido, pode-se considerar duas frentes principais no processo de ampliação de mercado. De um lado está a multiplicação dos produtos ofertados pelo USGBC ${ }^{\circledast}$, seja ela em sistemas LEED ${ }^{\circledR}$, em sistemas especializados ou em escala territorial. De outro lado da estratégia de expansão está a internacionalização do $\mathrm{LEED}^{\circledast}$ por meio do World GBC.

\section{UM SISTEMA PARA CADA PROGRAMA ARQUITETÔNICO}

Começando pela multiplicação de produtos vinculados ao USGBC ${ }^{\circledast}$, a dimensão mais imediata é a proliferação de sistemas LEED ${ }^{\circledR}$. Como visto, passou-se da versão piloto, com apenas um sistema genérico para novas construções (NC), para a versão 2 com cinco sistemas (CI, CS, EBOM, NC, Schools NC), a versão 3 com doze (CI, CS, EBOM, Healthcare, Homes, Midrise, NC, ND,

\footnotetext{
1. No original: "Speed is quality". David Gottfried, Explosion green: one man's journey to green the world's largest industry, Prefácio de Paul Hawken. Introdução de Rick Fedrizzi. (Nova York: Morgan James, 2014), 90, tradução nossa.

2. Gottfried, 90.
} 
ND Plan, Retail CI, Retail NC, Schools NC) e a versão 4 com vinte e quatro (CI, CS, Data Center EBOM, Data Center NC, EBOM, Healthcare, Homes, Hospitality CI, Hospitality EBOM, Hospitality NC, CI EBOM, Midrise, NC, ND, ND Plan, Retail CI, Retail EBOM, Retail NC, Schools EBOM, Schools NC, Warehouse and Distribution Centers EBOM, Warehouse and Distribution Centers NC, Communities e Cities). A quantidade cada vez maior de sistemas representa a estratégia de certificar cada vez mais programas arquitetônicos, aderindo a mercados antes afastados da sustentabilidade. $\mathrm{O} \mathrm{LEED}^{\circledR}$ conseguiu com isso tornar-se ubíquo no espaço construído. A entrada no setor residencial via LEED $^{\circledR}$ Homes e Midrise, por exemplo, representa parcela considerável dos certificados norte-americanos [fig 1.4]. Sistemas relacionados ao varejo, a data centers e centros logísticos, por sua vez, também trouxeram grande número de registros. Isso decorre da facilidade de sua aplicação, já que, como são programas de grande replicabilidade, a solução de um projeto inclui em si a dos demais: feito o detalhamento do projeto de uma loja ou de um galpão, os demais são copiados e adequados a suas respectivas implantações. Para esses programas, o USGBC ${ }^{\circledast}$ enfatiza os benefícios econômicos vindos da eficiência energética e de recursos naturais embutidos no LEED ${ }^{\circledR}$. O que é em muito potencializado pelos ganhos de escala presentes nesses programas - é o caso do Starbucks, que desde 2008 certifica todas suas lojas com LEED ${ }^{\circledast}$ e colaborou na criação da versão piloto para varejo. ${ }^{3}$

A profusão de sistemas ocorre dentro de uma tensão própria à lógica de certificação. $O$ interesse de uma certificação se dá pela sua comparabilidade e abrangência. Por um lado, comparabilidade porque a certificação por um sistema de avaliação busca a equivalência de diversos projetos dentro de um mesmo padrão. O padrão é um modelo ideal, contra o qual os projetos empíricos são equiparados, pontuados e classificados. Por outro lado, a abrangência estabelece o campo amostral em que os projetos são comparados. Quanto maior a amostra, mais preciso é o juízo do projeto, mais exata é a sua distinção. Por isso, apesar da diversidade crescente de sistemas, o LEED ${ }^{\circledast}$ mantém um substrato comum. Embora existam vinte e quatro sistemas da versão 4, a maior parte deles compartilha lógicas de pontuação, estrutura e objetivos, e em alguns casos mesmo créditos, estabelecendo diálogo entre si.

3. Gottfried, 221-22. 


\section{ECOSSISTEMA DE PADRÕES}

Quando esse substrato comum entre os sistemas não é possível, sendo necessária a reordenação completa do modelo, sem o compartilhamento de lógicas com o LEED ${ }^{\oplus}$, surgem sistemas adicionais. Esses representam a segunda vertente da dominação do mercado pela multiplicação dos produtos: os sistemas especializados. O USGBC ${ }^{\circledast}$ passou não só a criar novos sistemas LEED ${ }^{\circledR}$, como também a apoiar e criar outros sistemas, os quais também passaram a ser avaliados via $\mathrm{GBCI}^{\oplus}$. Assim, os produtos se multiplicam. Embora nem sempre tenham sido criados pelo US$\mathrm{GBC}^{\oplus}$, eles ainda assim estão sob sua tutela, já que o processo de certificação desses sistemas está centralizado no GBCI ${ }^{\oplus}$.

Convém um panorama desses diferentes produtos, para explicitar a abrangência de sua atuação. Um dos casos é o WELL ${ }^{\oplus}$ O sistema é um aprofundamento dos créditos relacionados à categoria Indoor Environmental Quality do LEED ${ }^{\circledR}$, funcionando em parceria com o próprio LEED $^{\curvearrowleft}$ e com o sistema Living Building Challenge. Foi criado pelo International Well Building Institute, de Paul Scialla, ex-sócio do Goldman Sachs, e teve apoio de instituições como Clinton Global Initiative, USGBC ${ }^{\oplus}$, International Living Future Institute, $\mathrm{GBCI}^{\oplus}$, Mayo Clinic, $\mathrm{CBRE}$ e Cleveland Clinic Wellness. Seu objetivo é avaliar o grau de bem-estar dos ocupantes dentro do edifício, focado em sua saúde e, também, no aumento de produtividade resultante para o empregador. É uma ferramenta que enfatiza ao mesmo tempo os ganhos de qualidade de vida decorrentes do projeto e o impacto de uma certa "cultura corporativa" ligada ao "capitalismo filantrópico".

O TRUE ${ }^{\bullet}$ (Total Resource Use and Efficiency), por sua vez, concentra-se na eliminação de resíduos. Foi criado em 2013 pelo US Zero Waste Business Council (USZWBC), com o intuito de considerar todo o ciclo de vida dos produtos da construção civil, de seu uso e rejeito. Desse modo, ao menos $90 \%$ dos rejeitos da construção certificada devem ser desviados de aterros sanitários e incineração através de sua redução ou reuso produtivo.

No SITES ${ }^{\circledast}$, acrônimo para Sustainable Sites Initiative ${ }^{\circledast}$ o foco é o paisagismo. Sua primeira versão é de 2007, desenvolvida pela American Society of Landscape Architects, o The Lady Bird Johnson Wildflower Center da University of Texas at Austin e o United States Botanic Garden. Como as reações e transformações do meio natural são difíceis de medir e monetizar, o SITES ${ }^{\bullet}$ pretende reforçar o valor econômico da paisagem e o horizonte de benefícios trazido por ela. Tal 


\begin{tabular}{|c|c|c|c|c|}
\hline Formação & Sistema & Desenvolvimento & Objetivo & Categorias de avaliação \\
\hline 2007 & SITES & $\begin{array}{l}\text { American Society of } \\
\text { Landscape Architects, } \\
\text { The Lady Bird Johnson } \\
\text { Wildflower Center da } \\
\text { University of Texas at } \\
\text { Austin e United States } \\
\text { Botanic Garden }\end{array}$ & Paisagismo & $\begin{array}{l}\text { Site Context, Pre-Design Assessment + } \\
\text { Planning, Site Design - Water, Site Design } \\
\text { - Soil + Vegetation, Site Design - Materials } \\
\text { Selection, Site Design - Human Health + } \\
\text { Well-Being, Construction, Operations + } \\
\text { Maintenance, Education + Performance } \\
\text { Monitoring, Innovation or Exemplary } \\
\text { Performance }\end{array}$ \\
\hline 2013 & TRUE $^{\ominus}$ & $\begin{array}{l}\text { United States Zero } \\
\text { Waste Business Council } \\
\text { (USZWBC) }\end{array}$ & Resíduos & $\begin{array}{l}\text { Redesign, Reduce, Reuse, Compost (Re-Earth), } \\
\text { Recycle, Zero Waste Reporting, Diversion, } \\
\text { Zero Waste Purchasing, Leadership, Training, } \\
\text { Zero Waste Analysis, Upstream Management, } \\
\text { Hazardous Waste Prevention, Closed Loop e } \\
\text { Innovation }\end{array}$ \\
\hline 2014 & Parksmart $^{\circ}$ & $\begin{array}{l}\text { Green Parking Council } \\
\text { e GBCI }^{\oplus}\end{array}$ & Estacionamentos & $\begin{array}{l}\text { Management, Programs, Technology and } \\
\text { Structure Design e Innovation }\end{array}$ \\
\hline 2014 & WELL ${ }^{\circ}$ & $\begin{array}{l}\text { International Well } \\
\text { Building Institute }\end{array}$ & $\begin{array}{l}\text { Saúde } \\
\text { e bem-estar }\end{array}$ & $\begin{array}{l}\text { Air, Water, Nourishment, Light, Fitness, } \\
\text { Comfort e Mind }\end{array}$ \\
\hline 2015 & $\mathrm{EDGE}^{\oplus}$ & $\begin{array}{l}\text { Corporação Financeira } \\
\text { Internacional }\end{array}$ & Sustentabilidade & Energia, Água e Materiais \\
\hline 2015 & $\mathrm{PEER}^{\circ}$ & $\mathrm{GBCI}^{\oplus}$ & Redes de energia & $\begin{array}{l}\text { Reliability and Resiliency; Operations, } \\
\text { Management and Safety; Energy Efficiency and } \\
\text { Environment; Grid Services; Innovation and } \\
\text { Exemplar Performance e Regional Priority }\end{array}$ \\
\hline
\end{tabular}

Tab 2.1. Sistemas administrados pelo GBCI ${ }^{\circledR}$. Elaborado pelo autor. 
valor estaria no custo baixo que medidas preventivas teriam face ao potencial desenrolar catastrófico de uma economia predatória, e mais diretamente nas "funções benéficas" do sequestro de carbono, filtragem do ar e da água e regulação do clima.

$\mathrm{O} \mathrm{PEER}^{\oplus}$ (Performance Excellence in Electricity Renewal) trata especificamente das redes de energia e de seu comportamento em situações de instabilidade do fornecimento. Já o sistema Excelence in Design for Greater Efficiencies $\left(\mathrm{EDGE}^{\oplus}\right)$ foi criado pela Corporação Financeira Internacional, do Banco Mundial, visando ganhos em escala na construção. Embora seja em muitos aspectos semelhante ao LEED ${ }^{\circledR}$, ainda que com menos aspectos avaliados, o sistema destaca que sua função se restringe à avaliação do uso de recursos e que, por isso, "é primeiro e acima de tudo um modelo financeiro e não deve ser usado para realizar decisões estratégicas de projeto." ${ }^{4}$

Por fim, o Parksmart ${ }^{\oplus}$ é o único produto dentre os apresentados com acesso restrito, criado com o objetivo de certificar "estacionamentos sustentáveis". Foi originalmente concebido como Green Garage Certification, depois renomeado quando incorporado pelo $\mathrm{GBCI}^{\oplus}\left[\mathrm{tab}^{2}\right.$ 2.1, fig 2.1].

Cada um desses sistemas avaliados pelo $\mathrm{GBCI}^{\circledR}$ possui particularidades nos métodos de avaliação e na sua relação com os demais e com a arquitetura. A enumeração apresentada acima, ainda que sem detalhamento, visa ressaltar o que Fedrizzi chama de um "ecossistema de ferramentas de avaliação, tecnologias e plataformas interconectadas". ${ }^{5}$ O USGBC ${ }^{\oplus}$, com maior ou menor participação, buscou estabelecer um conjunto de certificados que organizam o projeto e mesmo a experiência do ambiente construído. Cada ferramenta é disposta de modo independente, com um acrônimo atrativo próprio, embora trabalhem em parceria. Desses sistemas, somente o WELL ${ }^{\oplus}$ e o $\mathrm{EDGE}^{\oplus}$ não estão formalmente submetidos ao $\mathrm{GBCI}^{\circledR}$, utilizando apenas sua estrutura de avaliação. Mas mesmo esses sistemas independentes possuem algum grau de relação com o USGBC ${ }^{\circledast}$ O WELL, por exemplo, apesar de ter sido criado por outro órgão, é presidido por

4. No original: “... is first and foremost a financial model and should not be used for making strategic design decisions." Corporação Financeira Internacional, “EDGE. User guide for offices. Version 2.0”, 18 de julho de 2017, 9, tradução nossa.

5. Rick Fedrizzi, "Rick Fedrizzi to join the International WELL Building Institute as Chairman", USGBC, 6 de julho de 2016, https://www.usgbc.org/articles/rick-fedrizzi-join-international-well-building-institute-chairman. 

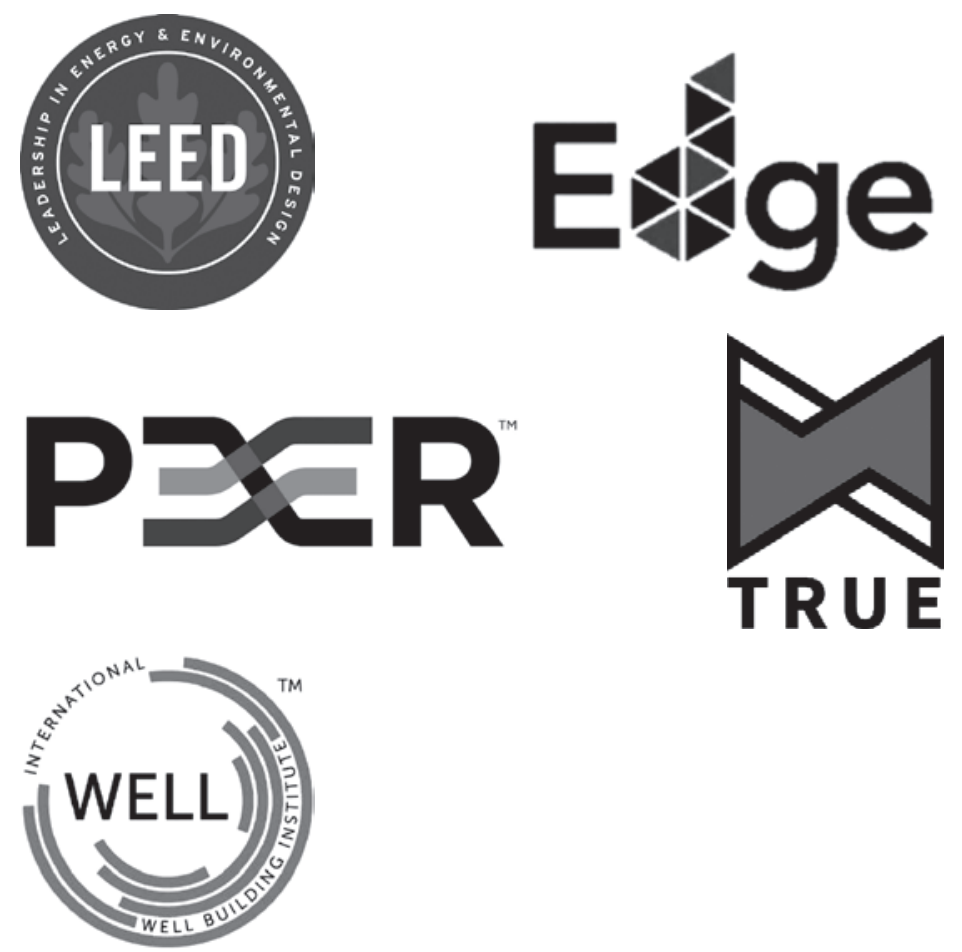

Fig 2.1. Sistemas administrados exclusivamente pelo Green Business Certification Inc.
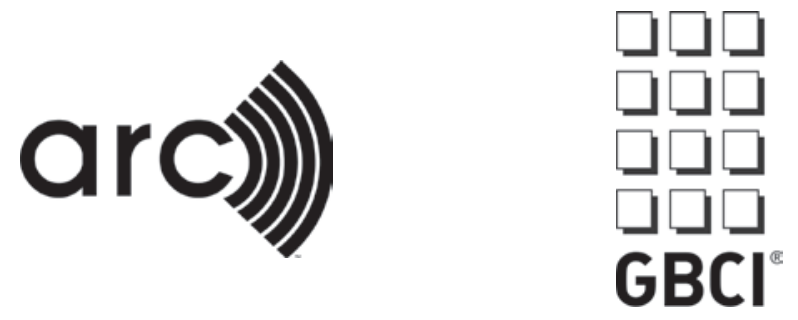

Fig 2.2. Plataformas vinculadas ao USGBC ${ }^{\circledast}$.

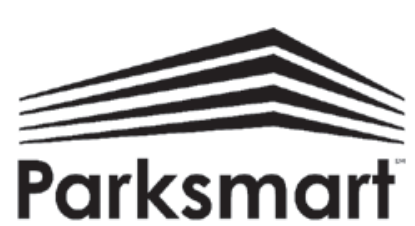

岸Sustainable SITES Initiative 
Rick Fedrizzi desde $2016 .{ }^{6}$ A relação com o LEED ${ }^{\circledR}$ e o USGBC ${ }^{\circledast}$ também se encontra na própria estrutura dos certificados, onde muitos usam o mesmo sistema de níveis do LEED ${ }^{\oplus}$ (Certificado, Silver, Gold e Platinum). O LEED ${ }^{\circledR}$ é então um modelo seguido em diversos desses certificados norte-americanos.

Além do conjunto de selos apresentado, fazem parte do "ecossistema" de Fedrizzi outras plataformas relacionadas a sua operação. A principal é o $\mathrm{GBCI}^{\circledR}$ que, como visto, gere o processo de submissão, avaliação e certificação de projetos. Mas há outras. $\operatorname{Arc}^{\circledast}$ é uma plataforma que concentra os dados de consumo de energia e água dos projetos registrados, com o objetivo de avaliar se a performance dos edifícios certificados é mantida durante a sua ocupação. Com ela, o USGBC ${ }^{\oplus}$ faz frente a alegações de que os edifícios certificados não atingiriam na sua operação a mesma eficiência prevista na documentação para certificação, levantada ao fim da construção do edifício. Com o $\mathrm{Arc}^{\oplus}$, o USGBC ${ }^{\circledast}$ poderia verificar o desempenho desses projetos - e também dispor de uma plataforma que centralizaria dados de performance de milhares de casos. Outra plataforma é o GRESB ${ }^{\oplus}$, Global Real Estate Sustainability Benchmark, que centraliza não os dados da performance no uso de recursos, mas do desempenho financeiro. Por meio dela, o impacto de medidas de sustentabilidade ambiental, social e de governança sobre a valorização de um empreendimento. Assim, o USGBC ${ }^{\circledast}$ busca explicitar os ganhos financeiros que edifícios certificados podem alcançar, utilizando esses dados para atrair mais incorporadores interessados em programas sustentáveis. A ferramenta foi criada originalmente por um grupo acadêmico com pesquisa sobre a valorização dos edifícios certificados, ligado a Maastricht University. Com sua compra pelo $\mathrm{GBCI}^{\oplus}$ em 2014, cinco anos depois da fundação do $\mathrm{GRESB}^{\oplus}$, seus estudos, que até então eram a principal avaliação de terceiros sobre o impacto de valorização do LEED ${ }^{\curvearrowleft}$ no mercado imobiliário, foi internalizada no USGBC ${ }^{\circledast}$. Segundo Fedrizzi:

O advento da construção sustentável criou uma indústria que tem sido difícil de ser avaliada pelos investidores... Os investidores entenderam que a construção sustentável representa um modo significativo de reduzir sua exposição a riscos relacionados a questões ambientais, sociais e de governança, mas, até recentemente, não havia modo de medir isso.

6. Fedrizzi. 
O GRESB entrega o elo faltante ao oferecer um quadro para sua mensuração dentro e entre portfólios... A fusão das duas organizações [GRESB ${ }^{\circledR}$ e $\left.\mathrm{GBCI}^{\circledR}\right]$ vai oferecer uma visão sem precedentes do setor imobiliário global que pode ajudar a proteger e aumentar o valor dos seus investimentos e ao mesmo tempo contribuir para um ambiente construído mais sustentável. ${ }^{7}$

Com essa centralização, hoje permanece difícil, portanto, encontrar estudos sobre a valorização de edifícios certificados em relação aos não-certificados sem conflitos de interesse. E com a combinação entre $\operatorname{Arc}^{\oplus}$ e $\mathrm{GRESB}^{\oplus}$, o $\mathrm{USGBC}^{\oplus}$ entra na fase do big data, almejando deter o conhecimento tanto da operação quanto da valorização de empreendimentos sustentáveis em escala global.

\section{LEED® PARA 0 URBANO}

Foi dito que a proliferação de produtos de sustentabilidade do USGBC ${ }^{\bullet}$ ocorre em diversas frentes. Na primeira, a multiplicação de sistemas LEED $^{\circledR}$ de acordo com os programas dos edifícios. Na segunda, a criação de selos com outras abordagens do objeto arquitetônico, constituindo uma rede de selos. No limite, um mesmo projeto pleitearia diversos certificados, exibindo sua qualidade a partir de diferentes aspectos: sustentabilidade ambiental, bem-estar, redução de lixo, paisagismo sustentável, eficiência energética, estacionamento sustentável etc. A terceira vertente de expansão de mercado se dá pela própria escala de certificação. Isso já podia ser visto no lançamento em 2009 do LEED ${ }^{\circledR}$ for Neighborhood Development, sistema para avaliação de empreendimentos que possuem no mínimo dois edifícios residenciais e no máximo $1,3 \mathrm{~km}^{2}$ de área de terreno. ${ }^{8}$ A certificação deixava, portanto, de abranger apenas edifícios, avaliando a qualidade de

\footnotetext{
7. No original: "The advent of green building created an industry that has been hard for investors to valuate... Investors have come to understand that green building represents a significant way to reduce their exposure to risk related to environmental, social and governance (ESG) issues, but until recently, there was no way to measure it. GRESB delivers the missing link by providing a framework for this measurement within and across portfolios... The merging of our two organizations will provide an unprecedented view of global real estate that can help protect and enhance the value of its investments and contribute to a more sustainable built environment at the same time." Marisa Long, "GBCI joins forces with GRESB", USGBC, out de 2014, https://www.usgbc.org/articles/gbci-joins-forces-gresb, tradução nossa.

8. USGBC (United States Green Building Council), Congress for the New Urbanism, e Natural Resources Defense Council, “LEED 2009 for neighborhood development rating system” (USGBC, 2011), xiv.
} 
bairros inteiros. O mais recente avanço na certificação do território urbano foi feito em 2016, pelo LEED $^{\circledast}$ for Communities e LEED ${ }^{\circledR}$ for Cities, no qual as cidades são avaliadas em parte ou todo de seu tecido urbano. Constam nesse conjunto: Washington DC, onde fica a sede do USGBC ${ }^{\circledast}$ (Platinum), Phoenix no Arizona (Platinum), a smart city Songdo na Coréia do Sul (pré-certificada), Savona na Itália (Gold) e Surat na Índia (pré-certificada). Se levado em conta que essas cidades precisam submeter informações de consumo na plataforma $\mathrm{Arc}^{\oplus}$, o volume de dados controlado pelo $\mathrm{USGBC}^{\circledast}$ atinge escala territorial.

\section{WORLD GBC E OS EMBATES DA INTERNACIONALIZAÇÃO}

LEED $^{\curvearrowleft}$ e USGBC ${ }^{\circledast}$ não se internacionalizaram depois de se tornarem conhecidos nos Estados Unidos. Pelo contrário, a internacionalização é uma estratégia paralela à hegemonização dentro do território norte-americano. De fato, como notado por Peter Templeton, vice-diretor de Desenvolvimento de Mercado Global do USGBC ${ }^{\oplus}$, a internacionalização do $\mathrm{LEED}^{\oplus}$ já estava presente desde a versão piloto, na qual um dos onze projetos certificados era o Kandalama Hotel, no Sri Lanka [fig 1.8]. Para Templeton, o escopo internacional do LEED ${ }^{\oplus}$ estaria então presente desde a fundação do sistema. ${ }^{9}$

Pela narrativa de Gottfried, o interesse de agentes internacionais em criar sistemas semelhantes ao LEED ${ }^{\curvearrowleft}$ também teria ocorrido rapidamente. Em primeiro lugar, houve o convite do japonês Takatoshi Ishiguro, arquiteto no escritório de engenharia Syska Hennessy Group, em Nova York. A empresa foi uma das fundadoras do USGBC ${ }^{\oplus}$, e Ishiguro pretendia começar sua própria organização sustentável no Japão. Após contato inicial com Gottfried em um evento de membros do USGBC ${ }^{\circledast}$, em 1995, Ishiguro realizou viagens a edifícios sustentáveis norte-americanos até fundar o Japan Green Building Council (JGBC) em 1998, com a ajuda do USGBC ${ }^{\circledast}$. O percurso não foi sem incidentes, e Gottfried relata em seu livro muita desconfiança ao não entender o que ocorria nas reuniões em japonês a que era convidado. O pressentimento era de que estaria sendo usado não para fundar outra ONG, mas para impulsionar os serviços de consultoria de Ishigu-

9. Peter Templeton, (Vice-diretor de Desenvolvimento de Mercado Global do USGBC), Entrevista para o autor, 20 de abril de 2018. 
ro. Tanto pior era seu diagnóstico quando, alguns anos depois, foi avisado que o termo "green building" fora registrado como marca por Ishiguro no Japão - ação criticada e posteriormente revertida. ${ }^{10} \mathrm{O}$ episódio não ficou isolado ao Japão e a narrativa de Gottfried alterna o desejo de expandir suas ideias para outros territórios com alguns ruídos nas diferenças culturais e a suspeição, por vezes comprovada, de que seus parceiros estrangeiros não compartilhavam seu ponto de vista sobre o modo de funcionamento do conselho.

Aproveitando a oportunidade de palestrante no evento de fundação do JGBC, Gottfried anunciou sua intenção de fundar um World Green Building Council, “imaginando que se o Japão estava interessado no modelo do conselho, outros países estariam também" ${ }^{11}$ Naquele momento, não havia nenhum movimento concreto, mas Gottfried já marcava sua posição. A primeira reunião de organização aconteceu um ano depois, em novembro de 1999, com a presença não só de Gottfried e Ishiguro, mas também de Nigel Howard, então diretor do Center for Sustainable Construction, órgão do Building Research Establishment que havia criado o sistema BREEAM; Che Wall, um consultor de sustentabilidade australiano; Aurelio Ramírez-Zarzosa, que já vinha tentando fundar um GBC España (GBCe) desde o primeiro semestre de 1999; um representante russo, não nomeado; Rick Fedrizzi e Mike Italiano; além de ao menos cinco outros membros não especificados. $^{12}$

Pelo relato do próprio Gottfried, a reunião foi tensa. Os envolvidos, e em especial Ishiguro, viam na proposta uma tentativa de o USGBC ${ }^{\circledast}$ controlar a rede global de conselhos sustentáveis - e por meio deles disseminar o uso do LEED ${ }^{\circledR}$. Gottfried apresenta em seu relato extensa defesa, argumentando que nem o controle norte-americano nem o uso compulsório do LEED ${ }^{\circledR}$ eram objetivos da organização em germe:

Eu já tinha explicado várias vezes para ele [Ishiguro] que nenhuma pessoa nem entidade controlaria o conselho diretor da coalizão sem fins lucrativos. Nós teríamos funcionários, mas o grupo reunido ainda não os havia eleito, embora eu esperasse que isso acontecesse até o fim do dia. Estava claro que ele pen-

\footnotetext{
10. Gottfried, Explosion green, 153-58.
}

11. No original: "figuring that if Japan was interested in the council model, other countries would be, too." Gottfried, 155, tradução nossa.

12. Gottfried, 159-60. 
sava que o USGBC e eu controlaríamos o World GBC. Pelo contrário, eu havia me esforçado para evitar que isso acontecesse. No lugar de fundar um conselho global de dentro do USGBC, eu o havia criado como uma entidade separada, convidando o conselho dos EUA para assumir apenas uma cadeira no conselho diretor. O USGBC tinha não só concordado com essa estrutura, mas também com o princípio de que o conselho global seria neutro em sistemas de avaliação: o USGBC não iria obrigar que o World GBC usasse apenas o LEED, abrindo a porta para que cada país determinasse qual abordagem de sistema de avaliação era melhor para o clima e cultura de seu país. ${ }^{13}$

Com o impasse, a reunião foi pouco conclusiva. A única decisão tomada foi a de fazer um site para a nova organização. De fato, a desconfiança quanto à possível hegemonia do USGBC ${ }^{\circledR}$ no World GBC representou um campo de disputa dentro da criação do conselho global e surgiu muitas vezes espontaneamente nas entrevistas realizadas para essa pesquisa. Uma fonte negou qualquer tentativa do USGBC ${ }^{\circledast}$ controlar o World GBC. Outra apontou o desconforto dos conselhos locais face ao USGBC ${ }^{\circledast}$, sugerindo que o motivo seria o poder financeiro superior dos

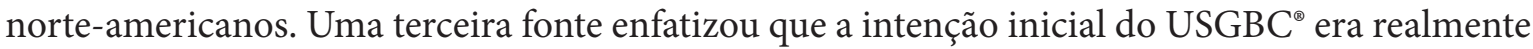
internacionalizar sua operação via World GBC, mudando em seguida a proposta em razão da resistência dos outros conselhos, que já possuíam certa autonomia de operação quando a coalizão global foi fundada em $2002 .^{14}$

A fundação do World GBC ocorreu em evento paralelo à primeira Greenbuild Conference and Expo, o congresso e feira de fabricantes anual do USGBC ${ }^{\circledast}$, mencionada acima. Além de ser a edição inaugural, essa foi a oportunidade de lançamento da versão 2.1 do sistema LEED $^{\circledR}$ NC; das versões piloto do $\mathrm{LEED}^{\circledR}$ EB-OM, CI, Retail e CS; e de grupos de trabalho para LEED $^{\circledR}$

\footnotetext{
13. No original: "I had already explained to him several times that no one person or entity would control the nonprofit coalition's board. We would have officers, but the assembled group hadn't yet elected them, though I hoped that would happen by the end of the day. It was clear he thought that the USGBC and I would control the WorldGBC. To the contrary, I had taken great effort to prevent such thing from happening. Instead of founding the world council from within the USGBC, I had set it up as a separate entity, inviting the US council to assume only one seat on its board. The USGBC had agreed not only to this structure, but also to the principle that the world council would be rating system neutral: USGBC would not mandate that the WorldGBC use only LEED, opening the door for each country to determine which rating system approach was best for its country's climate and culture." Gottfried, 161, tradução nossa.

14. Como o assunto é delicado e muitas fontes explicitaram se tratar de uma interpretação pessoal do processo mais do que um fato comprovável, as identidades foram mantidas anônimas.
} 

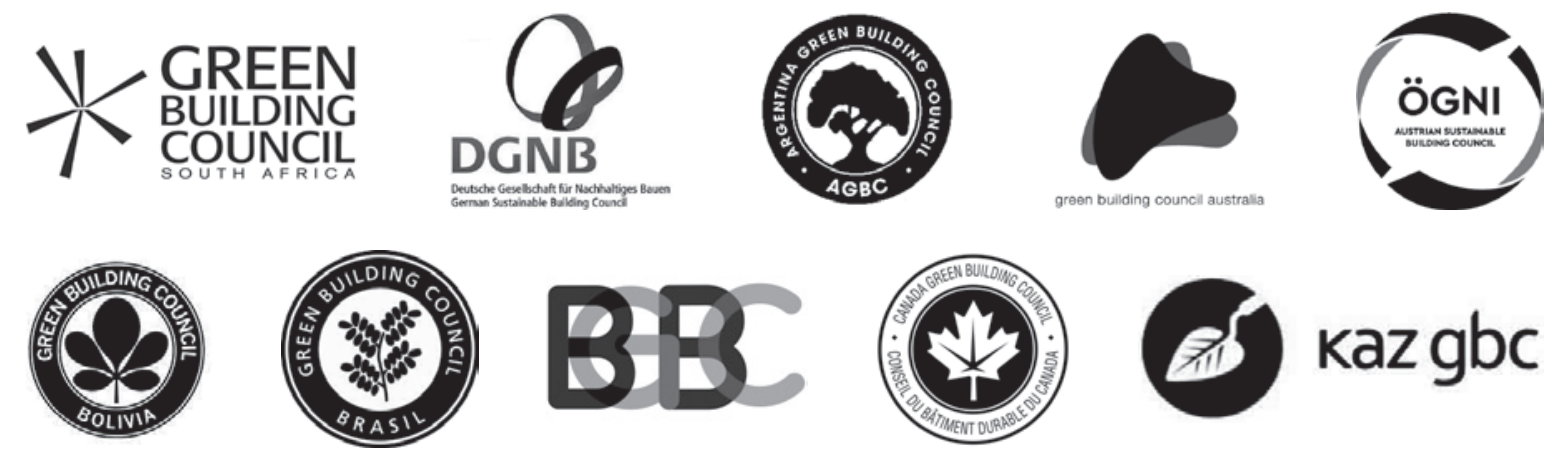

Kaz gbc
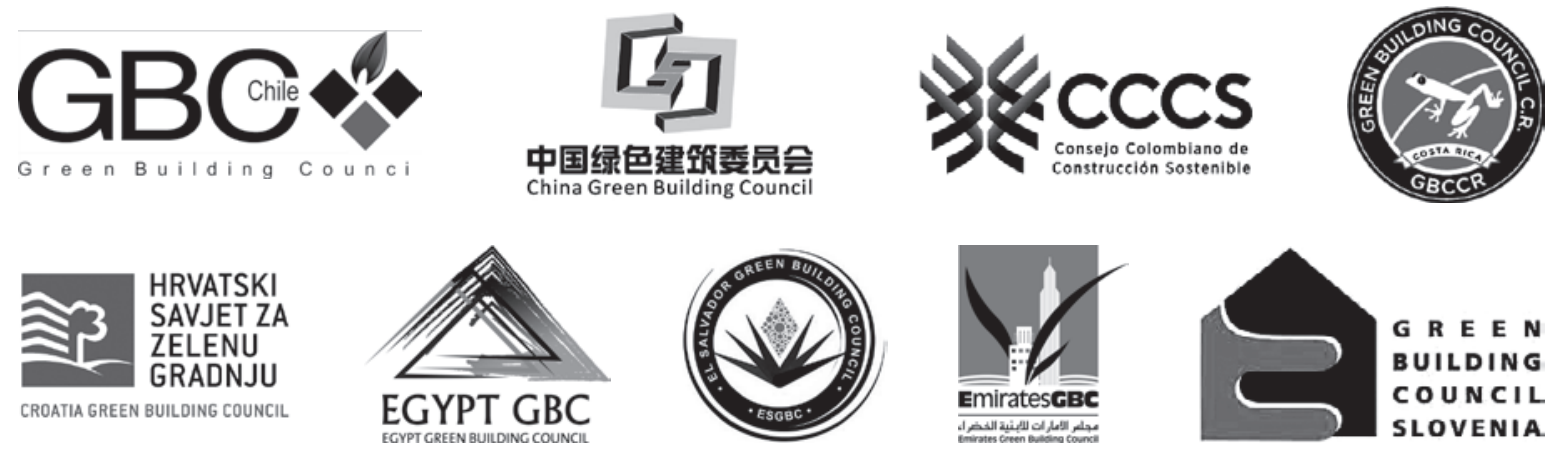

G R E E N

BUILDING

COUNCIL
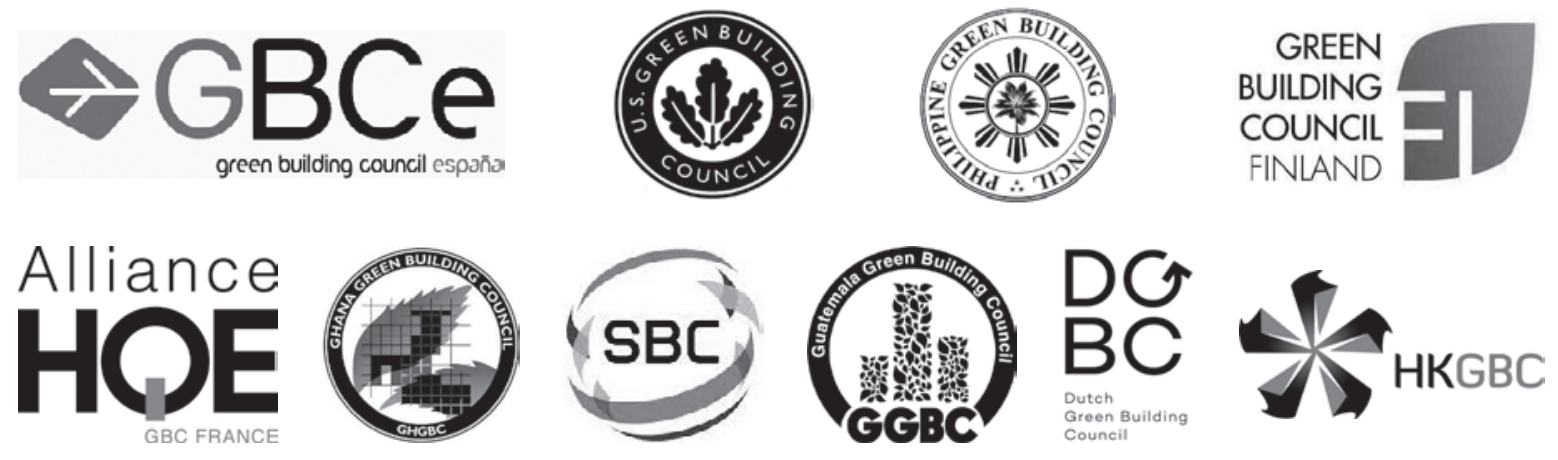

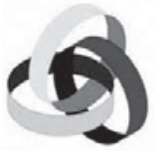

HuGBC
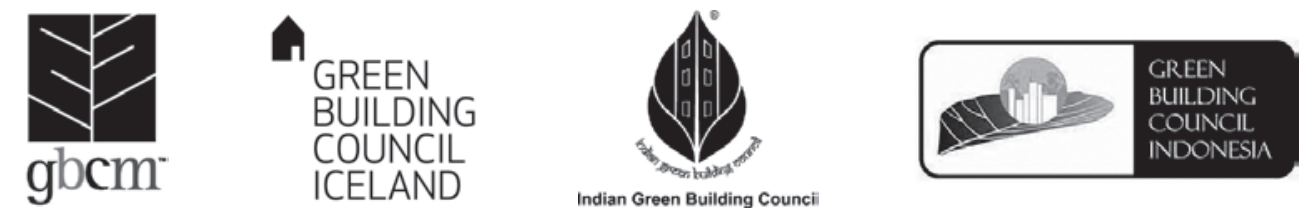

Indian Green Building Counci
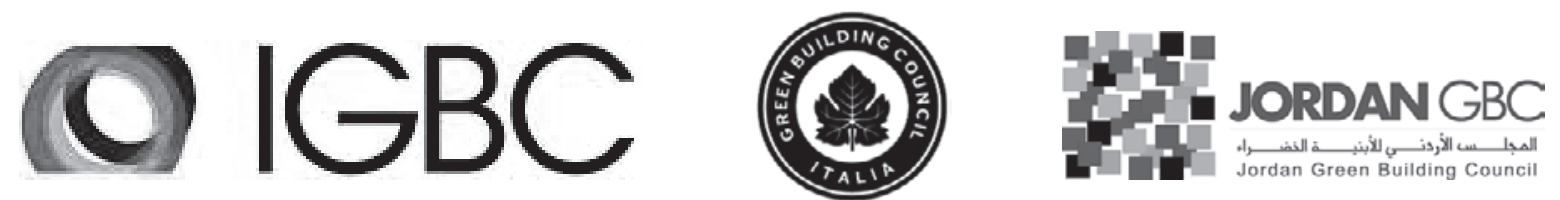

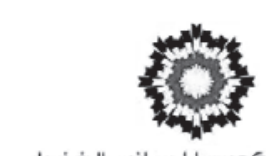

مجلس الكويت للمباني الخضراء

Kuwait Green Building Council
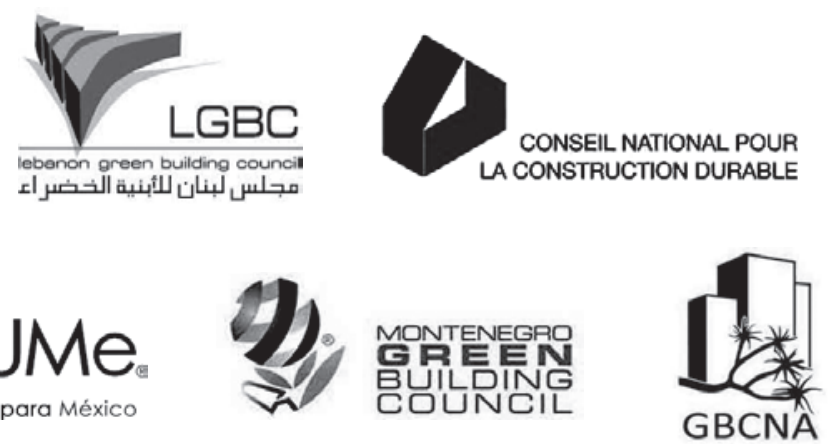
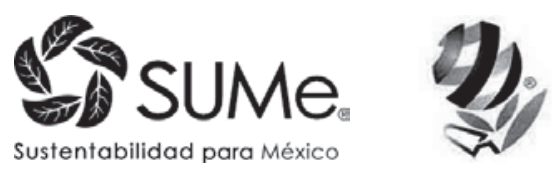

MONTENEGRO

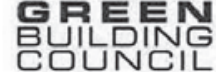

GBCNA

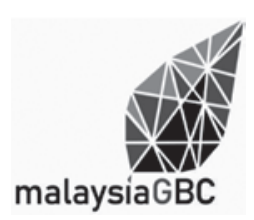



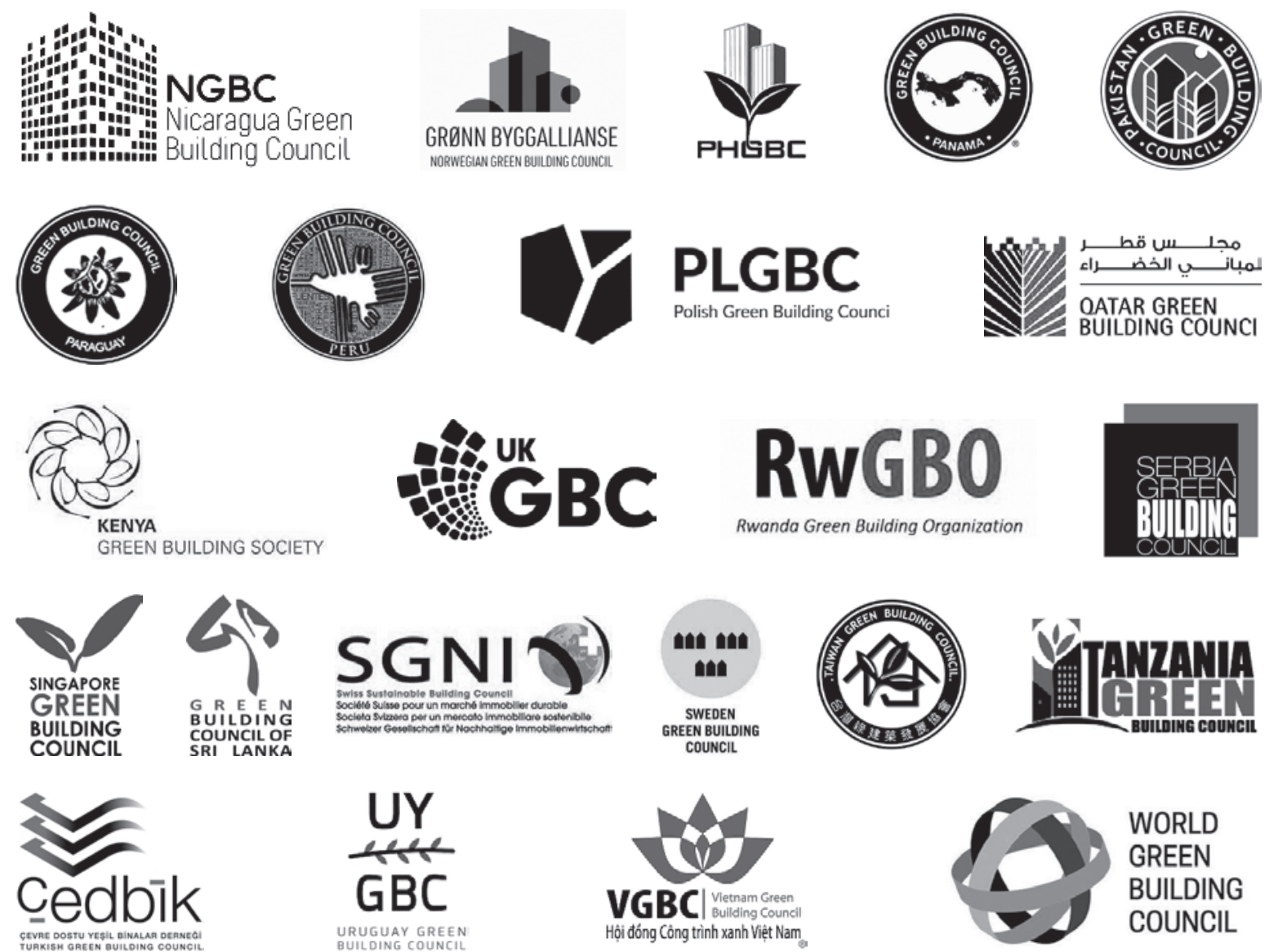

URUGUAY GREEN
BUILDING COUNCIL
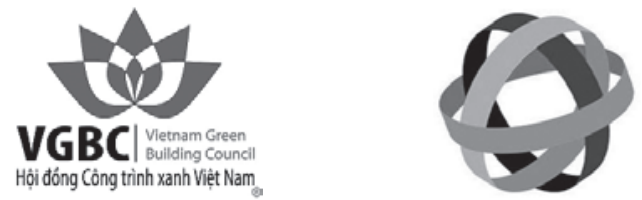

WORLD

GREEN

BUILDING

COUNCIL

Fig 2.3. Conselhos membros do World GBC, em ordem alfabética: África do Sul, Alemanha, Argentina, Austrália, Áustria, Bolívia, Brasil, Bulgária, Canadá, Cazaquistão, Chile, China, Colômbia, Costa Rica, Croácia, Egito, El Salvador, Emirados Árabes Unidos, Eslovênia, Espanha, Estados Unidos, Filipinas, Finlândia, França, Gana,

Grécia, Guatemala, Holanda, Hong Kong, Hungria, Ilhas Maurício, Islândia, Índia, Indonésia, Irlanda, Itália, Jordânia, Kuwait, Líbano, Luxemburgo, Malásia, Marrocos, México, Montenegro, Namíbia, Nova Zelândia, Nicarágua, Noruega, Palestina, Panamá, Paquistão, Paraguai, Peru, Polônia, Qatar, Quênia, Reino Unido, Ruanda, Sérvia, Singapura, Sri Lanka, Suécia, Suíça, Taiwan, Tanzânia, Turquia, Uruguai e Vietnã. Ao fim da lista, consta ainda o logotipo do World GBC. Levantamento realizado em 4 jan 2019. 


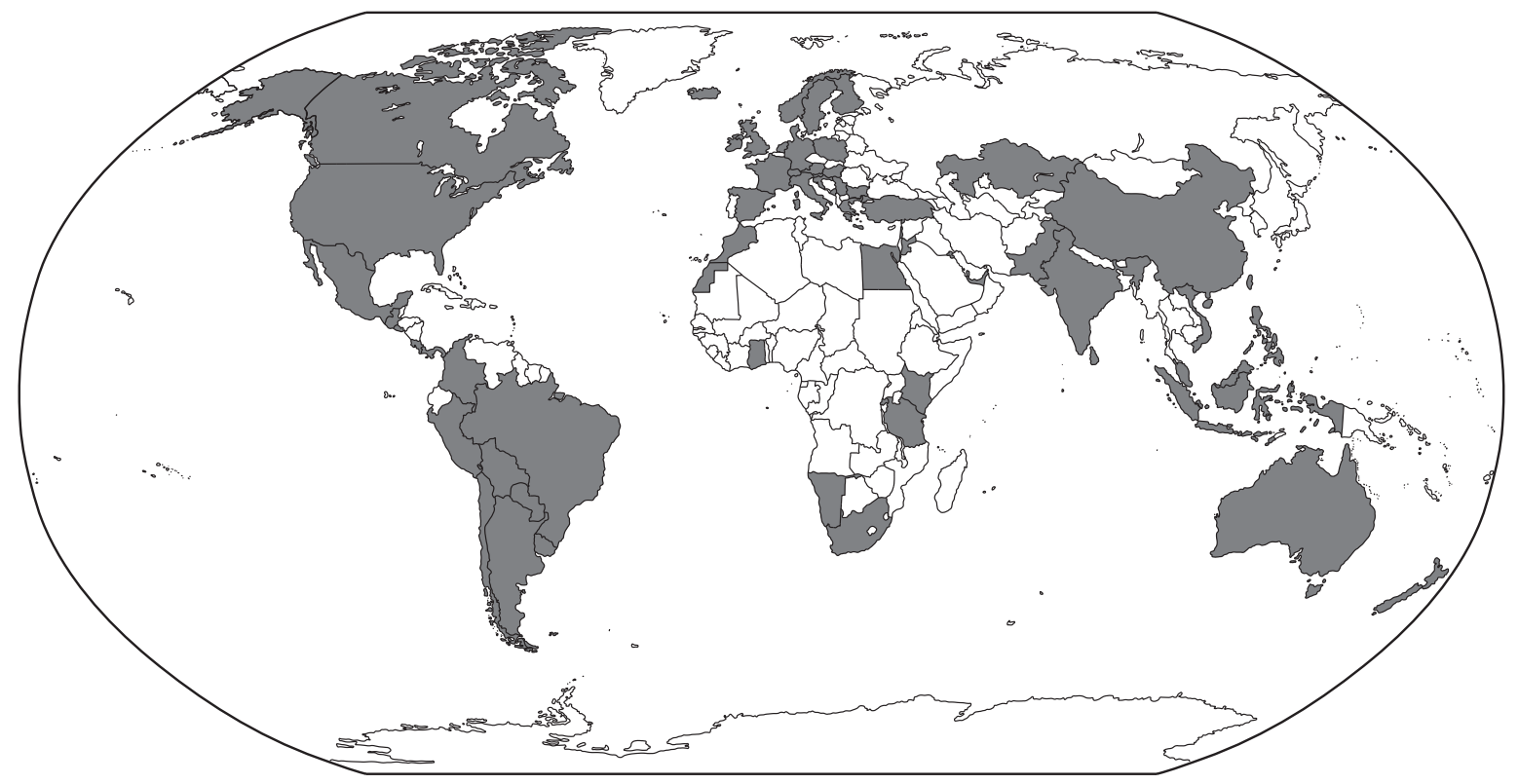

Fig 2.4. Países com conselhos membros do World GBC.

Fonte: World GBC, 4 jan 2019. Elaborado pelo autor. 
for Homes e ND. Nos dois dias anteriores à abertura do evento, em Austin, Texas, reuniram-se vinte representantes de oito países: Austrália, Japão, Espanha, Estados Unidos, Canadá, México, Índia e mesmo Brasil, cujo conselho será tratado no próximo capítulo. Dentre os nomeados no relato de Gottfried, estavam presentes, além daqueles citados na reunião três anos antes, Maria Atkinson do GBC Austrália; Roberto Teitelroit pelo Brasil; e um representante da Confederação da Indústria Indiana. Desta vez, os presentes não só reportaram seus avanços na formação de conselhos locais, como também decidiram quem integraria o corpo de funcionários e elegeram unanimemente Gottfried como presidente. Com isso, estava fundado o World GBC. ${ }^{15}$

Os objetivos do órgão foram explicados em entrevista ao autor pelo brasileiro Guido Petinelli, que foi Rector of Council Development no World GBC entre 2006 e 2008, a convite do engenheiro Kevin Hydes. Dentro do cargo, ele auxiliou na formação de conselhos nas Américas, Europa e Oriente Médio. Quando ainda estudava na McGill University, Petinelli havia sido assistente de Hydes em uma disciplina por ele ministrada. Após fundar o Canada Green Building Council (CaGBC) com Peter Busby - que depois venderia seu escritório para a firma norte-americana Perkins \& Will -, Jon Hobbs e Joe Van Belleghem, em 2002, Hydes havia assumido a presidência do World GBC. Segundo Petinelli, a missão da organização era dupla. Por um lado, a promoção da construção sustentável. Por outro lado, a estruturação de conselhos locais, que não só representam a expansão global da agenda, mas também garantem a própria sustentação financeira do World GBC, por meio de pagamento de taxas de associação. ${ }^{16}$

O objetivo de Hydes era criar cem conselhos locais, constando hoje 69 no diretório do World GBC. Com esse intuito, Petinelli viajava para identificar interessados, mediar conflitos e alianças entre agentes locais e auxiliar no levantamento de recursos. Para que o apoio do World GBC a grupos locais não fosse apenas verbal, Petinelli elaborou o Council Creation Toolkit. Nele, interessados acessavam um "road map" de medidas a serem tomadas para a criação dos conselhos e se informavam sobre melhores práticas de mercado. De modo geral, Petinelli enfatiza que um conselho bem-sucedido decorre da passagem rápida de uma gestão por voluntários para outra com funcionários profissionais: caso contrário, o trabalho do conselho em período extra

\footnotetext{
15. Gottfried, Explosion green, cap. 16.

16. Guido Petinelli, (Rector of Council Development no World GBC, 2006-2008; Co-fundador do GBC Brasil), Entrevista para o autor, $1^{\circ}$ de maio de 2018.
} 
geraria cansaço nos envolvidos e lentidão ou até suspensão das atividades. Para essa rápida profissionalização, o road map sugeria três passos ligados à sustentabilidade financeira do conselho. O primeiro passo era "maximize the launch": transformar a inauguração em um grande evento onde recursos são obtidos pela inscrição de membros [seat funding], de modo a financiar o conselho por dois ou três anos. O segundo era usar a certificação de edifícios como um primeiro produto, garantindo receita constante. O terceiro e último passo era a organização de eventos conferências e cursos - para disseminar a agenda sustentável e angariar recursos extras. ${ }^{17}$

O movimento de internacionalização foi permeado por conflitos. Um deles foi o uso indevido que os GBCs locais passaram a fazer do LEED ${ }^{\circledR}$. Os casos mais comentados são do CaGBC e do Indian GBC (IGBC). Ao oferecer o sistema LEED ${ }^{\circledR}$ para parceiros internacionais, o USGBC ${ }^{\circledast}$ não estabeleceu parâmetros de uso. O CaGBC e o IGBC fizeram alterações que descaracterizaram o sistema, embora mantivessem o nome LEED $^{\circledR}$, o que poderia levar à rápida desvalorização do produto. ${ }^{18}$ Assim, de modo tardio, o USGBC ${ }^{\circledast}$ buscou reaver a consistência global da marca, estabelecendo a partir da versão 2 elementos de adaptação geográfica: os créditos ligados à categoria Regional Priorities; a creditação alternativa via normas e leis locais, quando aceitos pelo GBC local; e a tradução dos sistemas. Essas alterações, que podem ser consideradas modestas dentro da estrutura do sistema, garantiram sua internacionalização sem maiores percalços. ${ }^{19} \mathrm{~A}$ aplicação do $\mathrm{LEED}^{\circledR}$ pelo CaGBC foi revisada e voltou ao modelo do USGBC . Quanto ao IGBC, foi criado o LEED ${ }^{\oplus}$ India, que até meados de 2014 ainda era avaliado dentro de seu próprio país; desde então, passou aos cuidados do $\mathrm{GBCI}^{\triangleright}$, mas se manteve como um sistema distinto.

Ainda que o World GBC tenha conquistado crescente autonomia, o USGBC ${ }^{\circledast}$ continua possuindo relevância global: pela disseminação do emprego do LEED ${ }^{\curvearrowleft}$, pela centralização da certificação via $\mathrm{GBCI}^{\circledR}$ e por ainda ser o conselho de maior poder financeiro.

\section{Petinelli.}

18. Petinelli; também Thassanee Wanick, (Fundadora do GBC Brasil), Entrevista para o autor, 24 de janeiro de 2017; e Felipe Faria, (Diretor executivo do GBC Brasil, 2012-atual), Entrevista para o autor, Presencial, 18 de dezembro de 2017.

19. Templeton, (Vice-diretor de Desenvolvimento de Mercado Global do USGBC), Entrevista para o autor. 


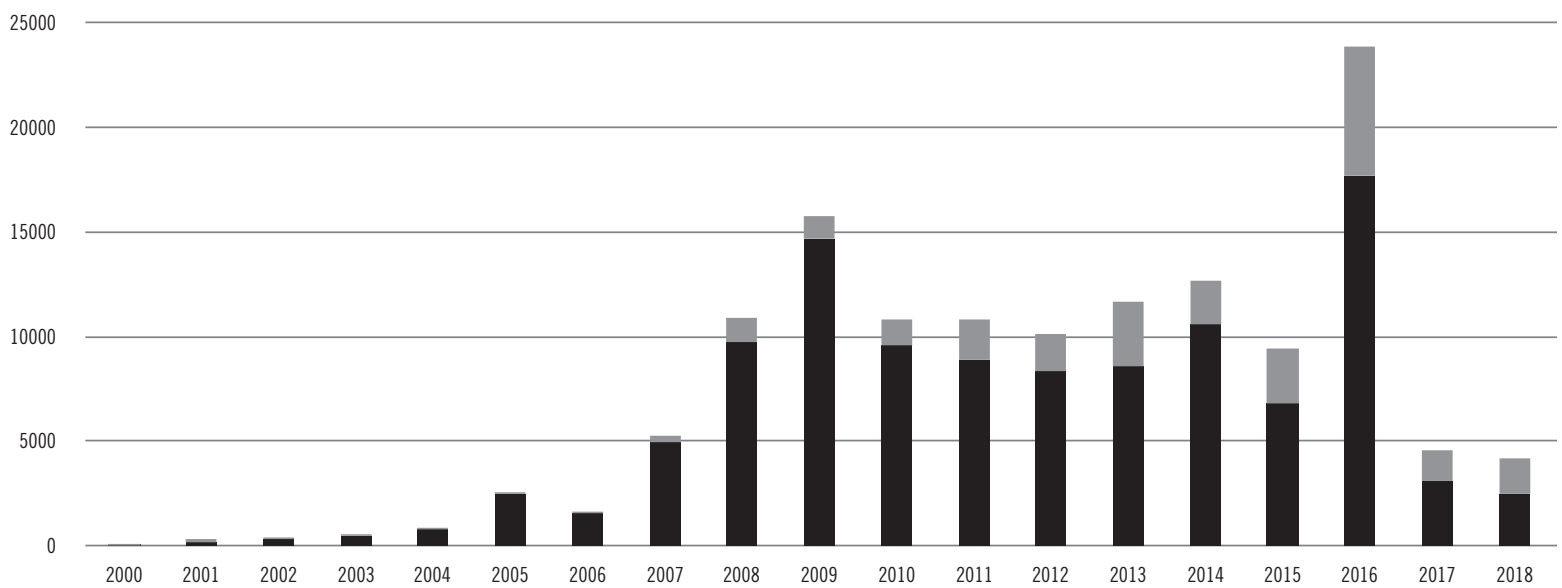

Estados Unidos Internacional

Fig 2.5. Registros LEED ${ }^{\circ}$, divididos entre Estados

Unidos e território internacional. Amostra de 136.241

empreendimentos. Fonte: LEED Project Directory, 4 jan

2019. Elaborado pelo autor.

15000

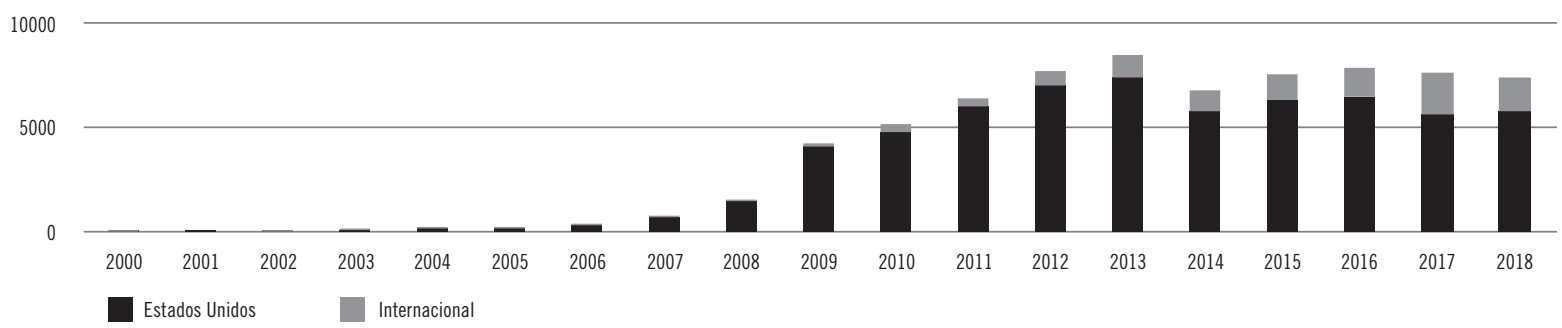

Fig 2.6. Certificados $L_{E E D}{ }^{\circledR}$, divididos entre Estados

Unidos e território internacional. Amostra de 71.837

empreendimentos. Fonte: LEED Project Directory, 4 jan 2019. Elaborado pelo autor.
Predominam as certificações em território norteamericano, mas há um aumento da importância internacional no tempo, em concordância com a observação de entrevistados sobre a importância da internacionalização nas estratégias de expansão do LEED ${ }^{\circ}$. O aumento proporcional é especialmente significativo nos registros internacionais, o que indica o aumento de interesse imediato no sistema LEED ${ }^{\circledR}$. Como visto anteriormente, há um pico de registros em 2016 por ser o último ano possível para a versão 3. Os registros diminuem significativamente nos anos seguintes, em resposta a maior dificuldade da versão 4 . 


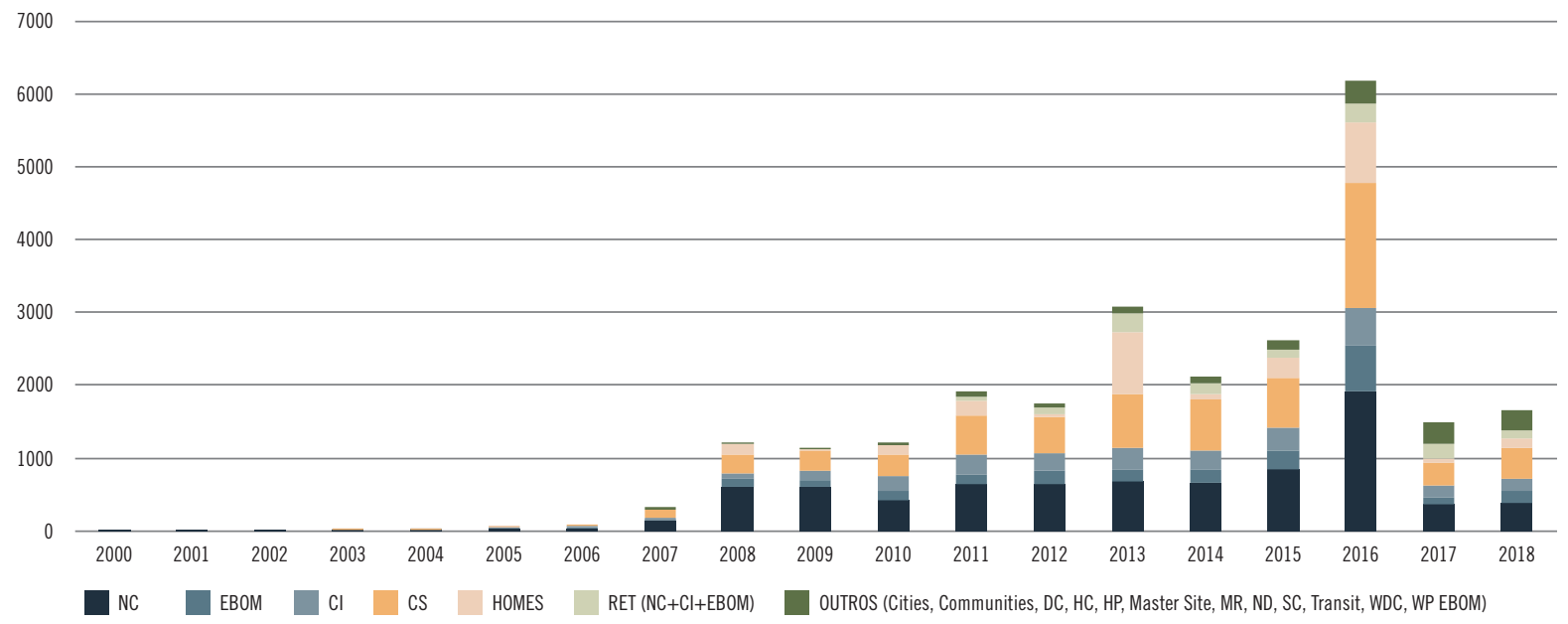

Fig 2.7. Registros LEED ${ }^{\circledR}$ fora dos Estados Unidos,

organizados por sistema. Amostra de 24.919

empreendimentos. Fonte: LEED Project Directory, 4 jan

2019. Elaborado pelo autor.

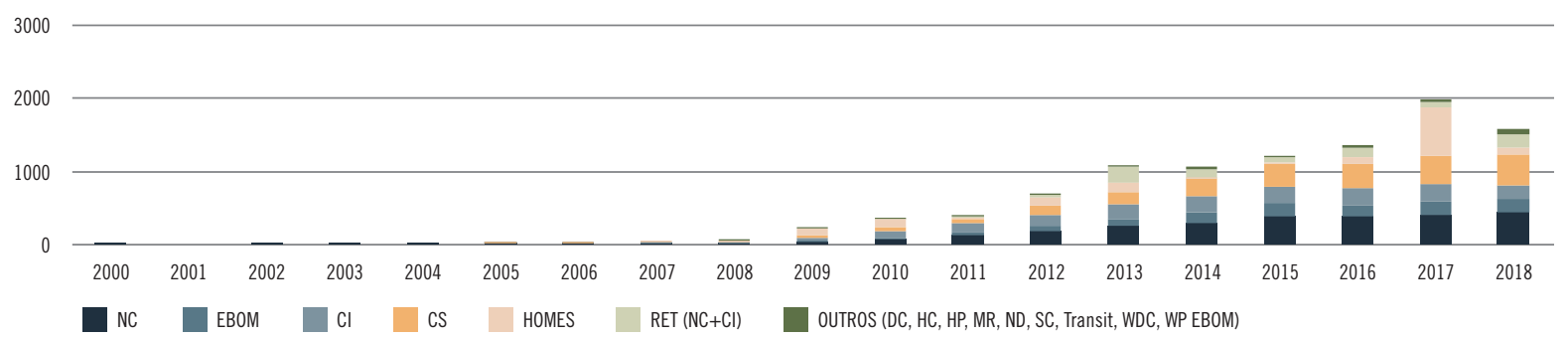

Fig 2.8. Certificados $\mathrm{LEED}^{\circledR}$ fora dos Estados

Unidos, organizados por sistema. Amostra de 10.057

empreendimentos. Fonte: LEED Project Directory, 4 jan

2019. Elaborado pelo autor.

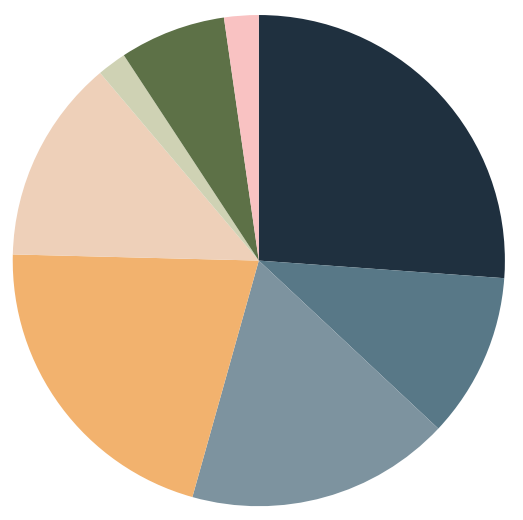

Fig 2.9. Proporção total por sistema. Fonte: LEED Project Directory, 4 jan 2019. Elaborado pelo autor.

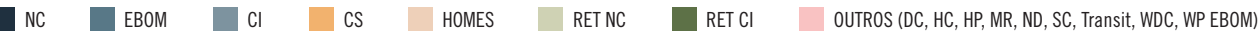




\section{CAPÍTULO 3}

\section{O MODELO BRASILEIRO DE CONSELHO VERDE}

\section{NETWORKING}

Em 2 de janeiro de 2007, cinco anos após o World GBC, quatorze anos após o USGBC ${ }^{\circledast}$, era formado o Green Building Council Brasil. ${ }^{1}$ Muitos dos envolvidos que foram consultados para a pesquisa consideram a organização brasileira muito bem-sucedida, seja pela alta adesão empresarial no seu financiamento de largada, seja pela grande quantidade de registros alcançados. É à história do modelo brasileiro de GBC que esse capítulo se dedica.

A fundação do GBC Brasil foi realizada pela Cônsul Geral da Tailândia no Brasil Thassanee Wanick, juntamente com o administrador de empresas José Moulin Netto. São ainda cofundadores Guido Petinelli, Roberto Teitelroit e Luciana Rossi; fundadores honorários os professores José Goldemberg e Siegbert Zanettini; e fundadores como pessoa jurídica outras trinta e quatro empresas e instituições. ${ }^{2}$ Os relatos sobre o processo de montagem da ONG não são completamente coincidentes, há escasso material publicado e muitas vezes não foi possível obter documentos que comprovassem as informações concedidas nas entrevistas. As atas das primeiras reuniões foram tidas como perdidas pelo GBC Brasil. Tal como nos Estados Unidos, a fundação aqui associava diversos profissionais com atuação prévia no tema da sustentabilidade e a existência de ações simultâneas na direção de constituir um conselho nacional. Antes da criação do GBC Brasil, havia até mesmo profissionais que já trabalhavam com o LEED ${ }^{\circledR}$ isoladamente. Mas os relatos convergem sobre a importância de Thassanee Wanick como fundadora principal da organização.

\footnotetext{
1. Green Building Council Brasil (GBC Brasil), "Estatuto do Green Building Council - Brasil”, s/d, http://www.gbcbrasil.org. br/pdf/Modelo_publicacao_site_05_07_2016.pdf.

2. "10 anos de história", Revista GBC Brasil, ago de 2017, 55.
} 
A relação de Wanick com o movimento ambientalista se deu desde a sua juventude, quando atuava na defesa da fauna na Tailândia, especificamente na proteção de tartarugas e elefantes, e em "fundraising" para o World Wide Fund for Nature (WWF). Ainda hoje envia recursos para seu país natal, onde tem uma elefanta adotada, conforme seu relato. Em paralelo, também realiza regularmente eventos oficiais do governo tailandês, com culinária típica e o elefante como símbolo. ${ }^{3}$ Mais tarde, novamente na captação de recursos, preparou uma campanha para desenvolvimento sustentável em Hollywood, em outubro de 2001, malsucedida em razão da comoção internacional em torno do ataque às torres do World Trade Center no mês anterior. Daquele momento até 2003, cursou um mestrado em Ciências Ambientais e Negócios, na Wharton Business School, da Universidade da Pensilvânia. Concluído o curso, Wanick continuou os estudos na State University of Colorado, além de começar uma formação para o uso do LEED ${ }^{\oplus}$ por meio do USGBC ${ }^{\circledast}$. De volta ao Brasil - onde residia desde a década de 1980 após casar-se com Eduardo Wanick, presidente da DuPont na América Latina e vice-presidente global para mercados emergentes $^{4}$ - a Cônsul Wanick começou a planejar uma campanha relacionada à preservação do meio ambiente. Para ela, apesar de os carros serem os principais emissores de poluentes responsáveis pelo aquecimento global, esse problema já estaria solucionado pelo etanol. Voltou-se então para o que considerava o segundo maior problema, o desperdício da construção civil: “[n] aquele momento o Brasil já era um líder mundial em energia alternativa, que é o etanol. Então havia muito pouco em que eu pudesse ajudar, o Brasil já era especialista. Então eu não posso fazer nada com as emissões de carros, mas posso ajudar na indústria da construção."

Por não pertencer ao setor da construção civil, Wanick tinha poucos contatos pessoais que pudessem ser acionados nesse novo plano. Para tanto, procurou a associação de alumni da Wharton Business School no Brasil. Foi assim que conheceu Luciana Rossi, filha de João Rossi,

\footnotetext{
3. Thassanee Wanick, (Fundadora do GBC Brasil), Entrevista para o autor, 24 de janeiro de 2017; Mônica Reolom, "Evento festeja o Elephant's Day na capital paulista”, O Estado de S. Paulo, ago de 2015, seç. Sustentabilidade, https://sustentabilidade. estadao.com.br/noticias/geral,evento-festeja-o-elephants-day-na-capital-paulista, 1743039.

4. Wanick, (Fundadora do GBC Brasil), Entrevista para o autor; Alvaro Leme, “Thassanee Wanick contra o aquecimento global”, Veja São Paulo, set de 2009, http://vejasp.abril.com.br/materia/thassanee-wanick-contra-aquecimento-global. 5. No original: "By that time Brazil was already a world leader in alternative energy, which is ethanol. So there is very little I can do to help, because Brazil is the expert. So, I cannot do anything with the cars emissions, but I can help with construction industry." Wanick, (Fundadora do GBC Brasil), Entrevista para o autor, tradução nossa.
} 
cujo sobrenome batiza a construtora. As conversas apontavam duas opções: ou levantar recursos para construírem, sozinhas, "o primeiro edifício sustentável” (sic) do Brasil; ou a formação de uma ONG, nos moldes do USGBC ${ }^{ø}$. Luciana também não possuía experiência na área, por trabalhar em um banco, razão pela qual sugeriu que Wanick conversasse com seu pai sobre as possibilidades de ação. A reunião malogrou, já que João Rossi divergia de Wanick: não via em sua proposta nem um plano de trabalho, nem qualquer atrativo para o mercado. Segundo a própria Wanick, ela não soube apresentar quais seriam os custos envolvidos na construção de um edifício sustentável, e tampouco porque isso seria de interesse para um investidor. ${ }^{6}$

Face às críticas de Rossi, Wanick montou um plano de negócios e saiu em busca de interessados. Para isso, estabeleceu quatro frentes de prospecção. A primeira foi de parceiros na iniciativa privada. Wanick começou pelos bancos, por ver neles a fonte dos recursos que procurava: “[e]u comecei batendo na porta dos bancos, porque... o chefe dos construtores são bancos, os investidores, é de onde o dinheiro vem. Então eu preciso ir falar com esse pessoal, e convencê-los a construir com sustentabilidade."” Após diversas tentativas, Wanick foi acolhida no Banco Real-ABN AMRO, então presidido por Fábio Barbosa. Segundo Marcos Casado - engenheiro que trabalhou no primeiro edifício certificado pelo LEED ${ }^{\circledR}$ no Brasil, uma agência do mesmo banco na Granja Viana ${ }^{8}$ - a empresa tinha o desenvolvimento sustentável como valor central de sua agenda de responsabilidade social corporativa. Wanick descobrira, portanto, terreno propício para seu projeto. Pelo seu relato:

Ele [Fábio Barbosa] me ouviu e então disse: "Espera um pouco, isso é exatamente o que estamos procurando, novas ideias. Até agora, o Brasil nunca falou sobre sustentabilidade, nós nem sabíamos como falar a palavra 'sustentabilidade', o que ela significa [...]. Tudo o que fazemos é dar dinheiro para comunidades

\footnotetext{
6. Wanick.

7. No original: "I started knocking at the banks, because... the boss of the builders are the bankers, the investors, that is where the money is from. So, I have to go to talk to these people, and convince them to build green." Wanick, tradução nossa.

8. O braço brasileiro do ABN AMRO era o Banco Real, comprado pela empresa holandesa em 1998, mas sem conversão imediata das bandeiras das agências - motivo pelo qual a construção do primeiro edifício certificado era inicialmente noticiada como sendo do Banco Real. O ABN AMRO foi comprado por um consórcio formado pelo Royal Bank of Scotland, pelo Santander e pelo Fortis em 2007. Em 2010, as agências do ABN AMRO no Brasil começaram a ser transferidas para a marca Santander.
} 
pobres como responsabilidade social. Mas isso não é sustentável, isso não nos dá nenhum produto nem dinheiro, isso só ajuda a comunidade. Dar dinheiro pra eles, [...] não tem nada a ver [com sustentabilidade]... Nós gostamos muito da sua ideia." E eu disse: "Bom, se eu conseguir construtores que seguiriam o LEED", desde que eles queiram se preocupar estritamente com água, energia, localização, projeto e depois manutenção dos edifícios, e construir com sustentabilidade, você daria para eles melhores acordos, [...] melhores taxas de empréstimo?” [Barbosa respondeu] “Com certeza, este é um novo projeto, estamos muito interessados nele." [...] Qual é a vantagem [...] deles fazerem isso, o que eles conseguem disso? [...] O projeto não vai ser barrado pelo Ibama, por exemplo. O projeto fica parado [no Ibama] por dez anos, onze anos, vinte anos, [...] quando eles não conseguem ter de volta nem dinheiro, nem empréstimos, nem nada. Os clientes vão abaixo, não conseguem pagar, e eles [os bancos] perdem seu investimento. Então isso ajudaria muito. ${ }^{9}$

Assim, o LEED ${ }^{\oplus}$ ia em direção aos interesses do banco, facilitando o cumprimento de sua agenda de responsabilidade social ao mesmo tempo em que eliminava ineficiências no sistema de crédito. E, além de tudo, atuava por dentro dos próprios produtos financeiros de empréstimos.

A segunda frente de prospecção foi o Estado, "porque os governos são o maior proprietário imobiliário em qualquer país." ${ }^{10}$ Como cônsul, Wanick tinha trânsito desimpedido não só no meio empresarial, mas também entre figuras do governo, e assim conseguiu marcar uma reunião com Geraldo Alckmin, então governador do Estado de São Paulo (2001-2006). Alckmin e seu Secretário do Meio Ambiente, José Goldemberg (2002-2006) - um dos precursores no estudo do etanol elogiado por Wanick, pesquisando-o desde meados dos anos 1970 -, também apoiaram a causa. ${ }^{11}$

\footnotetext{
9. No original: "He listened and then he said: 'Wait a minute, this is exactly what we are looking for, new ideas. As for now, Brazil never talked about sustainability, we then did not even know how to speak the word, "sustentabilidade", what does it mean, what is the meaning of sustainability. And all we do is giving money away to poor community as social responsibility. But this is not sustainable, it does not give any product or any money, it just helps the community. Giving them money, [...] it has nothing to do [with sustainability]... We like your idea very much.' And I said 'Well, if I can get the builders who would follow LEED ${ }^{\circledR}$, since that they strictly want to worry about the water, the energy, the location, the design, and the maintenance of the buildings afterwards, and build green, would you give them better deals, [...] better loan rates?' 'Absolutely, this is a new project, we are very interested in it.' [...] What is the advantage [...] for them to do that, what do they get from that? [...] the project will not be stopped by the Ibama, for example. The project gets stopped for ten years, eleven years, twenty years, [...] when they could not get that money and loans and anything back. And the customers go down, cannot pay, and they lost their investment. So that would help a lot." Wanick, (Fundadora do GBC Brasil), Entrevista para o autor, tradução nossa. 10. No original: "because governments are the biggest real estate owner in any country." Wanick, tradução nossa.

11. Wanick.
} 
Goldemberg, posteriormente nomeado fundador honorário do GBC Brasil, teria começado a participar nos trabalhos do conselho por volta de 2005, inicialmente com apresentações sobre eficiência energética em eventos ligados à formação do conselho. Segundo ele, sua atuação foi constante ao longo do tempo, mas restrita a eventos, onde dava palestras, anunciava prêmios e participava de coquetéis. ${ }^{12}$

Em terceiro lugar, Wanick buscou a legitimação internacional para a organização que criava ao entrar em contato com o USGBC ${ }^{\oplus}$. Ao fazê-lo, Wanick manifestava a intenção de ser a representante oficial para o uso do $\mathrm{LEED}^{\circledR}$ no Brasil. A cônsul disse não encontrar resistência quando conversava com os norte-americanos: segundo ela, o USGBC ${ }^{ø}$ não influía no uso internacional do sistema de avaliação e concedeu de bom grado sua utilização no Brasil. O reconhecimento como GBC oficial no Brasil, diziam os norte-americanos, não deveria vir do USGBC mas do World GBC, já em pleno exercício naquele momento. ${ }^{13}$

Wanick descobriu, no contato com o World GBC, que a criação de um GBC Brasil já havia sido ensaiada. Alguns anos antes, o arquiteto gaúcho Roberto Teitelroit havia iniciado a organização de um conselho local e estivera presente na fundação do World GBC, como mencionado no capítulo anterior segundo a autobiografia de David Gottfried. ${ }^{14}$ Teitelroit trabalhava no Grupo Zaffari na década de 1990 e passou uma temporada nos Estados Unidos no Rocky Mountain Institute. Com a experiência, trouxe professores do instituto para o Brasil. ${ }^{15}$ Mas, segundo Felipe Faria, diretor executivo do GBC Brasil desde 2012, Teitelroit "não conseguiu aglutinar grandes forças", e sua iniciativa não teve continuidade. ${ }^{16}$

Nesse ínterim, Guido Petinelli veio ao Brasil no fim de 2006 para acompanhar os trabalhos de criação do GBC Brasil e vinculá-lo ao World GBC.

12. José Goldemberg, (Fundador honorário do GBC Brasil), Entrevista para o autor, Presencial, 12 de setembro de 2016.

13. Wanick, (Fundadora do GBC Brasil), Entrevista para o autor.

14. David Gottfried, Explosion green: one man's journey to green the world's largest industry, Prefácio de Paul Hawken. Introdução de Rick Fedrizzi. (Nova York: Morgan James, 2014), 171.

15. As indicações são de Guido Petinelli. Ele ainda sugeriu que Teitelroit teria contribuído na vinda para o Brasil e na tradução para o português do livro Capitalismo natural, mas nenhuma referência oficial foi encontrada. Guido Petinelli, (Rector of Council Development no World GBC, 2006-2008; Co-fundador do GBC Brasil), Entrevista para o autor, $1^{\circ}$ de maio de 2018; Amory B. Lovins, L. Hunter Lovins, e Paul Hawken, Natural capitalism: the next industrial revolution (Washington DC: US Green Building Council, 2000).

16. Felipe Faria, (Diretor executivo do GBC Brasil, 2012-atual), Entrevista para o autor, Presencial, 18 de dezembro de 2017. 


\section{DISPUTA DA MARCA}

Como representante do World GBC, a vinda de Petinelli ao Brasil não era simplesmente um apoio protocolar a Wanick, mas também uma tentativa de solucionar uma cisão no grupo brasileiro de fundação do conselho. A disputa se dava entre Wanick e sua quarta frente de trabalho: a busca por adesão acadêmica, representada por professores majoritariamente ligados à Escola Politécnica da Universidade de São Paulo.

De um lado, o grupo liderado pelos politécnicos propunha a formação de diversos comitês específicos, com análises dos diferentes aspectos da construção sustentável. Por meio dessas discussões, criariam um certificado próprio e autóctone. Vislumbravam a filiação ao conselho apenas de pessoas físicas, no qual cada indivíduo teria um voto. Tal grupo era liderado por Marcelo Vespoli Takaoka, e contava com Vanessa Gomes, Vanderley Moacyr John, Roberto de Souza e Paulo Machado Lisboa, entre outros. ${ }^{17}$ Eles possuíam ainda contato com o International Initiative for a Sustainable Built Environment (iiSBE) ${ }^{18}$ de cujo conselho diretor Vanessa Gomes havia participado. Segundo Petinelli, já teria havido disputas em outros países entre iiSBE e USGBC ${ }^{\circledast}$, pois o primeiro defendia a criação de certificados nacionais enquanto o último propunha a importação do LEED ${ }^{\oplus}{ }^{19}$

Do outro lado, Thassanee Wanick considerava que a criação de tantos comitês tomaria muito tempo e enfraqueceria o empenho da iniciativa; defendia a importação de um certificado já existente, sugerindo o $\mathrm{LEED}^{\circledast}$ após pesar as vantagens e desvantagens entre aqueles disponíveis; propunha a aliança com representantes do mercado e a filiação de pessoas jurídicas - isto é, as empresas também teriam voto. ${ }^{20}$

Enquanto debatia com o grupo da Politécnica, Wanick havia conhecido o consultor de ges-

17. Petinelli, (Rector of Council Development no World GBC, 2006-2008; Co-fundador do GBC Brasil), Entrevista para o autor.

18. A ONG é sediada em Ottawa, Canadá, e dedica-se sobretudo à conexão entre profissionais e à divulgação de estratégias ambientais. Possui um sistema próprio de avaliação de sustentabilidade, o SBTool, e organiza conferências internacionais periódicas (Maastricht, 2000; Oslo, 2002; Tóquio, 2005; Melbourne, 2008; Helsinki, 2011; Barcelona, 2014; Hong Kong, 2017). 19. Petinelli, (Rector of Council Development no World GBC, 2006-2008; Co-fundador do GBC Brasil), Entrevista para o autor.

20. Wanick, (Fundadora do GBC Brasil), Entrevista para o autor. 
tão José Moulin Netto em um evento da Wharton Business School no Copacabana Palace. ${ }^{21}$ Ela apresentou uma conferência a respeito de turismo ecológico, pela qual Moulin mostrou-se interessado e se dispôs a colaborar. Com a oferta, Wanick requisitou ajuda para a fundação do GBC Brasil, pois necessitava legalmente de uma outra assinatura, além da sua própria, para a criação de um CNPJ para a ONG. Ela não pretendia compartilhar a fundação com o próprio marido, pois seriam "dois de nós" [two of us], ${ }^{22}$ isto é, reafirmaria sua rede de contatos e suas competências ao invés de ampliar sua atuação. Não só por isso, mas também porque Moulin compartilhava o diagnóstico de Wanick de que agentes do mercado deveriam ser convidados para o processo. Segundo Moulin:

Ela [Wanick] tinha a impressão que [...] [o grupo da Politécnica] tinha um viés de montar uma organização que fosse um pouco avessa às empresas, tanto é que os membros não pudessem ser empresas, só pessoas físicas, e isso não era muito alinhado com o que ela acreditava. Eu falei que eu também não acredito muito nisso, eu lembro que eu falei nessa época que a missão dessa organização devia ser transformar o mercado em direção à sustentabilidade na construção civil usando as forças de mercado. Tanto é que acabou virando parte da missão original. ${ }^{23}$

A tarefa de Petinelli era preparar o GBC local para facilitar seu crescimento, assim como definir qual grupo era mais promissor e que, portanto, receberia o aval do World GBC. Petinelli ao mesmo tempo conferia credibilidade internacional ao esforço organizacional dos grupos locais e realizava "due diligence" - o levantamento de informações e a comparação dos concorrentes. ${ }^{24}$ Em meio a reuniões com empresários locais e tendo como referência apenas Roberto Teitelroit, Petinelli tentava unir os dois grupos em apenas um GBC brasileiro. Face à disputa, o núcleo composto por Wanick e Moulin mostrava-se mais adequado pela lente do World GBC. Segundo Petinelli, a governança pela academia, ao invés de pelo mercado, não conseguiria man-

21. Evento citado por diversas fontes: Wanick; Faria, (Diretor executivo do GBC Brasil, 2012-atual), Entrevista para o autor; José Moulin Netto, (Co-fundador do GBC Brasil), Entrevista para o autor, Teleconferência, 4 de dezembro de 2017.

22. Wanick, (Fundadora do GBC Brasil), Entrevista para o autor.

23. Moulin Netto, (Co-fundador do GBC Brasil), Entrevista para o autor; grifo nosso.

24. Petinelli, (Rector of Council Development no World GBC, 2006-2008; Co-fundador do GBC Brasil), Entrevista para o autor. 
ter o ritmo de gestão no decorrer do tempo, conforme outras experiências de fundação assistidas pelo World GBC..$^{25}$

Constituía-se ali, portanto, um novo núcleo fundador para o GBC Brasil, de cujas relações públicas Wanick era a responsável; Moulin, por sua vez, delineava as estratégias e missões daquilo que viria a ser o conselho. ${ }^{26}$ Em 2 de janeiro de 2007 foi cadastrado o CNPJ do GBC Brasil. ${ }^{27}$

\section{CISÃO NO CONSENSO}

Wanick continuava o trabalho de consolidação de um órgão próprio, em oposição aos acadêmicos, para obter a validação via World GBC. A ação decisiva para o apoio da entidade global se deu em um coquetel no fim de janeiro de 2007. O evento ocorreu no Grand Hyatt, hotel localizado na Marginal Pinheiros, um cenário onde tantos edifícios certificados se concentrariam nos anos seguintes. Foram convidados CEOs que poderiam oferecer, por meio de suas empresas, recursos para a operação do GBC Brasil. Segundo Wanick, foram selecionadas companhias com valores corporativos de sustentabilidade ambiental e já membros do USGBC ${ }^{\circledast}$; segundo Felipe Faria, também foram levantadas as empresas filiadas à American Chamber of Commerce (AMCHAM) ${ }^{28}$

O evento contou com apresentações de José Moulin - sobre a missão, os valores e planos estratégicos - e de Guido Petinelli, naquele momento ainda efetuando due diligence para o posicionamento eventual do World GBC a respeito dos dois grupos. Sua participação no coquetel dava novas garantias para os executivos:

Então uma das lições que eu aprendi com o GBC Brasil é o quão importante é ter um representante do World GBC junto. A organização não existe, nesse momento ela provavelmente não tem CNPJ, não está registrada, e você precisa identificar um core founding group. A presença do World GBC traz bastante estabilidade nessa busca. Então eu imagino que o primeiro papel que eu exerci ali foi esse de identificar

\footnotetext{
25. Petinelli.
}

26. Petinelli; Moulin Netto, (Co-fundador do GBC Brasil), Entrevista para o autor.

27. Green Building Council Brasil (GBC Brasil), "Estatuto do Green Building Council - Brasil”.

28. Wanick, (Fundadora do GBC Brasil), Entrevista para o autor; Faria, (Diretor executivo do GBC Brasil, 2012-atual), Entrevista para o autor. 
os stakeholders e de tentar conversar com todos, fazer um pouco de due diligence, para que o World GBC pudesse se posicionar. O segundo papel que eu nem sabia que eu estava exercendo, era de estabelecer um pouco de credibilidade para os esforços iniciais que a Thassanee estava tendo. A presença do World GBC ali, acho que fez diferença.

[...] A Thassanee [...] percebeu que ser membro do World GBC ia ser uma vantagem competitiva. Ela foi incessante, ela não parou os esforços um minuto. ${ }^{29}$

Outros dois apoios garantiram o sucesso da reunião, vindos desta vez do público presente. O primeiro veio de José Goldemberg, que segundo Wanick teria frisado a importância da certificação para agilizar processos em trâmite no governo do Estado. O segundo apoio foi o de João Rossi, não mais reticente em relação à ONG, e que comprou a primeira cota de membro-fundador, na categoria Platinum. O gesto abriu caminho para a arrecadação da receita necessária ao funcionamento do conselho em seus primeiros anos. ${ }^{30}$

Esses diferentes pronunciamentos convenceram os CEOs da credibilidade da empreitada. Foram levantados 1,2 milhão de reais, equivalentes a dois anos de operação, a serem pagos pelas trinta e quatro empresas presentes no evento. A inscrição seria feita meses depois, e apenas uma das empresas presentes não participou da fundação. ${ }^{31}$ São, assim, membro-fundadores do GBC Brasil como pessoa jurídica, na categoria Platinum: Alcoa, Amanco, Cushman \& Wakefield, JHSF e Rossi; na categoria Gold: 3M, Bresco, BR Properties, Cebrace, Colliers International, Dow Chemical, Guardian, Henkel, Odebrecht Investimentos, Sherwin Williams, Uniflex, Wal Mart e WTorre; na categoria Silver: CB Richard Ellis, Cyrella Commercial Properties, Deca, Domus Urbanismo, Itambé Administradora de Condomínios, Johnson Controls, Método, Nalco, PwC, Santander, SustentaX, Tishman Speyer, Trane; como apoiadores institucionais: AMCHAM, AsBEA e Clinton Foundation [fig 3.1]. ${ }^{32}$

Para Felipe Faria, a combinação entre o comprometimento corporativo conquistado e a

29. Petinelli, (Rector of Council Development no World GBC, 2006-2008; Co-fundador do GBC Brasil), Entrevista para o autor.

30. Wanick, (Fundadora do GBC Brasil), Entrevista para o autor.

31. Wanick; Faria, (Diretor executivo do GBC Brasil, 2012-atual), Entrevista para o autor.

32. "10 anos de história". 
PLATINUM

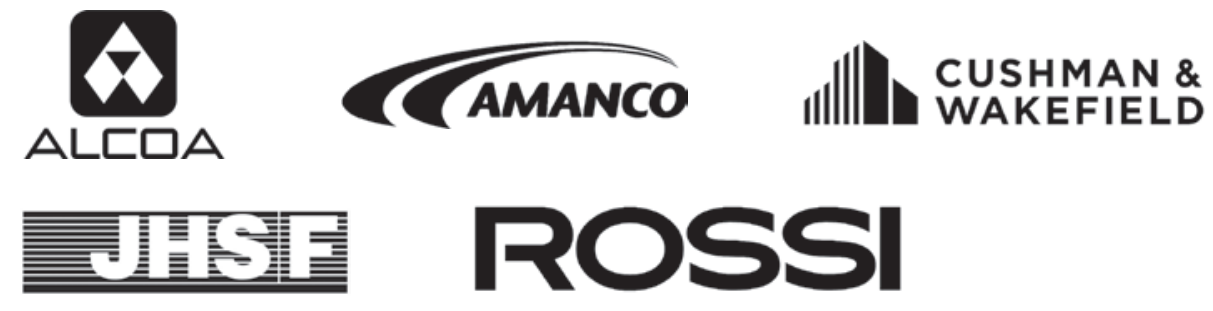

GOLD

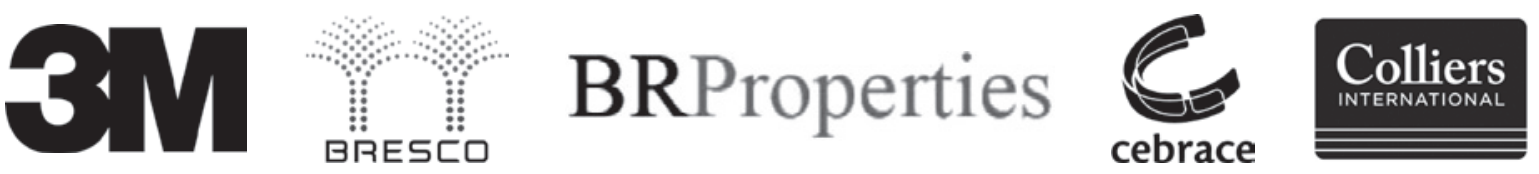

DOW ODEBRECHT
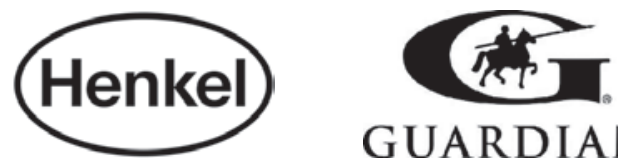

GUARDIAN ${ }^{a}$

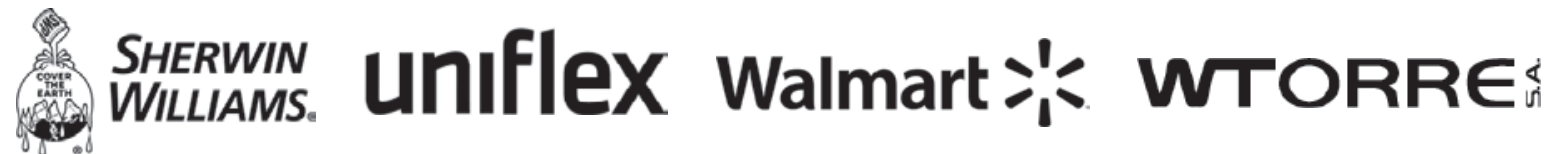

SILVER

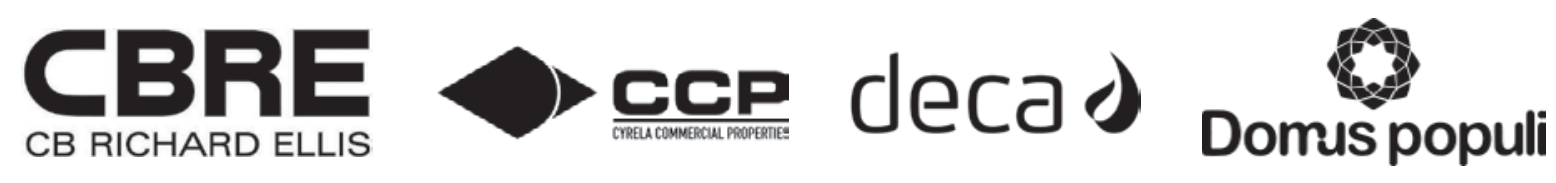

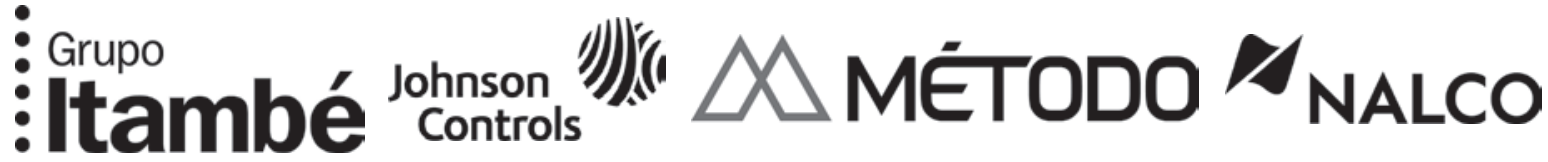

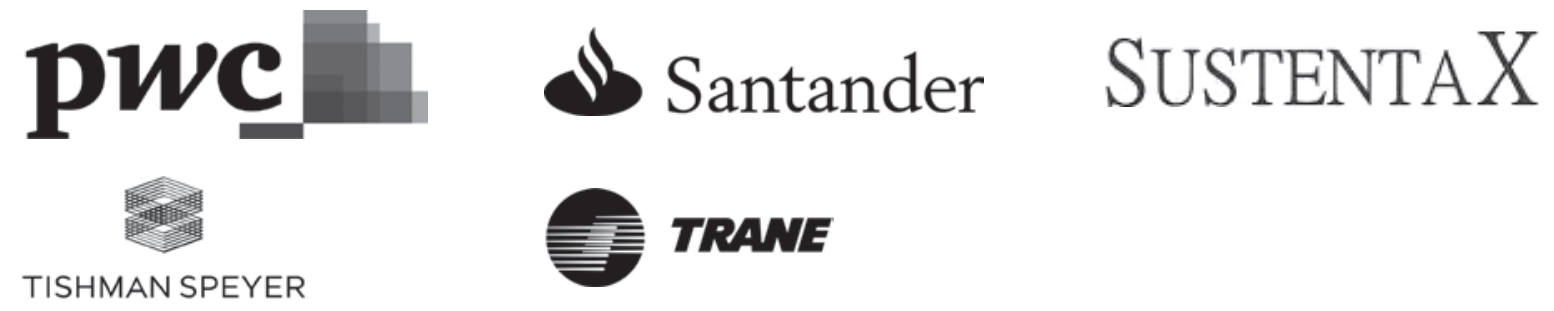
APOIO

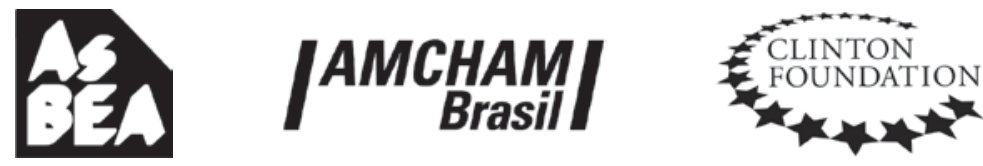

Fig 3.1. Membros-fundadores do GBC Brasil, organizados por nível de contribuição. 
eficiência nos planos de governança feitos por Moulin foram decisivos para a decisão do World GBC apoiar o grupo de Wanick:

\begin{abstract}
Primeiro, você ter um conselho fundador com várias empresas, a maioria delas que lideram os seus respectivos mercados, e sendo representados pelos seus diretores do alto escalão. Isso de fato foi um grande passo. E depois a elaboração e a ponderação de um planejamento estratégico muito bem definido, com os objetivos estratégicos bem definidos, valores, missão, visão. Os objetivos estratégicos, as áreas de atuação. Isso foi um ponto muito interessante de convencimento do World GBC para oficializar esse grupo. ${ }^{33}$
\end{abstract}

Esse suporte financeiro não existia no grupo acadêmico. Segundo Wanick, a ampla adesão corporativa foi fundamental porque o World GBC só aceitava a inscrição no caso de os fundadores já possuírem consigo dois anos de orçamento, com valores estimados pelo próprio grupo fundador. A falta de recursos teria sido, inclusive, o motivo pelo qual Roberto Teitelroit não pudera formar o GBC Brasil alguns anos antes. ${ }^{34}$

Em cerca de dois anos, Wanick havia então conseguido reunir uma rede de agentes para o Green Building Council Brasil, incluindo grande parcela do mercado, a representação do governo do Estado de São Paulo na figura de seu Secretário do Meio Ambiente e a chancela do World GBC.

O aceite do conselho global em relação à inscrição do conselho brasileiro foi anunciado em junho de 2007 em Toronto, no Canadá. ${ }^{35} \mathrm{O}$ World GBC estabelecia seu primeiro secretariado naquela mesma ocasião, ${ }^{36}$ dando maior estabilidade e continuidade a suas ações. Petinelli levou ao evento não só Wanick, mas também Marcelo Takaoka, representante do grupo acadêmico, embora não tenha sido alcançado consenso. Segundo Petinelli, a discordância em torno da inscrição de membros jurídicos mostrou-se intransponível. ${ }^{37} \mathrm{O}$ núcleo de Wanick e Moulin ficava

\footnotetext{
33. Faria, (Diretor executivo do GBC Brasil, 2012-atual), Entrevista para o autor.

34. Wanick, (Fundadora do GBC Brasil), Entrevista para o autor.

35. Petinelli, (Rector of Council Development no World GBC, 2006-2008; Co-fundador do GBC Brasil), Entrevista para o autor; Moulin Netto, (Co-fundador do GBC Brasil), Entrevista para o autor; Faria, (Diretor executivo do GBC Brasil, 2012-atual), Entrevista para o autor.

36. “Our story”, World Green Building Council, acessado 20 de novembro de 2018, https://www.worldgbc.org/our-story.

37. Petinelli, (Rector of Council Development no World GBC, 2006-2008; Co-fundador do GBC Brasil), Entrevista para o autor.
} 
com o GBC Brasil; Takaoka e os acadêmicos criavam paralelamente o Conselho Brasileiro de Construção Sustentável (CBCS). ${ }^{38}$ Para Petinelli, a diferença nas “missões" das duas organizações permitia sua fundação simultânea sem sobreposição no campo de atuação:

A ideia é que o GBC ia focar na promoção de certificações, e que ia ser liderado pelo mercado, e que o CBCS estava muito mais interessado com a iniciativa pública, políticas públicas, a pesquisa e desenvolvimento, ao desenvolvimento até mesmo de standards que o GBC poderia apoiar no futuro, mas que o GBC estava focado com a transformação de mercado, trabalhar junto com a cadeia do mercado, para avançar a adoção de green building. ${ }^{39}$

Tal situação não era exclusiva do Brasil. No Reino Unido, por exemplo, ocorreu um processo semelhante: por um lado, o BRE organizava as políticas públicas de eficiência e sustentabilidade; por outro lado o UKGBC, fundado no mesmo ano que o GBC Brasil, aliava-se aos agentes do mercado. ${ }^{40}$

Apesar da citação de Petinelli, naquele momento os dois conselhos surgiam em disputa, sobretudo em relação à hegemonia no mercado de certificação brasileiro. Segundo relato na

38. Primeiro Conselho Deliberativo do CBCS, gestão 2007-2011: Presidente do Conselho Deliberativo: Marcelo Vespoli Takaoka (professor, EP-USP); Conselheiros: Fabio Feldmann (deputado federal pelo PSDB, 1986-1998; secretário de Meio Ambiente do Estado de São Paulo, 1995-1998, gestão Mário Covas), Franscisco Antunes de Vasconcellos Neto (arquiteto e urbanista, FAUUSP; engenheiro civil, EP-USP), Hugo Marques da Rosa (diretor-presidente e sócio fundador da Método Engenharia; vice-presidente do conselho do Greenpeace Brasil, 2001-2005), Luiz Henrique Ceotto (diretor de design e construção da Tishman Speyer Properties, 2005-atual), Mario Prestes Monzoni Neto (professor FGV, 2005-atual), Olavo Kucker Arantes (mestre em engenharia de produção, UFSC), Orestes Marracini Gonçalves (professor titular, EP-USP), Paulo Augusto Oliveira Itacarambi (professor, UFSCar; fundador do Instituto Pólis), Paulo Machado Lisboa (arquiteto, ex-vice-presidente da AsBEA), Roberto de Souza (pesquisador e Diretor de Divisão de Edificações do IPT; diretor do CTE), Roberto Lamberts (engenheiro civil, professor titular, UFSC), Vahan Agopyan (professor titular, EP-USP), Vanderley Moacyr John (professor, EP-USP), Vanessa Gomes da Silva (professora, Unicamp); Diretoria: Diana Csillag (então mestranda, EP-USP), Wilson Saburo Honda (então mestrando, EP-USP); Conselho Fiscal, titulares: Mário Sérgio Pini (vice-presidente da editora PINI), Roberto Aflalo Filho (arquiteto, sócio-diretor do a/g arquitetos), Márcia Mikai Junqueira de Oliveira (então mestranda EP-USP); Conselho Fiscal, suplentes: Rubens de Almeida (engenheiro civil e jornalista), Franscico Ferreira Cardoso (professor titular, EP-USP), Valério Gomes Neto (presidente da Pedra Branca, ligada ao empreendimento homônimo em Palhoça, SC).

39. Petinelli, (Rector of Council Development no World GBC, 2006-2008; Co-fundador do GBC Brasil), Entrevista para o autor.

40. Petinelli. 
Folha de São Paulo, o CBCS pretendia criar um sistema próprio de certificação, com Wanick rebatendo, na paráfrase da jornalista, "que uma adequação do certificado [LEED] para o Brasil está quase pronta e que, se houver dois selos brasileiros, quem decidirá qual é o mais adequado será o mercado imobiliário." ${ }^{41} \mathrm{O}_{\mathrm{LEED}}{ }^{\oplus}$ tornou-se o principal sistema de avaliação no Brasil e o CBCS continua, ainda hoje, sem selo próprio, centrando sua ação em educação, pesquisa e políticas públicas ${ }^{42}$ - o que pode ser reflexo da criação em 2008 do Processo AQUA ${ }^{\circledR}$, adaptado do francês Haute Qualité Environnementale $\left(\mathrm{HQE}^{\circledR}\right)$, gerido pela Fundação Vanzolini, da Escola Politécnica da USP.

\section{OS 'PILARES' DO GBC BRASIL}

A primeira reunião do conselho deliberativo do GBC Brasil aconteceu em meados de 2007. Este era formado por cinco pessoas físicas - Wanick, Moulin, Petinelli, Luciana Rossi e Teitelroit - além de todas as empresas membro-fundadoras. ${ }^{43}$ As atividades, que antes aconteciam na própria residência de Wanick em Alphaville, foram transferidas para um pequeno escritório no centro empresarial de Barueri, onde o GBC Brasil continua até hoje. O influxo de recursos permitiu a contratação dos primeiros funcionários: César Brito, antes secretário pessoal de Wanick; Felipe Faria, advogado e ex-estagiário no consulado da Tailândia; Marcos Casado, engenheiro do primeiro edifício certificado pelo LEED $^{\circledR}$ no Brasil, foi chamado para coordenar os comitês técnicos e os programas educacionais; e Nelson Kawakami, até então diretor do banco Real-ABN AMRO, selecionado como diretor gerente. ${ }^{44}$ Segundo Faria, Kawakami "refez a parte de

\footnotetext{
41. Maria Carolina Nomura, "Especialistas divergem sobre selo", Folha de São Paulo, 8 de julho de 2007, seç. Construção, https://www1.folha.uol.com.br/fsp/construcao/cs0807200703.htm.

42. Marcelo Vespoli Takaoka, "Diretrizes de ação (revisão 1, em junho de 2013)” (CBCS, maio de 2013), http://www.cbcs. org.br/website/institucional/show.asp?ppgCode=CA4D48EC-82E0-4FED-BAF7-11E3DACBE63B.

43. Petinelli, (Rector of Council Development no World GBC, 2006-2008; Co-fundador do GBC Brasil), Entrevista para o autor. Esse conselho passou a ser eleito pelos associados. É formado por quatorze membros, sendo doze escolhidos por eleição. Esses doze cargos são distribuídos entre quatro a sete membros fundadores e cinco a oito membros do GBC Brasil. Os dois cargos restantes são ocupados por pessoas físicas escolhidas pelos doze membros eleitos. Cf. Green Building Council Brasil (GBC Brasil), "Estatuto do Green Building Council - Brasil”.

44. Wanick, (Fundadora do GBC Brasil), Entrevista para o autor; Moulin Netto, (Co-fundador do GBC Brasil), Entrevista para o autor; Petinelli, (Rector of Council Development no World GBC, 2006-2008; Co-fundador do GBC Brasil), Entrevista para o autor; Faria, (Diretor executivo do GBC Brasil, 2012-atual), Entrevista para o autor; Marcos Casado, (Engenheiro
} 
planejamento estratégico, dentro já de uma visão do que ele já fazia em banco", reorganizando as atividades do conselho. Kawakami continuaria no cargo de CEO até 2011, sucedido por Maria Clara Coracini - ex-executiva da DuPont, lá responsável pela infraestrutura latino-americana e projetos sociais - durante alguns meses. Ela foi substituída por Faria a partir de $2012 .{ }^{45} \mathrm{~A}$ contratação desse staff é defendida por Petinelli como essencial para o sucesso do conselho: se o GBC continuasse mantido por voluntários, logo perderia fôlego, como havia acontecido com o GBC Israel. ${ }^{46}$

Uma das primeiras decisões do conselho foi a posição oficial em relação à certificação: se usariam exclusivamente o LEED $^{\circledR}$ ou se procurariam alternativas. Após um bem-sucedido evento para impulsionar a arrecadação de recursos, tal como aquele do Grand Hyatt, o "road map" do World GBC sugeria a comercialização de um certificado. Por meio dele, o conselho teria um produto garantindo a entrada de recursos, conforme argumenta Petinelli:

\begin{abstract}
Para mim, o essencial era [que] você precisa ir o mais rápido possível para um modelo de secretariado em cima de um business plan que projeta autossuficiência financeira em dois ou três anos. Você tem que aproveitar o lançamento do conselho, isso é chave, a gente chamava de maximize the launch, para angariar os fundos, o seat funding, para você conseguir chegar a um ponto de equilíbrio operacional em dois ou três anos. Um conselho bem estruturado era um ponto-chave para que isso acontecesse. E trabalhar a certificação como um primeiro produto, para muitos GBCs que estavam lidando com o crescimento absurdo do LEED $^{\circledR}$ nos seus mercados, e aí eu traduzo isso para produtos de educação e capacitação em um primeiro momento, e eventualmente em eventos como fonte alternativa de renda. A premissa sendo que muitos desses GBCs não iam ter o seu próprio sistema de certificação. ${ }^{47}$
\end{abstract}

\footnotetext{
do $1^{\circ}$ edifício certificado no Brasil; Diretor educacional e de comitês técnicos no GBC Brasil, 2007-2013), Entrevista para o autor, Presencial, 18 de setembro de 2017.

45. Faria, (Diretor executivo do GBC Brasil, 2012-atual), Entrevista para o autor; iG São Paulo, "Maria Clara Coracini deixa DuPont e vai para a ONG GBC Brasil”, iG - Brasil Econômico, 21 de fevereiro de 2011, https://economia.ig.com.br/carreiras/ maria-clara-coracini-deixa-dupont-e-vai-para-a-ong-gbc-brasil/n1238080990703.html.

46. Petinelli, (Rector of Council Development no World GBC, 2006-2008; Co-fundador do GBC Brasil), Entrevista para o autor. Segundo ele, "Está ali [no GBC Israel] um exemplo de um GBC que não foi para a frente porque não conseguiu levantar grana rápido o suficiente para estabelecer um secretariado e os voluntários cansaram.”

47. Petinelli.
} 
Embora José Moulin defenda que o LEED ${ }^{\circledR}$ seja apenas uma ferramenta entre outras tantas, sem ver concorrência com outros certificados ${ }^{48}$ a estratégia do GBC Brasil manteve-se centrada no sistema norte-americano. Eram vários os motivos.

Em primeiro lugar, no momento da criação do CNPJ do conselho, havia oito projetos registrados para a certificação pelo $\mathrm{LEED}^{\oplus}$, contra poucos ou nenhum em outras certificações. O fato é utilizado como indício de que o LEED ${ }^{\circledR}$ já possuía inserção no mercado brasileiro, ainda que o anúncio do primeiro edifício aprovado para certificação tenha ocorrido algumas semanas após essa reunião do conselho deliberativo [fig 3.2]..$^{49} \mathrm{O}$ segundo motivo estava relacionado ao aparato normativo vinculado ao LEED $^{\circledR}$, pois já era comum o uso pelos engenheiros brasileiros das normas ASHRAE, referentes aos sistemas de ar condicionado. A norma era comum inclusive dentro de agremiações profissionais como a Associação Brasileira de Refrigeração, Ar Condicionado, Ventilação e Aquecimento (ABRAVA). ${ }^{50}$ Em seguida, o uso do LEED ${ }^{\circledR}$ ainda se justificaria segundo Wanick pelo compartilhamento de valores culturais com os norte-americanos: "talvez as pessoas não se lembrem disso, mas nós somos americanos". ${ }^{51} \mathrm{E}$ também por questões financeiras: segundo ela, a maior parte do investimento estrangeiro em território brasileiro vinha dos Estados Unidos. Desse modo, o LEED $^{\circledR}$ poderia se transformar em um meio das filiais brasileiras confirmarem para suas sedes norte-americanas que respeitavam suas diretrizes de responsabilidade

48. Moulin Netto, (Co-fundador do GBC Brasil), Entrevista para o autor.

49. São eles: sede do Serasa em São Paulo, LEED ${ }^{\circledast}$ EB OM v2, registrado em 10 mai 2004, não certificado; Colégio Cruzeiro no Rio de Janeiro, LEED ${ }^{\circledR}$ NC 2.1, registrado em 25 ago 2005, não certificado; Primavera Office Building em Florianópolis,

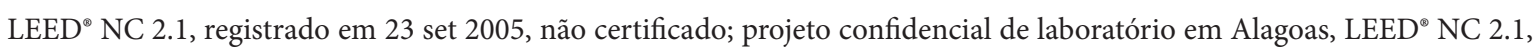
registrado em 22 dez 2005, não certificado; Banco Real (ABN AMRO) na Granja Viana, LEED $^{\circledR} \mathrm{NC}_{2.2}$, registrado em 25 mai 2006, certificação Silver em 6 ago 2007; Rochaverá Corporate Towers - Torre B, LEED ${ }^{\circledR}$ CS v2, registrado em 7 jul 2006, certificado Gold em 5 ago 2009; Ventura Corporate Towers - Torre Leste, LEED ${ }^{\circledR}$ CS v2, registrado em 7 jul 2006 , certificado Gold em 24 ago 2009; projeto confidencial em São Paulo, LEED ${ }^{\circledR}$ CS v2, registrado em 22 ago 2006, certificado Platinum em 19 ago 2009. Essa listagem é interrompida aqui em 2 de janeiro de 2007, momento da criação do CNPJ do GBC Brasil. Notar que há elevada taxa de rejeição dos registros: metade dos edifícios que requerem a certificação antes da criação do GBC Brasil não conseguem a pontuação mínima ou desistem do processo, o que ressalta a importância de um GBC local para facilitar os processos de trabalho. Há grande quantidade de edifícios registrados em 26 de junho de 2007 , o que pode ser um indício do início da atuação do conselho. Ver fig 3.3. Fonte: LEED Project Directory (USGBC $\left.{ }^{\circledast}\right), 4$ jun 2019.

50. Moulin Netto, (Co-fundador do GBC Brasil), Entrevista para o autor; Faria, (Diretor executivo do GBC Brasil, 2012-atual), Entrevista para o autor; Casado, (Engenheiro do $1^{\circ}$ edifício certificado no Brasil; Diretor educacional e de comitês técnicos no GBC Brasil, 2007-2013), Entrevista para o autor.

51. No original: “maybe people do not remember that, but we are Americans” Wanick, (Fundadora do GBC Brasil), Entrevista para o autor, tradução nossa. 


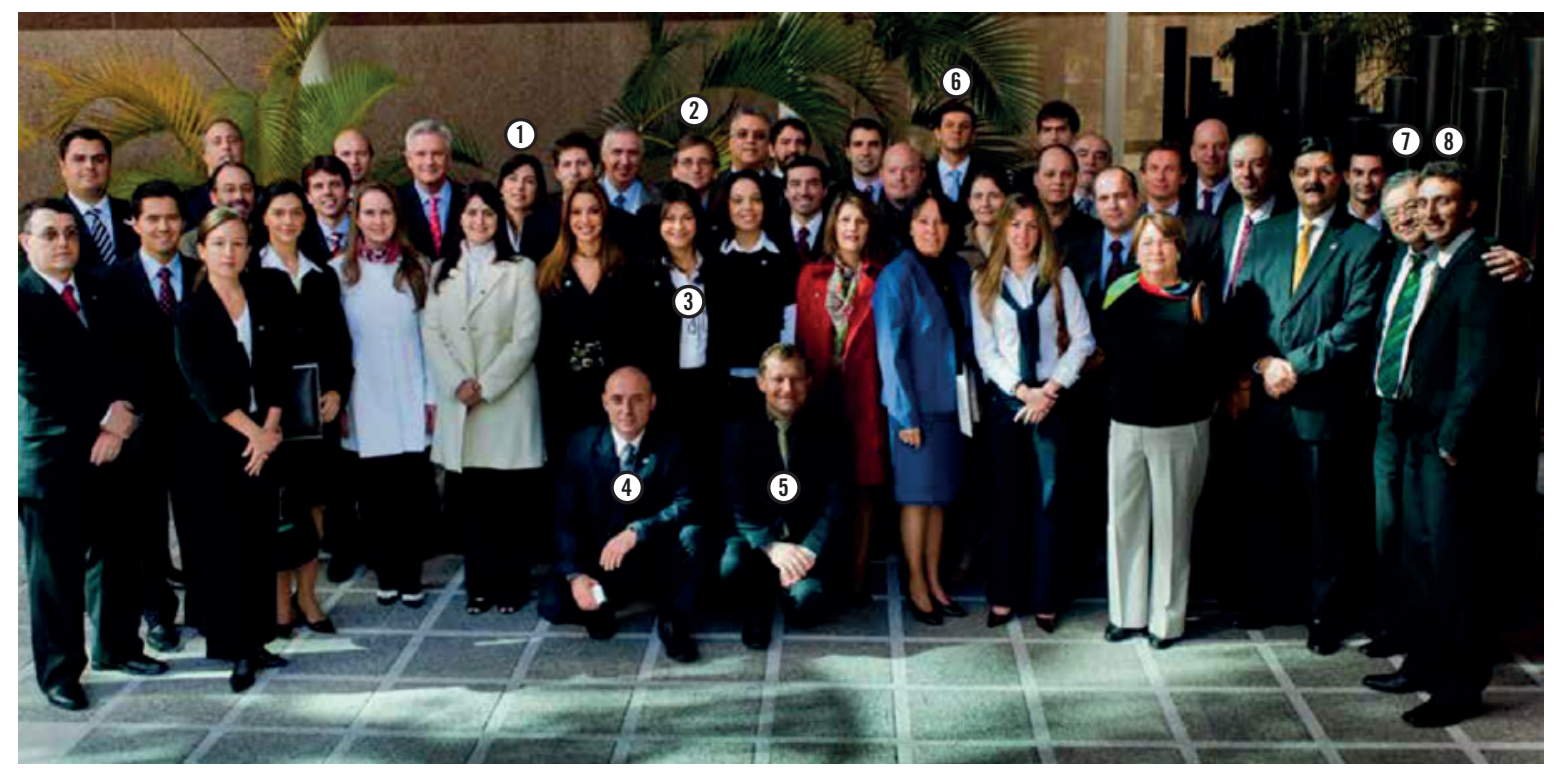

Fig 3.2. Fotografia oficial do primeiro conselho deliberativo do GBC Brasil, 18 jun 2009, na sede da Cushman \& Wakefield em São Paulo. Fonte: "10 anos fazendo história”, Revista GBC Brasil, n. 14, p. 54. Identificação pelo autor.
1. Celina Antunes (Cushman \& Wakefield)

2. José Moulin Netto (GBC Brasil)

3. Thassanee Wanick (GBC Brasil)

4. Cézar Velazquez (GBC Brasil)

5. Marcos Casado (GBC Brasil)

6. Adriano Sartori (CBRE)

7. Nelson Kawakami (GBC Brasil)

8. Felipe Faria (GBC Brasil)

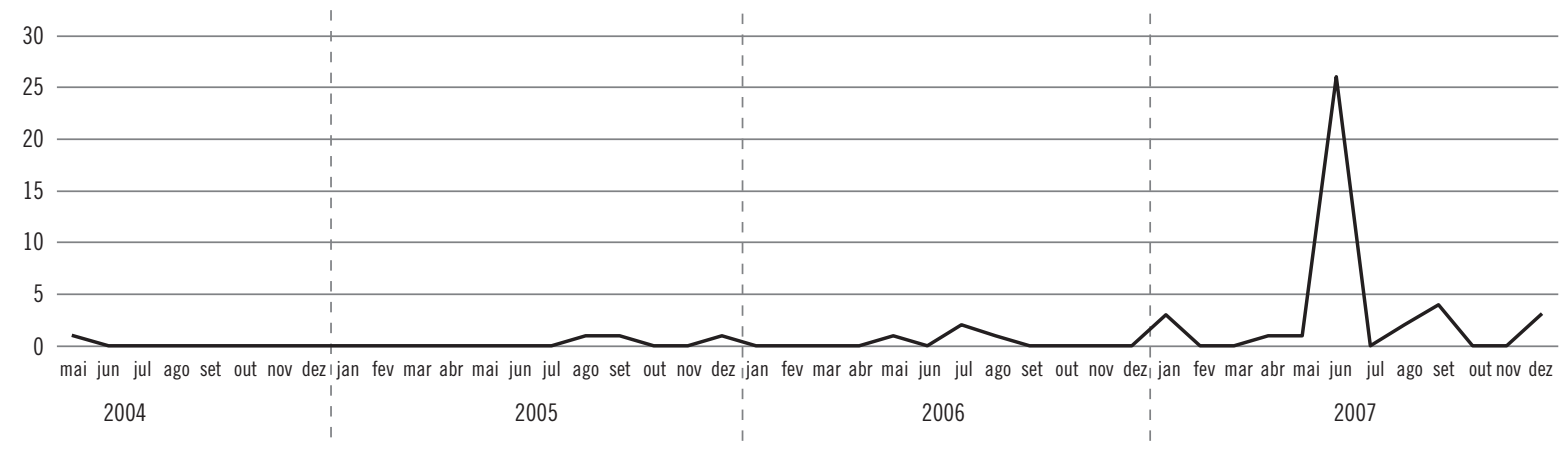

Fig 3.3. Detalhamento dos registros brasileiros no LEED ${ }^{\circledR}$, mai 2004-dez 2007. Fonte: LEED Project Directory, 4 jan 2019. Elaborado pelo autor.
O pico em junho de 2007, de 26 projetos em ao menos 14 empreendimentos diferentes, é indício do começo da intermediação do GBC Brasil e de seu impacto na promoção do LEED no Brasil. 
social corporativa, facilitando a chegada de recursos. Para tal, era importante que a comprovação fosse feita com uma ferramenta que os norte-americanos de fato conhecessem. ${ }^{52}$ Por fim, como último mas igualmente relevante motivo, os CEOs que participavam do conselho já consideravam o LEED ${ }^{\curvearrowleft}$ como a principal ferramenta do mercado imobiliário internacional e previam sua chegada no Brasil. Felipe Faria argumenta:

Em uma das nossas primeiras reuniões de conselho, eles estavam discutindo se a gente ia trabalhar com uma ferramenta de certificação existente, se a gente ia criar uma outra certificação. E, quase que unânime, nesses grandes executivos, é que a gente tinha que trabalhar na promoção do LEED ${ }^{\circledR}$. Porque eles já estavam vendo que nesse futuro próximo, ele ia ser a principal ferramenta do mercado imobiliário internacional..$^{53}$

Mais do que isso: considerando-se apenas os registros até a criação do CNPJ do GBC Brasil em 2 de janeiro de 2007, muitos desses executivos não só previam a internacionalização do LEED $^{\circledR}$, como já eram de fato agentes de sua implantação. Dois importantes empreendimentos, o Ventura e o Rochaverá Corporate Towers, contaram com serviços de empresas membro-fundadoras do GBC Brasil: a incorporação pela Tishman Speyer, a construção pela Método e a consultoria de sustentabilidade pela SustentaX.

Em suma, a escolha do LEED $^{\circledR}$ se deu por uma conjugação de fatores: uso prévio e previsão de expansão no mercado brasileiro, aproximações culturais e econômicas com os Estados Unidos, intercâmbio normativo e validade como evidência em relatórios de responsabilidade social corporativa.

A fundação do GBC Brasil é fundamental na proliferação do $\mathrm{LEED}^{\circledR}$ no país. Isso pode ser aferido no salto de registros e certificações no Brasil [fig 3.3 a 3.5]. E também no crescimento da participação brasileira no mercado mundial, em que vem galgando posições no ranking de países com maior utilização do LEED ${ }^{\circledR}$ fora dos Estados Unidos, estando em quinto lugar em 2018, por quantidade de empreendimentos certificados [fig 3.8].

52. Wanick.

53. Faria, (Diretor executivo do GBC Brasil, 2012-atual), Entrevista para o autor. 


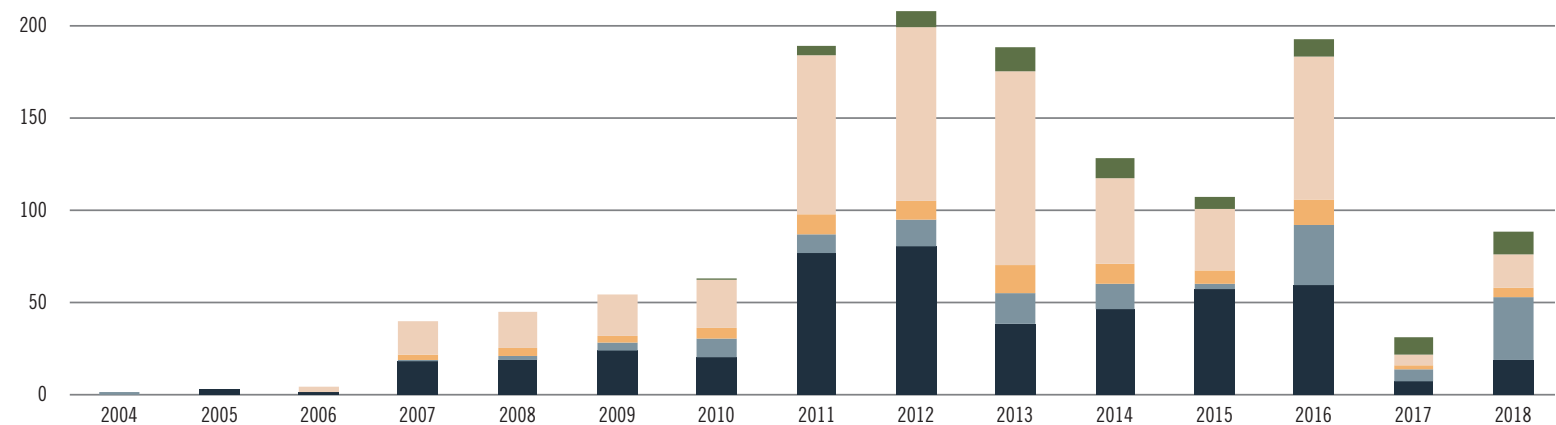

$\begin{array}{lllll}\text { NC } & \mathrm{EB} & \mathrm{Cl} & \mathrm{CS} & \text { OUTROS (DC, HC, HP, HOMES, ND, RET NC+Cl, SC NC, WDC) }\end{array}$

Fig. 3.4. Registros brasileiros no $\mathrm{LEED}^{\circledR}$, organizados por sistema. Amostra de 1342 empreendimentos. Fonte: LEED Project Directory (USGBC), com correções pelo autor em Empreendimentos LEED (GBC Brasil), 4 jan 2019. Elaborado pelo autor.
O aumento de registros em 2007 sugere o impacto da fundação do GBC Brasil, intermediando a certificação com o USGBC ${ }^{\circledR}$ e promovendo a aplicação do LEED ${ }^{\circledR}$ no Brasil. O pico em 2016, durante os anos de declínio em meio à crise econômico-política brasileira, é explicado pelos profissionais ouvidos - como Marcos Casado e Felipe Faria - como uma mudança de comportamento do mercado, que estaria então registrando projetos de edifícios existentes (EBOM) e lojas de varejo (RET). Pelos dados disponíveis, pode-se efetivamente observar o significativo crescimento do EBOM, mas relativa estabilização no RET (incluído em "Outros", devido a sua baixa quantidade anual) e mesmo no sistema Commercial Interiors (CI). Portanto, esse pico parece ser de outra natureza, não apresentada nas fontes consultadas, pois o sistema NC mantém-se estável e o CS mais que dobra em relação ao ano anterior: 2016 é o último ano de registro do LEED $^{\circledR}$ v3. Segundo o engenheiro Marcos Casado, o LEED ${ }^{\circledR}$ v4 é mais complexo, por exigir rotulagens de materiais incomuns no mercado brasileiro. Essa queda abrupta de registros a partir da v4 também pode ser observada nos Estados Unidos e internacionalmente, como foi apontado nos capítulos anteriores. 
150

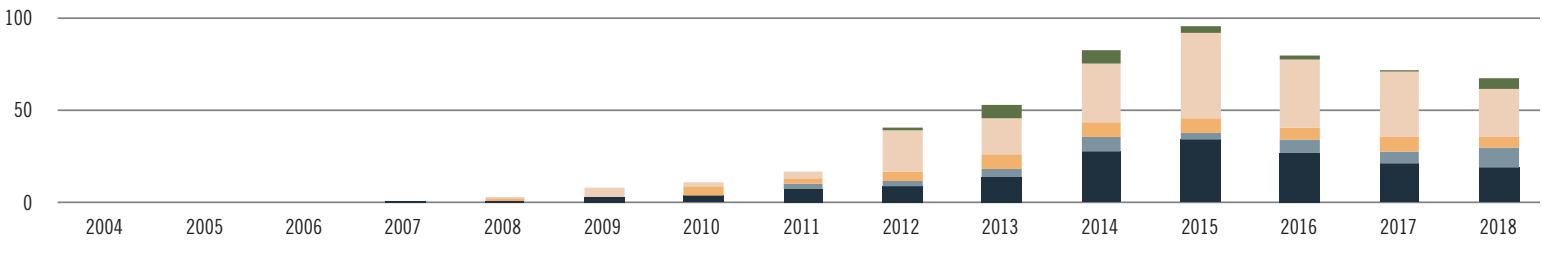

$\square$ NC $\quad$ EB $\quad \mathrm{Cl} \quad \mathrm{CS} \square$ OUTROS (HOMES, ND, RET NC+Cl, SC NC, WDC

Fig 3.5. Certificados $\mathrm{LEED}^{\circledR}$ no Brasil, organizados por sistema. Amostra de 533 empreendimentos. Fonte: LEED Project Directory (USGBC), com correções pelo autor a partir de Empreendimentos LEED (GBC Brasil), 4 jan 2019. Elaborado pelo autor.

Fig 3.6. Proporção total de certificados LEED ${ }^{\circledR}$ no Brasil, organizados por sistema. Amostra de 533 empreendimentos. Fonte: LEED Project Directory (USGBC), com correções pelo autor a partir de Empreendimentos LEED (GBC Brasil), 4 jan 2019. Elaborado pelo autor.

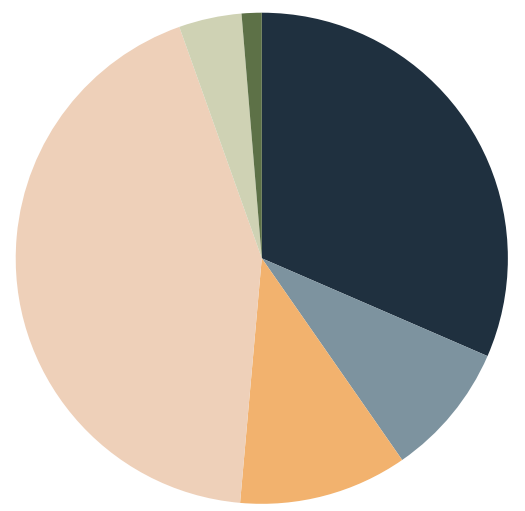

NC $\square$ EBOM $\square \mathrm{Cl} \square \mathrm{CS} \square$ RET (NC+Cl) $\square$ OUTROS (HOMES, ND, SC NC, WDC) 
Fig 3.7. Membros do GBC Brasil, organizados por setor profissional. Amostra de 735 membros. Fonte: GBC Brasil, 4 jan 2019. Classificação realizada pelo GBC Brasil. Gráfico elaborado pelo autor.

Pelo levantamento realizado no diretório de membros cadastrados no GBC Brasil, é possível identificar a predominância de filiados nos seguintes ramos: construtoras, escritórios de arquitetura e engenharia, prestadores de serviço (o que inclui consultorias) e produtores e distribuidores de materiais. Predominam, portanto, os profissionais especializados nos serviços de sustentabilidade, e não os clientes desses serviços (como seria o caso das incorporadoras).

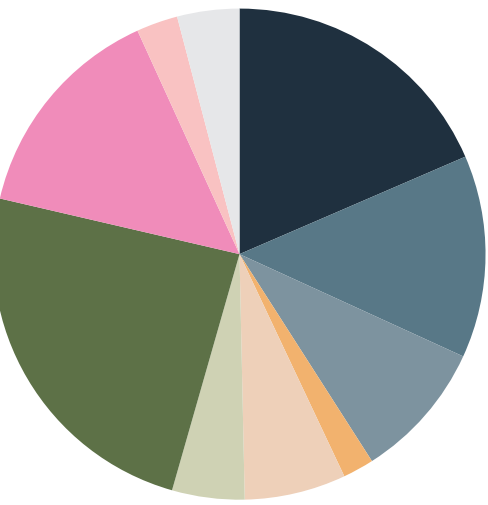

Construtoras

Escritórios de Arquitetura

Escritórios de Engenharia

Fabricantes de Equipamento

Fabricantes de Materiais

Incorporadoras

Prestadores de Serviço

Produtores e Distribuidores de Materiais
Varejias e Atacadistas Outros (Administradoras, Associações Profissionais, Autarquias, Empresas Públicas, Empresas de Economia Mista, Imobiliárias, Instituições de Ensino, Instituições Financeiras, Organizações Sociais)

1800

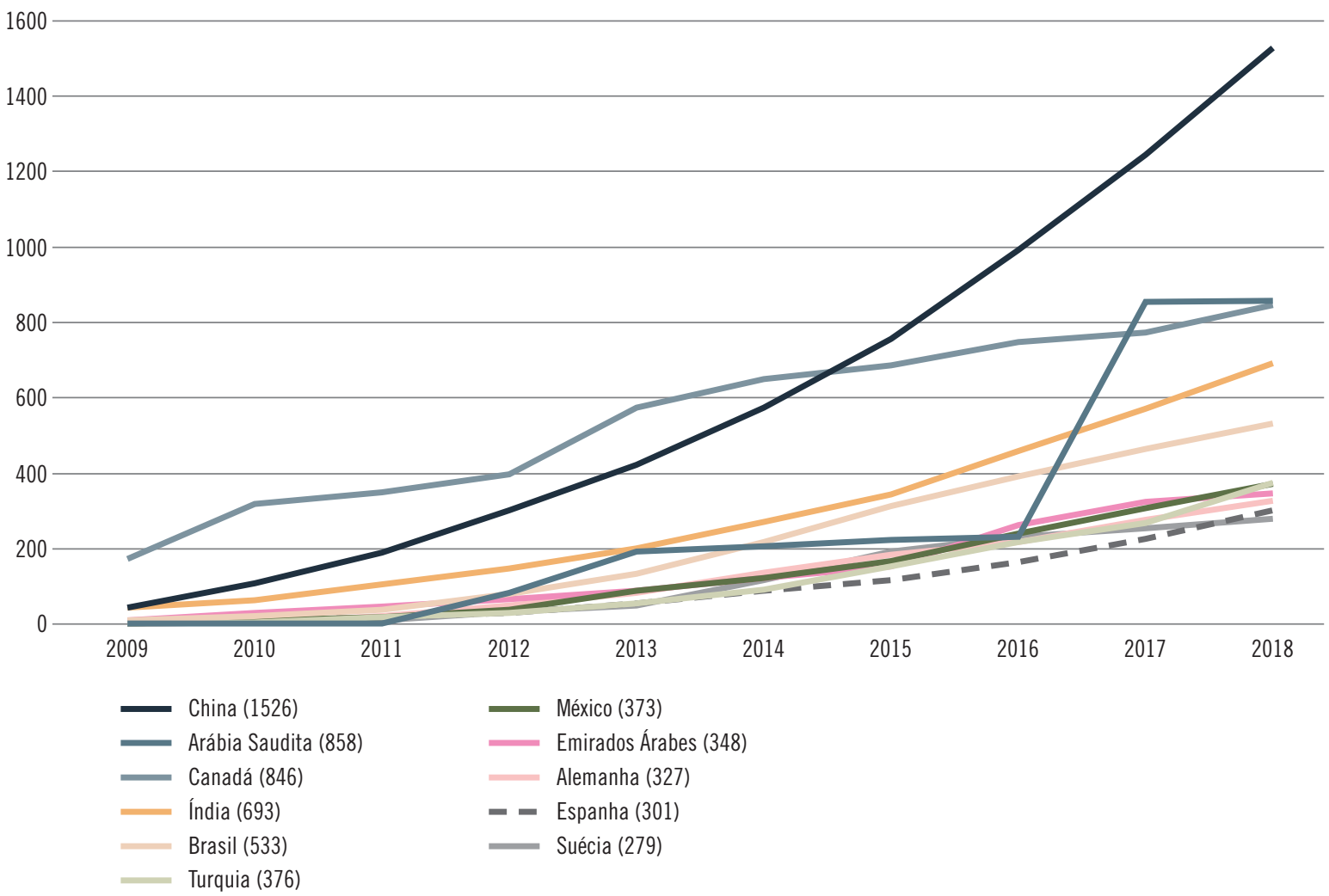

Fig 3.8. Desempenho dos países com mais certificados LEED $^{\circ}$, fora dos Estados Unidos, por quantidade de empreendimentos. Na legenda, países organizados por ordem de classificação em 2018. Entre parênteses, a quantidade de empreendimentos certificados até 2018.

Fonte: LEED Project Directory (USGBC), 4 jan 2019. Elaborado pelo autor. 
Mas a formação de um conselho verde nacional não significa apenas a inclusão de um mediador - e facilitador - entre os empreendedores brasileiros e a certificação, até 2007 ainda feita pelo USGBC . O GBC Brasil tem diversas estratégias de promoção da sustentabilidade, na maioria das vezes, ligadas ao LEED". É o que executivos ligados ao GBC Brasil chamam de "pilares" da operação do conselho: a própria certificação, a formação de técnicos capazes de aplicá-la no Brasil, a disseminação das "melhores práticas" do mercado por meio de um evento anual e a promoção de políticas públicas. ${ }^{54}$

A importação da certificação no Brasil exigiu medidas de adaptação, inicialmente chefiadas pelo engenheiro Marcos Casado. Com esse intuito, formaram-se comitês técnicos correspondentes a cada uma das categorias do sistema LEED ${ }^{\circledR}$ Sustainable Sites (SS), Water Efficiency (WE), Energy and Atmosphere (EA), Materials and Resources (MR) e Indoor Environmental Quality (EQ). Cada comitê era formado por especialistas, tanto acadêmicos ${ }^{55}$ quanto "players" do mercado, reunidos semanal ou quinzenalmente para avaliarem cada crédito. Após cada versão do LEED ${ }^{\circledR}$, ou novo certificado usado no Brasil, esses comitês reúnem-se para avaliar como se dará o uso nacional. Naquele momento, foram mais de duzentos profissionais, com atuação ao longo de 2007 e $2008 .^{56}$

Os grupos de trabalho concluíram não ser necessária nenhuma mudança no sistema de avaliação, embora houvesse medidas que demandassem novas práticas do mercado. Por um lado, o ajuste brasileiro ocorreu pelos créditos regionais, ausentes no LEED $^{\circledR}$ v2.2 em operação desde 2005, mas incorporados a partir da versão 3 de 2009. Segundo Felipe Faria, a iniciativa foi incen-

54. Moulin Netto, (Co-fundador do GBC Brasil), Entrevista para o autor; Felipe Faria também defende os mesmos quatro pilares em palestras para o Movimento Vida Saudável e para a Saint-Gobain. Cf. Felipe Faria, "MVS - Fórum Março 2016 - Palestra Felipe Faria - GBC Brasil (na íntegra)", YouTube, 11 de março de 2016, https://www.youtube.com/watch?v=qo53qUqPXdk; Felipe Faria, "A certificação LEED e os benefícios econômicos dos edifícios verdes - palestrante Felipe Faria", YouTube, 24 de maio de 2017, https://www.youtube.com/watch?v=iVg0RvUjetw.

55. Casado indica que haviam professores da USP, UFPR, UFRJ e UFSC, sem mencionar nenhum nome. Felipe Faria menciona Marcelo Romero, da FAUUSP; Alberto Hernandez Netto, do Departamento de Engenharia Mecânica da EP-USP; Vanessa Gomes da FEC-Unicamp; Roberto Lamberts, da Engenharia Civil da UFSC e ligado à criação do Procel. Cf. Casado, (Engenheiro do $1^{\circ}$ edifício certificado no Brasil; Diretor educacional e de comitês técnicos no GBC Brasil, 2007-2013), Entrevista para o autor; Faria, (Diretor executivo do GBC Brasil, 2012-atual), Entrevista para o autor.

56. Casado, (Engenheiro do $1^{\circ}$ edifício certificado no Brasil; Diretor educacional e de comitês técnicos no GBC Brasil, 2007-2013), Entrevista para o autor; Maria Carolina Fujihara, (Diretora de comitês técnicos do GBC Brasil, 2013-2016), Entrevista para o autor, Email, 23 de novembro de 2018. 
tivada por Scot Horst, então diretor técnico do USGBC ${ }^{\oplus}$, sendo o Brasil o primeiro a aprová-la. ${ }^{57}$ Assim, os créditos regionais foram resultado de uma seleção pelo comitê técnico brasileiro de bonificações em créditos já existentes no sistema LEED ${ }^{\circledR}$ e passíveis de pontuação extra por meio da nova categoria Regional Priorities, aplicáveis em todo o território nacional. Por meio dessa categoria, caso um empreendimento cumpra, mesmo se parcialmente, um crédito listado no Regional Priorities do país, ele ganha um ponto extra. Por exemplo: caso um empreendimento brasileiro cumpra, mesmo se parcialmente, o crédito de otimização de energia presente nos sistemas LEED ${ }^{\oplus}$ NC e CS (EA.1 Optimize Energy Performance), ele será bonificado com um ponto extra, pois o crédito é listado como prioridade regional. Um empreendimento pode obter até quatro pontos extras dessa maneira. ${ }^{58} \mathrm{~A}$ prática foi depois adotada por outros países, através do LEED International Roundtable, no qual questões de internacionalização do sistema são discutidas com representantes de cada conselho nacional. ${ }^{59}$

Por outro lado, foram criados os "Alternative Compliance Paths for Projects Outside US" (ACP), presentes no $\mathrm{LEED}^{\circ} \mathrm{NC}$ v3 em pouco mais de um terço dos créditos. ${ }^{60}$ Segundo Maria Carolina Fujihara, à época estagiária no GBC Brasil e posteriormente diretora dos comitês técnicos com a saída de Marcos Casado no fim de 2013, a criação dos ACPs foi iniciativa brasileira. ${ }^{61}$ A ação exigiu mesmo a tradução de determinadas normas, como as da ASHRAE, devido a dis-

57. Faria, (Diretor executivo do GBC Brasil, 2012-atual), Entrevista para o autor.

58. Os capítulos 7 e 8 discutem em detalhe o funcionamento dos sistemas LEED ${ }^{\circledR} \mathrm{NC}$ e CS.

59. Em julho de 2015, o LEED International Roundtable incluía representantes da Alemanha, Argentina, Brasil, Canadá, Cazaquistão, Chile, China, Colômbia, Coreia do Sul, Costa Rica, El Salvador, Emirados Árabes Unidos, Espanha, Estados Unidos, Finlândia, França, Guatemala, Hong Kong, Índia, Irlanda, Itália, Hungria, Japão, Jordânia, México, Noruega, Panamá, Peru, Polônia, Qatar, República Tcheca, Romênia, Rússia, Suécia, Suíça, Trindade e Tobago e Turquia. Cf. "Um panorama do LEED e sua internacionalização", Anuário GBC 2015, julho de 2015.

60. São eles: SS.1 Site Selection, SS.3 Brownfield Development, SS.4.1 Alternative Transportation - Public Transportation Access, SS.4.4 Alternative Transportation - Parking Capacity, SS.6.1 Stormwater Design - Quantity Control, SS.8 Light Pollution Reduction, WE.1 Water Efficient Landscaping, EA.Prereq.2 Minimum Energy Performance, EA.1 Optimize Energy Performance, MR.5 Regional Materials, EQ.Prereq.1 Minimum Indoor Air Quality Performance, EQ.Prereq.2 Environmental Tobacco Smoke Control, EQ.1 Outdoor Air Delivery Monitoring, EQ.2 Increased Ventilation, EQ.3.1 Construction Indoor Air Quality Management Plan - During Construction, EQ.4.3 Low-Emmiting Materials - Flooring Systems, EQ.5 Indoor Chemicals and Pollutant Source Control, EQ.6.2 Controllability of Systems - Thermal Comfort, EQ.7.1 Thermal Comfort - Design e EQ.7.2 Thermal Comfort - Verification. Cf. USGBC (United States Green Building Council), "LEED 2009 for new construction and major renovations with alternative compliance paths for projects outside the US; v. 3 reference guide" (USGBC, 2011). 61. Fujihara, (Diretora de comitês técnicos do GBC Brasil, 2013-2016), Entrevista para o autor. 
cordâncias de interpretação dos comitês. ${ }^{62}$ Por meio dos ACPs, determinados créditos do LEED ${ }^{\circ}$ associados a outras normas poderiam ser cumpridos ao serem satisfeitos padrões nacionais, no lugar de norte-americanos. Assim, ao invés de cumprir a norma ASHRAE 90.1, o projetista poderia provar o alinhamento como o Procel Nível A; para a produção de energia on site, o selo norte-americano Green-e foi trocado pelo Selo Energias Renováveis, da Associação Brasileira de Energia Eólica (ABEEólica) e da Associação Brasileira de Geração de Energia Limpa (ABRAGEL); e normas ecológicas do Inmetro, da ABNT e da Falcão Bauer se tornaram válidas. ${ }^{63} \mathrm{~A} \mathrm{fle-}$ xibilização do $\mathrm{LEED}^{\circledR}$ não era portanto em relação ao sistema de avaliação, mas sim dos padrões a ele associados.

Em paralelo a essas adaptações, o mercado ainda precisava suprir os projetos com os materiais necessários. Segundo Casado,

O que a gente ia fazer era fomentar esses novos produtos no Brasil. Para te dar um exemplo: quando a gente começou as agências do banco [Real-ABN AMRO], as trinta primeiras agências do banco, a gente pintava com tinta cal, era a única tinta no Brasil que não tinha composto orgânico volátil. E aí o mercado todo começou a desenvolver as tintas linha premium, que são as tintas sem cheiro, porque elas atendiam o nível de VOC [Volatile Organic Compound] que o LEED $^{\circ}$ permitia. Então elas começaram a criar um mercado para isso. [...] A partir do momento em que você cria o mercado no Brasil, as empresas começaram a trazer os produtos que normalmente tinham lá fora, para poder fornecer aqui no Brasil também. [...] Eu lembro, por exemplo, de carpete. Na época, você começava a comprar carpete, você comprava só carpete da Milliken ou da Interface, que eram carpetes americanos que atendiam os critérios que estavam lá. E já haviam revendedores no Brasil. Mas aí as empresas brasileiras de carpete começaram a certificar seus produtos lá fora também, para entrar nesse mercado. E tem várias empresas no Brasil que acabaram buscando o selo para poder atender essa demanda. Isso aconteceu com tinta e vários outros produtos. Então, no início, a gente tem um pouco mais de dificuldade, mas depois ela vai embora. ${ }^{64}$

62. Casado, (Engenheiro do $1^{\circ}$ edifício certificado no Brasil; Diretor educacional e de comitês técnicos no GBC Brasil, 20072013), Entrevista para o autor.

63. Faria, (Diretor executivo do GBC Brasil, 2012-atual), Entrevista para o autor; Casado, (Engenheiro do $1^{\circ}$ edifício certificado no Brasil; Diretor educacional e de comitês técnicos no GBC Brasil, 2007-2013), Entrevista para o autor. 64. Casado, (Engenheiro do $1^{\circ}$ edifício certificado no Brasil; Diretor educacional e de comitês técnicos no GBC Brasil, 20072013), Entrevista para o autor. 


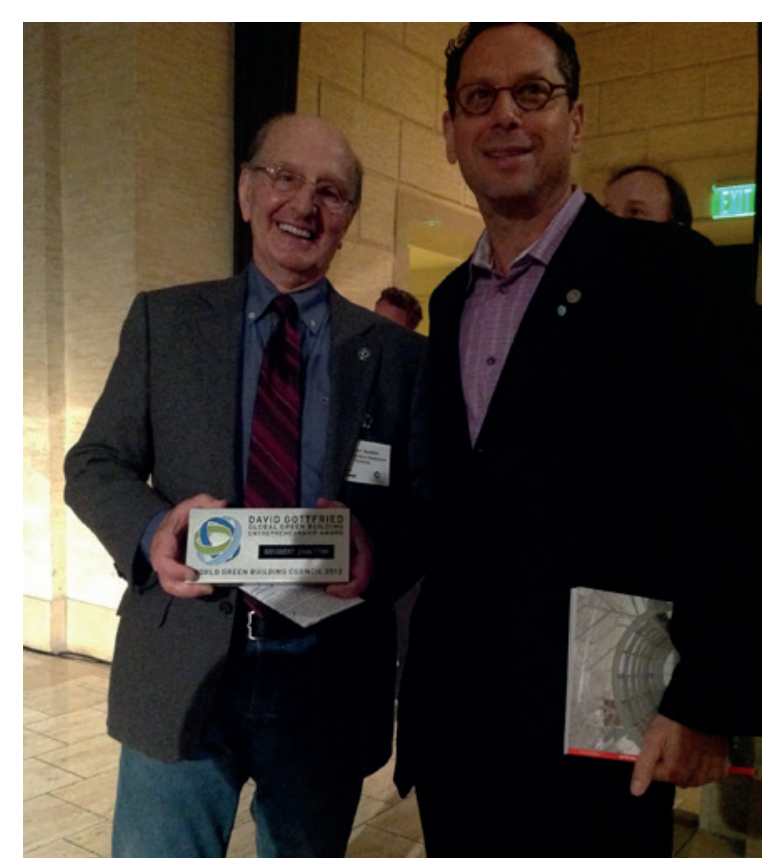

Fig 3.9. Siegbert Zanettini (esquerda) com David Gottfried (direita) durante premiação do David Gottfried Global Green Building Entrepreneurship Award, concedida pelo World GBC, em 13 nov 2012. Fonte: Pitanga Comunicação, via Flickr.

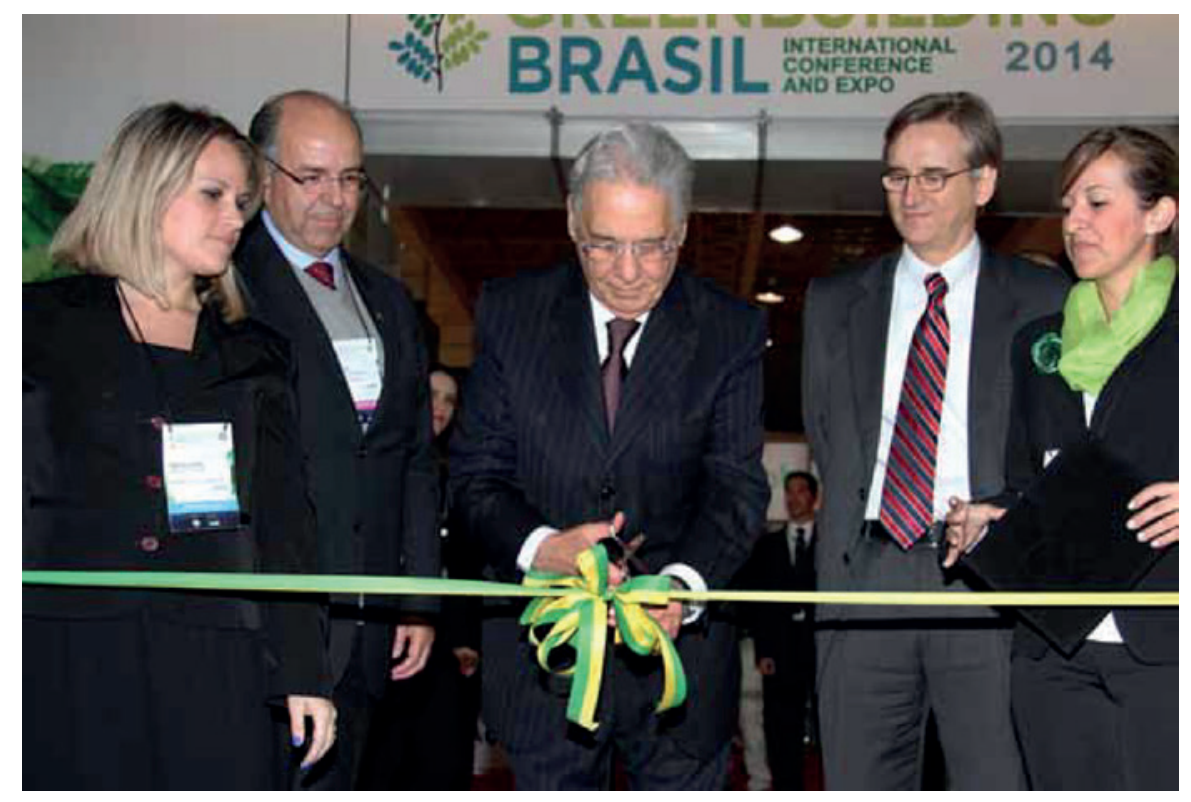

Fig 3.10. Fernando Henrique Cardoso inaugura a

conferência e feira Greenbuilding de 2014. À direita, o cofundador do GBC Brasil, José Moulin. Fonte: Revista $G B C$, n. 2, dez 2014, p. 24. 
Outro "pilar" do GBC Brasil, vinculado aos esquemas de certificação, é a formação de técnicos para os sistemas administrados pelo conselho. Pelos cursos oferecidos pelo GBC, os profissionais podem aprender como cumprir os certificados, crédito a crédito. É devido à participação nesse sistema educativo que o arquiteto Siegbert Zanettini é tido pelo GBC Brasil como um de seus fundadores. Zanettini dava cursos, palestras e workshops sobre sustentabilidade no início do conselho, embora, segundo ele, tenha se distanciado do GBC com o passar do tempo e nunca tenha de fato se especializado no sistema [fig 3.9] ${ }^{65}$

Assim como o USGBC ${ }^{\oplus}$, o GBC Brasil também realiza uma conferência e feira anual, o Greenbuilding, a partir de 2010 - o terceiro "pilar". O evento teve sua primeira edição fora de São Paulo em 2018, quando ocorreu em Curitiba, e já teve entre seus “keynote speakers" políticos como Fernando Henrique Cardoso [fig 3.10], Marina Silva, Joaquim Barbosa e Sérgio Moro [fig 4.2 a 4.4$]$.

Por fim, o quarto e último "pilar" são as políticas públicas, ainda que tenham menor centralidade nos objetivos do GBC Brasil do que nos do CBCS. Após a importação do LEED $^{\circledR}$ e a criação do sistema de formação, o GBC Brasil deu início a uma série de campanhas sobre políticas públicas. A primeira delas foi a One Degree Less, na qual era proposta a pintura voluntária dos tetos de branco, com o objetivo de reduzir o aquecimento global [fig 3.11]. A justificativa era que a medida aumentaria a reflexividade da cobertura, o que significaria menor absorção de calor e, projetava o conselho, implicaria desde a redução das ilhas de calor até o esfriamento em $1^{\circ} \mathrm{C}$ na temperatura global. Seu patrocínio foi realizado por três empresas, duas delas fabricantes de tinta: Sherwin Williams, Dow Chemical e MWM Motores Diesel. Para Felipe Faria não haveria conflito, mas interesse "natural". ${ }^{66}$

A campanha tomava como base estudos feitos por pesquisadores do Lawrence Berkeley National Laboratory da University of California, nos quais já era proposta a adoção dessa medida em grandes aglomerados urbanos. ${ }^{67}$ Segundo o estudo, o aumento do albedo - a refletividade de

65. Siegbert Zanettini, (Fundador honorário do GBC Brasil), Entrevista para o autor, Telefone, $1^{\circ}$ de novembro de 2016. 66. Marina Gazzoni, “Lei do telhado branco custará cerca de R\$ 380 milhões a São Paulo”, iG - Brasil Econômico, 7 de junho de 2011, https://economia.ig.com.br/lei-do-telhado-branco-custara-cerca-de-r-380-milhoes-a-sao-paulo/n1597009588177. html; também Casado, (Engenheiro do $1^{\circ}$ edifício certificado no Brasil; Diretor educacional e de comitês técnicos no GBC Brasil, 2007-2013), Entrevista para o autor.

67. Hashem Akbari, Surabi Menon, e Arthur Rosenfeld, "Global Cooling: Effect of Urban Albedo on Global Temperature”, 

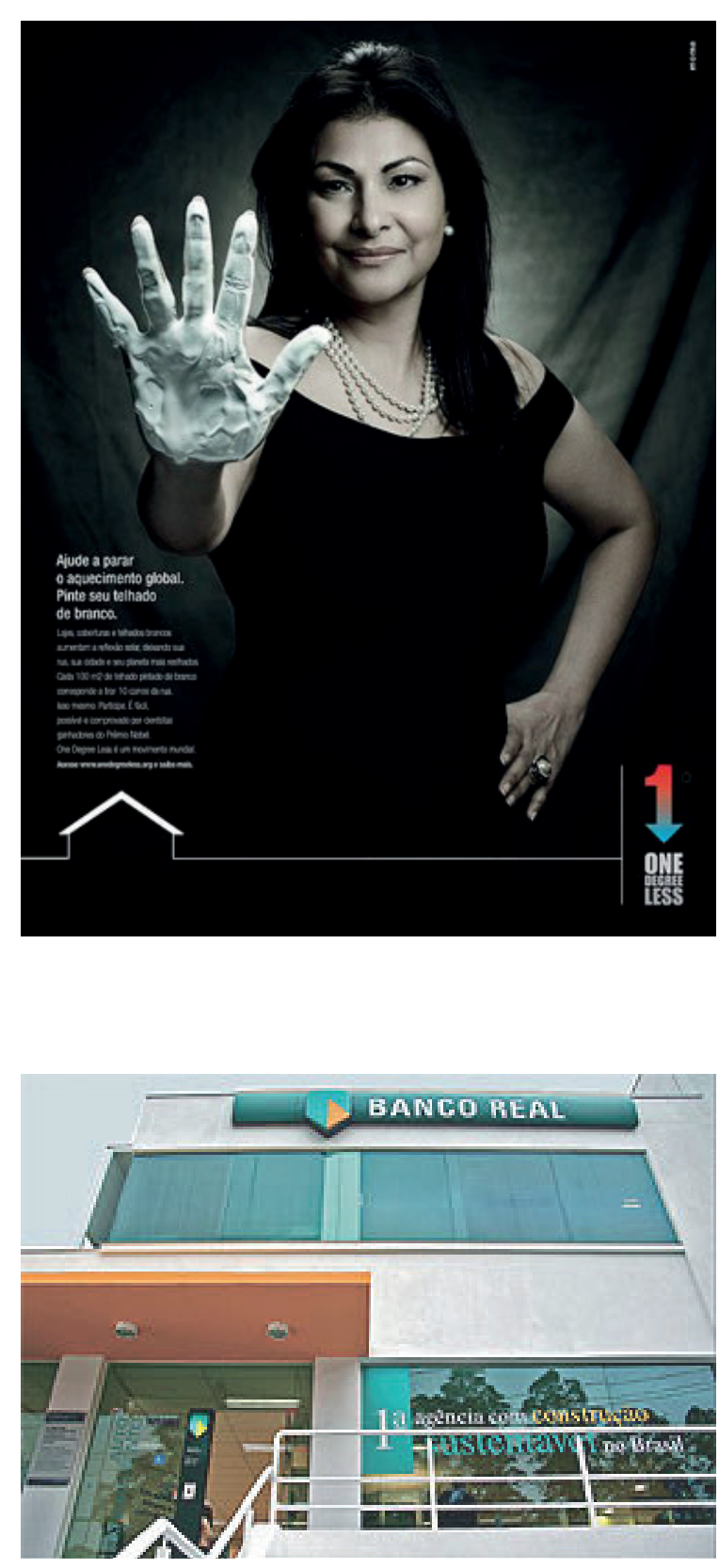

Fig 3.11. Thassanee Wanick, fundadora do GBC Brasil, na campanha One Degree Less. Fonte: “Green Building Council incentiva o uso de telhado branco", Casa, 22 abr 2010.

Fig 3.12. Agência do banco Real-ABN AMRO na Granja Viana, primeiro edifício certificado no Brasil. Projeto do corpo técnico do banco. Fonte: "Sustentável desde o canteiro", Téchne, n. 125, ago 2007. 
radiação solar em uma dada superfície - de coberturas representaria uma economia de 1,1 bilhão de dólares em refrigeração, compensaria as emissões de gás carbônico por onze anos e com isso postergaria o aquecimento global, sem ter, contudo, impacto sobre suas causas. ${ }^{68}$

Uma experiência semelhante já havia sido realizada nos Estados Unidos, onde a pintura em branco da cobertura de edifícios comerciais foi transformada em lei nos estados da Califórnia, Flórida e Georgia. ${ }^{69}$ Esse parecia o mesmo caminho a ser trilhado no Brasil. A medida foi adotada em conjuntos do CDHU em Ilhabela - onde Wanick tinha uma segunda residência e realizava regularmente eventos - e apoiada pelo governo do Estado de São Paulo, ${ }^{70}$ além de ser usada como base de um projeto de lei no município de São Paulo. O vereador Antonio Goulart ${ }^{71}$ criou o PL 615/2009, um adendo ao Código de Obras, segundo o qual:

\section{A Câmara Municipal de São Paulo DECRETA:}

Art. $1^{\circ}$ Fica acrescido item 9.2.5 à Seção 9.2 do Capítulo 9 do Anexo I, integrante à Lei no 11.228 , de 25 de junho de 1992, com a seguinte redação:

“9.2

[...] 9.2.5 Os telhados e coberturas das edificações deverão ser de cor branca. (NR)”

Art. $2^{\circ}$ As edificações deverão ser adaptadas à disposição desta lei no prazo de 180 (cento e oitenta) dias, contados da data de sua publicação.

Art. $3^{\circ}$ As despesas decorrentes da execução desta lei correrão por conta das dotações orçamentárias próprias, suplementadas se necessário.

Art. $4^{\circ}$ Esta lei entra em vigor na data de sua publicação, revogadas as disposições em contrário. ${ }^{72}$

2007, 5; Hashem Akbari, Surabi Menon, e Arthur Rosenfeld, "Global Cooling: Increasing World-Wide Urban Albedos to Offset CO2", Climatic Change 94, n 3-4 (junho de 2009): 275-86, https://doi.org/10.1007/s10584-008-9515-9.

68. Akbari, Menon, e Rosenfeld, "Global Cooling", 284.

69. Felicity Barringer, "White roofs catch on as energy cost cutters", The New York Times, 29 de julho de 2009, seç. Environment. 70. Victor Martinez, “CDHU adere à campanha One Degree Less para diminuir a temperatura do entorno”, Pini Web, 4 de novembro de 2009, http://piniweb17.pini.com.br/construcao/sustentabilidade/cdhu-adere-a-campanha-para-diminuir-a-temperatura-do-entorno-151013-1.aspx.

71. Foi filiado ao PMDB entre 1993 e 2011. Filiou-se ao PSD em 2011 e foi deputado federal pelo Estado de São Paulo entre 2014 e 2018.

72. Antonio Goulart, "Projeto de Lei 01-0615/2009 do Vereador Goulart (PMDB)", setembro de 2009. 
O projeto de lei foi aprovado na Câmara na primeira votação, mas a segunda rodada necessária antes da sanção do prefeito Gilberto Kassab (2006-2013) nunca aconteceu. A medida, a princípio de aplicação simples em uma cidade de construção formal, tornava-se complexa face ao contexto de ocupação predominantemente informal, no caso das cidades brasileiras. O pesquisador Hashem Abkari, do Lawrence Berkeley Laboratory, presente na sessão, sofreu forte oposição de professores da FAUUSP, como Silvio Macedo e Fábio Mariz. Na manifestação do último:

Essa proposta de lei é absolutamente patética se colocada diante da cidade que eu conheço. Mais de $70 \%$ de São Paulo é feita sem lei, é feita sem dinheiro, por autoconstrução. Uma parte da nossa população não tem janela no quarto. O teto pinga e a casa é mal construída. Se aprovarmos uma lei como essa, demandaria cuidado e rigor técnico enorme em troca de uma pequena contribuição. Estamos falando de um custo que nossa sociedade não tem condições de bancar. Se pedir para a população gastar $\mathrm{R} \$ 40$ para pintar de forma ordinária um barraco mal feito, ela não tem os R $\$ 40$. Essa é uma discussão absolutamente elitista. $^{73}$

Ademais, a literatura científica a respeito do tema não costuma tratar da cor isoladamente, devido à possibilidade de deterioração da tinta por intempéries. Por conta disso, o termo utilizado na literatura é "revestimento frio", e nunca apenas "pintura branca". Assim, a medida poderia perder rapidamente sua validade, apesar de sua execução compulsória prevista por lei. Segundo ainda um relatório do CBCS, o contexto construtivo precário no Brasil, tal como mencionado acima por Mariz, poderia acarretar outro problema: o dos acidentes sofridos por aqueles que tentassem cumprir a nova lei em telhados inclinados, mal mantidos e construídos com materiais frágeis. ${ }^{74}$

73. Roney Domingos, "Projeto que prevê telhados brancos provoca polêmica na Câmara de SP”, G1, 10 de outubro de 2011, seç. São Paulo, http://g1.globo.com/sao-paulo/noticia/2011/10/projeto-que-preve-telhados-brancos-provoca-polemica-na-camara-de-sp.html.

74. Notar ainda que os resultados de performance analisados nos artigos são mais substanciais em outras medidas, tal como no aumento de vegetação urbana. Comitê Temático de Materiais, "Posicionamento sobre tetos frios" (CBCS, setembro de 2011), http://www.cbcs.org.br/website/posicionamentos/show.asp?ppsCode=23E36908-D91D-4B00-BB52-33B805469A73; Anna Laura Pisello, "State of the Art on the Development of Cool Coatings for Buildings and Cities", Solar Energy 144 (março de 2017): 660-80, https://doi.org/10.1016/j.solener.2017.01.068; Noelia Liliana Alchapar, Cláudia Cotrim Pezzuto, e Erica Norma Correa, "Parámetros urbanos morfo-materiales y su correlación con las temperaturas de aire en verano", Ambiente Construído 18, nº 4 (outubro de 2018): 199-213, https://doi.org/10.1590/s1678-86212018000400301. 
Não foi encontrado nenhum documento ou informe oficial a respeito da interrupção no processo de votação do PL. Segundo Marcos Casado, a obrigatoriedade da pintura foi vista como um empecilho e, por isso, foi reproposta como incentivo, por meio de instrumentos do IPTU Verde. ${ }^{75}$

O GBC Brasil apoiou o IPTU Verde e a Quota Ambiental, ${ }^{76}$ instrumentos regulamentados durante a prefeitura de Fernando Haddad no município de São Paulo (2013-2017), fazendo parte das medidas adotadas dentro do Plano Diretor Estratégico (PDE). No primeiro, sem conclusão até 2018, as certificações de sustentabilidade ambiental poderiam representar descontos entre $4 \mathrm{e}$ 12\% do IPTU, a depender do nível de certificação, e apenas em edifícios residenciais. Apesar da defesa pelo GBC Brasil de se considerar a certificação em qualquer processo, Marcos Casado indica que a prefeitura interpretou que a certificação já apresentava incentivos suficientes no setor corporativo, mas ainda encontrava resistência no residencial. ${ }^{77}$ No segundo instrumento, este já aprovado, as certificações podem pleitear descontos na contrapartida financeira da outorga onerosa. Entretanto, embora se aproxime dos instrumentos legais, o aparato normativo do LEED ${ }^{\circledR}$ ainda não tem aplicação compulsória no Brasil - diferentemente dos Estados Unidos, onde já há leis em que determinados níveis do $\mathrm{LEED}^{\circledR}$ são obrigatórios em algumas tipologias de edifícios públicos.

\section{AS CERTIFICAÇÕES DE GRANDE REPERCUSSÃO}

Como visto, o LEED ${ }^{\circledR}$ chegou no Brasil antes do GBC. O conselho tentava alcançar o certificado já em andamento, mas também lhe dava impulso. Se era grande a dificuldade em certificar um projeto no Brasil antes do conselho, sua fundação facilitou a disseminação do sistema. Uma série de projetos marcaram sua história, entre 2007 e 2018.

\footnotetext{
75. Casado, (Engenheiro do $1^{\circ}$ edifício certificado no Brasil; Diretor educacional e de comitês técnicos no GBC Brasil, 20072013), Entrevista para o autor.

76. Câmara Municipal de São Paulo, "Lei n. 16402, de 22 de março de 2016. Disciplina o parcelamento, o uso e a ocupação do solo no Município de São Paulo, de acordo com a Lei n. 16050, de 31 de julho de 2014 - Plano Diretor Estratégico”, 22 de março de 2016; Gabinete do Prefeito, "Decreto n. 57.565, de 27 de dezembro de 2016. Regulamenta procedimentos para a aplicação da Quota Ambiental, nos termos da Lei n. 16.402, de 22 de março de 2016.", 27 de dezembro de 2016; “Projeto de Lei 01-00568/2015 do Executivo", 28 de outubro de 2015.

77. Casado, (Engenheiro do $1^{\circ}$ edifício certificado no Brasil; Diretor educacional e de comitês técnicos no GBC Brasil, 20072013), Entrevista para o autor.
} 


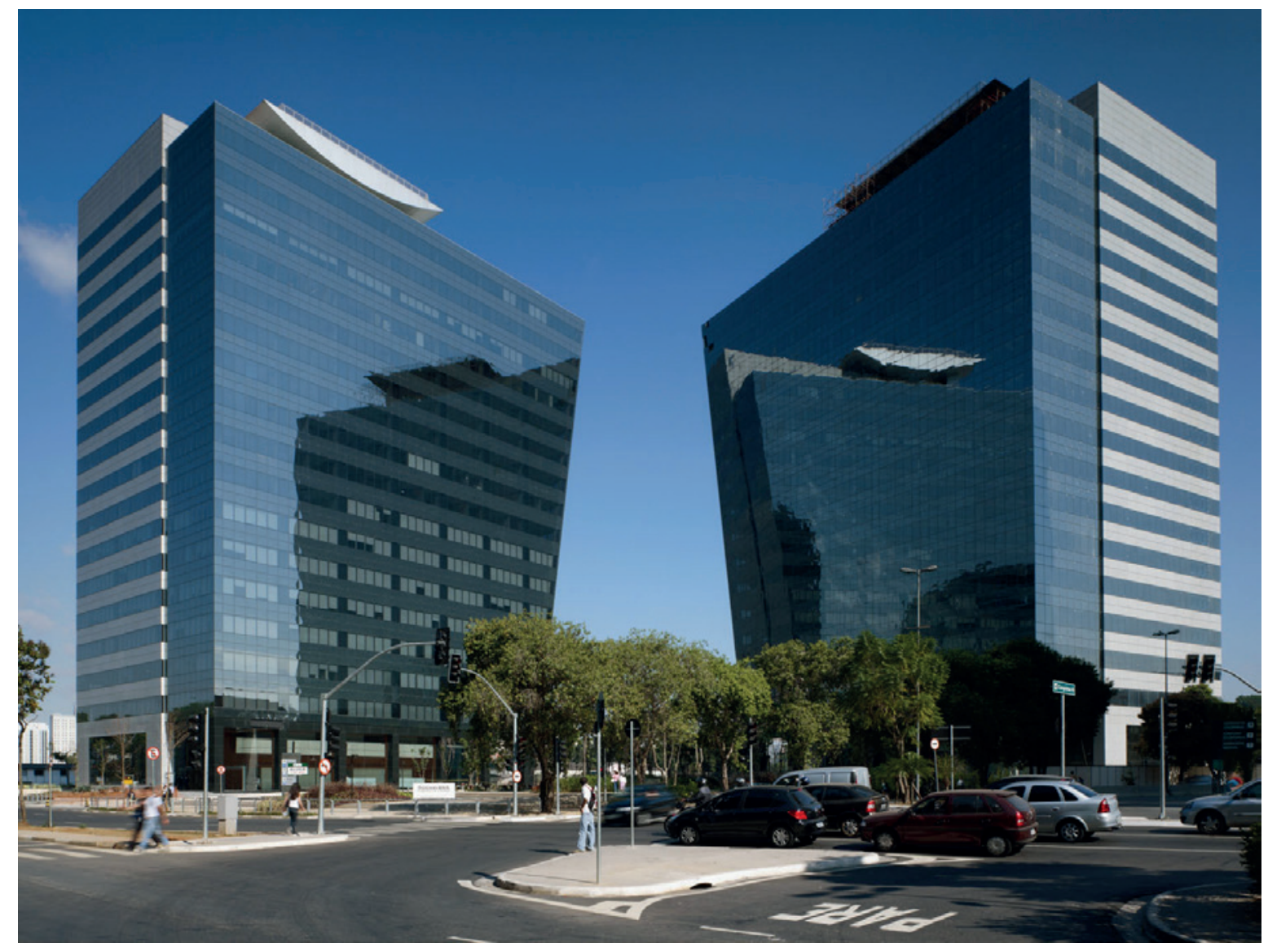

Fig 3.13. aflalo/gasperini arquitetos, Rochaverá Corporate Towers (1999/2008-2012). Primeiro conjunto corporativo de grande porte certificado no Brasil, em foto com apenas as duas primeiras torres inauguradas (2008). Fonte: Nelson Kon, acervo online. 
O primeiro edifício certificado não só no Brasil, como também na América do Sul, foi a agência na Granja Viana, a primeira de uma série projetada pela equipe do banco Real-ABN AMRO, na qual se testou a aplicação dos princípios de sustentabilidade por meio de uma certificação [fig 3.12].$^{78}$ Foi escolhido o LEED ${ }^{\oplus}$, já que à época não havia outros possíveis, conforme Marcos Casado:

A gente não tinha muita escolha. A gente acabou escolhendo o LEED porque já tinham outros projetos que estavam buscando a certificação LEED, essa empresa de consultoria [SustentaX] já tinha outros projetos também, ${ }^{79}$ e sabia do reconhecimento, porque várias empresas-membro lá do GBC eram grandes empresas, a gente sabia da seriedade do processo. O Procel ainda não existia, o Aqua estava ainda começando dentro do Brasil. E a gente conhecia o LEED então de pesquisas. A gente sabia que era um sistema que já estava há mais de dez anos nos Estados Unidos [na verdade, oito anos], que tinha uma forte demanda no mundo todo, e até por isso, pelo reconhecimento internacional, a gente acabou optando pelo LEED, porque o banco era um banco internacional, ele já reconhecia o LEED como um diferencial. Tanto é que na Holanda eles também certificaram uma das unidades pelo LEED também..$^{80}$

O motivo da certificação era tanto o alinhamento do projeto das agências às diretrizes de responsabilidade social corporativa do banco, que tinha a sustentabilidade como elemento principal, quanto a chancela de uma parte independente de que essas diretrizes estavam de fato sendo seguidas. A iniciativa da construção da agência com certificação havia partido do engenheiro Marcos Casado e seu diretor Nelson Kawakami, como forma de alinhar sua área de projeto de agências com as diretrizes do banco. ${ }^{81}$ Casado fez uma especialização em gestão ambiental pela

\footnotetext{
78. No contexto latino-americano, apenas um empreendimento mexicano precedeu a agência, o Centro Internacional de Negócios em Ciudad Juarez, com certificação em 19 jan 2005.

79. Provavelmente se trata do Ventura e do Rochaverá Corporate Towers.

80. Casado, (Engenheiro do $1^{\circ}$ edifício certificado no Brasil; Diretor educacional e de comitês técnicos no GBC Brasil, 20072013), Entrevista para o autor.

81. Luciana Presas e Arthur Mol tratam em artigo de um momento anterior ao aqui narrado por meio da entrevista com Marcos Casado. No texto, Presas e Mol analisam o início da agenda de sustentabilidade do ABN AMRO no Brasil e argumentam que as ações brasileiras tiveram caráter eminentemente local, embora em resposta às demandas de responsabilidade corporativa da sede holandesa. Isto é: após um período inicial onde a estratégias de sustentabilidade no Brasil eram difusas
} 


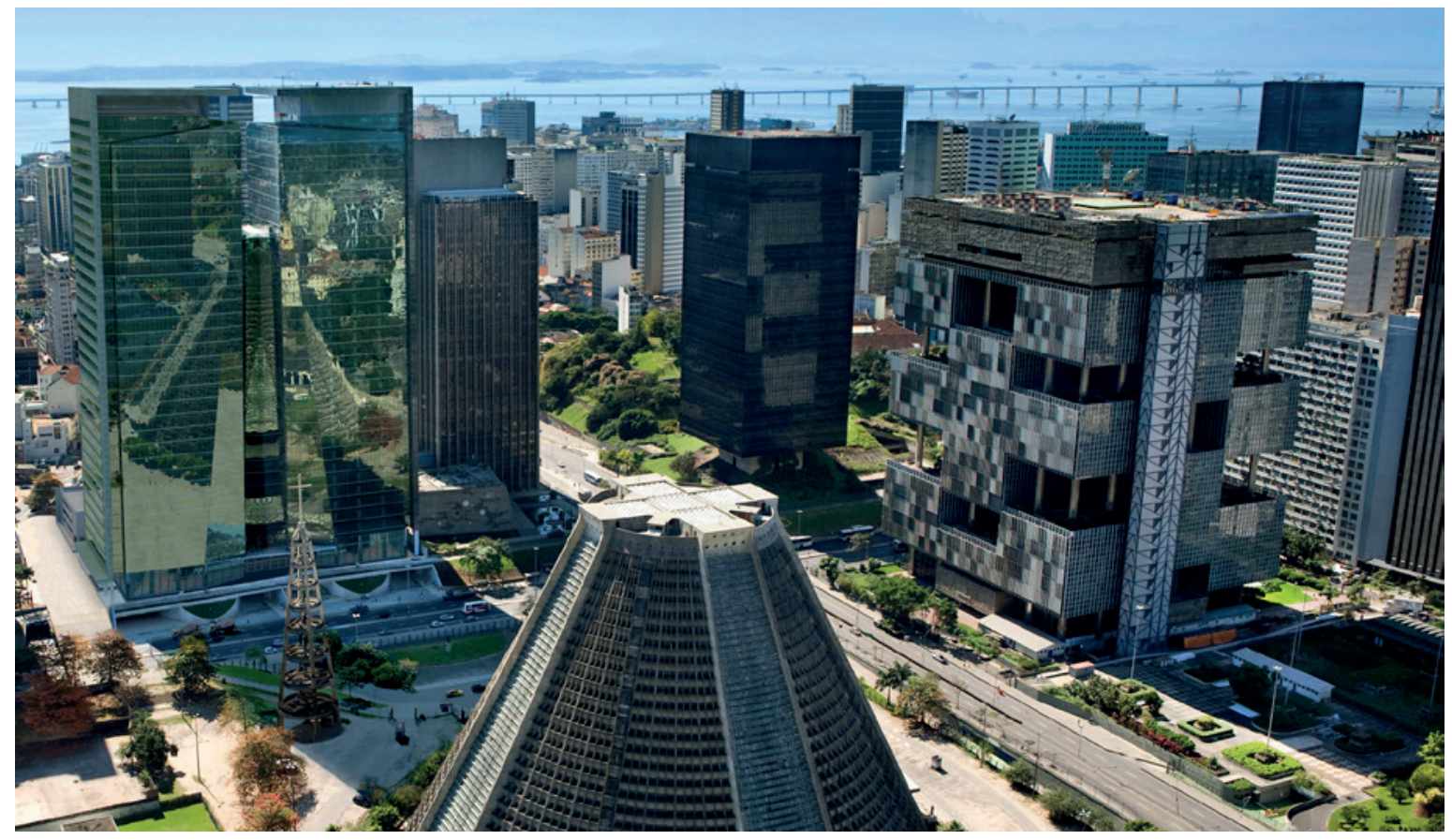

Fig 3.14. aflalo/gasperini arquitetos e KPF, Ventura

Corporate Towers (2005/2008-2010). Fonte: Tishman Speyer, acervo online.
O empreedimento, quase simultâneo ao Rochaverá Corporate Towers, reafirma a possibilidade de certificação corporativa no Brasil.

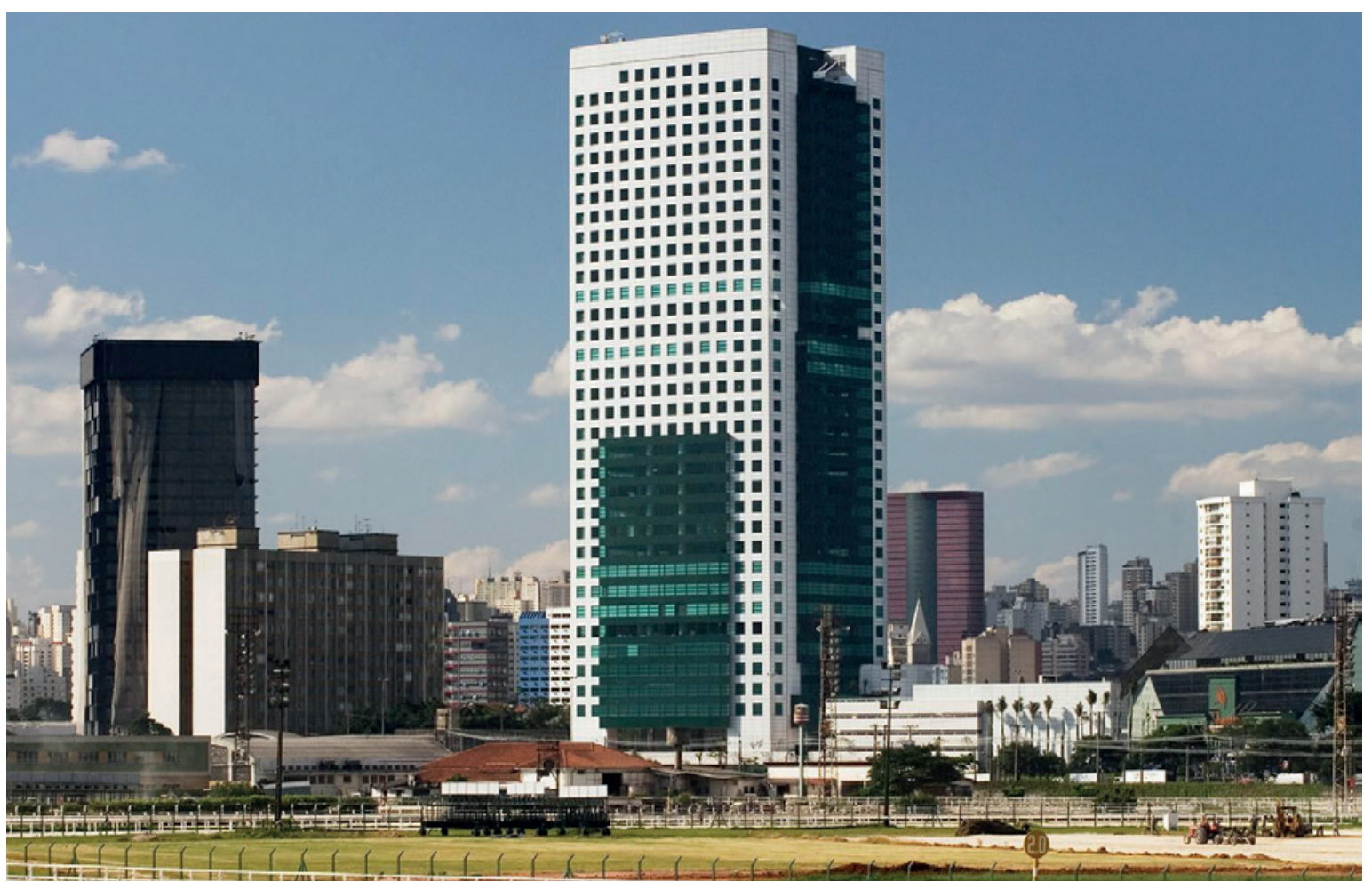

Fig 3.15. aflalo/gasperini arquitetos, Eldorado Business

Tower (1998/2007). Primeiro edifício nível Platinum

da América Latina. Fonte: Daniel Ducci, via Galeria de

Arquitetura. 
Fundação Educacional Inaciana (FEI), cuja monografia estabelecia as bases do que depois veio a ser o programa de sustentabilidade das agências. ${ }^{82}$ Pelo projeto, a agência economizava $85 \%$ de água e $15 \%$ de energia, usava tintas sem compostos orgânicos voláteis e reciclava o entulho dentro da própria obra. ${ }^{83}$ Essas medidas elevaram o preço da obra em cerca de $30 \%$, por causa das dificuldades que tal novidade trazia ao canteiro e pelo fato de diversos materiais não serem encontrados no mercado brasileiro. Mas o aumento na obra teve compensação pela divulgação da marca do banco, razão pela qual a disparidade de custo foi processada internamente no orçamento do departamento de marketing, e não de construção:

\begin{abstract}
A gente gastou em torno de 300 mil reais a mais para fazer essa agência sustentável, em relação às agências tradicionais que o banco tinha. Só que só no primeiro ano de operação da agência, só em mídia espontânea que o marketing teve, de rádio, jornal, televisão, [o marketing do banco] deixou de pagar quase dois milhões e meio de reais. Então foi algo que valeu a pena investir e ter um diferencial. Depois dessa agência piloto, o que a gente fez: tudo que deu certo - porque algumas coisas acabaram não dando certo, a gente teve muita dificuldade de comprar um material para distribuir para o Brasil inteiro - então a gente acabou incorporando tudo isso dentro de cadernos de encargos de projetos e de obras do banco e dali para a frente todas as agências passaram a seguir esse modelo. ${ }^{84}$
\end{abstract}

Entretanto, as fontes não concordam a respeito da publicidade: para Wanick, o forte aumento de preço teria representado uma antipropaganda, que precisou ser desarmada pelo conselho. ${ }^{85}$ Mas, para todos, o aumento substancial do custo teria se dado pelo pioneirismo do projeto. Para Marcos Casado, a estabilização do mercado e a experiência de projeto levaram aos acrés-

\footnotetext{
- tal como narrado no artigo -, teríamos a reorganização dessas ações via LEED®, tal como proposto no relato de Casado. Ver Luciana Melchert Saguas Presas e Arthur P.J. Mol, "Ecologizando edifícios transnacionais: entre fluxos globais e espaços locais", Ambiente \& Sociedade VII, no 1 (junho de 2004): 9-25, http://dx.doi.org/10.1590/S1414-753X2004000100002.

82. Casado, (Engenheiro do $1^{\circ}$ edifício certificado no Brasil; Diretor educacional e de comitês técnicos no GBC Brasil, 20072013), Entrevista para o autor.

83. Thiago Oliveira, "Sustentável desde o canteiro", Téchne, agosto de 2007.

84. Casado, (Engenheiro do $1^{\circ}$ edifício certificado no Brasil; Diretor educacional e de comitês técnicos no GBC Brasil, 20072013), Entrevista para o autor.

85. Wanick, (Fundadora do GBC Brasil), Entrevista para o autor.
} 


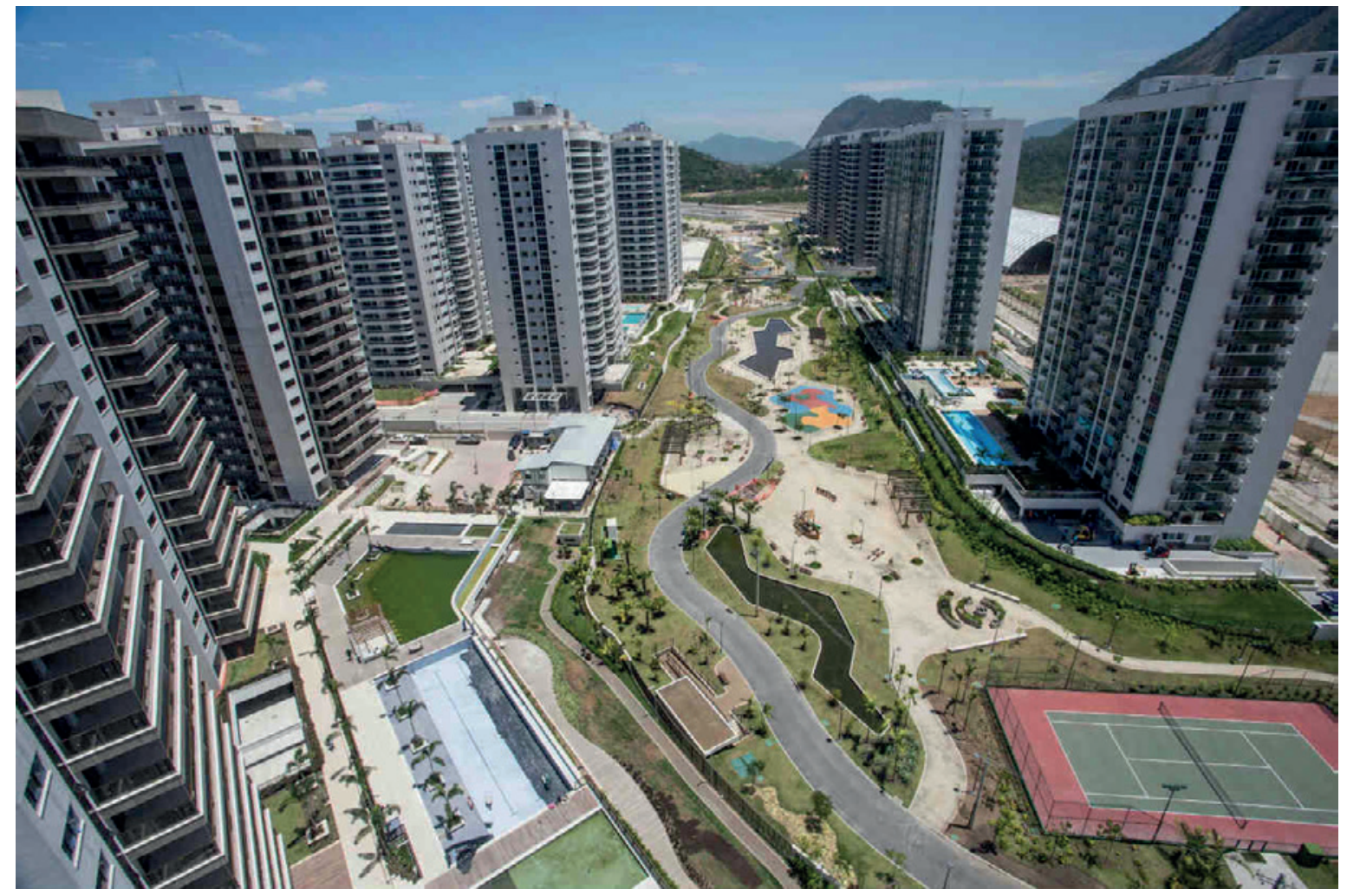

Fig 3.16. Bairro Ilha Pura, primeiro LEED ${ }^{\circ}$ ND no Brasil

(c2011/2016). Fonte: Luciano Pádua, "Vila Olímpica: encalhe monumental”, Exame, 8 jul 2016. 
cimos atuais de 1 a $7 \%$ do valor da obra ${ }^{86}$ - segundo seu relato, embora os estudos sobre o tema apresentem uma faixa maior de custo, como se verá no capítulo 5.

Depois da agência, um conjunto corporativo de certificações logo no início do GBC Brasil consolidou o instrumento dentro do mercado, representando a principal parcela de edifícios certificados. De fato, a criação do GBC Brasil em meio ao boom imobiliário de alto padrão fez com que o conselho se beneficiasse da expansão econômica, ${ }^{87}$ como no caso de grandes edifícios como Rochaverá [fig 3.13] e Ventura Corporate Towers [fig 3.14], ou do Eldorado Business Tower [fig 3.15], todos certificados nos primeiros anos do conselho.

Ao mesmo tempo, o GBC Brasil realizou um convênio com o Instituto Pereira Passos, no qual foram formados técnicos da prefeitura de César Maia (2001-2009) para o uso do LEED ${ }^{\circledR}$. A experiência levou à indicação do GBC Brasil para atuar em parceria com o Comitê Olímpico, primeiramente com uma consultoria de sustentabilidade no processo de seleção do Rio de Janeiro para as Olimpíadas de 2016. A aproximação com o comitê permitiu a certificação de estruturas para evento, como o Ilha Pura, onde os atletas se hospedaram e que é o primeiro LEED ${ }^{\circ} \mathrm{ND}$ do Brasil [fig 3.16]. A busca de empréstimos do Comitê Olímpico para o BNDES também aproximou o GBC Brasil dos organizadores da Copa do Mundo de 2014, pois o banco público havia demonstrado interesse pela certificação. Assim, o LEED ${ }^{\circledR}$ foi incorporado aos requisitos de crédito do BNDES e dez dos doze estádios do evento foram certificados. ${ }^{88}$

Apesar desses avanços, o GBC Brasil teve participação marginal no mercado residencial durante seus mais de dez anos de existência. Apenas uma casa e um edifício multifamiliar foram certificados. Ao tratar como pré-requisito a proibição de fumar em ambientes fechados, por exemplo, o LEED ${ }^{\curvearrowleft}$ dificulta em muito projetos desse tipo, o que levou certificados como o Aqua, da Fundação Vanzolini, a se tornarem mais comuns nesses casos. ${ }^{89}$ O GBC Brasil criou dois sis-

86. Casado, (Engenheiro do $1^{\circ}$ edifício certificado no Brasil; Diretor educacional e de comitês técnicos no GBC Brasil, 20072013), Entrevista para o autor. Ver capítulo 5 para maior detalhamento a respeito dos custos.

87. Faria, (Diretor executivo do GBC Brasil, 2012-atual), Entrevista para o autor.

88. Faria. Foram certificados: Arena da Amazônia (certificado), Mineirão (Platinum), Arena Fonte Nova em Salvador (Silver), Maracanã (Silver), Arena das Dunas em Natal (certificado), Arena Pernambuco (Silver), Estádio Atlético Paranaense (Silver), Estádio Beira Rio (Silver), Arena Corinthians (certificado) Arena Castelão (certificado). Não foram certificados o Estádio Nacional de Brasília e a Arena Cuiabá.

89. Casado, (Engenheiro do $1^{\circ}$ edifício certificado no Brasil; Diretor educacional e de comitês técnicos no GBC Brasil, 20072013), Entrevista para o autor. 
temas próprios adaptados do $\mathrm{LEED}^{\circledR}$ e melhor adequados ao contexto brasileiro: os referenciais Casa $^{\oplus}$, em 2012, e Condomínio ${ }^{\circledR}$, em 2017. Pretendiam, assim, aumentar sua inserção no setor: a própria tipologia “condomínio", ausente nos mercados internacionais e muito particular ao Brasil, enfatiza a estratégia.

A formação dos três conselhos - USGBC ${ }^{\oplus}$, World GBC e GBC Brasil - é representativa da força do terceiro setor ao longo das últimas décadas. A ascensão do terceiro setor como agente distinto do Estado é um tema recorrente em parte da sociologia a partir do fim dos anos 1980, e esses casos mostram como esse processo se deu na arquitetura e no urbanismo. Seus agentes não são propriamente militantes ambientalistas, mas profissionais do mercado que vislumbraram um nicho possível de atuação, potencialmente ético e rentável. Essa abordagem próxima à lógica do mercado teve forte impacto em como esses conselhos se organizam: é o caso de seu ímpeto de expansão geográfica, em busca de novos mercados; da sua capilaridade em diferentes categorias profissionais da construção civil, ao invés do foco em problemas ambientais específicos de alguma comunidade; da sua oposição a práticas de penalização, privilegiando as bonificações e distinções dos certificados; da sua atuação por meio de um produto, o $\mathrm{LEED}^{\circledR}$, e não pela participação em políticas públicas. Desse modo, as ações narradas na parte I seguem preceitos de como deve se dar a ação ambientalista, de seus objetivos e instrumentos. Esses preceitos, até aqui implícitos no desenrolar dos eventos, são o tema da parte II. 


\section{PARTE II}

\section{O EFICIENTE MOTOR DO STATUS QUO: FUNDAMENTOS AMBIENTALISTAS NO SISTEMA DE AVALIAÇÃO}

"Verde" e "sustentabilidade", os termos usados para nomear a resposta para o problema
mais urgente de nosso tempo, mantêm-se perigosamente à tona na ambiguidade e na
indeterminação. A arquitetura sustentável está em todo lugar e em lugar nenhum. Julien de Smedt, JDS Architects ${ }^{1}$

\footnotetext{
1. No original: “'Green' and 'Sustainability', the terms used to name the answer to the most pressing problem of our time, have become dangerously afloat in ambiguity and indeterminacy. Sustainable architecture is everywhere and nowhere." Julien de Smedt, “From 'Sustain' to 'Ability”'. In: Mohsen Mostafavi e Gareth Doherty, Ecological urbanism (Londres: Lars Müller Publishers, 2010), 122, tradução nossa.
} 



\section{CAPÍTULO 4 'DÓLARES TAMBÉM SÃO VERDES'}

\section{NEGÓCIOS SUSTENTÁVEIS}

A dominação de mercado por meio de estratégias de expansão internacional fez com que a certificação via LEED $^{\circledR}$ fosse vista como sinônimo de responsabilidade ambiental. Mas se o LEED ${ }^{\circledR}$ é um sistema de avaliação e por isso define o que são boas soluções ambientais, então quais são os princípios que o permitem selecionar e julgar essas soluções? A parte I examinou os agentes responsáveis pela criação do sistema, organizados em uma rede de indivíduos, empresas e instituições; a parte II tratará sobretudo das lógicas de valoração e valorização implícitas no LEED ${ }^{\circledR}$ e concebidas por esses agentes.

A atuação de mercado do LEED ${ }^{\oplus}$ ocorre após a hegemonia do termo "sustentabilidade" a partir da publicação em 1987 do relatório das Nações Unidas Our common future. ${ }^{1}$ O termo, atualmente onipresente na agenda ambiental, era raro na literatura anglo-saxã precedente, tendo se consolidado nesse relatório. ${ }^{2} \mathrm{O}$ marco do documento é o de, por um lado, articular em uma só agenda pautas tradicionais do ambientalismo, como segurança alimentar, redução da pobreza, pacifismo, preservação de fontes de recursos naturais e redução do consumo energético. E também, por outro lado, o de incluir pautas inusitadas - naquele momento e no contexto do ambientalismo, saliente-se -, como a diminuição do endividamento público e a reconstituição de taxas de crescimento "sustentáveis" e de menor vulnerabilidade a crises econômicas e ambientais. As-

\footnotetext{
1. World Comission on Environment and Development, "Our common future" (Organização das Nações Unidas, 1987), http://www.un-documents.net/our-common-future.pdf.

2. Veja-se gráficos e análise de uso do termo em Gabriel de Andrade Fernandes, "Entre ambientes, (contra)culturas e naturezas: o emergente discurso ambiental na literatura dos anos 1960 e 1970 a partir de Buckminster Fuller, Ian McHarg e Murray Bookchin" (Dissertação (Mestrado em Paisagem e Ambiente). Orientador: Euler Sandeville Jr., Faculdade de Arquitetura e Urbanismo da Universidade de São Paulo, 2017), 45, 80.
} 
sim, questões econômicas e ambientais passavam a ser vistas como problemas de mesma essência: a busca por uma sociedade de desenvolvimento consistente no tempo. Segundo o relatório,

o desenvolvimento sustentável é um processo de mudança no qual a exploração de recursos, a direção de investimentos, a orientação do desenvolvimento tecnológico e a mudança institucional estão todos em harmonia e intensificam o potencial tanto atual quanto futuro para atingir as necessidades e aspirações humanas. ${ }^{3}$

Surgindo seis anos após a publicação do relatório, o USGBC ${ }^{\circledR}$ alinha-se ao nele proposto. Assim como Our common future orientava a sustentação do crescimento econômico por meio do ambientalismo, assim também o fez Gottfried, como fundador do USGBC": "A mágica do USGBC e da outra centena de GBCs de outros países é que nós estamos disputando o jogo mais importante da Terra: crescimento e prosperidade contínuos apesar do risco ampliado de catástrofe ambiental."4

Nesse mesmo sentido, os agentes envolvidos nos conselhos verdes replicam o mote do "tripé social, econômico e ambiental" [triple bottom line], inexistente em Our common future, mas concebido pelo consultor britânico John Elkington sob a influência desse relatório pioneiro. ${ }^{5}$ O "tripé" foi elaborado por Elkington no campo da contabilidade corporativa e defendia que as empresas deveriam considerar essas três esferas para serem bem-sucedidas. Esse conceito implica então uma nova fórmula de auditoria, em que as métricas dos relatórios corporativos não seriam apenas as de perdas e ganhos de capital econômico, mas também aquelas relativas aos "capitais" humano e ambiental. Com origem na esfera contábil, o tripé tornou-se sinônimo de "sustentabilidade", e essa sinonímia também está presente no discurso dos GBCs. Diversos agen-

3. No original: "sustainable development is a process of change in which the exploitation of resources, the direction of investments, the orientation of technological development, and institutional change are all in harmony and enhance both current and future potential to meet human needs and aspirations." World Comission on Environment and Development, "Our common future", 43, tradução nossa.

4. No original: "The magic of USGBC and the one hundred other country GBCs is that we're playing in the Earth's most important game: continued growth and prosperity in the face of increased risk of environmental catastrophe." David Gottfried, Explosion green: one man's journey to green the world's largest industry, Prefácio de Paul Hawken. Introdução de Rick Fedrizzi. (Nova York: Morgan James, 2014), 246, tradução nossa.

5. John Elkington, “Accounting for the triple bottom line", Measuring Business Excellence 2, nº 3 (1998): 18-22, https://doi. org/10.1108/eb025539. 
tes usam a fórmula, a exemplo de David Gottfried no USGBC", para quem "nós tínhamos que ... definir a construção verde colaborativamente, fornecendo educação no tema e demonstrando os inúmeros benefícios ambientais, monetários e sociais que ela traz"; ${ }^{6}$ ou então Thassanee Wanick no GBC Brasil, quando argumenta que "sustentável” é aquilo "bom para o ambiente, bom para os negócios... e bom para as pessoas." " A conclusão é: o cumprimento simultâneo dos três fatores é condição necessária para definir uma ação como "sustentável".

Mas Gottfried dá um passo além. Se o termo "sustentabilidade" é apontado pela literatura justamente como a virada onde o ambientalismo é absorvido por instituições e corporações, ${ }^{8}$ ele já o considera excessivamente impregnado de uma retórica antinegócios. Por conta disso, dá preferência a "verde" no lugar de "sustentável", logo no início de seus planos, antes mesmo de conhecer Mike Italiano na cofundação do USGBC ${ }^{\circledR}$ :

Por volta dessa época [suas reuniões iniciais no COTE-AIA], a palavra verde começou a surgir como uma alternativa a sustentável. Para mim, ela tinha uma conotação mais ampla, incorporando as vantagens econômicas de um edifício eficiente e saudável, e que poderia mesmo trazer mais dinheiro ou ter mais valor. ${ }^{9}$

\section{Ainda no mesmo sentido:}

Nós escolhemos o nome "Construção verde" no lugar de "sustentável". Nós sentíamos que a palavra "sustentabilidade" havia sido manchada por organizações ambientais que naquele momento estavam ativamente engajadas em processar fabricantes de produtos. A palavra "verde" nos deu um escopo maior, e ela tinha conotações tanto de ambiente quanto de dinheiro - e nós queríamos atuar nesses dois campos. ${ }^{10}$

6. No original: "we had to...define green building collaboratively, providing education on the subject and demonstrating the multitude of environmental, monetary, and social benefits it brings." Gottfried, Explosion green, 233, grifo no original, tradução nossa.

7. No original: "it is good for the environment, it is a good business ... and it is good for the people". Thassanee Wanick, (Fundadora do GBC Brasil), Entrevista para o autor, 24 de janeiro de 2017, grifo nosso, tradução nossa.

8. Ver debate em Fernandes, "Entre ambientes, (contra)culturas e naturezas".

9. No original: "Around this time the word green began to pop up as an alternative to sustainable. To me it had a broader connotation, incorporating the economic advantages of an efficient and healthy building, and one that could even make more money or have a higher value." Gottfried, Explosion green, 35, grifo no original, tradução nossa.

10. No original: "We chose the name 'Green Building' instead of 'sustainable. We felt that the word 'sustainable' had been 
É por esse motivo que Gottfried chama sua organização de "Conselho de Construção Verde" e não de "Conselho de Construção Sustentável", em traduções literais. O "verde" remeteria aqui tanto à natureza e às árvores quanto ao dinheiro e às cédulas verdes dos dólares. O USGBC ${ }^{\circledast}$ deveria demonstrar os benefícios da construção verde, motivo pelo qual não seguiram o caminho de penalizar os fabricantes poluidores. ${ }^{11}$ A construção verde deveria ser a "cenoura" de incentivo aos negócios e não o "chicote" da regulação e punição de infratores. Para tal, é possível indicar a partir dos relatos ao menos duas táticas de mercado. A primeira é retórica, em que a ênfase do discurso é mudada. Segundo Gottfried:

Conseguir o apoio dos proprietários de edifícios foi um grande desafio. De imediato, eles estavam compreensivelmente mais interessados no balanço do que em salvar o planeta. No começo das minhas apresentações públicas para grupos imobiliários, eu cometi o erro de focar na degradação ambiental causada pelos edifícios. O clima da sala era de desânimo. Mais tarde eu aprendi a falar apenas sobre benefícios econômicos, usando a tradicional análise financeira em que eu confiava como incorporador. Eu entendi que, para o setor de negócios, o que nós precisávamos fazer era mostrar que a construção verde tinha benefícios econômicos enormes e era realmente uma alavanca estratégica para acelerar os negócios. A ética subjacente a todos os negócios é o lucro. [...] Isto é a América. [...] Proprietários de edifícios apenas vão abraçar a construção verde quando ela for diretamente ligada ao seu balanço: taxas de locação, inquilinos, despesas menores, maiores taxas de ocupação, maiores quantidades de empréstimos com taxas de juros menores, maiores preços de venda de edifícios e maiores retornos de investimento. ${ }^{12}$

\footnotetext{
tarnished by environmental organizations that were then actively engaged in suing product manufacturers. The word 'green' gave us more scope, and it had connotations of both environment and money - and we wanted to play in both of these fields." Gottfried, 231, tradução nossa.

11. Ver capítulo 1.

12. No original: "Getting building owners to support us was a greater challenge. They were, understandably, more immediately interested in the bottom line than in saving the planet. In my early public lectures to real estate groups, I made the mistake of focusing on the environmental degradation caused by buildings. The feeling in the room was dead. Later I learned to talk only about economic benefits, using the traditional financial analysis I'd relied on as a developer. I realized that for the business sector, what we needed to do was show them that green building had enormous financial benefits and was really a strategic lever to accelerating the business case. The underlying ethic of all business is profit. [...] That's America. [...] Building owners will only embrace green building when it is tied directly to their bottom line: rental rates, tenant leasing, lower expenses, higher occupancy rates, grater loan amounts at lower interest rates, higher building sales prices, and improved returns on investment." Gottfried, Explosion green, 71-72, tradução nossa.
} 
A orientação de discurso aprendida por Gottfried estaria presente, segundo Guido Petinelli em sua experiência no World GBC, desde o início do GBC Austrália, que teria intuído que as estratégias do marketing eram mais eficientes para a expansão de sua atuação do que das organizações técnicas. ${ }^{13}$ Assim, a arquitetura verde só seria de fato realizada se a comunicação com o setor corporativo se desse na chave de sua própria linguagem, a contábil. A economia "verde", defende Gottfried, "precisa ser contada no vocabulário e linguagem que os grandes executivos podem entender: dólares e centavos, vantagens competitivas, crescimento de mercado e maior lucratividade." ${ }^{14}$

O que leva à segunda tática: se a primeira é retórica - a ênfase nos ganhos financeiros e não nos ambientais -, a segunda é organizacional. Não se trata mais de uma parceria entre movimento ambientalista e mercado, mas da ecologia como negócio, na formulação de Fedrizzi: "algumas das organizações ambientais mais efetivas que você pode imaginar são negócios." ${ }^{15}$ Nos exemplos de Fedrizzi, esse seria o caso da fabricante de carpetes Interface, de Ray Anderson; ou da US-Eco Logic e da TexEnergy Solutions, ambas do empresário Steve Sauders; ou a fabricante de biomateriais Ecovative; ou mesmo a brasileira Natura. Desse modo, para ser efetivo, o alinhamento entre ecologia e economia não é apenas uma questão de comunicação, isto é, de adequação à linguagem corporativa, mas também na prática de gestão dos GBCs.

Com essa visão, tanto Gottfried quanto Fedrizzi ensaiam uma periodização do movimento ambientalista. No passado, coloca Fedrizzi, ambientalistas e empresários seriam adversários, em uma disputa onde os dois lados estariam certos. Os ambientalistas haviam conquistado avanços nos Estados Unidos - ele cita: Clean Air Act em 1970, proibição do DDT em 1972, Clean Water Act em 1972, Protocolo de Montreal em 1987, Oil Pollution Act em 1990 - unicamente por métodos políticos tradicionais da "agitação, legislação e regulação". O sucesso do movimento o mantinha em oposição ao setor corporativo. Os empresários, por sua vez, "esta-

13. Guido Petinelli, (Rector of Council Development no World GBC, 2006-2008; Co-fundador do GBC Brasil), Entrevista para o autor, $1^{\circ}$ de maio de 2018.

14. No original: "need to be told in a vocabulary and language that executives in the C-suite can understand: dollars and cents, competitive edge, market growth, and higher profitability." Gottfried, Explosion green, 268, tradução nossa.

15. No original: "some of the most effective environmental organizations you could possibly imagine are businesses." Rick Fedrizzi, Greenthink: how profit can save the planet, Prefácio de Leonardo DiCaprio (Charleston, SC: Disruption Books, 2015), 154, grifo no original, tradução nossa. 
vam certos também", pois a regulação ambiental implicaria despesas onerosas. Para Fedrizzi, essas despesas não seriam um incômodo apenas de CEOs, mas de qualquer um relacionado com a "economia global": "de gerentes financeiros a empregados de escritório, de acionistas individuais a fundos de pensão, de universidades a sindicatos". ${ }^{16}$ Assim, o problema de fundo no argumento não é estritamente o fracasso do movimento ambientalista: embora Gottfried e Fedrizzi apontem em suas narrativas que a atuação do movimento era limitada, o argumento de Fedrizzi sintetizado acima demonstra que avanços ecológicos vinham sendo alcançados. $\mathrm{O}$ problema em sua narrativa seria, isto sim, o obstáculo exercido pelo ambientalismo contra o dinamismo econômico e a criação de empregos. Em algumas passagens, Fedrizzi argumenta que os ambientalistas se opunham aos negócios, quando deveriam atacar a degradação do ambiente: ${ }^{17}$ sua interpretação equivale, ao preço de distorcer a agenda ecológica, "ambientalismo" a "antimercado" como modo de enfatizar a originalidade da solução proposta, do mercado verde. Por isso, haveria agora - leia-se: com o USGBC ${ }^{\circledR}$ e experiências análogas - uma nova fase do ambientalismo: o duplo ganho [win-win solution] da economia verde, ao mesmo tempo garantindo crescimento e preservação de recursos. O que naquele momento era a aproximação das duas esferas seria, argumenta Fedrizzi, um futuro incontornável, onde lucro e planeta [profit and planet] seriam "inseparáveis". ${ }^{18} \mathrm{O}$ modelo de inovação verde do USGBC ${ }^{\circledast}$ traria, segundo ele, não só menores perdas na produção, mas também produtos mais atraentes para os consumidores. ${ }^{19} \mathrm{E}$ também maiores retornos: seja pela simples economia de recursos, seja pela sua redistribuição aos acionistas. ${ }^{20}$

Assim, conforme apresentado na parte I, o USGBC ${ }^{\circledast}$ é gerido como um negócio. Como tal, o conselho não é inteiramente dependente de doações para sua operação, ao modo habitual dos movimentos ambientalistas. Os produtos, eventos e formações vinculados a sua marca são próprios de "startups de empreendedorismo privado" e lhe concedem estabilidade financeira e

\footnotetext{
16. No original: "from money managers to office workers, from individual shareholders to pension funds, from universities to labor unions". Fedrizzi, 5, tradução nossa.

17. Fedrizzi, 148.

18. Fedrizzi, 110-11.

19. Fedrizzi, 8-9.

20. Gottfried, Explosion green, 256; Fedrizzi, Greenthink, 76.
} 
independência, ainda que por ser uma ONG não almeje o lucro. ${ }^{21} \mathrm{~A}$ vinculação entre economia e ambiente faz parte da gestão do USGBC ${ }^{\oplus}$, mas também do que ele propõe para seus associados e para o papel da arquitetura ecológica contemporânea.

\section{TEORIAS NO LEED®}

A relação entre economia e ecologia defendida pelos agentes do USGBC ${ }^{\circledast}$ tem raízes no documento Our common future das Nações Unidas, mas também em referências teóricas nem sempre claramente enunciadas. Em vídeo institucional do GBC Brasil, é declarado que o conselho estaria alinhado à tendência "Save the planet" do movimento ambientalista. ${ }^{22} \mathrm{O}$ posicionamento é provavelmente uma citação indireta a uma "tipologia de movimento ambiental", em sistematização elaborada por Manuel Castells no segundo volume de sua obra $A$ era da informação, dedicado aos novos regimes identitários e seu impacto na organização da sociedade civil do fim do século $\mathrm{XX} .{ }^{23}$ Com a referência, o GBC Brasil indica como vê sua própria ação ambientalista, e também com quais tendências - ou "tipologias", na terminologia de Castells - ele não se identifica.

Para Castells, haveria cinco "tipologias". A primeira seria a preservação da natureza em grupos de defesa da vida selvagem, que, no caso norte-americano, correspondeu à criação de agências governamentais de regulação e a avanços institucionais. A segunda seria a militância comunitária resistindo a agentes poluidores nos seus espaços cotidianos, sobretudo de residência, com foco na qualidade de vida - o chamado "Não no meu quintal" [Not in my back yard]. A terceira tipologia seria a contracultura, sobretudo no fim dos anos 1960 e início dos 1970, na qual os movimentos sociais combinavam "ação ambiental e revolução cultural". A quarta seria a política verde de cidadãos operando na arena partidária. A quinta tipologia, por fim, seria o "Save the planet" supracitado, no qual o GBC Brasil se vê, que opera em meio a corporações em prol da sustentabilidade. Para Castells, essa "tipologia" se caracterizaria, entre outros pontos, por sua "atitude pragmática, do tipo empresarial". Exemplificada segundo Castells pelo Greenpeace,

\footnotetext{
21. Gottfried, Explosion green, 241.

22. gbcbrasil, GBC Brasil - Institucional, 2009, https://www.youtube.com/watch?v=S9vaF2NT4Lg.

23. Manuel Castells, "O 'verdejar' do ser: o movimento ambientalista", in A era da informação, Trad. de Klauss Brandini Gerhardt [1996], vol. 2, O poder da identidade, 3 vols. (São Paulo: Paz e Terra, 1999), 141-68.
} 
essa categoria criaria "campanhas específicas... em torno de metas palpáveis, seguidas de ações espetaculares com o objetivo de atrair a atenção da mídia”.".

Esses trechos destacados do texto de Castells parecem ser aqueles mais bem alinhados à autoimagem do GBC Brasil. Sua ação se daria por estratégias midiáticas, como o convite a celebridades políticas em eventos, ou como as campanhas de políticas públicas, frequentes sobretudo no início do conselho, como a campanha One Degree Less e o PL 615/2009 subsequente. ${ }^{25}$ Além disso, o GBC Brasil operaria pelo pragmatismo em relação ao mercado, a ele aliando-se e pressionando por mudanças graduais e consensuais.

Se por um lado Manuel Castells era um autor influente no início do século XXI no Brasil, e por isso foi citado implicitamente pelo GBC nacional, ${ }^{26}$ a discussão conceitual do USGBC ${ }^{\oplus}$ é mais explícita e refere-se a outros autores. Fedrizzi e Gottfried salientam em seus escritos a relação com pesquisadores do Rocky Mountain Institute (RMI), como Paul Hawken e o casal Amory e L. Hunter Lovins. O instituto foi fundado em 1982 em resposta à crise do petróleo na década anterior, com o objetivo de realizar pesquisas combinando inovação tecnológica na área energética e rendimentos financeiros. Podem ser encontrados diversos nexos entre o RMI e o USGBC ${ }^{\circledast}$ : a inscrição do instituto como um dos primeiros membros do USGBC ${ }^{\oplus}{ }^{27}$ citações reiteradas por Gottfried e Fedrizzi de obras de Paul Hawken e do casal Lovins; ${ }^{28}$ os prefácios de Hawken em Greed to green e Explosion green de Gottfried; a viagem de estudos para o instituto realizada pelo arquiteto gaúcho Roberto Teitelroit, que estabeleceu o primeiro contato entre o USGBC ${ }^{\circledR}$ e iniciativas brasileiras de criação de um conselho nacional. ${ }^{29}$

\section{Castells, 150. \\ 25. Cf. capítulo 3.}

26. Principalmente em sua guinada teórico-metodológica em direção à sociedade em rede e seu vínculo com o também sociólogo e ex-presidente Fernando Henrique Cardoso, que prefaciou Sociedade em rede, primeiro volume de A era da informação, em sua edição brasileira. Ambos os sociólogos colaboraram ainda em livros e debates. Em evento na inauguração do Rochaverá Corporate Towers, um dos primeiros grandes conjuntos corporativos certificados pelo LEED $^{\circledR}$ no Brasil, Cardoso falou sobre a globalização e a nova ordem financeira; em evento como "keynote speaker" no $5^{\circ}$ Greenbuilding Brasil, falou sobre o terceiro setor e a sociedade em rede. Castells certamente foi uma referência teórica para as duas comunicações. Ver também Fernando Henrique Cardoso e GBC Brasil, "Entrevista: Fernando Henrique Cardoso", Revista GBC Brasil, dezembro de 2014.

27. Cf. capítulo 1 .

28. Por exemplo: Fedrizzi, Greenthink, 16; Gottfried, Explosion green, 94-95. Ver capítulo 1.

29. Cf. capítulo 3. 
Em Natural capitalism, de 2000 e editado pelo USGBC ${ }^{\oplus}$, Hawken e o casal Lovins propunham a substituição da "aberração insustentável" do capitalismo industrial por um novo modelo econômico. Antes, afirmam eles, o capitalismo se caracterizaria pela abundância de recursos naturais e escassez de trabalho; agora, inversamente, haveria excesso de trabalho e escassez de recursos. O novo modelo proposto se daria pela ênfase na eficiência no uso de recursos em uma ordem superior àquela executada corriqueiramente nas linhas de produção industriais. Também se daria na biomimética, com o estudo de processos biológicos e ecológicos, tal como a circularidade dos produtos - sua reciclagem e reaproveitamento - no lugar da linearidade - extração, produção e descarte (pense-se no conhecido berço-a-berço de Braungart e McDonough, onde os materiais sempre poderiam ser reaproveitados em alguma etapa de seu ciclo produtivo, da extração ao rejeito)..$^{30} \mathrm{O}$ modelo estaria ainda na economia de serviços e fluxos, na qual não seriam mais vendidos os produtos, mas locados temporariamente para uso. Atualmente, o desdobramento dessa posição pode ser visto nos serviços de empréstimo de bicicletas, ou de locação, e não venda, de carpete pela empresa holandesa Desso Group, que cita explicitamente o berço-a-berço. Por fim, o modelo de Paul Hawken e do casal Lovins propunha, de modo tautológico, que o capitalismo natural se caracterizaria por investimentos no "capital natural" 31 - ou seja, investimentos em recursos naturais.

Por um lado, Natural capitalism define esse novo modelo econômico e, por outro lado, elenca experiências de negócios que já o colocariam em prática. O livro segue fundamentalmente a teoria previamente elaborada por um dos autores, Paul Hawken, em outra obra, The ecology of commerce, publicada sete anos antes. ${ }^{32} \mathrm{O}$ seu diagnóstico de época é diferente de alguns de seus contemporâneos, que após o fim do comunismo viam o "fim da história" e a vitória do liberalismo, como Francis Fukuyama. ${ }^{33}$ De certo modo, haveria para Hawken uma vitória de Pirro, na qual o êxito na Guerra Fria encobriria um atraso de concepção corporativa, em que "nosso entendimen-

30. William McDonough e Michael Braungart, Cradle to cradle: remaking the way we make things (Nova York: North Point Press, 2002).

31. Amory B. Lovins, L. Hunter Lovins, e Paul Hawken, Natural capitalism: the next industrial revolution (Washington DC: US Green Building Council, 2000).

32. Paul Hawken, The ecology of commerce: a declaration of sustainability (Nova York: HarperCollins Publishers, 1993). Convém lembrar que o livro foi central para a perspectiva de Fedrizzi sobre a sustentabilidade, ainda quando na Carrier. A respeito, conferir o capítulo 1 desta tese.

33. Francis Fukuyama, The end of history and the last man (Nova York: The Free Press, 1992). 
to de negócios... está preso em um nível primitivo.” ${ }^{34}$ Tal seria o caso do próprio vocabulário corporativo, inapto para separar o lucro de qualidade sustentável de outro meramente quantitativo. Afirma Hawken: os negócios só estão capacitados a discriminar lucro líquido e bruto, nada além disso. ${ }^{35}$ Qualquer distinção mais aprimorada do que essa estaria, portanto, fora das categorias operadas pelo aparato corporativo. Em suma: para Hawken, o nível primitivo dos negócios corresponderia ao objetivo único de ganhos financeiros; o novo capitalismo seria o setor de serviços, a invenção e a ética. Por meio dele seria compatibilizado o "oxímoro" do par ecologia e comércio.

No texto de Hawken de 1993, os negócios preconizados são aqueles do capitalismo natural ainda em elaboração; na obra de Rick Fedrizzi a respeito de seu desempenho à frente do USGBC ${ }^{\circledast}$, duas décadas depois, a dinâmica do modelo econômico de Hawken está perfeitamente aceita e operativa. As críticas de Fedrizzi ao capitalismo industrial são secundárias e os fundamentos para um novo sistema econômico não estão mais presentes. O argumento é mais pragmático e o ponto de vista é aquele das ações empresariais que unem ambientalismo e lucratividade, das "companhias esclarecidas" que alavancam lucros pela eficiência ambiental. O desperdício de recursos e a destruição ambiental não são mais "primitivos", como em Hawken, e sim a perda de oportunidades de crescimento que representaria a superação das empresas antiquadas, no seu devido tempo, pela competição de mercado. ${ }^{36} \mathrm{O}$ texto de Fedrizzi direciona-se ao público empresarial e por isso argumenta em termos superlativos:

O sucesso do movimento de construção verde me ensinou duas coisas. Primeira, só existe uma força suficientemente poderosa, e capaz de trabalhar suficientemente rápido, para reverter as tendências de erosão da segurança ambiental do nosso planeta e do futuro da humanidade: o capitalismo. Segunda, o pensamento verde é, simplesmente, a maior e mais incrível oportunidade de negócios do século XXI. ${ }^{37}$

\footnotetext{
34. No original: "our understanding of business... is stuck at a primitive level." Hawken, The ecology of commerce, 1, tradução nossa.

35. Hawken, 10-11.

36. O engenheiro Jerry Yudelson, que foi professor nos cursos do USGBC ${ }^{\oplus}$, além de participar de seu conselho diretor e da organização da feira Greenbuild, também argumenta nesse sentido. Para ele, um edifício aquém das demandas de sustentabilidade já estaria obsoleto em sua inauguração. Cf. Jerry Yudelson, The green building revolution, Prefácio de Rick Fedrizzi (Washington, DC; Covelo, CA; Londres: Island Press, 2008), 27.

37. No original: "The success of the green building movement has taught me two things. First, there is only one force powerful enough, and capable of working quickly enough, to reverse the trends eroding the environmental security of our planet
} 
O alinhamento entre economia e ecologia não começa nem em Fedrizzi, nem em Hawken, nem mesmo no relatório Our common future. A princípio, ele poderia ser recuado pelo menos até a década de $1960 .{ }^{38}$ Entretanto, dentre as influências mais diretas, está a da "modernização ecológica", corrente da sociologia ambiental existente na Europa desde a década de $1980 .{ }^{39}$ Embora ela não seja citada nem pelos fundadores do USGBC ${ }^{\oplus}$, nem pelos fundadores do Rocky Mountain Institute, o "capitalismo natural" pode ser apontado como a "modernização ecológica" em variante "American style" ${ }^{40}$ A modernização ecológica aprova e teoriza práticas de sustentabilidade muito próximas àquelas praticadas pelo USGBC ${ }^{\oplus}$, no que se refere a sua relação com o mercado, sua organização institucional e a técnicas de mercado privilegiadas, cujo ápice, no USGBC ${ }^{\circledast}$, é o "ecossistema" de produtos LEED॰.

A modernização ecológica surgiu na Alemanha e na Holanda no início dos anos 1980, com a proposta de aproximar ecologia e economia na solução de problemas ambientais. Seus primeiros defensores são os sociólogos Martin Jänicke e Joseph Huber, que deram início à ver-

and the future of humanity: capitalism. Second, greenthink is, simply put, the biggest and most incredible business opportunity of the twenty-first century." Fedrizzi, Greenthink, 12, grifo no original, tradução nossa.

38. Grandes narrativas do ambientalismo tendem a alargar o termo demasiadamente, abarcando de alimentação saudável no fim do século XIX à produção de carpetes ecológicos, da arquitetura medieval aos edifícios high tech contemporâneos. A indicação dos anos 1960 aqui realizada, limitando o espectro de estudo, é justificada por ser o início do argumento ecológico em termos de riscos globais de calamidades ambientais. Para uma história de "negócios verdes" ver Geoffrey Jones, Profits and sustainability: a history of green entrepreneurship (Oxford: Oxford University Press, 2017); para histórias da arquitetura ambiental, com igual problema de esvaziamento pela abrangência do argumento, ver Phillip James Tabb e A. Senem Deviren, The greening of architecture: a critical history and survey of contemporary sustainable architecture and urban design (Surrey, Inglaterra; Burlington, EUA: Ashgate Publishing, 2013); James Wines, Green architecture (Colônia: Taschen, 2000); por fim, para uma alternativa a leituras tão difusas do termo, ver a nossa interpretação em "A perspectiva tecnológica da sustentabilidade ambiental: Buckminster Fuller e a arquitetura dos anos 2000", Oculum Ensaios 15, n 1 (2018): 111-28, https://doi. org/10.24220/2318-0919v15n1a3374.

39. Harvey vê no Relatório Brundtland o apogeu da modernização ecológica. Em sua dialética, ele aposta mais nas soluções do relatório e da modernização ecológica do que esta tese. Entretanto, o desenrolar dessa posição nos últimos vinte anos coloca dúvidas na sua efetividade, como se argumentará. Cf. David Harvey, "What's green and makes the environment go round?", in The cultures of globalization, org. Fredric Jameson e Masao Miyoshi (Durnham; Londres: Duke University Press, 1998), 341. Para uma posição mais cética de Harvey sobre o mesmo tema, cf. Justice, nature and the geography of difference (Cambridge, Massachusetts; Oxford, UK: Blackwell Publishers, 1996), cap. 7, 8 e 13.

40. David Schlosberg e Sata Rinfret, "Ecological modernisation, American style", Environmental Politics 17, $\mathrm{n}^{\circ} 2$ (2008): 254-75, https://doi.org/10.1080/09644010801936206; Linda C. Forbes e John M. Jermier, "The new corporate environmentalism and The ecology of commerce", Organization \& Environment 23, no 4 (2010): 465-81, https://doi. org/10.1177/1086026610394639. 
tente. Mas suas ideias foram desenvolvidas e disseminadas sobretudo através dos trabalhos dos holandeses Gert Spaargaren e Arthur Mol e do norte-americano Frederick Buttel, a partir do fim dos anos 1980. Diferentemente das medidas tomadas pelo movimento ambientalista até então, a modernização ecológica propunha a ação imediata em prol do ambiente, sem a necessidade de mudanças sociais profundas prévias ao emprego de alternativas na produção, o que segundo eles permitiria transformações mesmo a curto prazo. Nesse sentido, segundo Martin Jänicke, "um problema ambiental se prova politicamente menos difícil de resolver quando uma solução de mercado existe" ${ }^{41}$ Isto é, a aproximação da ecologia ao mercado forneceria um atalho na ação ambiental, desvinculada, ao menos em um primeiro momento, de processos políticos que modificassem mais estruturalmente os modos de vida. Devido à urgência dos problemas ambientais, os modernizadores ecológicos argumentavam, a resposta passava a se dar dentro da estrutura socioeconômica presente, na qual a sua suplantação não seria uma condição necessária para a transição ecológica. ${ }^{42}$ Como nota Andrew Blowers, para a modernização ecológica não há crise ambiental, mas oportunidade de mercado. ${ }^{43}$

Tal interpretação é corroborada pelos seus principais epígonos no meio acadêmico. É o caso de Gert Spaargaren: para ele, a modernização ecológica seria um espelho, dentro da sociologia ambiental, do debate do desenvolvimento sustentável. ${ }^{44}$ Ou seja, ele reafirma a ideia de que a adoção de práticas sustentáveis seria possível dentro de lógicas de progresso econômico, de “desenvolvimento". Arthur Mol, por sua vez, define que "A teoria da modernização ecológica pode ser entendida como uma interpretação sociológica de como os países industrializados contemporâneos lidam (ou tentam lidar) com a crise ambiental”. ${ }^{45}$ Uma teoria que, portanto, toma a or-

\footnotetext{
41. No original: "an environmental problem proves politically less difficult to resolve if a marketable solution exists". Martin Jänicke, “Ecological modernisation: new perspectives", Journal of Cleaner Production 16 (2008): 557, tradução nossa.

42. Gert Spaargaren, "Ecological modernization theory and the changing discourse on environment and modernity", in Environment and global modernity, org. Gert Spaargaren, Arthur P.J. Mol, e Frederick H. Buttel (Londres, Reino Unido; Thousand Oaks, EUA; Nova Delhi, Índia: SAGE Publications, 2000), 45.

43. Andrew Blowers, “Environmental policy: ecological modernisation or the risk society?", Urban Studies 34, nº 5-6 (1997): 847, https://doi.org/10.1080/0042098975853.

44. Spaargaren, "Ecological modernization theory and the changing discourse on environment and modernity", 41.

45. No original: "Ecological modernisation theory can be understood as a sociological interpretation of how contemporary industrialised countries (try to) deal with the environmental crisis." Arthur P.J. Mol, "The environmental movement in an era of ecological modernisation", Geoforum, n 31 (2000): 46, https://doi.org/10.1016/S0016-7185(99)00043-3, tradução nossa.
} 
ganização político-econômica mundial como fato consolidado, sem discutir seus fundamentos. Por fim, para Frederick Buttel, a modernização ecológica seria um passo adiante em relação ao desenvolvimento sustentável do Our common future. Muito embora o desenvolvimento sustentável tivesse ampla aceitação e discussão em esferas institucionais internacionais, ele teria, para Buttel, uma base sociológica fraca. Donde certo ostracismo do conceito no espaço científico, o que era um desenrolar negativo com o qual os modernizadores ecológicos se ocupavam. ${ }^{46}$

Assim, de um lado, Gottfried busca intuitivamente com o USGBC ${ }^{\circledR}$ uma alternativa para a sustentabilidade, pelo que considera uma apropriação indevida de movimentos ambientalistas. De outro lado, Buttel e os modernizadores ecológicos também propõem uma revisão por identificarem na mesma sustentabilidade a ausência de uma "teoria sociológica". Com efeito, por ser um relatório institucional das Nações Unidas, Our common future não pretendia avançar na direção de implicações conceituais mais abrangentes, visando sobretudo interferir nas políticas governamentais internacionais.

Hawken não cita os modernizadores ecológicos em nenhum momento, talvez pela pouca literatura especializada em inglês no início dos anos $1990 .{ }^{47}$ Contudo, sua afirmação de que "os negócios são o problema e devem fazer parte da solução"48 encontra ressonância nos modernizadores ecológicos, para quem "as soluções dos problemas causados pela modernização, industrialização e ciência só podem ser resolvidos com mais modernização, industrialização e ciência." ${ }^{49}$

Seguindo Buttel, o alinhamento com as teorias da modernização ecológica pretendia constituir uma perspectiva não "romântica" dos movimentos sociais, apontando outras esferas de atu-

46. F. H. Buttel, "Ecological modernization as social theory”, Geoforum, n 31 (2000): 61-62.

47. Curiosamente, Hawken demonstra, contudo, estar a par de uma literatura radicalmente contrária à da economia política capitalista, como a do marxista heterodoxo Ivan lllich. Hawken cita Illich em The ecology of commerce, mas sem dele extrair as consequências de revolução social. Em relação à modernização ecológica, a escassez de literatura específica em inglês até 1992 - um ano antes da publicação de The ecology of commerce - pode ser aferida nas bases de dados: no Google Scholar, há quatro textos em inglês de Joseph Huber, sete de Martin Jänicke, cinco de Arthur Mol, cinco de Gert Spaargaren, dois de Frederick Buttel. A maior parte desses textos foi publicada em revistas científicas, provavelmente de difícil acesso ao empresário Hawken.

48. No original: "Business is the problem and it must be a part of the solution." Hawken, The ecology of commerce, 17, tradução nossa.

49. No original: "solutions to the problems caused by modernization, industrialization, and science can only be solved through more modernization, industrialization, and science." Buttel, "Ecological modernization as social theory", 62, tradução nossa. 
ação possíveis, como a ciência, a tecnologia, o capital e o Estado. ${ }^{50}$ Segundo o militante ambientalista Van Jones, entrevistado para um ensaio de Michael Shellenberger e Ted Nordhaus a respeito das mudanças nesse grupo de ativistas, essa seria a terceira onda desse movimento social: depois daquelas da conservação e da regulação, agora aquela do investimento. ${ }^{51}$

A guinada norte-americana da modernização ecológica é relativamente tardia, se comparada à europeia. De fato, chegou à política econômica nos anos 2000, por meio da militância do Democrata Al Gore e de medidas do Republicano Arnold Schwarzenegger enquanto governador da Califórnia (2003-2011). ${ }^{52}$ Nesse sentido, o USGBC ${ }^{\circledast}$ pode ser visto como uma manifestação relativamente precoce de modernização ecológica nos Estados Unidos, já que foi fundado em 1993.

Se na parte I foram examinados os eventos e agentes de formação do USGBC ${ }^{\oplus}$, o percurso por seus conceitos permite esclarecer quais são os conflitos e problemáticas subjacentes ao conselho norte-americano e, por consequência, ao GBC Brasil. A genealogia de suas linhas argumentativas, elaborada pelo exame dos escritos e depoimentos de seus fundadores, e também pelas referências bibliográficas neles presentes, permite aproximar iniciativas a princípio isoladas, que são os conselhos verdes liderados pelo USGBC ${ }^{\circledR}$, os ecocapitalistas norte-americanos e os modernizadores ecológicos europeus. Todos partilham de argumentos semelhantes, da aproximação entre economia e ecologia, donde seus modos de atuação e os conflitos enfrentados. Nisso encontra-se sobretudo o ímpeto de se diferenciarem tanto da sustentabilidade tal como elaborada pelo relatório Our common future das Nações Unidas - que já era um passo de aproximação à economia, mas em um grau considerado insuficiente pelas três iniciativas aqui abordadas -, quanto de superarem a contradição entre mercado e ambientalismo - motivo pelo qual esbarram continuamente em obstáculos, cuja dificuldade de superação o texto dessa tese busca explicitar. Uma dessas dificuldades é o argumento sempre hesitante, nos textos consultados, do incentivo ao mercado e à economia verde: na tentativa de privilegiarem as bonificações no lugar das punições,

\section{Buttel, 60-61.}

51. Michael Shellenberger e Ted Nordhaus, “The death of environmentalism: global warming politics in a post-environmental world", Social Policy, 2005, 29.

52. Schlosberg e Rinfret, "Ecological modernisation, American style” No seu artigo, Schlosberg e Rinfret propõem que a modernização ecológica só ganhou espaço nos Estados Unidos por questões de segurança nacional, como potenciais guerras por recursos, aumento de fluxos migratórios e dificuldades para a segurança alimentar, todos causados pelas mudanças climáticas. 
os autores são imprecisos em relação ao que fazer com as empresas não-alinhadas à agenda ambientalista. Outra dificuldade é o esclarecimento de como a "modernidade reflexiva" 53 subjacente ao seu argumento - a ideia de que os problemas da modernidade serão resolvidos com mais modernidade, os problemas do mercado com mais mercado, e assim por diante - pode efetivamente levar à superação das contradições atuais, e não apenas a sua reprodução.

Se o argumento aqui apresentado for verdadeiro e as três iniciativas podem ser alinhadas, então elas compartilham não só um campo teórico, mas também características de ação, colocada em prática pela eficiência e inovação tecnológica no mercado e pela autonomia política.

\section{EFICIÊNCIA E INOVAÇÃO TECNOLÓGICA}

A inovação tecnológica é um dos principais instrumentos de viabilização do capitalismo natural -termo de matriz norte-americana - e da modernização ecológica - aquele de matriz europeia. É por ela que é atingida maior eficiência nos processos produtivos, que por sua vez representaria menor consumo de recursos. Em seus argumentos, haveria ganhos para o meio ambiente, pela atenuação da degradação das fontes naturais. Também haveria ganhos para a economia, com um sistema de menor desperdício e maior aproveitamento dos investimentos.

A inovação tecnológica não pode ser apenas end-of-pipe. Tal estratégia, também chamada de add-on, ocorre quando a indústria toma medidas antipoluidoras apenas ao fim da cadeia produtiva, de modo que os processos de produção não são revistos em nenhum grau. Seriam exemplos desse caso os filtros em indústrias poluidoras do ar e da água ou o tratamento de resíduos tóxicos descartados ao fim da cadeia produtiva. Essa "indústria da poluição" trataria os contaminantes ao invés de evitar sua produção desde o princípio. Os modernizadores ecológicos não concordam com essa transformação de riscos ambientais em oportunidades de negócios, ${ }^{54}$ por mais que o end-of-pipe também seja uma saída de mercado para um problema ambiental. Como apontado na análise de Layrargues sobre indústrias sustentáveis, o end-of-pipe aumenta

\footnotetext{
53. O termo é do sociólogo Ulrich Beck e é frequentemente mencionado pelos modernizadores ecológicos. Cf. Ulrich Beck, Sociedade de risco: rumo a uma outra modernidade, Trad. de Sebastião Nascimento. 2a [Ed. orig. 1986] (São Paulo: Editora 34, 2011).

54. A associação entre risco e oportunidades de mercado é feita em Beck, 56.
} 
custos, enquanto uma indústria com tecnologia limpa aumenta a produtividade ${ }^{55}-$ um incentivo econômico visto como fundamental pelos modernizadores.

Tal tecnologia limpa seria não só a conformação de estruturas produtivas que incentivam inovações tecnológicas, mas também a difusão dessas inovações em todo o processo produtivo: na intensidade de uso de materiais e energia, na organização logística do transporte e do espaço no armazenamento e também no controle de riscos à saúde e ao meio ambiente presentes em diferentes substâncias, produtos e práticas. Entretanto, o modernizador ecológico Martin Jänicke, de modo pragmático, traça os limites da inovação: a nova tecnologia limpa não poderia intervir nos "padrões estabelecidos de produção, consumo ou transporte". Se assim ocorresse, a tecnologia sustentável encontraria resistência vinda do mercado, o que dificultaria a sua adoção. ${ }^{56}$

Esses avanços não buscam uma mudança radical do sistema econômico: o objetivo é antes aliar a modernização produtiva à ecológica. Na modernização produtiva, os objetivos da inovação são estritamente econômicos. Na modernização ecológica, o viés ambiental possibilitaria soluções de duplo ganho, tanto ecológico quanto econômico. Assim, a inovação tecnológica poderia, além de preservar o ambiente, oferecer oportunidades mais lucrativas de negócios. ${ }^{57}$

Os paralelos entre as estratégias de modernização ecológica e do USGBC ${ }^{\circledast}$ são, desse modo, significativos. Uma das ações fundamentais dos sistemas LEED $^{\circledR}$ é a eficiência no uso de recursos, seja na energia, água ou materiais. E, como apontado anteriormente, essas eficiências devem estar aptas à incorporação pelo mercado sem dificuldades substanciais. Na quarta versão do sistema LEED $^{\oplus} \mathrm{NC}$, há 37 pontos dentre os 126 pontos disponíveis, ou 30\% do total, relacionados diretamente à eficiência. A proporção é equivalente à de versões anteriores e pode ser maior caso os créditos geograficamente escolhidos para a categoria Regional Priority também tratem de eficiência.

A noção de eficiência no uso de recursos permite, em última instância, a continuidade dos esquemas produtivos vigentes: os modelos produtivos ganham sobrevida na medida em que recursos escassos passam a ser geridos com maior produtividade. O mesmo pode ser dito de esquemas tipológicos antes insustentáveis, em que o grande consumo de recursos torna-se viável por

55. Philippe Pomier Layrargues, A cortina de fumaça: o discurso empresarial verde e a ideologia da racionalidade econômica (São Paulo: Annablume, 1998), 62.

56. Jänicke, “Ecological modernisation: new perspectives”, 557.

57. Jänicke, 558. 
meio da maior eficiência. É o caso da mansão sustentável de Gottfried, mencionada no capítulo 1, em que a opulência do programa seria viabilizada pela sua eficiência. Um argumento radical dessa posição é defendido pelo fundador honorário do GBC Brasil José Goldemberg:

Eu fui lá [em uma das reuniões do GBC Brasil; não especifica data] e fiz uma outra palestra explicando o que seriam as coisas fundamentais [sobre energia]. Porque as pessoas têm ideias muito estranhas sobre a energia. Até o presidente Carter, dos Estados Unidos, tinha ideias estranhas. Uma vez, ele tentou explicar na televisão, isso durante a crise do petróleo, ${ }^{58}$ que as pessoas deveriam economizar energia. Então ele disse: "Abaixem o termostato, e em vez de utilizarem um suéter, utilizem dois durante o inverno." Mas essa é justamente a mensagem errada, porque dá a impressão que eficiência energética está tirando alguma coisa, você está se privando de alguma coisa. Foi muito ruim isso, porque não é verdade. Eficiência energética é simplesmente uma maneira mais inteligente de usar a energia. É como a lâmpada fluorescente, ela não esquenta. Chegue perto de uma lâmpada incandescente, você vai ver que ela produz calor, mas você não quer que ela produza calor, sobretudo em países tropicais. Entretanto, [no caso de] uma lâmpada que tem filamento de tungstênio, dois terços da energia é gasto em calor. Então, [se] você usar uma lâmpada fluorescente, e agora fluorescente compacta, você gasta muito menos energia para obter a mesma iluminação. Que é o end use, é o uso final. A ideia básica da eficiência energética é que você não está se privando de nada, você [só] está sendo menos ignorante. ${ }^{59}$

A particularidade dessa posição pode ser esclarecida por contraste, quando comparada a outras ordenações do movimento ambientalista. A modernização ecológica opõe-se a autores ambientalistas críticos dos modos de organização social e produtiva do capitalismo tardio - chamados pelos modernizadores, como mencionado acima, de "românticos". O caso mais paradigmático é o dos movimentos de contracultura, uma das vertentes de ambientalismo de Castells citadas acima.${ }^{60} \mathrm{O}$ modernizador ecológico Spaargaren agrupa esses autores sob a noção de "des-

\footnotetext{
58. Goldemberg provavelmente refere-se à segunda crise do petróleo, de 1979, já que a gestão de Carter ocorreu entre 1977 e 1981 .

59. José Goldemberg, (Fundador honorário do GBC Brasil), Entrevista para o autor, Presencial, 12 de setembro de 2016.

60. Conforme mencionado no início do capítulo. Cf. Castells, “O poder da identidade”.
} 
modernização" [de-modernization], que teria sido própria do ambientalismo da década de $1970 .{ }^{61}$ Segundo Spaargaren, os desmodernizadores viam como solução para os problemas ambientais a involução das forças produtivas, isto é, o abandono do modelo industrial-capitalista de produção. O autor dá alguns exemplos desse grupo, como o Clube de Roma, com suas teses de imposição de limites ao crescimento econômico e populacional; os defensores de "sociedades verdes" de pequena escala, tecnologia de ação limitada e autonomia de organização, como o economista Ernst Schumacher; ou os marxistas heterodoxos Ivan Illich e André Gorz, chamados de "teóricos da contra-produtividade". ${ }^{2}$ Em comum entre todos - segundo a interpretação de Spaargaren, pois os autores trabalham com matrizes teóricas radicalmente diferentes -, estaria a proposta de uma saída ecológica que abandonasse a teleologia do progresso presente nas sociedades industriais.

Essa saída não é admitida por modernizadores ecológicos ou capitalistas naturais, que propõem, pelo contrário, mais modernização, pelos instrumentos da economia de mercado, na tecnologia e na industrialização. O que, ademais, também figura em algumas das suas referências teóricas, como os pensadores Daniel Bell e Jürgen Habermas, ambos partidários da modernidade em meio à crítica que ela recebe no pós-guerra.

Considerados como movimento social, os conselhos verdes, USGBC ${ }^{\circledast}$ e GBC Brasil entre eles, não operam pela denúncia e oposição, mas pela cooperação e assessoramento, que o urbanista brasileiro Henri Acselrad chama de "pragmatismo da ação eficaz" ${ }^{63}$ Nesse sentido, produtos como o LEED ${ }^{\circledast}$, segundo David Gottfried, criam um modelo facilitador da aplicação da sustentabilidade e que reduz os gastos com consultoria por projeto ${ }^{64}$ - embora provavelmente aumentem a necessidade de consultorias no conjunto da prática projetual, como pode ser aferido pela alta

\footnotetext{
61. Spaargaren, "Ecological modernization theory and the changing discourse on environment and modernity", 41-44.

62. Cf. por exemplo D.H. Meadows et al., Limites do crescimento, [Ed. orig. 1972] (São Paulo: Perspectiva, 1978); Ernst F. Schumacher, Small is beautiful: economics as if people mattered (Londres: Blond \& Briggs, 1973); Ivan Illich, A convivencialidade, Trad. de Arsênio Mota [Ed. orig. 1973] (Lisboa: Publicações Europa-América, 1976); André Gorz, Ecológica, Trad. Celso Azzan Jr. [Ed. orig. 2008] (São Paulo: Annablume, 2010). De modo relevante para o argumento, Schumacher e Illich são citados por Charles Jencks como pioneiros da crítica à racionalidade moderna. Jencks menciona ainda Jacques Ellul, Hannah Arendt e Michael Oakshott. Cf. Charles Jencks, The language of post-modern architecture, 2a (Londres: Academy Editions, 1978), 24-25.

63. Henri Acselrad, “Ambientalização das lutas sociais - o caso do movimento por justiça ambiental”, Estudos avançados 24, n 68 (2010): 106, http://dx.doi.org/10.1590/S0103-40142010000100010.

64. David Gottfried, Greed to green: the transformation of an industry and a life, Prefácio de Paul Hawken (Berkeley, CA: WorldBuild Publishing, 2004), 172.
} 
quantidade de consultores progressivamente credenciados aos conselhos verdes. No LEED ${ }^{\oplus}$, portanto, está em questão a eficácia de aplicação de um padrão de avaliação, mas não métodos de organização social próprios de movimentos sociais de justiça ambiental, por exemplo, que têm ênfase mais contestatória do que profissional.

\section{AUTONOMIA POLÍTICA E ESPECTRO PARTIDÁRIO}

Acselrad identifica uma tendência paraempresarial ou paraestatal na modernização ecológica. ${ }^{65}$ Se aceita essa leitura, o USGBC ${ }^{\circledast}$ pode ser interpretado como um agente paraempresarial, ao organizar sua missão em torno de produtos verdes que garantiriam sua operação; e como um agente paraestatal, ao colocar-se como a esfera pública onde os parâmetros adequados a um edifício sustentável são estabelecidos. Extrapolando o sentido de Acselrad, pode ser afirmado não só que a modernização ecológica funciona paralelamente ao Estado, mas também que ela dele prescinde, ao menos ideologicamente. De fato, é comum aos modernizadores ecológicos o argumento do Estado como uma esfera obsoleta de atuação. Isso porque a globalização teria ultrapassado as fronteiras nacionais de ação governamental, além de o Estado não ter o dinamismo próprio do mercado para contornar a crise ambiental. ${ }^{66}$

Por esse motivo, Rick Fedrizzi coloca que o USGBC ${ }^{\oplus}$ foi formado espelhando-se em associações profissionais, como a American Society of Heating, Refrigerating and Air-Conditioning Engineers (ASHRAE) ou a American Society for Testing and Materials (ASTM), e não em ONGs e agências ambientalistas, como o Sierra Club, o Natural Resources Defense Council (NRDC) e a Audubon Society. ${ }^{67}$ Mesmo o desenho gráfico do logo foi pensado para a aproximação a agências e não a movimentos ambientalistas. ${ }^{68}$ Empresas poluidoras foram ativamente procuradas pelo conselho com o intuito de melhorar suas práticas. ${ }^{69}$ Ainda que o GBC Brasil preveja punir ações

\footnotetext{
65. Acselrad, “Ambientalização das lutas sociais”, 105.

66. Consultar Buttel, "Ecological modernization as social theory"; Spaargaren, "Ecological modernization theory and the changing discourse on environment and modernity"; Mol, “The environmental movement in an era of ecological modernisation"; Jänicke, "Ecological modernisation: new perspectives”.

67. Fedrizzi, Greenthink, 24.

68. Gottfried, Explosion green, 231-32.

69. Gottfried, 74, 225-26, 248.
} 
em que haja conflito de interesse,$^{70}$ a lógica organizacional do conselho é a de estruturar a representação da indústria e da construção civil para a autorregulação de sua entrada no mercado da sustentabilidade. Desse modo, o conselho parte das premissas dos modernizadores ecológicos do enfraquecimento do Estado e da atuação direta na organização e regulação do mercado.

Esse mesmo Estado, entretanto, foi primordial na fundação do USGBC ${ }^{\circledast}$. De fato, Gottfried admite que só se aproximou decididamente da arquitetura sustentável ao descobrir os financiamentos públicos disponíveis a partir do programa de edifício-modelo: "Quando o governo começa a jogar dinheiro em qualquer coisa verde, é da natureza humana entrar na fila. Eu não estou imune a isso. [...] Sim, eu já estava apaixonado por edifícios verdes, mas dólares também são verdes, e eu estaria mentindo se eu dissesse que nunca tinha percebido isso." ${ }^{11}$ Depois de fundado, também foi importante para a operação do USGBC ${ }^{\circledast}$ o subsídio concedido pelo Department of Energy sob a gestão de Mark Ginsberg. ${ }^{72} \mathrm{O}$ auxílio estatal manteve-se, contudo, restrito ao lançamento do USGBC ${ }^{\oplus}$, na medida em que novas doações não foram requisitadas, e a intervenção estatal na organização, ou a inscrição de agências do governo como membros, nunca foram permitidas. ${ }^{73}$

Como pano de fundo, a proposta dos modernizadores ecológicos na sua crítica ao Estado contemporâneo é a de constituir a ecologia como uma esfera decisória autônoma. Com essa autonomia, haveria não só a liberação da ecologia face a outras correntes de pensamento, como o ideário marxista ou contra-produtivista, mas também a organização em torno de uma agenda única, não mais vinculada a outras agendas sociais. O movimento ambientalista se dividiria, desse ponto de vista, em duas fases. A primeira é a ecologia pensada dentro de um debate amplo de reestruturação da sociedade, passando por tópicos tão diversos quanto as relações de produção e de gênero. A segunda fase é a especialização em direção a questões restritas à ecologia. Com

70. GBC Brasil, "Política - Conflito de interesse" (GBC Brasil), acessado 10 de outubro de 2017, http://gbcbrasil.org.br/ sistema/pdf/PoliticaConflitoInteresse.pdf.

71. No original: "When the government starts throwing money at anything green, it's human nature to get in line. I am not immune to this. [...] Yes, I was already passionate about green buildings, but bucks are green too, and I'd be lying if I said I never noticed that." Gottfried, Explosion green, 147, tradução nossa.

72. Gottfried, 127.

73. Gottfried, 235; Peter Templeton, (Vice-diretor de Desenvolvimento de Mercado Global do USGBC), Entrevista para o autor, 20 de abril de 2018. 
isso, o movimento ambientalista (ao menos como a modernização ecológica o vê), ao restringir suas demandas políticas, deixaria de lado a aversão às instituições modernas: a sua superação não seria mais vista como necessária ou mesmo desejável para a realização da agenda sustentável. ${ }^{74}$ A adequação às estruturas institucionais teria levado até mesmo ao aumento da força do movimento ambientalista, pois, ao operar dentro das esferas políticas tradicionais, teria alcançado um aumento de sua voz e uma melhor base organizacional e financeira de atuação. ${ }^{75}$

Nesse sentido, a ecologia seria uma nova esfera de ação, ladeada pelas esferas política, econômica e socioideológica. ${ }^{76} \mathrm{~A}$ formulação mais extrema dessa autonomia encontra-se no argumento de Robert Paehlke: ${ }^{77}$ a ecologia seria uma nova "ideologia", neutra dentro da disputa política. Para ele, a ecologia abarcaria o que fosse de seu interesse, sem se importar se de esquerda ou de direita, progressista ou conservador: "Um desenvolvimento completo das ideias ambientais - uma ideologia ambientalista - torna-se possível apenas quando o ambientalismo não é visto nem como 'de esquerda', nem como 'de direita"' ${ }^{8}$ Uma ideologia que tomaria distância e se colocaria como uma alternativa a outros movimentos políticos ocidentais de massa, nomeadamente o conservadorismo, o liberalismo e o socialismo. Assim, o "ambientalismo tem até mesmo o potencial de se tornar a primeira perspectiva ideológica a se desenvolver desde meados do século XIX."79 Essas formulações de Paehlke em 1989 são próximas ao elaborado dez anos depois pelos capitalistas naturais:

74. Mol, “The environmental movement in an era of ecological modernisation”, 48.

75. Mol, 52. Para posições radicalmente divergentes sobre os efeitos da restrição programática do movimento ambientalista, cuja elaboração excede nossos objetivos, ver Gorz, Ecológica, 10-11, 19-20, 30-31, 34; e também, para o caso brasileiro, Acselrad, "Ambientalização das lutas sociais".

76. Spaargaren, "Ecological modernization theory and the changing discourse on environment and modernity", 54; Mol, "The environmental movement in an era of ecological modernisation", 48.

77. Robert Paehlke, Environmentalism and the future of progressive politics (New Haven, Londres: Yale University Press, 1989), 1-7. Matthew Allan Cahn dá uma versão alternativa dessa organização autônoma da ecologia, em que vê como inconciliáveis as perspectivas políticas do ambientalismo e do liberalismo. Ver Matthew Alan Cahn, Environmental deceptions: the tension between liberalism and environmental policymaking in the United States (Albany: State University of New York Press, 1995).

78. No original: "A full development of enviromental ideas - an environmentalist ideology - becomes possible only when environmentalism is seen as neither 'left' nor 'right." Paehlke, Environmentalism and the future of progressive politics, 3 , tradução nossa.

79. No original: "Environmentalism even has the potential to become the first original ideological perspective to develop since the middle of the nineteenth century." Paehlke, 3 , tradução nossa. 


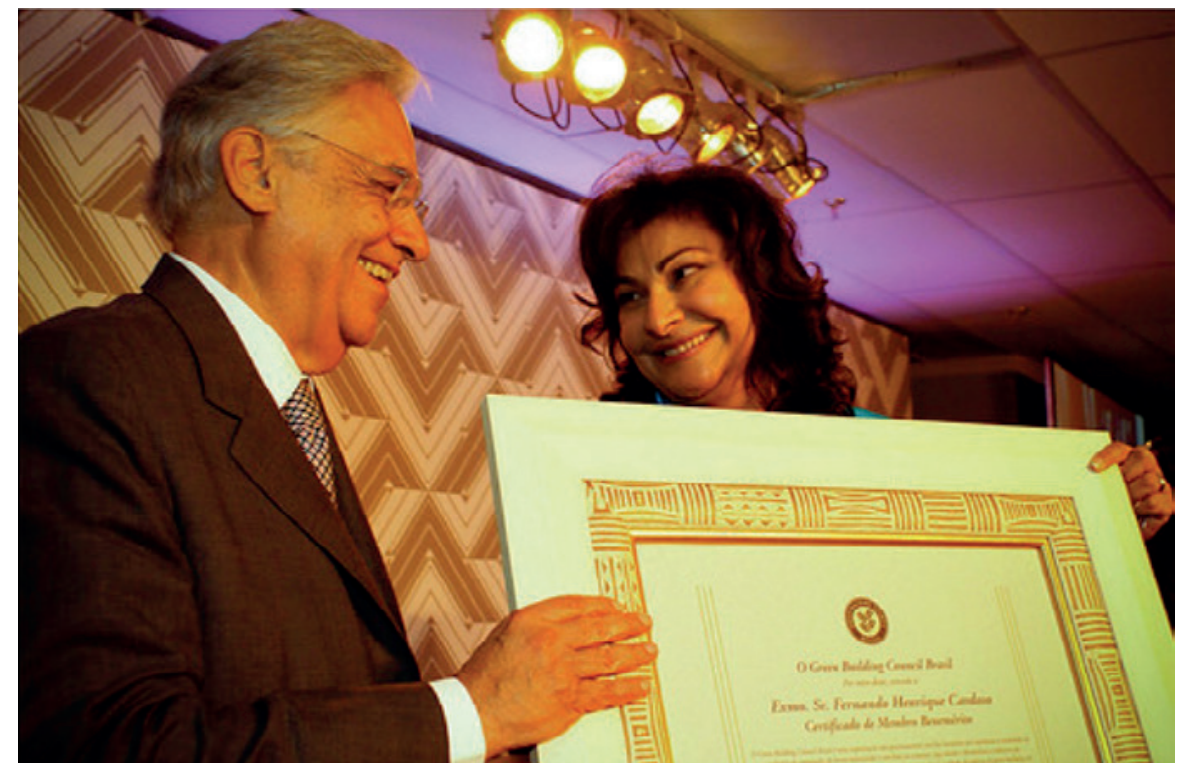

Fig 4.1. Fernando Henrique Cardoso recebe certificado de Thassanee Wanick durante evento de inauguração da primeira fase do Rochaverá Corporate Towers (6 fev 2009). Fonte: Weber, via Flickr.

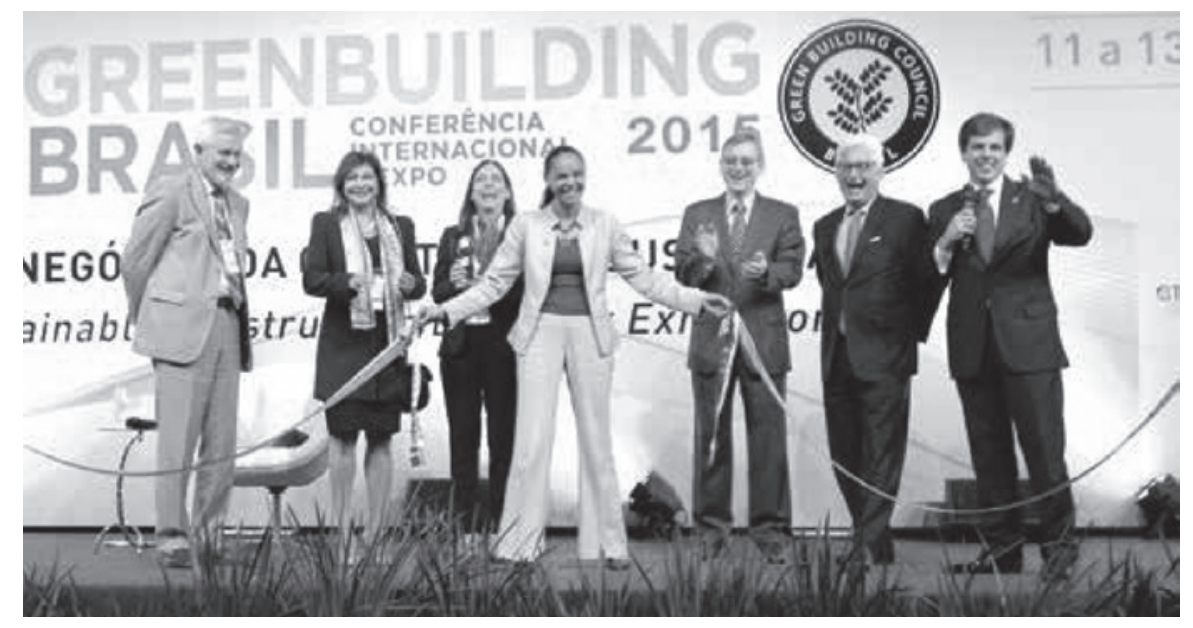

Fig 4.2. Marina Silva na $6^{\mathrm{a}}$ Greenbuilding, em 2015. Da esquerda para a direita, a segunda pessoa é Thassanee Wanick; ao centro, Marina Silva; logo a seguir da palestrante, José Moulin Netto. Fonte: Revista GBC, n. 6, out-nov 2015, p26. 
Ele [o capitalismo natural] não é nem conservador nem liberal em sua ideologia, mas apela para ambas as circunscrições. Como ele é um meio, e não um fim, ele não prescreve um desfecho social, mas antes torna possível diferentes resultados. Portanto, quaisquer que sejam as várias visões que diferentes partidos ou facções adotem, a sociedade pode trabalhar rumo à produtividade de recursos agora, sem esperar resolver disputas sobre políticas. ${ }^{80}$

A posição é equivalente, ainda, a formulações em termos mais triviais enunciadas por Rick Fedrizzi. Para ele, o caminho do ambientalismo não seria uma questão de votar "azul" - em alusão aos Democratas - ou "vermelho" - referente aos Republicanos; ${ }^{81}$ o caminho a ser seguido não deveria ser nem o do canal Fox - conhecido pelo seu conservadorismo - nem do MSNBC conhecido pelo seu liberalismo. ${ }^{82}$ A posição do USGBC ${ }^{\circledast}$ tampouco seria um caminho do meio, de centro geométrico da política, mas uma outra via, a par das agendas partidárias habituais.

Para Gert Spaargaren, essa autonomia da ecologia teria duas particularidades. A primeira é uma aproximação operativa com a economia, com a qual compartilharia diversos conceitos: haveria uma "afinidade eletiva" entre as duas. A segunda particularidade é que a autonomia não poderia ser vista como isolamento e superioridade hierárquica face às outras esferas (política, econômica e socioideológica) ${ }^{83}$ Ainda na interpretação de Spaargaren, haveria, assim, um processo duplo que já teria sido sintetizado por Joseph Huber no início da modernização ecológica. Por um lado, a ecologização da economia, com a internalização dos custos ecológicos antes externalizados. Por outro lado, a economização da ecologia, em que a ecologia poria fim à sua "inocência”: para uma alteração concreta dos processos produtivos com o objetivo de ganhos ambientais, eles deveriam ser quantificados para entrarem no mundo racional dos negócios. ${ }^{84}$

Convém observar que, apesar da autonomia aspirada, alianças políticas são eventualmente

80. No original: "It is neither conservative nor liberal in its ideology, but appeals to both constituencies. Since it is a means, and not an end, it doesn't advocate a particular social outcome but rather makes possible many different ends. Therefore, whatever the various visions different parties or factions espouse, society can work toward resource productivity now, without waiting to resolve disputes about policy." Lovins, Lovins, e Hawken, Natural capitalism, 20, tradução nossa.

81. Fedrizzi, Greenthink, 47.

82. Fedrizzi, 6-7.

83. Spaargaren, "Ecological modernization theory and the changing discourse on environment and modernity", 54-56.

84. Spaargaren, 50-51. 


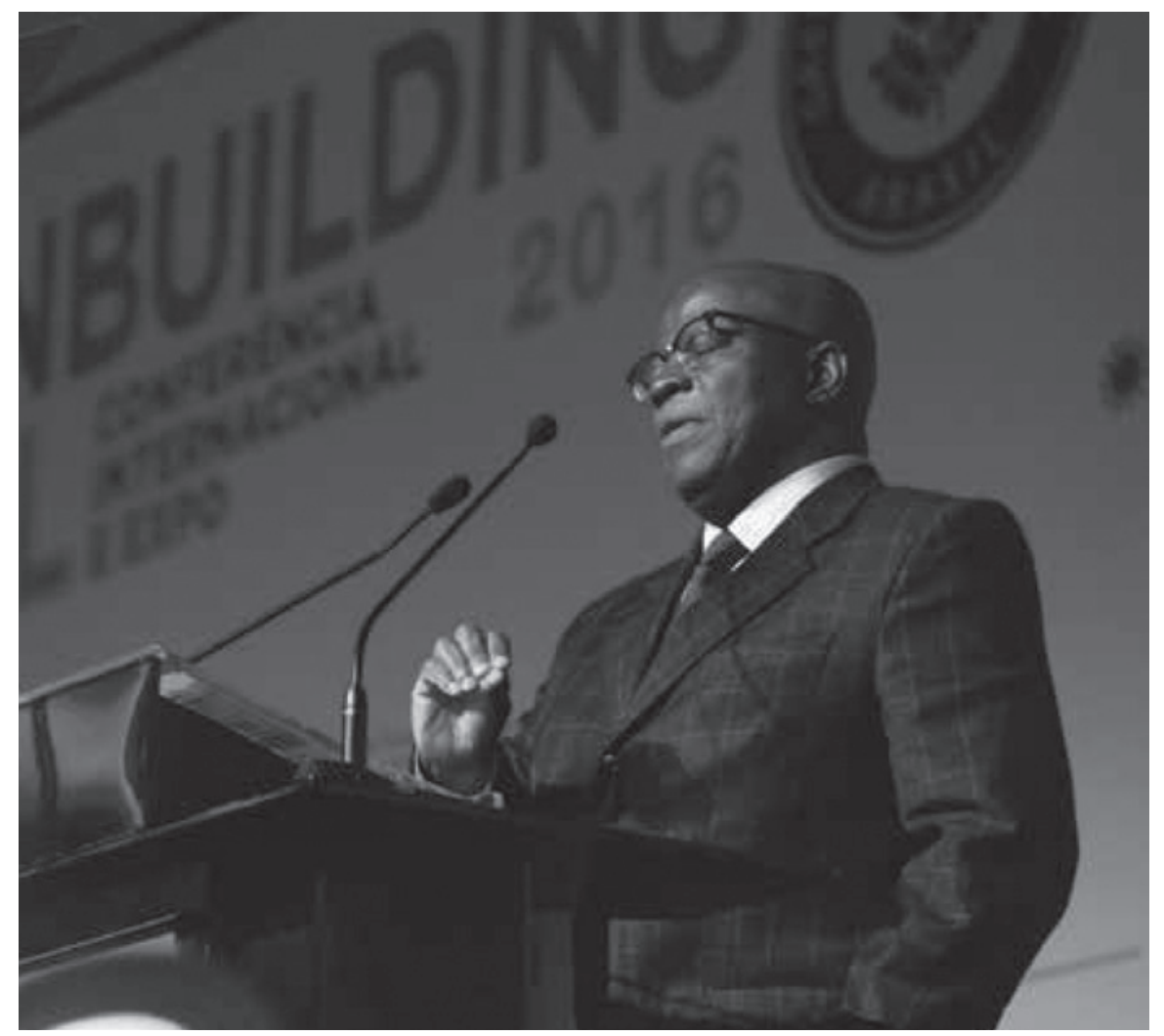

Fig 4.3. Joaquim Barbosa na 7a Greenbuilding, em 2016.

Fonte: Revista GBC, n. 10, set-out 2016, p36.

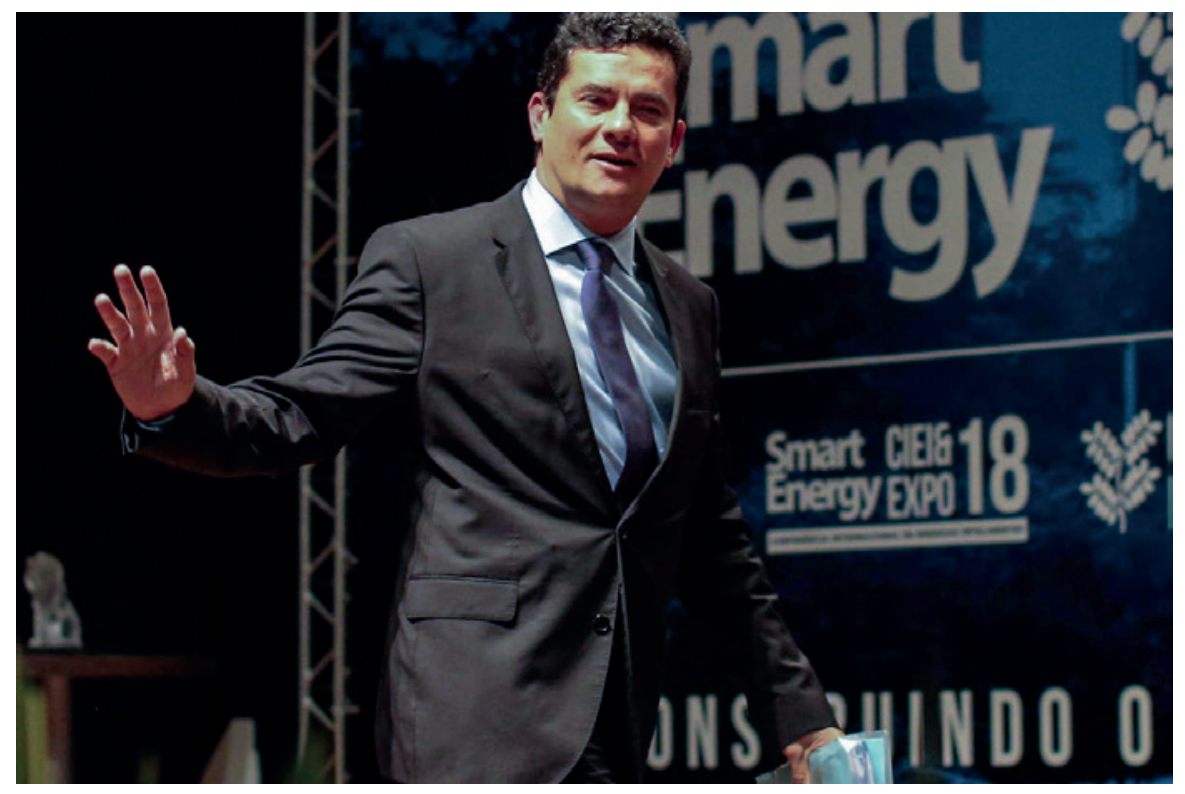

Fig 4.4. Sérgio Moro na $9^{a}$ Greenbuilding, em seu primeiro evento público após sua nomeação como ministro (5 nov 2018). Fonte: Geraldo Bubniak/AGB, via Katna Baran, "Não pretendo jamais disputar uma eleição, diz Moro", Folha de S. Paulo. 
necessárias na atuação dos diversos GBCs. O USGBC ${ }^{\circledast}$ tem forte apoio do casal Clinton, presentes tanto como "keynote speakers" nas feiras Greenbuild ${ }^{85}$ quanto por meio da colaboração de sua Fundação. Participaram dos Greenbuild, além disso, o independente Michael Bloomberg e os republicanos Colin Powell e Joe Scarborough, entre outros. ${ }^{86}$ No caso do GBC Brasil, os políticos mencionados na Revista GBC (n. 1-14) e nas entrevistas realizadas para esta pesquisa foram os seguintes: Geraldo Alckmin, José Goldemberg e Bruno Covas (PSDB), todos relacionados ao apoio inicial ao GBC Brasil ou a eventos e premiações a que eram convidados; César Maia (na época, DEM), com quem foram realizadas parcerias de formação em sustentabilidade para o Instituto Pereira Passos; o presidente Fernando Henrique Cardoso (PSDB), na abertura da feira Greenbuilding Brasil de 2014 e no lançamento da primeira fase do Rochaverá Corporate Towers; ${ }^{87}$ Marina Silva (à época, no Rede Sustentabilidade) na abertura do evento Greenbuilding de 2015; Joaquim Barbosa no evento de 2016, aposentado do STF dois anos antes; Sérgio Moro na abertura de 2018, no seu primeiro evento público após a nomeação como Ministro da Justiça da presidência de Jair Bolsonaro [fig 4.1 a 4.4].$^{88}$ Contrariando o foco em questões exclusivamente ambientais do sociólogo Paehlke, os últimos dois palestrantes fizeram apresentações com temas diversos: Barbosa falou sobre o poder de transformação do indivíduo; Moro, sobre seu trabalho com corrupção.

\section{LEED®, UM PRODUTO DE MODERNIZAÇÃO ECOLÓGICA}

O argumento apresentado até aqui inclui os sistemas $\mathrm{LEED}^{\circledR}$ dentro da modernização ecológica. Martin Jänicke faz uma síntese do que seriam medidas adequadas a essa vertente:

85. Bill Clinton abriu a feira em 2007 e 2017; Hillary o fez em 2013.

86. Michael Bloomberg era independente quando participou da Greenbuild em 2011, embora tenha sido filiado tanto ao Partido Democrata quanto ao Republicano. Colin Powell foi Secretário de Estado de George W. Bush entre 2001 e 2005 e abriu a Greenbuild de 2010. Joe Scarborough foi deputado federal pela Flórida entre 1995 e 2001, e abriu o Greenbuild em 2012, à época apresentador de um programa matinal de notícias da MSNBC.

87. O ex-presidente apresentou uma palestra na inauguração do empreendimento, com tema "A globalização e a nova ordem financeira mundial". Conforme divulgado em: "Prêmio AsBEA 2008: Prêmio Roberto Cláudio dos Santos Aflalo - Aflalo \& Gasperini Arquitetos", Projeto Design, dezembro de 2008, https://www.arcoweb.com.br/projetodesign/especiais/premio-asbea-2008-premio-roberto-claudio-dos-santos-aflalo-01-12-2008.

88. Katna Baran, "Não pretendo jamais disputar uma eleição, diz Moro", Folha de São Paulo, 5 de novembro de 2018, seç. Poder, https://www1.folha.uol.com.br/poder/2018/11/nao-pretendo-jamais-disputar-uma-eleicao-diz-moro.shtml. 
Instrumentos são propícios à inovação se eles...

- oferecerem incentivos econômicos [1],

- agirem em combinação,

- forem baseados em planejamento estratégico e formulação de metas [2],

- apoiarem a inovação como um processo e considerarem as diferentes fases de inovação/difusão [3].

Um estilo de política é propício à inovação se é...

- baseado em diálogo e consenso [4],

- calculável, confiável e tem continuidade [5],

- decisivo, pró-ativo e exigente,

- aberto e flexível [6],

- orientado para gestão [7]

Uma configuração de atores é propícia à inovação, se...

- ela favorece integração horizontal e vertical de políticas,

- os vários objetivos de regulação estão interligados [8],

- a rede entre regulador e regulado é cerrada [9],

- as partes interessadas e relevantes estão incluídas na rede [9]. ${ }^{89}$

Há várias características da modernização ecológica de Jänicke em que a lógica do LEED ${ }^{\circledR}$ e a estratégia de operação do USGBC ${ }^{\circledast}$ podem ser incluídas.

(1) As certificações de sustentabilidade ambiental oferecem incentivos econômicos para seu

89. No original: "Instruments are innovation-friendly if they provide economic incentives; act in combination; are based on strategic planning and goal formulation; support innovation as a process and take account of the different phases of innovation/diffusion. A policy style is innovation-friendly if it is based on dialog and consensus; calculable, reliable, and has continuity; decisive, proactive, and demanding; open and flexible; management-oriented. A configuration of actors is innovation-friendly, if it favours horizontal and vertical policy integration; the various objectives of regulation are networked; the network between regulator and regulated is a tight one; the relevant stakeholders are included in the network." Martin Jänicke et al., "Environmental policy and innovation: an international comparison of policy frameworks and innovation effects", in Innovation-oriented environmental regulation. Theoretical Approaches and Empirical Analysis, org. Jens Hemmelskamp, Klaus Rennings, e Fabio Leone (Heidelberg: Springer, 2000), 135, tradução nossa. Grifos nossos para características que julgamos atendidas pelo LEED ${ }^{\circ}$. 
emprego, na medida em que os edifícios certificados possuem maior valor de comercialização por metro quadrado, menor depreciação de valor em períodos de crise, menor taxa de vacância e menores custos de operação, que serão abordados no próximo capítulo.

(2) Há organização clara das metas a serem cumpridas para que a pontuação pretendida seja atendida. São estabelecidos patamares de desempenho [benchmarks] de relativa facilidade de compreensão pelos candidatos, ainda que na maioria das vezes consultorias especializadas auxiliem na montagem da documentação.

(3) O USGBC ${ }^{\circledast}$ incentiva a inovação no cumprimento do LEED ${ }^{\circledast}$. O sistema apresenta créditos diretamente vinculados a processos inovadores de obtenção dos pontos, através da categoria Innovation in Design: 5 de 110 pontos lhe são atribuídos, tanto no caso do LEED ${ }^{\circledR}$ NC v3 quanto no $\mathrm{LEED}^{\oplus} \mathrm{CS}$ v3, o que equivale a $4,5 \%$ do total de pontos disponíveis. O órgão ainda oferece um banco de dados online (LEED ${ }^{\circledR}$ Credit Library) com a relação das diversas inovações já empregadas - para a obtenção de pontos nesse quesito, são válidos apenas processos ausentes dessa lista.

(4) Ao que consta na apresentação dos diversos sistemas LEED ${ }^{\circledR}$, todas as medidas são tomadas por diálogo e consenso [consensus based; consensus-focused] - ainda que o consenso seja apenas dos representantes do conselho diretor..$^{90}$

(5) O sistema LEED ${ }^{\oplus}$, de modo mais evidente do que seus concorrentes, tem pontuação vinculada a quesitos claramente quantificáveis, de mensuração científica - ao invés de parâmetros subjetivos de cumprimento, como em alguns créditos do concorrente Aqua, cujo cumprimento é justificado por argumentos dissertativos e não patamares de desempenho.

(6) Como existem poucos grupos de pontos compulsórios, a maior parte dos pontos disponíveis é livremente escolhida pelos candidatos, o que seria um indício de abertura e flexibilidade de emprego do sistema.

(7) Incentiva-se uma relação de gestão com o projeto arquitetônico-urbanístico, em que os processos são parte fundamental de pontuação. Tal decisão levaria a procedimentos de projeto que não buscariam apenas inovações pontuais, mas também uma gestão do projeto que oriente

90. USGBC (United States Green Building Council), "LEED 2009 for new construction and major renovations with alternative compliance paths for projects outside the US; v. 3 reference guide" (USGBC, 2011), i, xi. 
as decisões desde os primeiros passos de elaboração do partido arquitetônico até a entrega do edifício construído. São parte dessa ênfase de gestão os seguintes créditos:

- Integrative Process, com levantamento das necessidades do cliente e leitura do contexto de implantação do projeto (1 ponto a partir do $\operatorname{LEED}^{\oplus}$ v4);

- SS.9 Tenant Design and Construction Guideline (1 ponto, LEED ${ }^{\circledR}$ CS), com criação de manual ilustrado que oriente o inquilino no uso das instalações do edifício;

- EA.Prereq.1 Fundamental Comissioning of Building Energy Systems (obrigatório), com auditorias que verifiquem e controlem a qualidade dos sistemas de energia do edifício;

- EA.3 Enhanced Comissioning (6 pontos), com acompanhamento de auditor desde a fase de projetos, com o objetivo de potencializar ganhos energéticos;

- ID.2 LEED Accredited Professional (1 ponto), em que um consultor creditado pelo US$\mathrm{GBC}^{\oplus}$ deve fazer parte da equipe desde o início do projeto. ${ }^{91}$

A maior facilidade de diálogo entre clientes e os diversos projetistas também foi enfatizada por entrevistados. ${ }^{92}$

(8) Ainda que a pontuação seja flexível, o cumprimento de determinados créditos do LEED $^{\circledast}$ facilita a obtenção de outros, pois em certa medida os pontos estão vinculados.

(9) O USGBC ${ }^{\oplus}$, em sua história e formação, abre a participação para as diversas partes interessadas [stakeholders], sejam reguladores ou regulados, que compartilham responsabilidades na elaboração dos sistemas $\mathrm{LEED}^{\oplus}$, conforme visto na parte I.

Ao longo deste capítulo, foram elaboradas três características da modernização ecológica presentes no LEED ${ }^{\oplus}$ a aproximação com o mercado na conciliação do par economia e ecologia; a ênfase na inovação tecnológica produtora de eficiências; e a autonomia da esfera ecológica. A partir dessas características e em adição aos nove pontos anteriores, destaque-se:

91. USGBC (United States Green Building Council), "LEED 2009 for new construction and major renovations with alternative compliance paths for projects outside the US; v. 3 reference guide”; USGBC (United States Green Building Council), "LEED 2009 for core and shell development” (USGBC, agosto de 2011); USGBC (United States Green Building Council), "LEED v4 for interior design and construction" (USGBC, 2 de julho de 2018).

92. Wanick, (Fundadora do GBC Brasil), Entrevista para o autor; a diretora associada do aflalo/gasperini arquitetos Flávia Marcondes, (Diretora associada no aflalo/gasperini arquitetos), Entrevista para o autor, Presencial, 27 de setembro de 2016; o diretor ZGF Architects Chris Flint Chatto, (Diretor no ZGF Architects), Entrevista para o autor, Telefone, 23 de março de 2018. 
(10) O LEED ${ }^{\circledR}$ incentiva o emprego de soluções tecnológicas, baseando sua pontuação nas possibilidades existentes e consolidadas de seu emprego [existing and proven technology]; ${ }^{93}$ que sejam, portanto, mensuráveis e consensualmente aceitas no meio científico.

(11) O USGBC ${ }^{\circledast}$ organiza-se em relação com o mercado e funciona sob sua lógica [market-driven], até mesmo pela formação de seu conselho diretor, como apresentado no ponto (9), e leva em conta os impactos de sua avaliação nos custos e valorização do ambiente construído [recognize the market implications of point allocation $].{ }^{94}$

(12) Em adição ao ponto (11), o USGBC ${ }^{\circledast}$ incentiva valores de competição: a lógica de dominação de mercado e vitória competitiva está presente tanto no nome de seu certificado (Liderança em Projeto Ambiental e Energético, em tradução livre) quanto em seu acrônimo (a homofonia entre LEED $^{\circledR}$ e to lead - liderar - não é fortuita).

(13) Tanto a gestão do LEED ${ }^{\circledR}$ quanto a atribuição de certificados são realizadas pelo USGBC ${ }^{\circledast}$ (com a colaboração, a partir de 2009, do GBCI), uma organização sem fins lucrativos e de associação voluntária, paralela aos interesses de Estado e convergente à cooperação com o mercado, tendo membros em todo o ciclo produtivo das edificações. ${ }^{95}$

(14) O LEED ${ }^{\circ}$ restringe sua avaliação aos limites estritos da construção sustentável, sem interferir nos programas abrigados pelos edifícios: uma autonomização da esfera ecológica, tal como indicado anteriormente. A pontuação é conferida levando em conta exclusivamente os parâmetros de desempenho do edifício, o qual pode abrigar mesmo empresas cujas atividades principais sejam controversas, ou projetos reconhecidos pela crítica especializada como daninhos ao tecido urbano. Como casos paradigmáticos, tomando exemplos somente no Brasil e sem esgotar o tópico, podem ser citados projetos para Bunge, Coca-Cola, McDonald's e PepsiCo, além dos superdimensionados estádios da Copa do Mundo da FIFA $2014^{\circledast}$ e inúmeros shoppings centers. ${ }^{96}$

93. USGBC (United States Green Building Council), "LEED 2009 for new construction and major renovations with alternative compliance paths for projects outside the US; v. 3 reference guide", i, xi.

94. USGBC (United States Green Building Council), xi-xii.

95. USGBC (United States Green Building Council), i, xi-xii.

96. Dados do LEED Project Directory, 4 jan 2019. 


\section{MALOGRO DA EQUIVALÊNCIA INTEGRAL DO PAR ECONOMIA-ECOLOGIA}

A neutralização das contradições entre economia e ecologia é fundamental para o USGBC ${ }^{\bullet}$ e as diversas organizações filiadas ao World GBC. Ela é vista por seus partidários como a condição da rápida expansão e crescimento do LEED $^{\circ}$. Sem essa neutralização, a ecologia ainda estaria restrita a grupos isolados, argumentam seus defensores. Como meio de justificação, Gottfried narra um episódio relacionado ao início da divulgação de seu trabalho em sustentabilidade, quando ainda se encontrava no escritório de sua prima. Durante uma reunião com uma representante do Worldwatch, um instituto sediado em Washington com trabalho sobre sustentabilidade, Gottfried não teria conseguido vender seus serviços, ao falhar na comunicação dos possíveis gastos de um retrofit sustentável do instituto. O Worldwatch não havia se interessado, conclui Gottfried, porque os custos são centrais em qualquer empreendimento: "era tudo questão de dinheiro". ${ }^{97}$

A história dessa estratégia poderia ser contada por meio dos seus excessos retóricos, já que, como visto em Fedrizzi e Gottfried, parte importante do trabalho seria a comunicação eficaz das atividades do USGBC ${ }^{\circledast}$. De fato, foram encontrados limites da equivalência entre economia e ecologia, que não foi aceita por diversos participantes e colaboradores. A expressão “Tudo é questão de dinheiro", por exemplo, foi radicalizada por Gottfried em uma palestra em 2000 para a Pacific Gas and Electric Company (PG\&E). No seu discurso, inspirado no personagem de Michael Douglas no filme Wall Street (1987), Gottfried testou uma radicalização de seu ecocapitalismo, exclamando: "A ganância é boa" [greed is good], e cita o personagem: "A ganância é o certo. [...] A ganância funciona. A ganância esclarece, atravessa e captura a essência do espírito evolucionário. A ganância, em todas as suas formas - a ganância pela vida, pelo dinheiro, pelo amor, conhecimento - marcou a ascensão da espécie humana." Ainda na mitologia cinematográfica, cita Jerry Maguire (1996): "Me mostre o dinheiro!" ${ }^{88}$ Ou seja, para Gottfried, a cobiça capitalista, motor da mão invisível do mercado, conduziria à virada ecológica. Entretanto, o público reagiu com "per-

\footnotetext{
97. No original: "it was all about the money." Gottfried, Explosion green, 46, tradução nossa.

98. No original: “Greed is right. [...] Greed works. Greed clarifies, cuts through, and captures the essence of the evolutionary spirit. Greed, in all its forms - greed for life, for money, for love, knowledge - has marked the upward surge of mankind"; e também "Show me the money!" Gottfried, Greed to green, 194-95, tradução nossa.
} 
plexidade”. Provavelmente devido à má recepção, Gottfried não voltou a utilizar o lema. Sugestivamente, a interpretação sobre a ganância é invertida no título de seu livro: ele não se chama "A ganância é verde" mas "Da ganância ao verde". A "ganância" é o passado condenável, e o "verde" é a nova ordem produtiva. ${ }^{99}$ Sugestivamente também, todo o episódio só aparece no primeiro livro (2004), sendo suprimido em Explosion green (2014).

É recorrente no livro de Gottfried certo desconforto com sua própria decisão de tornar o USGBC $^{\otimes}$ uma organização sem fins lucrativos. Se fosse privado, argumenta Gottfried, "poderia ter ganhado milhões". ${ }^{100}$ A tensão em torno do tema reaparece ao longo do livro, muitas vezes ligada à frustração com o baixo retorno financeiro pessoal permitido pelo USGBC ${ }^{\circledast}$.

Por essa razão, Gottfried ensaia uma tentativa de emular a experiência do USGBC ${ }^{\circledast} \mathrm{em}$ uma organização privada, a Regenerative Network, em 2010. A organização integraria fabricantes de produtos sustentáveis de toda a cadeia produtiva da construção civil, com uma diferença em relação ao USGBC $C^{\oplus}$ os membros não seriam concorrentes entre si. Desse modo, a rede faria uma integração de contatos corporativos, no qual empresas envolvidas em um determinado projeto entrariam em contato com o Regenerative Network quando precisassem de serviços fora de sua área de competência. Com a rede, haveria um grupo coeso de empresas que poderia responder, no limite, a qualquer demanda de projeto e construção, isentas de rivalidade interna, e mais bem organizadas para competir no mercado. Não há listagem completa dos envolvidos publicamente disponível, mas eram dezenove membros, entre eles Sloan (eficiência hídrica), Shaw Carpet e Interface (carpetes), Carrier, Armstrong e empresas de vulture capital como View Glass e Lucid (gestão de sistemas de energia). Dentre os clientes, estavam Whole Foods Market, Starbucks, Walmart e Clif Bar. ${ }^{101}$ Assim como no caso do USGBC ${ }^{\bullet}$, a fundação do Regenerative Network nos Estados Unidos foi rapidamente sucedida pelo RegenX, um correlato global do World GBC, no fim de 2013. ${ }^{102}$ Gottfried replicava, desse modo, o método de composição da organização, incluindo toda a cadeia produtiva da construção, assim como a máxima "velocidade é qualidade".

99. Gottfried, Greed to green.

100. Gottfried, Explosion green, 213, 222, tradução nossa.

101. Gottfried, 217; David Gottfried, (Fundador do USGBC e do World GBC), Entrevista para o autor, Email, 7 de junho de 2018.

102. Gottfried, Explosion green, 222. 
Entretanto, o Regenerative Network não prosperou e há pouca informação disponível a respeito de seu fechamento em $2017 .{ }^{103}$

Entre os fracassos da retórica com ênfase nos lucros e da versão privada do USGBC ${ }^{\circledR}$, Gottfried parece desconsiderar que grande parte do sucesso do conselho verde decorre do enorme contingente de voluntários envolvidos na criação, verificação e atualização do LEED ${ }^{\circ}$. A partir de um certo ponto, como nesses casos narrados, a vinculação entre arquitetura ambiental e lucratividade entra em contradição com os princípios que guiam a auto-organização da sociedade civil por meio de entidades como o USGBC ${ }^{\circledR}$. A equivalência integral entre economia e ecologia encontrou seu termo.

103. Explosion Green foi escrito quando a ação estava no início. Procurado, Gottfried não deu detalhes sobre a situação atual da rede. Gottfried, (Fundador do USGBC e do World GBC), Entrevista para o autor. 


\section{CAPÍTULO 5}

\section{TRIPLE A COMO VANGUARDA DO MERCADO}

\section{'SUBINDO A BARRA'}

No capítulo anterior, foi elaborado como o marketing ligado ao LEED $^{\circledR}$ coloca-o não apenas como uma ferramenta do mercado, mas sobretudo como um sistema direcionado a setores corporativos de inovação. Isso porque a inovação concederia um nicho próprio, de maior lucratividade, às empresas compromissadas com a sustentabilidade. Alguns problemas nesse modelo proposto pelo $\mathrm{USGBC}^{\circledR}$ se apresentam. Pelos dados encontrados, não se trata propriamente da transformação integral do mercado, mas da preponderância de um setor avançado mais apto à competição, que, mais do que uma orientação e um estímulo ao mercado em geral, prevalece em função de vantagens estratégicas de valorização. Mas, para o USGBC ${ }^{\circledR}$, a hipótese contrária que é defendida: a vanguarda do mercado transformaria, com seus negócios inovadores, o conjunto da construção civil.

Esse é o setor das “companhias esclarecidas", nas palavras de Rick Fedrizzi; as "melhores" do mercado, nos termos de Felipe Faria, CEO do GBC Brasil, para quem esse "movimento"

\footnotetext{
é a melhor opção de negócio para o mercado imobiliário em qualquer segmento de atuação. Então isso a gente comprovou, independente de qual é a sua atuação, e qual é o setor que você está atuando, a gente consegue criar uma linha de convencimento, mostrando números e argumentos convincentes que, se você está querendo se posicionar como um dos melhores daquele mercado, daquele segmento, tem que fazer dessa forma. ${ }^{1}$
}

1. Felipe Faria, (Diretor executivo do GBC Brasil, 2012-atual), Entrevista para o autor, Presencial, 18 de dezembro de 2017. 
As empresas verdes estariam, portanto, na vanguarda do mercado, destacando-se dos concorrentes pela sua gestão de negócios aprimorada. No setor imobiliário, o elemento distintivo seria a certificação pelo LEED ${ }^{\circledast}$. Como tal, os parâmetros utilizados pelo LEED ${ }^{\circledast}$ não podem ser sempre os mesmos, de modo que são continuamente lançadas novas versões - v1: 1998, v2: 2000, v3: 2009, v4: 2013 - e atualizações - v2.1: 2002, v2.2: 2005, v4.1: 2018. ${ }^{2}$ Cada nova versão "sobe a barra" [raise the bar] dos requisitos de certificação, aumentando a dificuldade dos créditos: como elemento distintivo dentro do mercado, o LEED ${ }^{\circledR}$ precisa, ao menos teoricamente, ${ }^{3}$ estar sempre à frente das práticas correntes. Como mencionado no capítulo anterior, mesmo o nome e acrônimo do sistema estão relacionados à ideia de vanguarda, devido à homofonia com to lead, liderar. E essa dianteira ocorre em meio à tensão entre a pressão pela revisão dos meios de produção e o que as empresas consideram praticável para si mesmas sem a inibição de seus negócios.

$\mathrm{Na}$ interpretação dos agentes dos diversos GBCs, o LEED ${ }^{\circledR}$ não é apenas uma vantagem competitiva, mas também uma mudança completa do modelo de negócios. Isto é, "subir a barra" não resultaria apenas na seleção de empresas cada vez mais comprometidas com a sustentabilidade, mas também na transformação total do mercado. Isso porque as ações dos GBCs ressoariam além dos edifícios certificados e dos membros afiliados. Assim, Gottfried estima, intuitivamente e sem apresentar dados, que para cada edifício registrado no LEED ${ }^{\circledR}$, outros cinco usariam o sistema como modelo de sustentabilidade, mas sem a verificação oficial. ${ }^{4}$ A presunção não tem fundamento estatístico e é difícil de ser justificada com dados. Apesar disso, evidências dessa estimativa podem ser encontradas no depoimento do engenheiro Marcos Casado, que comenta ser habitual o uso do LEED $^{\circledR}$ como guia de projeto, mas sem registro no GBCI. ${ }^{5}$ Também podem ser vistas em um estudo de Simcoe e Toffel, com amostra nos Estados Unidos, que conclui haver maior quantidade de edifícios certificados nos municípios vizinhos àqueles onde o LEED ${ }^{\circledast}$ é

\footnotetext{
2. Ver cap. 1, seção "LEED", produto de sustentabilidade financeira".

3. Como argumentado por Jerry Yudelson, essa lógica nem sempre é verdadeira: muitos requisitos já são práticas correntes de mercado, mas são apresentados como padrões de excelência pelo LEED ${ }^{\circledR}$. Esse ponto será novamente abordado mais à frente. Cf. Jerry Yudelson, Reinventing green building: why certification systems aren't working and what we can do about it, Prefácio de Pamela Lippe (Gabriola Land, Canada: New Society Publishers, 2016).

4. David Gottfried, Explosion green: one man's journey to green the world's largest industry, Prefácio de Paul Hawken. Introdução de Rick Fedrizzi. (Nova York: Morgan James, 2014), 174.

5. Marcos Casado, (Engenheiro do $1^{\circ}$ edifício certificado no Brasil; Diretor educacional e de comitês técnicos no GBC Brasil, 2007-2013), Entrevista para o autor, Presencial, 18 de setembro de 2017.
} 
legalmente exigido do que àqueles onde o sistema é voluntário. ${ }^{6} \mathrm{O}$ impacto da ferramenta seria, assim, maior do que o verificável nas quantidades de registros e certificações.

Outro aspecto dessa discussão é a relevância internacional dos programas de escritórios nos sistemas LEED ${ }^{\circledR}$. Na sua concepção inicial, a ferramenta concentrava-se em um programa específico: o de novos edifícios verticais de escritórios. Ao longo da atuação do USGBC ${ }^{\circledast}$, essa característica perdeu força, com o aparecimento de sistemas específicos, como para centros de distribuição, reformas, operação de edifícios existentes etc. No mercado norte-americano, o LEED $^{\circledR}$ Homes, por exemplo, é hoje responsável por quase 45\% dos certificados [fig 1.4]. Em contrapartida, o sistema tem menor relevância internacionalmente, com $13 \%$ dos certificados concentrados em poucos países [fig 2.4, 5.1 a 5.3], e no Brasil há apenas um caso. O sistema mais antigo, de maior quantidade de programas possíveis e que é modelo para os sistemas seguintes é o LEED $^{\oplus} \mathrm{NC}$, e este sistema tinha como objeto principal o mercado de edifícios de escritório, de acordo com o exposto por Jerry Yudelson, um colaborador do USGBC.$^{7}$ Por esse motivo, há poucas diferenças entre o $\mathrm{LEED}^{\circledR} \mathrm{NC}$ e o posterior LEED ${ }^{\circledR} \mathrm{CS}$, lançado em 2000 especificamente para edifícios de escritório para locação [speculative buildings]. Em geral, essas diferenças se restringem a pontos relacionados ao detalhamento dos materiais dos interiores, já que edifícios para locação são normalmente construídos sem informações sobre os futuros ocupantes, e por isso são entregues sem acabamento.

A combinação entre mercado de vanguarda e edifícios de escritório para locação converge nos chamados Triple A, empreendimentos que se destacam no mercado imobiliário pela construção de alta qualidade e adequação às "melhores práticas". A nota AAA é a máxima possível dentre aquelas atribuídas por gestores de investimento imobiliário.

Nesse contexto, o LEED ${ }^{\circledR}$ torna-se uma ferramenta importante para facilitar o diálogo entre os envolvidos no projeto. Ainda que ela possa ser útil em um projeto pequeno, a integração entre os projetistas em obras de grande escala como os edifícios para locação analisados aqui torna-se fundamental. De acordo com os entrevistados, o LEED ${ }^{\circledR}$ permite, por um lado, a

6. Timothy Simcoe e Michael W. Toffel, “Government green procurement spillovers: evidence from municipal building policies in California", Journal of Environmental Economics and Management, $\mathrm{n}^{\circ} 68$ (2014): 411-34, https://doi.org/10.1016/j. jeem.2014.09.001.

7. Yudelson, Reinventing green building, 122. 

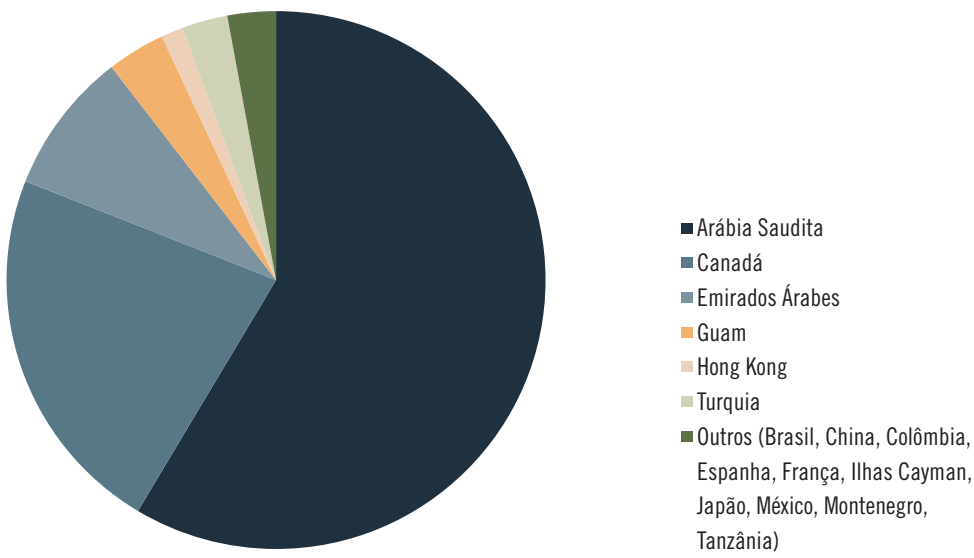

Fig 5.1. Distribuição do LEED ${ }^{\circledR}$ Homes fora dos Estados Unidos. Amostra de 1.378 empreendimentos. Fonte: LEED Project Directory, 4 jun 2019. Elaborado pelo autor.
A amostra do gráfico indica a diferença de grandezas entre o uso do LEED ${ }^{\circledR}$ Homes nos Estados Unidos e internacionalmente: no primeiro, foram certificados 28.388 empreendimentos, enquanto fora do país são apenas 1.378, incluindo tanto residências unifamiliares quanto edifícios de baixa altura e multifamiliares. Internacionalmente, há pouco interesse no LEED ${ }^{\circledR}$ Homes, possivelmente por idiossincrasias da construção civil norte-americana para residências. Destaque-se, entretanto, a relevância do Oriente Médio, com grande quantidade de certificados na Arábia Saudita e nos Emirados Árabes Unidos. A representatividade do LEED $^{\circledR}$ Homes na Arábia Saudita explica, ainda, o salto de certificações que pode ser percebido no país em 2017, apresentado na fig 3.8. Não se deve, contudo, induzir uma capilaridade nesses países em razão de sua alta quantidade: na Arábia Saudita, 615 de 807 certificados no LEED ${ }^{\circledR}$ Homes estão vinculados ao empreendimento Al Waseel Hills e outros 191 ao KAPSARC; nos Emirados Árabes, todos os 118 certificados pertencem ao Bayti Villas. 


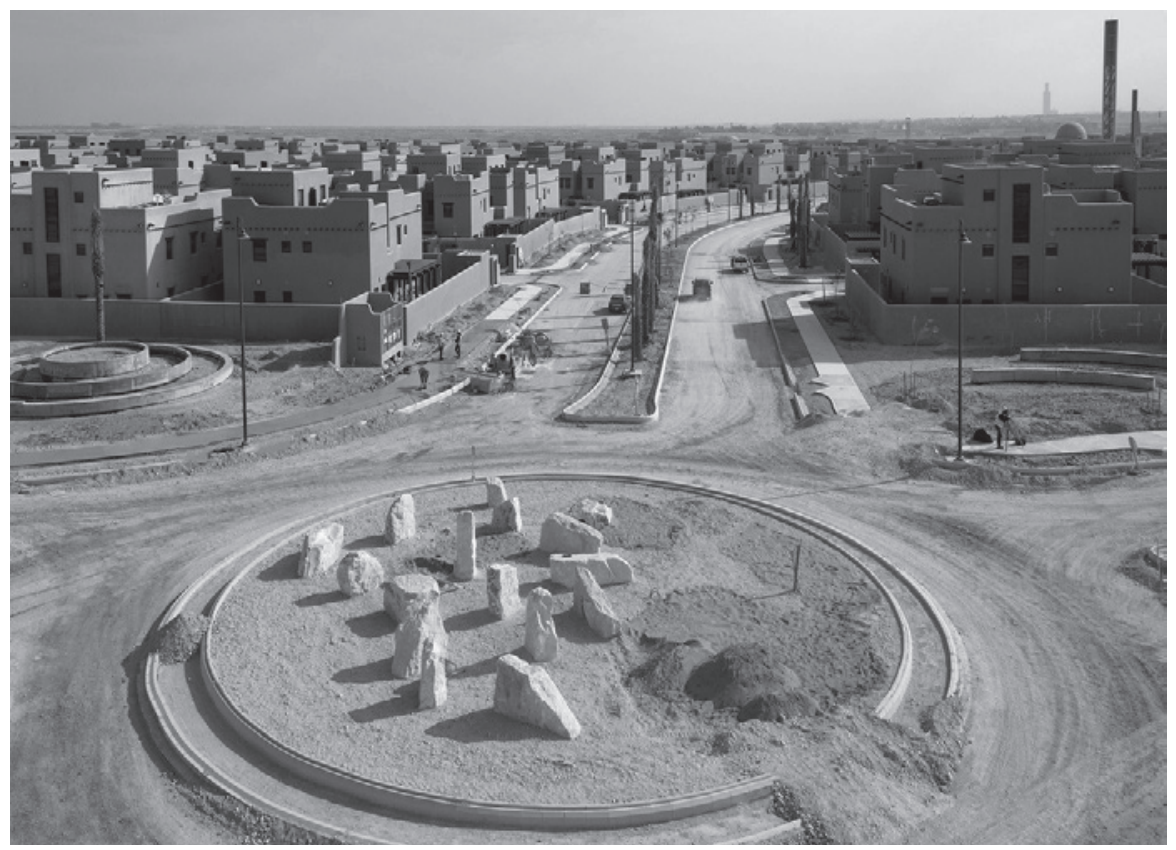

Fig 5.2. Al Waseel Hills, em Riad, capital da Arábia Saudita, onde se encontram 615 certificados LEED ${ }^{\circ}$ Homes. Fonte: Joannou \& Paraskevaides Group, 23 jan 2017.

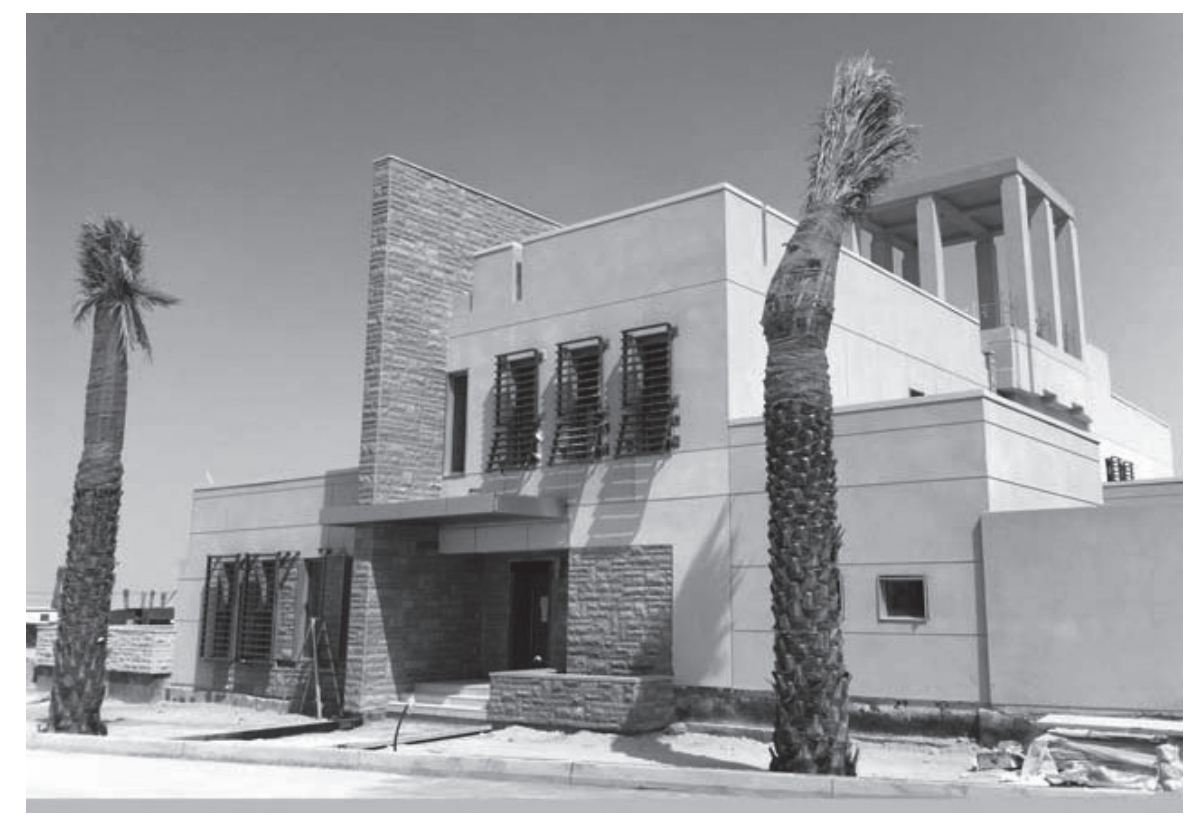

Fig 5.3. KAPSARC, primeiro empreendimento certificado LEED $^{\circledR}$ Homes fora da América do Norte, com 191 residências em sua fase final. O projeto é do escritório HOK e também se situa em Riad. Em suas imediações, encontra-se o Centro de Estudos e Pesquisas de Petróleo Rei Abdullah, do Zaha Hadid Architects. Fonte: HOK, 31 out 2012, acervo online. 
organização clara dos diversos projetos complementares em torno de metas. Por outro lado, os objetivos especificados por projetistas e clientes, por serem escolhidos dentro do checklist dos sistemas LEED ${ }^{\oplus}$, permitem avaliar o desempenho de cada projetista com parâmetros tangíveis e previamente estabelecidos. ${ }^{8}$

Paralelamente, há ainda não só a concentração em um mercado de ponta, mas também a construção de um mercado próprio. A rápida ascensão do LEED $^{\oplus}$ no Brasil foi possível não só pelo fornecimento de materiais adequados às diretrizes do sistema, mas também pela disponibilidade de um campo profissional especializado, formado pelos cursos do GBC Brasil. A partir do LEED $^{\oplus}$, estabeleceu-se um nicho de sustentabilidade para a construção civil antes inexistente no mercado internacional e particularmente escasso no território brasileiro. É o caso das tintas sem compostos orgânicos voláteis, que só ficaram disponíveis após o estabelecimento do conselho. ${ }^{9}$ É o caso também do grande grupo de consultores, muitos deles envolvidos na fundação do GBC Brasil, que passaram a oferecer serviços especializados de sustentabilidade ambiental, eficiência energética e processos de certificação.

\section{BENEFÍCIOS FINANCEIROS DO EDIFÍCIO VERDE}

As estratégias de mercado que extrapolam mecanismos financeiros e contábeis, incorporando aspectos sociais ou ambientais, são conhecidas na teoria de administração de empresas como "responsabilidade social corporativa" [Corporate Social Responsability - CSR]. Para seus defensores, esse tipo de gestão implicaria vantagens socialmente disseminadas: a acionistas, pois essas estratégias representariam investimentos de rentabilidade estável a longo prazo; a empregados, pelas condições de trabalho melhores e mais seguras; a habitantes do entorno das empresas, já que a responsabilidade corporativa se preocuparia com a inserção das estruturas na trama do bairro; ao terceiro setor, por ter suas demandas mais facilmente atendidas; e mesmo ao público em geral,

\footnotetext{
8. Com diferentes ênfases, o argumento foi mencionado por Thassanee Wanick, (Fundadora do GBC Brasil), Entrevista para o autor, 24 de janeiro de 2017; Flávia Marcondes, (Diretora associada no aflalo/gasperini arquitetos), Entrevista para o autor, Presencial, 27 de setembro de 2016; Chris Flint Chatto, (Diretor no ZGF Architects), Entrevista para o autor, Telefone, 23 de março de 2018.

9. Casado, (Engenheiro do $1^{\circ}$ edifício certificado no Brasil; Diretor educacional e de comitês técnicos no GBC Brasil, 20072013), Entrevista para o autor. 
visto como mais informado e propenso a fiscalizar as operações das empresas. ${ }^{10}$ Vinculados a essa estratégia empresarial, surgiram os "investimentos socialmente responsáveis" [Socially Responsible Investments - SRI], um conjunto de portfólios que entrevê uma vantagem financeira nesse modelo. Tanto maior é o interesse nessa estratégia quanto mais significativos forem o aperfeiçoamento no desempenho financeiro e a minimização de riscos dos investimentos. ${ }^{11}$

O LEED é usado como mais um elemento de "responsabilidade social corporativa", pois as características de projeto e operação avaliadas em seus créditos têm impacto, como mencionado acima, em usuários dos edifícios e de seu entorno, administradores de condomínio, clientes e proprietários. E esse efeito de amplo espectro teria resultado nos ganhos financeiros do ambiente construído sob diversos pontos de vista, nem todos passíveis de mensuração.

O sistema LEED ${ }^{\circledast}$ é um vetor de valorização do metro quadrado construído, constituindo-se como uma estratégia importante de competição com empreendimentos não-certificados. O acesso aos preços de comercialização de edifícios de escritório é frequentemente confidencial. Entretanto, pesquisas apontam uma valorização média de projetos certificados variando entre 2,9 e $24 \%$ na locação, e entre 13 e $25 \%$ na venda, a depender da metodologia e amostra considerada [fig 5.4 a 5.7]. ${ }^{12}$ Segundo os pesquisadores Piet Eichholtz, Nils Kok e Jon Quigley, em contexto norte-americano, a valorização de edifícios certificados é proporcionalmente maior em localizações menos centrais, embora também esteja presente em centros urbanos. Por outro lado, ela

10. Justyna Przychodzen e Wojciech Przychodzen, "Corporate sustainability and shareholder wealth", Journal of Environmental Planning and Management 56, no 4 (mai de 2013): 474-75, https://doi.org/10.1080/09640568.2012.685927.

11. David Lorenz e Thomas Lützkendorf, "Sustainability in property valuation: theory and practice", Journal of Property Investment \& Finance 26, n. 6 (2008): 483, http://dx.doi.org/10.1108/14635780810908361.

12. Para os estudos completos, ver: Piet Eichholtz, Nils Kok, e Jon M. Quigley, "Doing well by doing good? Green office buildings", The American Economic Review 100, nº 5 (dez de 2010): 2492-2509, https://doi.org/10.1257/aer.100.5.2492; Franz Fuerst e Patrick McAllister, "Green noise or green value? Measuring the effects of environmental certification on office values", Real Estate Economics 39, n 1 (2011): 45-69, https://doi.org/10.1111/j.1540-6229.2010.00286.x; Alexander Reichardt et al., "Sustainable building certification and the rent premium: a panel data approach", Journal of Real Estate Research 34, no 1 (2012): 99-126; Piet Eichholtz, Nils Kok, e Jon Quigley, “The economics of green building”, The Review of Economics and Statistics 95, $\mathrm{n}^{\circ} 1$ (março de 2013): 50-63, https://doi.org/10.1162/REST_a_00291; Eddie Chi-Man Hui, Eric Wing-Fai Chan, e Ka-Hung Yu, "The effect of LEED certification on Shanghai's pime office rental value", Journal of Facilities Management 13, nº 3 (2015): 297-310, https://doi.org/10.1108/JFM-10-2014-0033; “Desempenho LEED”, Anuário GBC 2016, julho de 2016; Wilson Saburo Honda, "Certificação da sustentabilidade de edifícios de escritórios corporativos no Brasil" (Tese (Doutorado em Engenharia da Construção Civil e Urbana). Orientador: João da Rocha Lima Jr., Escola Politécnica da Universidade de São Paulo, 2016). 


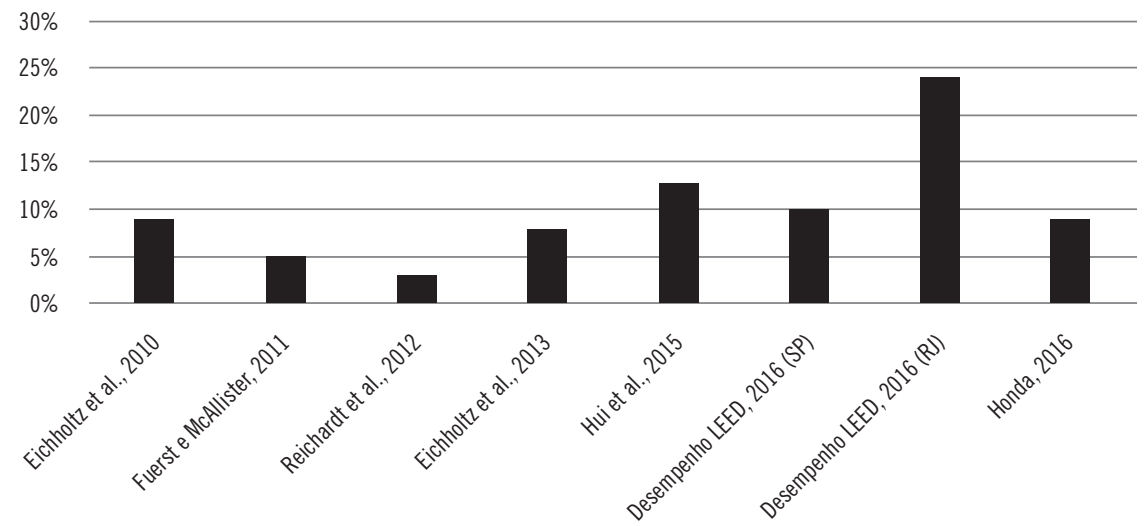

Fig 5.4. Comparação da proporção de aumento do valor médio de locação de edifícios de escritório certificados pelo LEED ${ }^{\circledR}$, segundo dados disponíveis na literatura. Elaborado pelo autor.
Amostras: Eichholtz et al., 2010: 10.000 edifícios, entre certificados com LEED ${ }^{\circledR}$ e/ou Energy Star ${ }^{\oplus}$ e de controle, nos EUA; Fuerst \& MacAllister, 2011: 197 certificados, 15.000 edifícios de controle, localização não discriminada; Reichardt et al., 2012: 7.140 edifícios, entre certificados com LEED ${ }^{\circledR}$ e/ou Energy Star ${ }^{\circledR}$ e de controle, nos EUA; Eichholtz et al., 2013: 30.000 edifícios, entre certificados com LEED ${ }^{\circledR}$ e/ou Energy Star ${ }^{\circledR}$ e de controle, nos EUA; Hui et al., 2015: 23 edifícios certificados, 56 edifícios de controle, em Xangai; Desempenho LEED, 2016: quantidade não discriminada, dividida entre mercados de São Paulo e Rio de Janeiro; Honda, 2016: 15 edifícios certificados e 58 de controle, sem método probabilístico, em São Paulo. 
- Alto padrão convencional

- Certificado LEED®

Fig 5.5. Detalhamento dos valores de metro quadrado corporativo ( $\mathrm{R} \$ / \mathrm{m}^{2} / \mathrm{mês}$ ) para locação em São Paulo. Fonte: Desempenho LEED, 2016. Redesenhado pelo autor.
Pelos dados disponíveis do mercado brasileiro, não existe correlação clara entre a centralidade da localização, a concentração de edifícios certificados e a valorização do empreendimento. Se projetos certificados na Faria Lima têm valorização significativamente maior do que suas contrapartes convencionais, no caso dos Jardins há, pelo contrário, desvalorização. Ao contrário de estudos mais detalhados no mercado internacional (como os produzidos por Eichholtz, Kok e Quigley), não são discriminadas características como a idade ou tamanho do edifício que poderiam explicar as disparidades.

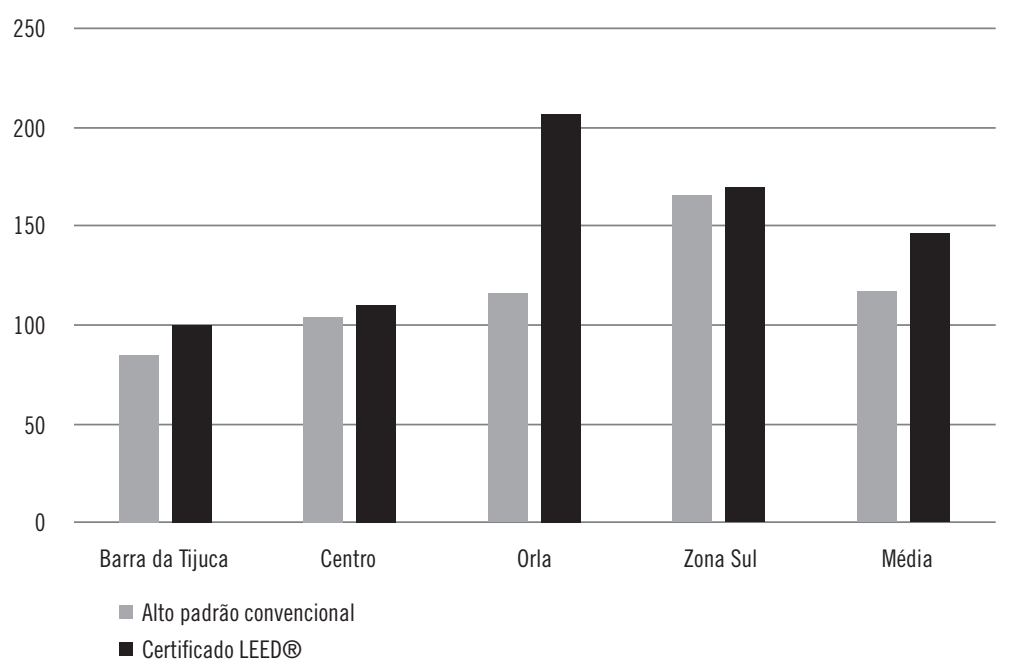

Fig 5.6. Detalhamento dos valores de metro quadrado corporativo ( $\$$ \$ $/ \mathrm{m}^{2} / \mathrm{mês}$ ) para locação no Rio de Janeiro. Fonte: Desempenho LEED, 2016. Redesenhado pelo autor. 


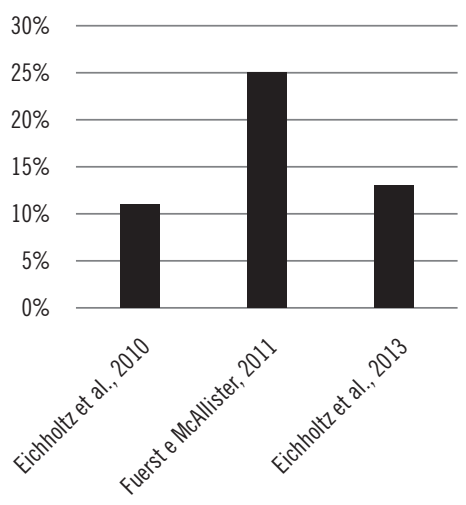

Fig 5.7. Comparação da proporção de aumento do valor médio de venda de edifícios de escritório certificados pelo LEED $^{\oplus}$, segundo dados disponíveis na literatura. Elaborado pelo autor.

Amostras: Eichholtz et al., 2010: 10.000 edifícios, entre certificados com LEED ${ }^{\circledR}$ e/ou Energy Star ${ }^{\circledR}$ e de controle, nos Estados Unidos; Fuerst \& MacAllister, 2011: 127 edifícios certificados, 15.000 edifícios de controle, localização não discriminada; Eichholtz et al., 2013: 30.000 edifícios, entre certificados com LEED ${ }^{\circledR}$ e/ou Energy Star ${ }^{\circledR}$ e de controle, nos Estados Unidos.

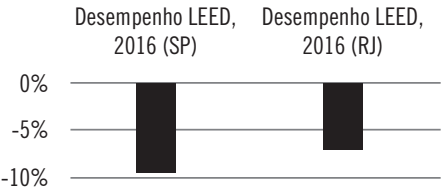

Fig 5.8. Comparação da proporção de diminuição da taxa de vacância de edifícios de escritório certificados pelo LEED ${ }^{\star}$. Redesenhado pelo autor.

Amostras: Desempenho LEED, 2016: quantidade não discriminada, dividida entre mercados de São Paulo e Rio de Janeiro.

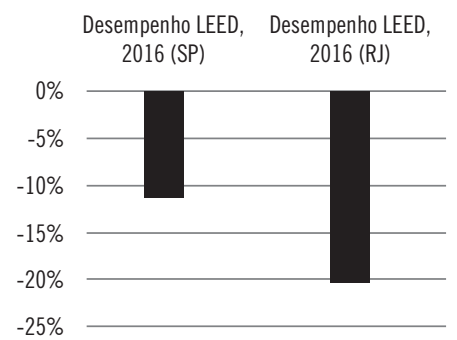

Fig 5.9. Comparação da proporção de diminuição do valor de condomínio de edifícios de escritório certificados pelo LEED $^{\circledR}$. Redesenhado pelo autor.

Amostras: Desempenho LEED, 2016: quantidade não discriminada, dividida entre mercados de São Paulo e Rio de Janeiro.

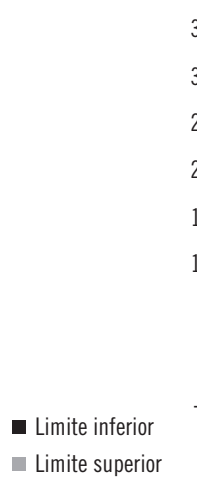

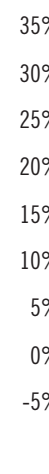

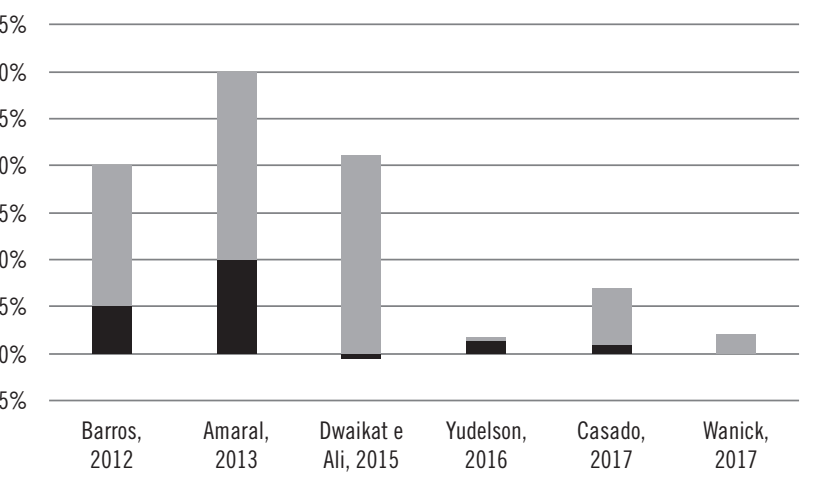

Fig 5.10. Comparação de estimativas de custos de edifícios certificados pelo LEED $^{\circ}$, segundo dados disponíveis na literatura. O gráfico indica os aumentos médios inferiores e superiores estimados nas referências. Elaborado pelo autor. 
cai quando há alta concentração de edifícios certificados, mas ainda assim eles mantêm maior valor do que os edifícios convencionais. ${ }^{13}$ Em contexto brasileiro, entretanto, pode ser vista uma tendência inversa, na qual os edifícios localizados em áreas com alta concentração de certificados podem ter aumento até superior à média. É o caso dos dados divulgados pelo GBC Brasil a respeito de edifícios corporativos em São Paulo: se por um lado a média de valorização no estado é de $10 \%$ pela certificação, por outro lado os edifícios certificados na Faria Lima obteriam um aumento de $40 \%$ no valor de locação, e aqueles localizados na marginal Pinheiros teriam um aumento de quase 20\% [fig 5.5]. ${ }^{14}$ Donde uma diferença, pelos dados disponíveis, entre o mercado nacional e internacional: enquanto no Brasil localizações com alta concentração de certificados têm valorização média superior a outros endereços, no mercado internacional a valorização diminui com a proximidade de oferta de edifícios certificados.

Além disso, seguindo o proposto por Eichholtz, Kok e Quigley, edifícios certificados ainda acumulam outras vantagens competitivas, como menor taxa de vacância [fig 5.8], menores custos de operação [fig 5.9], maior vida útil e menor volatilidade dos preços. ${ }^{15}$ Assim, a sustentabilidade ambiental torna-se um princípio de distinção mercantil com o objetivo de aumentar os ganhos e reduzir os riscos de investimento. E os certificados de sustentabilidade ambiental como os concedidos pelo LEED $^{\oplus}$, ao serem utilizados por consultores de ativos imobiliários, respondem a essa demanda de segurança de investimento. Eichholtz, Kok e Quigley notam ainda, embora admitam a impossibilidade de comprovar por completo a hipótese, que edifícios de escritórios para locação certificados possuem maior preço de comercialização do que aqueles adequados a princípios de sustentabilidade ambiental, mas não certificados. ${ }^{16} \mathrm{O}$ que revela a importância dos certificados no mercado, ao atribuírem valores intangíveis de maior segurança para o investidor negociar espaços cuja sustentabilidade foi assegurada por certificadoras. Extrapolando o argumento dos pesquisadores, a título de hipótese a ser verificada, pode ser induzido que o LEED ${ }^{\circledR}$ é uma vantagem competitiva em momentos de super-oferta e alta taxa de vacância.

13. Eichholtz, Kok, e Quigley, “Doing well by doing good? Green office buildings”, 2504.

14. "Desempenho LEED".

15. Eichholtz, Kok, e Quigley, “Doing well by doing good? Green office buildings”, 2493-94; Eichholtz, Kok, e Quigley, “The economics of green building”, 51 .

16. Eichholtz, Kok, e Quigley, “Doing well by doing good? Green office buildings”, 2507. 
Destaque-se que as características de sustentabilidade valorizadas nos empreendimentos variam de acordo com os agentes em vista, em que custos extras para alguns podem ser vantagens estratégicas para outros. Assim, por um lado o inquilino está preocupado com o espaço como um fator da produção, privilegiando menores contas de energia e água. Por outro lado, o investidor privilegia a flexibilidade dos espaços (com redução da obsolescência e aumento da vida útil do edifício) e diminuição da taxa de vacância. ${ }^{17}$

Os edifícios certificados têm ganhos de valorização, mas para isso há também maiores custos de projeto e construção. Os GBCs enfatizam que esses valores são próximos aos do mercado convencional. Segundo eles, casos como o do Banco Real-ABN AMRO, o primeiro edifício certificado no Brasil no qual o custo foi 30\% maior, seriam excepcionais. O aumento de experiência profissional com o certificado e o fornecimento de materiais adequados no mercado local corrigiriam rapidamente essas distorções. Assim, os relatos de profissionais ligados à certificação apontam custos de $1 \%$ até $20 \%$ superiores, a depender da pontuação almejada. Há pouca literatura científica disponível sobre o assunto, mas nela a faixa de custos extras fica entre -0,4\% e $21 \%$ [fig 5.10]. ${ }^{18}$

Pelos dados apresentados, é possível detectar uma faixa de ganhos para os edifícios certificados, ainda que os valores precisos não possam ser estabelecidos. Os edifícios certificados apresentam maiores retornos na venda e na locação, passam menos tempo ociosos e têm menor custo de operação, o que representa vantagens competitivas em relação a empreendimentos não certificados -

17. Lorenz e Lützkendorf, "Sustainability in property valuation: theory and practice", 499, 508.

18. Wanick aponta que o custo não chega a 2\%, cf. (Fundadora do GBC Brasil), Entrevista para o autor. Marcos Casado sugere aumento médio de 1 a 7\%, mas haveria casos de certificações Gold com acréscimo de 0,5\% e apenas certificados com 10\%, cf. (Engenheiro do $1^{\circ}$ edifício certificado no Brasil; Diretor educacional e de comitês técnicos no GBC Brasil, 2007 2013), Entrevista para o autor. Jerry Yudelson argumenta a partir de pesquisas que os custos seriam de $1,5 \%$ a $2 \%$ maiores para certificações simples e Silver, cf. Reinventing green building, 119. Ana Dorys Barros encontra o intervalo de 5 a $20 \%$ do custo total a partir de entrevistas com sete empreendedores, "A adoção de sistemas de avaliação ambiental de edifícios (LEED e Processo Aqua) no Brasil: motivações, benefícios e dificuldades” (Dissertação (Mestrado em Arquitetura, Urbanismo e Tecnologia). Orientador: Marcio Minto Fabrício, Instituto de Arquitetura e Urbanismo da Escola de Engenharia de São Carlos, Universidade de São Paulo, 2012). Já um dos arquitetos entrevistados por Marco A. Amaral indica entre 10 e $20 \%$ de aumento no custo do projeto, cf. "Green building: análise das dificuldades (ainda) enfrentadas durante o processo de certificação LEED no Brasil” (Dissertação (Mestrado Executivo em Gestão Empresarial). Orientação de Hélio Arthur Reis Irigaray, Escola Brasileira de Administração Pública e de Empresas da Fundação Getúlio Vargas, 2013). Para uma revisão sistemática dos custos de edifícios sustentáveis, ver Luay N. Dwaikat e Kherun N. Ali, "Green buildings cost premium: a review of empiral evidence”, Energy and Buildings, no 110 (2015): 396-403, http://dx.doi.org/10.1016/j.enbuild.2015.11.021. Não está explícito nas referências encontradas se esses custos incluem as taxas de certificação cobradas pelo GBCI. 
mesmo no caso daqueles que também seguem estratégias de sustentabilidade. Sua lógica de atuação é, portanto, calcada na valorização imobiliária como modo de alavancar os ganhos ambientais. Uma estratégia que, como visto no capítulo anterior, constantemente se encontra no impasse entre a aceleração da transição ecológica e os incentivos para o mercado não deixar de utilizar o sistema LEED .

\section{PRODUTIVIDADE DO COLARINHO BRANCO}

Além dos ganhos que impactam estritamente o edifício - como valorização de metro quadrado, redução da vacância e de custo do condomínio, aumento de vida útil -, a certificação via LEED ${ }^{\circ}$ também pode representar melhor qualidade de espaço para os usuários. Tal característica é normalmente referida não tanto pelo bem-estar dos ocupantes, mas como um ganho de produtividade do trabalhador. Como argumenta Julie Cidell, no LEED" "o capitalismo nunca está longe da superfície". ${ }^{19}$ Assim, as características ligadas à qualidade espacial, em geral encontradas na categoria Indoor Environmental Quality (EQ), também são convertidas à narrativa dos negócios. A poluição passa de uma questão de saúde a um "risco de saúde econômica".20

A produtividade seria aumentada com a diminuição do absenteísmo, o maior conforto térmico e luminotécnico, mais bem-estar e menos componentes tóxicos nos materiais e equipamentos instalados, como gás carbônico decorrente de má ventilação ou filtragem do ar nos ambientes e compostos orgânicos voláteis emitidos por colas e tintas. ${ }^{21}$ De fato, Ivo Wohnrath, CEO do escritório de arquitetura Athié Wohnrath, aponta o ganho na produtividade dos trabalhadores como uma nova "tendência" no mercado corporativo, em busca de maior eficiência no trabalho. ${ }^{22}$

19. No original: "capitalism is never far from the surface". Julie Cidell, "A political ecology of the built environment: LEED certification for green buildings", Local Environment 14, n. 7 (ago de 2009): 629, https://doi.org/10.1080/13549830903089275, tradução nossa.

20. No original: "economic health risk". Rick Fedrizzi, Greenthink: how profit can save the planet, Prefácio de Leonardo DiCaprio (Charleston, SC: Disruption Books, 2015), 7, grifo no original, tradução nossa.

21. Christina M. Hepner e Richard A. Boser, "Architect's perceptions of LEED Indoor Environmental Quality checklist items on employee productivity", International Journal of Construction Education and Research 2, no 3 (2006): 193-208, https:// doi.org/10.1080/15578770600907156; ver também literatura discutida em James DeLisle, Terry Grissom, e Lovisa Högberg, "Sustainable real estate: an empirical study of the behavioural response of developers and investors to the LEED rating system", Journal of Property Investment \& Finance 31, n. 1 (2013): 14, https://doi.org/10.1108/14635781311292953; e ainda Lorenz e Lützkendorf, "Sustainability in property valuation: theory and practice”, 489-90.

22. João Dória Jr. e Ivo Wohnrath, “[Programa Show Business] - Caito Maia e Ivo Wohnrath”, YouTube, out de 2013, https:// 
Isso porque os custos com empregados são, para as empresas, muito superiores ao consumo de recursos naturais na operação dos edifícios, relativo aos custos condominiais. Ganhos de produtividade implicam, portanto, um ganho financeiro maior do que aquele obtido pela eficiência energética de um edifício, sobretudo por se tratarem de funcionários de "colarinho branco" bem remunerados. ${ }^{23}$ Não por acaso, dentre todos os sistemas LEED ${ }^{\circledR}$, só pode ser localizado um crédito, de um ponto, com referência direta a trabalhadores que não sejam diretamente os ocupantes dos edifícios. ${ }^{24}$ Da mesma forma, no sistema especializando em bem-estar WELL ${ }^{\circ}$, apenas dois créditos dentre os 105 disponíveis citam diretamente procedimentos para a saúde dos trabalhadores de manutenção. ${ }^{25} \mathrm{O}$ operário da construção é, portanto, uma figura ausente dos "stakeholders" em consenso do $\mathrm{USGBC}^{\oplus}$ e dos benefícios disseminados pela responsabilidade social corporativa.

\section{GESTÃO DE RISCO E IMAGEM CORPORATIVA}

Em Sociedade de risco, o sociólogo alemão Ulrich Beck encontrava uma particularidade do período pós-1960: a consciência do risco contínuo e iminente de catástrofes ambientais. Essas catástrofes não estariam mais limitadas geograficamente, mas sim disseminadas extraterritorialmente: Chernobyl, Bhopal, Cubatão eram exemplos em que a percepção da população sobre o risco e

www.youtube.com/watch?v=jA0PfZ2mAMA; Sergio Waib e Ivo Wohnrath, "Giro Business com Ivo Wohnrath - História e tendências da arquitetura corporativa - Parte 03/04", YouTube, abr de 2017, https://www.youtube.com/watch?v=4EtxltIYx70. Segundo o próprio Ivo Wohnrath, a empresa seria responsável pelo "market share" de cerca de metade dos projetos de escritórios Triple A em São Paulo e no Rio de Janeiro, e também possuiria a maior quantidade de certificações LEED ${ }^{\circ}$ na América Latina. Cf. Luiz Marins e Ivo Wohnrath, “Programa Show Business - Ivo Wohnrath”, YouTube, set de 2016, https:// www.youtube.com/watch?v=hJICnnTQs48\&list=PLb_X8C8ocZw8cQVFpeiHJNpnmSJzD47Y4\&index=16.

23. O ponto é defendido em Gottfried, Explosion green, 132; Jerry Yudelson, The green building revolution, Prefácio de Rick Fedrizzi (Washington, DC; Covelo, CA; Londres: Island Press, 2008), 33-34 e cap. 13; Amory B. Lovins, L. Hunter Lovins, e Paul Hawken, Natural capitalism: the next industrial revolution (Washington DC: US Green Building Council, 2000), 90. Em um artigo sobre o LEED ${ }^{\circledR} \mathrm{EQ}$, Hepner e Boser estudam como os arquitetos interpretam os impactos do sistema no projeto, e quais são os créditos mais eficientes. A metodologia é de entrevistas e questionários, o que não permite induzir se os ganhos percebidos de produtividade correspondem aos efetivos. Mas o artigo interessa aqui por revelar qual é a posição disciplinar sobre o tema. Cf. Hepner e Boser, "Architect's perceptions of LEED Indoor Environmental Quality checklist items on employee productivity". 24. É o crédito EQ.3 Construction Indoor Air Quality Management Plan. USGBC (United States Green Building Council), "LEED v4 for building design and construction" (USGBC, 5 de abril de 2016); USGBC (United States Green Building Council), "LEED v4 for interior design and construction" (USGBC, 2 de julho de 2018).

25. São os créditos Air.25 Toxic Material Reduction e Air.26 Enhanced Material Safety. International Well Building Institute, “The WELL building standard v1 with Q4 2017 addenda” (Delos Living, 2017). 
as possibilidades de fuga foram modificadas. De fato, os perigos tornavam-se invisíveis, pois a radiação e a poluição não podiam mais ser percebidas, e seu raio de efeito era, no limite, global. Beck identifica que "Na modernidade tardia, a produção social de riqueza é acompanhada sistematicamente pela produção social de riscos" ${ }^{26}$, ou seja, o risco passou a ser uma constante na reprodução do capitalismo tardio. ${ }^{27}$ Por esse motivo, o termo "risco" toma protagonismo cada vez maior da organização produtiva, e a sua gestão é uma atividade central dos mecanismos de investimento contemporâneo. Uma empresa inepta a lidar com o risco pode deparar-se com sua rápida desvalorização em contextos adversos. Ocorre, assim, um deslizamento conceitual, em que o risco ambiental passa a também significar risco financeiro, isto é, a aparência de sustentabilidade no tempo dos rendimentos de um investimento.

Ferramentas como o LEED $^{\circledR}$ são usadas no ambiente corporativo justamente como um modo de gestão de riscos. $\mathrm{O}_{\text {LEED }}{ }^{\circledR}$ é utilizado em portfólios de fundos imobiliários como um aspecto de expectativa de retorno em oposição aos riscos conjecturados. Os Fundos de Investimento Imobiliário (FIIs) e sua atratividade financeira são resultado de diversas leis e regulamentações realizadas no Brasil entre meados das décadas de 1990 e de $2000 .{ }^{28}$ Os FIIs podem ser criados tanto no momento de concepção do edifício quanto já em estágio de operação, e sua composição deve ser de ao menos 75\% dos recursos em bens imobiliários, com a possibilidade de o restante ser aplicado em fundos de renda fixa. As novas regulações aumentaram a liquidez no

26. Ulrich Beck, Sociedade de risco: rumo a uma outra modernidade, Trad. de Sebastião Nascimento. 2a [Ed. orig. 1986] (São Paulo: Editora 34, 2011), 23.

27. Andrew Blowers também nota como a insegurança ambiental ganha gradual protagonismo nos debates sociais, sobretudo após o fim da Guerra Fria e a hegemonia capitalista. Cf. "Environmental policy: ecological modernisation or the risk society?", Urban Studies 34, n 5-6 (1997): 845-46, https://doi.org/10.1080/0042098975853.

28. Essas medidas estão relacionadas ao aumento da liquidez nos investimentos imobiliários e na regulamentação dos fundos imobiliários. Por um lado, há três resoluções da Comissão de Valores Imobiliários. A primeira, Resolução 2.517, de junho de 1998, insere o setor imobiliário na bolsa de valores ao considerar os Certificados de Recebíveis Imobiliários (CRIs) como títulos mobiliários. A segunda, Resolução 2.518, também de junho de 1998, permite que entidades de previdência privada possam investir em CRIs para potencializar seus ganhos. A terceira, Instrução 472, de outubro de 2008, cria os Fundos de Investimento Imobiliário (FIIs), os quais são formados pelos CRIs. Por outro lado, há ainda três leis. A primeira, Lei 8.668/1993, cria os FIIs dentro da estrutura jurídica brasileira. A segunda, Lei 11.033/2004, isenta do imposto de renda CRIs e papéis ligados ao crédito imobiliário. A terceira, Lei 12.020/2009, isenta do imposto de renda também os FIIs. Ver Daniel de Mello Sanfelici, "A metrópole sob o ritmo das finanças: implicações socioespaciais da expansão imobiliária no Brasil" (Tese (Doutorado em Geografia Humana). Orientadora: Amélia Luísa Damiani, Departamento de Geografia - Faculdade de Filosofia, Letras e Ciências Humanas da Universidade de São Paulo, 2013), 90. 
financiamento imobiliário e permitiram angariar capitais antes dispersos no mercado, aumentando o volume de recursos disponível para a construção civil e incorporação imobiliária. Assim, os edifícios de escritórios para locação passaram a ser propriedade dos fundos de investimento, ambos geridos por um administrador que trabalha em prol dos interesses dos investidores.

É característica dos FIIs uma rentabilidade estável e homogênea, donde medidas com o objetivo de diminuição dos riscos de investimento. É por esse motivo que os fundos de pensão investem neles: sua meta não é a alta lucratividade, mas a manutenção de patrimônio com correções inflacionárias e adequação às taxas de juros em vigor. ${ }^{29}$

Além de terem impacto indireto na valorização dos FIIs, decorrente do aumento do preço do metro quadrado, certificados como o LEED $^{\circledR}$ são utilizados como garantia de segurança do investimento e minimização de riscos. Isso pode ser depreendido por meio da análise de prospectos de FIIs publicados por corretoras de valores. É o caso de um fundo ligado ao Tower Bridge Corporate, em que a certificação com LEED garantiria "conforto", "uso racional de recursos" e "longevidade do empreendimento, com vistas à capacidade de adaptação às demandas futuras". Também é o caso no Eldorado Business Tower, na sua inauguração o edifício melhor avaliado na América Latina pelo LEED", "considerado um dos edifícios mais eficientes em São Paulo com custo de ocupação, aproximadamente, 38\% inferior à média dos demais imóveis do Fundo" [fig 3.15]..$^{30}$ Assim também na oferta de ações BR Properties, investidora imobiliária que é membro-fundadora do GBC Brasil, segundo a qual há "no país demanda crescente por imóveis que adotem elevados padrões de sustentabilidade, o que, somado à oferta limitada deste tipo de empreendimento, tende a garantir alto potencial de valorização destes imóveis", o que seria um elemento distintivo da carteira de imóveis com que a empresa trabalha. ${ }^{31}$ Por fim, a WTorre, tam-

\footnotetext{
29. Paola Torneri Porto, "Método para gestão de portfólios de investimentos em edifícios de escritórios para locação no Brasil” (Tese (Doutorado em Engenharia de Construção Civil e Urbana). Orientador: João da Rocha Lima Jr., Escola Politécnica da Universidade de São Paulo, 2010), 58-59. Para o impacto dos fundos de pensão na produção imobiliária, ver Mariana Fix, São Paulo cidade global: fundamentos financeiros de uma miragem (São Paulo: Boitempo, 2007). Esse assunto será novamente abordado na parte IV.

30. "Prospecto definitivo de oferta pública de distribuição de cotas do Fundo de Investimento Imobiliário - FII BTG Pactual Corporate Office Fund", 8 de janeiro de 2013, http://www.merrilllynch-brasil.com.br/pdf/FII\%20BTG\%20PACTUAL/ prospecto\%20definitivo\%2020130107.pdf.

31. "Prospecto definitivo de oferta pública de distribuição primária e secundária de ações ordinárias de emissão da BR Properties", 4 de março de 2010, http://www.safranet.com.br/ADS/Download/15_2-2-2012_8-41-03_PM.pdf.
} 
bém membro-fundadora do GBC Brasil, trata o LEED ${ }^{\circledR}$ como um nicho de oferta, ou seja, uma distinção no mercado decorrente da "inovação" técnica de seus empreendimentos. ${ }^{32}$

Nesse sentido, a valorização alavancada pelo LEED $^{\circledR}$ é sólida em períodos de crise. Isso se mostra não só nos prospectos dos fundos apresentados acima, mas também na medição da demanda por edifícios certificados. Essa não diminuiu no mercado norte-americano durante a crise de $2008{ }^{33}$ indicando uma característica de estabilidade desse retorno financeiro lastreado no certificado.

Essas características de gestão de risco, comprovadas no marketing dos fundos e na medição de demanda, também podem representar impactos de maior alcance na valorização da imagem corporativa. Os pesquisadores Przychodzen e Przychodzen, ${ }^{34}$ por exemplo, selecionaram 85 empresas com princípios de sustentabilidade corporativa e integrantes do S\&P 500, ${ }^{35}$ e as compararam com as empresas convencionais do mesmo índice, dentro do período de dezembro de 2005 a dezembro de 2010. Segundo o estudo, as empresas com princípios de sustentabilidade ambiental apresentaram, por um lado, um retorno de investimento em média 9,4\% maior. Por outro, a volatilidade do preço de suas cotas foi 8,2\% menor, representando maior resistência desses papéis a depreciações. Desse modo, a sustentabilidade como valor da imagem corporativa pode ter impactos muito concretos de aumento de retorno e estabilidade do investimento. Além disso, empresas sob gestão sustentável são distinguidas em mercados próprios, como o Dow Jones Sustainability Index e o Índice de Sustentabilidade Empresarial (ISE) ligado à BM\&F-Bovespa, que concentram as oportunidades de investimento nessa estratégia corporativa. No caso norte-americano, há mesmo fundos imobiliários que restringem a sua carteira a empreendimentos sustentáveis. ${ }^{36}$

Face a essas vantagens, a certificação via LEED $^{\circledR}$ testemunha, por meio de um órgão independente, a adequação corporativa a ações sustentáveis. O LEED ${ }^{\circledast}$ é um roteiro pelo qual as empresas podem demonstrar que responderam às demandas de gestão de seus conselhos diretores. A certificação excede, assim, os possíveis benefícios ambientais, para se tornar uma denominação

32. “WTorre S.A. Demonstrações financeiras em 31 de dezembro de 2014", dez de 2014, http://www.wtorre.com.br/_docs/ WTorreSA/Demonstracoes_Financeiras_4T14.pdf.

33. Eichholtz, Kok, e Quigley, “The economics of green building”, 54.

34. Przychodzen e Przychodzen, “Corporate sustainability and shareholder wealth”, 474-93.

35. Przychodzen e Przychodzen, 483. Os autores indicam que ao menos parte dessas empresas comprova sua sustentabilidade corporativa por meio do LEED ${ }^{\circledR}$.

36. Lorenz e Lützkendorf, "Sustainability in property valuation: theory and practice”. Alguns casos são elencados na p. 488. 


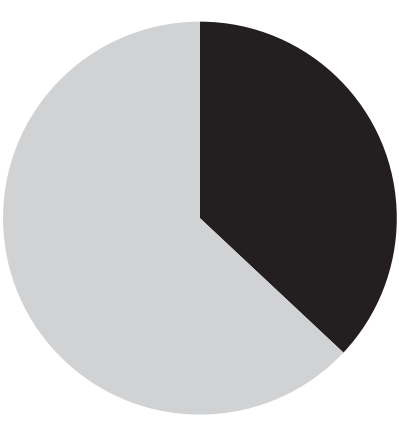

São Paulo

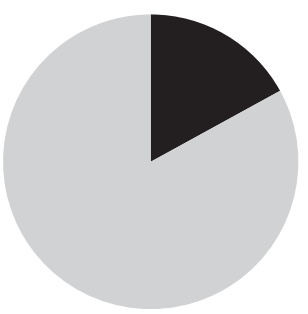

Alphaville

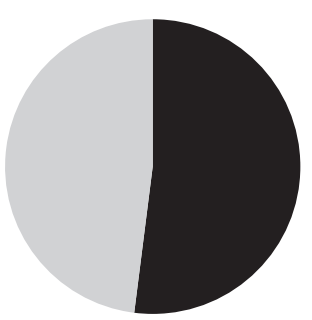

Berrini

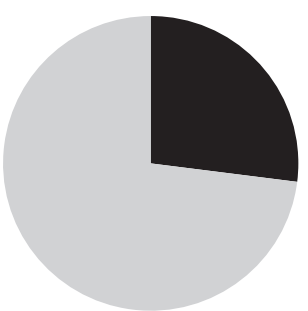

Jardins

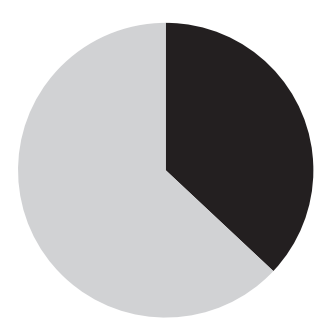

Vila Olímpia

- Certificado LEED $尺$

- Alto padrão convencional

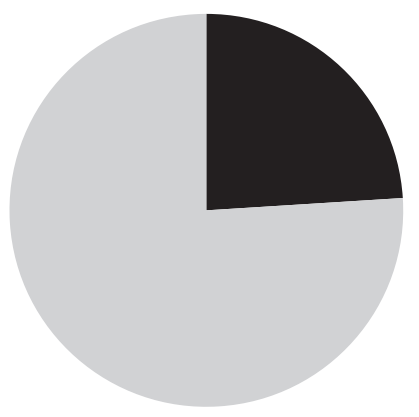

Rio de Janeiro

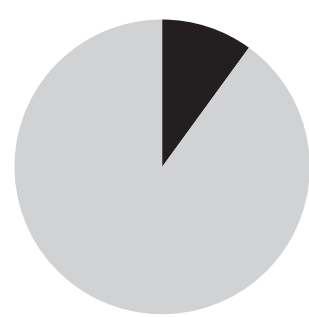

Barra

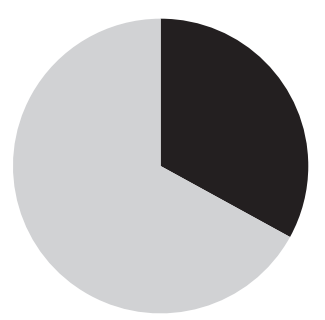

Centro

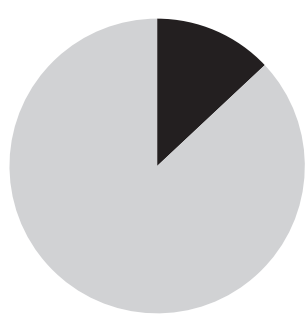

Orla

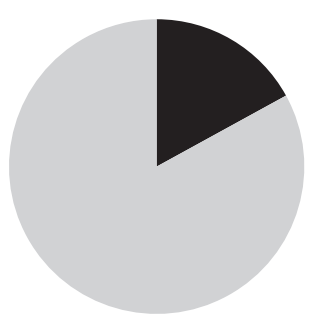

Zona Sul

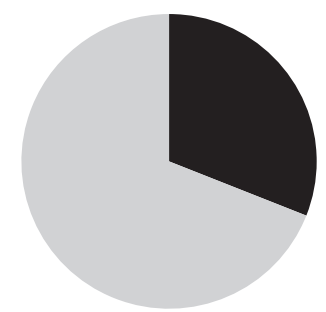

Marginal

Fig 5.11. Participação de edifícios certificados LEED ${ }^{\circledR}$ no mercado corporativo de alto padrão, em São Paulo e Rio de Janeiro. Fonte: Desempenho LEED, 2016. Editado e redesenhado pelo autor. 
distintiva fundamental para a valorização de ativos imobiliários e a não volatilidade de seus preços, além de servir como evidência em relatórios corporativos como modo de garantir a transação de papeis de suas empresas em índices especializados nas bolsas de valores.

\section{LEED®, ELEMENTO DISTINTIVO EM MERCADO ESPECIALIZADO}

O sistema LEED $^{\oplus}$, atrelado a valores de eficiência econômico-energética, é uma vantagem em ambiente de negócios competitivo e globalizado, e sobretudo como elemento de distinção no mercado de alto padrão. Por esse motivo, o certificado tornou-se moeda corrente, embora ainda não predominante, entre os empreendimentos Triple A. Os dados disponíveis permitem observar o fenômeno no mercado brasileiro: no estoque corporativo premium em São Paulo, 37\% dos edifícios são certificados; no Rio de Janeiro, são 24\%. Determinadas áreas, como Faria Lima e Berrini, têm pouco mais de metade do estoque corporativo de alto padrão certificado pelo LEED ${ }^{\circledR}$ [fig. 5.11]. ${ }^{37} \mathrm{O}$ que corrobora uma fala de José Goldemberg: "você vê que os prédios que obedecem às regras do Green Building [Council] são todos prédios de primeira linha." 38

A distinção é elemento central da certificação. Nesse sentido, relatos indicam que o mercado imobiliário prefere o nível Gold como mais vantajoso para a comercialização. ${ }^{39}$ Isso se dá por diversas razões, como argumentado por Pavel Sandoval e Aseem Prakash por meio de entrevistas com incorporadores norte-americanos. O nível Platinum seria significativamente mais difícil de alcançar do que o Gold em razão da especificação dos materiais e de ajustes a contextos locais, levando a custos superiores. Essas especificações e ajustes levariam, por seu turno, ao aumento de contradições de projeto, cada vez mais difíceis de ser conciliadas, como nas escolhas entre luz natural e redução da carga térmica. Por fim, a própria nomenclatura "Gold" seria buscada pelos incorporadores pelo seu valor de marca, o que valorizaria o empreendimento. Segundo o obtido pelos pesquisadores, o público entende que o nível mais elevado seria o Gold, pois "Ouro é tipi-

37. Convém notar que a pesquisa foi realizada pelo GBC Brasil e não por pesquisadores independentes, o que pode representar conflito de interesse. "Desempenho LEED", 56.

38. José Goldemberg, (Fundador honorário do GBC Brasil), Entrevista para o autor, Presencial, 12 de setembro de 2016.

39. Cf. uma diretora associada da firma norte-americana Skidmore, Owings \& Merrill: Arathi Gowda, (Diretora associada no SOM), Entrevista para o autor, Teleconferência, 24 de agosto de 2018. 


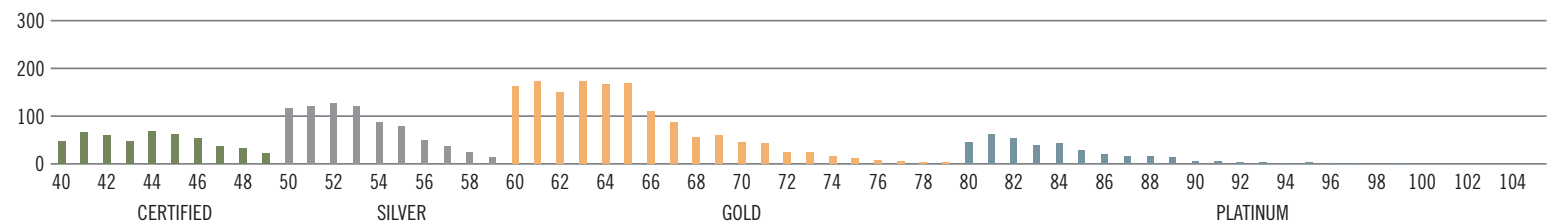

Fig 5.12. Distribuição de edifícios certificados com LEED ${ }^{\circledR}$

CS v3, no mundo, de acordo com sua pontuação. Amostra

de 3.088 projetos. Fonte: LEED Project Directory, 4 jan

2019. Elaborado pelo autor.

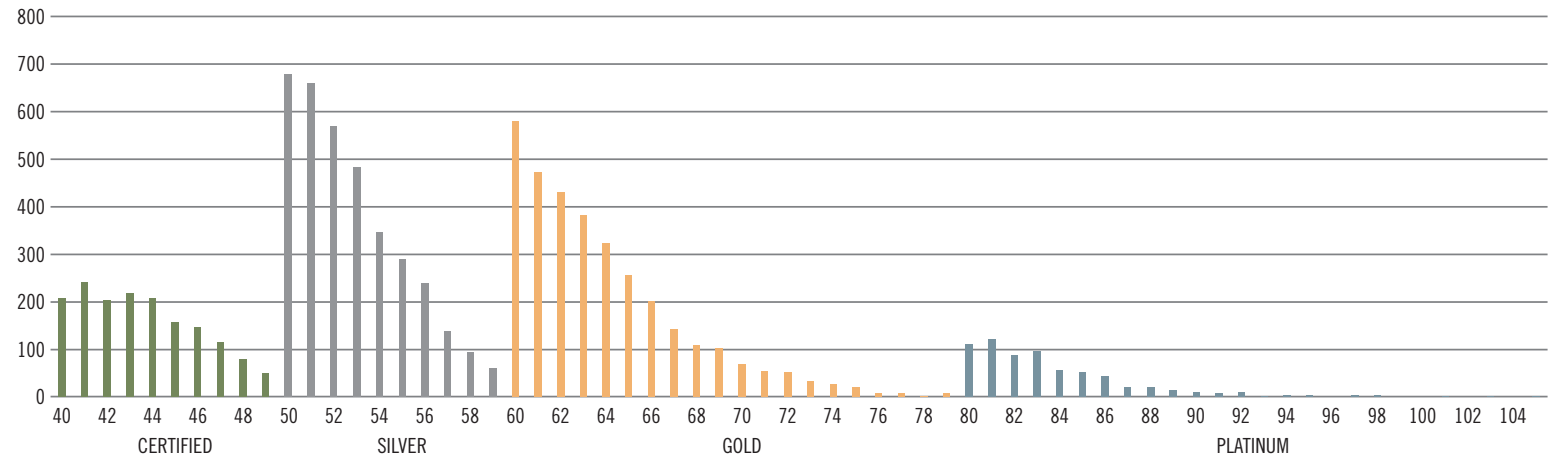

Fig 5.13. Distribuição de edifícios certificados com LEED ${ }^{\circ}$

NC v3, no mundo, de acordo com sua pontuação. Amostra

de 9.139 projetos. Fonte: LEED Project Directory, 4 jan

2019. Elaborado pelo autor.

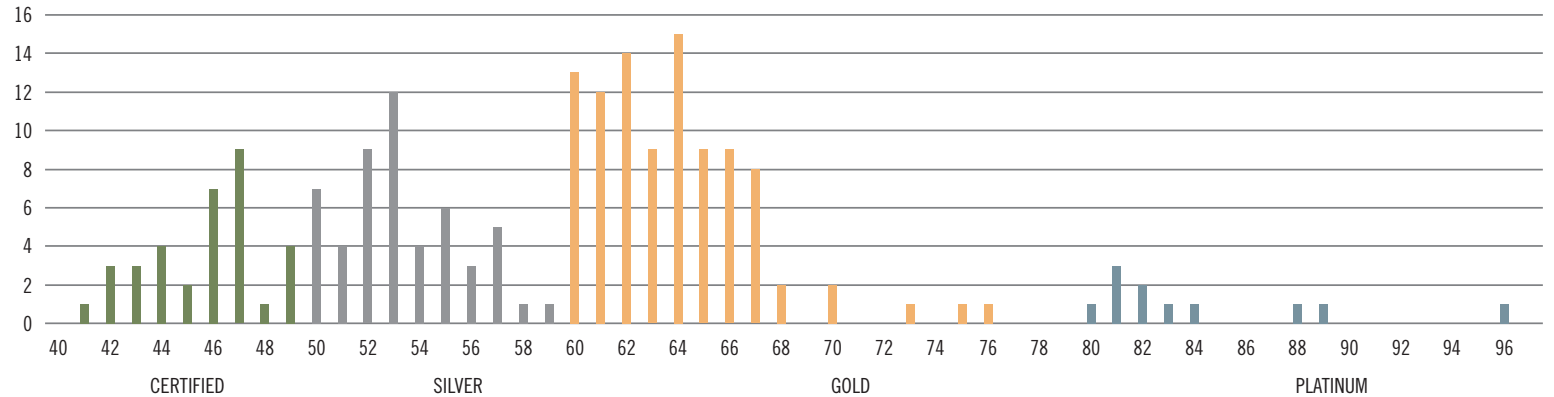

Fig 5.14. Distribuição de edifícios certificados com LEED ${ }^{\circledR}$

CS v3, no Brasil, de acordo com sua pontuação. Amostra

de 193 projetos. Fonte: LEED Project Directory, 4 jan 2019.

Elaborado pelo autor. 


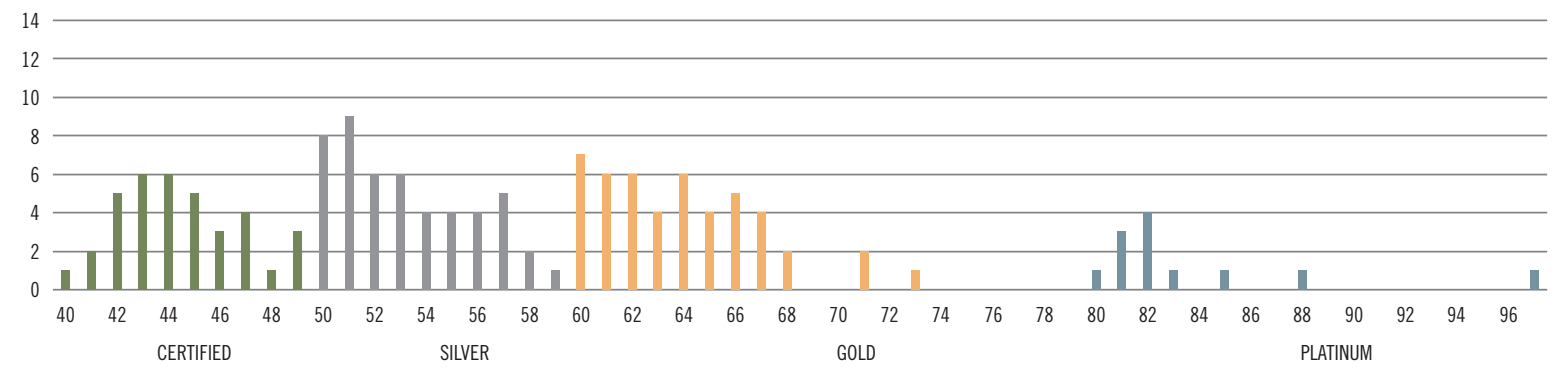

Fig 5.15. Distribuição de edifícios certificados com LEED NC v3, no Brasil, de acordo com sua pontuação. Amostra de 144 projetos. Fonte: LEED Project Directory, 4 jan 2019. Elaborado pelo autor.
Embora a amostra brasileira seja menor, as suas tendências de certificação correspondem, em linhas gerais, às globais. Os gráficos foram limitados à versão 3 , que possui a maior quantidade de empreendimentos certificados. No sistema LEED $^{\circledR} \mathrm{NC}$ v3, o nível com maior quantidade de edifícios é o Silver, ligeiramente superior ao Gold; no CS v3, mais comum para a comercialização imobiliária, o nível mais frequente é o Gold. Além de serem mais frequentemente vendidos ou locados, e não diretamente projetados para os contratantes, o nível CS também é mais simples de ser cumprido por não requerer a especificação dos interiores. Os edifícios tendem a se localizar junto ao piso do nível, se distanciando gradualmente conforme se aproximam do seu teto. Por exemplo, no LEED ${ }^{\circledR}$ CS v3 em escala global [fig 5.12] há 162 empreendimentos com 60 pontos e apenas 3 com 79 pontos, que são os limites inferior e superior do nível Gold. Os dados não permitem concluir os motivos desse comportamento. Ele pode se dar, por um lado, pelos empreendedores visarem o nível mais alto possível com os menores custos - afinal, no intervalo de 20 pontos do nível Gold, todos têm a mesma distinção, mas pontuações maiores em geral significam custos maiores. Por outro lado, as quedas e os picos podem estar relacionados a distorções na avaliação dos projetos pelo GBCI. Além disso, as certificações Platinum tendem a se distribuir mais entre os limites de pontuação, com alguns empreendimentos buscando avaliação muito alta. Esses edifícios almejam a distinção de alcançarem a maior pontuação possível em suas categorias. 


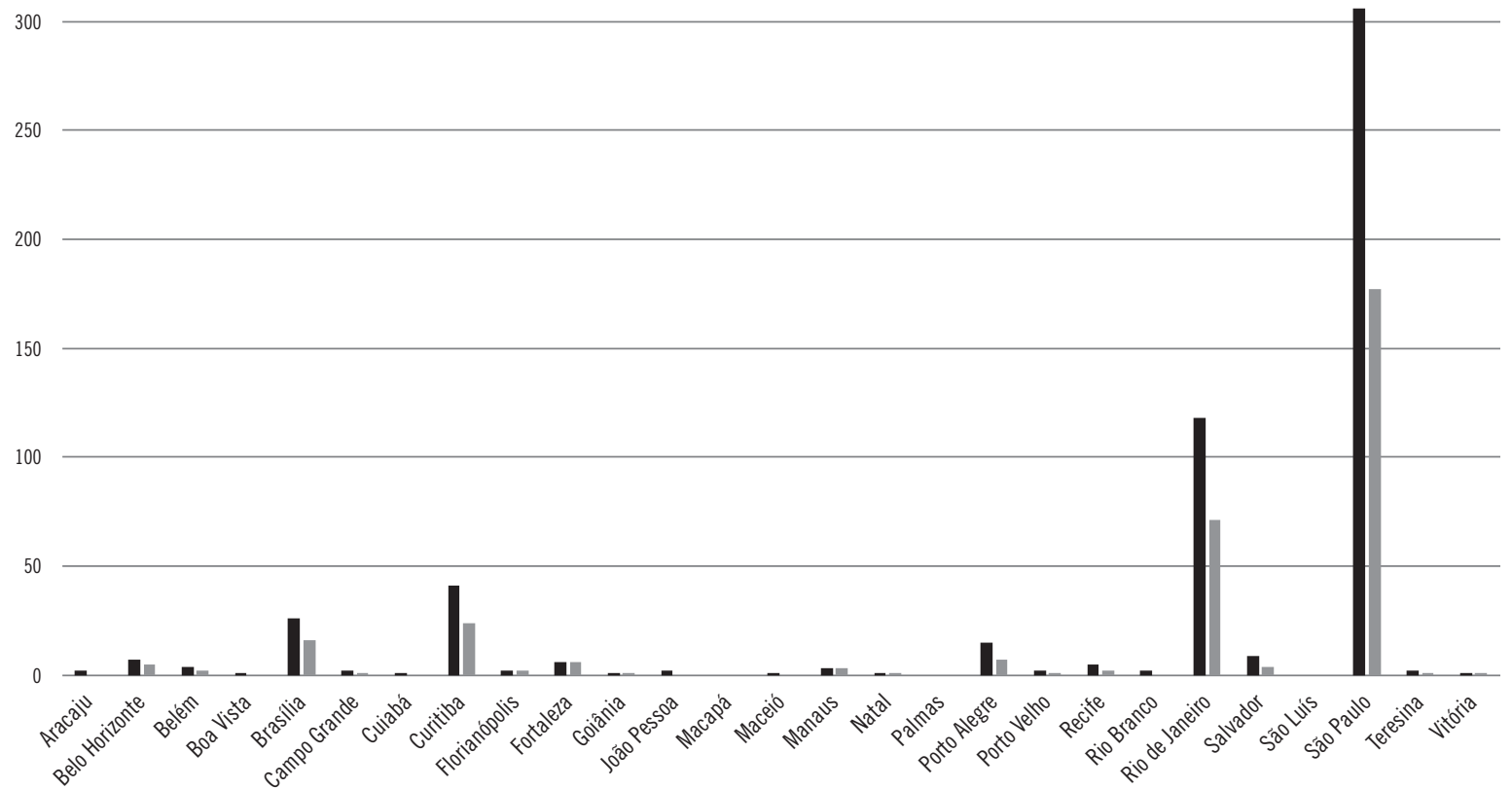

Fig 5.16. Gráfico com quantidade de empreendimentos

- Registros

por capitais brasileiras. Fonte: LEED Project Directory, 4

- Certificados jan 2019.

Pelo gráfico, nota-se a forte concentração de empreendimentos registrados e certificados nas cidades de São Paulo e Rio de Janeiro. Por outro lado, Macapá, Palmas e São Luís não possuem nem mesmo registros. Há grande concentração também nas capitais: cerca de $40 \%$ dos registros brasileiros e $60 \%$ dos certificados se localizam nelas. 

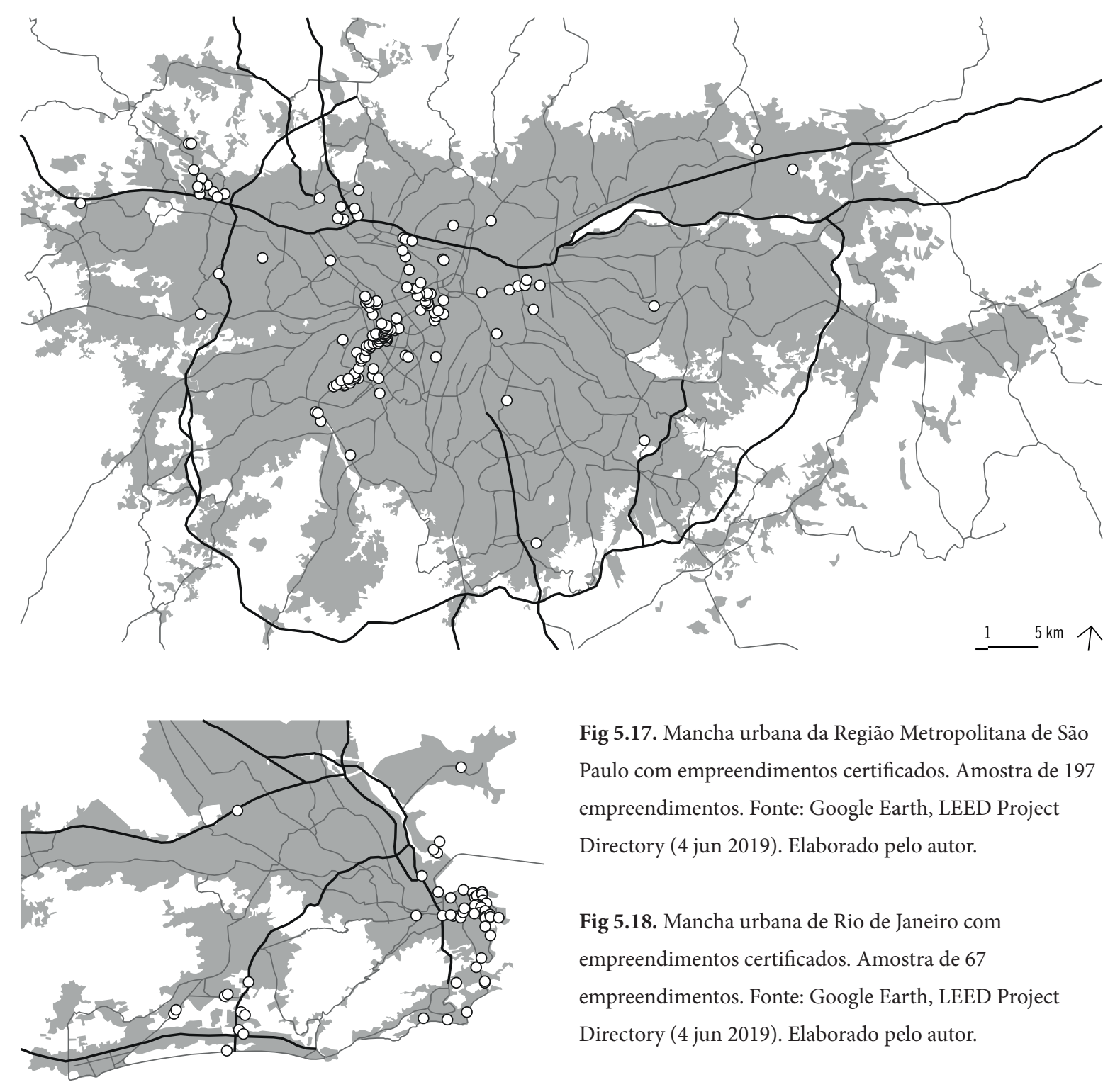

Fig 5.17. Mancha urbana da Região Metropolitana de São Paulo com empreendimentos certificados. Amostra de 197 empreendimentos. Fonte: Google Earth, LEED Project Directory (4 jun 2019). Elaborado pelo autor.

Fig 5.18. Mancha urbana de Rio de Janeiro com empreendimentos certificados. Amostra de 67 empreendimentos. Fonte: Google Earth, LEED Project Directory (4 jun 2019). Elaborado pelo autor.

Fig 5.19. Mancha urbana da Região Metropolitana de

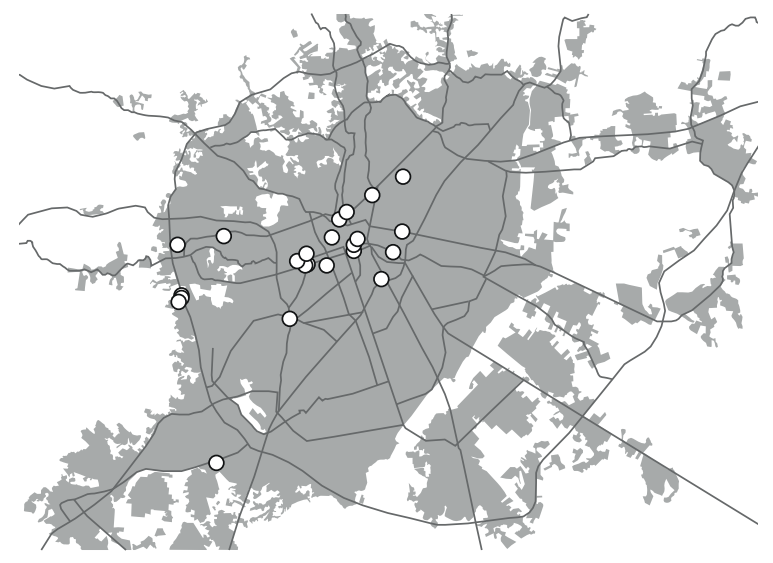

Curitiba com empreendimentos certificados. Amostra de 24 empreendimentos. Fonte: Google Earth, LEED Project Directory (4 jun 2019). Elaborado pelo autor.

As três cidades aqui representadas são aquelas que apresentam as maiores quantidades de empreendimentos certificados no Brasil. Por meio dos mapas, pode ser percebida a sua alta concentração. Em São Paulo, a primeira cidade com maior número de empreendimentos LEED $^{\circledR}$, eles se localizam ao longo da marginal Pinheiros e das avenidas Faria Lima e Paulista; no Rio de Janeiro, a segunda cidade com maior número de certificados, eles se encontram no Centro e na Barra da Tijuca; por fim, em Curitiba, a terceira cidade no ranking, eles se encontram sobretudo no Centro e em Batel. 


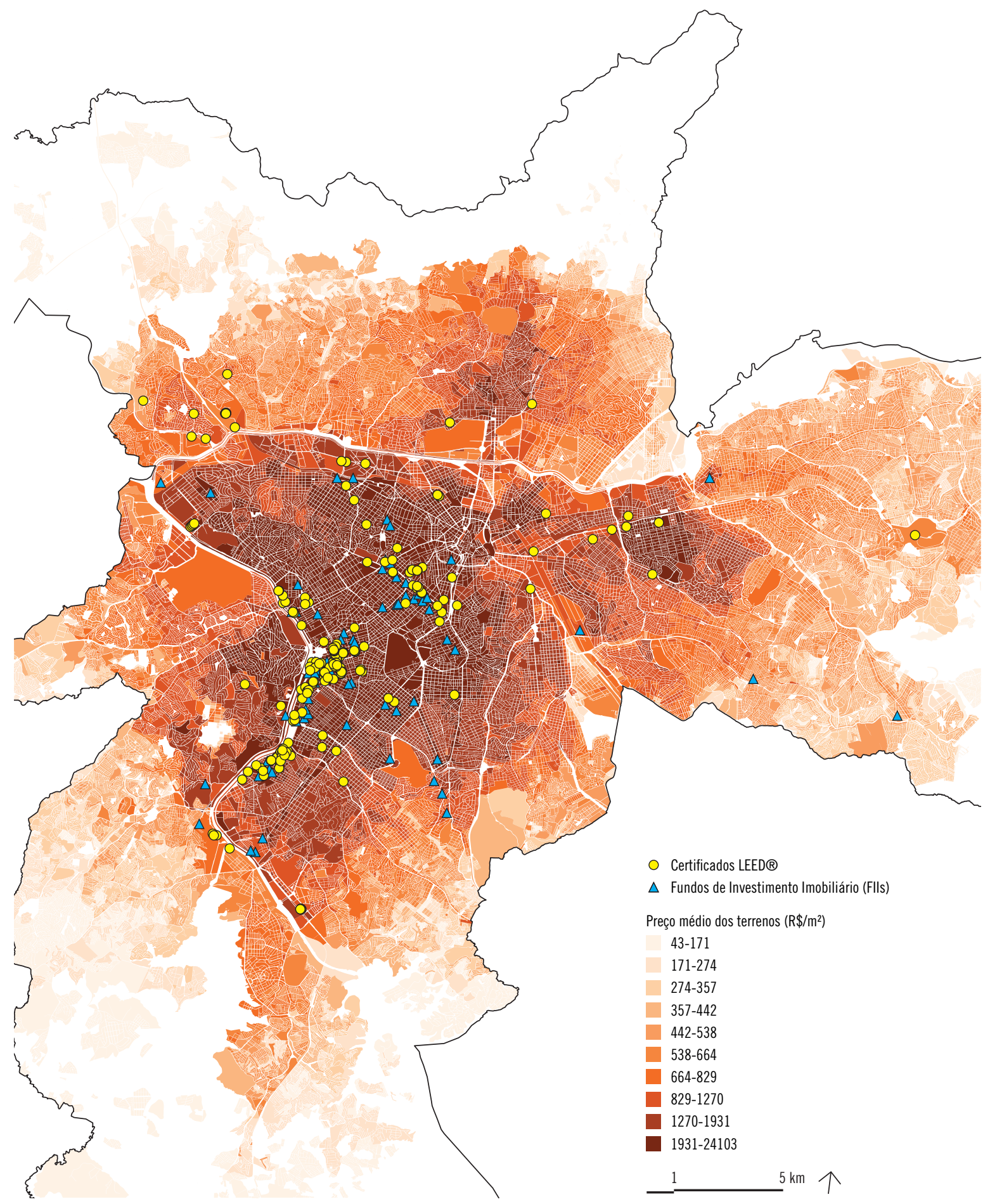

Fig 5.20. Empreendimentos $\mathrm{LEED}^{\circ}$ e preço médio do $\mathrm{m}^{2}$ dos terrenos por quadra fiscal no município de São Paulo. Divisão em decis. Fonte: Dados IPTU/PMSP 2016; LEED Project Directory, 4 jun 2019. Base cartográfica: MDC/SMDU; Emplasa 2007. Elaborado por Hannah Machado e Miguel Jacob. Organização dos ativos de
FIIs por Isabel Pinto Alvarez com elaboração de Alex da Silva Dias Américo, via Alvarez, "A produção de espaços financeirizados na metrópole de São Paulo", 260. Edição final e levantamento de empreendimentos LEED ${ }^{\oplus}$ pelo autor. 


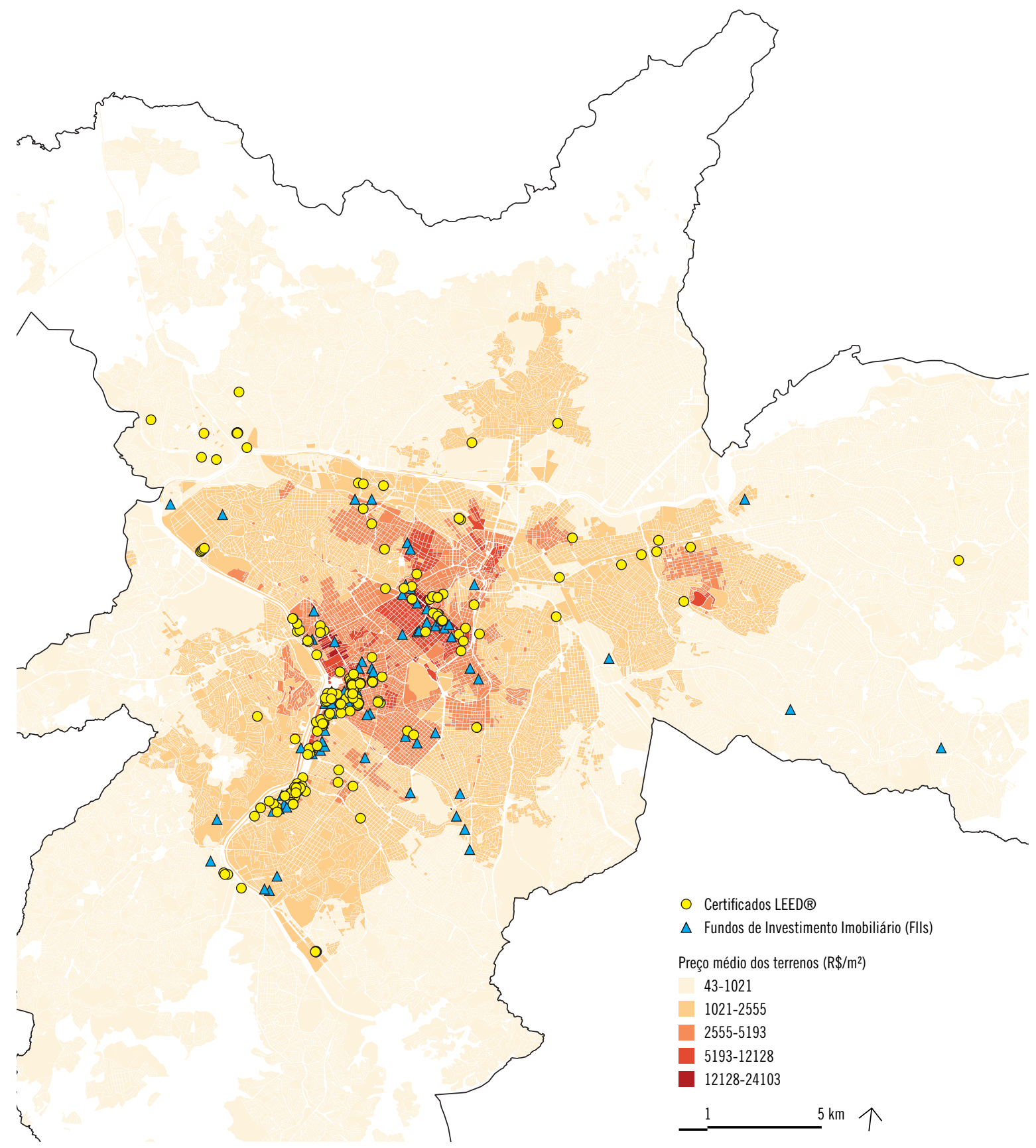

Fig 5.21. Empreendimentos LEED ${ }^{\circ}$ e preço médio do $\mathrm{m}^{2}$ dos terrenos por quadra fiscal no município de São Paulo. Divisão em Natural Breaks (Jenks). Fonte: Dados IPTU/ PMSP 2016; LEED Project Directory, 4 jun 2019. Base cartográfica: MDC/SMDU; Emplasa 2007. Elaborado por Hannah Machado e Miguel Jacob. Organização dos ativos de FIIs por Isabel Pinto Alvarez com elaboração de Alex da Silva Dias Américo, via Alvarez, "A produção de espaços financeirizados na metrópole de São Paulo", 260. Edição final e levantamento de empreendimentos LEED ${ }^{\circledR}$ pelo autor.
O cruzamento entre as informações de preço dos terrenos e localização dos empreendimentos certificados permite notar como o LEED ${ }^{\circ}$ não apenas potencializa os ganhos imobiliários, como também se concentra nos endereços mais valorizados de São Paulo. Assim, o LEED ${ }^{\circledR}$ não só se encontra nas áreas de maior valorização, representadas na divisão dos valores por decis [fig 5.20], como o faz no estrato caro dessas áreas, revelado na divisão por Natural Breaks [fig 5.21]. Além disso, a confrontação dos dados de localização dos certificados LEED ${ }^{\circledR}$ e dos FIIs demonstra que ambos são implementados nos mesmos espaços da cidade de São Paulo. 
camente presumido para sinalizar o nível mais alto", como no caso das medalhas nas Olimpíadas, enquanto o "Platinum às vezes é difícil de ser entendido em termos de percepção de valor." ${ }^{40} \mathrm{~A}$ tendência pode ser vista sobretudo nos edifícios certificados pelo LEED $^{\circledR} \mathrm{CS}$, direcionado para edifícios de locação corporativa [fig 5.12 a 5.15].

Os clientes de certificações são um mercado de alto padrão muito especializado e altamente concentrado espacialmente. Por esse motivo, os edifícios certificados tendem a se agrupar, como acontece com diversos sistemas de avaliação. ${ }^{41}$ No caso do LEED ${ }^{\oplus}$, em qualquer território estudado, também podem ser observados clusters de edifícios, acumulados em determinadas cidades e em endereços específicos. No caso de São Paulo, pôde ser aferido que esses locais possuem os preços de terreno mais elevados do município e grande concentração de FIIs, ${ }^{42}$ conclusão possivelmente válida também para outras cidades brasileiras [fig 1.9, 5.16 a 5.21].

Os edifícios certificados são, desse modo, valorizados tanto por suas vantagens de operação, presentes na produtividade dos ocupantes e nos menores custos condominiais, quanto por suas vantagens financeiras, como quando são transacionados ou na imagem corporativa de seus ocupantes. A valorização decorrente da certificação tem lastro nas qualidades de eficiência e bem-estar dos materiais e equipamentos especificados no projeto, mas também instituem uma nova fronteira de valorização artificial. O edifício passa, assim, a ser valorizado pela imagem ambiental garantida pela certificação, ao que se associa tanto uma expectativa de qualidade de seus espaços quanto da sustentabilidade de sua valorização financeira no tempo. Entretanto, as qualidades que permitem essa valorização não correspondem necessariamente a um possível papel do LEED $^{\oplus}$ na transição ecológica: como ferramenta de incentivo ao mercado, o LEED ${ }^{\circledR}$ não pode nunca lhe ser um obstáculo. É dessa conjunção de princípios que decorrem os limites do LEED ${ }^{\circledR}$, no próximo capítulo.

\footnotetext{
40. No original: "Typically, Gold is supposed to signal the highest value" e "Platinum is sometimes difficult to relate in terms os value perceptions." Pavel Sandoval e Aseem Prakash, "The Gold Rush: the popularity of the Gold tier in LEED certification”, Environmental Policy and Governance 26 (2016): 552-53, https://doi.org/10.1002/eet.1724, tradução nossa.

41. Para o mercado londrino do sistema BREEAM", ver Andrea Chegut, Piet Eichholtz, e Nils Kok, "Supply, demand and the value of green buildings", Urban Studies 51, n. 1 (janeiro de 2014): 22-43, https://doi.org/10.1177/0042098013484526. A respeito da concentração desses ativos, consultar ainda Isabel Pinto Alvarez, "A produção de espaços financeirizados na metrópole de São Paulo", in O espaço e a metropolização: cotidiano e ação, org. Alvaro Ferreira, João Rua, e Regina Célia de Mattos (Rio de Janeiro: Consequência, 2017), 241-66.

42. A respeito da espacialização dos FIIs, cf. Alvarez, "A produção de espaços financeirizados na metrópole de São Paulo".
} 


\section{CAPÍTULO 6 ALÉM DO LEED®}

\section{FISSURAS NO TRIPLE A}

Foi elaborado no capítulo 4 como a agenda ambientalista do USGBC ${ }^{\circledast}$ estava alinhada à modernização ecológica, na qual instrumentos como o LEED ${ }^{\circledR}$ colocavam o mercado imobiliário e da construção civil em uma pauta até então restrita, na arquitetura, a movimentos de contracultura. Em seguida, no capítulo 5, foi visto como o LEED ${ }^{\circledR}$ não é apenas um instrumento de mercado em geral, mas do nicho de edifícios de alto padrão. Os GBCs atraem esse nicho com a expectativa de potencialização de ganhos, expandindo, em contrapartida, sua quantidade de edifícios certificados. E isso ocorre não de modo contingente, mas planejado: o Triple A, as companhias esclarecidas, os inovadores conduziriam o mercado para um novo estágio de operação. Para isso, têm a sua disposição um campo profissional especializado e materiais construtivos e sistemas antes inexistentes ou agora com melhor performance.

Mas procedimentos de nicho têm impacto no conjunto do mercado? A pergunta se direciona, portanto, ao que poucas vezes é tratado pelos diversos GBCs: as práticas externas aos estratos de alto padrão. A indução de que mudanças no mercado de ponta teriam impacto generalizado pode ser falaciosa: não existe nenhum argumento lógico garantindo a generalização desse particular. Pelo contrário: como a eficiência do LEED $^{\circledR}$ é obtida por meio de materiais e sistemas de ponta, e o encarecimento dos produtos tende a mantê-los em um mercado especializado.

Essa indução rumo a uma "revolução verde" (sic) também é difícil de ser aferida empiricamente, mas alguns dados sugerem sua restrição a essa arquitetura de ponta. A fonte desses dados e sua interpretação são insuspeitas: foram realizadas por Jerry Yudelson, um engenheiro que colaborou em diversas frentes do USGBC ${ }^{\oplus}$. Yudelson enfatiza a distância entre as pretensões 
em torno do LEED ${ }^{\oplus}$ e os resultados de certificação: enquanto o USGBC ${ }^{\circledR}$ pretendia ter $25 \%$ do estoque imobiliário norte-americano certificado, na realidade, até o fim de 2015, ainda estava em 0,7\% dos edifícios não residenciais e $0,04 \%$ dos residenciais. ${ }^{1}$ Nas palavras de Yudelson:

O LEED nunca vai alcançar esse objetivo. Usando a sua [do USGBC ${ }^{\circledR}$ ] própria definição de meta [25\% dos edifícios norte-americanos] e após 15 anos de esforço por muitos milhares de profissionais, não é hora de admitir que o LEED é basicamente um sistema de avaliação da elite, usado principalmente por ricos proprietários de edifícios, que nunca será popularizada?²

Yudelson nota que houve estabilização na quantidade anual de edifícios registrados e certificados nos Estados Unidos a partir de 2010, embora a construção civil tenha aumentado

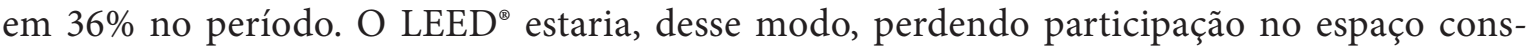
truído. Para ele, isso seria uma evidência de "saturação de mercado", em que o USGBC e o LEED $^{\circledast}$ estariam tirando proveito da inércia do sucesso inicial, mais do que da dinamização do mercado. ${ }^{3}$ Isso porque as estratégias de "velocidade é qualidade" e de organização em torno do marketing, mais do que da normatização técnica, garantiram então a rápida ampliação do LEED $^{\oplus}$, a ponto de os profissionais relutarem em aprender novos sistemas, como nota Yudelson. ${ }^{4}$ A saturação, atingida quando o LEED ${ }^{\oplus}$ ainda estava nas casas decimais, levou Yudelson a chamá-lo de "sistema do um por cento", em alusão implícita ao lema do Occupy Wall Street, movimento social que denunciava a excessiva concentração de renda em $1 \%$ da população norte-americana. Por esse motivo, o uso do LEED" estaria confinado a "mercados de alto padrão que sabem como extrair valor para compensar os custos". Trata-se de "empreendedores e proprietários de escritórios de alto padrão, grandes corporações globais e algumas das maiores

\footnotetext{
1. Jerry Yudelson, Reinventing green building: why certification systems aren't working and what we can do about it, Prefácio de Pamela Lippe (Gabriola Land, Canada: New Society Publishers, 2016), 45.

2. No original: "there is no way that LEED will ever reach this goal. Using its own definition of this target and after 15 years of effort by many thousands of professionals, isn't it time to admit that LEED is basically an elite rating system, used primarily by wealthy building owners, which will never reach the mainstream?” Yudelson, 46, grifo no original, tradução nossa.

3. Yudelson, 46-47.

4. Yudelson, 150 .
} 
universidades norte-americanas". ${ }^{5}$ Agentes esses que são fortemente ligados ao capital financeiro criticado no movimento Occupy. ${ }^{6}$

Desse modo, a retórica "market-friendly" do LEED e dos GBCs não teve como resultado a "revolução verde", mas o acréscimo de mais uma distinção ao estrato de alto padrão, ou seja, a criação de novos mecanismos de valorização financeira. A tendência de estabilização de registros e certificados continua presente nos três anos entre 2015 e 2018 que separam a amostra de Yudelson desta pesquisa [fig 1.2, 2.7, 3.4]. Ela ocorre no mercado norte-americano, global e brasileiro de modo semelhante para todos os sistemas. No contexto brasileiro a tendência é mais dramática, com abrupta redução em 2017, resultado não só do cenário econômico adverso após o impeachment da presidenta Dilma Rousseff, como também pelo início da versão 4, mais exigente.

Em razão dessa saturação, a estratégia do $\mathrm{USGBC}^{\circledast}$ de rapidamente internacionalizar o LEED $^{\circledast}$, como visto no capítulo 2, torna-se central para sua continuidade. Mais do que isso: segundo relatos, a dificuldade de crescer no território norte-americano colocou o mercado internacional como objeto principal do USGBC.$^{7}$ A internacionalização do USGBC ${ }^{\oplus}$ deu-se não só de modo mediado por via do World GBC, mas sobretudo pelo uso do LEED ${ }^{\circledR}$. Se no princípio o $\mathrm{USGBC}^{\circledast}$ não colocava restrições a adaptações locais ao $\mathrm{LEED}^{\circledR}$ - Canadá, Índia e Itália chegaram a ter sistemas LEED $^{\circledR}$ próprios, e os fundadores do GBC Brasil narram como o USGBC ${ }^{\circledast}$ não controlava o uso internacional ainda em meados da década de 2000 -, o aumento de relevância internacional exigiu regulação rigorosa. Caso contrário, haveria perda de valor e consistência da marca, fundamental nas ações de marketing. Os diversos $\mathrm{LEED}^{\oplus}$ foram gradualmente encerrados e incorporados pelo $\mathrm{GBCI}^{\oplus}$.

Uma das soluções de Yudelson para o impasse do mercado saturado é revisar o sistema de avaliação. ${ }^{8}$ No lugar de o LEED ${ }^{\circledR}$ privilegiar edifícios de ponta, ele poderia advogar eficiências

\footnotetext{
5. No original: "high-end office developers and owners, large global corporations, and some top US colleges and universities" e "high-end markets that know how to extract value to offset LEED’s costs." Yudelson, 57,126, tradução nossa.

6. Há diversas obras que discutem esse processo de concentração de renda que levou a transformações no espaço, como as torres de escritório de grandes corporações privilegiadas pelo LEED ${ }^{\circ}$. O tema será abordado nas partes III e IV desta tese. Para evidências dessa concentração de renda em contexto de modernidade tardia e neoliberalismo, ver, por exemplo, David Harvey, A brief history of neoliberalism (Nova York: Oxford University Press, 2005), especialmente os dados do cap. 1.

7. Maria Carolina Fujihara, (Diretora de comitês técnicos do GBC Brasil, 2013-2016), Entrevista para o autor, Email, 23 de novembro de 2018. Em alguma medida, esse também é o argumento de Yudelson, Reinventing green building.

8. De fato, Yudelson tem ainda uma segunda proposta, que até mesmo ocupa um espaço maior de seu argumento: a ade-
} 
menores, mas que fossem popularizadas. Assim, diz Yudelson, se em 2015 havia 4\% de estoque certificado com uma eficiência em média 25\% maior, então o impacto seria mais do que duplicado se o objetivo fosse garantir em 50\% do estoque uma eficiência de apenas 5\%. ${ }^{9}$ Nesse sentido, a certificação poderia ser descartada e trocada por uma norma compulsória que de fato agisse sobre a totalidade do mercado formal, sem a mediação de uma vanguarda do mercado. É o que propõe José Goldemberg: para ele, a solução de eficiência se daria por imposições no Código de Obras. ${ }^{10}$ Não mais a "cenoura" da certificação, mas o "chicote" da lei.

Essa é então a primeira renúncia operada pelo LEED $^{\circledR}$ para seu sucesso: o foco no alto padrão. A ela se soma outra, descrita ao longo dos dois últimos capítulos: a restrição a aspectos econômico-energéticos, especialmente na versão $3 .{ }^{11}$ Desse modo, o sistema de avaliação constrói torres de alto desempenho, mas não interfere na massa da produção imobiliária - algo ainda mais relevante em contexto brasileiro, onde grande parte da cidade nem mesmo é formal. Nas obras dos fundadores do USGBC ${ }^{\circledast}$ Gottfried e Fedrizzi, há apenas um trecho desse último que trata desse contraste:

Eu me lembro de me sentir, estando fora dessa torre da era espacial [em Mumbai] justaposta a uma favela da Idade da Pedra ao seu redor, como se eu tivesse aterrissado em outro planeta.

Essa justaposição é tragicamente comum. Das favelas de São Paulo às comunidades desfavorecidas no Bronx, pobreza e desolação são frequentemente encontradas não muito longe de novos e brilhantes edifícios LEED. No caminho de volta para o meu hotel em Mumbai, eu fiquei pensando nesses fortes contrastes e, honestamente, eles me deixaram muito desconfortável. ${ }^{12}$

quação do LEED ${ }^{\circ}$ ao mundo digital. A avaliação e o certificado passariam a um sistema de aplicativo, mais rápido e menos oneroso, que tornaria o LEED ${ }^{\circledR}$ algo como um Uber ou AirBnB da sustentabilidade (os exemplos são dele). De certo modo, Yudelson reforça a modernização ecológica do $\mathrm{LEED}^{\circledR}$, como se o sistema estivesse atrasado para um novo estágio de inovação, donde a obsolescência vislumbrada pelo autor: Yudelson é um intérprete radical dos conselhos de Fedrizzi.

9. Yudelson, Reinventing green building, 163. As proporções mencionadas mantêm o exemplo de Yudelson, embora em outras partes do livro ele afirme que o estoque certificado nos Estados Unidos é de menos de 1\%, e não de 4\%.

10. José Goldemberg, (Fundador honorário do GBC Brasil), Entrevista para o autor, Presencial, 12 de setembro de 2016.

11. David Hart identifica uma ênfase em aspectos energéticos, que estariam ligados ao efeito estufa, sobretudo na passagem da versão 2 para a 3. A versão 4, posterior a sua avaliação, volta a incorporar aspectos mais plurais do ambientalismo. Cf. David M. Hart, "Don't worry about the government? LEED Green Building Rating System and Energy Efficiency in US Commercial Buildings", MIT Industrial Performance Center. Energy Innovation Working Paper, nº 09-001 (março de 2009): 9-11. 12. No original: "I remember, standing outside this space-age tower juxtaposed with the Stone Age shantytown surrounding 
A experiência espacial descrita por Fedrizzi representa o caminho oferecido pelo LEED ${ }^{\circledR}$, independentemente das intenções do empresário: de um lado, arquiteturas cada vez mais sofisticadas; do outro lado, o efeito colateral de uma cidade intocada pelo mercado imobiliário e seus certificados. ${ }^{13}$

\section{EFICIÊNCIA EM PARADOXO}

$\mathrm{O}$ LEED $^{\circledR}$ adota uma sustentabilidade de sentido instrumental, seguindo uma definição do urbanista Henri Acselrad. ${ }^{14}$ Isso pode ser afirmado porque o sistema enfatiza uma sustentabilidade baseada no otimismo do desenvolvimento tecnológico ligado à maior eficiência no uso de recursos e à melhor performance de materiais e sistemas mecânicos. Ao fazê-lo, o LEED ${ }^{\circledR}$, e também a modernização ecológica, realiza uma inversão. Embora a princípio pareça resgatar a ecologia como um fator a ser considerado na economia, o que faz, na verdade, é dar sentido ecológico a categorias clássicas da produção capitalista. De fato, termos como "eficiência" e "inovação" são historicamente utilizados na reflexão da economia política. Eles já estão há muito tempo presentes em William Petty, Richard Cantillon, Adam Smith, Jean-Baptiste Say, Lord Lauderdale, David Ricardo, Jean Simonde de Sismondi, Thomas Robert Malthus, John McCulloch, Richard Jones, Charles Babbage, John Rae, John Stuart Mill, William Hearn e Karl Marx, que foram

\footnotetext{
it, feeling as though I had landed on another planet. This juxtaposition is tragically common. From the favelas of São Paulo to disadvanteged communities in Bronx, poverty and desolation are often found not very far from gleaming new LEED buildings. On the way back to my hotel in Mumbai, I kept thinking about these stark contrasts, and honestly, it made me really uncomfortable." Rick Fedrizzi, Greenthink: how profit can save the planet, Prefácio de Leonardo DiCaprio (Charleston, SC: Disruption Books, 2015), 54, tradução nossa.

13. Um problema que é equivalente ao encontrado na modernização ecológica: pela sua ideia de consenso e crescimento econômico, a modernização ecológica desconsidera a disputa de interesses própria das instituições modernas, do que segue suas discrepâncias de poder e riqueza, além de sua fundamentação principalmente nos quadros institucionais do norte global. Cf. Andrew Blowers, “Environmental policy: ecological modernisation or the risk society?”, Urban Studies 34, $\mathrm{n}^{\circ}$ 5-6 (1997): 853-54, https://doi.org/10.1080/0042098975853. O urbanista Alexander Cuthbert também destaca como o desenvolvimento tecnológico faz parte da construção de poder e desigualdade em nível global, o que acarreta conclusões semelhantes a respeito das ênfases realizadas pelos sistemas LEED ${ }^{\circ}$. Cf. Alexander Cuthbert, The form of cities: political economy and urban design (Malden, EUA; Oxford, Inglaterra; Victoria, Austrália: Blackwell Publishing, 2006), 151.

14. Henri Acselrad, "Sentidos da sustentabilidade urbana", in A duração das cidades: sustentabilidade e risco nas políticas urbanas, 2a (Rio de Janeiro: Lamparina, 2009), 47-48, 57.
} 
revisados por Blake Alcott especificamente sobre suas diferentes noções de "eficiência". ${ }^{15}$ Desse modo, um tema clássico da economia política, ligado a medidas corriqueiras da sobrevivência empresarial, passa a ser visto pelos modernizadores ecológicos como estratégias extraordinárias de transição ecológica.

Ao visar a eficiência, o LEED ${ }^{\circledR}$ busca minorar o uso de recursos naturais ao invés de trabalhar com conceitos de autonomia - não existe pontuação para independência energética total - ou regeneração. Embora mesmo fundadores do USGBC ${ }^{\bullet}$ como David Gottfried e Robert Berkebile enfatizem o objetivo da arquitetura regenerativa, o LEED ${ }^{\circ}$ não atua nesse escopo, o que fez Berkebile procurar sistemas mais exigentes e estratégias de projeto que abrangessem outras características ambientais além da econômico-energética para utilizar em seus próprios projetos. ${ }^{16}$ Caso o LEED ${ }^{\circledR}$ incorporasse a arquitetura regenerativa e aspectos ambientais sem fins econômicos diretos, ele não poderia mais atuar pelo expediente de incentivos ao mercado.

Mas o LEED ${ }^{\circledR}$ garante mesmo eficiências tão altas? Embora se coloque em posição de liderança, o teto de pontuação no sistema NC é a eficiência energética de 48\%, o que alguns profissionais consideram baixo para edifícios de ponta. ${ }^{17}$ Além disso, muitas das medidas exigidas pelo LEED ${ }^{\oplus}$ já estão presentes em leis, na prática corrente do mercado, sobretudo o de alto padrão, ou são relativamente simples de serem atendidas. É o caso, por exemplo, de pré-requisitos como o da proibição de fumar cigarros no interior dos edifícios, eficiência energética 5\% maior do que o habitual, o compartilhamento de informações de operação por cinco anos ou a instalação de medidores individuais de consumo de água: esses pré-requisitos são simples para um edifício que

15. Blake Alcott, "Historical overview of the Jevons Paradox in the literature", in The Jevons paradox and the myth of resource efficiency improvements (Londres: Earthscan, 2008), 7-78.

16. David Gottfried, Explosion green: one man's journey to green the world's largest industry, Prefácio de Paul Hawken. Introdução de Rick Fedrizzi. (Nova York: Morgan James, 2014), 277; Robert Berkebile, (Diretor em BNIM), Entrevista para o autor, Telefone, 29 de junho de 2018.

17. Opinião presente em Yudelson, Reinventing green building; e Chris Flint Chatto, (Diretor no ZGF Architects), Entrevista para o autor, Telefone, 23 de março de 2018. O argumento é ainda mais válido se considerado que, além de pretensão de liderança do LEED $^{\circ}$, já existem sistemas que exigem a completa autossuficiência energética de um empreendimento, tal como acontece no Living Building Challenge. Os pontos de eficiência energética estão vinculados ao crédito EA.1 Optimize Energy Performance. USGBC (United States Green Building Council), "LEED 2009 for new construction and major renovations with alternative compliance paths for projects outside the US; v. 3 reference guide" (USGBC, 2011). Na quarta versão do sistema, o teto subiu para 50\%. USGBC (United States Green Building Council), "LEED v4 for building design and construction" (USGBC, 5 de abril de 2016). 
busca certificação. ${ }^{18}$ Para Yudelson, considerando-se que a versão 4 ainda estará em operação até 2022, a transformação proposta é excessivamente lenta. Sobretudo porque as eficiências atingidas não são tão altas. Para edifícios construídos nos Estados Unidos entre 2000 e 2006, a eficiência era em média $28 \%$ maior, e havia mesmo edifícios certificados com consumo um quarto maior do que os convencionais. Em outro estudo no Canadá, a eficiência era apenas 9\% maior em relação a edifícios convencionais. ${ }^{19}$ Em mais outro estudo, entre 28 e $35 \%$ dos edifícios certificados consumiam mais energia do que suas contrapartes. ${ }^{20}$ Essas variações e o consumo maior podem decorrer de fatores como concentração da pontuação dos empreendimentos em créditos que não tratam de energia, da falta de formação dos ocupantes em relação ao uso correto dos equipamentos ou a eventuais fraudes no envio da documentação. ${ }^{21}$

Ainda assim, mesmo na situação de um desempenho isento de falhas, a noção de eficiência é relevante para o ambientalismo? Parte da literatura de sociologia ambiental discorda. A divergência resulta da redescoberta de um autor de origem teórica imprevista: um dos fundadores da Escola Neoclássica, William Stanley Jevons. ${ }^{22} \mathrm{O}$ economista inglês descobriu um paradoxo: perguntado sobre a possibilidade da escassez de carvão ameaçar a supremacia econômica britânica no fim do século XIX, Jevons argumentou que a ameaça era real, e que soluções tecnológicas

18. Yudelson, Reinventing green building, 143. O autor apresenta uma tabela de análise dos pré-requisitos na qual critica todos os pré-requisitos do sistema LEED ${ }^{\circ}$.

19. Yudelson, 59, 77.

20. Guy R. Newsham, Sandra Mancini, e Benjamin J. Birt, “Do LEED-certified buildings save energy? Yes, but...”, Energy and Buildings, ${ }^{\circ} 41$ (2009): 897-905, https://doi.org/10.1016/j.enbuild.2009.03.014.

21. Arquitetos sob anonimato relataram fraudes na documentação enviada para o GBCI, como indicações falsas de consumo de água no paisagismo ou equipamentos com eficiência maior do que a real. Com isso, os projetos conseguiriam atingir pontuações e níveis maiores do que tinham direito. O problema decorre do fato de o LEED ${ }^{\circledR}$ basear sua avaliação na documentação enviada, com auditoria facultativa, e não no desempenho efetivo do edifício. Esse método burocrático é discutido por autores como Julie Cidell, "A political ecology of the built environment: LEED certification for green buildings", Local Environment 14, n. 7 (ago de 2009): 621-33, https://doi.org/10.1080/13549830903089275; e Yudelson, Reinventing green building. O impacto da recenta ferramenta Arc, que acompanha em tempo real o desempenho dos edifícios certificados, precisa ser mensurado após a consolidação de seu uso. Consultar ainda Joana Carla Soares Gonçalves e Klaus Bode, orgs., Edifício ambiental (São Paulo: Oficina de Textos, 2015), cap. “A certificação ambiental de edifícios".

22. John Polimeni et al., The Jevons paradox and the myth of resource efficiency improvements (Londres: Earthscan, 2008); John Bellamy Foster, Brett Clark, e Richard York, "Capitalism and the curse of energy efficiency: the return of the Jevons Paradox", Monthly Review 62, n ${ }^{\circ} 6$ (1 ${ }^{\circ}$ de novembro de 2010), https://monthlyreview.org/2010/11/01/capitalism-and-the-curse-of-energy-efficiency/; Richard York, "Ecological paradoxes: William Stanley Jevons and the paperless office", Human Ecology Review 13, nº 2 (2006): 143-47. 
não resolveriam o problema. Para ele, máquinas mais eficientes, com menor consumo de carvão, levariam ao aumento de demanda no longo prazo.

Evidentemente, Jevons estava errado: não houve escassez energética que pusesse limites à expansão industrial. Isso porque, ao contrário do previsto, surgiram outras fontes energéticas para substituir o carvão. Contudo, como apontado pelos ecomarxistas Foster, Clark e York, a análise de Jevons interessa pela sua posição face aos avanços tecnológicos. Ao estudar o desenvolvimento histórico das máquinas a vapor, o economista destacou como o surgimento de máquinas com maior eficiência energética e de menor desperdício levaram ao contraintuitivo aumento no consumo de carvão. Segundo Jevons, "Cada aperfeiçoamento do maquinário, quando efetuado, não faz mais do que acelerar novamente o consumo de carvão... [Assim] trabalhos que não eram comercialmente possíveis com o uso de energia mais cara podem ser realizados."23 Os ecomarxistas apontam ainda o quanto a interpretação de Jevons estava imbuída de um referencial teórico malthusiano, no qual a expansão da produção seria um dado natural, e não uma lógica inerente à auto-expansão capitalista. Assim, eles propõem que a teoria de Jevons seja ampliada, nela incluindo o movimento inerente do capital: a diminuição de custos com combustível levaria à realocação dos investimentos na expansão da produção.

Apesar de potencialmente controversa, a tese de Jevons foi aceita em seu tempo devido à noção empírica dos produtores da época, pela qual o desenvolvimento industrial dependia da capacidade de expansão barata da produção. Reduções no uso de carvão levariam à automática reinserção do excedente com os objetivos de aumentar a capacidade industrial e conquistar mais mercado. ${ }^{24}$

Não há em Jevons nenhum debate ecológico, nem críticas à organização capitalista. Há, entretanto, a compreensão da existência de um impasse econômico. Segundo o economista inglês:

A economia multiplica o valor e a eficiência de nossos principais materiais; ela aumenta indefinidamente

\footnotetext{
23. No original: "Every such improvement of the engine, when effected, does but accelerate anew the consumption of coal... works can be undertaken which were not commercially possible by the use of the more costly steam-power." William Stanley Jevons, The coal question: an inquiry concerning the progress of the nation, and the probable exhaustion of our coal-mines, [Ed. orig. 1865] (Londres: Macmillan, 1906) apud Foster, Clark, e York, “Capitalism and the curse of energy efficiency”, tradução nossa.

24. Foster, Clark, e York, "Capitalism and the curse of energy efficiency".
} 
nossa riqueza e meios de subsistência, e conduz a um crescimento de nossa população, obras e comércio, que, ainda que gratificantes para o presente, devem conduzir a um fim próximo. ${ }^{25}$

São os autores ecomarxistas que relacionam as constatações de Jevons com a crise capitalista e ambiental, indicando como a transformação tecnológica teria limites de aplicação e como sua lógica faria parte de uma estratégia estrutural do capital para o aumento da taxa de lucro. $\mathrm{O}$ aumento de eficiência levaria, na verdade, à escassez de recursos: a inovação tecnológica é baseada em valores de mercado, de compra e venda, e não ambientais. ${ }^{26}$ Para John Bellamy Foster, Brett Clark e Richard York:

Um sistema econômico devotado a lucros e acumulação e expansão econômicas sem fim tenderá a usar qualquer ganho de eficiência ou redução de custos para expandir a escala global de produção. A inovação tecnológica será, portanto, fortemente dirigida a esses mesmos fins expansivos. [...] Economias em materiais e energia, no contexto de um dado processo de produção, não têm nada de novo; elas são parte do dia-a-dia da história do desenvolvimento capitalista. [...] Qualquer noção de que a redução na taxa de transferência de materiais, por unidade de renda nacional, é um fenômeno novo é, portanto, "profundamente ahistórica".27

Assim, a defesa da modernização ecológica na qual, por uma lógica inerente ao mercado, haveria um movimento gradual em direção a práticas mais sustentáveis de produção, “é incon-

25. No original: "Economy multiplies the value and efficiency of our chief material; it indefinitely increases our wealth and means of subsistence, and leads to an extension of our population, works, and commerce, which is gratifying to the present, but must lead to an earlier end." Jevons, The coal question apud Foster, Clark, e York, "Capitalism and the curse of energy efficiency", tradução nossa.

26. Nahide Konak, "Ecological modernization and eco-marxist perspectives: globalization and gold mining development in Turkey", Capitalism Nature Socialism 19, n 4 (dez de 2008), http://www.cnsjournal.org/cns/back-issues/cns-journal-vol19-4-december-2008/.

27. No original: "An economic system devoted to profits, accumulation, and economic expansion without end will tend to use any efficiency gains or cost reductions to expand the overall scale of production. Technological innovation will therefore be heavily geared to these same expansive ends. [...] savings in materials and energy, in the context of a given process of production, as we have seen, are nothing new; they are part of the everyday history of capitalist development. [...] Any notion that reduction in material throughput, per unit of national income, is a new phenomenon is therefore "profoundly ahistorical."' Foster, Clark, e York, "Capitalism and the curse of energy efficiency", tradução nossa. 
sistente com a realidade cotidiana, já que a crise ecológica continua a piorar" ${ }^{28}$ Ainda nesse sentido, Alcott aponta haver, mesmo em economistas clássicos como Adam Smith e John Rae, a interpretação de que "sem inovações, a água e o vento não são de nenhum modo usados, mas que, assim que o equipamento adequado está disponível, a energia é usada mais e mais... Assim que uma invenção ocorre, o consumo de um insumo é positivamente proporcional à eficiência de seu uso" ${ }^{29}$ Logo, para Alcott, a invenção tecnológica não cria necessariamente sustentabilidade, e sim novos campos possíveis de expansão capitalista: "Que uma sociedade como um todo - macroeconomicamente - possa escolher pela versão [de eficiência] 'mesma produção, menos insumo’ é impossível."30

Em oposição ao argumento ecomarxista está a dificuldade de medição do efeito colateral proposto pelo Paradoxo de Jevons, como aceito por seus próprios defensores. Devido à leitura estrutural do sistema capitalista e à busca de efeitos macroeconômicos por meio de ações de produtores isolados, por ora não há instrumentos suficientes para a confirmação dos efeitos negativos, conhecidos como rebote [backfire]. Ainda assim, como afirma Alcott, os problemas ambientais são globais e por isso devem ser considerados nessa mesma escala: na ausência de dados empíricos, deve-se recorrer aos instrumentos existentes na teoria. ${ }^{31}$

Entretanto, mesmo alguns modernizadores ecológicos aceitam os limites das esferas industrial e econômica na solução dos problemas ambientais. Martin Jänicke admite que, apesar de defender a tecnologia como solução de curto prazo para a crise ambiental, ela não pode ser vista como uma panaceia, e uma resposta duradoura só seria possível pela mudança estrutural das relações sociais. Nesse sentido, tanto problemas que exigem abordagens políticas de maior escala - como expansão urbana e erosão do solo, conforme exemplos dados pelo próprio Jänicke que

28. No original: "is inconsistent with the reality on the ground, since the ecological crisis continues to get worse" Konak, "Ecological modernization and eco-marxist perspectives: globalization and gold mining development in Turkey", 6, tradução nossa.

29. No original: "without inventions, water and wind are not used at all, but that once the right equipment is avaiable, the energy is used more and more... Once invention has ocurred, the consumption of an input is positively proportional to the efficiency of its use". Polimeni et al., The Jevons paradox and the myth of resource efficiency improvements, 43, tradução nossa.

30. No original: "That society as a whole - macroeconomically - could choose the version 'same output less input' is impossible." Alcott, "Historical overview of the Jevons Paradox in the literature", 20, tradução nossa.

31. Polimeni et al., The Jevons paradox and the myth of resource efficiency improvements, 63. 
são mais próximos à prática arquitetônica - quanto a possibilidade do efeito de rebote colocariam obstáculos a uma ação direcionada apenas à eficiência dos processos produtivos. ${ }^{32}$

Importante notar, contudo, que o Paradoxo de Jevons parte da análise da produção de bens móveis e de consumo até média duração. Por um lado, há relativo consenso de que aperfeiçoamentos de eficiência em bens como eletrodomésticos e carros levaram a backfire via generalização de consumo, aumento de potência, aumento da quantidade de bens per capita e aumento de tamanho dos bens, anulando os ganhos de eficiência. ${ }^{33}$

Por outro lado, não há literatura a respeito do Paradoxo de Jevons na arquitetura. Como hipótese teórica, pode-se supor que o efeito de rebote manifesta-se pela obsolescência acelerada dos edifícios, havendo a necessidade de construção de novos espaços mais adequados às últimas inovações:

Mas eles [os edifícios feitos na fase anterior] não têm o padrão de sofisticação que têm os edifícios hoje em dia. Sofisticação no sentido... você tem que deixar uma grande flexibilidade no uso da planta. [...] Devem ter, por exemplo, pisos elevados para a passagem de todas as instalações, tratamento acústico nas fachadas para combater o ruído externo, tratamento de insolação com vidros especiais quando é a fachada envidraçada, ou então aberturas menores para combater a insolação direta (...). Esse grau de sofisticação exige por parte dos arquitetos um trabalho muito mais técnico, muito mais voltado para a tecnologia mais avançada. ${ }^{34}$

Mas, na corrida por essa tecnologia mais avançada, a arquitetura sempre será retardatária, devido a sua perenidade intrínseca. A fundamentação da arquitetura na noção de eficiência pode levá-la a um paradoxo semelhante ao de Jevons: se cada edifício construído precisa adequar-se à técnica "up-to-date" para ser considerado um bom projeto - e para sua valorização imobiliária -, então estará necessariamente sempre atrasado em relação aos padrões de eficiência, e, logo, pas-

32. Martin Jänicke, “Ecological modernisation: new perspectives”, Journal of Cleaner Production 16 (2008): $562-63$.

33. Polimeni et al., The Jevons paradox and the myth of resource efficiency improvements, 86-91; York, "Ecological paradoxes: William Stanley Jevons and the paperless office".

34. Entrevista de Gian Carlo Gasperini apud Isadora de Andrade Guerreiro, “Arquitetura-capital: a funcionalidade dos edifícios corporativos paulistas” (Dissertação (Mestrado em Projeto, Espaço e Cultura). Orientadora: Vera Maria Pallamin, Faculdade de Arquitetura e Urbanismo da Universidade de São Paulo, 2010), 163, grifo nosso. 
sível de demolição e reconstrução. Sistemas como o DGNB ${ }^{\circledR}$ combatem essa obsolescência pela avaliação do ciclo de vida do edifício, e o próprio LEED $^{\circledR}$ passou a ter iniciativas nesse sentido a partir da versão 4 , o que revela tensões dentro do sistema. ${ }^{35}$

Além disso, a ênfase na eficiência pode levar à generalização de sistemas mecânicos. Estratégias de ventilação natural, antes comuns na arquitetura brasileira, perderam espaço para uma hegemonia cada vez maior de sistemas de ar condicionado e a dependência tecnológica decorrente, com resultados no conforto dos ocupantes e no projeto. Desse modo, por maiores que tenham sido as padronizações e políticas ambientais das últimas décadas, o consumo energético por edifício subiu, ao invés de diminuir. ${ }^{36} \mathrm{O}$ impacto dessa estratégia para a arquitetura corporativa é o tema da próxima parte.

\footnotetext{
35. Crédito Life Cycle Cost, no tópico Economic Quality do DGNB`, cf. DGNB (Deutsche Gesellschaft für Nachhaltiges Bauen), "DGNB - Core and scheme sheet. Offices, version 2014" (DGNB, 2014); crédito MR Building Life-Cycle Impact Reduction do LEED ${ }^{\circ}$, cf. USGBC (United States Green Building Council), "LEED v4 for building design and construction”. 36. Ellis G. Guiles Jr., "Building professional accreditation, construction quality control and better buildings", ASHRAE Transactions 117, $\mathrm{n}^{\circ} 1$ (2011): 170-77. O autor aponta o crescimento real de 12\% no consumo energético norte-americano entre 1985 e 2005, enquanto as previsões oficiais eram de redução de 29\%. A questão é central, pois somente o condicionamento de ar representa $10 \%$ do consumo energético mundial, e sua parcela no consumo total tem crescido significativamente nas últimas décadas. Cf. International Energy Agency, The future of cooling: opportunities for energy-efficient air conditioning (IEA Publications, 2018), 23-24.
} 


\section{PARTE III}

\section{TORRE AMBIENTAL: \\ OS PADRÕES ARQUITETÔNICOS DO LEED®}

Não importa o quão comercial ela possa parecer, mesmo a chamada arquitetura de empreendedores nunca é inteiramente redutível aos interesses econômicos por trás dela.

Reinhold Martin ${ }^{1}$

\footnotetext{
1. No original: "However commercial it may seem, even so-called developer architecture is never entirely reducible to the economic interests behind it." Reinhold Martin, Utopia’s ghost: architecture and postmodernism, again (Minneapolis, Londres: University of Minnesota Press, 2010), 96.
} 



\section{CAPÍTULO 7 \\ TRIPLE A COMO ARQUITETURA DE VANGUARDA}

\section{OS SISTEMAS LEED® NEW CONSTRUCTION E CORE \& SHELL}

O que é um edifício sustentável para o LEED $^{\circledR}$ ? $^{1}$ Se na parte I deste trabalho foi descrito como e por quem o certificado foi criado, e se na parte II foram discutidas as premissas ecológicas com que isso foi feito, cabe agora investigar como a forma arquitetônica certificada produz espacialmente a modernização ecológica. Os edifícios certificados, como se verá, respondem ao ambientalismo dentro de uma genealogia tipológica específica, alinhada a desdobramentos da arquitetura corporativa norte-americana ao longo da década de 1990.

Para isso, o foco se direciona sobre o principal sistema do LEED ${ }^{\circledR}$, o New Construction (NC). O sistema foi o primeiro a ser concebido, orientado para edifícios corporativos, ${ }^{2}$ ainda que seja no Core \& Shell (CS) que a arquitetura de edifícios para locação tenha sido especificamente tratada. Há poucas diferenças entre o LEED ${ }^{\circ} \mathrm{NC}$ e o CS, em geral relacionadas ao desconhecimento de quem será o usuário final, como é o caso do CS [tab 7.1 e 7.2]. O LEED ${ }^{\circledR}$ CS tem créditos específicos dedicados a manuais para ensinar os inquilinos a operar seu espaço sustentável e à mensuração por unidade do consumo de energia. ${ }^{3}$ Além disso, como não é feito o acabamento dos interiores em razão do projeto sem ocupante definido, os créditos vinculados a essas especi-

\footnotetext{
1. A questão é incomum na literatura, mas foram encontradas duas referências com esse mesmo objetivo principal: Fernanda Ikert, “A discussão da certificação LEED na relação edifício-cidade: explorando casos brasileiros” (Dissertação (Mestrado em Urbanismo, História e Arquitetura da Cidade). Orientadora: Lisete Assen de Oliveira, Departamento de Arquitetura e Urbanismo da Universidade Federal de Santa Catarina, 2010); Marita Wallhagen e Mauritz Glaumann, “Design consequences of differences in building assessment tools: a case study", Building Research \& Information 39, n 1 (2011): 16-33, https:// doi.org/10.1080/09613218.2010.513210. Entretanto, esta tese não dá seguimento às conclusões desses trabalhos.

2. Também mencionado no capítulo 5, seguindo Jerry Yudelson, Reinventing green building: why certification systems aren't working and what we can do about it, Prefácio de Pamela Lippe (Gabriola Land, Canada: New Society Publishers, 2016), 122. 3. No LEED ${ }^{\circledR}$ CS, SS.9 Tenant Design and Construction Guidelines e EA.5.2 Measurement and Verification - Tenant Submetering.
} 
ficações foram suprimidos. ${ }^{4} \mathrm{O}$ LEED ${ }^{\bullet} \mathrm{CS}$ também apresenta alguns pontos a mais para a proximidade com transporte público e para a otimização energética do empreendimento. ${ }^{5}$

Nos Estados Unidos, o sistema LEED $^{\circledR}$ mais frequente se tornou o Homes. Também são representativos no país outros sistemas, como o Commercial Interiors (CI), Existing Buildings: Operations \& Maintenance (EBOM), Retail e Schools, este último exigido por lei em certos municípios, assim como o NC para novos edifícios públicos [fig 1.4]. Como observado anteriormente, a tendência de ênfase na certificação no mercado corporativo vem da versão piloto do LEED ${ }^{\circ}$ NC. Mas essa tendência se desenvolve ao longo do tempo de modo mais agudo em contexto internacional, onde o $\mathrm{LEED}^{\circledR} \mathrm{CS}$ é, depois do $\mathrm{LEED}^{\circledR} \mathrm{NC}$, o principal sistema [fig 2.9]. E, no Brasil, é o LEED ${ }^{\circledR}$ CS o sistema típico, no qual cerca de $85 \%$ dos empreendimentos são da versão 3, motivo pelo qual ela é utilizada como base de análise para esta tese [fig 3.6]. Se, ao invés de considerado o número absoluto de empreendimentos, o fator a ser levado em conta for a área total construída, o LEED ${ }^{\circledR}$ CS torna-se o principal sistema fora dos Estados Unidos, com mais de 80 milhões de metros quadrados certificados [fig 7.1 e 7.2$].^{6}$

Os sistemas LEED ${ }^{\circledR} \mathrm{NC}$ e CS v3, como colocado no primeiro capítulo, são organizados por meio de cinco categorias fundamentais [base points] no total de cem pontos: Sustainable Sites (SS), Water Efficiency (WE), Energy and Atmosphere (EA), Materials and Resources (MR), Indoor Environmental Quality (EQ); e outras duas categorias extras com total de dez pontos: Innovation in Design (ID) e Regional Priorities (RP) [tab 7.1 e 7.2]. Embora ênfases e créditos possam variar, essas categorias também estão presentes em todos os outros sistemas LEED $^{\curvearrowleft}$ v3, com exceção do LEED $^{\circledast}$ for Neighborhood Design (ND), tema da parte IV deste trabalho.

As cinco categorias avaliam diferentes aspectos de um empreendimento. No LEED ${ }^{\circledR} \mathrm{NC}$, a categoria SS tem um quarto dos pontos fundamentais e relaciona-se à escolha do terreno e à implantação do empreendimento. Seus créditos podem ser agrupados, por um lado, naqueles

4. No LEED ${ }^{\oplus}$ NC, MR.1.2 Building Reuse - Maintain Existing Interior Nonstructural Elements e menos pontos no MR.3 Materials Reuse.

5. SS.4.1 Alternative Transportation - Public Transportation Access e EA.1 Optimize Energy Performance.

6. Segundo dados tratados pelo autor a partir do LEED Project Directory. Todd et al. encontram outro resultado, em que o sistema EBOM teria protagonismo, o que pode se dever a menor amostra e menos versões analisadas. Cf. Joel Ann Todd, Chris Pyke, e Robert Tufts, "Implications of trends in LEED usage: rating system design and market transformation", Building Research \& Information 41, nº 4 (2013): 384-400, https://doi.org/10.1080/09613218.2013.775565. 
relacionados às pré-existências naturais ou urbanas, privilegiando a preservação natural e a inserção dentro do tecido urbano consolidado. ${ }^{7}$ Por outro lado, e mais numerosos, estão os créditos relativos à minimização do impacto do empreendimento no entorno, incentivando o acesso a transporte coletivo e não motorizado, o aumento das áreas verdes e o controle da água da chuva, de ilhas de calor e da poluição luminosa. ${ }^{8}$ Há, ainda, um crédito especificamente dedicado à revitalização do terreno, quando este estiver contaminado. ${ }^{9}$

Na categoria WE, dedicada aos recursos hídricos, estão $10 \%$ dos pontos fundamentais. Os créditos podem ser divididos entre os relativos à redução no consumo de água potável ${ }^{10} \mathrm{e}$ os concernentes ao tratamento de parte do esgoto dentro do empreendimento, evitando seu despejo no sistema de saneamento da cidade. ${ }^{11}$

A categoria EA é aquela com maior quantidade de pontos possíveis (35), logo é central no cumprimento do sistema LEED ${ }^{\oplus}$. Seus procedimentos, relacionados ao consumo de energia na operação do edifício, dividem-se entre a redução no consumo de energia, ${ }^{12}$ a verificação dos sistemas mecânicos e elétricos projetados ${ }^{13}$ a produção in loco de energia elétrica a partir de fontes limpas ${ }^{14}$ e a proscrição de elementos químicos daninhos à camada de ozônio. ${ }^{15}$ Nesta categoria se encontra o crédito EA.1 Optimize Energy Performance, o mais importante dos sistemas NC e CS v3, por ser aquele com maior quantidade de pontos possíveis: 19 para o NC, 21 para o CS. Com essa quantidade, o crédito concentra sozinho cerca de $20 \%$ dos pontos fundamentais. Depois

7. SS.1 Site Selection, SS.2 Development Density and Community Connectivity, SS.4.1 Alternative Transportation - Public Transportation Access e SS.5.1 Site Development - Protect or Restore Habitat.

8. SS.Prereq.1 Construction Activity Pollution Prevention, SS.4.2 Alternative Transportation - Bicycle Storage and Changing Rooms, SS.4.3 Alternative Transportation - Low-Emitting and Fuel-Efficient Vehicles, SS.4.4 Alternative Transportation - Parking Capacity, SS.5.2 Site Development - Maximize Open Space, SS.6.1 Stormwater Design - Quantity Control, SS.6.2 Stormwater Design - Quality Control, SS.7.1 Heat Island Effect - Nonroof, SS.7.2 Heat Island Effect - Roof e SS.8 Light Pollution Reduction.

9. SS.3 Brownfield Redevelopment, embora o crédito SS.5.1 potencialmente trate também de revitalização.

10. WE.Prereq.1 Water Use Reduction, WE.1 Water Efficient Landscaping e WE.3 Water Use Reduction.

11. WE.2 Innovative Wasterwater Technologies.

12. EA.Prereq.2 Minimum Energy Performance e EA.1 Optimize Energy Performance, de modo que esse último possui quase um quinto dos pontos possíveis dentro dos créditos fundamentais.

13. EA.Prereq.1 Fundamental Commissioning of Building Energy Systems, EA.3 Enhanced Commissioning e EA.5 Measurement and Verification.

14. EA.2 On-Site Renewable Energy e EA.6 Green Power.

15. EA.Prereq.3 Fundamental Refrigerant Management e EA.4 Enhanced Refrigerant Management. 


\begin{tabular}{|c|c|c|c|}
\hline \# & Categorias e créditos & Pontos & $\%$ \\
\hline SS & Sustainable Sites & 26 & 23,6 \\
\hline SS.Prereq.1 & Construction Activity Pollution Prevention & - & - \\
\hline SS.1 & Site Selection & 1 & 0,9 \\
\hline SS.2 & Development Density and Community Connectivity & 5 & 4,5 \\
\hline SS.3 & Brownfield Redevelopment & 1 & 0,9 \\
\hline SS.4.1 & Alternative Transportation - Public Transportation Access & 6 & 5,5 \\
\hline SS.4.2 & Alternative Transportation - Bicycle Storage and Changing Rooms & 1 & 0,9 \\
\hline SS.4.3 & Alternative Transportation - Low-Emitting and Fuel-Efficient Vehicles & 3 & 2,7 \\
\hline SS.4.4 & Alternative Transportation - Parking Capacity & 2 & 1,8 \\
\hline SS.5.1 & Site Development - Protect or Restore Habitat & 1 & 0,9 \\
\hline SS.5.2 & Site Development - Maximize Open Space & 1 & 0,9 \\
\hline SS.6.1 & Stormwater Design - Quantity Control & 1 & 0,9 \\
\hline SS.6.2 & Stormwater Design - Quality Control & 1 & 0,9 \\
\hline SS.7.1 & Heat Island Effect - Nonroof & 1 & 0,9 \\
\hline SS.7.2 & Heat Island Effect - Roof & 1 & 0,9 \\
\hline SS.8 & Light Pollution Reduction & 1 & 0,9 \\
\hline WE & Water Efficiency & 10 & 9,1 \\
\hline WE.Prereq. 1 & Water Use Reduction & - & - \\
\hline WE.1 & Water Efficient Landscaping & 4 & 3,6 \\
\hline WE.2 & Innovative Wastewater Technologies & 2 & 1,8 \\
\hline WE.3 & Water Use Reduction & 4 & 3,6 \\
\hline EA & Energy and Atmosphere & 35 & 31,8 \\
\hline EA.Prereq.1 & Fundamental Commissioning of Building Energy Systems & - & - \\
\hline EA.Prereq.2 & Minimum Energy Performance & - & - \\
\hline EA.Prereq.3 & Fundamental Refrigerant Management & - & - \\
\hline EA.1 & Optimize Energy Performance & 19 & 17,3 \\
\hline EA.2 & On-Site Renewable Energy & 7 & 6,4 \\
\hline EA.3 & Enhanced Commissioning & 2 & 1,8 \\
\hline EA.4 & Enhanced Refrigerant Management & 2 & 1,8 \\
\hline EA.5 & Measurement and Verification & 3 & 2,7 \\
\hline EA.6 & Green power & 2 & 1,8 \\
\hline MR & Materials and Resources & 14 & 12,7 \\
\hline MR.Prereq.1 & Storage and Collection of Recyclables & - & - \\
\hline MR.1.1 & Building Reuse - Maintain Existing Walls, Floors and Roof & 3 & 2,7 \\
\hline MR.1.2 & Building Reuse - Maintain Existing Interior Nonstructural Elements & 1 & 0,9 \\
\hline MR.2 & Construction Waste Management & 2 & 1,8 \\
\hline MR.3 & Materials Reuse & 2 & 1,8 \\
\hline MR.4 & Recycled Content & 2 & 1,8 \\
\hline MR.5 & Regional Materials & 2 & 1,8 \\
\hline MR.6 & Rapidly Renewable Materials & 1 & 0,9 \\
\hline MR.7 & Certified Wood & 1 & 0,9 \\
\hline
\end{tabular}




\begin{tabular}{llll}
\hline$\#$ & Categorias e créditos & Pontos & \% \\
\hline EQ & Indoor Environmental Quality & $\mathbf{1 5}$ & $\mathbf{1 3 , 6}$ \\
\hline EQ.Prereq.1 & Minimum Indoor Air Quality Performance & - & - \\
EQ.Prereq.2 & Environmental Tobacco Smoke (ETS) Control & - & - \\
EQ.1 & Outdoor Air Delivery Monitoring & 1 & 0,9 \\
EQ.2 & Increased Ventilation & 1 & 0,9 \\
EQ.3.1 & Construction Indoor Air Quality Management Plan - During Construction & 1 & 0,9 \\
EQ.3.2 & Construction Indoor Air Quality Management Plan - Before Occupancy & 1 & 0,9 \\
EQ.4.1 & Low-Emitting Materials - Adhesives and Sealants & 1 & 0,9 \\
EQ.4.2 & Low-Emitting Materials - Paints and Coatings & 1 & 0,9 \\
EQ.4.3 & Low-Emitting Materials - Flooring Systems & 1 & 0,9 \\
EQ.4.4 & Low-Emitting Materials - Composite Wood and Agrifiber Products & 1 & 0,9 \\
EQ.5 & Indoor Chemical and Pollutant Source Control & 1 & 0,9 \\
EQ.6.1 & Controllability of Systems - Lighting & 1 & 0,9 \\
EQ.6.2 & Controllability of Systems - Thermal Comfort & 1 & 0,9 \\
EQ.7.1 & Thermal Comfort - Design & 1 & 0,9 \\
EQ.7.2 & Thermal Comfort - Verification & 1 & 0,9 \\
EQ.8.1 & Daylight and Views - Daylight & 1 & 0,9 \\
EQ.8.2 & Daylight and Views - Views & 1 & 0,9 \\
\hline ID & Innovation in Design & $\mathbf{6}$ & $\mathbf{5 , 5}$ \\
\hline ID.1 & Innovation in Design & 5 & 4,5 \\
ID.2 & LEED Accredited Professional & $\mathbf{4}$ & 0,9 \\
\hline RP & Regional Priority & $\mathbf{3 , 6}$ \\
\hline RP.1 & Regional Priority & 3,6 \\
\hline & & 1 & 1 \\
\hline
\end{tabular}

Tab 7.1. Créditos do LEED ${ }^{\circ}$ New Construction, versão 3 . Porcentagens pelo autor. 


\begin{tabular}{|c|c|c|c|}
\hline$\#$ & Categorias e créditos & Pontos & $\%$ \\
\hline SS & Sustainable Sites & 28 & 25,5 \\
\hline SS.Prereq.1 & Construction Activity Pollution Prevention & - & - \\
\hline SS.1 & Site Selection & 1 & 0,9 \\
\hline SS. 2 & Development Density and Community Connectivity & 5 & 4,5 \\
\hline SS. 3 & Brownfield Redevelopment & 1 & 0,9 \\
\hline SS.4.1 & Alternative Transportation - Public Transportation Access & 6 & 5,5 \\
\hline SS.4.2 & Alternative Transportation - Bicycle Storage and Changing Rooms & 2 & 1,8 \\
\hline SS.4.3 & Alternative Transportation - Low-Emitting and Fuel-Efficient Vehicles & 3 & 2,7 \\
\hline SS.4.4 & Alternative Transportation - Parking Capacity & 2 & 1,8 \\
\hline SS.5.1 & Site Development - Protect or Restore Habitat & 1 & 0,9 \\
\hline SS.5.2 & Site Development - Maximize Open Space & 1 & 0,9 \\
\hline SS.6.1 & Stormwater Design - Quantity Control & 1 & 0,9 \\
\hline SS.6.2 & Stormwater Design - Quality Control & 1 & 0,9 \\
\hline SS.7.1 & Heat Island Effect - Nonroof & 1 & 0,9 \\
\hline SS.7.2 & Heat Island Effect - Roof & 1 & 0,9 \\
\hline SS. 8 & Light Pollution Reduction & 1 & 0,9 \\
\hline SS.9 & Tenant Design and Construction Guidelines & 1 & 0,9 \\
\hline WE & Water Efficiency & 10 & 9,1 \\
\hline WE.Prereq.1 & Water Use Reduction & - & - \\
\hline WE.1 & Water Efficient Landscaping & 4 & 3,6 \\
\hline WE. 2 & Innovative Wastewater Technologies & 2 & 1,8 \\
\hline WE.3 & Water Use Reduction & 4 & 3,6 \\
\hline EA & Energy and Atmosphere & 37 & 33,6 \\
\hline EA.Prereq.1 & Fundamental Commissioning of Building Energy Systems & - & - \\
\hline EA.Prereq. 2 & Minimum Energy Performance & - & - \\
\hline EA.Prereq. 3 & Fundamental Refrigerant Management & - & - \\
\hline EA.1 & Optimize Energy Performance & 21 & 19,1 \\
\hline EA.2 & On-Site Renewable Energy & 4 & 3,6 \\
\hline EA.3 & Enhanced Commissioning & 2 & 1,8 \\
\hline EA.4 & Enhanced Refrigerant Management & 2 & 1,8 \\
\hline EA.5.1 & Measurement and Verification - Base Building & 3 & 2,7 \\
\hline EA.5.2 & Measurement and Verification - Tenant Submetering & 3 & 2,7 \\
\hline EA.6 & Green power & 2 & 1,8 \\
\hline MR & Materials and Resources & 13 & 11,8 \\
\hline MR.Prereq.1 & Storage and Collection of Recyclables & - & - \\
\hline MR.1 & Building Reuse - Maintain Existing Walls, Floors and Roof & 5 & 4,5 \\
\hline MR.2 & Construction Waste Management & 2 & 1,8 \\
\hline MR.3 & Materials Reuse & 1 & 0,9 \\
\hline MR.4 & Recycled Content & 2 & 1,8 \\
\hline MR.5 & Regional Materials & 2 & 1,8 \\
\hline MR.6 & Certified Wood & 1 & 0,9 \\
\hline
\end{tabular}




\begin{tabular}{llll}
\hline$\#$ & Categorias e créditos & Pontos & \% \\
\hline EQ & Indoor Environmental Quality & $\mathbf{1 2}$ & $\mathbf{1 0 , 9}$ \\
\hline EQ.Prereq.1 & Minimum Indoor Air Quality Performance & - \\
EQ.Prereq.2 & Environmental Tobacco Smoke (ETS) Control & - & - \\
EQ.1 & Outdoor Air Delivery Monitoring & 1 & 0,9 \\
EQ.2 & Increased Ventilation & 1 & 0,9 \\
EQ.3 & Construction Indoor Air Quality Management Plan - During Construction & 1 & 0,9 \\
EQ.4.1 & Low-Emitting Materials - Adhesives and Sealants & 1 & 0,9 \\
EQ.4.2 & Low-Emitting Materials - Paints and Coatings & 1 & 0,9 \\
EQ.4.3 & Low-Emitting Materials - Flooring Systems & 1 & 0,9 \\
EQ.4.4 & Low-Emitting Materials - Composite Wood and Agrifiber Products & 1 & 0,9 \\
EQ.5 & Indoor Chemical and Pollutant Source Control & 1 & 0,9 \\
EQ.6 & Controllability of Systems - Thermal Comfort & 1 & 0,9 \\
EQ.7 & Thermal Comfort - Design & 1 & 0,9 \\
EQ.8.1 & Daylight and Views - Daylight & 1 & 0,9 \\
EQ.8.2 & Daylight and Views - Views & 1 & 0,9 \\
\hline ID & Innovation in Design & $\mathbf{6}$ & $\mathbf{5 , 5}$ \\
\hline ID.1 & Innovation in Design & 5 & 4,5 \\
ID.2 & LEED Accredited Professional & 1 & 0,9 \\
\hline RP & Regional Priority & $\mathbf{4}$ & $\mathbf{3 , 6}$ \\
\hline RP.1 & Regional Priority & 3,6 \\
\hline
\end{tabular}

Tab 7.2. Créditos do $\mathrm{LEED}^{\circledR}$ Core \& Shell, versão 3 . Porcentagens pelo autor. 


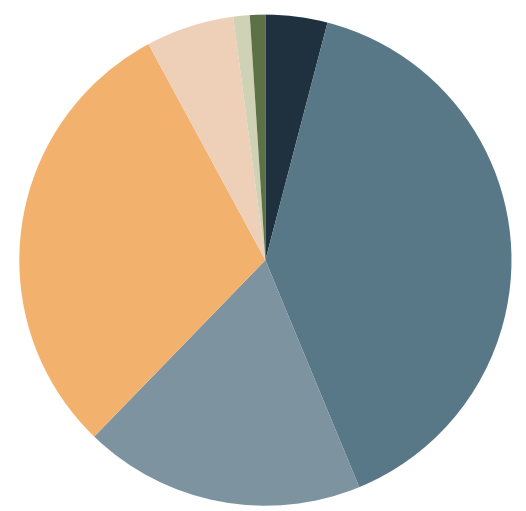

$\square \mathrm{Cl} \square \mathrm{CS} \square \mathrm{EBOM} \square \mathrm{NC} \square \mathrm{ND} \square$ Retail $\square$ Outros (DC, HC, Homes, HP, Schools, Transit, WDC)

Fig 7.1. Área construída bruta certificada pelo LEED $^{\oplus}$ fora dos Estados Unidos, divisão por sistema. Fonte: LEED Project Directory (USGBC), com correções pelo autor a partir de Empreendimentos LEED (GBC Brasil), 4 jan 2019. Elaborado pelo autor.

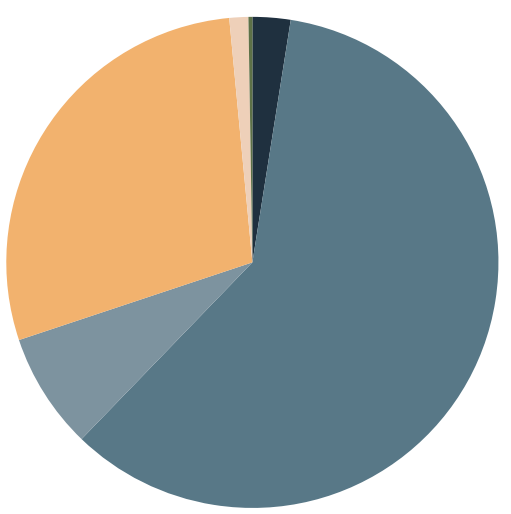

$\square \mathrm{Cl} \square \mathrm{CS} \square \mathrm{EBOM} \square \mathrm{NC} \square \mathrm{ND} \square$ Outros (Homes, Retail, Schools, WDC)

Fig 7.2. Área construída bruta certificada pelo LEED ${ }^{\circ}$ no Brasil, divisão por sistema. Fonte: LEED Project Directory (USGBC), com correções pelo autor a partir de Empreendimentos LEED (GBC Brasil), 4 jan 2019. Elaborado pelo autor.

Desvios são possíveis pois nem todos os empreendimentos têm áreas divulgadas pelo USGBC . 
dele, o segundo crédito com maior concentração tem quantidade muito inferior de pontos: é o caso do EA.2 On-Site Renewable Energy, com no máximo sete pontos no sistema NC; ou do SS.4.1 Alternative Transportation - Public Transportation Access, com até seis pontos no sistema CS.

Na categoria MR são enfocados os materiais empregados na construção, com 14 pontos possíveis. Há pelo menos três frentes de avaliação. A primeira frente é a redução no consumo de materiais, seja pela manutenção de elementos construtivos pré-existentes em uma intervenção, seja pelo reuso de resíduos do próprio canteiro na construção. ${ }^{16}$ A segunda é a gestão dos resíduos da construção e operação do empreendimento. ${ }^{17}$ Já a terceira frente trata de questões relacionadas à produção e proveniência dos materiais, incentivando o conteúdo reciclado, proximidade de extração e materiais renováveis. ${ }^{18}$

Por fim, a categoria EQ trata da qualidade ambiental para os ocupantes dos edifícios e nela encontram-se os 15 pontos restantes do sistema. Por um lado, ela avalia estratégias para aumentar a qualidade do ar interno, pelo aumento da ventilação e redução de compostos químicos no ar. ${ }^{19}$ Por outro lado, trata do conforto do usuário em questões como iluminação, temperatura e sensação de confinamento. ${ }^{20}$

Há oito pré-requisitos nessas categorias: um na SS, um na WE, três na EA, um na MR e dois na $\mathrm{EQ}$.

A partir desse panorama, a certificação via LEED $^{\oplus}$ tenderia a que edifício padrão? É constante nas entrevistas feitas para essa pesquisa o argumento de que o LEED $^{\circledR}$ não interfere no projeto de um edifício. Entretanto, pode-se notar alguns padrões de avaliação no que foi até aqui apresentado sobre o sistema. Esses padrões de avaliação podem ser incorporados de modo "auto-

16. MR.1.1 Building Reuse - Maintain Existing Walls, Floors and Roof, MR.1.2 Building Reuse - Maintain Existing Nonstructural Elements e MR.3 Materials Reuse.

17. MR.Prereq.1 Storage and Collection of Recyclables e MR.2 Construction Waste Management.

18. MR.4 Recycled Content, MR.5 Regional Materials, MR.6 Rapidly Renewable Materials e MR.7 Certified Wood.

19. EQ.Prereq.1 Minimum Indoor Air Quality Performance, EQ.Prereq.2 Environmental Tobacco Smoke (ETS) Control, EQ.1 Outdoor Air Delivery Monitoring, EQ.2 Increased Ventilation, EQ.3.1 Construction Indoor Air Quality Management Plan During Construction, EQ.3.2 Construction Indoor Air Quality Management Plan - Before Occupancy, EQ.4.1 Low-Emitting Materials - Adhesives and Sealants, EQ.4.2 Low-Emitting Materials - Paints and Coatings, EQ.4.3 Low-Emitting Materials - Flooring Systems, EQ.4.4 Low-Emitting Materials - Composite Wood and Agrifiber Products e EQ.5 Indoor Chemical and Pollutant Source Control.

20. EQ.6.1 Controllability of Systems - Lighting, EQ.6.2 Controllability of Systems - Thermal Comfort, EQ.7.1 Thermal Comfort - Design, EQ.7.2 Thermal Comfort - Verification, EQ.8.1 Daylight and Views - Daylight e EQ.8.2 Daylight and Views - Views. 
mático" pelos projetistas, como expressado por um dos arquitetos entrevistados para a pesquisa: o fluxo de trabalho no projeto integraria soluções desde as etapas iniciais, já prevendo o cumprimento de créditos em etapas posteriores. Nesse sentido, ao invés de tomar como ponto de partida a multiplicidade de pontuações possíveis por um incorporador, que sempre escolherá aqueles pontos mais fáceis de serem alcançados, ou com maior retorno financeiro em um prazo por ele estipulado, este capítulo toma como premissa o cumprimento, no limite, integral do certificado. O capítulo também tomará como premissa o uso do LEED ${ }^{\circledR}$ desde as etapas iniciais de projeto. Ou seja: levando em conta que todas as premissas do LEED ${ }^{\circledR}$ são cumpridas tal como esperado pelo sistema, e não segundo eventuais distorções no seu uso empírico, quais são as estratégias de projeto privilegiadas? Qual é a virtualidade prefigurada no $\mathrm{LEED}^{\circledR}$ ?

\section{MECANIZAÇÃO DO AMBIENTE}

Eliminada por enquanto a relação com o uso empírico dos sistemas LEED ${ }^{\circledR} \mathrm{NC}$ e CS, a primeira característica mais proeminente de projeto é o aperfeiçoamento dos sistemas prediais, sejam hidráulicos, elétricos ou mecânicos. É pela maior eficiência desses sistemas que o edifício cumpre seus objetivos de sustentabilidade. $\mathrm{O} \mathrm{LEED}^{\circledR}$ não exige estratégias de todo inusuais no mercado imobiliário corporativo, mas uma performance melhor dos sistemas prediais habituais. São necessários melhores projetos complementares, mas também, ao menos idealmente, sua inclusão em etapas cada vez mais iniciais do projeto arquitetônico. Desse modo, o projeto do edifício dialogaria desde até mesmo o estudo preliminar com as necessidades dos projetos complementares. Por exemplo: considerar o $\mathrm{LEED}^{\circledR}$ desde as etapas preliminares significaria especificar um pé-direito adequado ao sistema de climatização e antever seus efeitos na altura dos pavimentos e seus resultados na fachada do empreendimento.

A especificação desses sistemas é tanto mais importante porque, nos edifícios de escritórios para locação, os sistemas prediais são elementos centrais do projeto arquitetônico. Associado ao núcleo de transporte vertical e instalações de serviços formam o core do edifício, em contraposição ao envelope - o shell. Esses dois elementos principais, core e shell, formam basicamente a arquitetura do edifício. Apenas os sistemas prediais são previstos pelo projeto arquitetônico no intervalo espacial entre o núcleo e o envelope, o restante sendo decidido pelos futuros inquili- 
nos. Saliente-se que a princípio isso só seria característico nos edifícios para locação, objetos do sistema LEED ${ }^{\oplus}$ CS. Entretanto, o sistema LEED $^{\circledR}$ NC, dedicado a novas construções em geral e a intervenções substanciais em edifícios existentes, tem igual ênfase nos sistemas prediais, o que indica como a lógica de projeto do edifício de escritórios para locação reverbera nos diversos programas avaliados pelo LEED ${ }^{\oplus}$.

Embora seja comum o argumento de que o LEED "fornece parâmetros de referência aos edifícios verdes, mas não conta aos candidatos como conseguir os pontos", ${ }^{21}$ aqui na formulação de David Gottfried, o que se pode depreender do sistema, pelo contrário, é que os quesitos avaliados garantem maiores benefícios a arquiteturas de ponta do que àquelas em técnicas tradicionais.

Essa ênfase nos sistemas prediais é chamada na literatura de "verde claro" [light green]. Para Eric Boschmann e Jessica Gabriel, esse seria o caso de arquiteturas que atingem a sustentabilidade por meio de "inovações tecnológicas, incluindo isolamento ou janelas de ponta, iluminação de baixo consumo energético, termostatos inteligentes no estado da arte em sistemas de aquecimento, ventilação e condicionamento de ar, ou painéis solares fotovoltaicos nas coberturas." ${ }^{22} \mathrm{O}$ projeto está relacionado, portanto, mais à aparelhagem high tech do que a abordagens vernaculares ou regionais, que não são recompensadas nos sistemas LEED ${ }^{\circledR}$ com pontuações específicas. O "claro" é um juízo sobre as técnicas ambientais pelas quais esses edifícios empregam aparato tecnológico e de consumo energético para operarem e alcançarem os índices pretendidos - são as chamadas estratégias "ativas". Aqueles procedimentos de projeto que levariam a um "verde profundo" [deep green] são chamados de "passivos", por funcionarem sem intervenção, pelo próprio modo como o projeto é concebido e construído. Assim, a arquitetura de "verde profundo" serve-se da ventilação natural ao invés do condicionamento de ar; da opacidade e da inércia térmica ao invés de vidros sofisticados; da luz solar e sua melhor distribuição pelo

21. No original: "provides the green building benchmarks, but doesn't tell applicants how to get the points" David Gottfried, Explosion green: one man's journey to green the world’s largest industry, Prefácio de Paul Hawken. Introdução de Rick Fedrizzi. (Nova York: Morgan James, 2014), 128, tradução nossa.

22. No original: "technological innovations, including cutting-edge insulation or windows, low-energy lighting, 'smart' thermostats with state-of-the-art heating, ventilation and air conditioning (HVAC) systems, or rooftop photovoltaic solar panels." E Eric Boschmann e Jessica N Gabriel, "Urban sustainability and the LEED rating system: case studies on the role of regional characteristics and adaptive reuse in green building in Denver and Boulder, Colorado", The Geographical Journal 179, $\mathrm{n}^{\circ} 3$ (setembro de 2013): 223, https://doi.org/10.1111/j.1475-4959.2012.00493.x, tradução nossa. 
ambiente ao invés da iluminação artificial; das soluções historicamente testadas ao invés dos avanços tecnológicos mais recentes.

Se é pelo controle mecânico dos ambientes que é garantida a sustentabilidade dos espaços corporativos certificados pelo sistema LEED $^{\circledast}$, e não por soluções tipológicas, então os projetos têm aqui menos uma questão espacial do que de regulação tecnológica. O procedimento projetual principal no LEED ${ }^{\circledR}$ não trata de cortes e plantas adaptados aos fluxos de ar e à penetração da luz, tal como nos diagramas comuns em arquiteturas ambientais, mas sobretudo da mecanização do ambiente. Esse procedimento, embora marginal na história da arquitetura, foi explorado por Reyner Banham em seu A arquitetura do ambiente bem controlado, em tradução livre. Banham de certo modo anteviu a expansão dos espaços climatizados nas décadas seguintes, tanto em edifícios de escritórios como nos shopping centers. Para ele, essas tipologias espaciais da modernidade só foram permitidas pelo desenvolvimento e disponibilização comercial dos sistemas mecânicos. Caso contrário, seria impossível utilizar esses ambientes profundos, distantes de janelas, sem luz ou ventilação naturais, mas concebidos para terem alta ocupação de pessoas, atividades e equipamentos. ${ }^{23}$ Seu argumento interessa aqui por esses dois aspectos: o da viabilização de espaços pela climatização artificial, já que sua geometria não permitiria a ocupação de outro modo; e o de como é a comercialização dos sistemas mecânicos, mais do que a sua invenção isolada, que permite generalizar no território tipologias como a dos edifícios de escritórios. Se os sistemas LEED $^{\circledast}$ podem ter um papel na história da arquitetura tal como lida por Banham, seria o de promover e viabilizar comercialmente sistemas mecânicos cada vez mais eficientes em seu funcionamento e responsivos em sua operação - como nos equipamentos de ar condicionado ou de iluminação elétrica não só de menor consumo, mas também autonomamente adaptáveis à temperatura ou luminosidade de pontos específicos do pavimento-tipo.

Certamente, o $\mathrm{LEED}^{\circledR}$ não é o único responsável pelos edifícios progressivamente mais mecanizados. A historiografia de Banham já mostrava como esse processo é regular na arquitetura do século XX. Mas o LEED ${ }^{\circ}$ reforça a mecanização da arquitetura no campo ambiental, um fenômeno incomum antes da década de 1990.

23. Reyner Banham, The architecture of the well-tempered environment (Londres, Reino Unido; Chicago, EUA: The Architectural Press; The University of Chicago Press, 1969), 71, 86. 
Créditos como EA.Prereq.1 Fundamental Commissioning of Building Energy Systems e EA.3 Enhanced Commissioning, encontrados tanto no LEED ${ }^{\circledR}$ NC quanto no CS, estão diretamente relacionados à verificação dos sistemas prediais, e pelo menos 58 pontos do LEED ${ }^{\circ} \mathrm{NC}$ v3 tratam ao menos parcialmente desse tema. ${ }^{24}$ Embora os créditos nunca se reduzam explicitamente aos sistemas prediais, prevendo soluções com iluminação e ventilação naturais, há uma tendência do LEED $^{\circledast}$ em tratar desses sistemas mais do que das estratégias passivas. Arquitetos ouvidos para a pesquisa argumentam que a ausência da mecanização dificultaria a obtenção de grande parte dos índices exigidos pelos sistemas LEED ${ }^{\oplus}$. Isso porque os índices exigidos não são adequados para climas tropicais, como notado por Jerry Yudelson, em relação a empreendimentos norte-americanos:

A verdade é que um projeto de nova construção que visa a certificação LEED vai descobrir que é muito fácil ser certificado, se ele cumpre todos os pré-requisitos e lembra de documentar os critérios específicos no momento apropriado. Entretanto, tipos de projeto inusuais podem descobrir que conseguir a aprovação do modelo energético pode ser um grande obstáculo, já que o cumprimento do requisito de performance energética mínima [EA.Prereq.2] depende do uso de um protocolo de modelo ASHRAE específico. Um exemplo é o dos projetos em regiões que não usam nenhum ar condicionado, como as do Caribe ou Havaí. ${ }^{25}$

\footnotetext{
24. Nessa listagem, foram considerados os seguintes créditos, por tratarem de sistemas e equipamentos hidráulicos, elétricos, de condicionamento de ar e de saneamento: SS.4.3 Alternative Transportation - Low-Emitting and Fuel-Efficient Vehicles, SS.6.1 Stormwater Design - Quantity Control, SS.6.2 Stormwater Design - Quality Control, SS.8 Light Pollution Reduction, WE.Prereq.1 Water Use Reduction, WE.1 Water Efficient Landscaping, WE.2 Innovative Wasterwater Technologies, WE.3 Water Use Reduction, EA.Prereq.1 Fundamental Commissioning of Building Energy Systems, EA.Prereq.2 Minimum Energy Performance, EA.Prereq. 3 Fundamental Refrigerant Management, EA.1 Optimize Energy Performance, EA.2 On-Site Renewable Energy, EA.3 Enhanced Commissioning, EA.4 Enhanced Refrigerant Management, EA.5 Measurement and Verification, EQ.Prereq.1 Minimum Indoor Air Quality Performance, EQ.1 Outdoor Air Delivery Monitoring, EQ.2 Increased Ventilation, EQ.5 Indoor Chemical and Pollutant Source Control, EQ.6.1 Controllability of Systems - Lighting, EQ.6.2 Controllability of Systems - Thermal Comfort, EQ.7.1 Thermal Comfort - Design, EQ.7.2 Thermal Comfort - Verification.

25. No original: "[T] he reality is that a new construction project that aims at LEED certification will find it pretty easy to get certified, if it meets all prerequisites and remembers to document specific criteria at the appropriate time. However, unusual project types may find that getting an energy model accepted could be the biggest obstacle, since meeting the minimum energy performance prerequisite depends on using a specific ASHRAE modeling protocol. In some instances, even low-energy-using projects may have a hard time meeting the energy prerequisite. An example is projects in regions that don't use any air-conditioning, such as the Caribbean or Hawaii." Yudelson, Reinventing green building, 115-16, grifo no original, tradução nossa.
} 
"Projeto inusual" é, portanto, todo aquele fora do contexto geográfico em que o LEED ${ }^{\circledR}$ foi inicialmente concebido. A dificuldade em modelar os edifícios para operar sem climatização mecânica aliada à resistência dos clientes corporativos em utilizar ventilação natural levam à generalização e reafirmação das estratégias ativas nos sistemas LEED ${ }^{\circledR}$.

A otimização e sofisticação dos sistemas prediais é coerente com a modernização ecológica do LEED ${ }^{\oplus}$, já que desse modo a sustentabilidade é atingida pelo desenvolvimento de novos produtos da construção civil. A sustentabilidade está nas especificações de produtos elaborados por fornecedores e não no projeto arquitetônico ou mesmo na eventual supressão desses produtos, o que não tem espaço dentro da política de incentivos, e não de penalizações, do USGBC .

Por outro lado, a American Society of Heating, Refrigerating and Air-Conditioning Engineers (ASHRAE), ligada à climatização dos ambientes, é protagonista no LEED ${ }^{\circledR}$. A versão piloto do $\mathrm{LEED}^{\circledR} \mathrm{NC}$ tem pouco material próprio, referindo-se constantemente a inúmeras outras normas, leis, regulações e protocolos, vindos da ANSI, ASHRAE, ASTM, DOE, Energy Star, EPA, GSA, NJDEP, OSHA, OSWER (atual OLEM), SMACNA e leis municipais específicas de maior exigência no território dos Estados Unidos. A partir da versão 2, a maior parte dessas referências é retirada, mas são mantidas aquelas da ANSI, ASHRAE e ASTM, proeminentes até a atual versão 4.1, o que é evidência da centralidade dessas entidades na concepção do LEED ${ }^{\circledR}$ desde a fundação do USGBC ${ }^{\oplus}$.

\section{A ARQUITETURA DO ENVELOPE}

Uma das principais normas atreladas ao LEED ${ }^{\circledR}$ v3 é a ASHRAE Standard 90.1-2007 Energy Standard for Buildings - Except Low-Rise Residential Buildings, elaborada com o American National Standards Institute (ANSI) e a Illuminating Engineering Society of North America (IESNA). As versões do LEED ${ }^{\circledR}$ acompanham as diferentes versões da norma. Ela é exigida em dois créditos dos sistemas $\mathrm{LEED}^{\circledR} \mathrm{NC}$ e CS na categoria de energia: um pré-requisito e o crédito que concentra a maior quantidade de pontos possíveis nos dois sistemas. ${ }^{26}$ Ela foi, ainda, utilizada como base para o sistema brasileiro de avaliação energética, o Procel.

26. EA.Prereq.2 Minimum Energy Performance e EA.1 Optimize Energy Performance. 
Como Rodrigo Cavalcante explica em sua dissertação, a norma ASHRAE 90.1 é dividida em diversas seções e apêndices, sendo o $G$ referenciado pelo LEED ${ }^{\circledR}$ nesses dois créditos. Esse apêndice, de nome Performance Rating, trata da avaliação dos projetos com desempenho melhor do que o previsto na norma. De acordo com essa metodologia, dois modelos devem ser aferidos em simulação digital: de um lado, o projeto de fato proposto, e, de outro, um edifício de referência [baseline building]. Os dois edifícios modelados devem ser iguais, salvo: 1) as propriedades do envelope e o tamanho das aberturas, em que o "modelo de comparação deve ser modelado com cobertura isolada termicamente, paredes externas como steel-framed, pisos como steel-joist e WWR [Window-to-Wall Ratio] com 40\% ou igual ao de projeto, qual dos dois for menor"; ${ }^{27} 2$ ) qualquer tipo de quebra-sol, que deve ser removido no modelo de referência; 3 ) a orientação do projeto, em que o modelo de referência deve ter carga térmica estimada a partir da média entre a orientação do edifício proposto e as performances em outras três orientações, obtidas pela rotação do projeto em $90^{\circ}, 180^{\circ}$ e $270^{\circ}$; 4) a carga proveniente da iluminação artificial, que deve seguir a prescrição da norma no caso do modelo de referência; e 5) os sistemas de condicionamento de ar, que também devem seguir a prescrição da norma para a referência. Em resumo, as diferenças entre os dois modelos simulados são a orientação, as especificações dos sistemas prediais e as características do envelope.

Para cumprir o pré-requisito 2 de energia no LEED $^{\circledR}$, o candidato precisa demonstrar que o desempenho energético do seu projeto é pelo menos $10 \%$ melhor do que o modelo de referência. Já para conseguir um ponto no crédito Optimize Energy Performance do LEED ${ }^{\circledR}$ NC, o projeto precisa ser $12 \%$ melhor e, a cada $2 \%$ de incremento, um ponto a mais é concedido, com teto em 48\%; acima disso, são os mesmos 19 pontos que são conferidos. O mesmo vale para o LEED ${ }^{\circledR}$ CS, com pequenas diferenças nos limites inferior e superior: iguais $12 \%$ de eficiência equivalem agora a três pontos, e $48 \%$ atingem agora 21 pontos. A versão 4 do LEED $^{\circledR}$ mantém parâmetros semelhantes, em que a norma ASHRAE 90.1 é usada em sua versão 2010, mais exigente, mas os sistemas, por sua vez, requerem um incremento menor. ${ }^{28}$

\footnotetext{
27. Rodrigo de Castro Dantas Cavalcante, "Simulação energética para análise da arquitetura de edifícios de escritório além da comprovação de conformidade com códigos de desempenho" (Dissertação (Mestrado em Tecnologia da Arquitetura), Orientador: Ualfrido Del Carlo, Faculdade de Arquitetura e Urbanismo da Universidade de São Paulo, 2010), 44.

28. No LEED ${ }^{\circ} \mathrm{NC}$ v4 o pré-requisito é de um desempenho 5\% melhor para o pré-requisito; o limite inferior é um ponto para
} 
Cavalcante fez simulações energéticas no software Energy Plus, com estudos de caso anônimos e projetos fictícios, e as comparou com o estabelecido na ASHRAE 90.1. Com isso, ele demonstra que geometrias com melhor desempenho energético não significam necessariamente uma melhor avaliação na norma. Afinal, mesmo se uma dada geometria for mais eficiente - conforme seus exemplos: por dispor a torre de circulação e serviços fora do edifício, em uma fachada com alta carga térmica, sombreando o volume principal ocupado, ou pela criação de um átrio interno para iluminação e ventilação -, ela não tem impacto no cálculo de eficiência, por ser uma constante. ${ }^{29} \mathrm{Tal}$ como exposto acima, as variáveis de cálculo são o envelope, os sistemas prediais e a orientação, essa última em menor medida. A geometria é inescrutável à ASHRAE e ao LEED ${ }^{\circledR}$.

Ao submeter a documentação para avaliação pelo LEED $^{\oplus}$, um empreendimento brasileiro pode demonstrar o cumprimento do Procel Nível A no lugar da ASHRAE 90.1, uma substituição que tem pouco efeito nas conclusões apresentadas: o sistema brasileiro apenas avalia a envoltória em termos de transmitância térmica, cor, absortância e iluminação zenital relacionados ao condicionamento de ar. Ainda que um "fator de forma" seja incluído no cálculo, igualmente não há interferência na geometria do edifício, e mesmo medidas simples como a pintura de superfícies externas com tintas de baixa absortância é suficiente para classificar um edifício convencional no Nível A. ${ }^{30}$

É essa a norma ASHRAE mencionada na seção anterior, quando Yudelson foi citado sobre a dificuldade de ser bem avaliado pelo LEED ${ }^{\circledR}$ sem o uso de sistemas mecânicos. Tem-se então outro aspecto do projeto arquitetônico no LEED ${ }^{\circledR}$ : a ênfase no projeto do envelope. As duas características operam conjuntamente, pois quanto melhor a performance do envelope, menor o consumo energético no condicionamento de ar.

O envelope tende, por esse motivo, a ser selado para reduzir a troca de calor pela ventilação do ar. Para o LEED ${ }^{\circledR}$ o envelope precisa também de um bom desempenho térmico, a

6\% e 18 para 50\%. No CS v4 o pré-requisito é de $2 \%$; o limite inferior é um ponto para $3 \%$ e 18 para $47 \%$.

29. Cavalcante, "Simulação energética para análise da arquitetura de edifícios de escritório além da comprovação de conformidade com códigos de desempenho". Outros autores enfatizam como esse procedimento reforça necessidade de uma boa especificação de vidro no lugar de outras soluções de projeto, o que é especialmente problemático no Brasil; cf. Joana Carla Soares Gonçalves e Klaus Bode, orgs., Edifício ambiental (São Paulo: Oficina de Textos, 2015), 532.

30. Norma do Nascimento Batista, Emilio Lèbre La Rovere, e João Carlos Rodrigues Aguiar, "Energy efficiency labeling of buildings: An assessment of the Brazilian case", Energy and Buildings 43, nº 6 (junho de 2011): 1179-88, https://doi.org/10.1016/j.enbuild.2010.11.010. 
princípio obtido pela redução da área de vidro. O vidro normalmente tem índices térmicos inferiores a materiais opacos, então a solução de projeto mais simples seria a diminuição da área de janelas, o WWR, de resto um dos elementos levados em conta na simulação da ASHRAE 90.1. Embora não seja compulsória, a proporção de no máximo 40\% de área envidraçada é relevante nos cálculos e imperativa no projeto, à revelia da sua localização geográfica e do seu entorno urbano. Por esse motivo, arquitetos de edifícios corporativos queixam-se da perda de autonomia na decisão de projeto, como faz Alberto Botti, do Botti Rubin, em entrevista para a pesquisadora Isadora Guerreiro:

E agora tem o problema do pessoal do LEED, do 'verde', que chega assim e diz para você: "diminui a janela do prédio porque senão eu não te dou ponto"... Entre as regras cuspidas por estes grandes escritórios de comercialização, principalmente entre escritórios de origem americana e as regras de LEED e outras coisas assim, o negócio está engessando a arquitetura de uma maneira incrível. Você sabe qual é a proporção que o LEED propõe? Este prédio [Edifício Plantar, IG] não serve. Tem que ter 50\% de vão [na verdade $40 \%, \mathrm{RG}$ ] para 50\% de parede [na verdade 60\%, RG]. Pelo amor de Deus! Cada caso é um caso! Se esta sala tem seis metros, esta janela está dimensionada de um jeito. Se ela tivesse oito metros, e não tivesse aquela parede, por exemplo, esta janela tinha que ser maior para dar mais iluminação. Então isso é um absurdo! $!^{31}$

No exercício proposto neste capítulo, do edifício virtualmente prefigurado pelo LEED $^{\circledR}$, o envelope selado, com $60 \%$ de superfície opaca, teria ainda formas puras e concisas. O aumento do perímetro do edifício por meio de dobras na fachada é um recurso possível para ganhar um ponto no crédito EQ.8.1 Daylight and Views - Daylight, que requer entre 108 e 500 lux de luz natural em ao menos $75 \%$ do espaço ocupado. Em contrapartida, essa mesma medida pode representar o aumento da carga térmica do edifício, comprometendo a pontuação no crédito principal dos sistemas LEED ${ }^{\circ} \mathrm{NC}$ e CS, o Optimize Energy Performance, donde maior relevância para a pontuação, a princípio, de um projeto de menor perímetro para a mesma área de pavimento-tipo.

\footnotetext{
31. Isadora de Andrade Guerreiro, "Arquitetura-capital: a funcionalidade dos edifícios corporativos paulistas" (Dissertação (Mestrado em Projeto, Espaço e Cultura). Orientadora: Vera Maria Pallamin, Faculdade de Arquitetura e Urbanismo da Universidade de São Paulo, 2010), 185.
} 


\section{IMPLANTAÇÃO E ÁREAS VERDES}

A limitação do perímetro para reduzir a carga térmica e a baixa WWR podem levar à menor incidência de luz natural no interior dos espaços ocupados. Para resolver esse problema em edifícios de múltiplos andares, não são possíveis claraboias para iluminar espaços profundos. Poços de iluminação no centro do edifício, por sua vez, além de serem soluções formais sem privilégios na ASHRAE 90.1, podem também levar ao aumento do perímetro do edifício e consequentemente de sua carga térmica. Existem diversas estratégias de difusão da luz natural pelos ambientes, mas interessa aqui a possibilidade de apenas limitar a profundidade do edifício. Essa solução simples pode ajudar na obtenção de um ponto não só em EQ.8.1 Daylight and Views - Daylight, mas também potencialmente em EQ.8.2 Daylight and Views - Views, no qual deve-se garantir uma linha direta de visão para o exterior em 75\% do espaço ocupado.

Evidentemente, soluções mais aprimoradas do que essa também podem ser empregadas para garantir a iluminação natural, como prateleiras de luz, quebra-sóis para impedir ofuscamento ou controle fotossensível. A redução da profundidade do edifício, entretanto, a priori não representa aumento no custo e tem efeito em diversos outros créditos, a começar pelo SS.5.2 Site Development - Maximize Open Space, no qual é exigida uma redução na área ocupada pelo edifício de modo a aumentar em $25 \%$ a área livre no térreo. Essa redução, por sua vez, leva à maior quantidade de áreas permeáveis exigida em SS.6.1 e SS.6.2 Stormwater Design. Ela também abre espaço para vegetação de sombreamento requisitada em SS.7.1 Heat Island Effect - Nonroof, além da restauração da flora em SS.5.1 Site Redevelopment - Protect or Restore Habitat. Esse último crédito sugere "limites claramente marcados na construção", a concentração do programa e o reforço da separação entre edifício e entorno que garantiriam a preservação de parte da vegetação do terreno. ${ }^{32}$ O crédito SS.1 Site Selection igualmente defende "um edifício com projeção mínima"

\footnotetext{
32. Em um dos cursos de formação do GBC Brasil realizados pelo autor durante essa pesquisa, a diminuição da área de ocupação no térreo como estratégia com impacto na redução das ilhas de calor e no aumento de área permeável foi mencionada pelo instrutor. Os créditos SS.5.1 e SS.5.2 também sugerem a sobreposição do programa do empreendimento em andares como solução. A citação no original é “clearly-marked construction boundaries”. Cf. USGBC (United States Green Building Council), "LEED 2009 for new construction and major renovations with alternative compliance paths for projects outside the US; v. 3 reference guide”, 12-14, tradução nossa; Stephen Del Percio também nota como os créditos vinculados à categoria SS incentivam a construção em altura, embora, para ele, os incentivos para essa solução ainda fossem baixos -
} 
como modo de dirimir impactos no entorno. ${ }^{33}$ Desse modo, a combinação entre redução na profundidade do edifício, seu isolamento e o paisagismo impactam potencialmente em oito pontos dos sistemas LEED ${ }^{\oplus} \mathrm{NC}$ e CS.

Tomando como referência apenas os motivos expostos nos próprios sistemas, o aumento de espaços livres e vegetação resultante dessas medidas leva a benefícios ambientais como maior biodiversidade e infiltração de água e menor impacto térmico na fauna e nos ocupantes do edifício. Entretanto, o provimento de áreas livres não acarreta necessariamente seu usufruto direto pela população do entorno, pois os sistemas NC e CS não dispõem sobre o fechamento do empreendimento. Essas áreas livres podem permanecer de acesso privado, a depender do estipulado pelo proprietário - o que é diferente do sistema $\mathrm{LEED}^{\circ} \mathrm{ND}$, a ser tratado na parte IV.

O aumento de áreas livres previsto nos sistemas NC e CS tampouco representa necessariamente o adensamento de atividades para a população. Muito embora os sistemas sugiram a implantação em área de grande oferta de serviços, portanto em um local de centralidade urbana, os créditos usufruem do seu entorno sem oferecer contrapartida. Assim, o crédito SS.2 Development Density and Community Connectivity oferece cinco pontos para o empreendimento localizado: 1) em área já ocupada, 2) a até 800 metros de um bairro com pelo menos 10 unidades por acre (1 un./400 $\left.\left.\mathrm{m}^{2}\right), 3\right)$ a até 800 metros de dez serviços básicos, 4) em área com percurso possível por pedestres. Desses dez serviços básicos contados para os pontos - restaurantes, igrejas, parques, farmácias, escolas etc. -, apenas um pode se localizar dentro do projeto certificado. É assegurado, com isso, que o empreendimento tenha uso único.

Nesse sentido, as exigências de implantação do LEED ${ }^{\oplus}$ têm um efeito duplo: por um lado, edifícios isolados em meio à vegetação, que pode ser cercada sem impacto na pontuação; por outro, o beneficiamento com a pluralidade de atividades no entorno, sem que o empreendimento também precise apresentar aos vizinhos novas funções.

uma interpretação que não é seguida por essa pesquisa. Cf. "The skyscraper, green design, \& the LEED green building rating system: the creation of uniform sustainable standards for the 21st century or the perpetuation of an architectural fiction?", Environs: Environmental Law and Policy Journal 28, $\mathrm{n}^{\circ} 1$ (2004): 117-54.

33. USGBC (United States Green Building Council), "LEED 2009 for new construction and major renovations with alternative compliance paths for projects outside the US; v. 3 reference guide", 3. 


\begin{tabular}{|c|c|c|}
\hline Fase & Membros GBC (US\$) & $\begin{array}{l}\text { Membros organizacionais } \\
\text { e não-membros (US\$) }\end{array}$ \\
\hline Registro & $\$ 900$ & $\$ 1.200$ \\
\hline Pré-certificação $\left(\right.$ LEED $\left.^{\circledR} \mathrm{CS}\right)$ & $\$ 3.250$ & $\$ 4.250$ \\
\hline \multicolumn{3}{|l|}{ Análise de projeto } \\
\hline Até $50.000 \mathrm{ft}^{2}$ (aprox. $4.645 \mathrm{~m}^{2}$ ) & $\$ 2.250$ & $\$ 2.750$ \\
\hline $\begin{array}{l}50.000 \text { a } 500.000 \mathrm{ft}^{2} \\
\left(\text { aprox. } 4.645 \text { a } 46.451 \mathrm{~m}^{2} \text { ) }\right.\end{array}$ & $\$ 0,45 / \mathrm{m}^{2}$ & $\$ 0,55 / \mathrm{m}^{2}$ \\
\hline $\begin{array}{l}\text { Acima de } 500.000 \mathrm{ft}^{2} \\
\left(\text { aprox. } 46.451 \mathrm{~m}^{2}\right)\end{array}$ & $\$ 22.000$ & $\$ 27.500$ \\
\hline \multicolumn{3}{|l|}{ Análise de obra } \\
\hline Até $50.000 \mathrm{ft}^{2}$ (aprox. $4.645 \mathrm{~m}^{2}$ ) & $\$ 500$ & $\$ 750$ \\
\hline $\begin{array}{l}50.000 \text { a } 500.000 \mathrm{ft}^{2} \\
\left(\text { aprox. } 4.645 \text { a } 46.451 \mathrm{~m}^{2} \text { ) }\right.\end{array}$ & $\$ 0,10 / \mathrm{m}^{2}$ & $\$ 0,15 / \mathrm{m}^{2}$ \\
\hline $\begin{array}{l}\text { Acima de } 500.000 \mathrm{ft}^{2} \\
\left(\text { aprox. } 46.451 \mathrm{~m}^{2} \text { ) }\right.\end{array}$ & $\$ 5.000$ & $\$ 7.500$ \\
\hline
\end{tabular}

Tab 7.3. Taxas de certificação para o sistema $\mathrm{LEED}^{\circledR} \mathrm{BD}+\mathrm{C}$ v4. Fonte: USGBC, fevereiro 2014 via material didático GBC Brasil, “Como se tornar um LEED BD+C”, 2015.

Essa tabela de custos, desatualizada, é aqui apresentada por ser a mais próxima da empregada nos empreendimentos mencionados ao longo da tese, especialmente no próximo capítulo. 


\begin{tabular}{|c|c|c|}
\hline Fase & Membros GBC (US\$) & $\begin{array}{l}\text { Membros organizacionais } \\
\text { e não-membros (US\$) }\end{array}$ \\
\hline Registro & $\$ 1.200$ & $\$ 1.500$ \\
\hline \multicolumn{3}{|l|}{ Pré-certificação } \\
\hline Taxa fixa & $\$ 4.000$ & $\$ 5.000$ \\
\hline Taxa expressa (redução de 20-25 para 10-12 dias úteis) & $\$ 5.000$ & \\
\hline \multicolumn{3}{|l|}{ Análise da certificação registrada } \\
\hline Área bruta do projeto (sem estacionamento), até & $\$ 0,057 / \mathrm{ft}^{2}$ (aprox. $\left.\$ 0,61 / \mathrm{m}^{2}\right)$ & $\$ 0,068 / \mathrm{ft}^{2}$ (aprox. $\$ 0,73 / \mathrm{m}^{2}$ ) \\
\hline $250.000 \mathrm{ft}^{2}$ (aprox. $23.225 \mathrm{~m}^{2}$ ) & Mínimo $\$ 2.850$ & Mínimo $\$ 3.420$ \\
\hline Área bruta do projeto (sem estacionamento), $250.000 \mathrm{a}$ & $\$ 0,055 / \mathrm{ft}^{2}$ (aprox. $\left.\$ 0,59 / \mathrm{m}^{2}\right)$ & $0,066 / \mathrm{ft}^{2}$ (aprox. $\$ 0,71 / \mathrm{m}^{2}$ ) \\
\hline $499.999 \mathrm{ft}^{2}$ (aprox. 23.225 a $46.451 \mathrm{~m}^{2}$ ) & Mínimo \$14.250 & Mínimo \$17.100 \\
\hline Área bruta do projeto (sem estacionamento), $500.000 \mathrm{a}$ & $0,05 / \mathrm{ft}^{2}$ (aprox. $\$ 0,53 / \mathrm{m}^{2}$ ) & $0,06 / \mathrm{ft}^{2}$ (aprox. $\$ 0,64 / \mathrm{m}^{2}$ ) \\
\hline $749.999 \mathrm{ft}^{2}$ (aprox. 46.451 a $69.677 \mathrm{~m}^{2}$ ) & Mínimo $\$ 27.500$ & Mínimo $\$ 33.000$ \\
\hline $\begin{array}{l}\text { Área bruta do projeto (sem estacionamento), } 750.000 \\
\mathrm{ft}^{2} \text { ou acima (aprox. } 69.677 \mathrm{~m}^{2} \text { ) }\end{array}$ & Cotação sob demanda & Cotação sob demanda \\
\hline Taxa expressa & $\$ 10.000$ & \\
\hline \multicolumn{3}{|l|}{ Análise em etapas - Projeto } \\
\hline Área bruta do projeto (sem estacionamento), até & $\$ 0,047 / \mathrm{ft}^{2}$ (aprox. $\left.\$ 0,50 / \mathrm{m}^{2}\right)$ & $\$ 0,055 / \mathrm{ft}^{2}$ (aprox. $\$ 0,59 / \mathrm{m}^{2}$ ) \\
\hline $250.000 \mathrm{ft}^{2}$ (aprox. $23.225 \mathrm{~m}^{2}$ ) & Mínimo \$2.325 & Mínimo $\$ 2.740$ \\
\hline Área bruta do projeto (sem estacionamento), $250.000 \mathrm{a}$ & $\$ 0,045 / \mathrm{ft}^{2}$ (aprox. $\$ 0,48 / \mathrm{m}^{2}$ ) & $\$ 0,053 / \mathrm{ft}^{2}$ (aprox. $\$ 0,57 / \mathrm{m}^{2}$ ) \\
\hline $499.999 \mathrm{ft}^{2}$ (aprox. 23.225 a $46.451 \mathrm{~m}^{2}$ ) & Mínimo \$11.625 & Mínimo \$13.760 \\
\hline Área bruta do projeto (sem estacionamento), $500.000 \mathrm{a}$ & $\$ 0,041 / \mathrm{ft}^{2}$ (aprox. $\$ 0,44 / \mathrm{m}^{2}$ ) & $\$ 0,049 / \mathrm{ft}^{2}$ (aprox. $\$ 0,52 / \mathrm{m}^{2}$ ) \\
\hline $749.999 \mathrm{ft}^{2}$ (aprox. 46.451 a $69.677 \mathrm{~m}^{2}$ ) & Mínimo \$22.500 & Mínimo \$26.625 \\
\hline $\begin{array}{l}\text { Área bruta do projeto (sem estacionamento), } 750.000 \\
\mathrm{ft}^{2} \text { ou acima (aprox. } 69.677 \mathrm{~m}^{2} \text { ) }\end{array}$ & Cotação sob demanda & Cotação sob demanda \\
\hline Taxa expressa & $\$ 10.000$ & \\
\hline \multicolumn{3}{|l|}{ Análise em etapas - Construção } \\
\hline Área bruta do projeto (sem estacionamento), até & $\$ 0,016 / \mathrm{ft}^{2}$ (aprox. $0,17 / \mathrm{m}^{2}$ ) & $\$ 0,018 / \mathrm{ft}^{2}$ (aprox. $\$ 0,19 / \mathrm{m}^{2}$ ) \\
\hline $250.000 \mathrm{ft}^{2}$ (aprox. $23.225 \mathrm{~m}^{2}$ ) & Mínimo $\$ 775$ & Mínimo $\$ 910$ \\
\hline Área bruta do projeto (sem estacionamento), $250.000 \mathrm{a}$ & $\$ 0,015 / \mathrm{ft}^{2}$ (aprox. $\$ 0,16 / \mathrm{m}^{2}$ ) & $\$ 0,018 / \mathrm{ft}^{2}$ (aprox. $\$ 0,19 / \mathrm{m}^{2}$ ) \\
\hline $499.999 \mathrm{ft}^{2}$ (aprox. 23.225 a $46.451 \mathrm{~m}^{2}$ ) & Mínimo \$3.875 & Mínimo \$4.585 \\
\hline Área bruta do projeto (sem estacionamento), $500.000 \mathrm{a}$ & $\$ 0,014 / \mathrm{ft}^{2}$ (aprox. $\$ 0,15 / \mathrm{m}^{2}$ ) & $\$ 0,016 / \mathrm{ft}^{2}$ (aprox. $\$ 0,17 / \mathrm{m}^{2}$ ) \\
\hline $749.999 \mathrm{ft}^{2}$ (aprox. 46.451 a $69.677 \mathrm{~m}^{2}$ ) & Mínimo $\$ 7.500$ & Mínimo $\$ 8.875$ \\
\hline $\begin{array}{l}\text { Área bruta do projeto (sem estacionamento), } 750.000 \\
\mathrm{ft}^{2} \text { ou acima (aprox. } 69.677 \mathrm{~m}^{2} \text { ) }\end{array}$ & Cotação sob demanda & Cotação sob demanda \\
\hline Taxa expressa & $\$ 10.000$ & \\
\hline \multicolumn{3}{|l|}{ Apelações } \\
\hline Créditos complexos & $\$ 800$ por crédito & \\
\hline Créditos & $\$ 500$ por crédito & \\
\hline Revisão expressa & $\$ 500$ por crédito & \\
\hline Consulta formal sobre créditos & $\$ 220$ por crédito & \\
\hline
\end{tabular}

Tab 7.4. Taxas de certificação para o sistema LEED ${ }^{\circledR} \mathrm{BD}+\mathrm{C}$

v4. Fonte: GBCI, 14 março 2019, tradução nossa. 

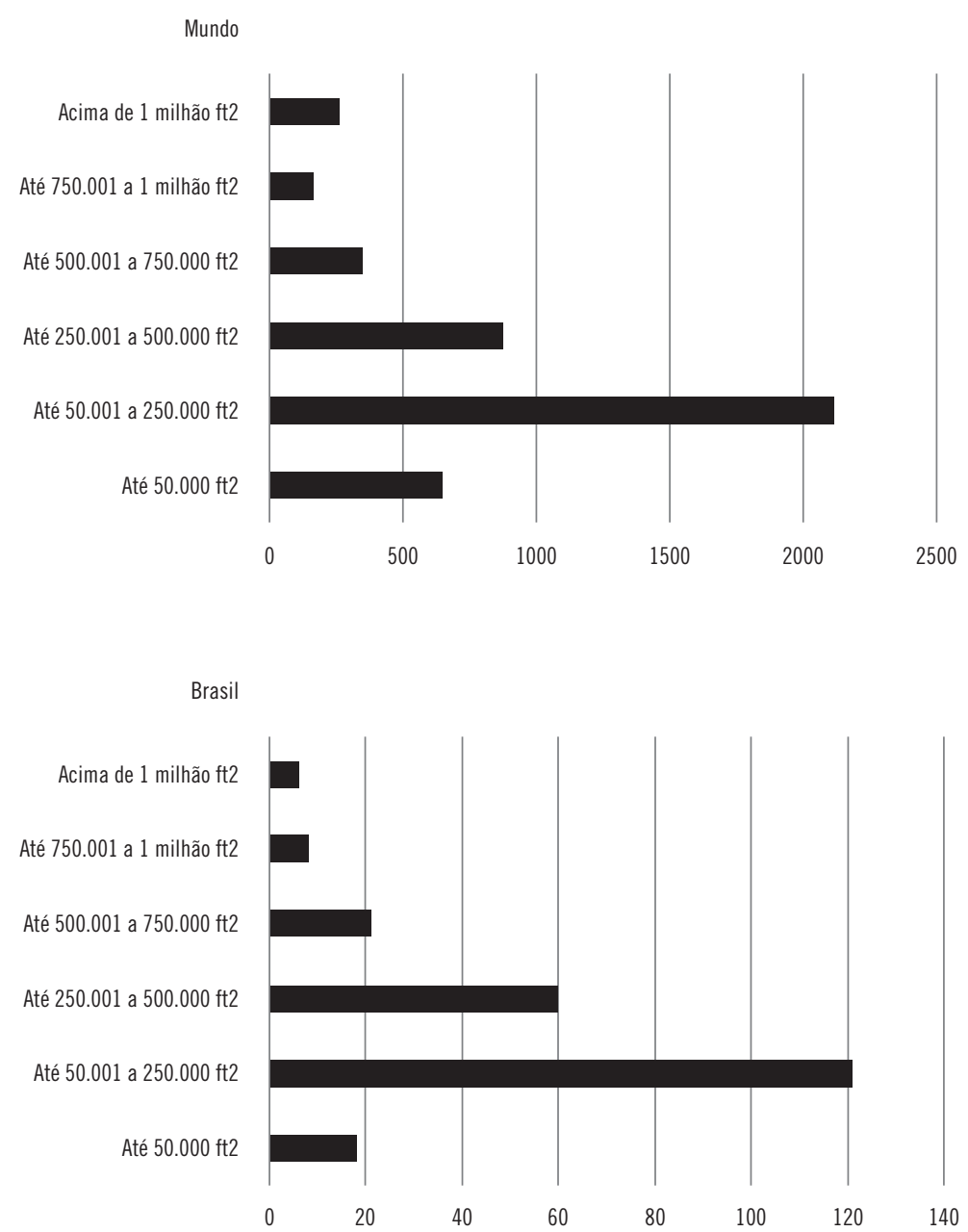

Fig 7.3. Distribuição das áreas dos edifícios certificados no sistema LEED ${ }^{\circ}$ CS. Fonte: LEED Project Directory (USGBC), com correções pelo autor a partir de Empreendimentos LEED (GBC Brasil), 4 jan 2019.

Elaborado pelo autor. 


\section{GRANDE PORTE}

A opção por estratégias ativas de regulação térmica [light green] e por materiais de alto desempenho no envelope repercute no aumento dos custos da construção e operação desses edifícios, quando comparados com as alternativas passivas [deep green]. Mas o custo decorre não só dos equipamentos mais sofisticados, incluindo sensores e performance adaptável, mas também pelas equipes de consultores e especialistas contratados.

Como já comentado, ${ }^{34}$ os principais relatos apontam entre 1 e $20 \%$ de aumento de custo. Ainda que os diversos GBCs enfatizem a redução gradual desses valores, eles continuam altos. Considerando como base esse intervalo de 1 a $20 \%$, pode-se inferir que a fração referente às medidas para certificação em um edifício de 500 milhões de reais, um investimento condizente a muitos dos empreendimentos tidos como modelos pelo GBC Brasil, corresponde a um aumento de valor entre 4,9 e 83,3 milhões de reais. ${ }^{35}$

Os limites inferior e superior têm diversas causas, como o grau de certificação almejado e a experiência em certificação de empreendedores, projetistas e construtores. Além disso, há as taxas pagas ao Green Business Certification Inc. (GBCI) para o processo de certificação [tab 7.3 e 7.4].

Edifícios maiores têm proporcionalmente menores custos, não só pelos ganhos de escala em equipamentos e vidros, como também pela diluição dos preços fixos de certificação e pelo fato de atingirem patamares de área com menores taxas de revisão pelo GBCI, como pode ser visto nas tabelas 7.3 e 7.4. A análise das áreas divulgadas pelo USGBC ${ }^{\oplus}$ são pouco conclusivas, pois há diversos empreendimentos sem área ou com área errada. Também porque, para efeito de cobrança de taxas, a área para estacionamentos é suprimida, constando esse valor nos dados divulgados. Por fim, empreendimentos grandes podem ser subdivididos no processo de certificação, como é o caso dos conjuntos de torres. Mas a grande área dos empreendimentos pode ser

\footnotetext{
34. Capítulo 5, Seção "Benefícios financeiros do edifício verde".

35. Como referências para os custos dos edifícios corporativos: o Rochaverá Corporate Towers teve investimento de 600 milhões de reais, cf. Ledy Valporto Leal, "Inclinação para o verde”, aU - Arquitetura \& Urbanismo, ago de 2008; o Morumbi Corporate custou 478 milhões de reais, cf. Heloísa Medeiros, “Fachada ajustável”, Téchne, ago de 2013; 220 milhões de dólares para o Ventura Corporate Towers e 117,18 milhões dólares para o Eldorado Business Tower, cf. "Most expensive buildings in South America”, Emporis, s/d, https://www.emporis.com/statistics/most-expensive-buildings/continent/100003/ south-america.
} 
verificada até mesmo nos patamares de cobrança do GBCI, já que a edição mais recente estabelece níveis de orçamento mais detalhados para empreendimentos maiores.

Para a certificação dos empreendimentos é uma vantagem, portanto, sua grande área. Conforme argumenta Jerry Yudelson:

Custos fixos para cumprir pré-requisitos para a certificação LEED - modelos de energia (exigidos apenas para novos edifícios), comissionamento de edifício (exigido para edifícios tanto novos quanto existentes), medidas específicas de projeto, custos de documentação e certificação - são proibitivos para esses edifícios menores. ${ }^{36}$

Além de maiores custos relativos em edifícios pequenos, a taxa de retorno ainda é dificultada fora de grandes centros urbanos, onde a construção sustentável é dificilmente uma vantagem relativa em um mercado imobiliário menos competitivo.

Como solução, Yudelson propõe a imediata passagem para a esfera digital, com a criação de um aplicativo para substituir o processo de certificação e a padronização de soluções para reduzir custos de projeto. Em alguma medida, já é essa a direção tomada pelo USGBC ${ }^{\oplus}$, a passo mais lento do que Yudelson propõe, com a criação da plataforma Arc para centralização online e em tempo real do desempenho de novos empreendimentos certificados. O plano pode colocar o $\mathrm{USGBC}^{\circledR}$ no campo das big techs, mas não resolve o obstáculo dos custos advindos da aparelhagem tecnológica inerente aos requisitos dos sistemas $\mathrm{LEED}^{\circledR} \mathrm{NC}$ e CS.

\section{EXPERIMENTAÇÕES FORMAIS NA ARQUITETURA AMBIENTAL CORPORATIVA}

Convém um recuo estratégico no argumento. Se o LEED ${ }^{\circledR}$ trabalha por meio desses atributos, quais seriam as alternativas da arquitetura ambiental - e sobretudo da arquitetura ambiental corporativa? O objetivo desta tese é o exame da arquitetura do LEED ${ }^{\oplus}$, sem registrar contra-a-

\footnotetext{
36. No original: "Fixed costs to meet prerequisites for LEED certification, energy modeling (required only for new buildings), building commissioning (required for both new buildings and existing buildings), specific design measures, operational changes, documentation and certification costs, are prohibitive for these smaller buildings." Yudelson, Reinventing green building, 99, grifo no original, tradução nossa.
} 
gendas. A apresentação de outras soluções para a arquitetura ambiental tem aqui a função mais de contraste do que de prescrição.

Para os fins desta pesquisa, a arquitetura autodefinida como ambiental pode ser lida por uma dupla origem, em geral conflituosa: na contracultura dos anos 1960 e na crise do petróleo em 1973. Essa afirmação vai contra muitas leituras da história da arquitetura. É comum nelas a busca de indícios de ambientalismo na arquitetura moderna, ao verem nas estratégias de ventilação e iluminação naturais, no resgate dos cobogós e técnicas tradicionais, e no desenho de quebra-sóis e novos dispositivos, se não de fato o início, ao menos o prelúdio da arquitetura ambiental. ${ }^{37}$ Entretanto, os arquitetos modernos nunca aludem em seus projetos ao meio ambiente, mas sim à higiene e ao bem-estar em oposição à decadência da cidade industrial. Mesmo que esses projetos possam excepcionalmente ter bom desempenho de conforto, a ecologia não faz parte da sua concepção e as estratégias de conforto não são encontradas em todo o conjunto da arquitetura moderna. Pelo contrário, para Alexander Cuthbert:

De modo geral, o modernismo foi um completo desastre para a prática da sustentabilidade, onde a maior parte dos edifícios altos, senão todos, tinha ganhos térmicos enormes, nenhuma proteção solar, pouca ou nenhuma ventilação natural, baixo ou nenhum isolamento, consumo energético indevido sem nenhuma produção e enormes infiltrações devido a cortinas de vidro ruins e outros fatores. ${ }^{38}$

As histórias da arquitetura ambiental elencadas acima são, portanto, inconsistentes em suas noções e instrumentais como discurso - um problema cujo debate historiográfico já está plenamente apresentado ao menos desde a análise de Manfredo Tafuri em 1968 sobre a "crítica operativa". Ou seja, a análise da crítica operativa é mesmo anterior às primeiras iniciativas da ar-

37. Consultar James Wines, Green architecture (Colônia: Taschen, 2000); Brian Edwards e Chrisna du Plessis, "Snakes in utopia: a brief history of sustainability", Architectural Design, julho de 2001; Phillip James Tabb e A. Senem Deviren, The greening of architecture: a critical history and survey of contemporary sustainable architecture and urban design (Surrey, Inglaterra; Burlington, EUA: Ashgate Publishing, 2013).

38. No original: "Overall, modernism was a wholesale disaster for the practice of sustainability, where most if not all high rises had massive solar gain, no sunscreening, poor or no natural ventilation, little or no insulation, undue energy consumption with no production, and massive leaks due to poor curtain walling and other factors." Alexander Cuthbert, Understanding cities: method in urban design (Oxford: Routledge, 2011), 176, tradução nossa. 


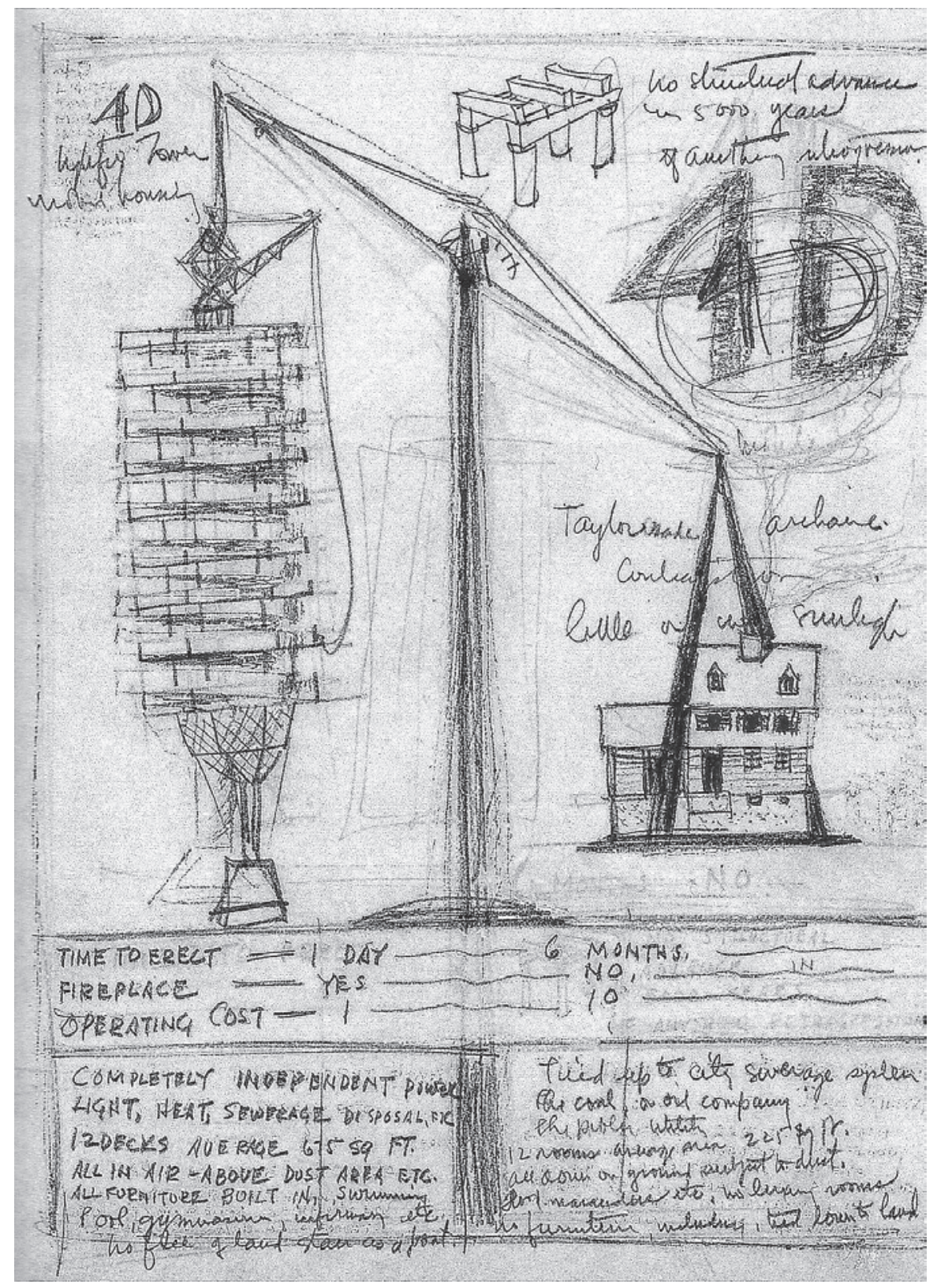

Fig 7.4. Buckminster Fuller, 4D Lightful Tower (1928). Fonte:

Foster e Fernández-Galiano, AV Monografias, n. 143, 5.

Croqui comparativo entre a solução de projeto e a construção tradicional, que demonstraria a maior leveza e eficiência no uso de recursos do projeto, precursor da arquitetura ambiental. 

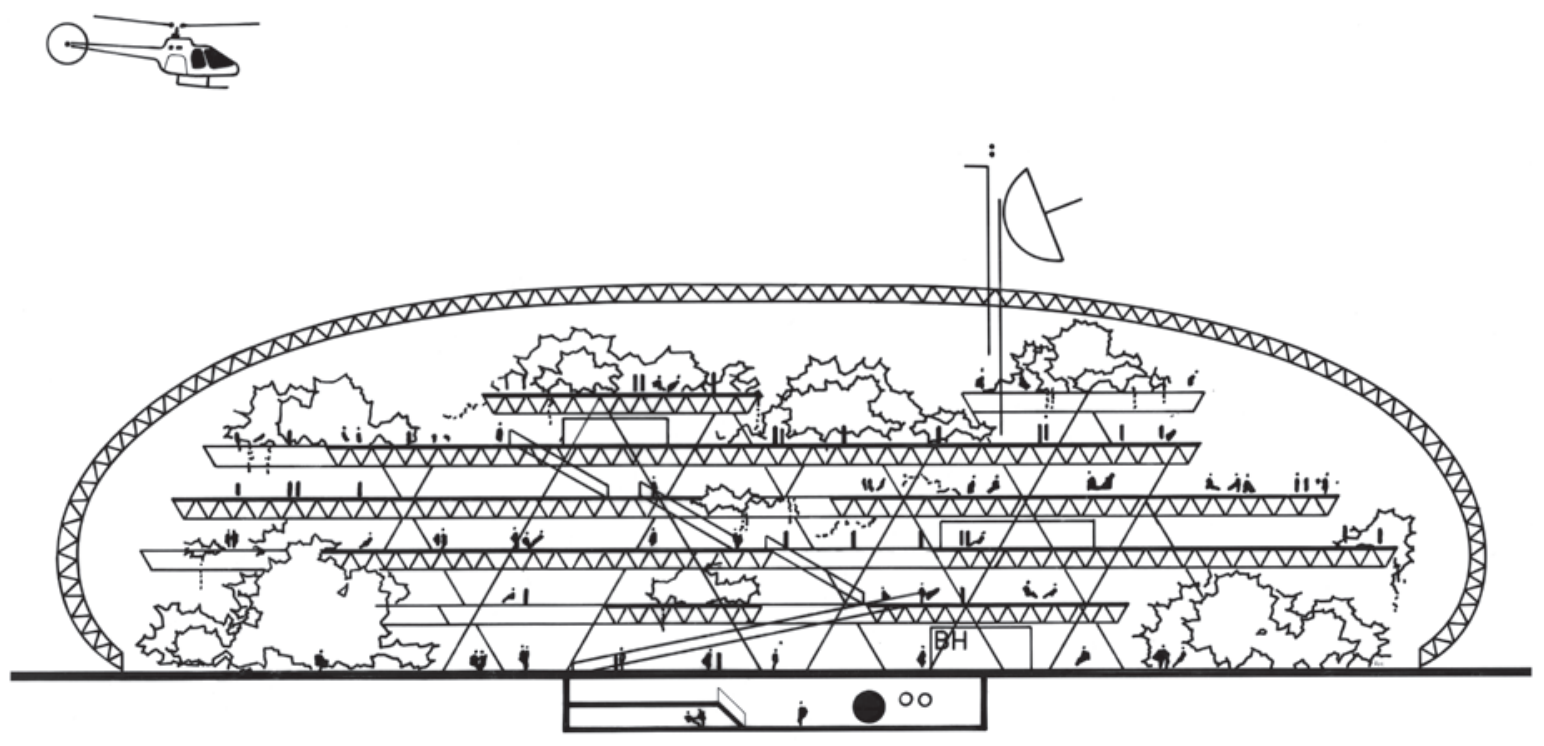

Fig 7.5. Buckminster Fuller e Norman Foster, Climatroffice (c1971). Fonte: Norman Foster Foundation Archive. Concepção de escritórios com preceitos ambientais.

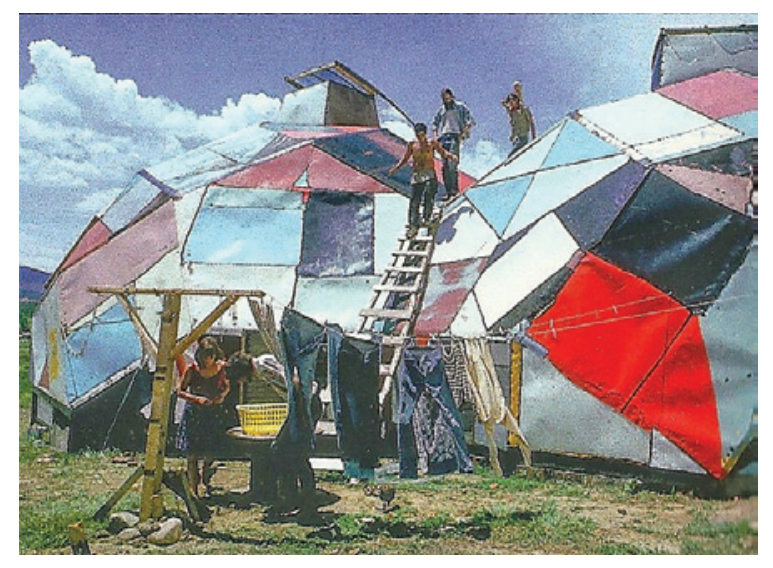

Fig 7.6. Construção de geodésicas na Drop City (c1965). Fonte: Foster e Fernández-Galiano, AV Monografias, n. 143,112 .

Essas construções são um exemplo da incorporação da arquitetura de Buckminster Fuller no movimento hippie.

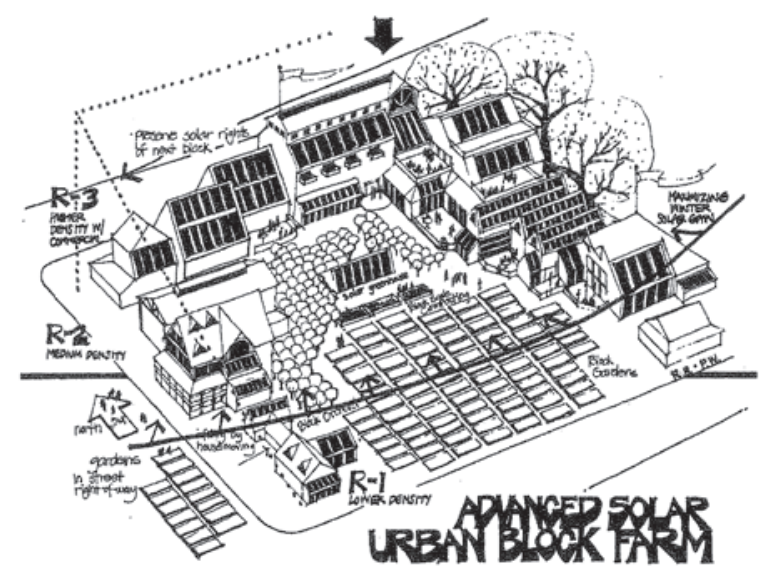

Fig 7.7. Tipologia de quarteirão urbano com produção de alimentos e energia solar de Richard Britz, em The edible city. Fonte: Cuthbert, Understanding cities, 182. 

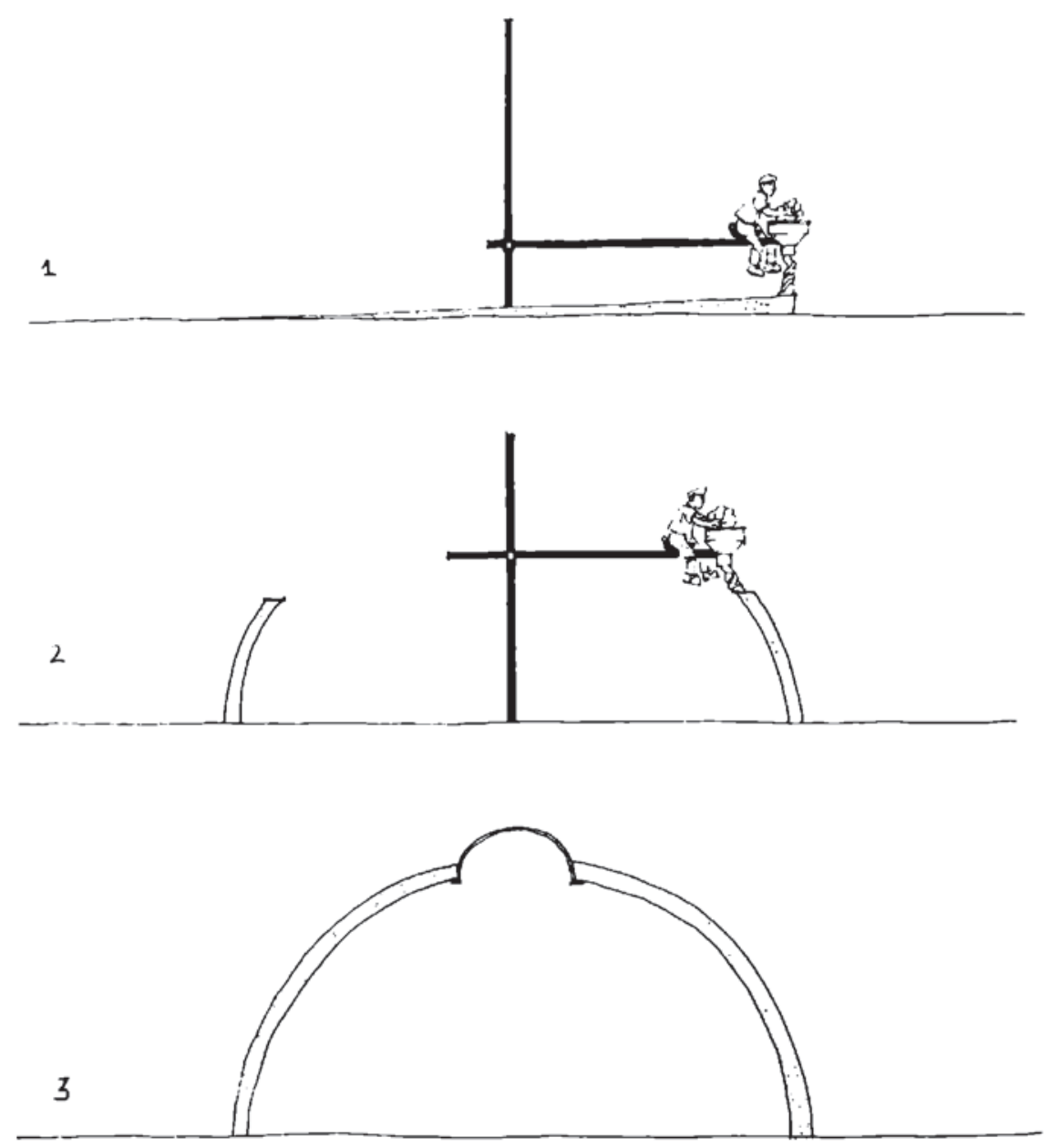

Fig 7.8. Dow Chemical, domo de isopor (1966). Fonte:

Smit Vajaramant, via Papanek, Design for the real world, 10.
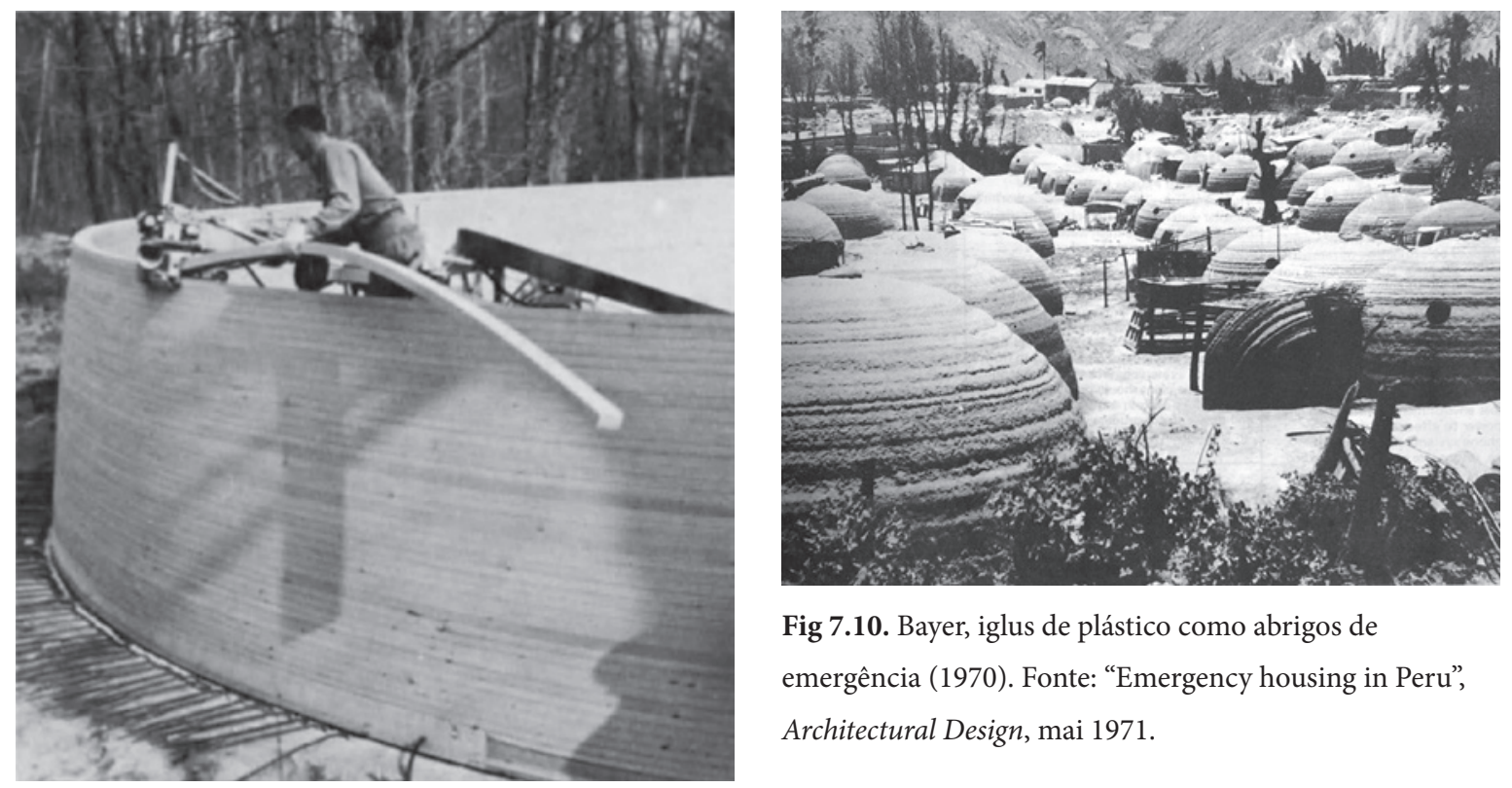

Fig 7.10. Bayer, iglus de plástico como abrigos de emergência (1970). Fonte: "Emergency housing in Peru”, Architectural Design, mai 1971.

Fig 7.9. Dow Chemical, domo de isopor (1966). Fonte: Rosato et al., Designing with plastics and composites, 22. 
quitetura autonomeada como ambiental, o que coloca em questão as iniciativas historiográficas que atribuem ambientalismo a projetos dele ausentes. Seguindo Tafuri, essas iniciativas "forçam a história do passado", eliminando as contradições em prol de uma narrativa única, e "forçam o futuro" porque prescrevem poéticas ao invés de repertoriá-las. Desse modo, no lugar de "fazer história faz-se ideologia: o que, além de trair a tarefa da história, esconde as possibilidades reais de transformar a realidade." 39

Deve-se, portanto, buscar outras abordagens da história dessa arquitetura. Na dupla origem da arquitetura ambiental, o ponto de vista cultural foi elaborado por Felicity Scott em seu Architecture or techno-utopia, no qual propõe uma história paralela à hegemonia tecnológica na arquitetura no pós-guerra. Para isso, Scott privilegia a arquitetura da contracultura e a diluição dos limites disciplinares que ela opera, logo uma experiência de premissas diametralmente opostas à modernização ecológica do USGBC ${ }^{\circledast}$ quase trinta anos depois. As casas em domo da Drop City, por exemplo, foram construídas em uma lógica de off grid, propositalmente distantes dos centros urbanos. Elas não usavam matérias-primas ou aparelhagem elaboradas para construir a estrutura e cobri-la, e sim resíduos de carros abandonados. Essa técnica baseava-se na geodésica de Buckminster Fuller [fig 7.4 e 7.5], talvez o primeiro arquiteto a se referir à finitude dos recursos naturais e à necessidade de sua preservação em seu Manual de operação para a espaçonave Terra, em tradução livre. ${ }^{40}$ Mas os hippies da Drop City não absorveram a serialização e industrialização da arquitetura prevista na teoria - e na patente - das geodésicas de Fuller. Pelo contrário, eles incorporaram as ideias de Fuller como um "faça-você-mesmo" de uma ferramenta de projeto avançada em sua concepção e simples em sua aplicação. Contra a industrialização prevista nas geodésicas, os militantes da Drop City fabricavam suas casas com pouco conhecimento técnico e pelas próprias mãos [fig 7.6]. ${ }^{41}$

\footnotetext{
39. Na tradução em inglês: "Instead of making history one makes ideology: which, besides betraying the task of history, hides the real possibilities of transforming reality." Manfredo Tafuri, Theories and history if architecture, [4a ed. orig. 1976; 1a ed orig. 1968] (Nova York: Harper \& Row Publishers, 1980), 151, tradução nossa, grifo no original.

40. Richard Buckminster Fuller, Operating manual for spaceship Earth ([s. 1.]: Lars Müller Publishers, 1969).

41. Cf. Felicity D. Scott, Architecture and techno-utopia: politics after modernism (Cambridge, Massachusetts; Londres: The MIT Press, 2007); Fred Turner, "A technocrat for the counterculture", org. Norman Foster e Luis Fernández-Galiano, $A V$ Monografías, no 143: Buckminster Fuller 1895-1983 (junho de 2010): 102-15; e também o nosso "A perspectiva tecnológica da sustentabilidade ambiental: Buckminster Fuller e a arquitetura dos anos 2000", Oculum Ensaios 15, nº 1 (2018): 111-28, https://doi. org/10.24220/2318-0919v15n1a3374.
} 
Outra direção à época era não a transformação das relações de produção na arquitetura pelo abandono da técnica industrial, mas a incorporação do meio ambiente no planejamento urbano. Foi o que fez Ian McHarg em seu Design with nature, de 1969, ao pensar o desenho não do edifício, mas de rodovias, diques e de áreas de expansão urbana. ${ }^{42}$ Foi também o trabalho de Richard Britz em The edible city, de 1981, em que propõe a superação dos limites entre campo e cidade. Para Britz, o urbano deveria se tornar uma área de produção de alimentos e preservação ambiental, e com isso transformar as relações sociais cotidianas [fig 7.7]. ${ }^{43}$

O partido de modernização ecológica tomado pelo USGBC ${ }^{\circledast}$ contradiz as tendências da contracultura. De certo modo, tem-se no USGBC ${ }^{\circledast}$ o oposto do objeto privilegiado por Felicity Scott: não os fenômenos no limite da disciplina, mas aqueles do pragmatismo de mercado. Entretanto, mesmo na década de 1960 já havia incursões da iniciativa privada no ambientalismo, por meio de experiências com novas técnicas e materiais. É o caso de um domo de isopor projetado pela Dow Chemical em 1966, construído por um só operário, ou de iglus de plástico produzidos pela Bayer em 1970 para utilização após catástrofes naturais [fig 7.8 e 7.9]. ${ }^{44}$ Eram experiências da iniciativa privada, mas ainda sem impacto na produção e sem interferência na arquitetura corporativa. Décadas depois, tanto a Bayer como a Dow Chemical seriam parceiras do USGBC .

Donde a segunda origem da arquitetura ambiental: se a primeira é a contracultura, a segunda é a economia. Luis Fernández-Galiano argumenta nesse sentido em uma edição especial da revista Arquitectura Viva sobre certificações ambientais, ao ver nos ciclos de crise do petróleo a renovação do interesse pela ecologia. O aumento do preço de combustíveis fósseis - e, em decorrência, da energia - corresponderia à maior preocupação com eficiência energética - e, por extrapolação, com o ambientalismo. Para a arquitetura, haveria duas crises relevantes: a de 1973 e a do fim dos anos 1990, com o aumento de tensão no Oriente Médio. A resposta à última crise foi dada, segundo Fernández-Galiano, por projetos de alta tecnologia e pelo desenvolvimento de um campo arquitetônico específico:

42. Ian L. McHarg, Design with nature, 2a [1a ed. 1969] (John Wiley \& Sons, 1992).

43. O livro está esgotado e é hoje raro. Cf. Cuthbert, Understanding cities, 180-84.

44. Victor Papanek, Design for the real world: human ecology and social change, 2a ed (Londres: Thames \& Hudson, 1984), 10-12; Donald V. Rosato, David P. DiMattia, e Dominick V. Rosato, Designing with plastics and composites: a handbook (Nova York: Springer Science+Business Media, 1991); "Emergency housing in Peru”, Architectural Design, maio de 1971. 
A construção sustentável é hoje um setor em crescimento, que tem suas próprias feiras e congressos, suas próprias revistas e seus próprios prêmios, um setor alimentado por normas exigentes e subvenções generosas da administração, e um setor que procura compensar suas menos-valias estéticas com rankings, homologações e etiquetas verdes cuja aura ética pode outorgar legitimidade social e visibilidade pública a seus autores e a suas obras. ${ }^{45}$

É no contexto narrado por Fernádez-Galiano que são inaugurados diversos edifícios ambientais corporativos. Ex-aluno de Ian McHarg, o arquiteto malaio Kenneth Yeang incorporou a ecologia do professor no estudo de torres bioclimáticas, com exemplo mais conhecido na torre Mesiniaga. A torre foi inaugurada em 1992 para uma filial da IBM e se localiza nas proximidades de Kuala Lumpur [fig 7.11]. Sua envoltória se organiza em uma espiral de placas de sombreamento, jardins e circulação, com o objetivo de proteger a área de escritórios do forte calor da região equatorial [fig 7.12 e 7.13]. A ecologia implica, portanto, a mudança na concepção de projeto. Os edifícios de Yeang adotam "formas arquitetônicas únicas", afirma Cuthbert, "que são radicalmente diferentes de outros edifícios altos pelo esforço de criar um ecossistema mais estável e produtivo". ${ }^{46}$

Empreendimentos como o Commerzbank (1991/1997), em Frankfurt, ou o 30 St Mary Axe (1997/2004), em Londres, ambos da empresa Foster + Partners, também são exemplos de grandes edifícios projetados com o intento de criar novas tipologias arquitetônicas. No caso do primeiro, o projeto foi realizado antes da existência da maior parte dos certificados hoje em atuação, e a escala de aplicação de estratégias ambientais é superior à de projetos anteriores - a torre Mesiniaga, por exemplo, tem cerca de $6.500 \mathrm{~m}^{2}$, contra mais de $120.700 \mathrm{~m}^{2}$ do Commerzbank. A ventilação e iluminação naturais eram favorecidos pela forma triangular e pelos átrios

45. No original: "La construcción sostenible es hoy un sector en auge, que tiene sus propias ferias y congresos, sus propias revistas y sus propios premios, un sector alimentado por las exigentes normativas y generosas subvenciones de la administración, y un sector que procura compensas sus minusvalías estéticas con rankings, homologaciones y etiquetados verdes cuya aura ética pueda otorgar legitimidad social y visibilidad pública a sus autores y a sus obras." Luis Fernández-Galiano, “¿La economía, ecologistas!: la construcción sostenible ante la crisis del petróleo”, Arquitectura viva, n 105: Etiquetas verdes (2005): 24, tradução nossa.

46. No original: "unique architectural forms that are radically different to other high rises in the effort to create a more stable and productive ecosystem". Cuthbert, Understanding cities, 178, tradução nossa. 
internos da torre, a ponto de o projeto destacar-se pelo seu desempenho ambiental anos depois de finalizado. ${ }^{47}$ Apesar da sua escala - a torre mais alta da Europa em sua inauguração -, o projeto se articula, no térreo, com o desenho do quarteirão. No Commerzbank, tal como na torre Mesiniaga, "a lógica arquitetônica do edifício alto de escritórios é completamente reformulada para atingir novos valores ambientais, econômicos e sociais", ${ }^{48}$ no argumento de Joana Gonçalves e Érica Umakoshi [fig 7.14 a 7.16].

A implantação articulada ao entorno no Commerzbank não é replicada no 30 St Mary Axe, onde a torre reforça a integridade da forma e aterra isolada no lote. Esse empreendimento, cujo proprietário já foi a resseguradora Swiss Re, e pertence atualmente ao banco brasileiro Safra, também emprega a solução de andares com vazios em espiral, de modo a aumentar a ventilação natural. Mas, se na torre Mesiniaga essa espiral criava vazios na fachada, e se no Commerzbank a torre se organizava em diversos blocos - as "vilas de escritórios" -, no 30 St Mary Axe seu átrio é integrado perifericamente na forma, garantindo sua leitura icônica [fig 7.17 a 7.19$]$.

As tipologias da arquitetura ambiental são, portanto, variadas. Com o intuito de repertoriá-las, Josep Maria Montaner elenca seis de seus "fragmentos tipológicos": as peles, os pátios e estufas, os grandes elementos de vidro, o escalonamento das formas, a dispersão e aterramento dos edifícios e as estruturas leves, recicláveis e transitórias. ${ }^{49}$

$\mathrm{O} \mathrm{LEED}^{\circledR}$ certamente não privilegia todas essas estratégias projetuais. Os quatro itens anteriormente apresentados - mecanização, envelope selado, figura-fundo e grande porte - indicam um repertório diferente das experimentações formais apresentadas ao longo desta seção. Por elas se vislumbra outros caminhos possíveis da arquitetura ambiental, alternativos ao modelo estabelecido pelos sistemas $\mathrm{LEED}^{\circledR} \mathrm{NC}$ e CS.

\footnotetext{
47. Cf. Joana Carla Soares Gonçalves e Érica Mitie Umakoshi, The environmental performance of tall buildings (Londres; Washington, DC: Earthscan, 2010).

48. No original: "the architectural logic of the tall office building is completely reformulated to meet new environmental, economic and social values." Gonçalves e Umakoshi, 102, tradução nossa.

49. Josep Maria Montaner, "Belleza de las arquitecturas tecnológicas", in La modernidad superada: arquitectura, arte y pensamiento del siglo XX, 2a ed (Barcelona: Editorial Gustavo Gili, 1998), 207-22.
} 


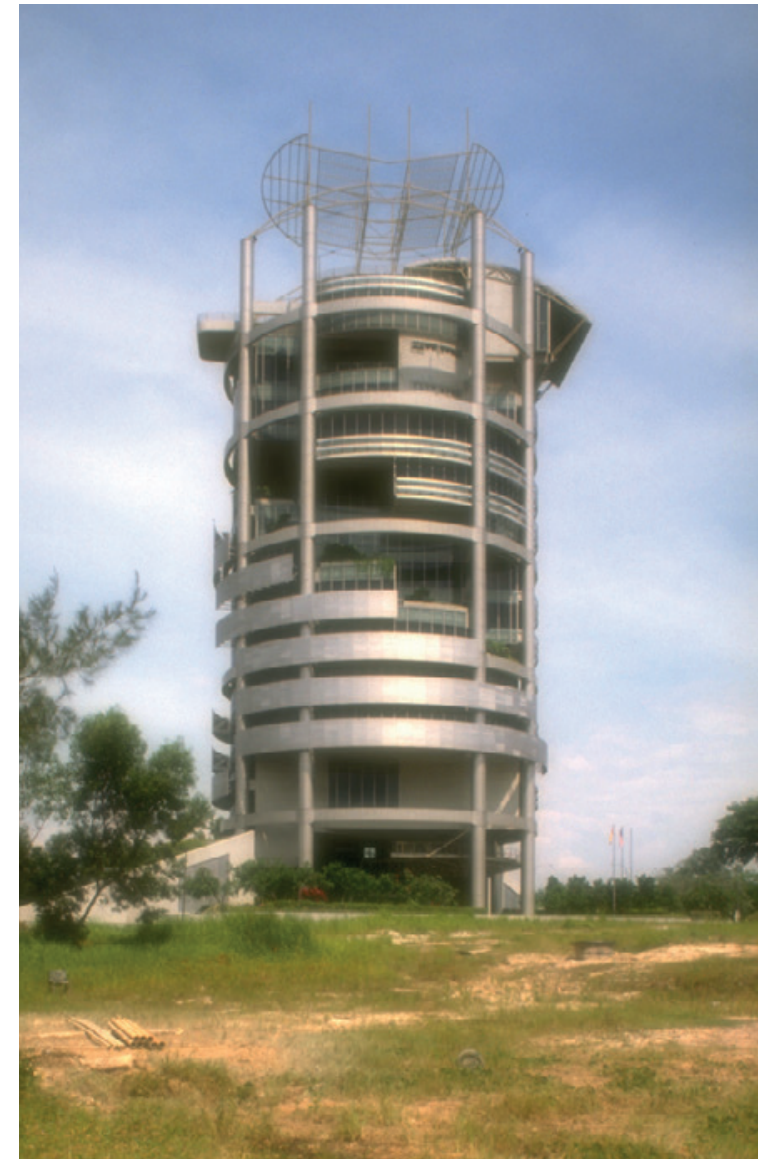

Fig 7.11. Kenneth Yeang, torre Mesiniaga (c1989/1992).

Vista geral. Fonte: NG KL/Aga Khan Trust for Culture, via Archdaily.

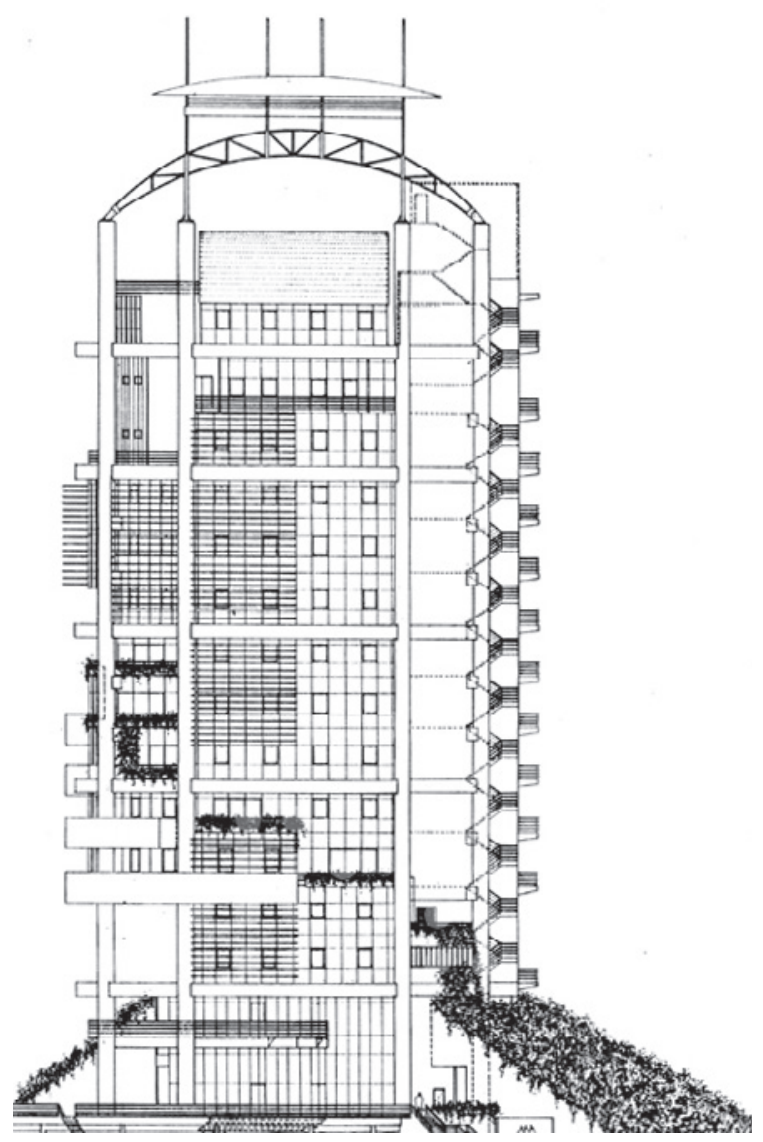

Fig 7.12. Kenneth Yeang, torre Mesiniaga (c1989/1992). Elevação sudoeste. Sem escala. Fonte: Acervo do arquiteto, via Archdaily.

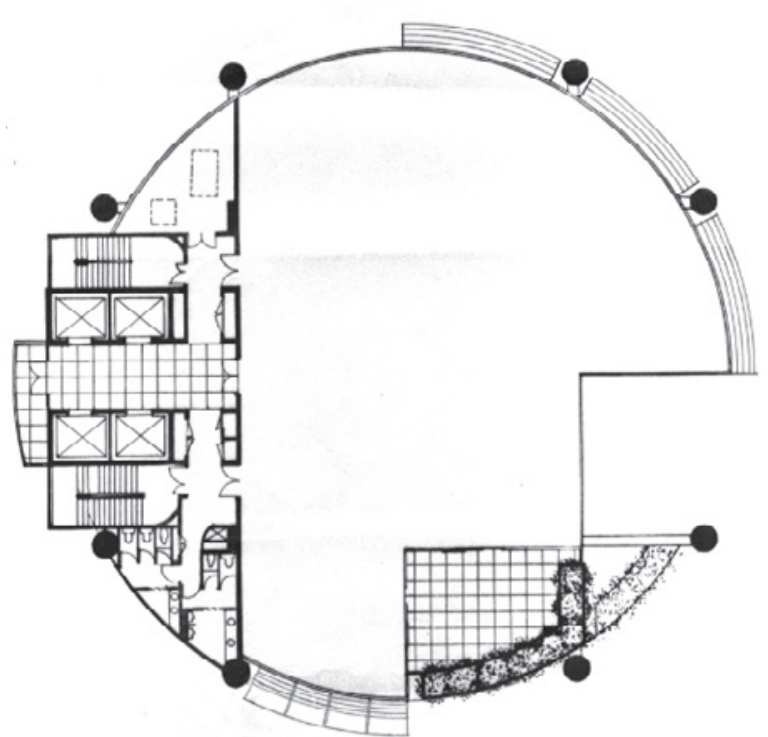

Fig 7.13. Kenneth Yeang, torre Mesiniaga (c1989/1992). Planta de um pavimento de escritórios. Sem escala. Fonte: Acervo do arquiteto, via Archdaily. 


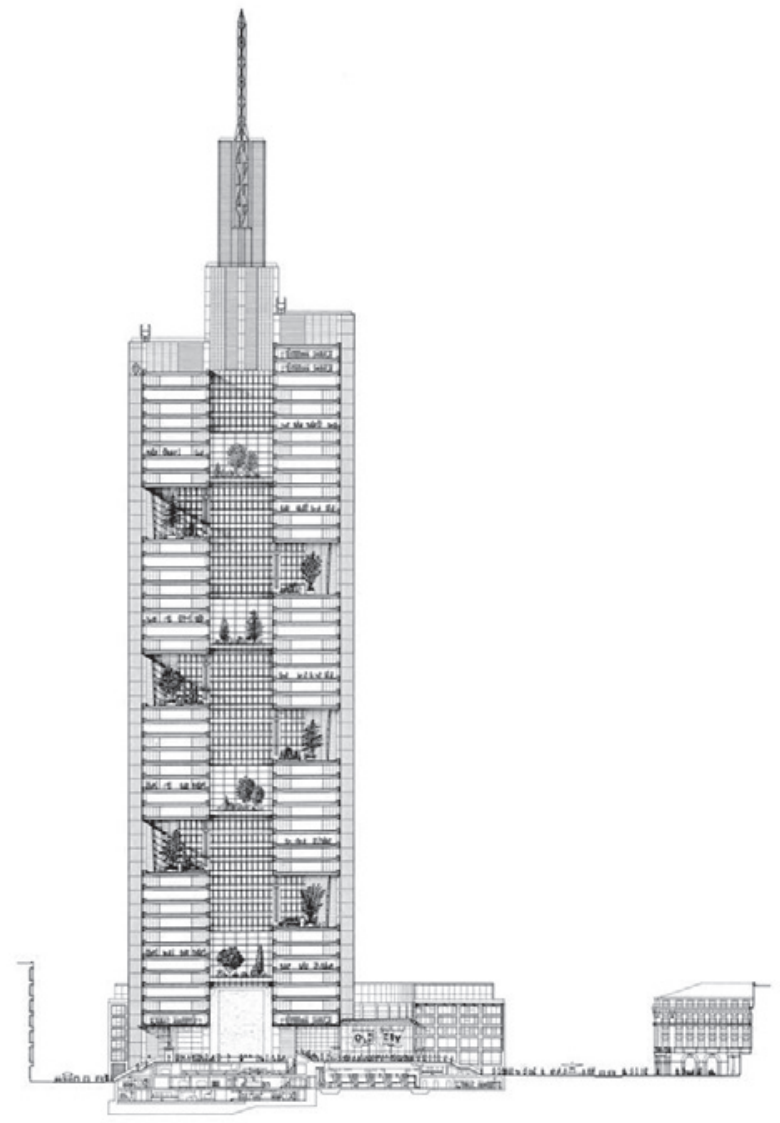

Fig 7.14. Foster + Partners, Commerzbank (1991/1997). Corte. Sem escala. Fonte: Foster + Partners, acervo online.

Fig 7.15. Foster + Partners, Commerzbank (1991/1997). Planta de pavimentos dos escritórios. Sem escala. Fonte: Foster + Partners, acervo online.
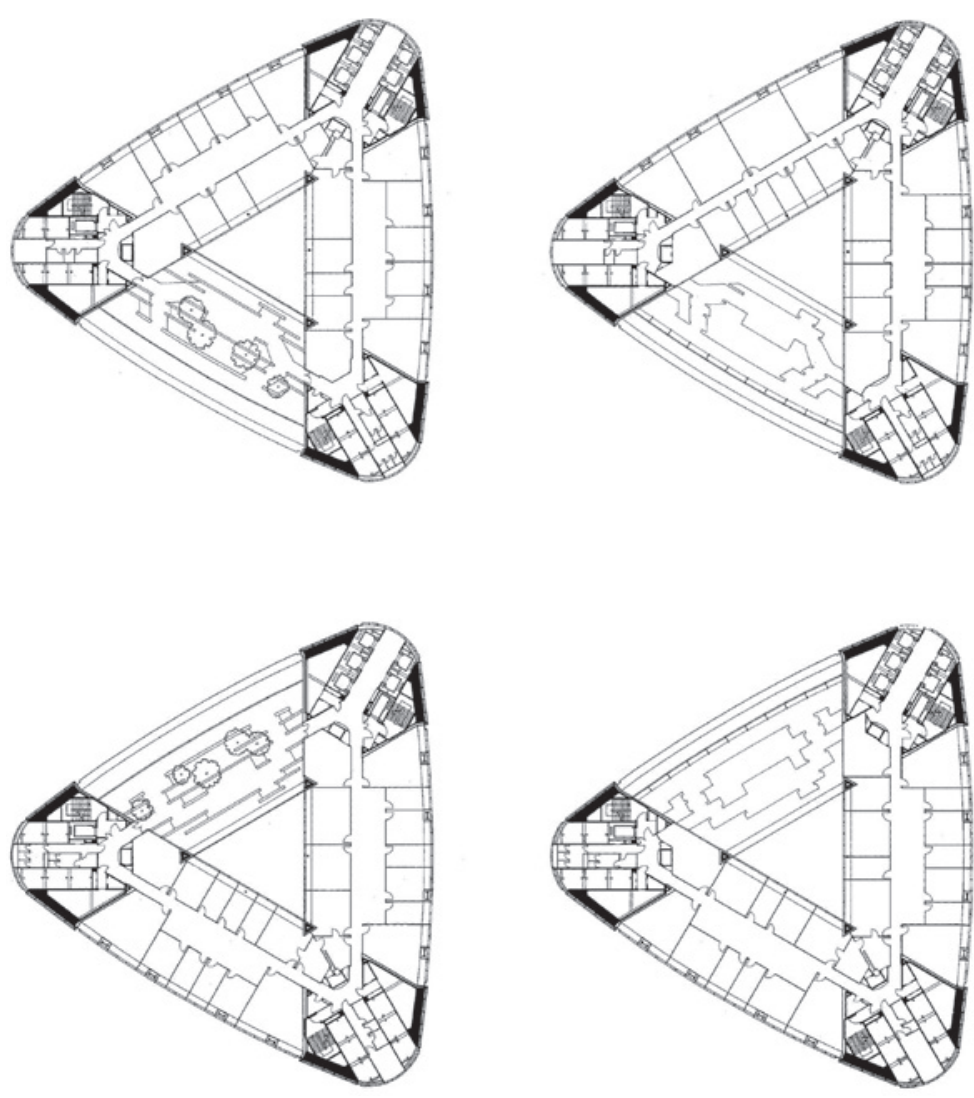
Fig 7.16. Foster + Partners, Commerzbank (1991/1997). Planta do pavimento térreo da torre. Sem escala. Fonte: Foster + Partners, acervo online.

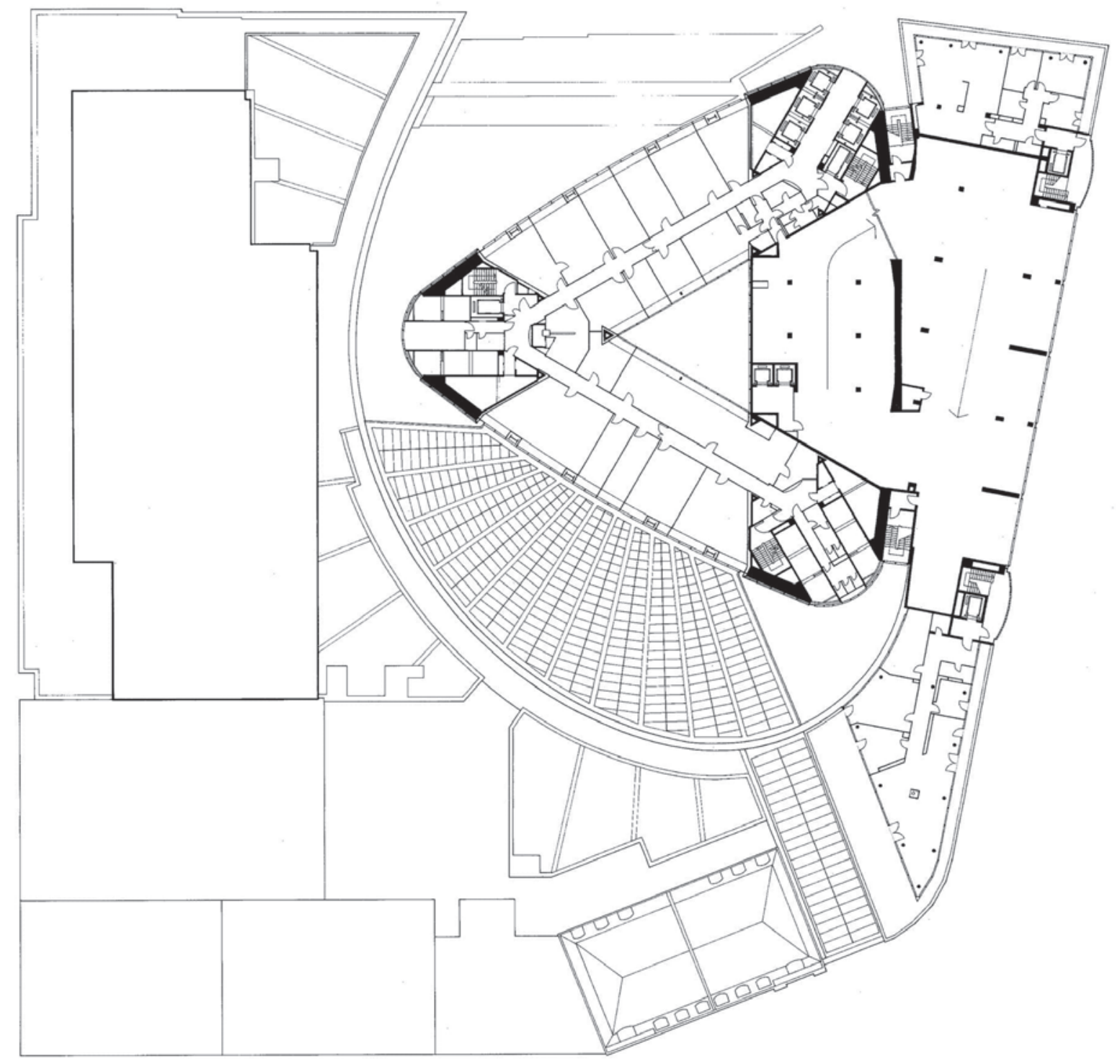




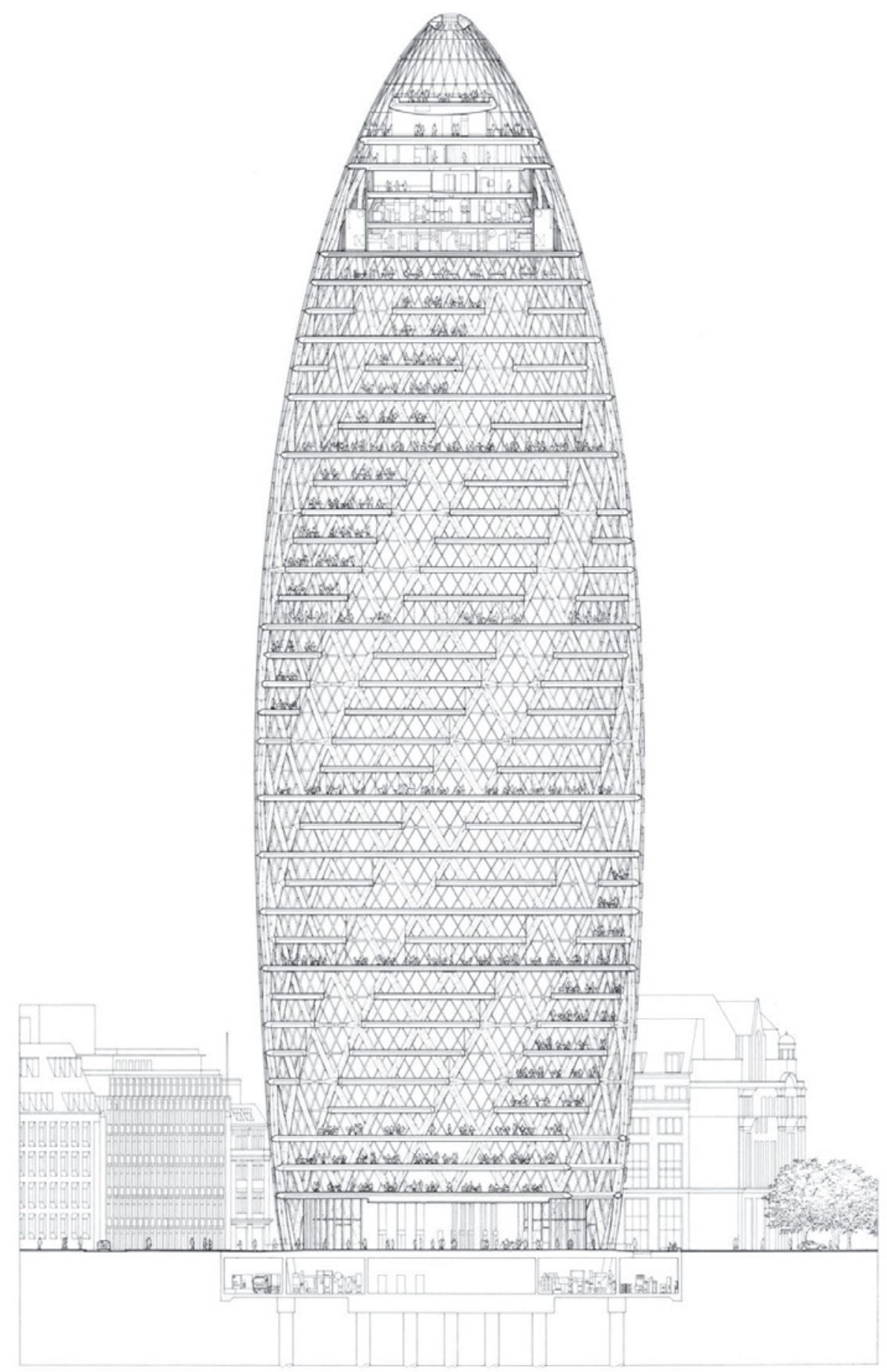

Fig 7.17. Foster + Partners, 30 St Mary Axe (1997/2004).

Corte. Sem escala. Fonte: Foster + Partners, acervo online. 


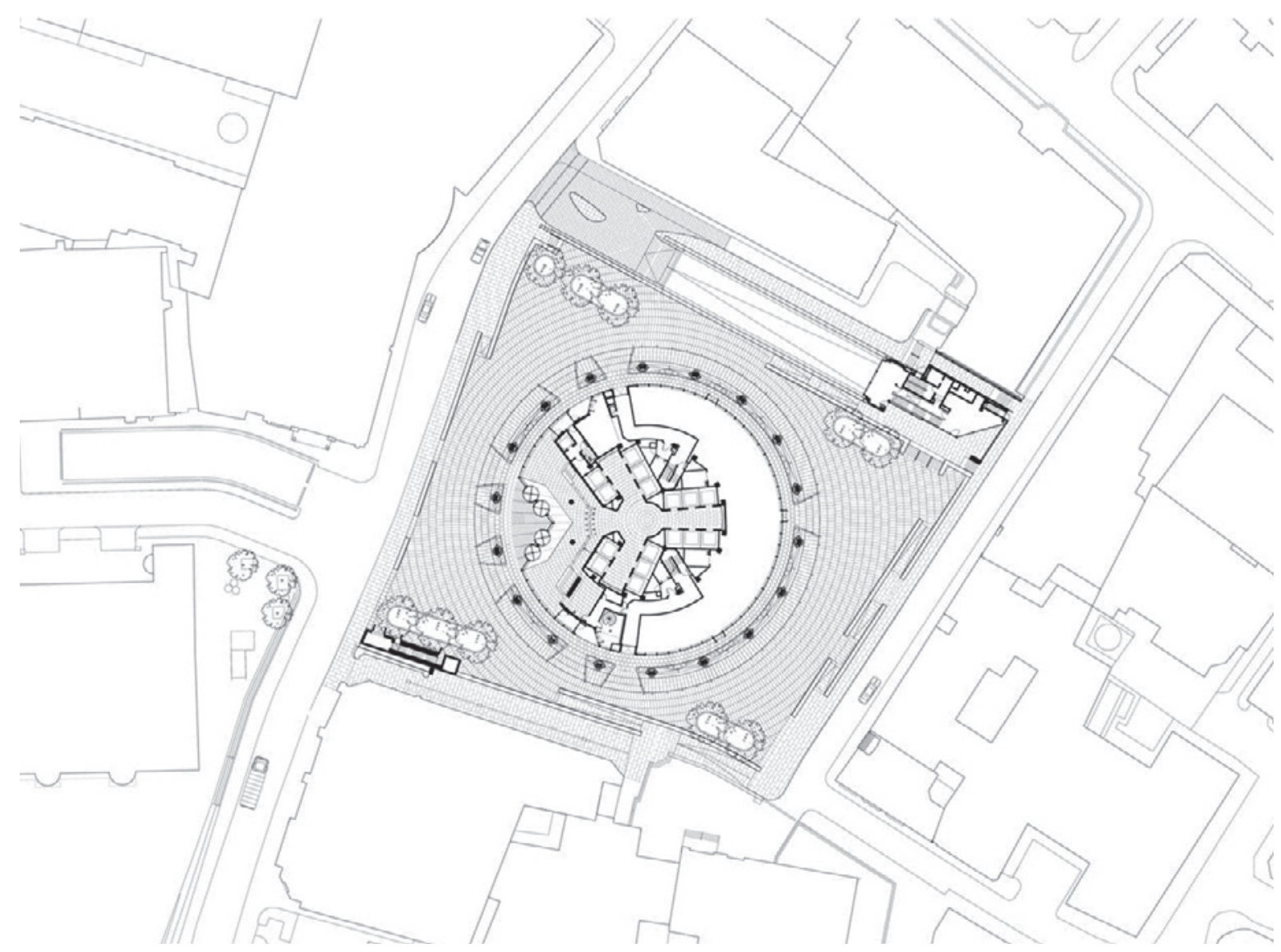

Fig 7.18. Foster + Partners, 30 St Mary Axe (1997/2004)

Planta do pavimento térreo da torre. Sem escala. Fonte: Foster + Partners, acervo online.
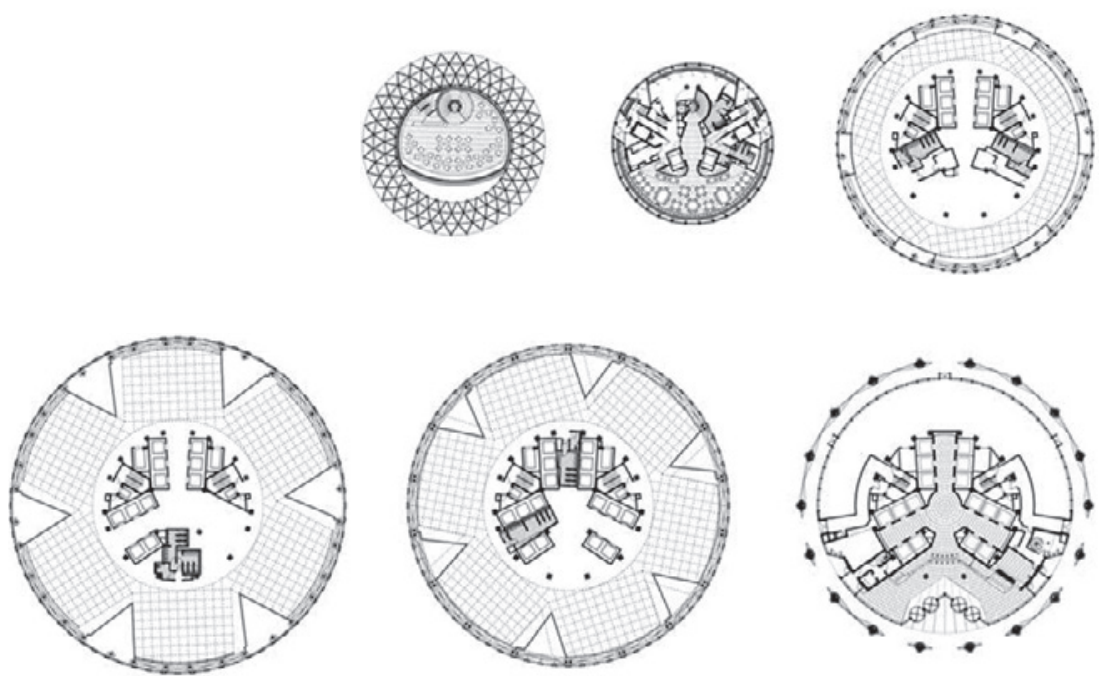

Fig 7.19. Foster + Partners, 30 St Mary Axe (1997/2004). Planta dos pavimentos de escritório, do topo ao térreo. Sem escala. Fonte: Foster + Partners, acervo online. 


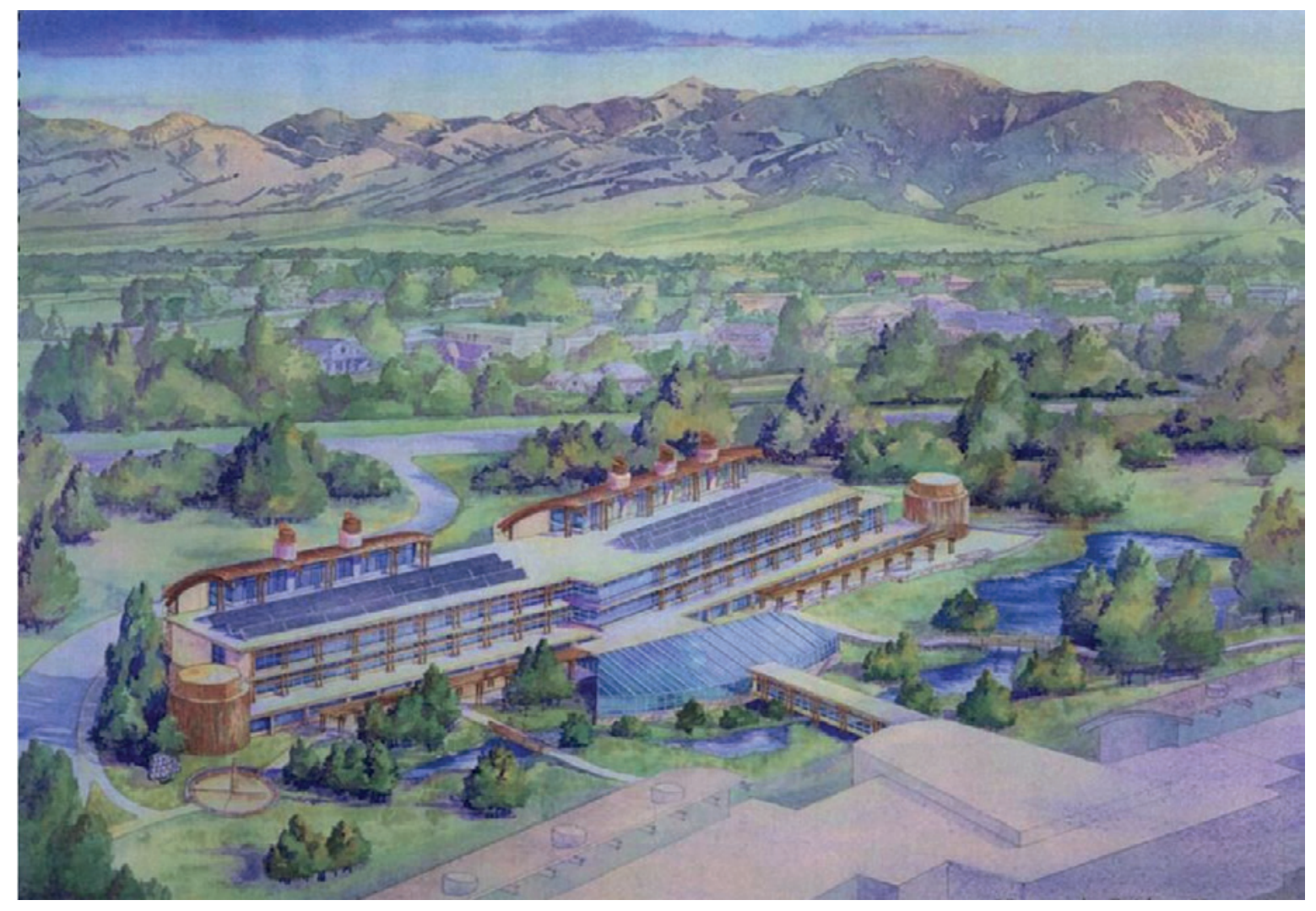

Fig 7.20. BNIM, MSU EPICenter (1997). Fonte: BNIM, acervo online. 


\section{VIABILIZAÇÃO DO MODELO DE MERCADO NORTE-AMERICANO}

Para o arquiteto Robert Berkebile, presente nas primeiras reuniões após a fundação do USGBC ${ }^{\oplus}$, um dos protótipos para a criação do LEED $^{\circledR}$ foi o Educational Performance \& Innovation Center (EPICenter), de 1997 [fig 7.20]. Diversos colaboradores desse laboratório ligado à Montana State University participaram depois dos comitês técnicos da versão piloto do LEED ${ }^{\oplus}$ NC. ${ }^{50}$ Embora Berkebile frise a relevância do EPICenter, sua arquitetura de átrios ajardinados e estratégias passivas parece distante do que se tornou o sistema LEED ${ }^{\circledR}$. Por esse motivo Berkebile orientou-se em seguida para sistemas de avaliação mais exigentes, como o Living Building Challenge. ${ }^{51}$

Como estratégia de projeto, não é o EPICenter nem os projetos de Foster ou Yeang que se tornaram hegemônicos dentro do LEED ${ }^{\oplus}$. Essa origem pode ser melhor encontrada no projeto de uma torre na área central de Manhattan, a 4 Times Square, conhecida na sua inauguração como Condé Nast, por conta de seu inquilino principal [fig 7.21 a 7.25]. Embora inaugurada depois do lançamento da versão piloto do $\mathrm{LEED}^{\circledR}$, a construção terminou antes e sua particularidade já era discutida pela imprensa ao menos desde $1996 .{ }^{52}$ Se o EPICenter é um projeto típico da versão piloto do LEED ${ }^{\circledR} \mathrm{NC}$, mais recorrente em laboratórios e estabelecimentos de ensino universitário, o 4 Times Square corresponde à arquitetura generalizada no LEED ${ }^{\circledR}$ NC v2. A partir dele, a arquitetura verde foi desatada para arquitetos e incorporadores. "Ninguém entendia o projeto verde ou quais eram as suas vantagens", disse um empreendedor anônimo citado para a Architectural Record, "Mas depois do Four Times Square, todos pensaram: 'Nós também conseguimos fazer isso’. E o LEED nos deu o mapa para entender como chegar lá." ${ }^{33}$

50. Robert Berkebile, (Diretor em BNIM), Entrevista para o autor, Telefone, 29 de junho de 2018.

51. Berkebile; Brian Barth, “Is LEED tough enough for the climate-change era?", Citylab, 5 de junho de 2018, https://www. citylab.com/environment/2018/06/is-leed-tough-enough-for-the-climate-change-era/559478/?utm_source=citylab-daily\&silverid=NDA0MDc4ODA2Nzk4S0.

52. Percio, "The skyscraper, green design, \& the LEED green building rating system: the creation of uniform sustainable standards for the 21st century or the perpetuation of an architectural fiction?", 138; John Holusha, "Technology in the front seat at 4 Times Square", The New York Times, 30 de março de 1997, https://www.nytimes.com/1997/03/30/realestate/technology-in-the-front-seat-at-4-times-square.html; Herbert Muschamp, "Smaller is better: Conde Nast in Times Sq.", The New York Times, 18 de maio de 1996.

53. No original: "No one understood green design or what its advantages were. But after Four Times Square, everyone thought, 'We can do that too.' And LEED gave us a blueprint for understanding how to get there." Deborah Snoonian Glenn, "Green grows up... and up and up and up", Architectural Record, $1^{\circ}$ de outubro de 2003, https://www.architecturalrecord. 

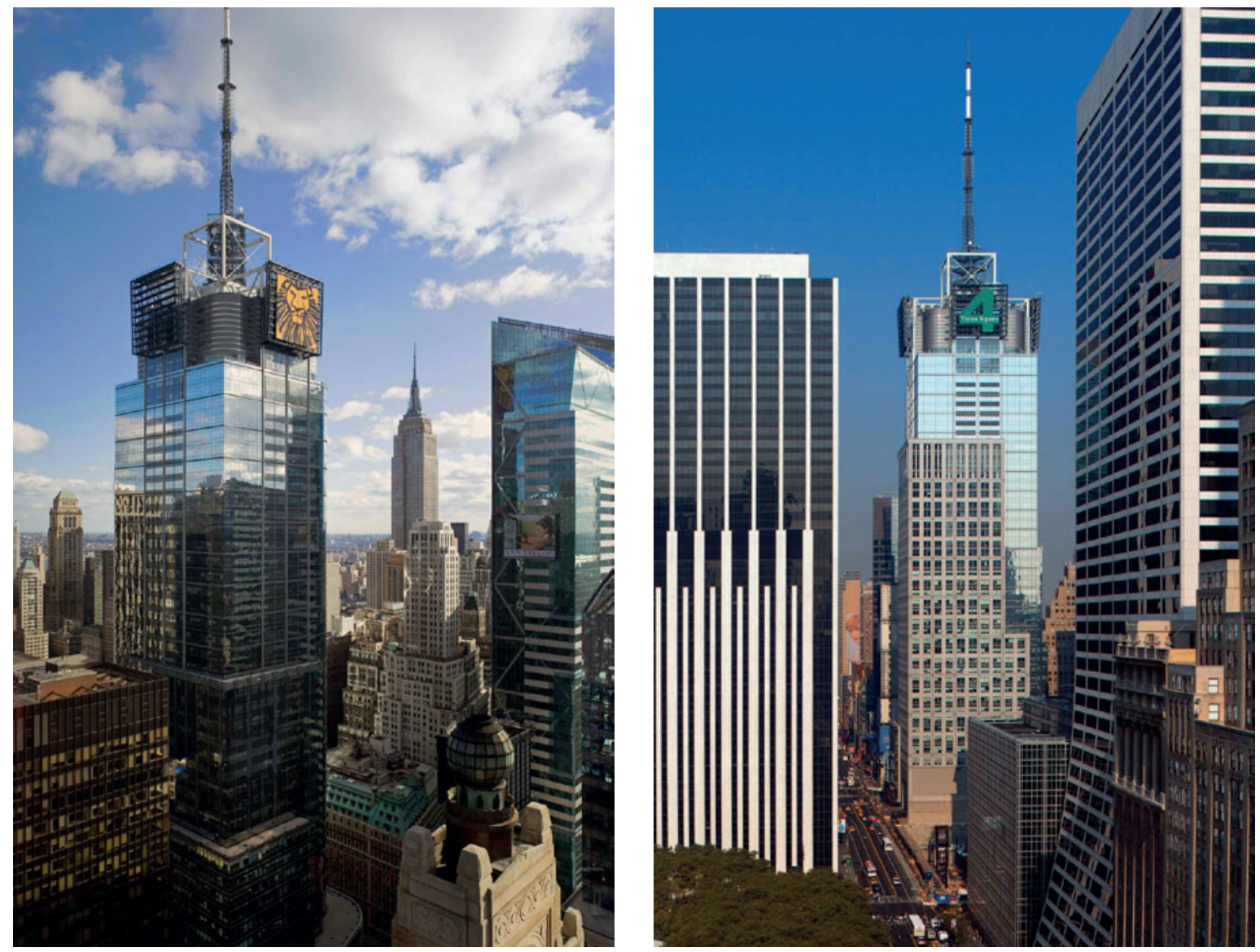

Fig 7.21 e 7.22. Fox \& Fowle, 4 Times Square (1995/1999). Fonte: FX Collaborative, acervo online.

O edifício do Bank of America, vizinho ao 4 Times Square e um dos primeiros a ser certificado LEED ${ }^{\circledR}$ Platinum, encontrava-se em construção na época. Note-se que, embora o edifício tenha sido inaugurado em 1999, no ano intermediário entre as duas primeiras versões do LEED ${ }^{\circ}$, ele já era publicamente discutido pelo menos desde 1996, como revela coluna do crítico Herbert Muschamp.

Fig 7.23. Fox \& Fowle, 4 Times Square (1995/1999). Detalhe do painel luminoso. Fonte: Architectural Record, março 2000.

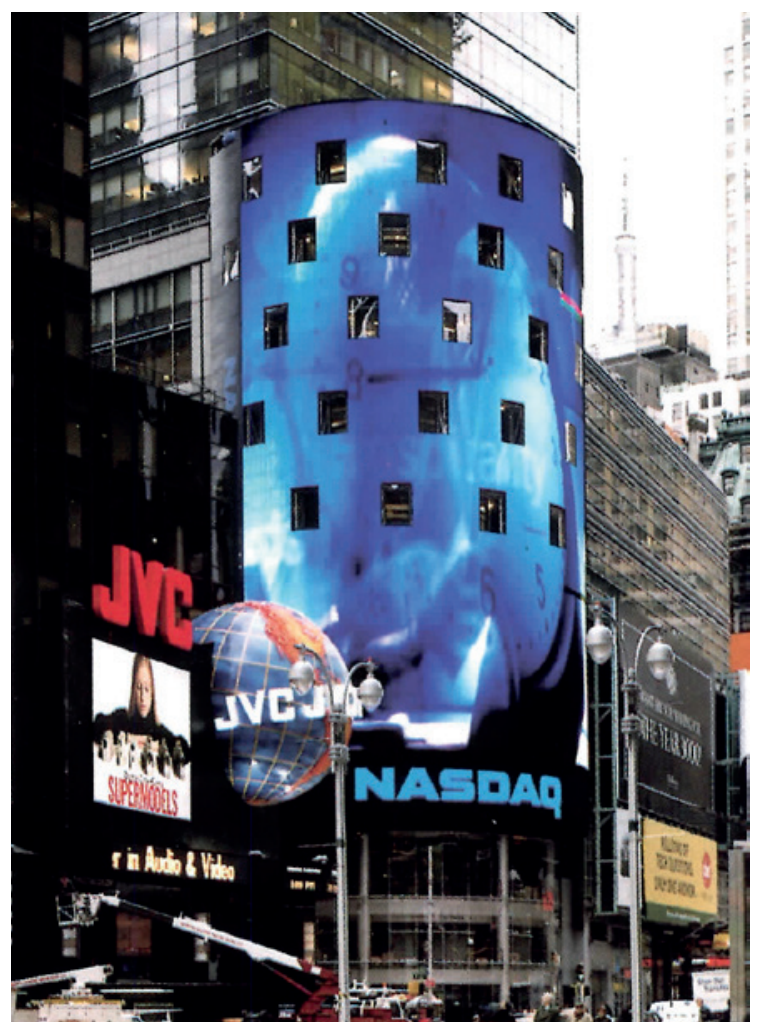




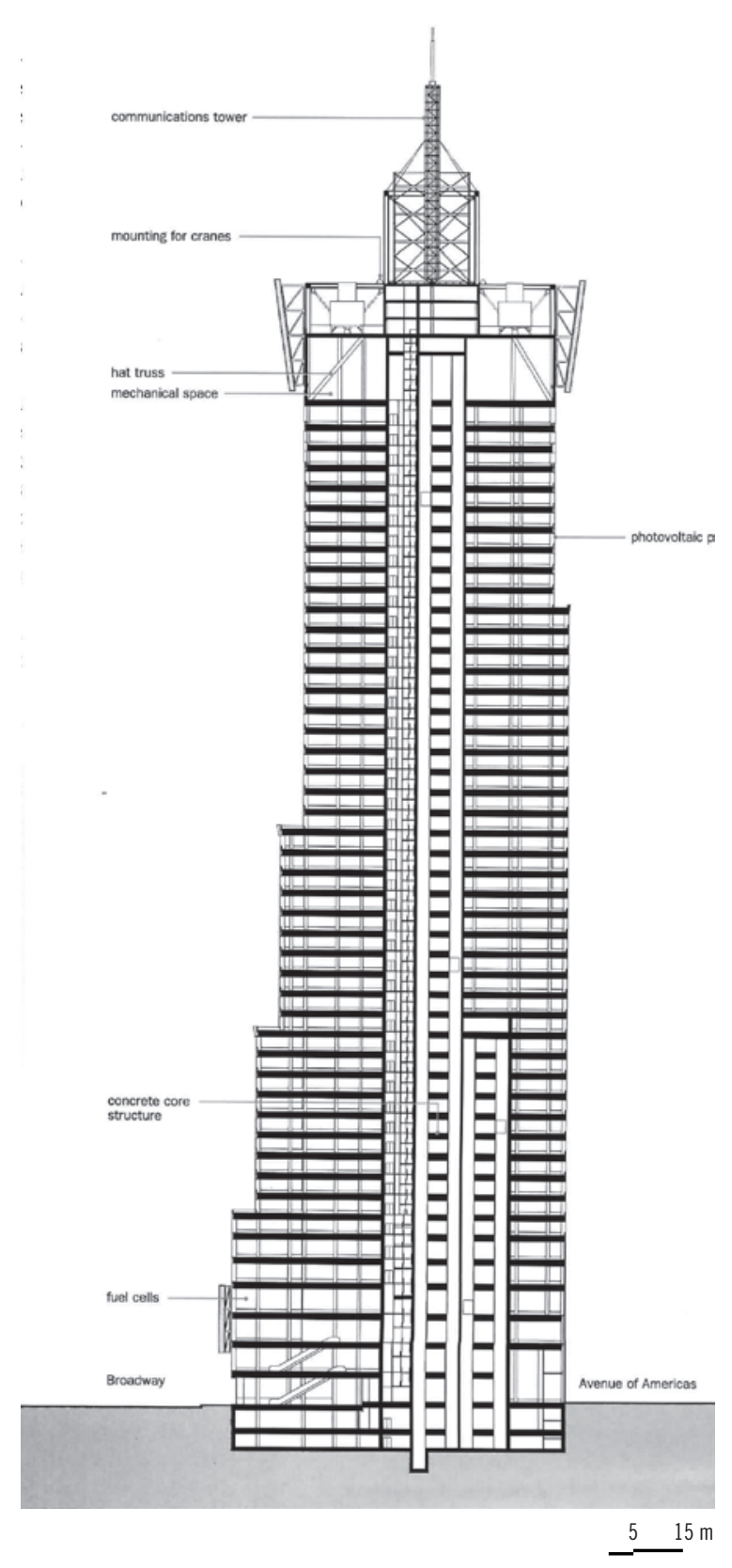

Fig 7.24. Fox \& Fowle, 4 Times Square (1995/1999). Corte leste-oeste. Sem escala. Fonte: Architectural Record, março 2000.
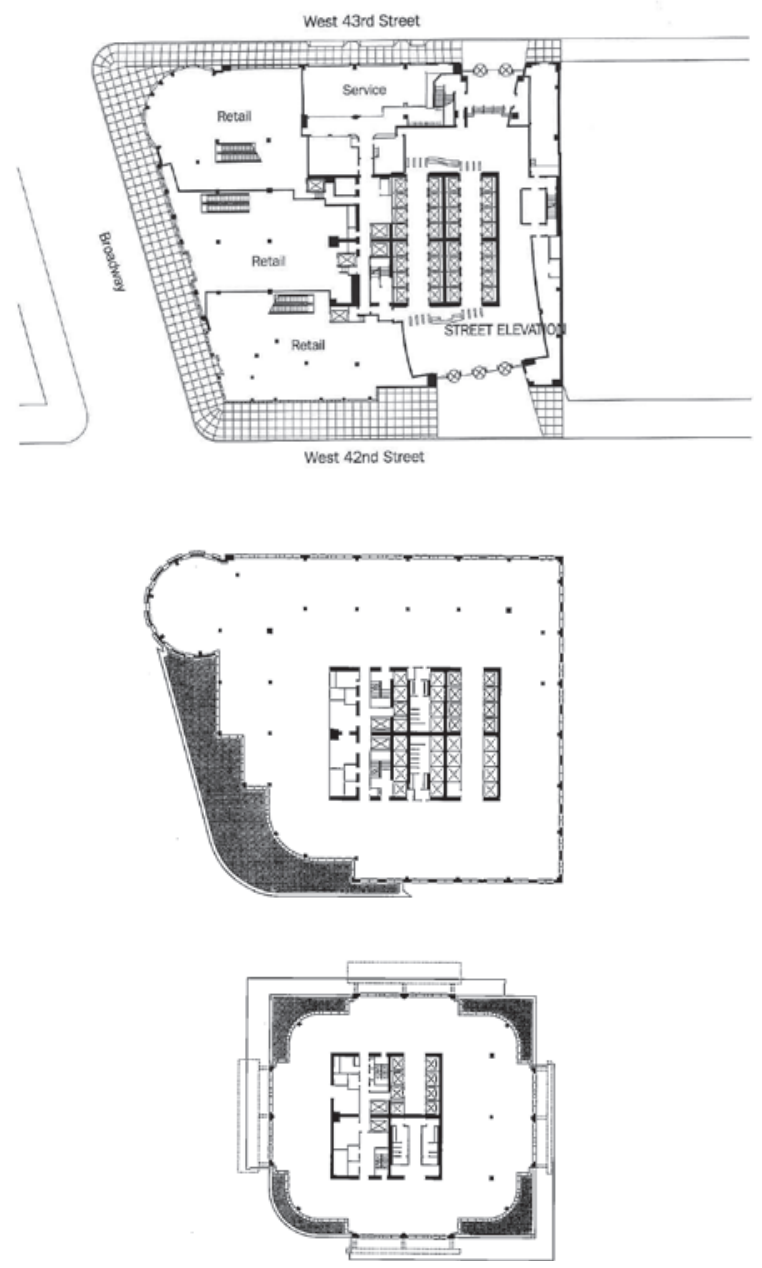

$\stackrel{5}{-15} \mathrm{~m} \quad$

Fig 7.25. Fox \& Fowle, 4 Times Square (1995/1999).

Plantas do térreo, oitavo e quadragésimo oitavo pavimentos. Sem escala. Fonte: Architectural Record, março 2000. 


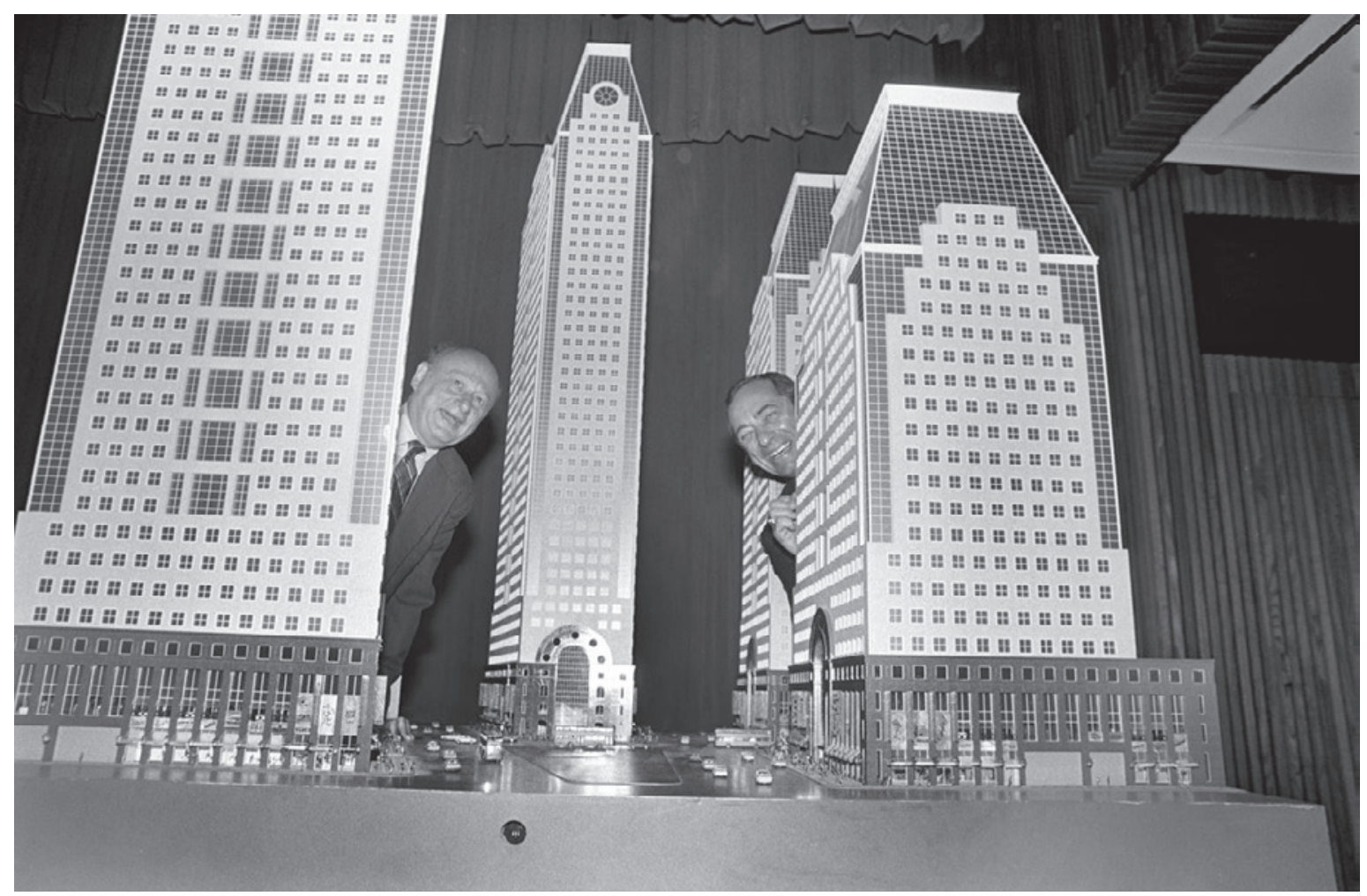

Fig 7.26. Philip Johnson e John Burgee, Times Square (1984). Fonte: Neal Boenzi via Alan Feuer, "100 years of cleaning up Times Square", The New York Times, 16 out 2015.

Na maquete estão o prefeito Edward I. Koch, à esquerda, e o governador Mario M. Cuomo, à direita.

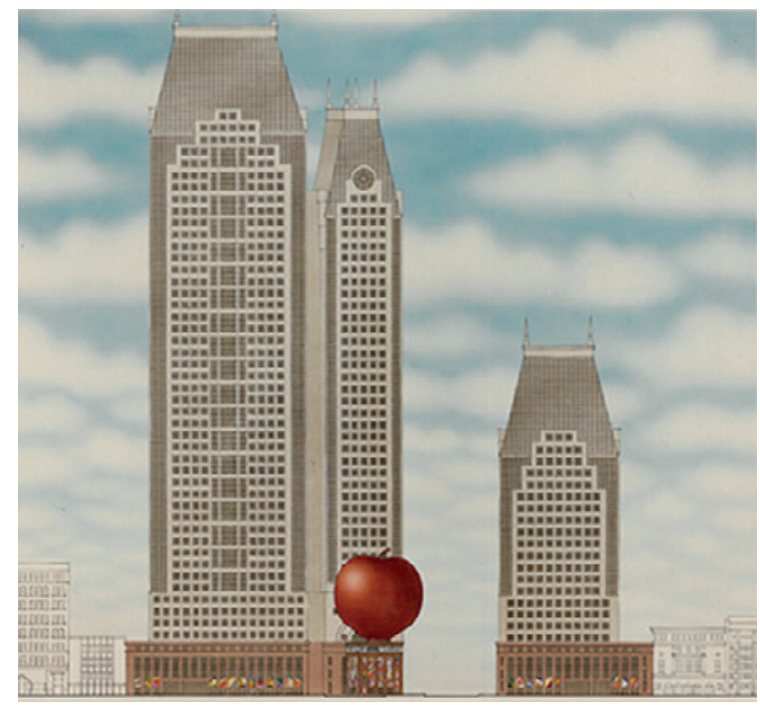

Fig 7.27. Venturi, Rausch \& Scott Brown, intervenção sobre projeto da Times Square de Philip Johnson e John Burgee (s/d). Fonte: The Skyscraper Museum via Urban Omnibus.

A aposta política no projeto, que tomava o Rockfeller Center como referência, foi derrotada pela pressão popular contrária a sua grande escala de intervenção. Uma das manifestações da reação é a escultura de Venturi, Rausch \& Scott Brown. A crise de 1991, mencionada no capítulo 1 , levou ao fim do empreendimento no ano seguinte. O empreendimento 4 Times Square efetivamente construído acompanha, portanto, a mesma crise econômica e virada sustentável que levou David Gottfried a criar o USGBC ${ }^{\oplus}$. 
Embora o projeto tenha circulado pouco pelas revistas especializadas em arquitetura, sua relevância é tanto urbana quanto ecológica. Do ponto de vista urbano, o 4 Times Square é dos primeiros projetos corporativos na área central de Manhattan a partir do fim dos anos 1990, e reconstruindo justamente um de seus trechos mais degradados à época, a Times Square. A praça, formada pelo cruzamento entre a 7th Av. e a Broadway, era desde os anos 1970 uma região de cinemas de conteúdo sexual e sex shops. Ela possuía uma das taxas de criminalidade mais altas da cidade, com índice elevado de crimes hediondos como assassinatos e estupros. O local manteve-se à margem do setor imobiliário nova yorkino, em decorrência da crise fiscal municipal de meados da década de 1970 e da crise imobiliária norte-americana de 1991 - a mesma que levou David Gottfried a procurar um novo campo de negócios na sustentabilidade, como narrado no capítulo 1. O projeto do 4 Times Square emergiu após décadas de impasse político-econômico para intervenções tanto na praça quanto na West 42 nd St. O primeiro projeto para o cruzamento entre a West 42nd St., a 7th Av. e a Broadway era de quatro grandes torres, uma em cada esquina, projetadas por Philip Johnson e John Burgee e anunciadas pelo poder público em $1984 .{ }^{54} \mathrm{~A}$ resistência popular face à grande escala do projeto e a crise de 1991 impediram sua realização [fig 7.26 e 7.27]. Após anos de negociação, foi construído outro projeto, para apenas uma das esquinas, o 4 Times Square de Fox \& Fowle. Entre os principais inquilinos, o mercado de ações da Nasdaq no térreo, a editora de revistas fashion e gourmet Condé Nast e o escritório de advocacia Skadden Arps Slate Meagher \& Flom. ${ }^{55}$ A torre conta, ainda, com o primeiro projeto de Frank Gehry em Nova York, um café para os funcionários da Condé Nast no quarto andar.

O edifício é uma colagem. Na direção do Bryant Park, onde havia diversos edifícios históricos em alvenaria, o edifício tem grelhas revestidas em granito. Já na esquina para a Times Square, o volume é escalonado e revestido com cortinas de vidro. Donde seu duplo contextualismo: para a praça, a modernidade do vidro e a propaganda luminosa no embasamento e no coroamento, parte dela incentivada pelo zoneamento; para o canyon da West 42 nd e os fundos do lote, a grelha. O topo expõe ainda, de modo muito mais explícito do que as outras grandes torres da região, a aparelhagem técnica do edifício, de antenas e caixas d'água.

com/articles/12266-green-grows-up-and-up-and-up-and-up, tradução nossa.

54. Muschamp, "Smaller is better: Conde Nast in Times Sq."

55. Holusha, "Technology in the front seat at 4 Times Square". 
O edifício possui diversos equipamentos para melhor desempenho ambiental, cuja alta tecnologia era promovida nas diretrizes de construção como modo de atrair "inquilinos sofisticados".56 Seu sistema de ar condicionado é eficiente, com alta renovação de ar e sem uso de CFC, e as fachadas têm vidros duplos. Após tentativas frustradas com produção eólica de energia, foram instaladas células eletroquímicas no interior do edifício e células fotovoltaicas no lugar de placas de vidro do envelope. O avanço tecnológico do edifício faz parte de sua linguagem arquitetônica, tanto na já comentada exibição no coroamento quanto pela exposição dos painéis fotovoltaicos nas fachadas: "especialistas em energia dizem que o valor dos painéis e células era duplo: demonstrar que essas técnicas tinham avançado além de uma etapa experimental e eram agora realmente utilizadas em edifícios, e dar-lhes uma vitrine em uma localização proeminente." ${ }^{57}$

Entretanto, houve redução da quantidade prevista tanto das células fotovoltaicas quanto eletroquímicas, em razão do alto custo. Embora a energia produzida pelo edifício seja suficiente para suprir quase seis residências (norte-americanas), ela só corresponde a 0,5\% de seu consumo elevado - decorrente, por exemplo, de 37 elevadores, equipamentos de climatização obrigatórios em um edifício de janelas não-operáveis e painéis luminosos para a Times Square. As grandes lajes, com cerca de $3.250 \mathrm{~m}^{2}$, e profundidade entre envelope e núcleo variando entre 18 e $22 \mathrm{~m}$ nos pisos mais baixos, e entre 12 e 15 m nos superiores, faz com que a iluminação natural só seja possível em $25 \%$ da área, mesmo com o aumento dos pés-direitos. Na esquina da Broadway com a West 43 St., algumas pequenas janelas recortadas no painel revelam a contradição da solução - e, além de pequenas, sua iluminação ainda é prejudicada pela profundidade necessária para o sistema de refrigeração do letreiro [fig 7.25]. ${ }^{58}$

O edifício tem, portanto, relevância urbana pelo seu papel na reconfiguração de uma par-

\footnotetext{
56. The Durst Organization, incorporadora do edifício, citada em Percio, “The skyscraper, green design, \& the LEED green building rating system: the creation of uniform sustainable standards for the 21 st century or the perpetuation of an architectural fiction?”, 138.

57. No original: "Energy specialists say that the value of the panels and cells would be twofold: to demonstrate that these techniques have advanced beyond the experimental stage and are now actually usable in buildings, and to give them a showcase in a prominent location.” Holusha, “Technology in the front seat at 4 Times Square”, tradução nossa.

58. Suzanne Stephens, "Fox \& Fowle creates a collage in Four Times Square, using skyscrapers past and present and a touch of 'green", Architectural Record, março de 2000; Gonçalves e Umakoshi, The environmental performance of tall buildings, $278-79$.
} 
te importante do tecido de Nova York, na qual sua retórica ambiental certamente teve papel de melhorar a opinião pública após os empreendimentos anteriormente malsucedidos. Por outro lado, o edifício tinha relevância na agenda ecológica ao apontar outro caminho: nem aquele dos produtos ambientais dificilmente comercializáveis da Bayer e Dow Chemical nas décadas de 1960 e 1970, nem o das formas inusitadas do 30 St Mary Axe e do Commerzbank. Com efeito, a matriz ambiental norte-americana critica esse último. Segundo Joana Gonçalves:

$\mathrm{Na}$ lista de críticas está a baixa eficiência do espaço (baixa proporção entre líquida e bruta), especialmente por causa dos átrios e jardins elevados, a maior proporção entre fachada e área de pavimento e, finalmente, o custo de operar tanto a ventilação mecânica quanto as janelas para a ventilação natural. Além disso, a eficiência da estratégia de ventilação natural e sua real contribuição em reduzir o consumo energético do edifício é questionada pelos representantes e defensores mais radicais da abordagem por ar condicionado. ${ }^{59}$

O protótipo do $\mathrm{LEED}^{\oplus}$ é, portanto, o tradicional edifício de escritórios norte-americano, acrescido de aparato tecnológico. Entre o 4 Times Square e o Lever House, de Skidmore, Owings \& Merrill em 1952, há poucas diferenças tipológicas. O 4 Times Square centraliza o núcleo de circulação, como já era habitual na arquitetura corporativa mas ainda era colocado originalmente na divisa de lote no caso do Lever House, e mantém o pano de vidro contínuo, sem interferências nem mesmo das esquadrias. Com efeito, ao contrário da arquitetura corporativa de Mies van der Rohe, onde os montantes eram expostos e aludiam à serialização da arquitetura, o Lever House - localizado face à torre Seagram, atravessada a rua - esconde as esquadrias na pele de vidro, preservando a homogeneidade total do envelope, como analisado por Iñaki Ábalos e Juan Herreros:

59. No original: "On the list of criticisms there is the low efficiency of space (low net to gross ratio), especially because of atriums and sky-gardens, the larger façade to floor area ratio and, finally, the cost of operating both mechanical ventilation and windows for natural ventilation. In addition, the efficiency of the natural ventilation strategy and its real contribution to reducing the building's energy consumption is questioned by the more radical representatives and defenders of the air-conditioning approach." Gonçalves e Umakoshi, The environmental performance of tall buildings, 113, tradução nossa. Ver também Michelle Schneider Santos, "Entre a transparência e a espessura: a moderna fachada do edifício comercial americano 1945-1975” (Tese [Doutorado em Arquitetura e Urbanismo]. Orientação de Ruth Verde Zein, Universidade Presbiteriana Mackenzie, 2016). 
Os edifícios de Bunshaft exibem, portanto, uma imagem da planaridade que colocava uma alternativa à voluminosidade sutil da cortina de vidro miesiana. Os contemporâneos de Bunshaft adotaram essa imagem em um momento em que as afiliações formais do arranha-céu estavam passando do universo de orientação maquinista em direção à abstração característica da arte contemporânea, especialmente a estética reducionista da abstração geométrica e em seguida do minimalismo. ${ }^{60}$

O 4 Times Square mantém a solução do Lever House para seu volume e o desenho do envelope, o que de resto já havia se tornado recorrente na arquitetura corporativa norte-americana. Entretanto, como a proposta do 4 Times Square era a de ser a primeira torre ambiental de Manhattan, é contraditório buscar uma referência no Lever House, um edifício impossível de ser operado sem equipamentos de climatização: seu vidro simples e as janelas seladas requerem obrigatoriamente $\mathrm{o}$ ar condicionado para manter uma temperatura satisfatória no interior. ${ }^{61}$ Uma lógica tão inerente ao projeto que se manifesta na fachada do Lever House, como nota Charles Jencks:

Por causa dos pavimentos muito profundos que as novas tecnologias permitiram, um forro profundo que abrigava esses mecanismos tornou-se uma realidade e uma que poderia ser expressa, junto com a estrutura, no exterior. Por isso o ritmo horizontal "grande/pequeno" que o edifício Lever estabeleceu e se tornou a norma nos anos cinquenta. ${ }^{62}$

60. No original: "Bunshaft's buildings thus display an image of planarity that posed an alternative to the subtle voluminosity of the Miesian curtain wall. Bunshaft's contemporaries adopted this image at a time when the skyscraper's formas affiliations were shifting from a machine-oriented universe toward the abstraction characterizing contemporary art, especially the reductionist aesthetics of geometric abstraction and subsequently of minimalism." Iñaki Ábalos e Juan Herreros, Tower and office: from modernist theory to contemporary practice., org. Joan Ockman, [Ed. orig. 1992] (Cambridge, Massachusetts; Londres: The MIT Press, 2003), 113, tradução nossa. Também em prefácios para livros do SOM, apesar do evidente conflito de interesse, podem ser encontradas defesas de que é o Lever House, mais do que o modelo miesiano, o projeto que definitivamente estabelece uma origem da arquitetura corporativa norte-americana. Henry-Russell Hitchcock vê no Lever House uma combinação entre Mies, a sede da ONU e o MESP brasileiro. Cf. Henry-Russell Hitchcock e Ernst Danz, SOM: Architecture of Skidmore, Owings \& Merrill, 1950-1962, Introdução de 1961 (New York: The Monacelli Press, 2009). Ver ainda debate em Reinhold Martin, The organizational complex: architecture, media, and corporate space (Cambridge, Massachusetts: The MIT Press, 2005), 101-2.

61. David Arnold, “Air conditioning in office buildings after World War II”, ASHRAE Journal, julho de 1999, 33-41.

62. No original: "Because of the very deep plans which the new technologies allowed, a deep ceiling which housed these mechanisms became a reality and one which could be expressed, along with the structure, on the exterior. Hence the horizontal rhythm of "large/small" which the Lever Building established and which became the norm in the fifties." Charles Jencks, Skyscrapers-Skyprickers-Skycities (Londres: Academy Editions, 1980), 9, tradução nossa. 
Só não há contradição nessa solução se seu ambientalismo for circunscrito à otimização desses equipamentos, sem colocar em questão a necessidade de seu uso. É essa, pois, a contradição que o 4 Times Square supera.

Vizinho ao 4 Times Square, foi construído o One Bryant Park, primeira torre corporativa a obter o nível Platinum no LEED $^{\oplus}$ CS v1 [fig 7.28 a 7.34]. A princípio, a obra também seria da Fox \& Fowle, mas Robert Fox levou o projeto para a Cook + Fox após o fim da sociedade com Bruce Fowle. Inaugurado em 2009, o projeto feito para o Bank of America mantém o envelope único e as soluções high tech. Como estratégias sustentáveis, o edifício coleta toda a água da chuva e privilegia o uso de materiais de construção dentro de um raio de $800 \mathrm{~km}$. Durante a noite, gelo é produzido e armazenado no topo do edifício para diminuir o uso de energia para o resfriamento do edifício no pico de demanda. Dobras na fachada potencializam vistas e entrada de luz - uma estratégia comum em edifícios de escritórios, nos quais a uniformidade da mera replicação dos pavimentos-tipo é contrabalançada pelo envelope vistoso.

Outros edifícios, sobretudo em Nova York, fizeram parte da difusão do LEED ${ }^{\circledR}$, como o One World Trade Center (SOM, 2005/2014, CS v2 Gold) [fig 7.35] - incorporado pela Durst Organization, também responsável pelo One Bryant Park e o 4 Times Square, e que também teve como primeiros inquilinos a editora Condé Nast -, a torre Hearst (Foster + Partners, 2000/2006, NC v2 Gold) [fig 7.36] e o 10 Hudson Yards (KPF, 2010/2016, CS v3 Platinum) [fig 7.37]. Em termos ambientais, deve ainda ser mencionada a nova sede do The New York Times (2000/2007), propriedade também da Forest City Ratner, incorporadora do empreendimento. O projeto foi feito pelo Renzo Piano Building Workshop (RPBW), com colaboração de Bruce Fowle, à época no escritório FXFowle (posteriormente FXColabborative) [fig 7.38]. O projeto venceu uma competição fechada com Pelli Clarke Pelli, Foster + Partners, Frank Gehry e SOM, e a torre foi inaugurada em $2007 .{ }^{63}$ Apesar dos quebra-sóis cerâmicos e de maior ênfase na iluminação natural, o edifício mantém a solução do Lever House. Para o crítico Nicolai Ouroussoff, "As características mais contemporâneas - as claraboias computadorizadas e as persianas que regulam a entrada de luz nos interiores - são mais inovações tecnológicas do

63. Suzanne Stephens, “The New York Times Building”, Architectural Record, 19 de fevereiro de 2008, https://www.architecturalrecord.com/articles/8081-the-new-york-times-building. 
que arquitetônicas" ${ }^{64}$, o que reforça o argumento até aqui apresentado. Entretanto, o edifício não foi certificado pelo LEED $^{\oplus}$ : pensado para tal, os incorporadores desistiram face aos altos custos envolvidos.

Desde o protótipo do LEED $^{\circledR}$ até seus casos exemplares, a estratégia é portanto única:

A abordagem em direção a eficiência energética e desempenho ambiental no contexto norte-americano é fortemente relacionada à tecnologia de engenharia de sistemas mecânicos e elétricos. A esse respeito, o conceito arquitetônico básico do projeto comercial não é questionado ou desafiado, principalmente por causa de valores culturais e econômicos, mas a especificação de materiais e de componentes dos edifícios mudou para obedecer a códigos e padrões ambientais mais novos e mais estritos e objetivos de eficiência energética relacionados à operação de sistemas técnicos dos edifícios. ${ }^{65}$

\section{VIRTUALIDADE DA EXCEÇÃO}

Retomemos as conclusões tiradas no capítulo 6, agora à luz não só das táticas de marketing, mas também da forma arquitetônica. As estratégias de projeto do LEED $^{\circledR}$ apostam na excepcionalidade da eficiência energética, mas almejam impactar a totalidade da arquitetura. Entretanto, seu método não pode ser generalizado. Sistemas mecânicos eficientes, envelopes de alto desempenho e grande porte são possíveis apenas com grandes investimentos.

Tomando como exemplo os expoentes da certificação nos Estados Unidos, deve-se mesmo questionar se as melhorias alcançadas correspondem à propaganda e aos investimentos realizados. O One World Trade Center obteve 37 pontos no LEED $^{\circledR}$ CS v2, com 30\% de redução no uso de água e o mínimo de economia em energia estabelecido em um dos pré-requisitos com-

\footnotetext{
64. No original: "The most contemporary features — the computerized louvers and blinds that regulate the flow of light into the interiors - are technological innovations rather than architectural ones." Nicolai Ouroussoff, "Pride and nostalgia mix in The Times's new home”, The New York Times, 20 de novembro de 2007, grifo no original, tradução nossa.

65. No original: "the approach towards energy efficiency and environmental performance in the North American context is closely related to the technology of mechanical and electrical engineering systems. In this respect, the basic architectural concept of commercial design is not questioned or challenged, mainly because of cultural and economic values, but the specification of materials and building components has changed to comply with newer and stricter environmental standards/codes and energy efficiency targets related to the operation of building technical systems." Gonçalves e Umakoshi, The environmental performance of tall buildings, 13 , tradução nossa.
} 

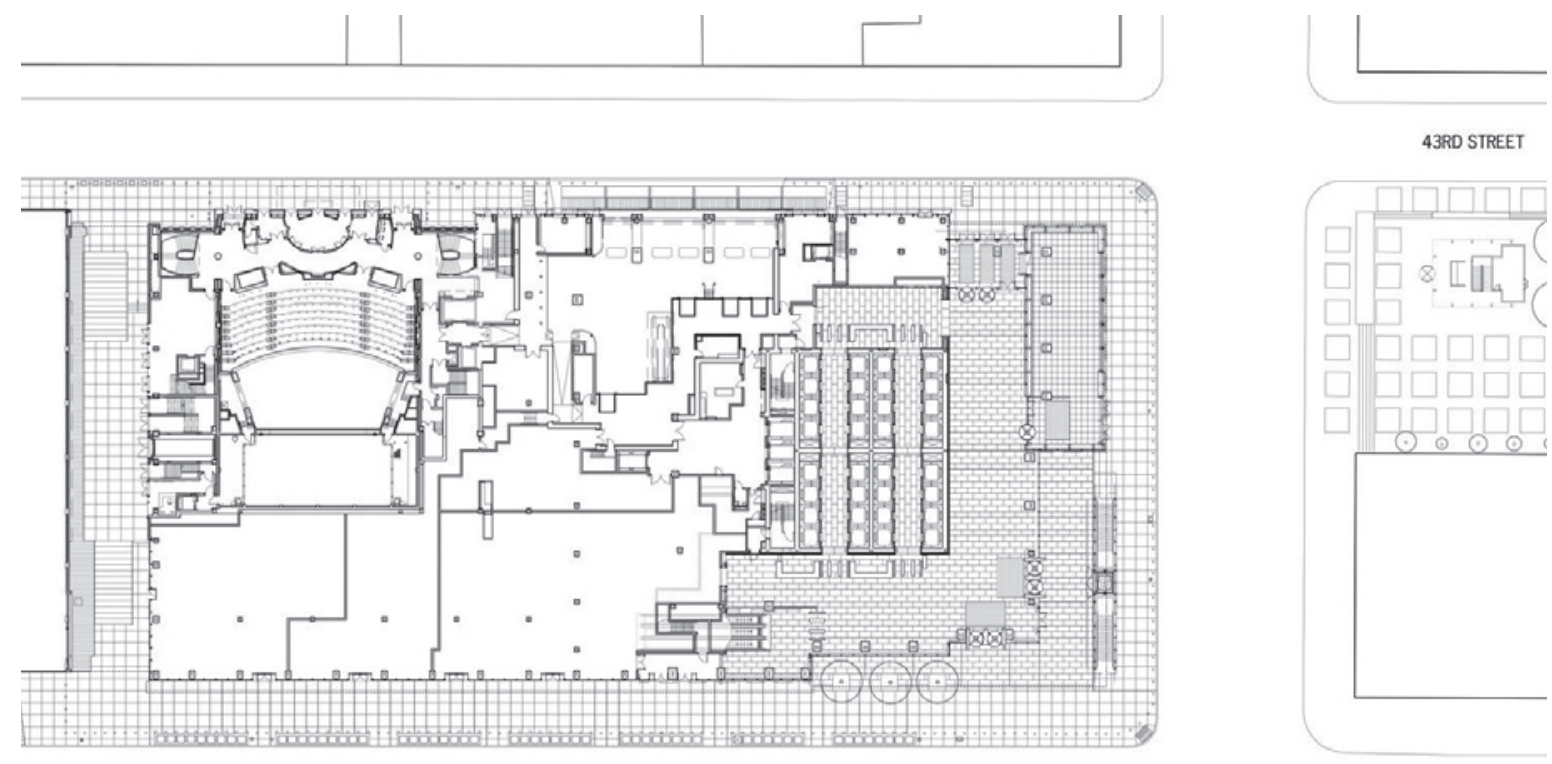

42ND STREET
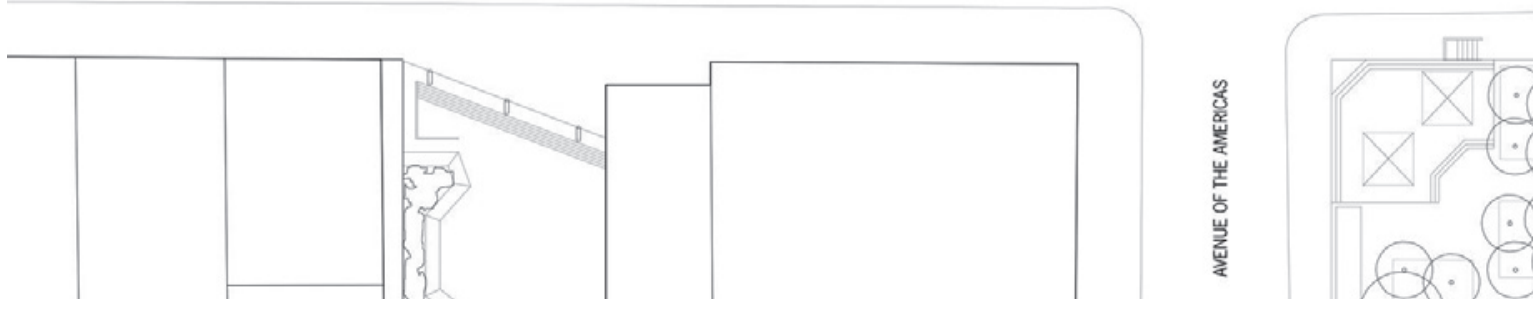

Fig 7.28. Cook Fox, One Bryant Park (2004/2009).

Implantação. Sem escala. Fonte: Acervo dos arquitetos via

Architecture Week.

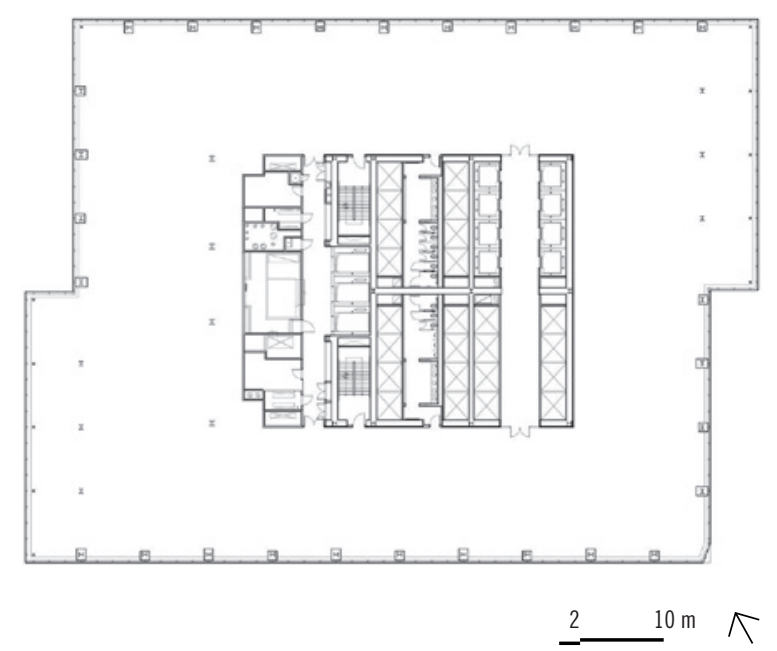

Fig 7.29. Cook Fox, One Bryant Park (2004/2009). Planta do vigésimo pavimento. Sem escala. Fonte: Acervo dos arquitetos via Architecture Week. 


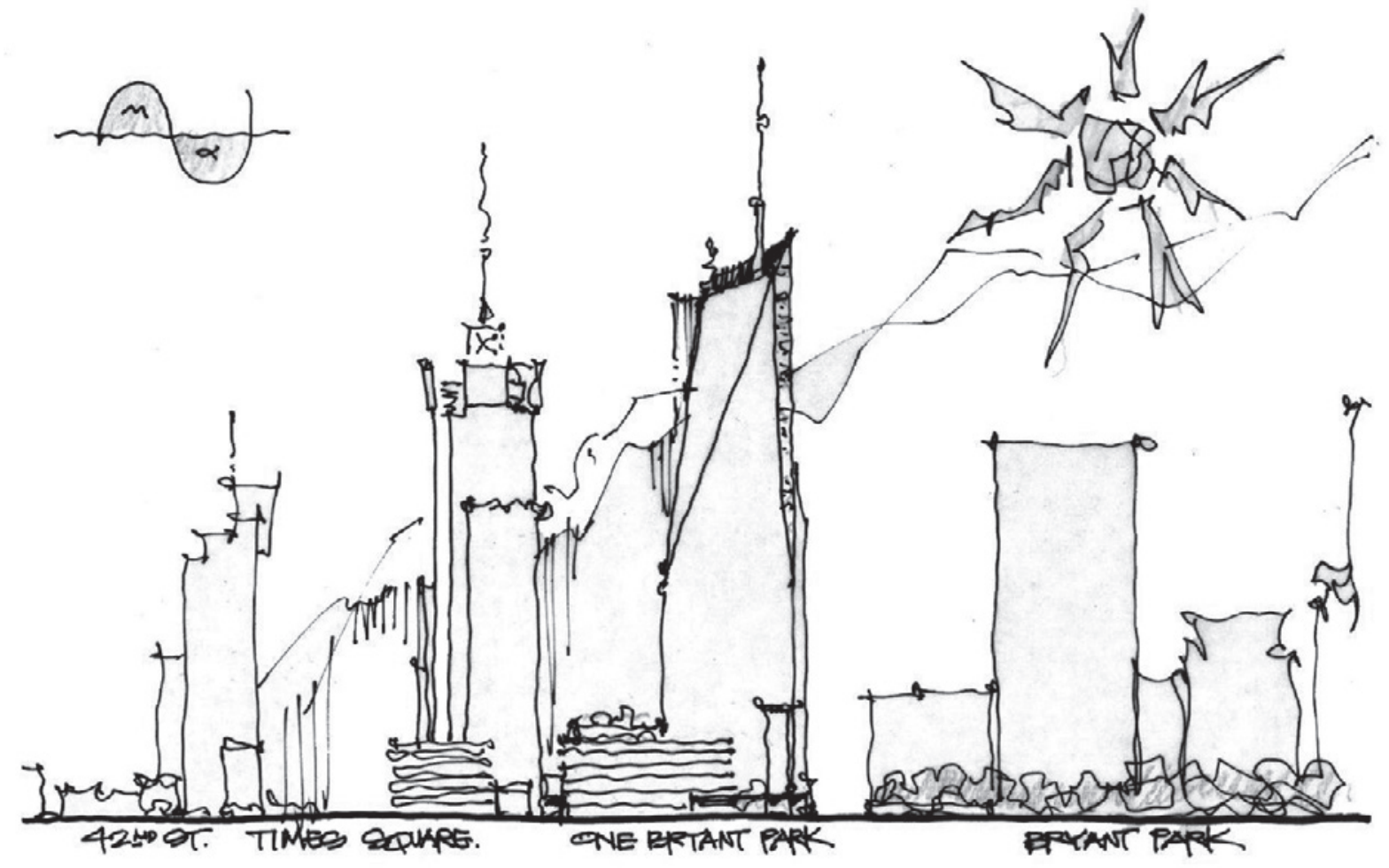

Fig 7.30. Cook Fox, One Bryant Park (2004/2009). Croqui do empreendimento, incluindo o 4 Times Square. Fonte: Acervo dos arquitetos via Archdaily.

Fig 7.31. Cook Fox, One Bryant Park (2004/2009). Esquema de captação e reaproveitamento de água. Sem

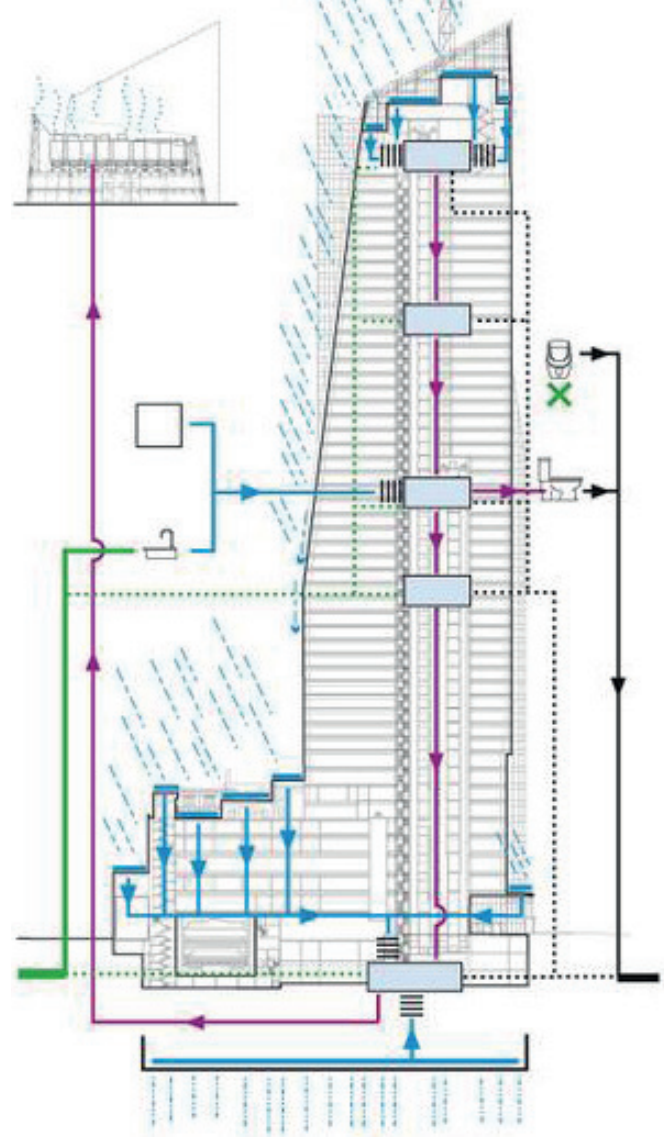
escala. Fonte: Detail, mai 2009. 


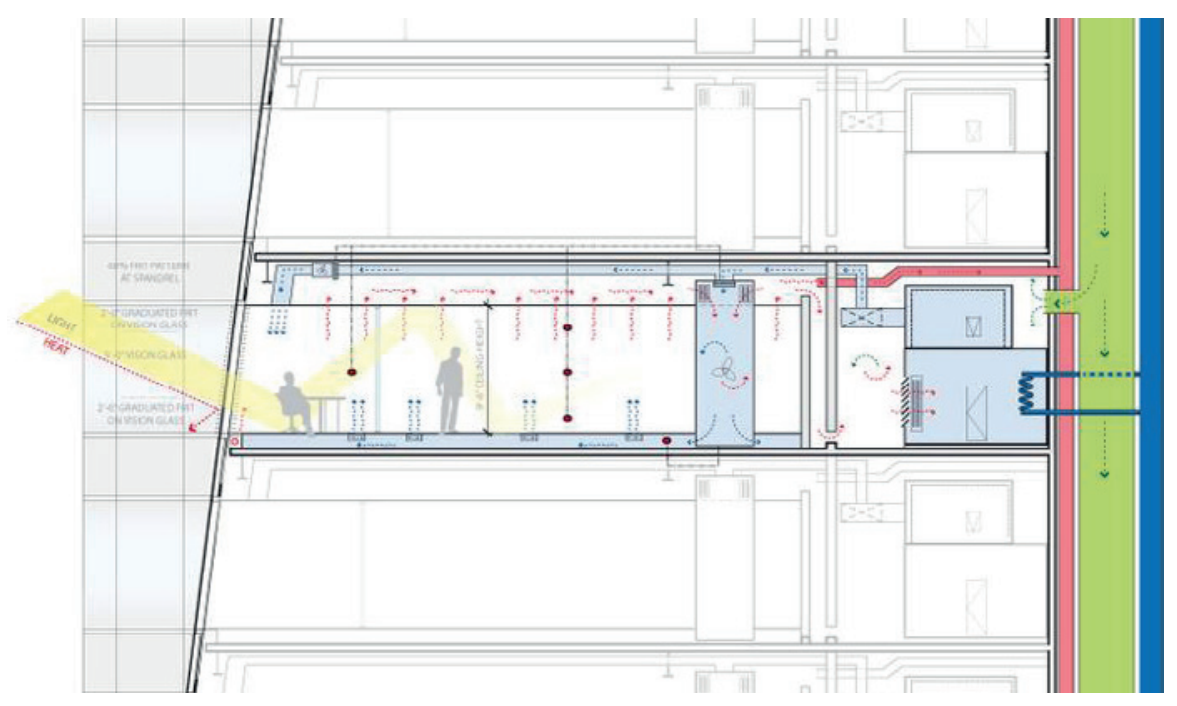

Fig 7.32. Cook Fox, One Bryant Park (2004/2009).

Esquema de iluminação e controle térmico. Sem escala.

Fonte: Detail, mai 2009.

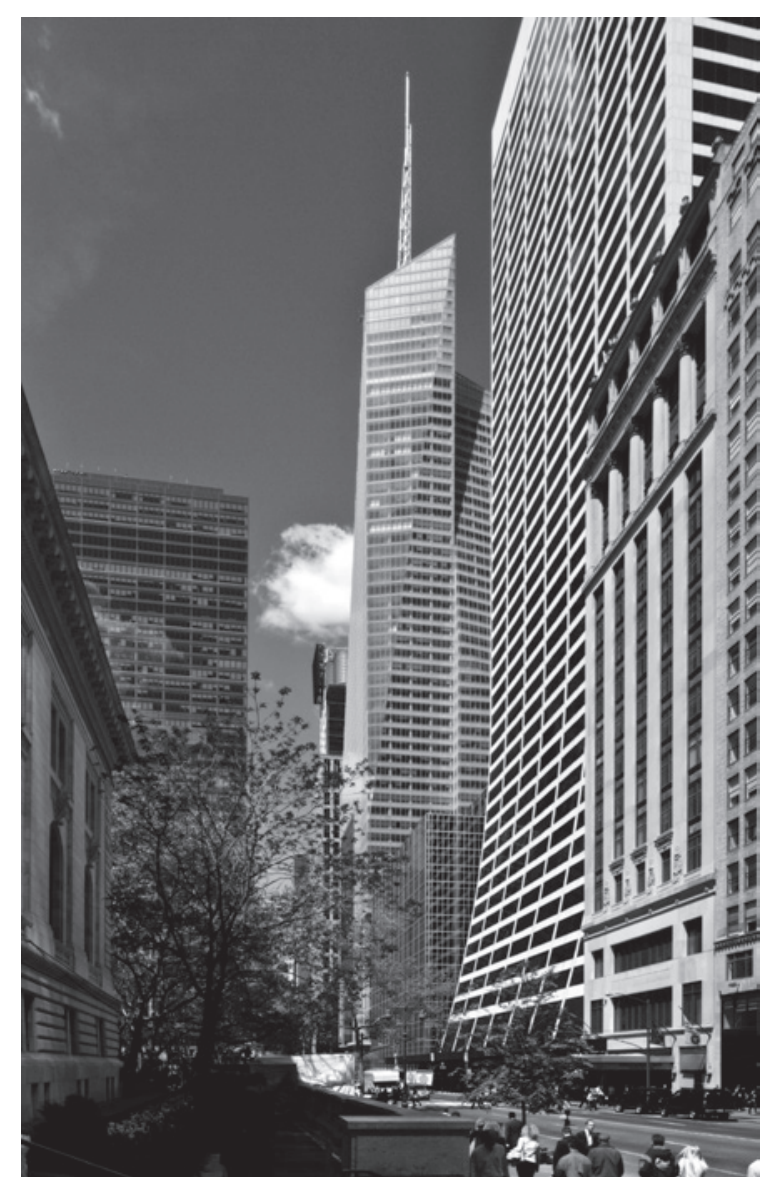

Fig 7.33. Cook Fox, One Bryant Park (2004/2009). Vista a partir da 42nd East St. Fonte: Cook Fox, acervo online.

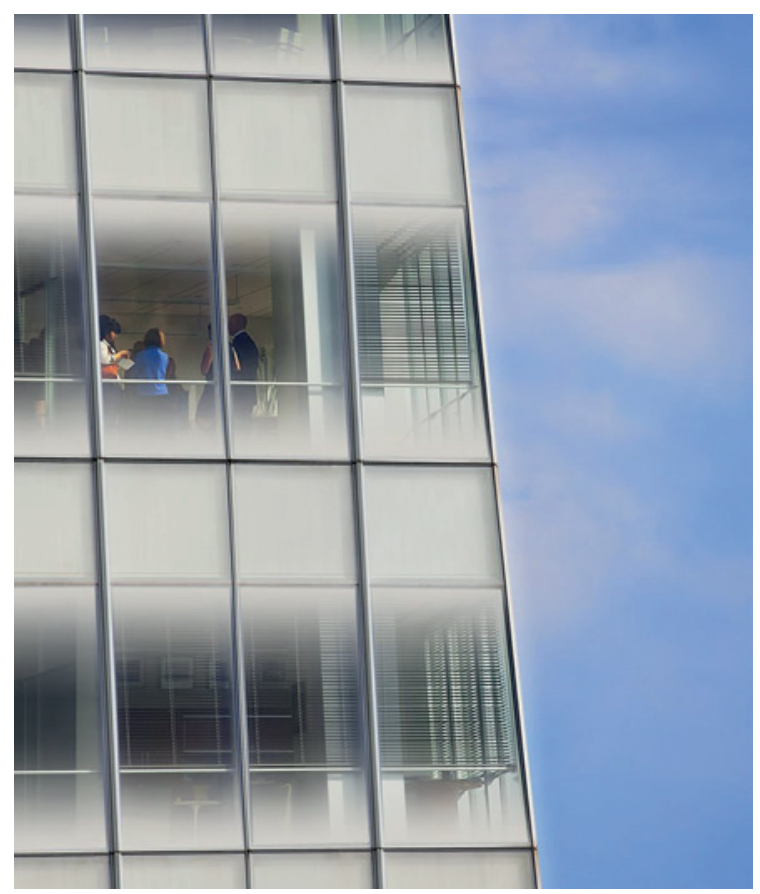

Fig 7.34. Cook Fox, One Bryant Park (2004/2009). Detalhe da fachada. Fonte: Acervo dos arquitetos, via Archdaily. 


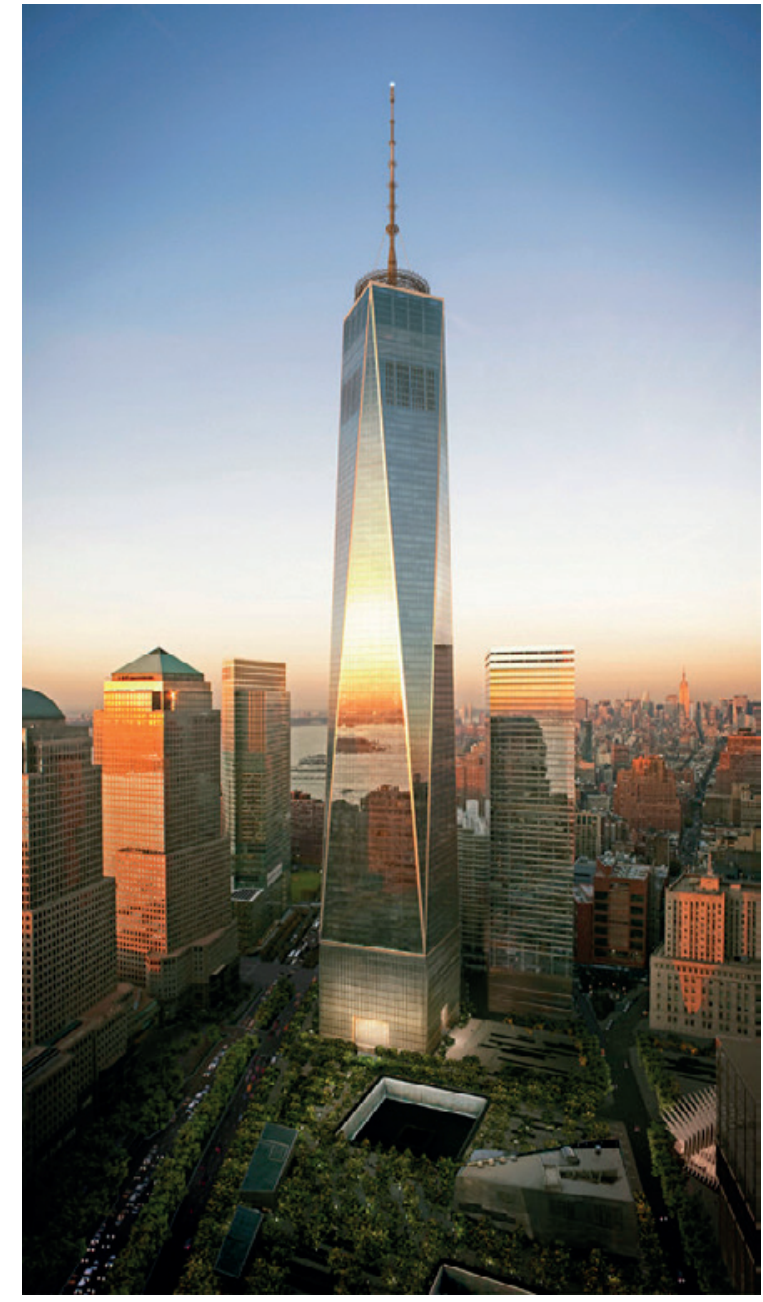

Fig 7.35. SOM, One World Trade Center (2005/2014). Fonte: SOM, acervo online.

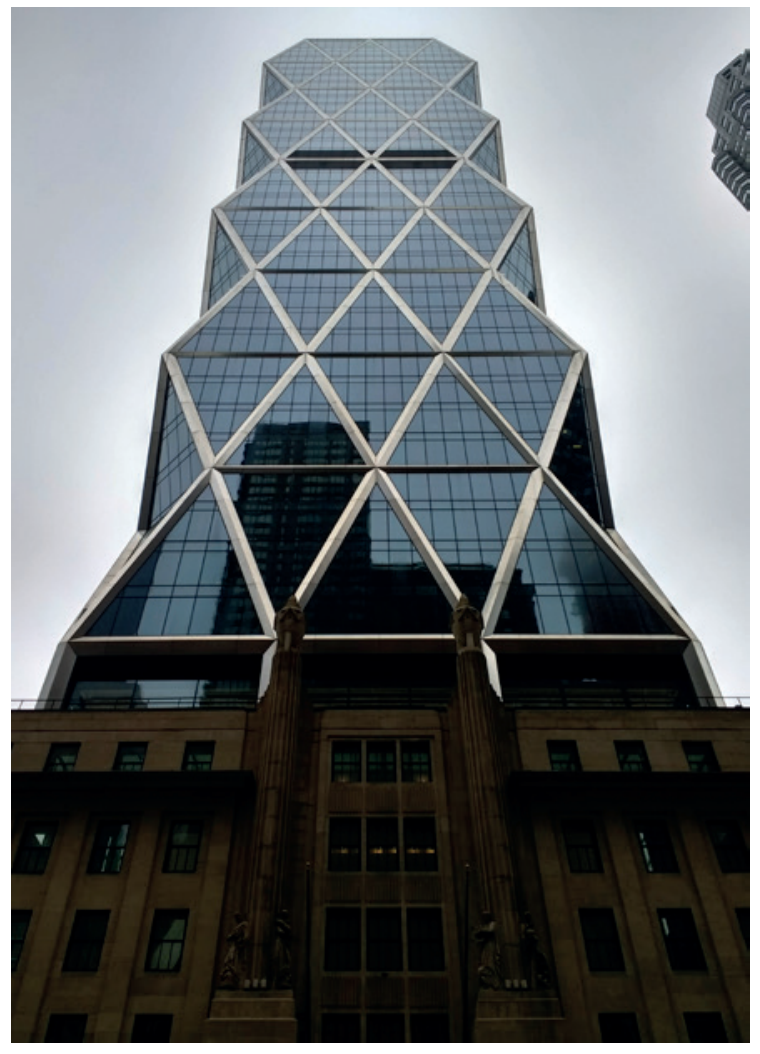

Fig 7.36. Foster + Partners, torre Hearst (2000/2006). Fonte: Acervo do autor, 2018. 
pulsórios. Isso para o edifício - por enquanto - mais caro do mundo, com custo de 4 bilhões de dólares, o equivalente ao PIB de várias cidades médias brasileiras: considerando 2016 como ano base, quando a torre foi inaugurada, o valor é equivalente a cidades na sexagésima posição de maiores economias no Brasil naquele ano. Com 50 pontos no CS v1, o One Bryant Park não teve a pontuação detalhada divulgada, mas custou um bilhão de dólares. O 10 Hudson Yards, implantado na área de Nova York com maior transformação e investimento dos últimos vinte anos depois do Ground Zero, tem 28\% de economia em energia e 35\% em água. Por mais que esses sejam edifícios particulares dentre inúmeros certificados, é sintomático que eles sejam os modelos projetuais celebrados pelo USGBC ${ }^{\circledast}$ e que as eficiências alcançadas não correspondam ao vulto de capital envolvido. As eficiências são tímidas em comparação aos investimentos e à promoção publicitária desses modelos.

A estratégia "market friendly" do USGBC ${ }^{\circledast}$ foi resolvida no âmbito arquitetônico com a fundamentação do certificado no modelo da torre corporativa de vidro e tecnologicamente avançada. Desse modo, o LEED $^{\circledR}$ contribui na operação do mercado ao viabilizar ambientalmente o modelo corporativo norte-americano: as torres core \& shell cuja lógica projetual é a sobreposição de áreas máximas de pavimentos-tipo, e não qualquer grau de transição ecológica. A observação de outros experimentos da arquitetura ambiental ao longo da segunda metade do século XX esclareceu o quão contrastantes são os diferentes modelos, e como o 4 Times Square e o LEED ${ }^{\circ}$ buscaram resolver mais esse oximoro: a torre de vidro e o ambientalismo.

Se os modernizadores ecológicos, vistos no capítulo 4, tentavam resolver um oximoro semelhante, entre ecologia e economia, e por isso encontravam constantes impasses, então igual situação é encontrada na arquitetura. A eficiência buscada pelas estratégias ativas, sem interferir nos esquemas de projeto já encontrados no mercado, não leva à sua generalização, e sim à criação de excepcionalidades. $\mathrm{O} \mathrm{LEED}^{\circledR}$ não provocou a transformação total do mercado, mas sim uma distinção de nicho, e as eficiências alcançadas não são de ordem tão elevada para justificar seu escopo restrito de atuação.

O foco em eficiência tampouco aborda outras questões ambientais relevantes em um projeto arquitetônico. Em termos ainda de eficiência energética, o sistema Living Building Challenge exige autonomia total no uso de recursos, e mesmo devolve-os à rede - como na produção de energia ou no tratamento total da água. Seu objetivo não é o de reduzir o impacto, mas de fato 


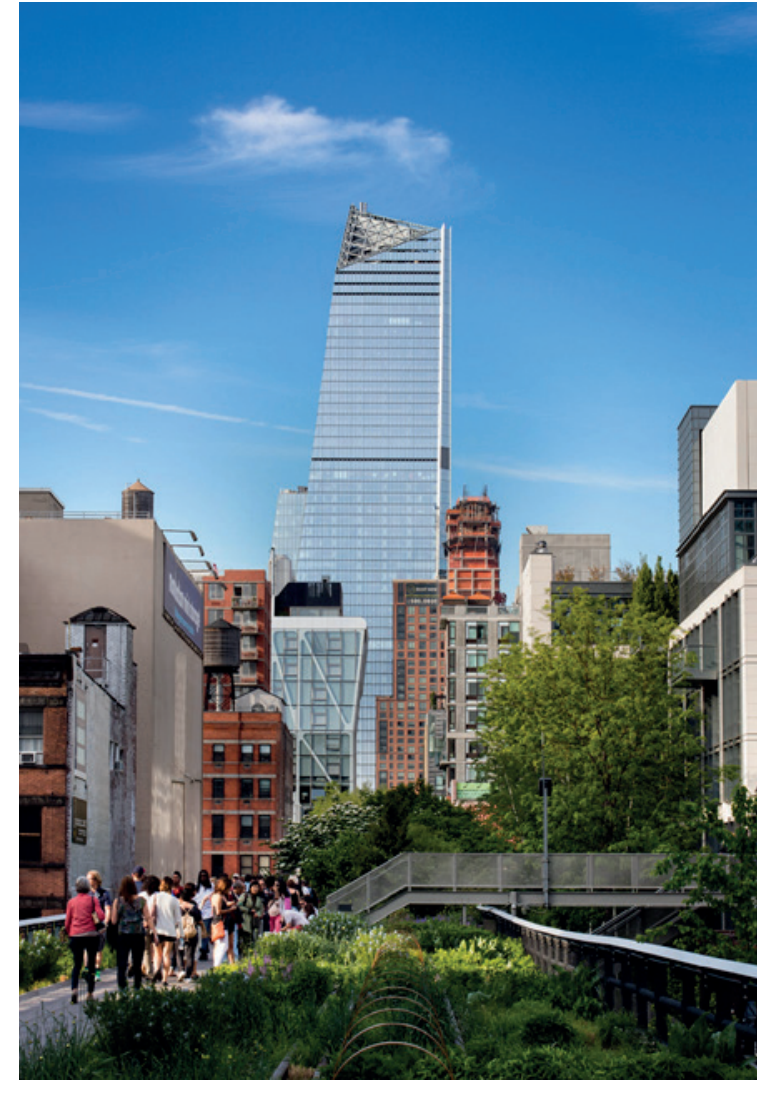

Fig 7.37. KPF, 10 Hudson Yards (2010/2016). Fonte: Dan Howarth/Dezeen.

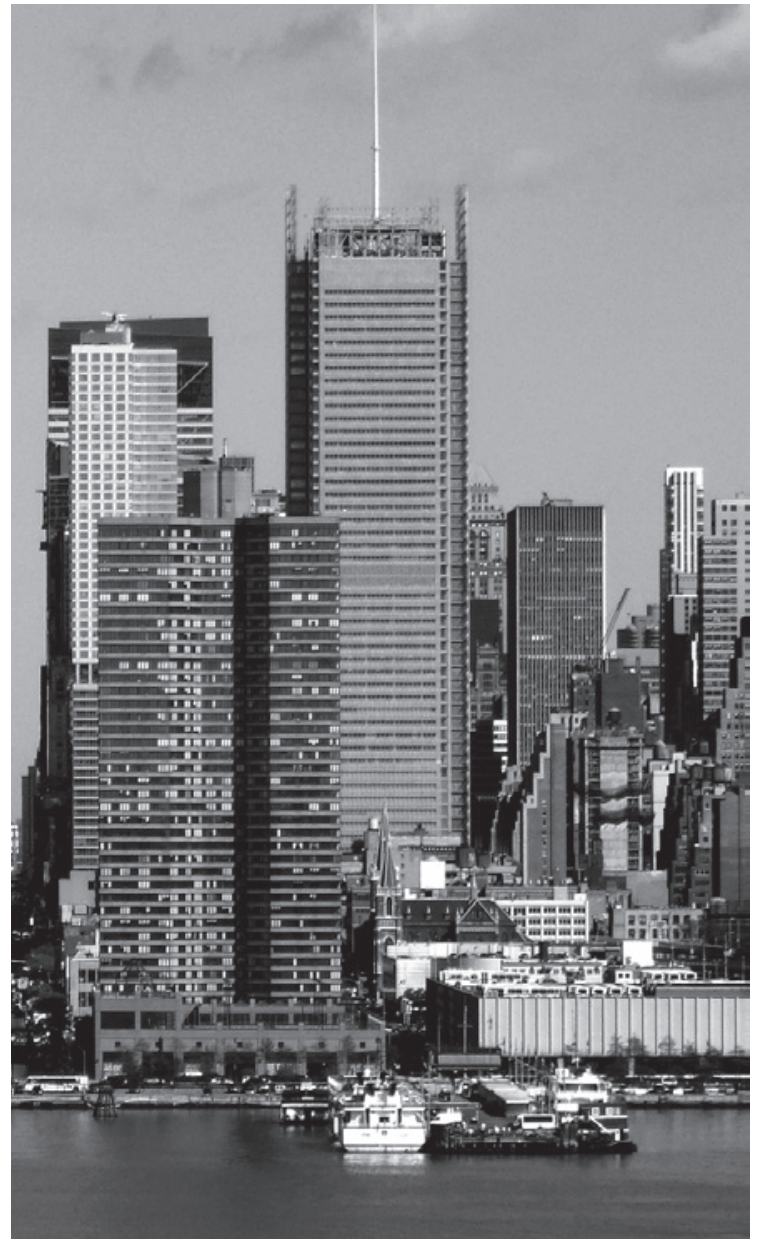

Fig 7.38. Renzo Piano Building Workshop e

FXCollaborative, The New York Times (2000/2007). Fonte: John W. Cahill, via Council of Tall Buildings and Urban Habitat (CTBUH). 
regenerar o ambiente. ${ }^{66}$ Já o certificado alemão DGNB aborda temas externos ao par economia-ecologia do LEED ${ }^{\circledR}$ o uso do edifício ao longo do tempo, como a análise do ciclo de vida do empreendimento por cinquenta anos, sua adaptabilidade a novos usos e possibilidade de desmontagem; as condições da extração de materiais como proteção contra trabalho infantil ou inseguro; estratégias passivas; o impacto e eventuais conflitos com a população do entorno pelo empreendimento; e obrigatoriamente a abertura das áreas do térreo para uso público, dentre outros pontos. ${ }^{67}$ Deve-se, assim, sair do objetivo único na ecoeficiência como modo de transição ecológica: os resultados obtidos nem permitem induzir uma redução relevante do uso de recursos, como argumenta John Ehrenfeld, nem levam em conta a desigualdade dos efeitos da crise ambiental, como nota Andrew Blowers. ${ }^{68}$

O contraste entre a torre de cristal e a favela do CEO Rick Fedrizzi, citada no capítulo 6, não é acidental, mas inerente ao LEED ${ }^{\circledR}$. As suas virtualidades não permitem generalização: elas foram concebidas para o mercado formal em contexto geográfico preciso. Situações fora de sua lógica de origem são "projetos inusuais" ao LEED, passíveis de certificação, mas que produzem desigualdades na produção arquitetônica cada vez mais latentes.

A virtualidade do $\mathrm{LEED}^{\oplus}$, pelo exposto, aponta para o que já pode ser observado nos dados empíricos: um mercado saturado de edifícios de alto padrão. A estratégia de expansão de mercado global do $\mathrm{LEED}^{\oplus}$, sua generalização por apenas um sistema adaptável, o incentivo a produtos de alto desempenho e a opção por altos ganhos de eficiência em estratégias ativas limitam o LEED ${ }^{\circledast}$ à arquitetura de alto padrão.

Mas até agora a análise centrou-se na virtualidade do LEED $^{\circledR} \mathrm{NC}$ e CS, sem se dedicar a pontuação e projetos específicos. Se essa é a virtualidade do LEED ${ }^{\circledR}$ NC e CS, como eles são usados pelo mercado? Qual é a passagem do ideal para o empírico?

66. International Living Future Institute, "Living Building Challenge 3.1” (International Living Future Institute, 2016).

67. DGNB (Deutsche Gesellschaft für Nachhaltiges Bauen), "DGNB - Core and scheme sheet. Offices, version 2014" (DGNB, 2014).

68. John R. Ehrenfeld, "Eco-efficiency: philosophy, theory, and tools", Journal of Industrial Ecology 9, no 4 (2005): 6-8; Andrew Blowers, “Environmental policy: ecological modernisation or the risk society?", Urban Studies 34, n 5-6 (1997): 845-71, https://doi.org/10.1080/0042098975853. 


\title{
CAPÍTULO 8
}

\section{A TENSÃO COM O CAPITAL SIMBÓLICO}

\begin{abstract}
Para mudar um pouco a metáfora, o investimento profissional pode ser comparado àqueles concursos em jornais em que os competidores têm de escolher os seis rostos mais bonitos dentre uma centena de fotografias, o prêmio sendo dado ao competidor cuja escolha melhor corresponda à preferência média do total de competidores; de modo que cada competidor deverá escolher não os rostos que ele próprio considere mais bonitos, mas aqueles que ele imagina mais próximos de reunirem as preferências dos outros competidores, todos eles encarando o problema do mesmo ponto de vista. Não se trata de escolher os rostos que, no julgamento individual, são realmente os mais bonitos, nem mesmo aqueles que a opinião média considera realmente como os mais bonitos. Nós chegamos ao terceiro grau, no qual utilizamos a nossa inteligência para antecipar o que a opinião geral espera que a opinião geral seja. E há alguns, eu acredito, que trabalham no quarto, no quinto ou em ainda maiores graus.

John Maynard Keynes ${ }^{1}$
\end{abstract}

No capítulo anterior foram vistas quais eram as virtualidades ou potencialidades do LEED ${ }^{\circledR}$ pela extrapolação das premissas de projeto nos sistemas New Construction (NC) e Core \& Shell (CS). Esses sistemas favorecem "padrões" ou "fragmentos tipológicos", usando expressões de Monta-

\footnotetext{
1. No original: "Or, to change the metaphor slightly, professional investment may be likened to those newspaper competitions in which the competitors have to pick out the six prettiest faces from a hundred photographs, the prize being awarded to the competitor whose choice most nearly corresponds to the average preferences of the competitors as a whole; so that each competitor has to pick, not those faces which he himself finds prettiest, but those which he thinks likeliest to catch the fancy of the other competitors, all of whom are looking at the problem from the same point of view. It is not a case of choosing those which, to the best of one's judgment, are really the prettiest, nor even those which average opinion genuinely thinks the prettiest. We have reached the third degree where we devote our intelligences to anticipating what average opinion expects the average opinion to be. And there are some, I believe, who practise the fourth, fifth and higher degrees." John Maynard Keynes, The general theory of employment, interest and money, Introdução de Paul Krugman. Posfácio de Robert Skidelksy. [Ed. orig. 1935] (Cambridge, UK: Palgrave Macmillan, 2018), 137, https://doi.org/10.1007/978-3-319-70344-2, tradução nossa.
} 


\begin{tabular}{|c|c|c|c|c|c|c|}
\hline & $\begin{array}{l}\text { Rochaverá } \\
\text { Corporate } \\
\text { Towers }\end{array}$ & $\begin{array}{l}\text { Morumbi } \\
\text { Corporate }\end{array}$ & WT Morumbi & $\begin{array}{l}\text { Parque da } \\
\text { Cidade }\end{array}$ & $\begin{array}{l}\text { São Paulo } \\
\text { Corporate } \\
\text { Towers }\end{array}$ & $\begin{array}{l}\text { Complexo } \\
\text { WTJK }\end{array}$ \\
\hline Arquitetura & $\begin{array}{l}\text { aflalo/ } \\
\text { gasperini } \\
\text { arquitetos }\end{array}$ & $\begin{array}{l}\text { aflalo/ } \\
\text { gasperini } \\
\text { arquitetos }\end{array}$ & $\begin{array}{l}\text { aflalo/ } \\
\text { gasperini } \\
\text { arquitetos }\end{array}$ & $\begin{array}{l}\text { aflalo/ } \\
\text { gasperini } \\
\text { arquitetos } \\
\text { (HKS para } \\
\text { Four Seasons) }\end{array}$ & $\begin{array}{l}\text { Pelli Clarke } \\
\text { Pelli e aflalo/ } \\
\text { gasperini } \\
\text { arquitetos }\end{array}$ & Arquitectonica \\
\hline Início do projeto & 1999 & 2008 & 2009 & 2010 & 2008 & 2007 \\
\hline $\begin{array}{l}\text { Conclusão da } \\
\text { obra }\end{array}$ & $\begin{array}{l}\left.2008 \text { ( } 1^{\text {a }} \text { fase }\right) \\
2012\end{array}$ & 2013 & 2016 & $\begin{array}{l}\left.2015 \text { ( } 1^{\mathrm{a}} \text { fase }\right), \\
2018\left(2^{\mathrm{a}} \text { fase }\right), \\
3^{\mathrm{a}} \text { fase em } \\
\text { andamento }\end{array}$ & 2015 & 2014 \\
\hline Incorporação & $\begin{array}{l}\text { Tishman } \\
\text { Speyer }\end{array}$ & Multiplan & WTorre & $\begin{array}{l}\text { Odebrecht } \\
\text { Realizações }\end{array}$ & $\begin{array}{l}\text { Camargo } \\
\text { Corrêa De- } \\
\text { senvolvimento } \\
\text { Imobiliário }\end{array}$ & WTorre \\
\hline Construção & Método & Racional & WTorre & Odebrecht & $\begin{array}{l}\text { Camargo } \\
\text { Corrêa }\end{array}$ & WTorre \\
\hline Área construída & $233.704 \mathrm{~m}^{2}$ & $135.230,07 \mathrm{~m}^{2}$ & $170.428 \mathrm{~m}^{2}$ & $595.929,94 \mathrm{~m}^{2}$ & $257.799,74 \mathrm{~m}^{2}$ & $422.000 \mathrm{~m}^{2}$ \\
\hline Área do terreno & $33.515 \mathrm{~m}^{2}$ & $19.977,32 \mathrm{~m}^{2}$ & $21.111,21 \mathrm{~m}^{2}$ & $82.218,63 \mathrm{~m}^{2}$ & $38.000 \mathrm{~m}^{2}$ & $61.055,85 \mathrm{~m}^{2}$ \\
\hline Área do pav. tipo & $\begin{array}{l}1.642 \text { a } 1.976 \\
\mathrm{~m}^{2}\end{array}$ & $\begin{array}{l}2.300 \mathrm{~m}^{2} \\
\text { (Diamond } \\
\text { Tower); } 1.600 \\
\mathrm{~m}^{2} \text { (Golden } \\
\text { Tower) }\end{array}$ & $\mathrm{c} 1.500 \mathrm{~m}^{2}$ & $\begin{array}{l}\text { c1.500 m² } \\
\text { (Sucupira), } \\
\text { c } 900 \mathrm{~m}^{2} \\
\text { (Tarumã) }\end{array}$ & $\begin{array}{l}1.805-2.570 \\
\mathrm{~m}^{2}\end{array}$ & $\begin{array}{l}2.000 \mathrm{~m}^{2} \\
\text { (Torre São } \\
\text { Paulo), } 706 \\
\mathrm{~m}^{2} \text { (torre E), } \\
1.371,77 \mathrm{~m}^{2} \\
\text { (torre D) }\end{array}$ \\
\hline Nível LEED ${ }^{\circledast}$ & CS v2 Gold & CS v3 Gold & CS v3 Silver & $\begin{array}{l}\text { CS v3 Gold } \\
\text { (Sucupira), } \\
\text { ND } 2009 \\
\text { Silver }\end{array}$ & $\begin{array}{l}\text { CS v3 } \\
\text { Platinum }\end{array}$ & $\begin{array}{l}\text { CS v2 Gold } \\
\text { (Torre São } \\
\text { Paulo), CS v3 } \\
\text { Gold (torre } \\
\text { B), CS v2 } \\
\text { Silver (torres } \\
\text { D e E) }\end{array}$ \\
\hline $\begin{array}{l}\text { Consultoria de } \\
\text { sustentabilidade }\end{array}$ & Sustentax & ConAm & Sustentax & Arup e CTE & $\begin{array}{l}\text { Atelier Ten e } \\
\text { CTE }\end{array}$ & CTE \\
\hline
\end{tabular}

Tab 8.1. Dados dos empreendimentos estudados. Elaborado pelo autor. 
ner, ${ }^{2}$ como a generalização dos sistemas mecânicos, o envelope estanque, o aumento de áreas verde e as características potenciais de monofuncionalidade, enclausuramento e o grande porte dos empreendimentos.

Mas os sistemas LEED ${ }^{ø}$ não são o ponto de partida para um projeto corporativo. Embora exigente na documentação e na gestão de obra, o LEED ${ }^{\oplus}$ é mais maleável na arquitetura e por vezes aplicado apenas na fase de projeto executivo, à revelia do aconselhamento técnico de seus consultores. Poucos são os casos nos quais o cumprimento se aproxima do total de pontos possíveis, sendo a pontuação máxima impossível, pois há créditos com temas específicos, como a descontaminação do solo ou a conservação de estruturas pré-existentes, ${ }^{3}$ nem sempre encontrados caso a caso. Os projetos não respondem integralmente às demandas em razão da estrutura flexível dos sistemas LEED", o que permite aos agentes envolvidos - os "stakeholders", no jargão corporativo - decidirem quais são os créditos mais adequados uma vez cumpridos os pré-requisitos compulsórios. Pela sua própria natureza, o projeto arquitetônico faz a mediação entre a concepção do edifício e as diversas tensões nela atuantes, sendo as diretrizes de certificação apenas uma delas.

Segundo arquitetos entrevistados para a pesquisa, os projetos corporativos começam em geral com um estudo de viabilidade requisitado pelo incorporador, a partir de uma prospecção de terrenos. É feito então um estudo sobre a possibilidade de construir um edifício corporativo nesse terreno, a volumetria permitida e a legislação incidente, a área comercializável das lajes e, ao fim e ao cabo, se o empreendimento se encontra dentro das margens de remuneração visadas. Caso o estudo seja aceito, é decidido então o tratamento do envelope a partir da localização geográfica do terreno, segundo a preferência de mercado para a área, como seria o caso dos invólucros de vidro nas regiões da Faria Lima e Berrini. ${ }^{4}$ Como os edifícios Triple A abrigam clientes multinacionais, os projetos devem atender padrões internacionais, como regras de bombeiros norte-americanas, maior altura de pé-direito e a maior flexibilidade possível de layout, entre

2. Josep Maria Montaner, "Belleza de las arquitecturas tecnológicas", in La modernidad superada: arquitectura, arte y pensamiento del siglo XX, 2a ed (Barcelona: Editorial Gustavo Gili, 1998), 207-22.

3. Nos sistemas NC e CS, trata-se dos créditos SS.3 Brownfield Redevelopment, MR.1.1 Building Reuse - Maintain Existing Walls, Floor and Roof e MR.1.2 Building Reuse - Maintain Existing Interior Nonstructural Elements.

4. Luciana Maki e Luiz Nogueira, (Arquitetos no aflalo/gasperini arquitetos), Entrevista para o autor, Presencial, 5 de fevereiro de 2019. 

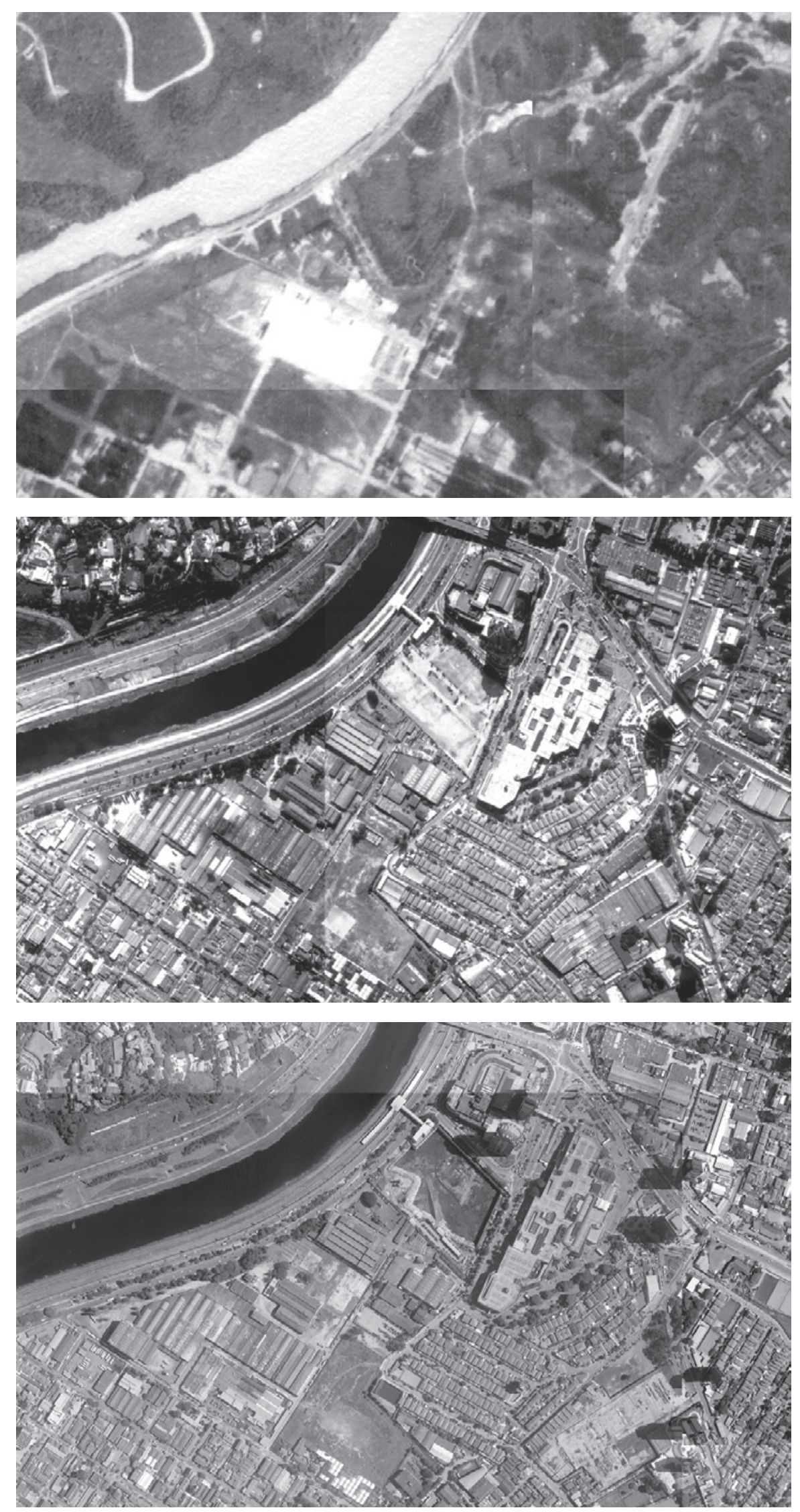

Fig 8.1 a 8.3. Imagens aéreas do setor Chucri Zaidan: 1954,

2000 e 2004. Fonte: Geosampa. 

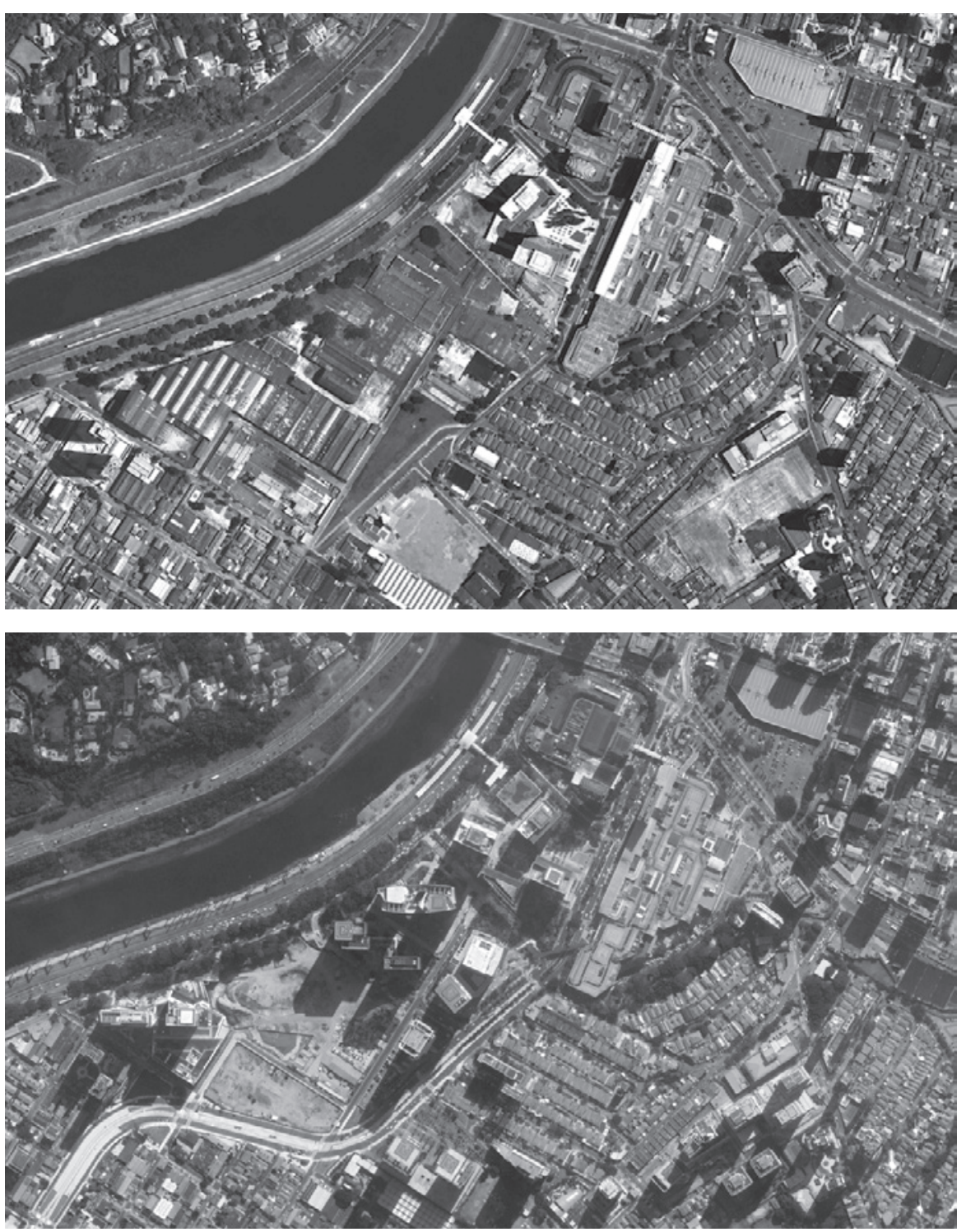

Fig 8.4 e 8.5. Imagens aérea do setor Chucri Zaidan: 14 dez 2008 e 10 mai 2018. Fonte: Google Earth. 


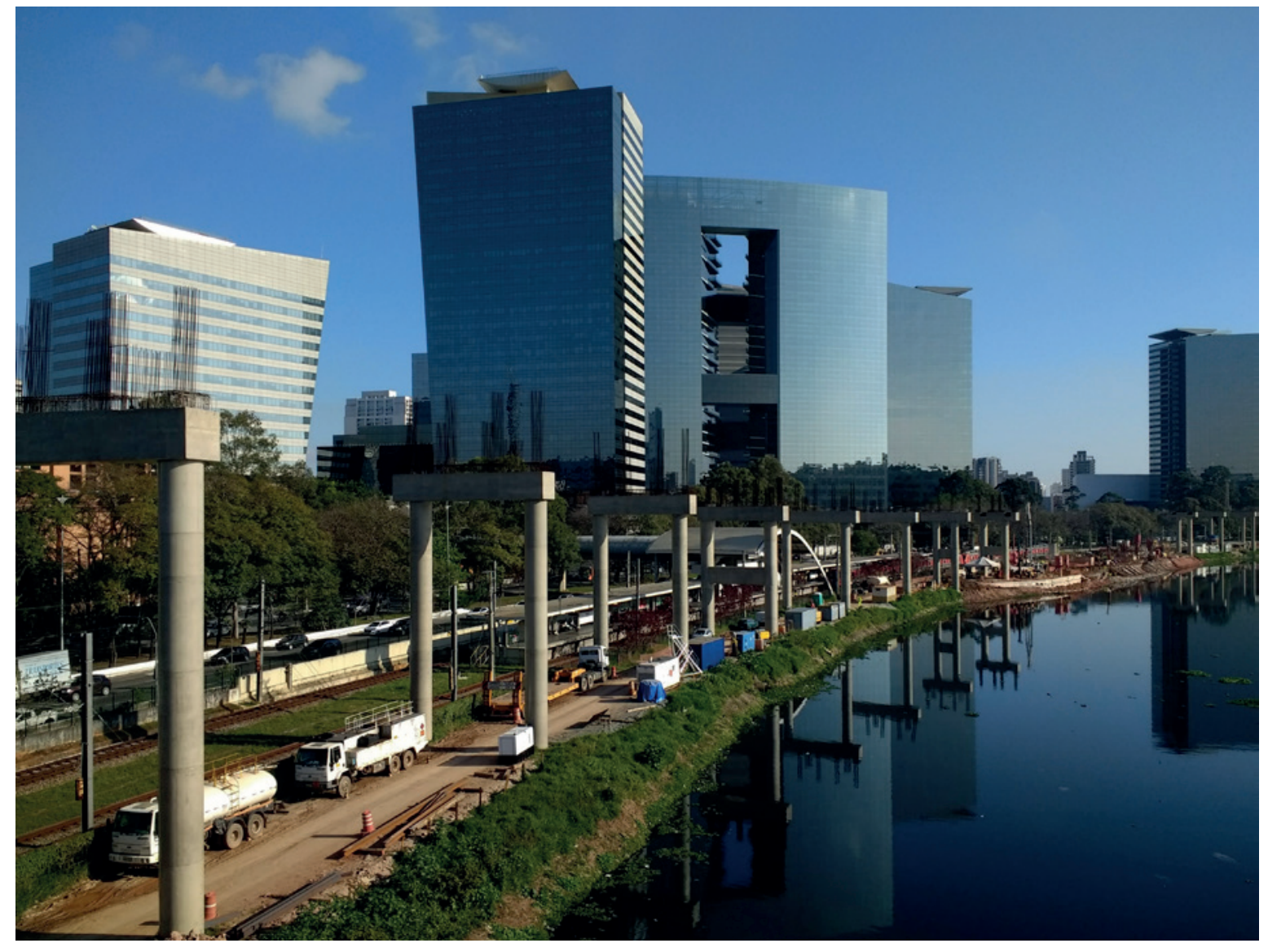

Fig 8.6. Vista geral do setor Chucri Zaidan. Fonte: autor, 6 set 2018 . 
outros. O LEED ${ }^{\oplus}$ é um dos potenciais padrões de impacto no projeto. ${ }^{5}$ Como ele é então desenvolvido efetivamente, face às outras demandas do projeto?

Os projetos escolhidos localizam-se em duas áreas da marginal Pinheiros, uma lindeira à avenida Chucri Zaidan, outra à avenida Juscelino Kubitschek. Alguns desses projetos são notabilizados na história do $\mathrm{LEED}^{\circledR}$ no Brasil, muitas vezes promovidos por seu pioneirismo no país: o Rochaverá Corporate Towers está entre os primeiros grandes empreendimentos certificados; o Parque da Cidade é um dos únicos a aplicar o sistema para bairros; e o São Paulo Corporate Towers é, atualmente, o mais bem avaliado pelo sistema no país. Outros projetos, como o Morumbi Corporate, o WT Morumbi e o WTJK, concentram uma grande quantidade de certificados e, por terem terreno adjacente ao primeiro grupo, constituem setores que permitem compreender qual seriam os atributos de uma cidade guiada pelo LEED $^{\oplus}$ [tab 8.1]. A escolha dos projetos foi feita, então, por critérios de sua relevância na história do sistema e do salto qualitativo resultante de sua proximidade. Esse último critério permite, além disso, entender como os projetos arquitetônicos sugerem uma configuração urbana, razão pela qual o desenho urbano também será enfatizado nas análises.

\section{SETOR CHUCRI ZAIDAN: EDIFÍCIOS DE AFLALO/GASPERINI ARQUITETOS}

Os estudos empíricos dividem-se em dois setores com diversos projetos certificados e grande área. O primeiro setor a ser detalhado encontra-se entre a rua engenheiro Mesquita Sampaio e as avenidas João Dória, Nações Unidas e Chucri Zaidan. Nele, concentram-se quase trinta certificações obtidas em diferentes sistemas $\mathrm{LEED}^{\oplus}$, com diferentes programas arquitetônicos. As torres foram construídas onde havia galpões remanescentes do uso industrial da marginal Pinheiros. Sua mudança gradual de uso deu-se em consequência dos investimentos públicos na região por meio de operações urbanas, que inclui a própria ligação da avenida Chucri Zaidan com a Faria Lima e sua extensão na direção sul [fig 8.1 a 8.5]. ${ }^{6}$

O setor Chucri Zaidan possui uma característica excepcional para a produção da cidade

5. Adriano Sartori, (Vice-presidente CBRE Brasil), Entrevista para o autor, Email, 31 de novembro de 2017.

6. Ver parte IV. 

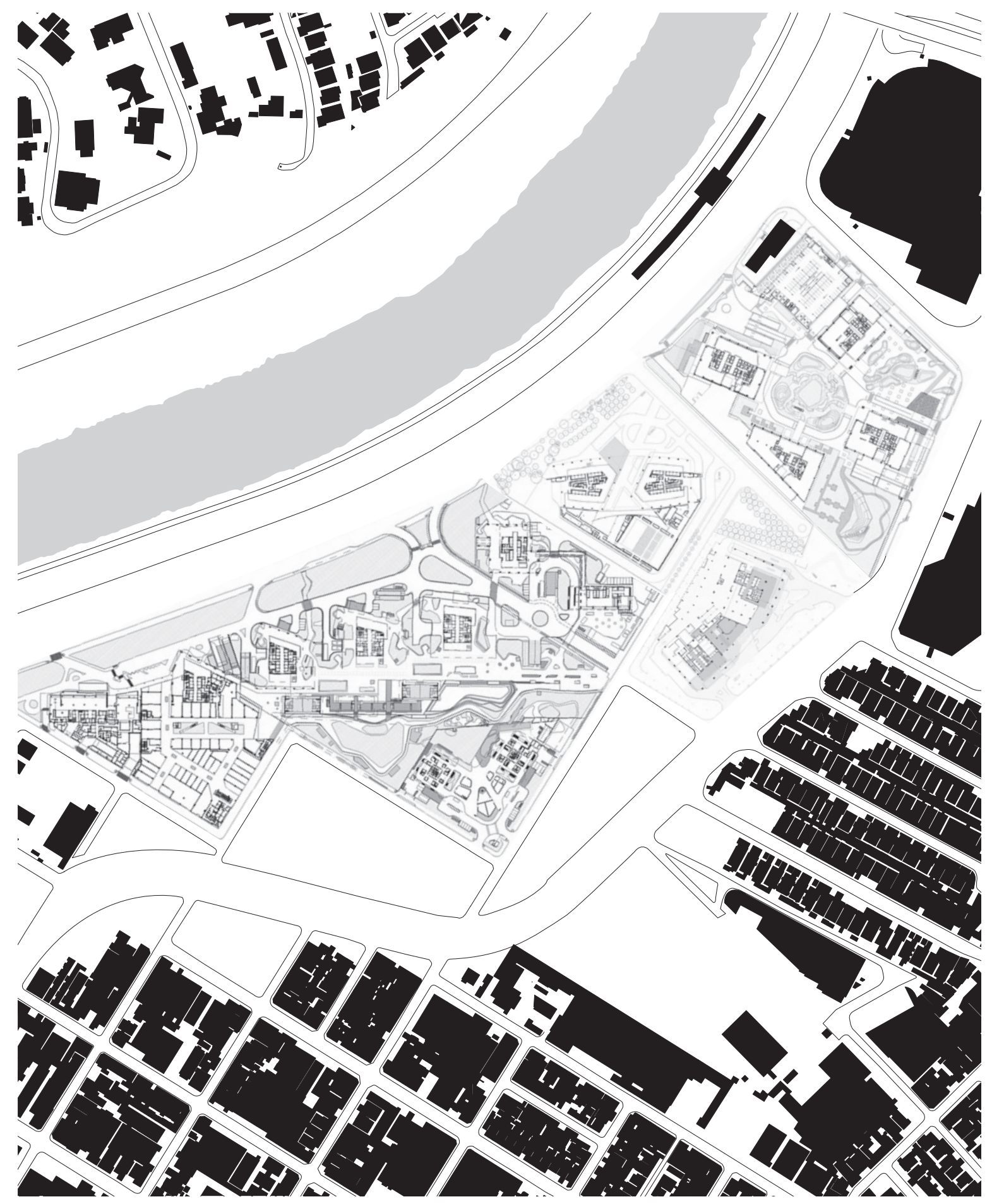

Fig 8.7. Implantação dos empreendimentos no setor Chucri Zaidan. Escala 1:5000. Elaborado pelo autor. Fonte: Geosampa, Google Earth, implantações dos empreendimentos. 
e da arquitetura: a realização de quatro empreendimentos vizinhos por um mesmo escritório, o aflalo/gasperini arquitetos. A área ultrapassa um milhão de metros quadrados projetados, distribuídos no Rochaverá Corporate Towers (1999/2008-2012), no Morumbi Corporate (2008/2013), no WT Morumbi (2009/2016) e no Parque da Cidade (2010/em andamento) [fig 8.6 e 8.7]. Se os arquitetos normalmente estão restritos em seu poder de intervenção pelos limites estreitos do lote urbano, nesse caso o aflalo/gasperini tem uma escala atípica de intervenção e a potencial permeabilidade espacial entre os empreendimentos, para além da lógica estrita do lote. Esses projetos são uma oportunidade única e contingente, pois não são resultado de uma única proposta, e sim produto de incorporadores distintos: o Rochaverá pela Tishman Speyer, o Morumbi pela Multiplan, o WT Morumbi pela WTorre e o Parque da Cidade pela Odebrecht Realizações Imobiliárias. Não por acaso, face a tão grande área, a edição especial da revista Monolito sobre o escritório chama-se $O$ desenho da cidade. ${ }^{7}$ Assim, não se trata de modelar a cidade a partir de projetos restritos ao lote, mas sim de um desenho efetivo do espaço urbano proporcionado pela escala das comissões.

A grande área dos empreendimentos decorre do crescimento econômico brasileiro na década de 2000, do qual o LEED ${ }^{\circledR}$ se beneficiou na sua chegada ao país. Com o empuxo do crescimento vieram demandas como as de grandes lajes para locação, maiores do que $1.000 \mathrm{~m}^{2}$, exigidas pelas grandes corporações globais. Estas foram abrigadas nas torres corporativas construídas ao longo da década de 2000, no eixo sudoeste de São Paulo, cuja transformação foi facilitada por operações urbanas e seus coeficientes de aproveitamento superiores ao restante da cidade, além de permitirem a compra de Certificados de Potencial Adicional de Construção (CEPACs). ${ }^{8}$ Os projetos estudados beneficiaram-se diretamente desse crescimento, com significativo aumento de potencial construtivo. ${ }^{9}$

\footnotetext{
7. Fernando Serapião, Monolito, vol. Extra: Aflalo \& Gasperini Arquitetos (São Paulo: Editora Monolito, 2012).

8. Evelise Grunow et al., "Entrevista: 'Sabíamos que não dependíamos de uma pessoa apenas", Projeto Design 424 (agosto de 2015). Flávia Marcondes também indicou a busca por maiores lajes: Flávia Marcondes, (Diretora associada no aflalo/ gasperini arquitetos), Entrevista para o autor, Presencial, 27 de setembro de 2016.

9. Côrrea indica que a promulgação da lei dobrou o coeficiente de aproveitamento do terreno (CA), de 1,5 para 3. Cf. Cristiane Côrrea, Edifícios sustentáveis: Rochaverá - Aflalo \& Gasperini (São Paulo: C4, 2008), 22. Entretanto, a área construída é de sete vezes a área do terreno: $230.000 \mathrm{~m}^{2} \mathrm{em} 33.500 \mathrm{~m}^{2}$. Isso pode decorrer de ganhos de potencial construtivo em retribuição a remembramento de lotes, como previstos na OUCAE (Lei n. 13.260 de 28 de dezembro de 2001). A OUCAE também prevê, contrariando a fonte, que o CA da área pode chegar a 4 (cap. 2, seç. 2, V). Além disso, o empreendimento
} 
Quando finalizado, do ponto de vista do uso cotidiano da área, é o Parque da Cidade que estruturará a região, pois sua área supera em muito a dos outros conjuntos. Mas, por outro lado, “a ideia do Parque da Cidade começou no Rochaverá...”, em gênese proposta por um de seus arquitetos, Luiz Felipe Aflalo. ${ }^{10}$ Assim, ainda que o Parque da Cidade, o último dos projetos contratados para a gleba, possa estruturar a futura experiência espacial dos usuários da região pela sua escala, o Rochaverá é visto pelo aflalo/gasperini como aquele que estabeleceu os fundamentos arquitetônicos de toda a espacialidade da Chucri Zaidan modelada pelo escritório. Imaginado sem vizinhos conhecidos, o Rochaverá, cujas duas primeiras torres foram inauguradas em 2008, ${ }^{11}$ já estava quase pronto quando os demais projetos ainda estavam sendo contratados [fig 8.8 a 8.27].

A fala de Luiz Felipe Aflalo, citada no parágrafo anterior, ainda continuava: “... no Rochaverá, em que já havia aquela proposta com os prédios focados nas praças internas, que geram diversos espaços externos por conta desse quarteirão, são praças totalmente abertas". ${ }^{12}$ De fato, no projeto, as torres são dispostas isoladamente em um parque. Em sua implantação, a esquina com a via local da marginal é ocupada pela estação de trem da CPTM - que futuramente terá integração com a linha Ouro do monotrilho - e, ao seu lado, por um edifício-garagem de quatro andares, desenhado com peitoris e cobertura ajardinados, integrando-se visualmente ao jardim. Assim, os usuários que chegam tanto por veículos próprios, quanto pelo trem, entram no conjunto por essa área na implantação setorizada para o transporte. O acesso que pode ser chamado de principal se dá pela esquina seguinte, da secundária avenida João Dória com o claro vetor da Chucri Zaidan. Após subir um ligeiro lance de escadas, o pedestre encontra-se em uma praça, em uma espacialidade definida por um aparente eixo de simetria, coincidente com a bissetriz do ângulo da esquina. Desse modo, essa praça é espacialmente conformada por duas torres de faces trapezoidais com dezesseis pavimentos cada uma, alinhadas com as ruas. Ao subir as escadas, o

\footnotetext{
comprou CEPACs: $1.920 \mathrm{~m}^{2}$ (processo 2006-0.033.291-4 em $28 \mathrm{dez} 2006$ ), $76 \mathrm{~m}^{2}$ (mesmo processo, 24 abr 2007) e $74.290,69$ $\mathrm{m}^{2}$ (2007-0.173.371-0 em 4 ago 2008). Já no Morumbi Corporate, foram doados 704,81 $\mathrm{m}^{2}$ do terreno para alargamento das calçadas e comprados CEPACs para um adicional construtivo de 58.523 m² (processo 2010-0.074.379-5 em 23 mar 2010); no WTorre, adquiridos $66.806 \mathrm{~m}^{2}$ (processo 2010-0.343.298-7 em 15 dez 2010); no Parque da Cidade, adquiridos 246.076 $\mathrm{m}^{2}$ em CEPACs (processo 2014-0.147.872-3 em 27 mai 2014). Tomando como base o estoque consumido na OUCAE até o fim de 2018, o Parque da Cidade adquiriu, sozinho, 7,5\% da área adicional em CEPACs.

10. Serapião, Monolito, Extra: Aflalo \& Gasperini Arquitetos:18.

11. Nanci Corbioli, “Fachadas inclinadas atendem à estética e à lógica do mercado”, Projeto Design 350 (abr de 2009): 46-57.

12. Serapião, Monolito, Extra: Aflalo \& Gasperini Arquitetos:18.
} 
pedestre encontra outra praça e se dá conta de que ela é, na verdade, uma rotatória que organiza o acesso de veículos de visitantes. Essa rotatória é cercada, nos seus pontos extremos, pelos quatro edifícios do conjunto: chegando aqui, o pedestre tem os dois volumes trapezoidais às suas costas, um edifício mais baixo de sete pavimentos a sua esquerda e outro trapézio mais alto, com trinta pavimentos e ângulo menos pronunciado, a sua direita, impedindo a visão da via expressa. Originalmente, nessa rotatória se localizaria um café proposto pelos arquitetos, mas não realizado por consumir área construída com um uso menos rentável do que o corporativo. ${ }^{13}$ Pelos desenhos da implantação do empreendimento, pode-se notar que a disposição de volumes e vazios se dá por um ritmo constante, em que volumes e praças de dimensões muito semelhantes se intercalam, criando uma grade cujo centro é a rotatória. Há uma aparente exceção a esse esquema, a do edifício-garagem situado ao lado de uma das torres. Contudo, a leitura rítmica do espaço é mantida pelo tratamento com vegetação nas fachadas e cobertura do edifício. Pela experiência do espaço, essa alternância de cheios e vazios é ratificada, embora o paisagismo sinuoso force a desorientação do transeunte. O projeto de paisagismo é do escritório californiano de Pamela Burton com o brasileiro Sérgio Santana, também autores do Parque da Cidade. Versões anteriores da implantação mostram como o paisagismo exuberante e desnorteante foi decidido em etapas mais avançadas de projeto - anteriormente fora concebida uma praça seca com maior permeabilidade do sistema viário [fig 8.8 a 8.13].

A implantação das torres respeita critérios de sustentabilidade, no qual as torres fazem sombra mútua, em solução também adotada no Parque da Cidade. Assim, a solução da implantação tem dupla motivação: por um lado, o desenho urbano, como na criação da esquina com os dois prismas principais (torres $\mathrm{A}$ e $\mathrm{B}$ ) e a torre maior próxima à marginal como uma referência urbana; por outro lado, o respeito a critérios de sustentabilidade e eficiência energética. Suas fachadas são superfícies reluzentes, de modo que as torres se configuram como volumes claros, sem reentrâncias significativas, apenas uma pequena saliência que separa uma área da superfície revestida exclusivamente de vidro de outra com linhas horizontais de vidro e granito, alternadas e de dimensões semelhantes [fig 8.26]. Assim, uma face maior é revestida inteiramente em vidro, enquanto a outra face maior possui alternância entre granito e vidro, o que revela as divisões de

13. Côrrea, Edifícios sustentáveis: Rochaverá - Aflalo \& Gasperini, 25. 

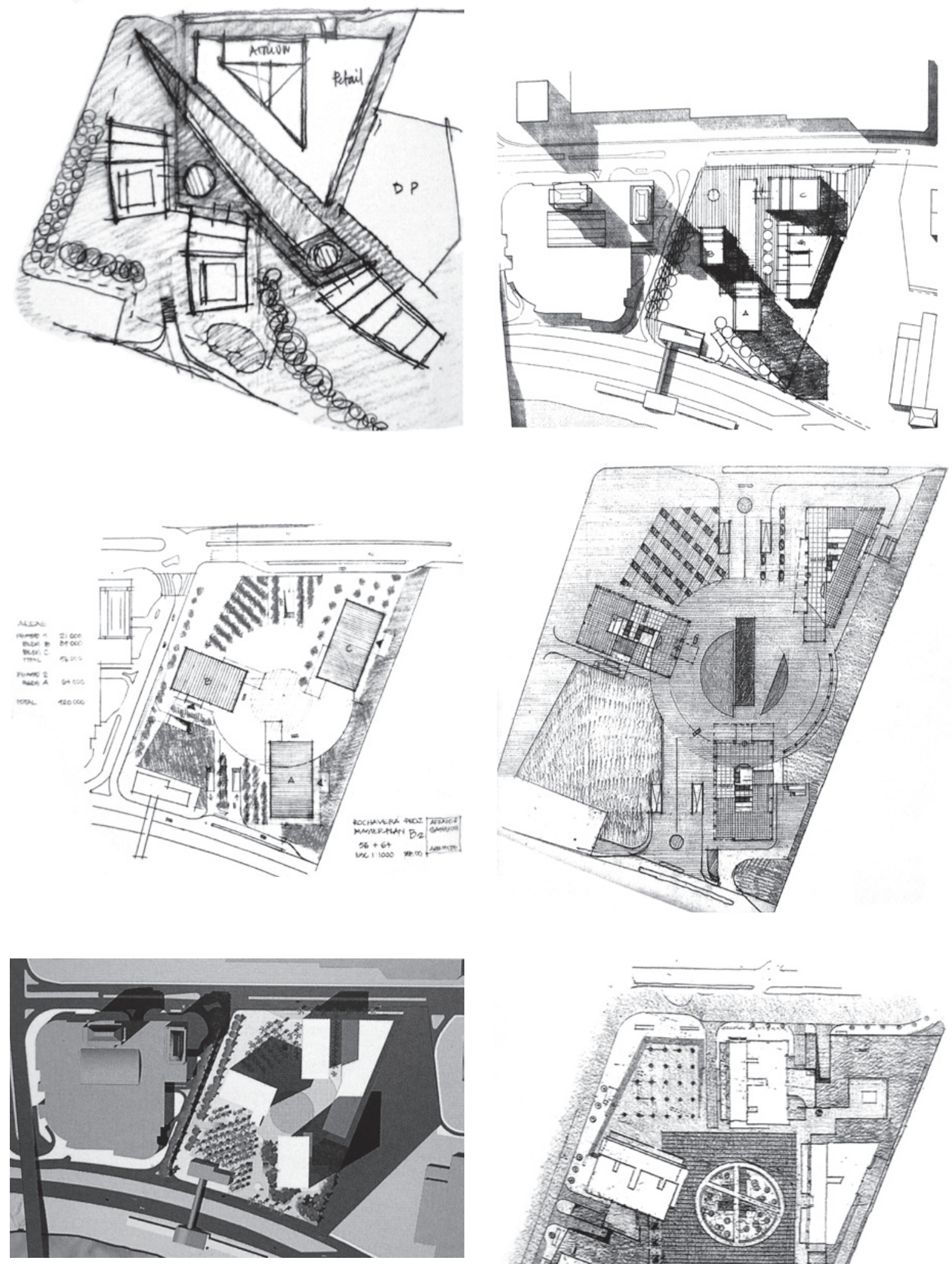

Fig 8.8 a 8.13. aflalo/gasperini arquitetos, Rochaverá

Corporate Towers (1999/2008-2012). Implantação, versão preliminar. Sem escala. Fonte: Fonte: Corbioli, "Fachadas inclinadas atendem à estética e à lógica do mercado", Projeto Design, abr 2009, 52-53.

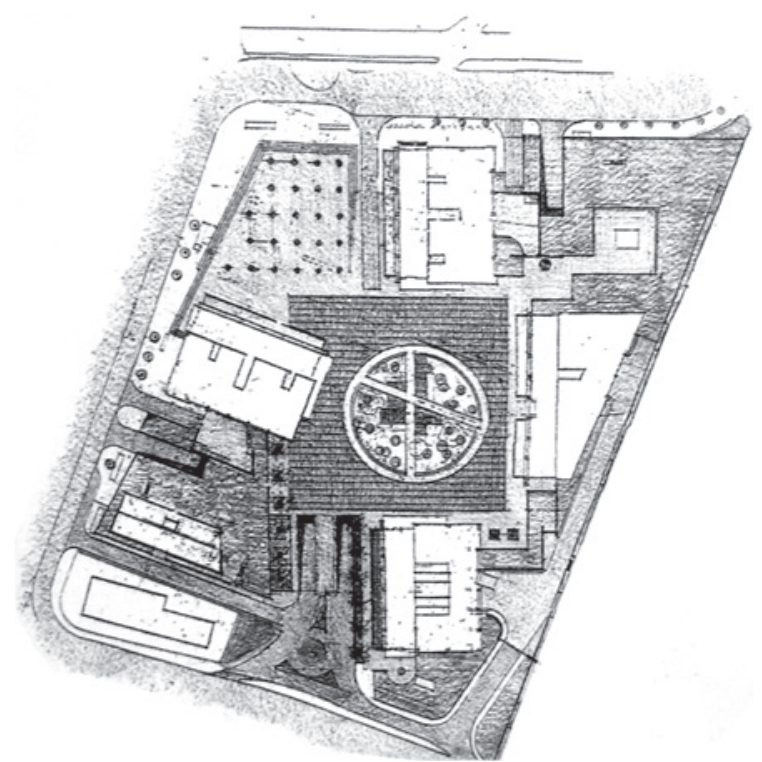




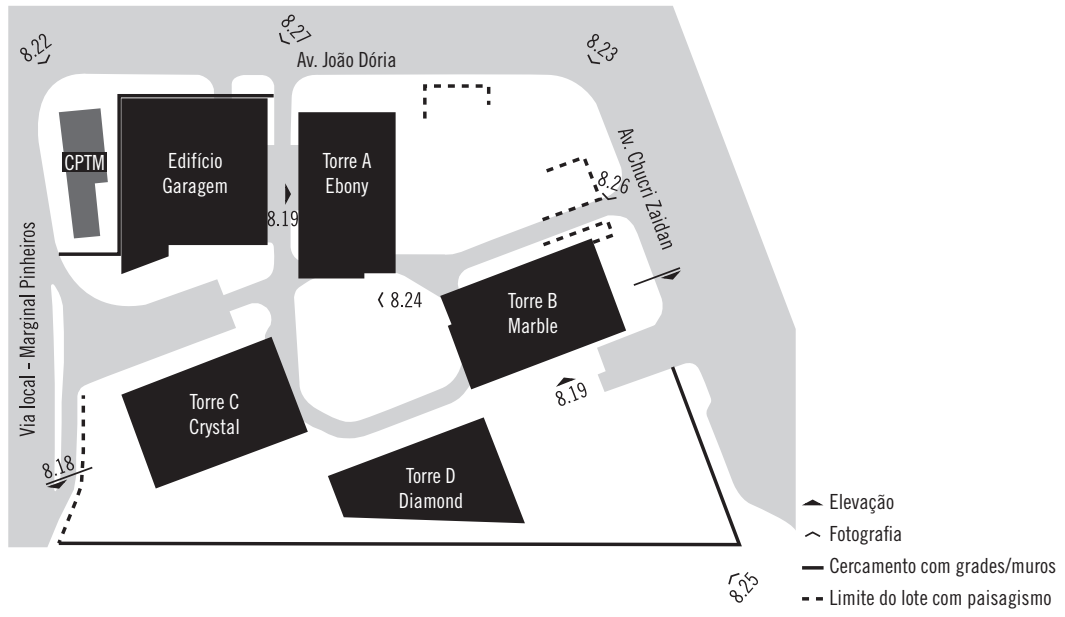

Fig 8.14. Diagrama do Rochaverá Corporate Towers.

Elaborado pelo autor.

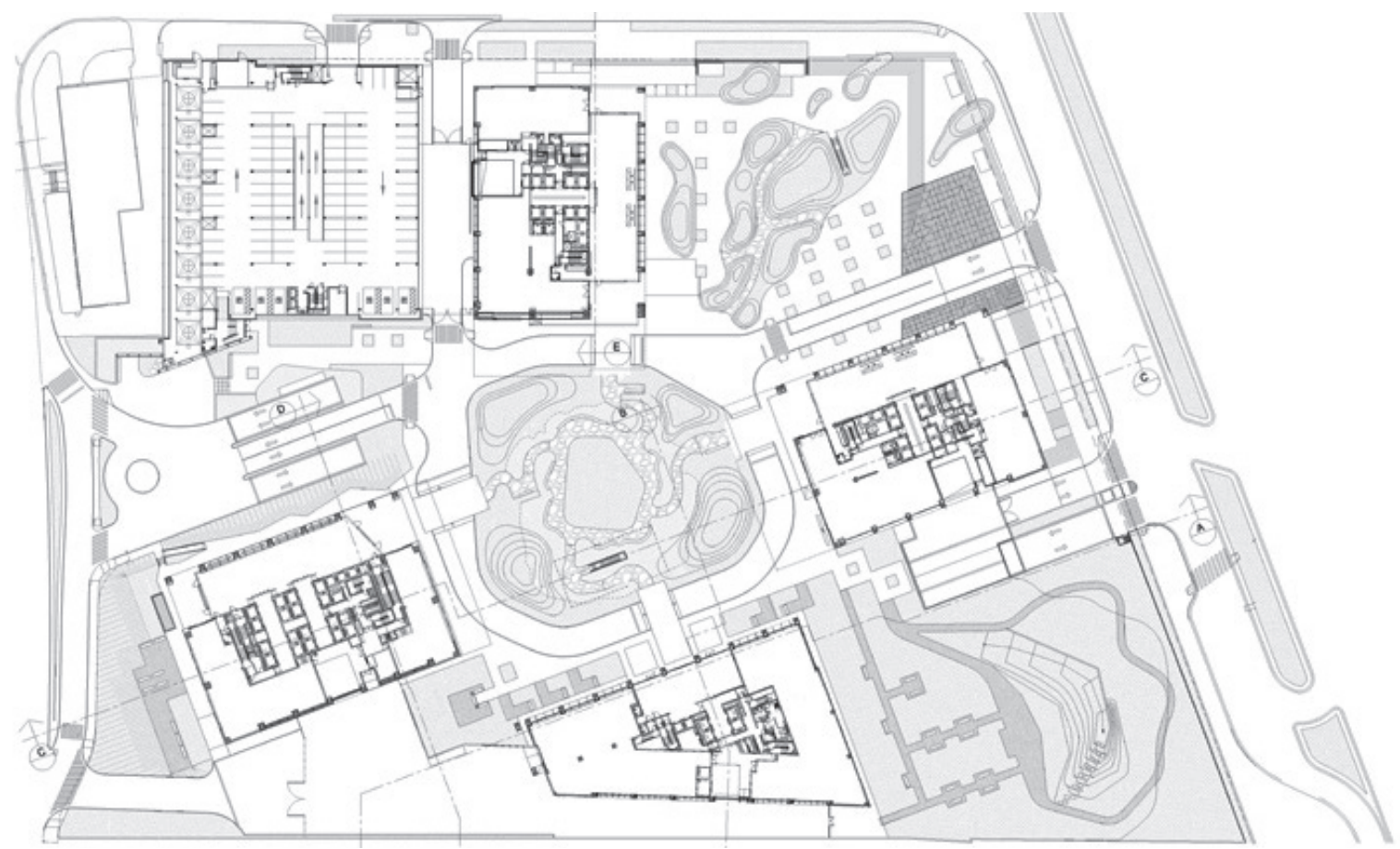

Fig 8.15. aflalo/gasperini arquitetos, Rochaverá Corporate

Towers (1999/2008-2012). Implantação. Sem escala. Fonte:

Pura Arquitetura, acervo online. 


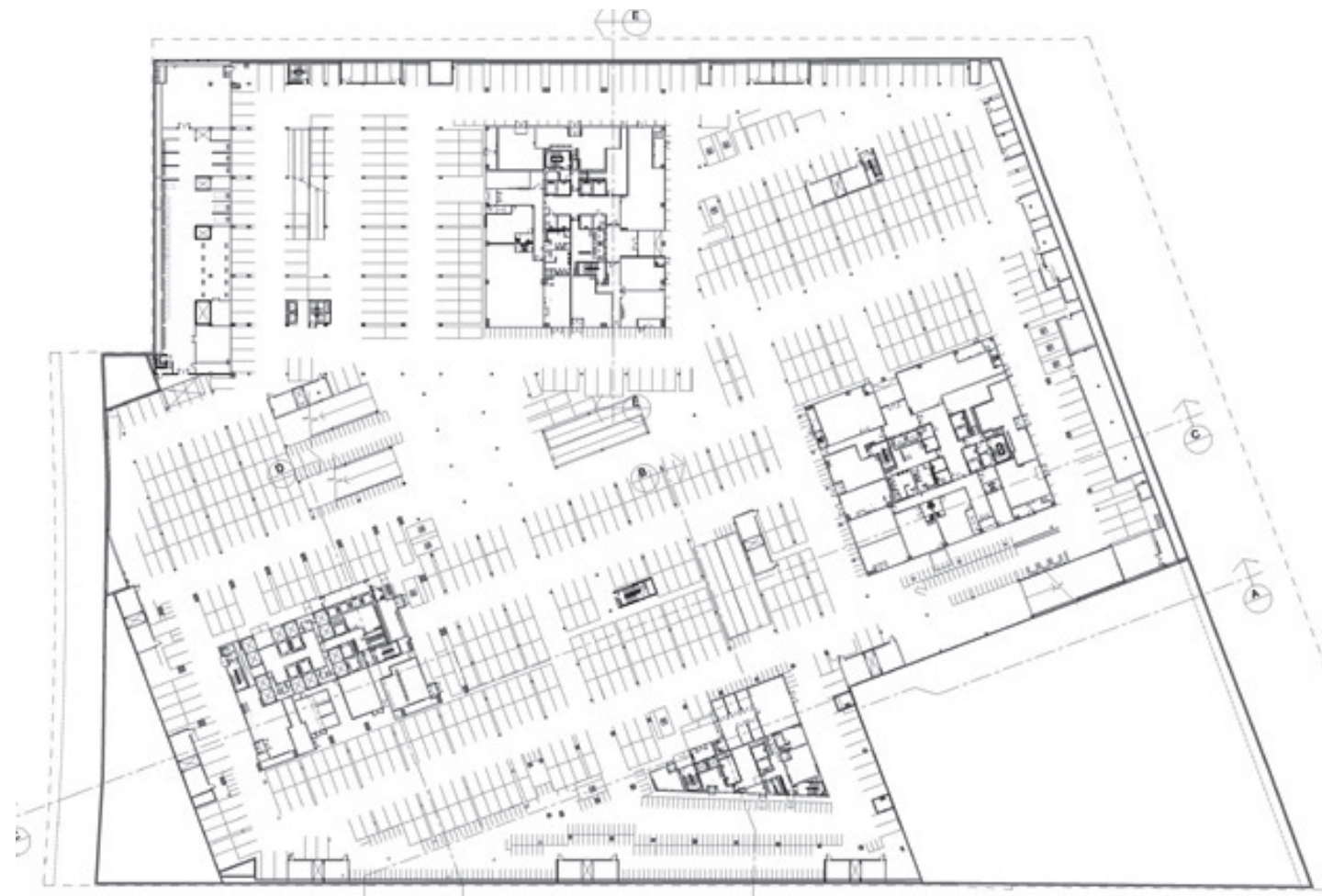

Fig 8.16. aflalo/gasperini arquitetos, Rochaverá Corporate

Towers (1999/2008-2012). $1^{\circ}$ subsolo. Sem escala. Fonte:

Pura Arquitetura, acervo online.

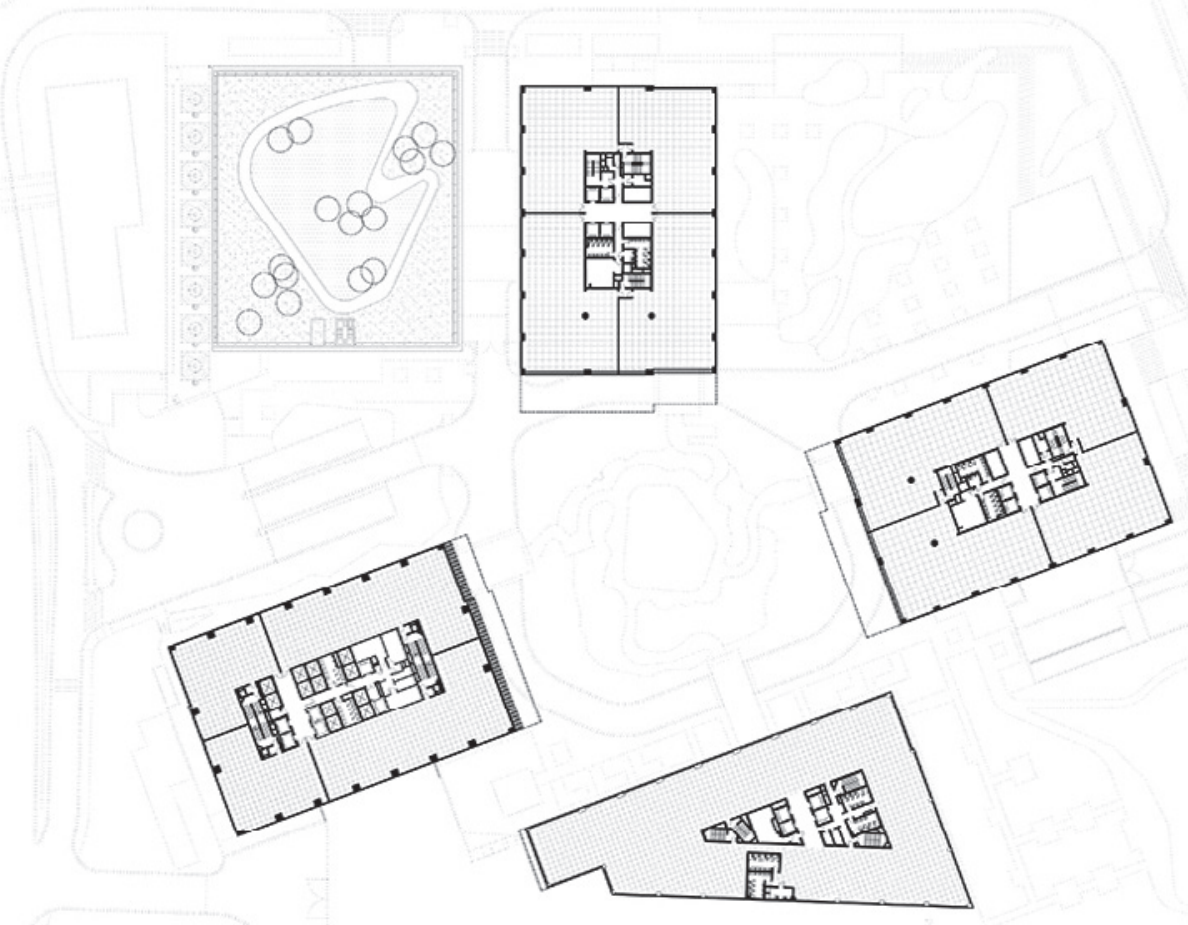

Fig 8.17. aflalo/gasperini arquitetos, Rochaverá Corporate

Towers (1999/2008-2012). Pavimento-tipo. Sem escala.

Fonte: aflalo/gasperini arquitetos, acervo online. 


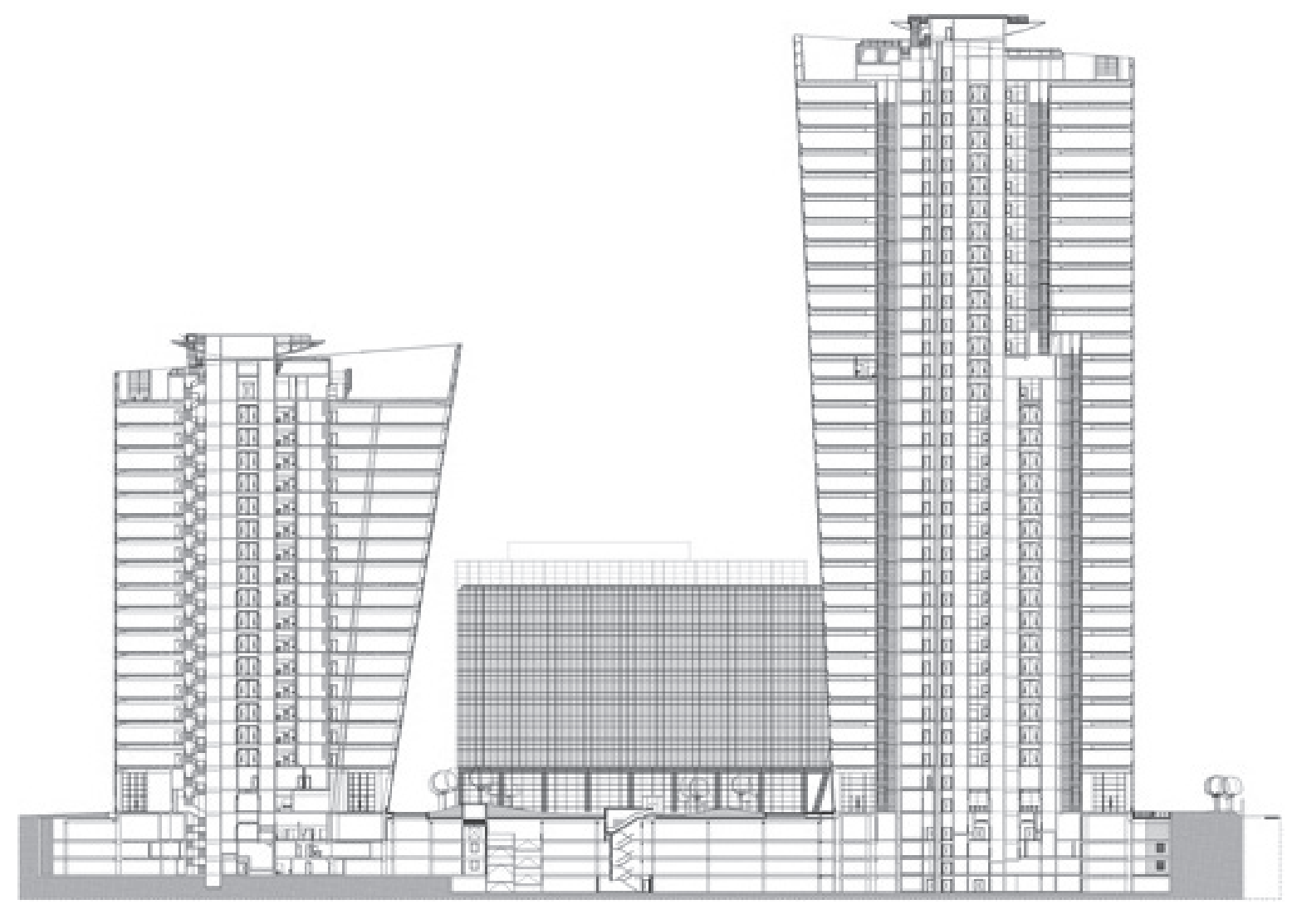

Fig 8.18. aflalo/gasperini arquitetos, Rochaverá Corporate

Towers (1999/2008-2012). Corte da implantação. Sem

escala. Fonte: Pura Arquitetura, acervo online.

Fig 8.19. aflalo/gasperini arquitetos, Rochaverá Corporate Towers (1999/2008-2012). Elevação das torres A e B. Sem escala. Fonte: Pura Arquitetura, acervo online.

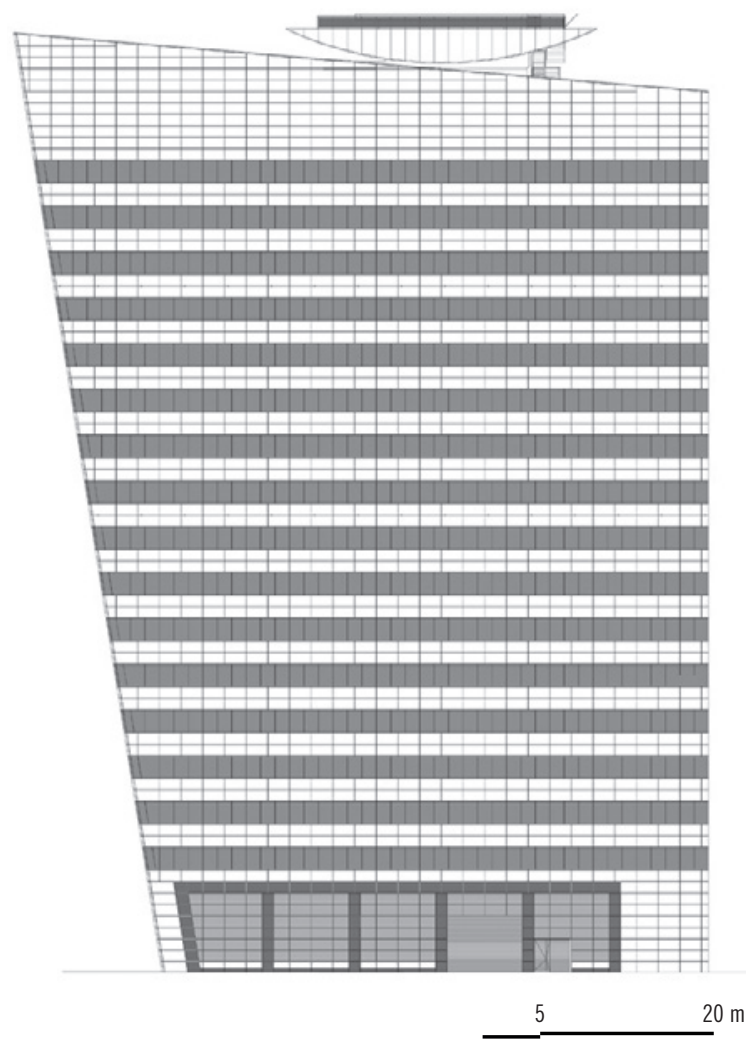




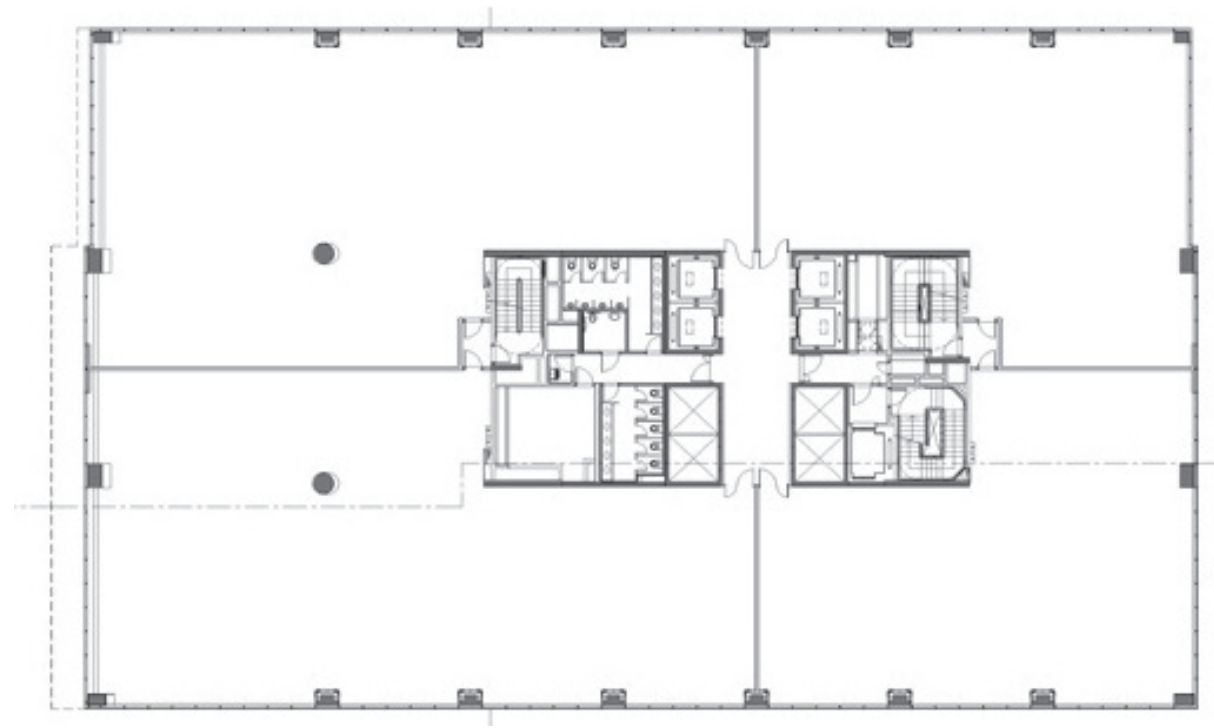

Fig 8.20. aflalo/gasperini arquitetos, Rochaverá Corporate $10 \mathrm{~m}$ Towers (1999/2008-2012). Planta do $18^{\circ}$ pavimento das torres A e B. Sem escala. Fonte: Pura Arquitetura, acervo online.

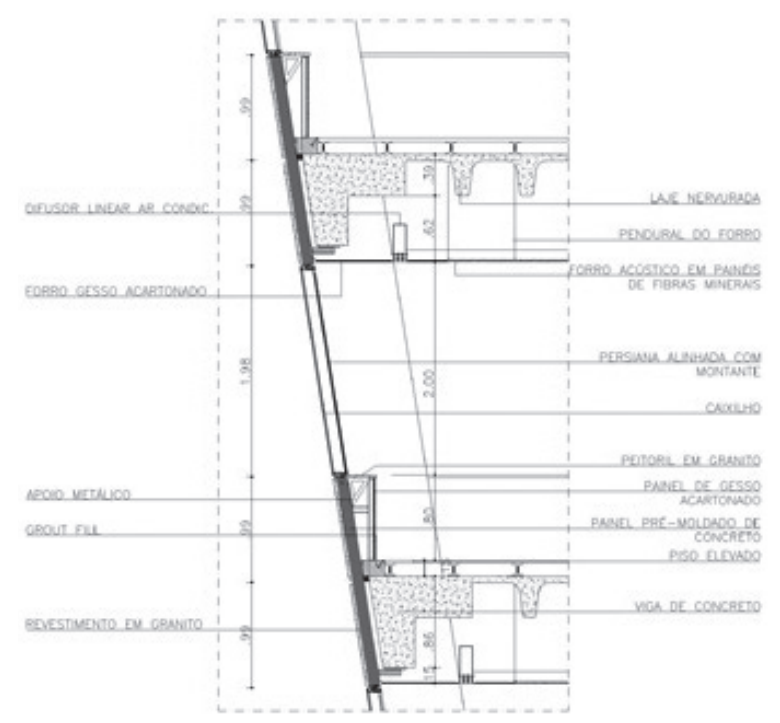

Fig 8.21. aflalo/gasperini arquitetos, Rochaverá Corporate Towers (1999/2008-2012). Detalhes de fachadas das torres A e B. Sem escala. Fonte: Pura Arquitetura, acervo online.

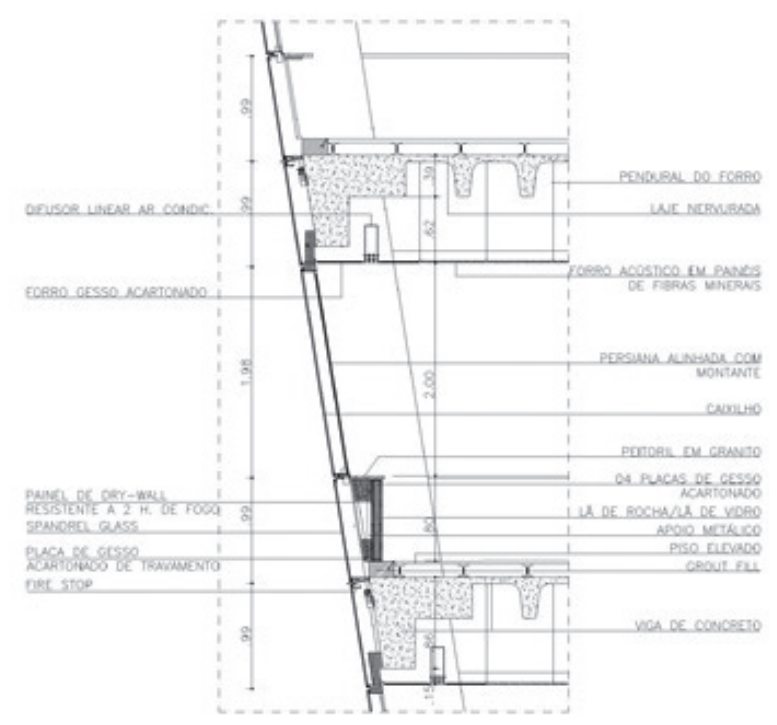

1 $4 \mathrm{~m}$ 

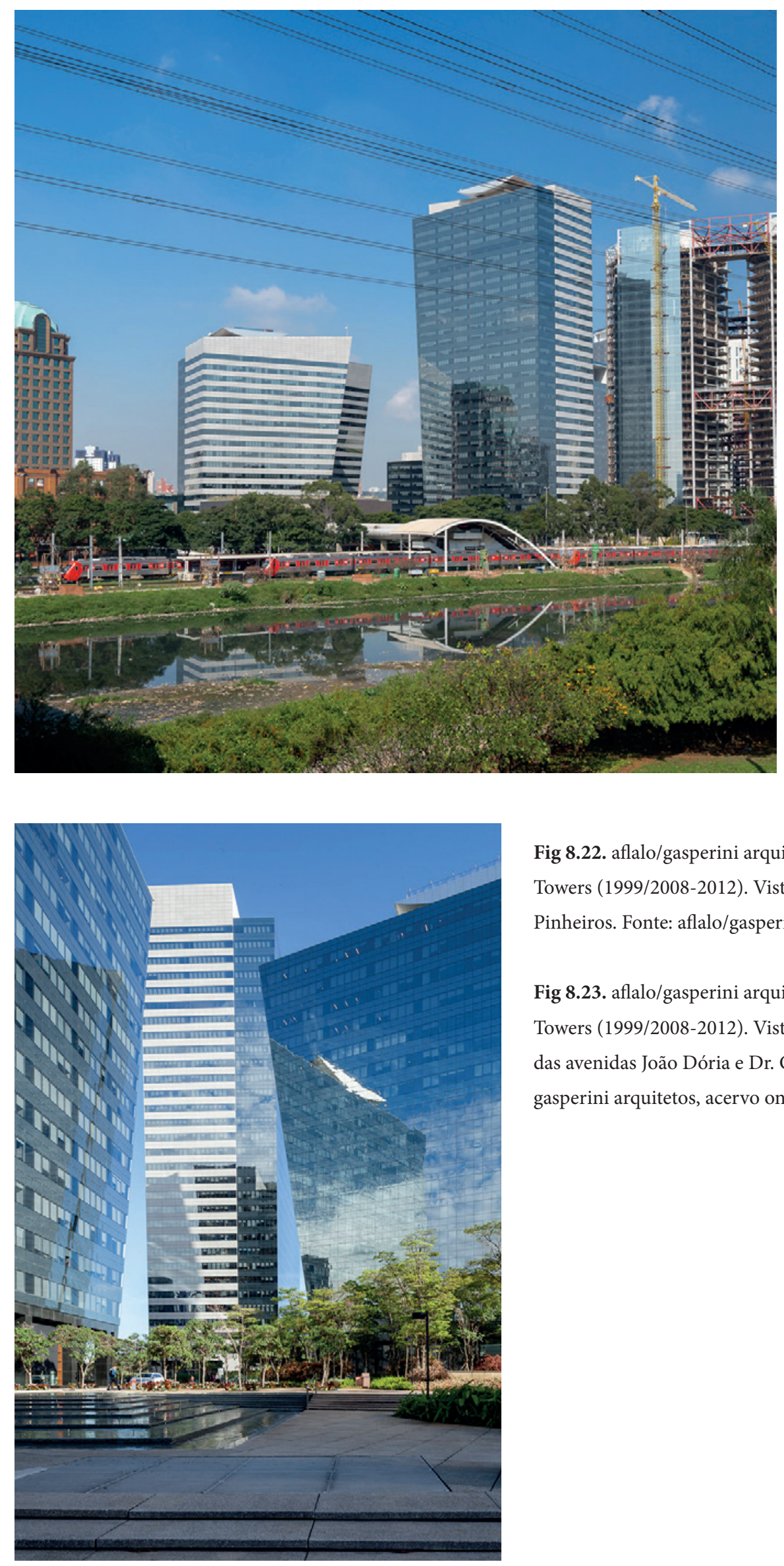

Fig 8.22. aflalo/gasperini arquitetos, Rochaverá Corporate Towers (1999/2008-2012). Vista a partir da marginal Pinheiros. Fonte: aflalo/gasperini arquitetos, acervo online.

Fig 8.23. aflalo/gasperini arquitetos, Rochaverá Corporate Towers (1999/2008-2012). Vista a partir do cruzamento das avenidas João Dória e Dr. Chucri Zaidan. Fonte: aflalo/ gasperini arquitetos, acervo online. 


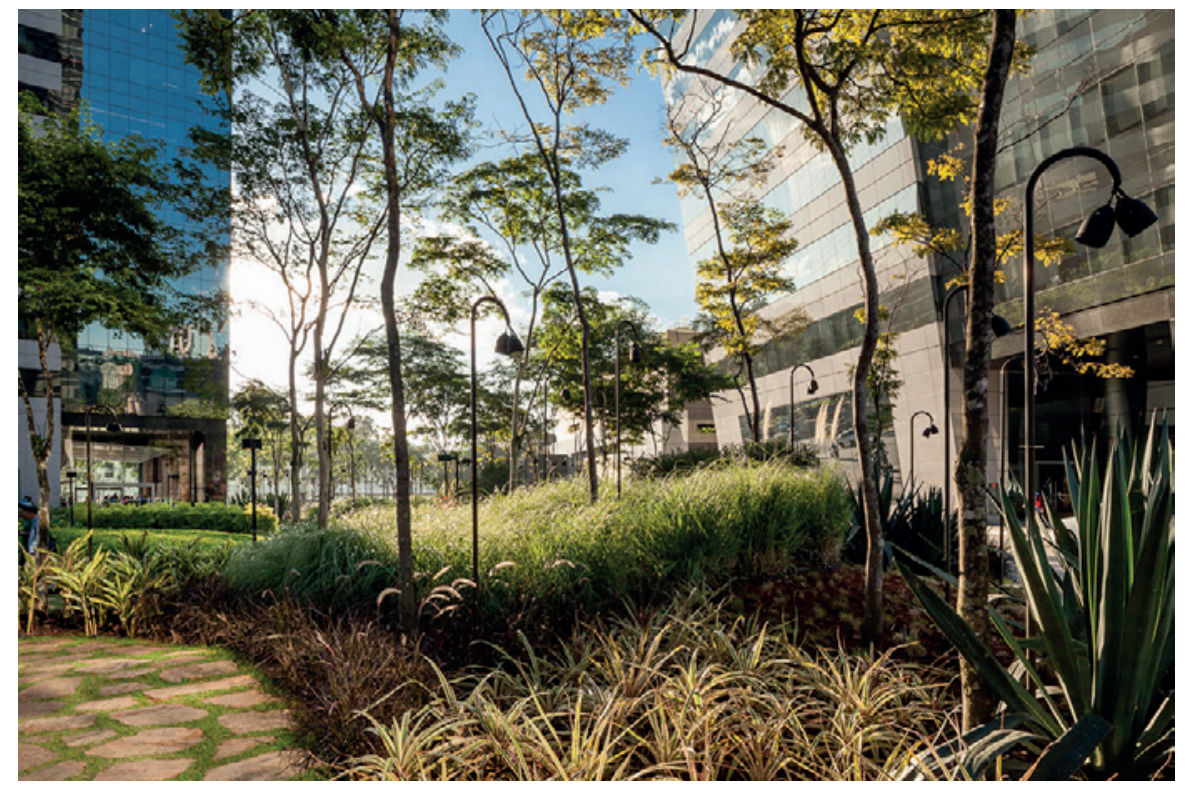

Fig 8.24. aflalo/gasperini arquitetos, Rochaverá Corporate

Towers (1999/2008-2012). Vista a partir da praça interior.

Fonte: aflalo/gasperini arquitetos, acervo online.

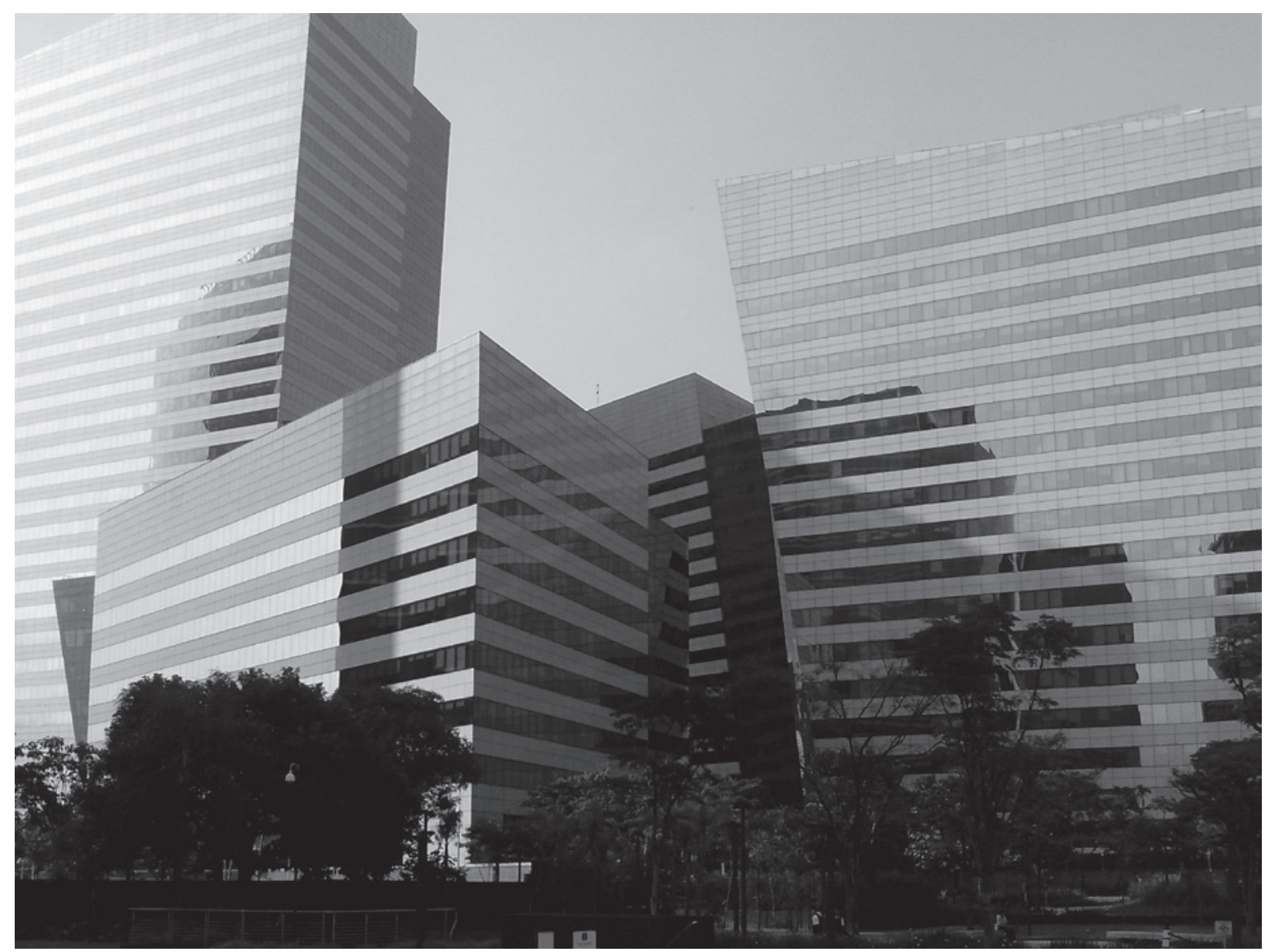

Fig 8.25. aflalo/gasperini arquitetos, Rochaverá Corporate

Towers (1999/2008-2012). Vista a partir dos fundos do

empreendimento. Fonte: Acervo do autor, 12 nov 2015. 

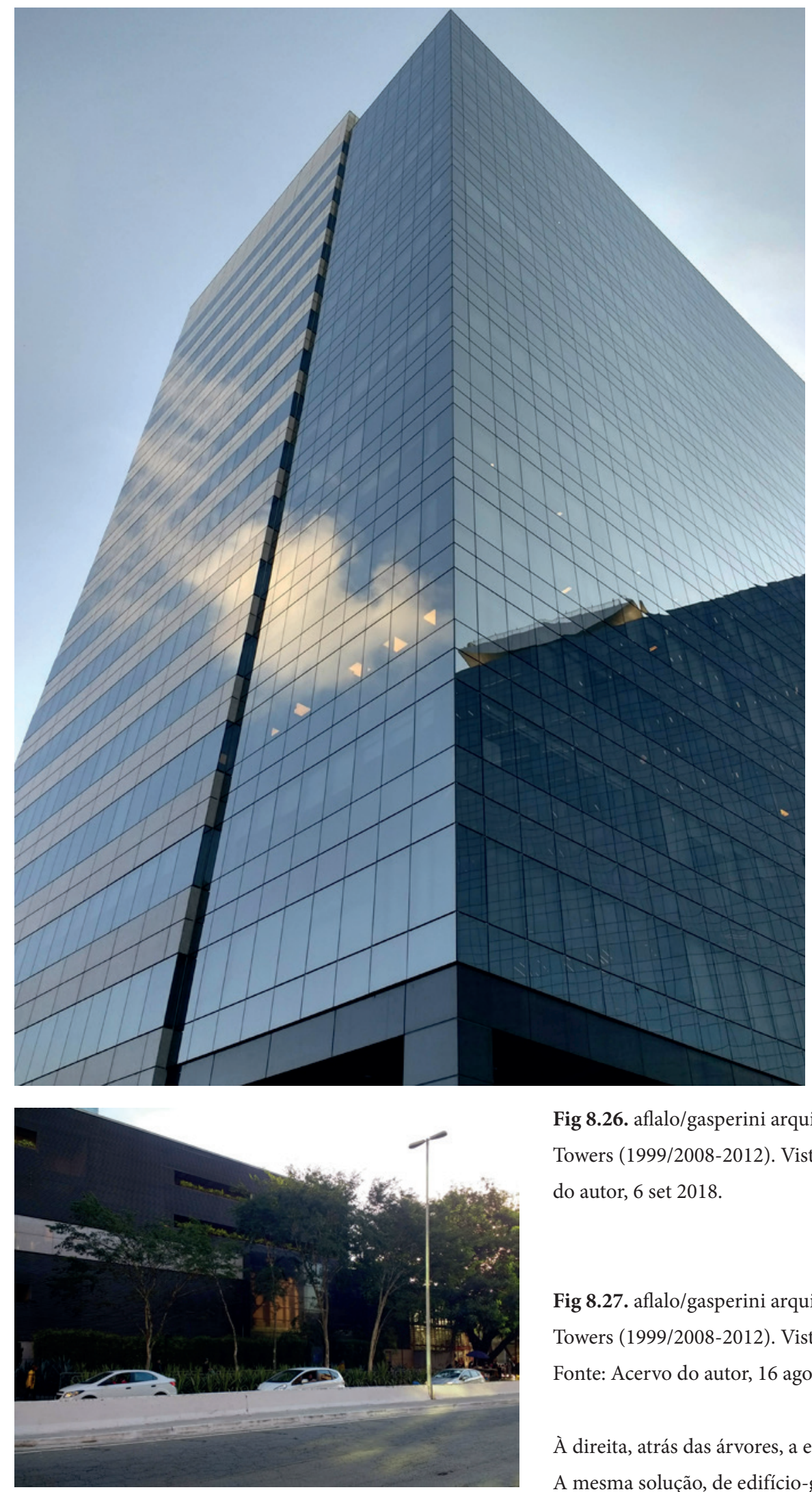

Fig 8.26. aflalo/gasperini arquitetos, Rochaverá Corporate Towers (1999/2008-2012). Vista da lateral. Fonte: Acervo do autor, 6 set 2018

Fig 8.27. aflalo/gasperini arquitetos, Rochaverá Corporate Towers (1999/2008-2012). Vista do edifício-garagem. Fonte: Acervo do autor, 16 ago 2019.

À direita, atrás das árvores, a estação Morumbi da CPTM. A mesma solução, de edifício-garagem ajardinado, será aplicada de modo mais decisivo no Morumbi Corporate [fig 8.35]. 
vigas e de peitoris escondidas na opção anterior; nas faces menores, ambas soluções estão presentes, separadas pela saliência. Segundo o memorial publicado na revista Monolito, a decisão se daria por uma questão de sustentabilidade: "Esta divisão foi proposta para diminuir a incidência de sol nos ambientes internos, ao mesmo tempo em que permite a entrada de iluminação natural, sem que seja necessário o uso de brises, aumentando a eficiência energética de todo o conjunto". ${ }^{14}$ De fato, a preocupação tradicional do escritório com estratégias passivas de sustentabilidade fez com que a certificação LEED $^{\circledR}$ fosse atingida, mesmo se sua aplicação tenha sido buscada já com o projeto em andamento. ${ }^{15}$ Entretanto, um arquiteto do empreendimento sugeriu que a alternância era resultado do custo muito alto do vidro na época do projeto. ${ }^{16}$ Além disso, o memorial faz crer que a solução segue critérios exclusivamente técnicos, mas algumas faces importantes para a carga térmica não são tratadas com o granito. É o caso das faces norte/nordeste das torres $\mathrm{B}$ e $\mathrm{C}, \mathrm{e}$ da face sul/sudeste da torre A. Essas faces estão dispostas nas principais vistas do conjunto: o ângulo agudo da entrada principal, assim como as principais perspectivas da torre C, que pelo seu ângulo inclinado abre visuais tanto para o pedestre que vem da estação, quanto para o motorista que está na outra margem do rio Pinheiros. Dessa maneira, além da razão técnica, existe uma segunda razão para o desenho da fachada, por vezes conflitante, por outras associada à sustentabilidade: certa separação entre frente e fundos das torres, em que o usuário muda sua percepção sobre os prismas conforme os circunda.

Vizinhos ao Rochaverá estão os conjuntos Morumbi Corporate e WT Morumbi. Ambos os empreendimentos são compostos por duas torres que, diferentemente do Rochaverá, não estão dispostas isoladamente, mas formam conjuntos. Em primeiro lugar, o Morumbi Corporate [fig 8.28 a 8.36], cujas torres - uma mais baixa com dezoito pavimentos, mas de maior área no

\footnotetext{
14. Serapião, Monolito, Extra: Aflalo \& Gasperini Arquitetos:40.

15. Isadora de Andrade Guerreiro, “Arquitetura-capital: a funcionalidade dos edifícios corporativos paulistas” (Dissertação (Mestrado em Projeto, Espaço e Cultura). Orientadora: Vera Maria Pallamin, Faculdade de Arquitetura e Urbanismo da Universidade de São Paulo, 2010), 205. Também segundo depoimento de Flávia Marcondes, em entrevista citada acima. 16. Takuji Nakashima, (Arquiteto no aflalo/gasperini arquitetos, 2000-2016), Entrevista para o autor, Telefone, 29 de janeiro de 2019.
} 


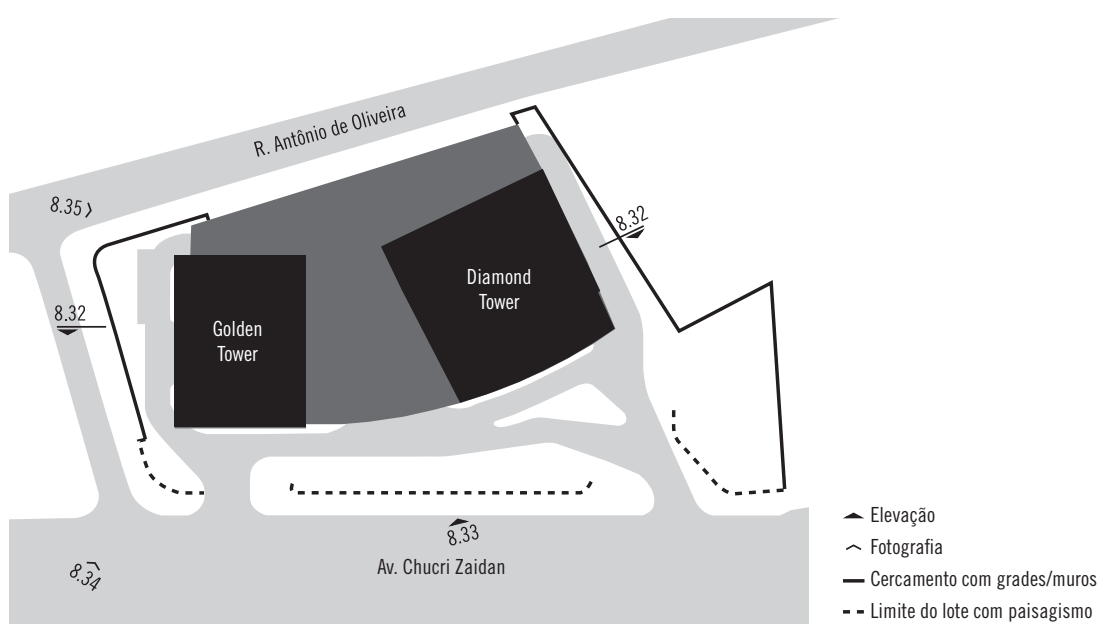

Fig 8.28. Diagrama do Morumbi Corporate. Elaborado pelo autor.

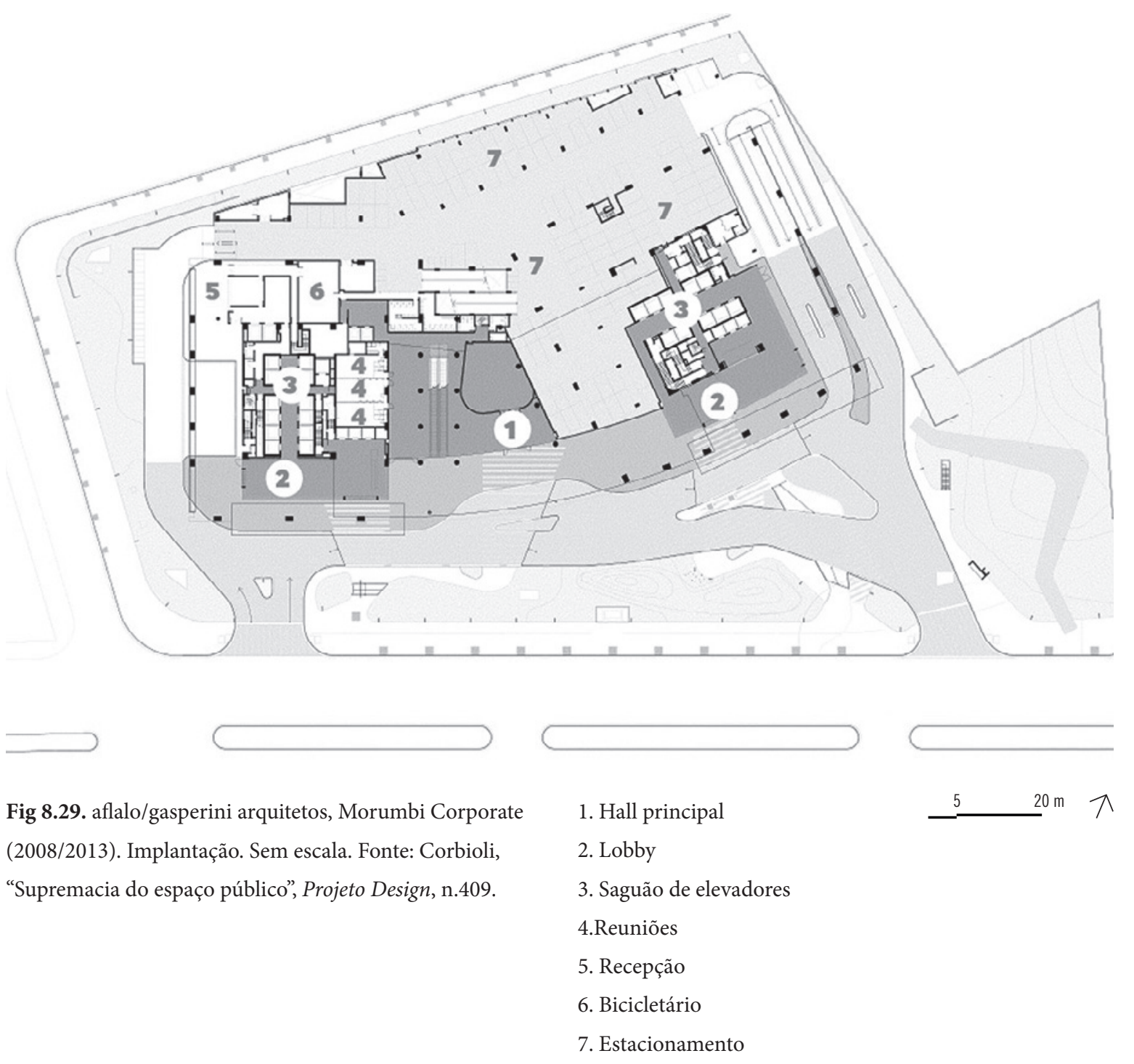




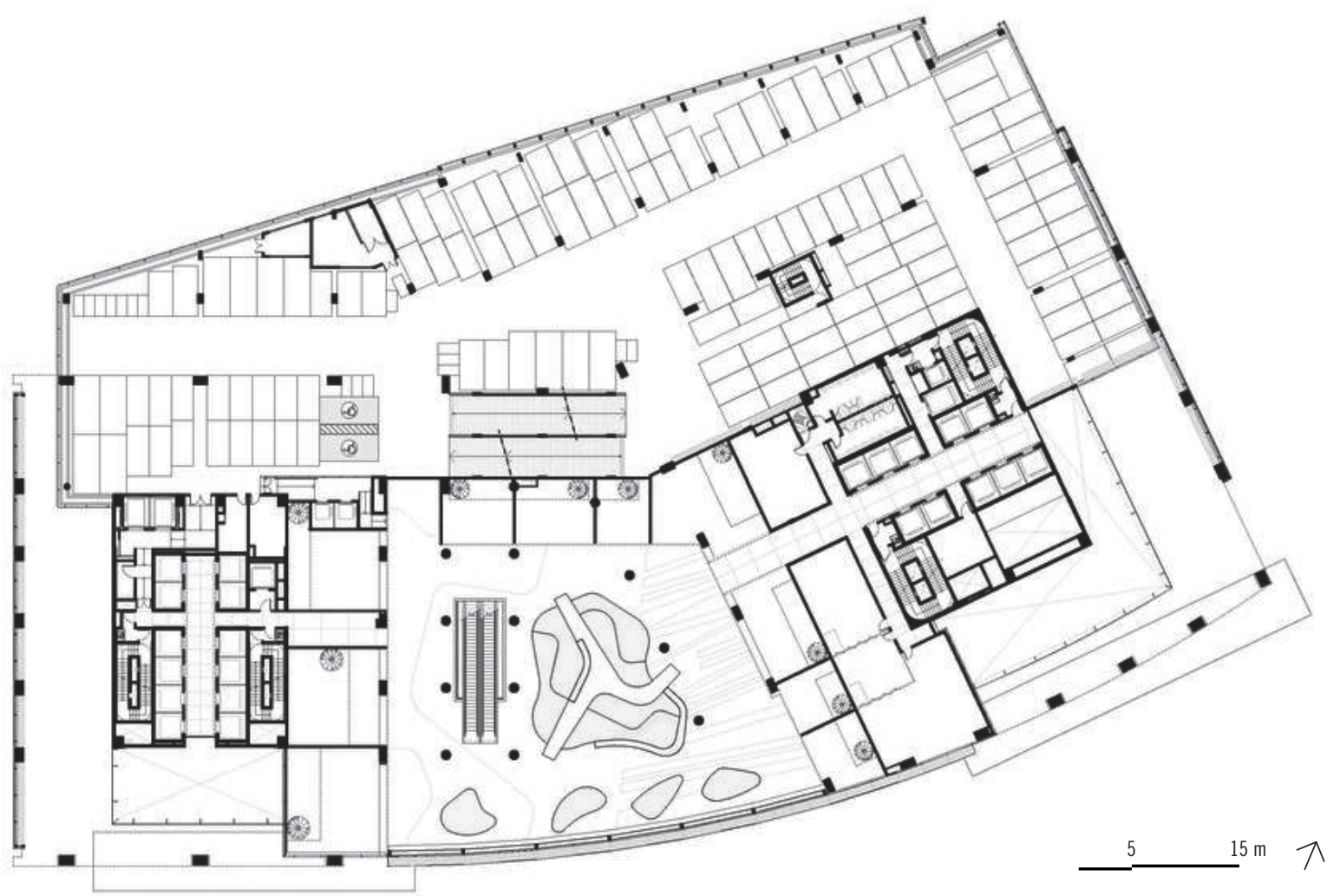

Fig 8.30. aflalo/gasperini arquitetos, Morumbi Corporate (2008/2013). Mezanino de serviços. Sem escala. Fonte: Archdaily.

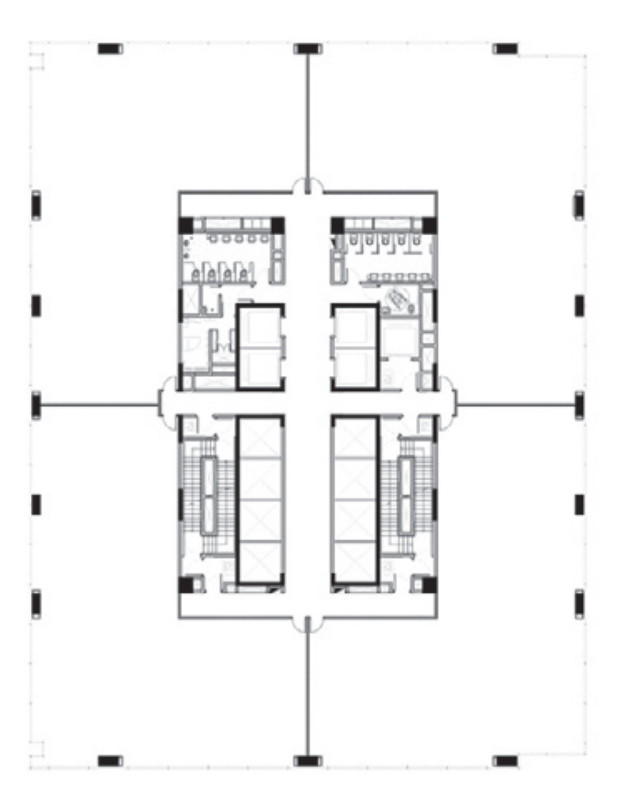

Golden Tower

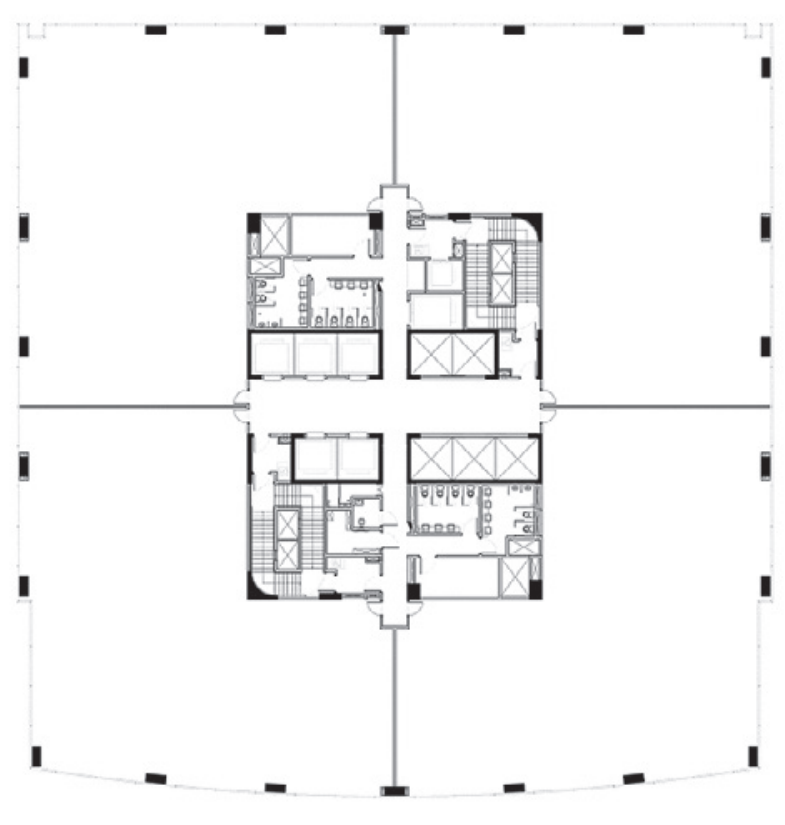

Diamond Tower $10 \mathrm{~m}$

Fig 8.31. aflalo/gasperini arquitetos, Morumbi Corporate (2008/2013). Pavimento-tipo das torres. Sem escala. Fonte: Corbioli, "Supremacia do espaço público", Projeto Design, n.409. 


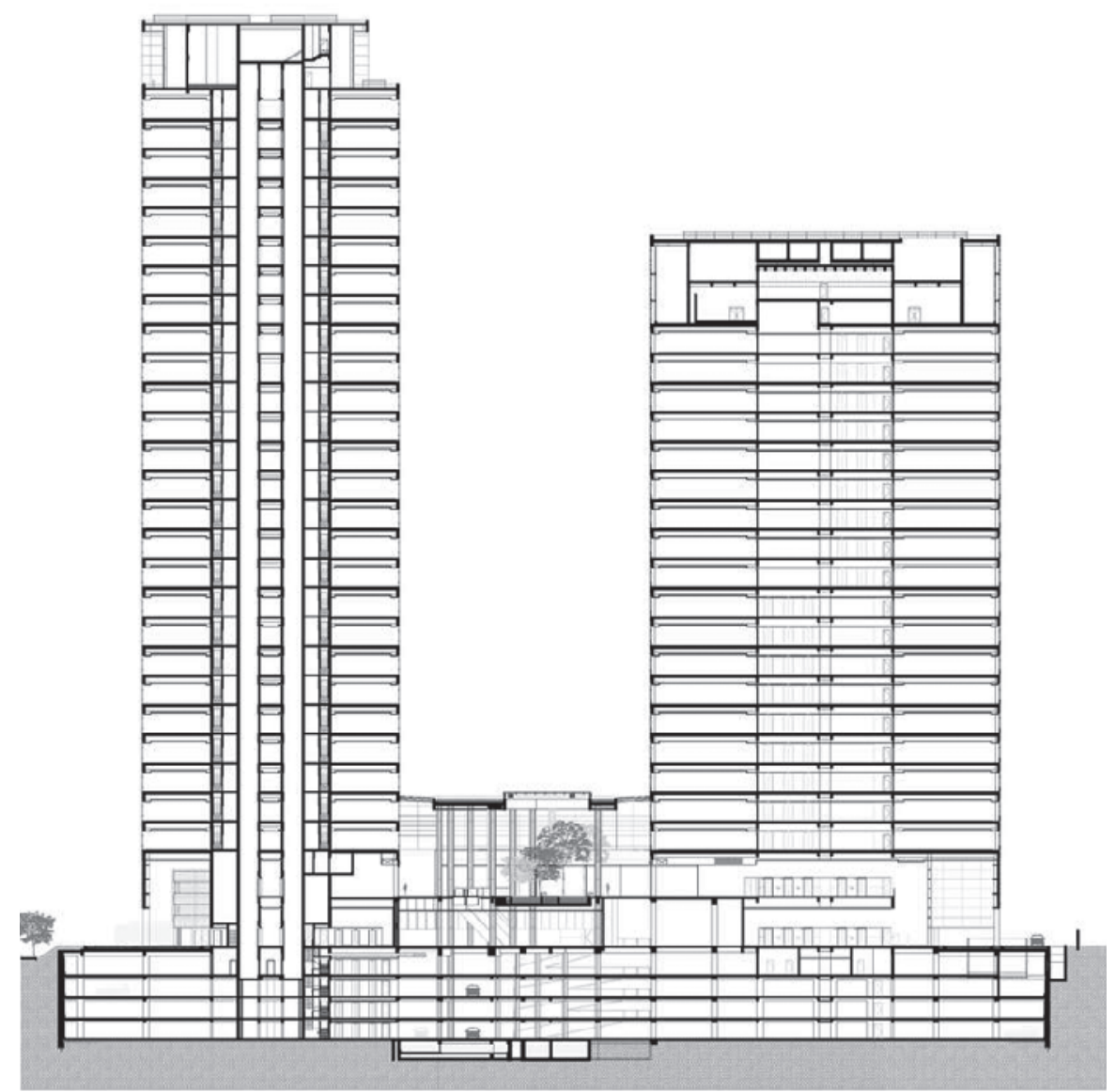

Fig 8.32. aflalo/gasperini arquitetos, Morumbi Corporate

(2008/2013). Corte longitudinal. Sem escala. Fonte:

Archdaily.

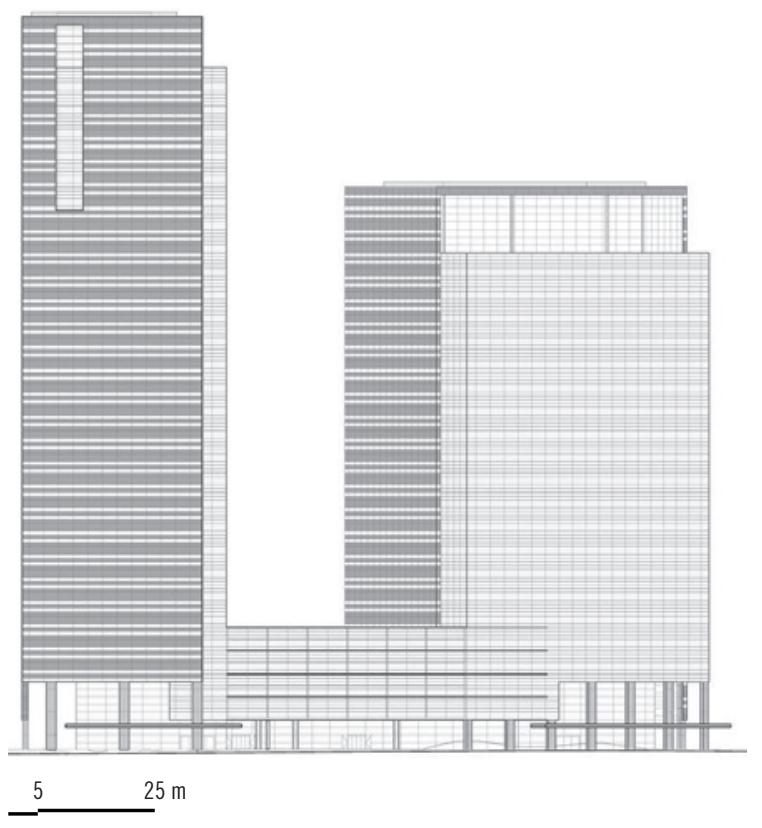

Fig 8.33. aflalo/gasperini arquitetos, Morumbi Corporate (2008/2013). Elevação frontal. Sem escala. Fonte: Archdaily. 

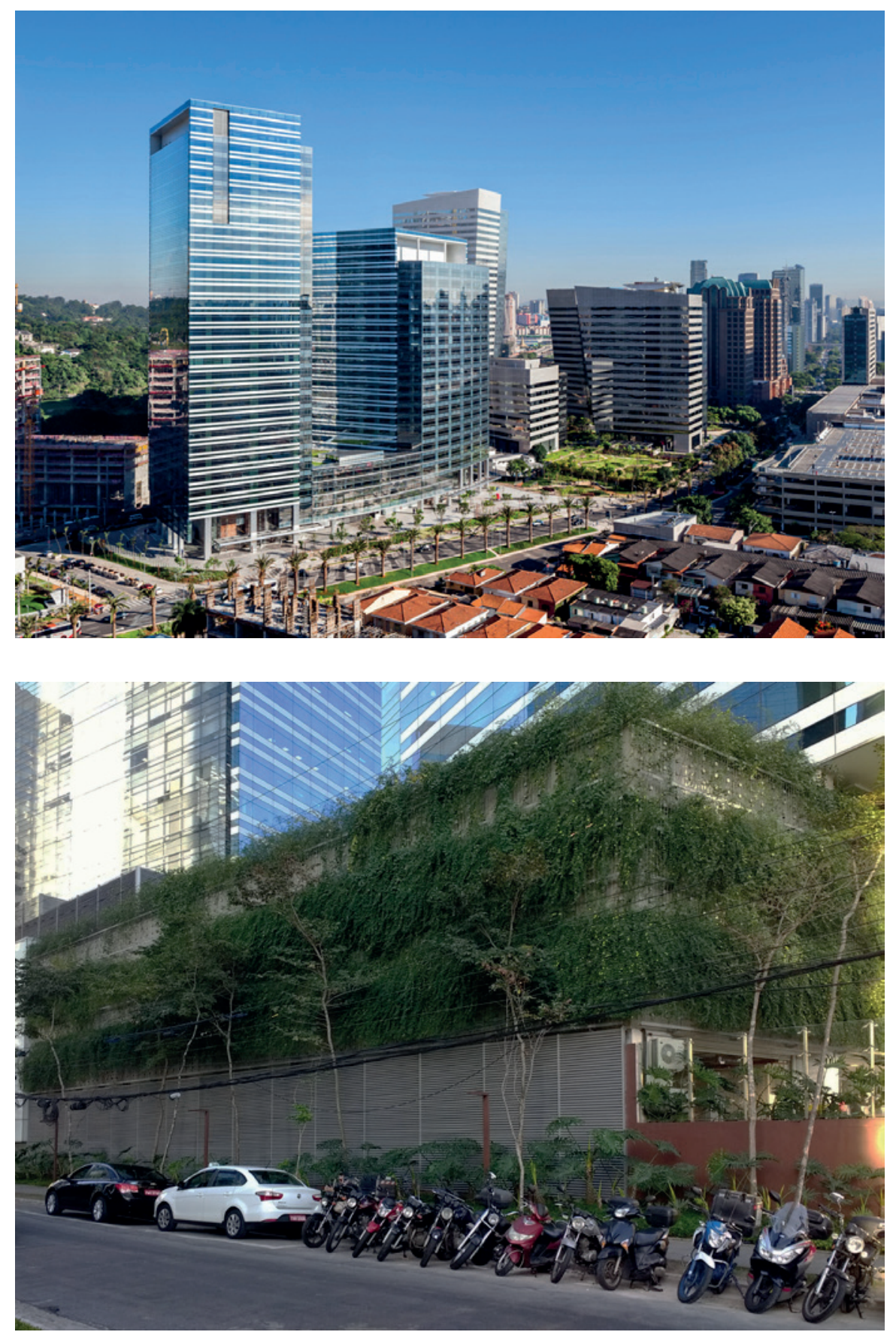

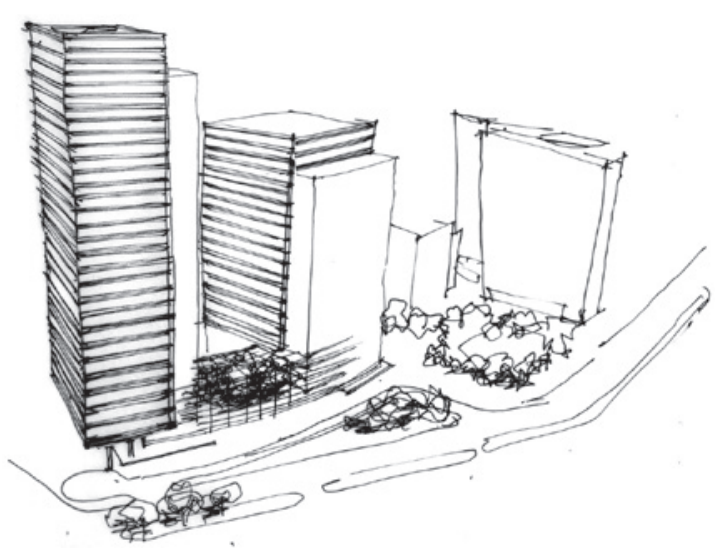

Fig 8.34. aflalo/gasperini arquitetos, Morumbi Corporate (2008/2013). Vista frontal, com Rochaverá Corporate Towers à direita. Fonte: Ana Mello, jul 2014, acervo online.

Fig 8.35. aflalo/gasperini arquitetos, Morumbi Corporate (2008/2013). Vista do edifício-garagem. Fonte: Acervo do autor, 16 ago 2019.

Fig 8.36. aflalo/gasperini arquitetos, Morumbi Corporate (2008/2013). Croqui de possível integração com o Rochaverá, pela leitura dos arquitetos. Fonte: Archdaily. 
pavimento-tipo, outra mais esbelta e alta, com vinte e seis pavimentos - são unificadas por um embasamento que contém a entrada, o estacionamento e uma praça de alimentação. Elas são unificadas pelo embasamento, mas ainda assim distintas, pois cada torre possui seu próprio lobby e núcleo de circulação. Mais ainda: pelo que se apreende dos desenhos do projeto, seriam três lobbies, um para cada torre, e ainda outro unicamente para atingir as escadas rolantes que levam à praça de alimentação no primeiro pavimento.

Entre os casos estudados na Chucri Zaidan, esse é o único a apresentar uma relação mais direta com a rua: seus acessos se dão diretamente pela calçada, mesmo se com um recuo maior do que o habitual na região, resultado de doação de parte do terreno para o município. ${ }^{17}$ Os acessos estão em cota acima da calçada, mas com desnível vencido por um aclive tênue, e não por escadas como no Rochaverá. Por fim, não há confusão entre frente e fundos dos edifícios, com clara orientação do conjunto para a Chucri Zaidan, sobretudo tendo-se em mente o modelo do Rochaverá, em que as diferenças entre frente e fundos dos edifícios são dadas pelo tratamento da superfície dos volumes - em vidro ou vidro e granito polido - e, ainda assim, não correspondem propriamente aos pontos de acesso aos edifícios (em todas as torres do Rochaverá, os acessos se dão pelo que seria sua lateral, a julgar pelos materiais das fachadas, e não pela sua frente). Em sentido contrário à relação com a rua, está o desenho do embasamento. Diz o memorial: "a [torre] de gabarito mais reduzido tem a face principal ligeiramente curva, acompanhando o traçado da via", ${ }^{18}$ ou, por outra, "[a] integração com o entorno foi o principal ponto de partida do projeto, desde a implantação das torres, uma delas paralela ao edifício vizinho, e a outra suavemente rotacionada para acompanhar a curvatura da rua". ${ }^{19}$ Mas se o desenho do embasamento parece a princípio dever sua volumetria ao traçado da avenida Chucri Zaidan, sua referência é, pelo contrário, o desenho de uma via de acesso de veículos projetada pelos próprios arquitetos. O empreendimento alinha-se ao largo por ele mesmo criado, e não às pré-existências urbanas. Quanto à "proposta paisagística [que] praticamente dá continuidade à do vizinho Rochaverá", ${ }^{20}$ destaque-se que a edificação ocupa maciçamente o terreno, ao contrário do ritmo de cheios e va-

17. Ver nota acima sobre doações de área e consumo de CEPACs para os valores.

18. Serapião, Monolito, Extra: Aflalo \& Gasperini Arquitetos:49.

19. Heloísa Medeiros, “Fachada ajustável”, Téchne, ago de 2013, 41.

20. Serapião, Monolito, Extra: Aflalo \& Gasperini Arquitetos:49. 


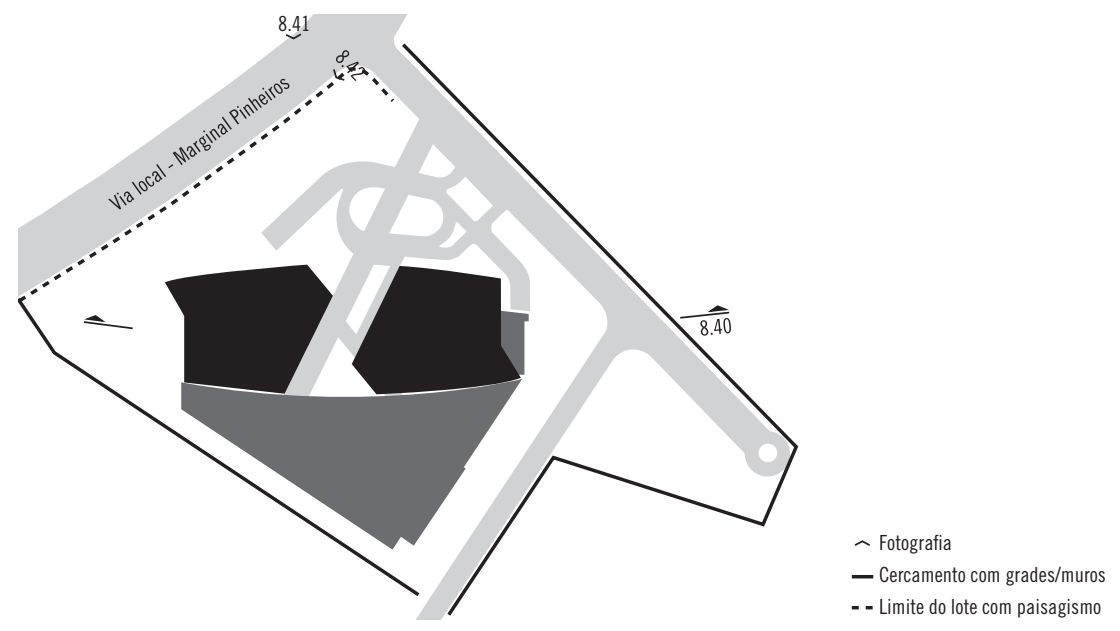

Fig 8.37. Diagrama do WT Morumbi. Elaborado pelo autor.

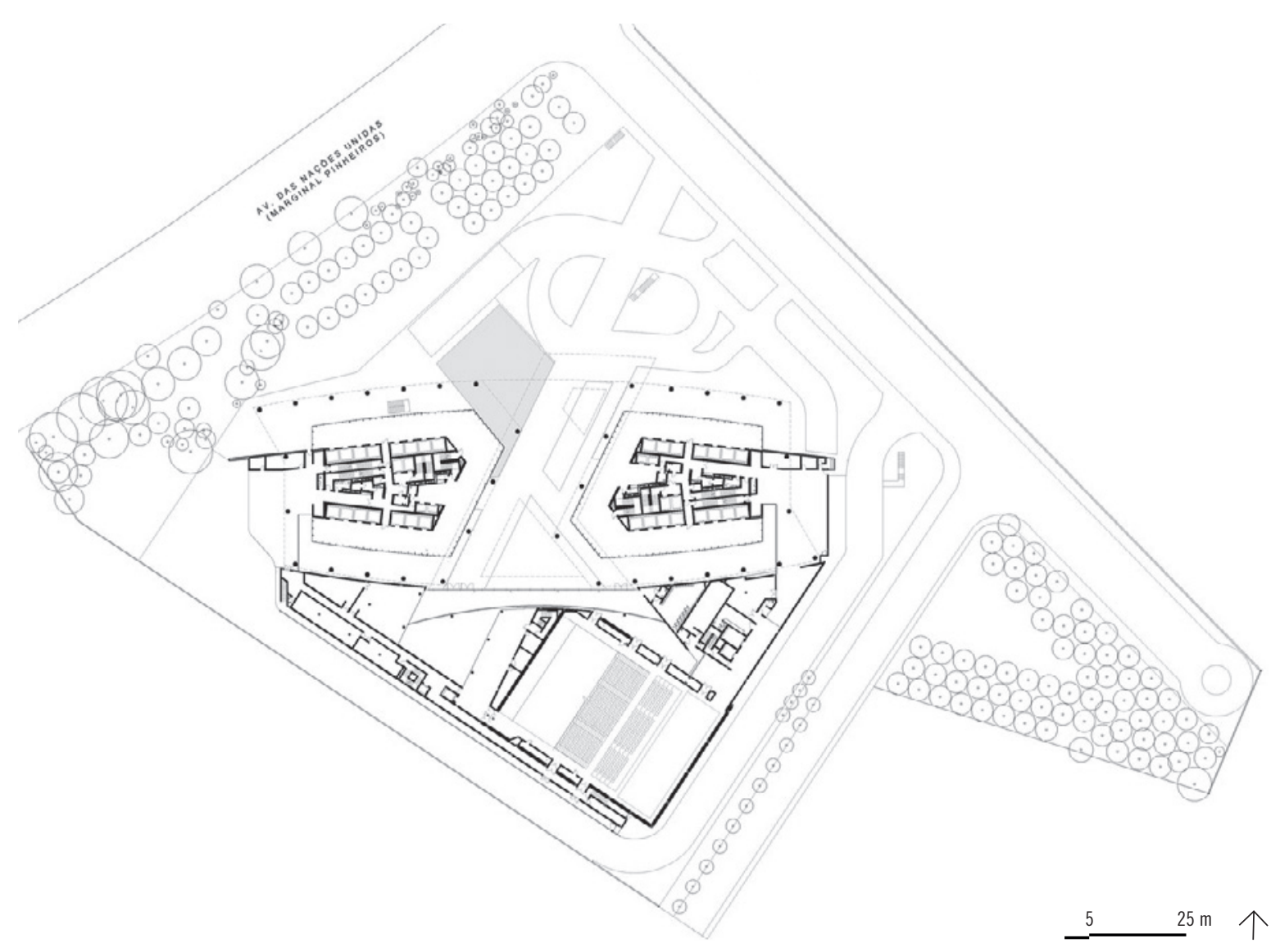

Fig 8.38. aflalo/gasperini arquitetos, WT Morumbi

(2009/2016). Implantação. Sem escala. Fonte: Acervo dos arquitetos, via Archdaily. 


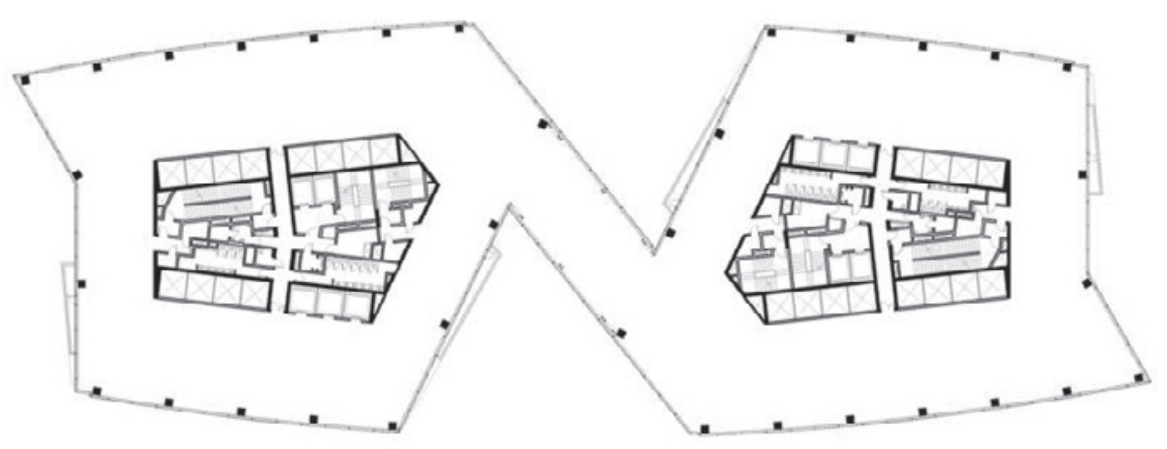

Fig 8.39. aflalo/gasperini arquitetos, WT Morumbi

(2009/2016). Planta do décimo pavimento. Sem escala.

Fonte: Acervo dos arquitetos, via Archdaily.

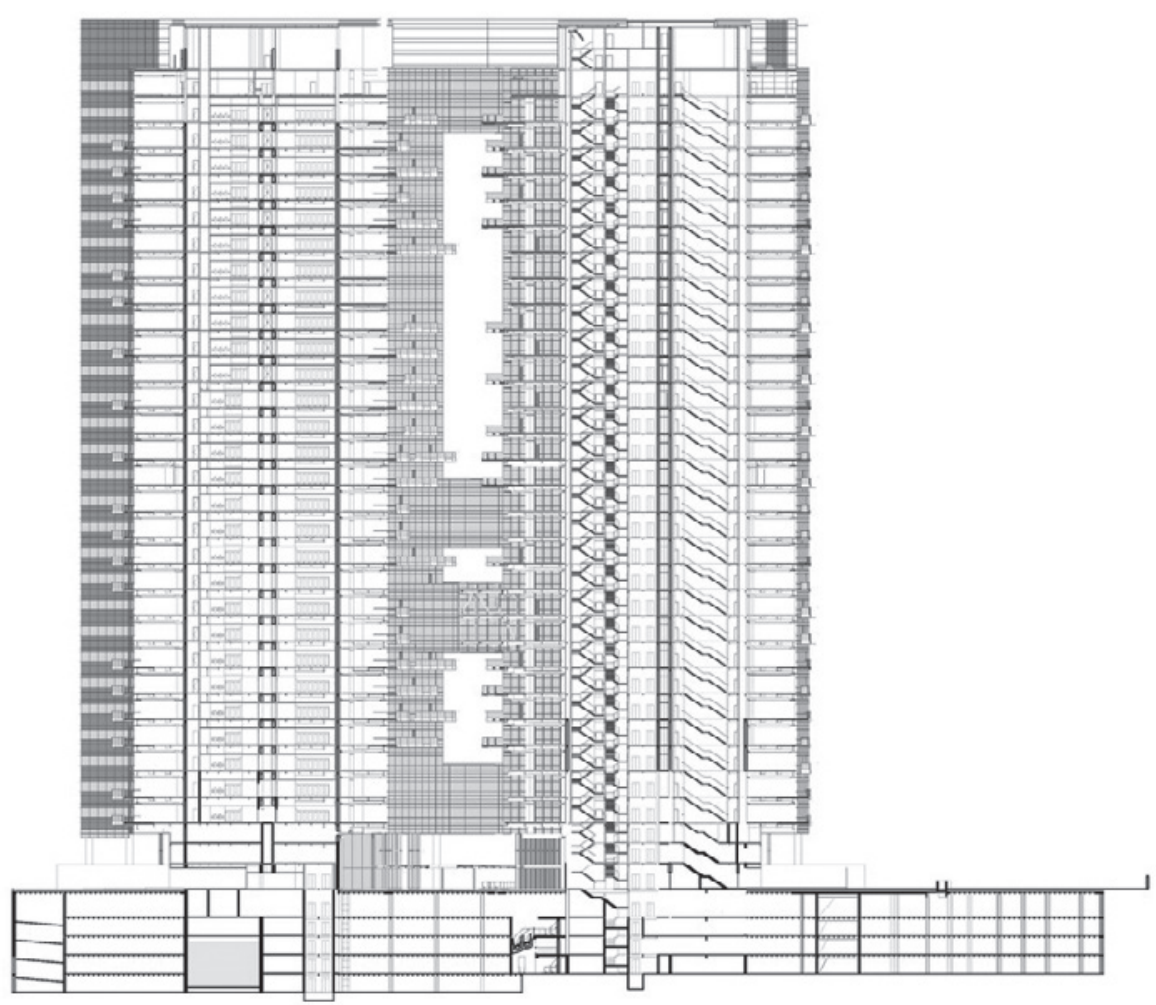

Fig 8.40. aflalo/gasperini arquitetos, WT Morumbi

(2009/2016). Corte longitudinal. Sem escala. Fonte: Acervo dos arquitetos, via Archdaily. 

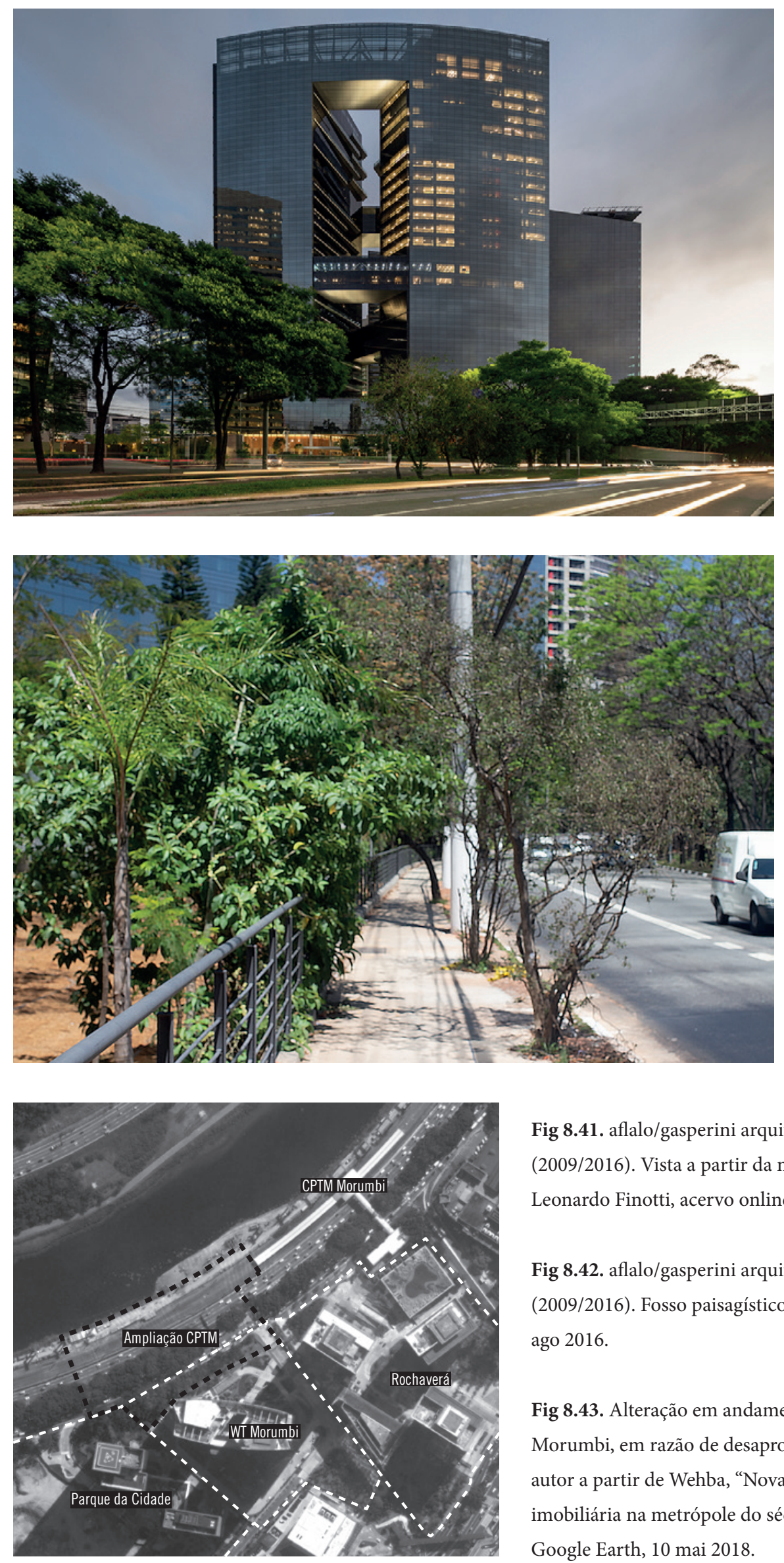

Fig 8.41. aflalo/gasperini arquitetos, WT Morumbi (2009/2016). Vista a partir da marginal Pinheiros. Fonte: Leonardo Finotti, acervo online.

Fig 8.42. aflalo/gasperini arquitetos, WT Morumbi (2009/2016). Fosso paisagístico. Fonte: Acervo do autor, 27 ago 2016.

Fig 8.43. Alteração em andamento da entrada do WT Morumbi, em razão de desapropriação. Elaborado pelo autor a partir de Wehba, "Novas relações de produção imobiliária na metrópole do século XXI", 140. Imagem: Google Earth, 10 mai 2018. 
zios daquele. Logo, o paisagismo limita-se aos bolsões que restam fragmentados entre a calçada e a via de acesso auxiliar. Assim, a derrubada dos muros que separam os dois empreendimentos e a correção do desnível de cotas, desejada pelos arquitetos, ${ }^{21}$ até poderia garantir a continuidade do trajeto do pedestre, mas não a continuidade do próprio projeto.

Por outro lado, a relação entre as torres é criada no terceiro projeto, o WT Morumbi, não só pelo embasamento [fig 8.37 a 8.41]. O térreo é formado por pilotis que abrigam os dois lobbies, um para cada torre, e um centro de convenções na aresta do lote que unifica visualmente o térreo, mas há também passarelas colocadas em três pontos das torres, unindo os pavimentos para empresas que busquem áreas maiores. Os dois últimos andares foram concebidos como unidades duplex com o mesmo objetivo. Na cobertura de cada passarela, há ainda uma área livre e vegetada. Com o perfil de sua elevação, o empreendimento é, no setor Chucri Zaidan, aquele com volumetria mais icônica. Para isso contribui o desenho das fachadas: apesar das varandas de desenho variado nas laterais, o edifício é o mais uniformemente tratado entre aqueles do setor, não só pela continuidade dos panos de vidro, mas também pela simplificação dos caixilhos e uniformização do vidro [fig 8.41].

O térreo apresenta um volume isolado para receber o centro de convenções com paisagismo distribuído em meio a um intricado sistema de vias que conectam a marginal Pinheiros, os lobbies, o estacionamento no subsolo e a rua Antônio de Oliveira aos fundos, conectando o WT Morumbi, o Morumbi Corporate e o Parque da Cidade. Se o Rochaverá se conectava sem nenhum obstáculo com a marginal Pinheiros, mais diretamente até do que com a avenida Chucri Zaidan, o WT Morumbi empregava outra estratégia de projeto, com um jardim em fosso acompanhado de guarda-corpo em ferro. Atualmente, o fosso foi aterrado e encontra-se em obras, em razão de sua desapropriação para dar espaço a um novo acesso para a estação da CPTM, em ampliação [fig 8.42 e 8.43]. ${ }^{22}$

\footnotetext{
21. Serapião, Extra: Aflalo \& Gasperini Arquitetos:17.

22. Cristina Wehba, "Novas relações de produção imobiliária na metrópole do século XXI: Odebrecht, Água Espraiada e o Parque da Cidade em São Paulo" (Dissertação (Mestrado em Planejamento Urbano e Regional). Orientadora: Maria Beatriz Cruz Rufino, Faculdade de Arquitetura e Urbanismo da Universidade de São Paulo, 2018), 140.
} 
O último dos empreendimentos da gleba da Chucri Zaidan, e também aquele em estágio mais inicial de construção, é o Parque da Cidade. Ele terá sozinho quase $600.000 \mathrm{~m} 2$ de área construída distribuída em cinco torres corporativas, uma torre de salas comerciais, um hotel da franquia Four Seasons, dois edifícios residenciais e um shopping center. O empreendimento está implantado em área antes ocupada pela fabricante de bicicletas Monark, demolida para dar espaço aos novos programas. Espera-se que a grande quantidade de atividades na gleba atraia diariamente cerca de 65 mil pessoas ao local - o equivalente ao bairro de Pinheiros, segundo uma matéria na revista Época. ${ }^{23}$

O projeto pretende se destacar por sua abertura para o entorno, diferentemente dos projetos típicos tradionalmente implantados nessa região, o que foi resultado de um entendimento entre prefeitura e incorporadora:

Então quando compramos o terreno fomos provocados pela prefeitura e eles disseram olha, nós vemos este setor Chucri Zaidan de forma diferente. Queremos que tenha equipamento para a população, e foi daí que surgiu a ideia de, ao invés de fazer um empreendimento que vivesse do muro para dentro, nós optamos por um empreendimento aberto. Já tinha um exemplo aqui, do Aflalo, o Rochaverá. Lá infelizmente é só comercial, e no nosso comportava fazer um empreendimento de uso misto e maior, então aceitamos a provocação e no nosso entendimento, e da prefeitura também, acabamos dando um presente pra cidade. Porque você tem uma área privada de utilização pública, sem gradil.. ${ }^{24}$

Entre os empreendimentos dos setores estudados, esse é o único ainda em construção. Apesar do faseamento normal de uma obra desse porte, ${ }^{25}$ a execução encontra-se atrasada pelos

23. Época Negócios Online, “Empreendimento no Brooklin será o maior de São Paulo", Época Negócios, 5 de agosto de 2012, https://epocanegocios.globo.com/Informacao/Acao/noticia/2012/08/empreendimento-no-brooklin-sera-o-maior-de-sao-paulo.html.

24. Saulo Nunes, diretor de incorporação da OR, em depoimento para Wehba, "Novas relações de produção imobiliária na metrópole do século XXI", 108. A gestão da prefeitura, citada no depoimento, provavelmente se encontrava sob Gilberto Kassab, já que o registro para certificação ocorreu já nos primeiros meses do mandato de Fernando Haddad.

25. Wehba, 116. 

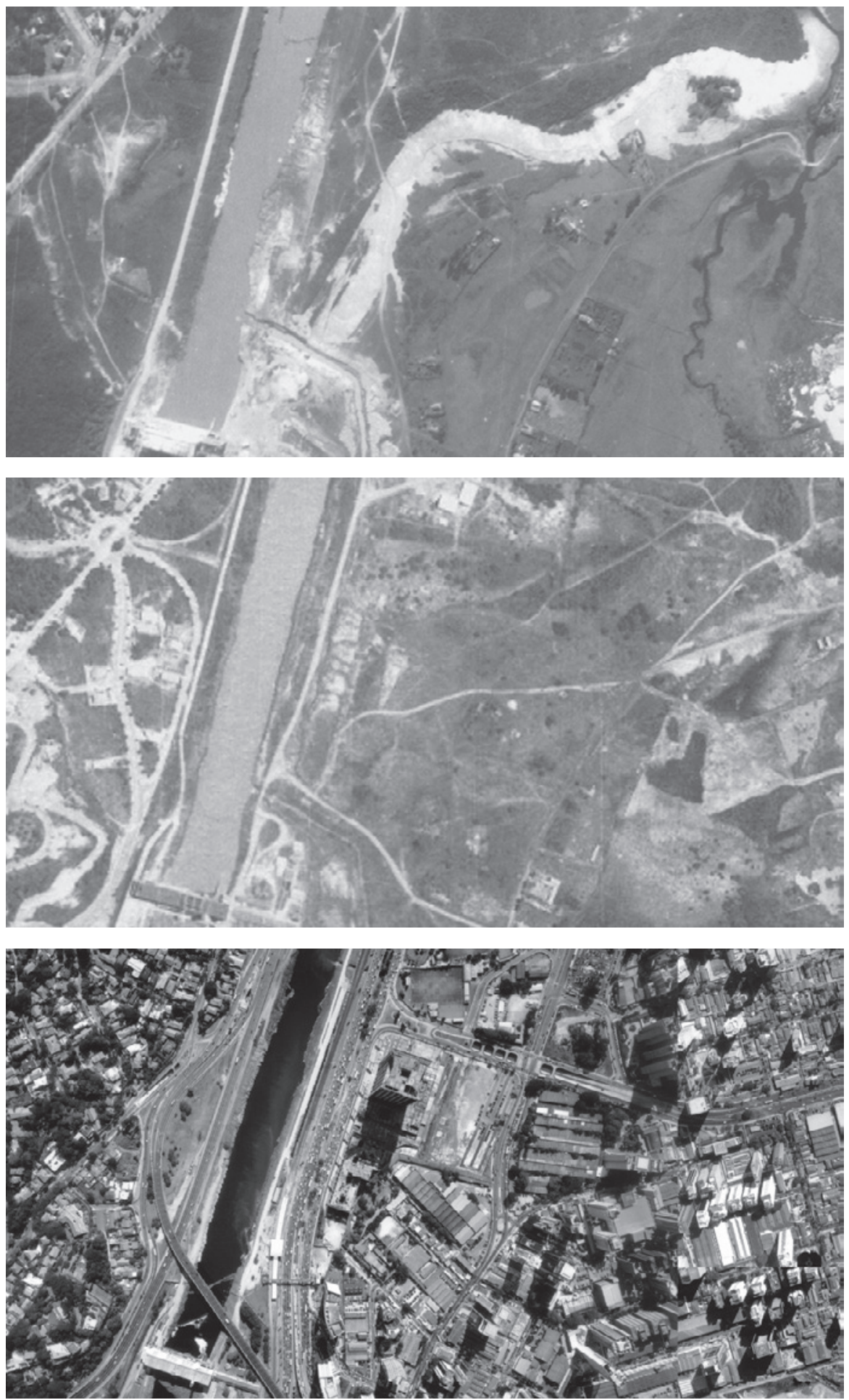

Fig 8.44 a 8.46. Imagens aéreas do setor Juscelino Kubitschek: 1940, 1954 e 2000. Fonte: Geosampa. 


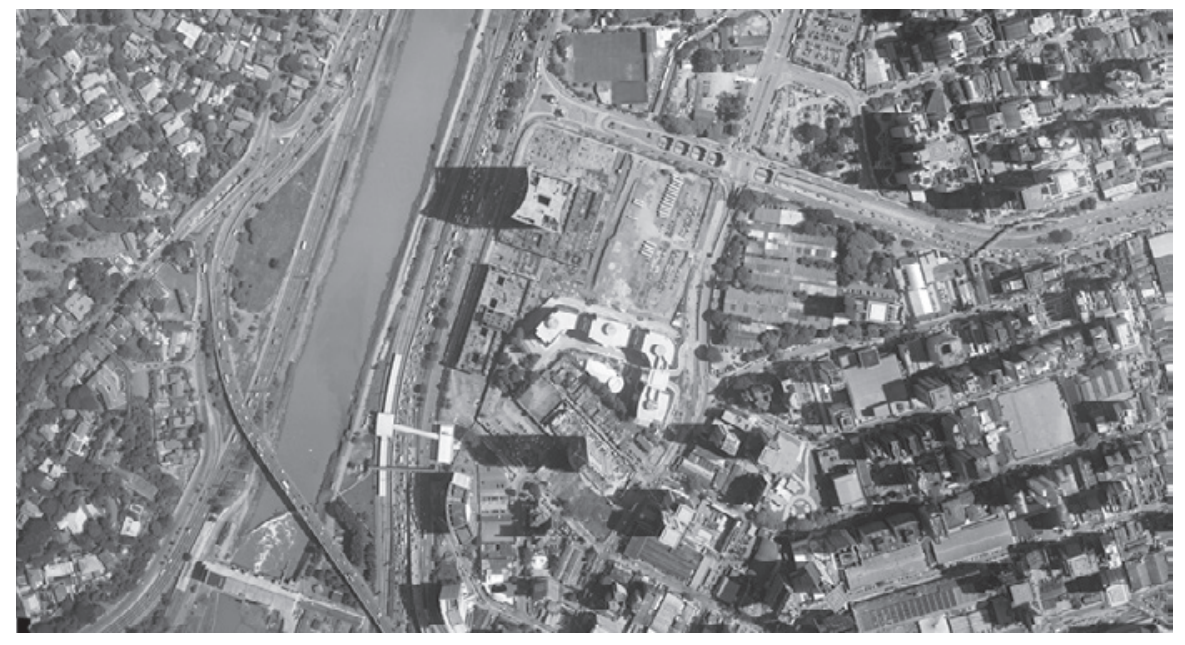

Fig 8.47. Imagem aérea do setor Juscelino Kubitschek.

Fonte: Geosampa, 2004.
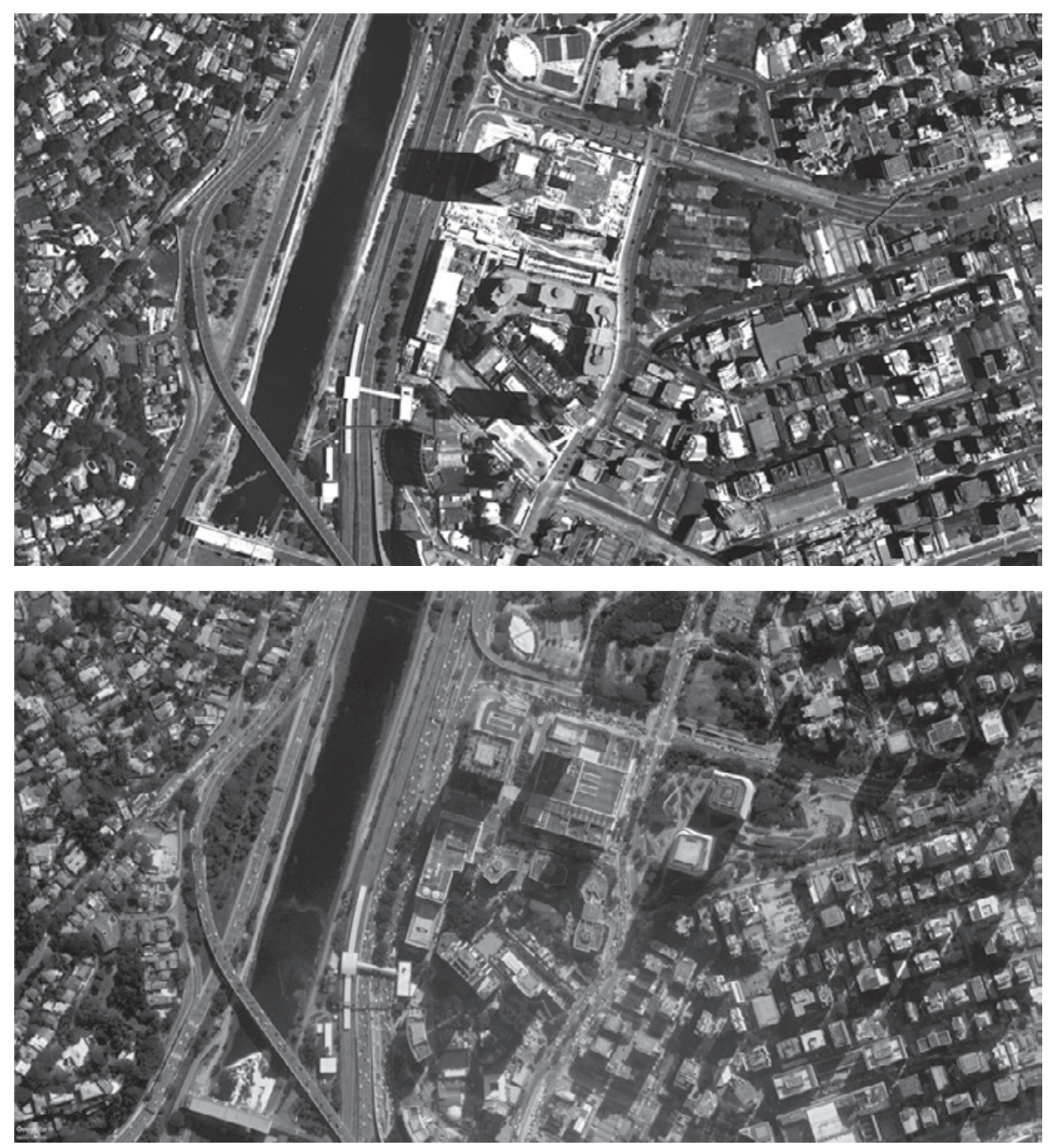

Fig 8.48 e 8.49. Imagens aéreas do setor Juscelino

Kubitschek: 14 dez 2008 e 10 mai 2018. Fonte: Google

Earth. 


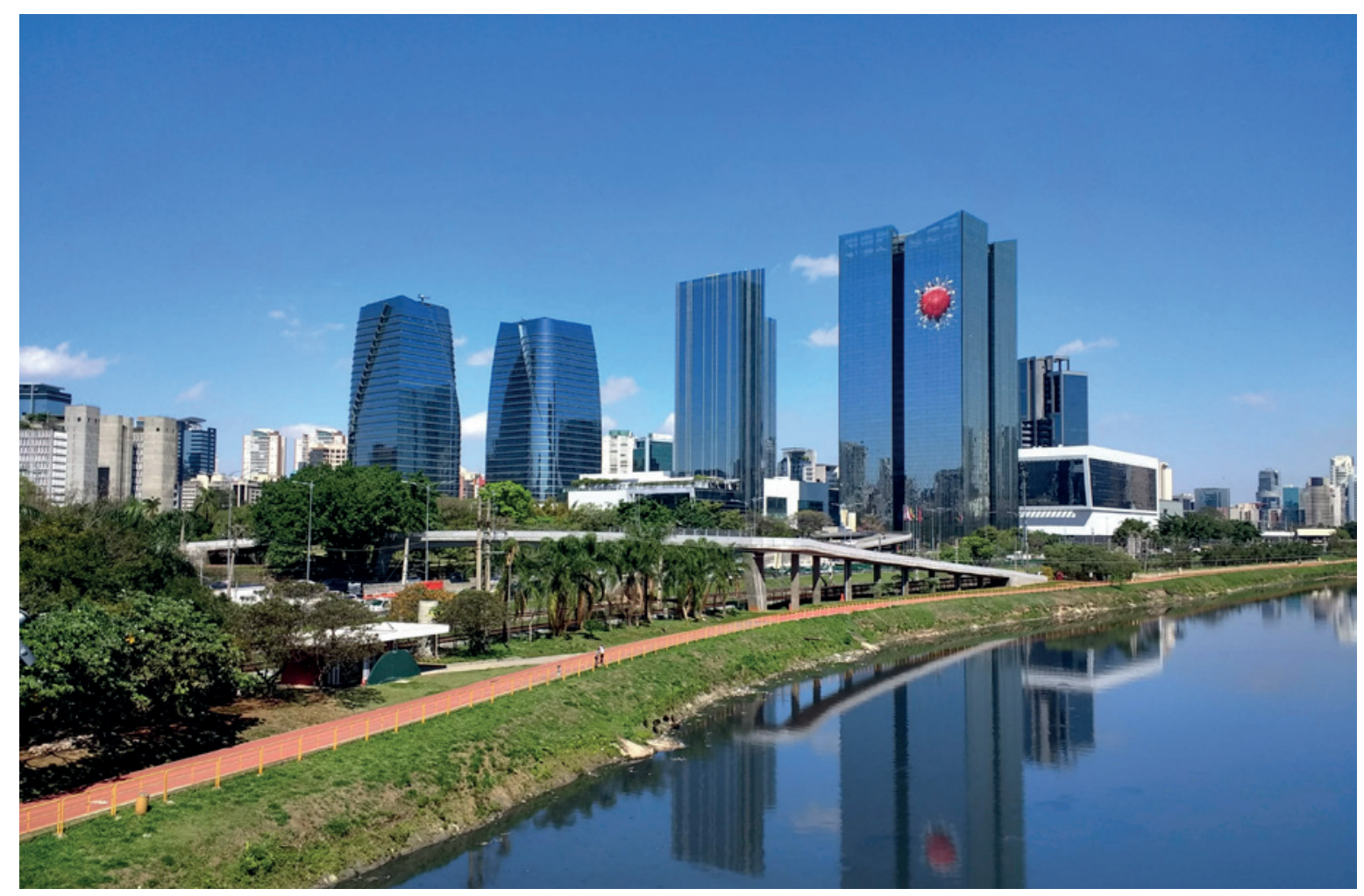

Fig. 8.50. Vista geral do setor Juscelino Kubitschek. Fonte:

Acervo do autor, 6 set 2018.

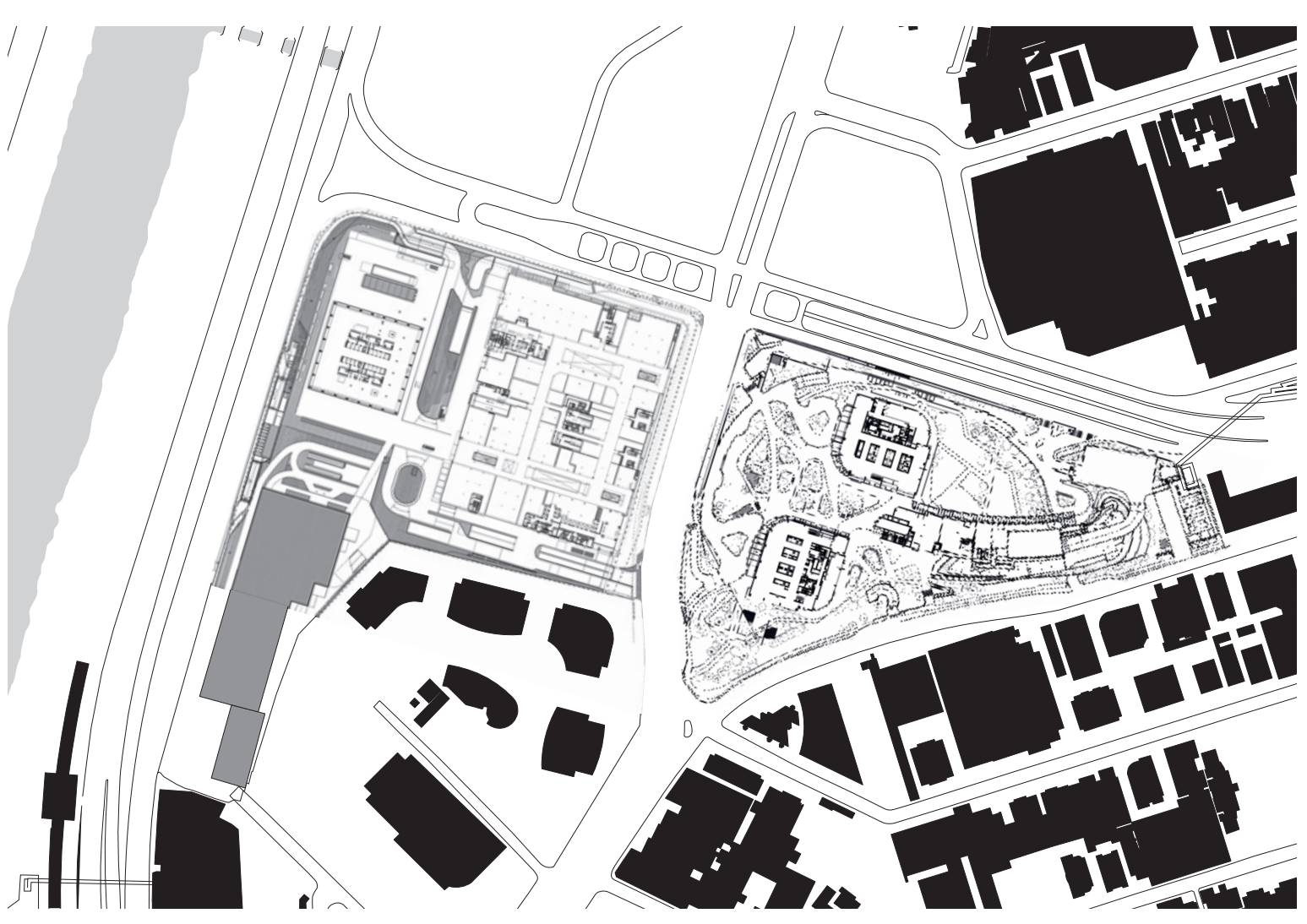

Fig 8.51. Implantação dos empreendimentos no setor

Juscelino Kubitschek. Escala 1:5000. Elaborado pelo autor. 

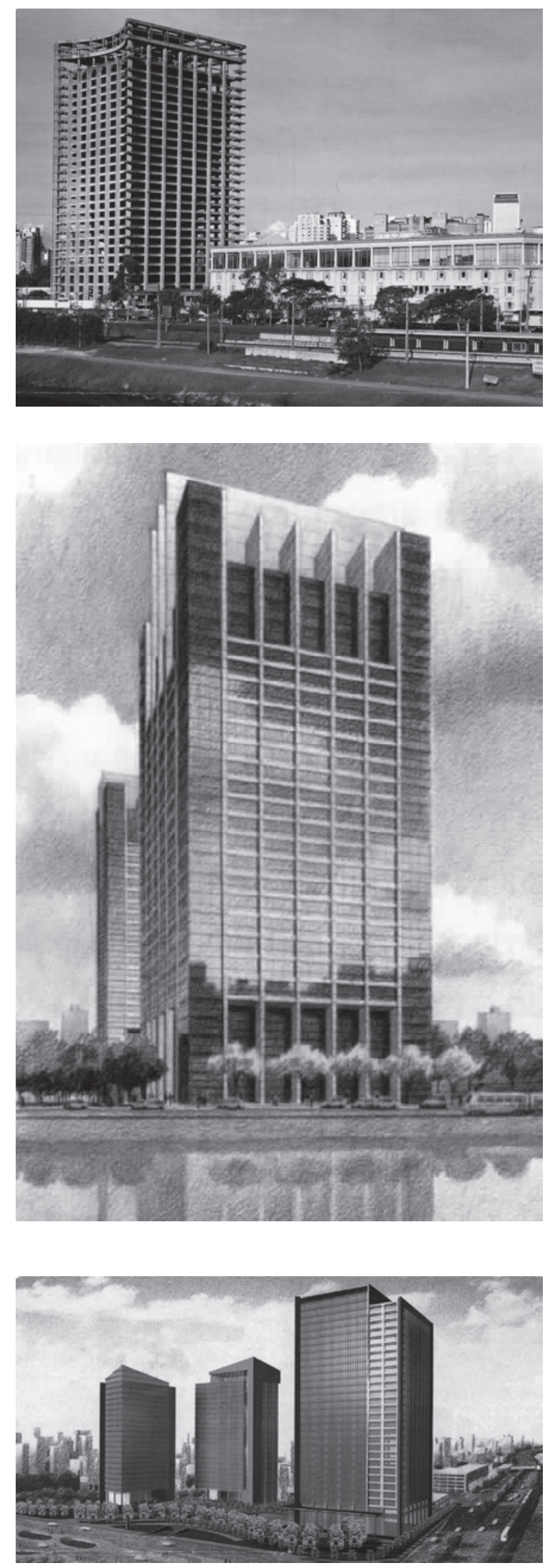

Fig 8.52. Edifício Eletropaulo, com construção embargada. Fonte: Serapião, “Esqueletos no armário", Projeto Design, out 2010, 74 .

Fig 8.53. Complexo em versão do aflalo/gasperini para a Tishman Speyer, não construído. Fonte: Serapião, “Esqueletos no armário", Projeto Design, out 2010, 76.

Fig 8.54. Complexo em versão do KPF para a Tishman Speyer, não construído. Fonte: Serapião, "Esqueletos no armário", Projeto Design, out 2010, 76. 
próprios prazos anunciados no site do empreendimento, quando era prevista a conclusão do shopping e da torre corporativa vizinha em 2016. A demora está relacionada não só ao arrefecimento da construção civil com a crise econômica, mas também em razão da crise advinda da Operação Lava Jato sofrida pela Odebrecht. ${ }^{26}$ Até meados de 2019, foram inauguradas a torre comercial - que possui a maior área de superfície opaca em qualquer um dos estudos de caso -, duas das torres corporativas, o hotel e o shopping.

O Parque da Cidade será retomado, do ponto de vista do planejamento da gleba, no capítulo 10 desta tese.

\section{SETOR JUSCELINO KUBITSCHEK: PARCERIAS INTERNACIONAIS}

Se o setor Chucri Zaidan do estudo realizado se encontra na Operação Urbana Consorciada Água Espraiada (OUCAE), em uma das áreas da operação com esse mesmo nome, o segundo setor encontra-se próximo à avenida Juscelino Kubitschek, na área "Olimpíadas" da Operação Urbana Consorciada Faria Lima (OUCFL). São dois os empreendimentos analisados aqui, que incluem oito certificações pelo $\mathrm{LEED}^{\circledR}$ e se caracterizam pelas colaborações internacionais nos projetos [fig 8.44 a 8.51 ].

Por ordem cronológica, o primeiro projeto é o Complexo WTJK, do escritório peruano-estadunidense Arquitectonica, dirigido por Bernardo Fort-Brescia e Laurinda H. Spear. A nacionalização do projeto foi feita pelo escritório do falecido arquiteto Washington Fiúza, e as atuais parcerias nacionais com o Arquitectonica são realizadas pelo Athié Wohnrath. O conjunto possui uma franquia de shopping center do Grupo Iguatemi, quatro torres corporativas e um teatro. Mas a história da gleba é atribulada. ${ }^{27}$ Ela começou pela estrutura da atual Torre São Paulo, onde se situa a sede do banco Santander. O empreendimento reaproveitou uma construção abandonada, feita originalmente para abrigar a sede da Eletropaulo, projetada em 1990

\footnotetext{
26. Murilo Ramos, “Mantega pressionou fundo de pensão a investir em empreendimento da Odebrecht”, Época, 23 de setembro de 2016, https:/epoca.globo.com/tempo/expresso/noticia/2016/09/mantega-pressionou-fundo-de-pensao-investir-em-empreendimento-da-odebrecht.html.

27. A narrativa, mas não a interpretação, seguida é aquela de Fernando Serapião, "Esqueletos no armário", Projeto Design, $n^{\circ} 368$ (out de 2010): 74-81.
} 

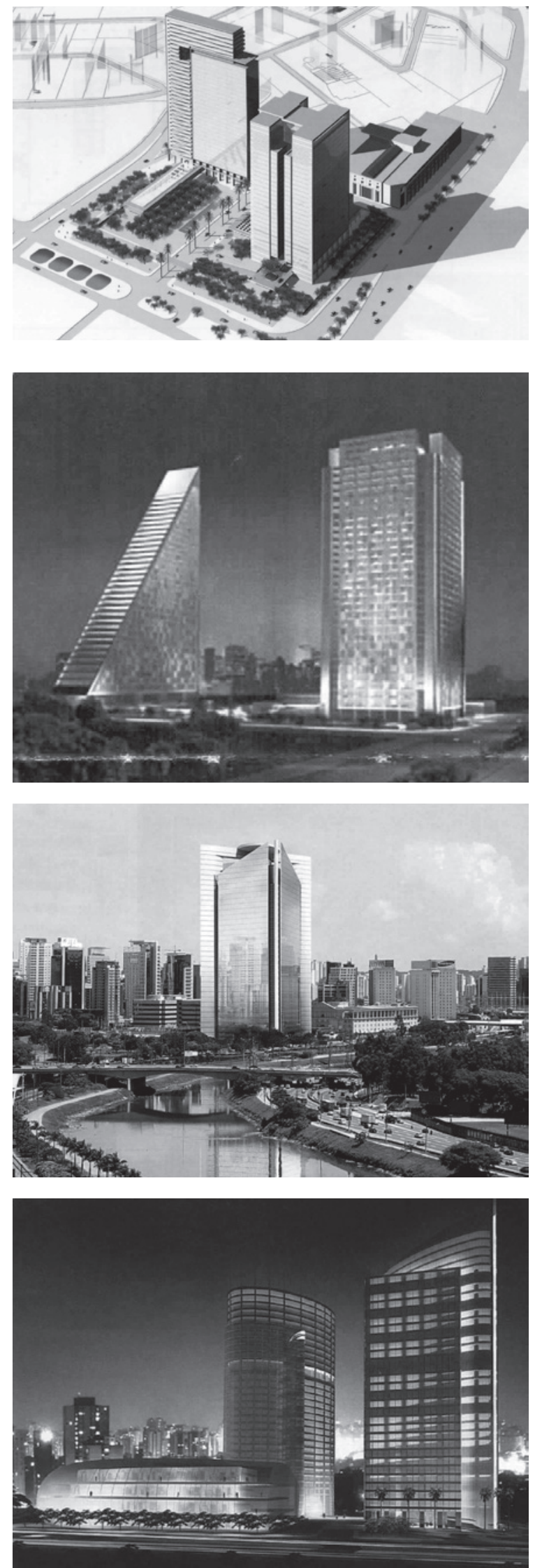

Fig 8.55. Complexo em versão do aflalo/gasperini para a Ergi, não construído. Fonte: Serapião, "Esqueletos no armário", Projeto Design, out 2010, 78.

Fig 8.56. Complexo em versão de Botti Rubin para a Ergi, não construído. Fonte: Serapião, "Esqueletos no armário", Projeto Design, out 2010, 77.

Fig 8.57. Complexo em versão de Botti Rubin para a WTorre, não construído. Fonte: Serapião, "Esqueletos no armário", Projeto Design, out 2010, 79.

Fig 8.58. Complexo em versão de Edo Rocha para a WTorre, não construído. Fonte: Serapião, "Esqueletos no armário", Projeto Design, out 2010, 80. 
pelo arquiteto Júlio Neves para responder à comanda do então governador de São Paulo Orestes Quércia (PMDB; 1987-1991) e construída a partir de 1991 pela Andrade Gutierrez na gestão de Luiz Antonio Fleury Filho (PMDB; 1991-1995) [fig 8.52]. Em 1995, já sob Mário Covas (PSDB; 1995-2001), a obra foi paralisada pelo Tribunal de Contas do Estado (TCE) por suspeitas de superfaturamento - posteriormente confirmadas. No final da década de 1990, foi iniciada uma nova etapa de projetos para a torre, ao invés da conclusão do projeto anterior. De início, um leilão vencido pela Tishman Speyer, com projeto de aflalo/gasperini arquitetos e depois do norte-americano KPF [fig 8.53 e 8.54]; impossibilitada de cumprir no prazo as exigências do leilão, a Tishman Speyer perdeu sua posição para a segunda colocada, a igualmente norte-americana Hines, a qual tampouco pôde concluir sua proposta. Em seguida, a privatização da Eletropaulo em 1998 levou a uma segunda tentativa de venda, com novo projeto de aflalo/gasperini para a Tishman Speyer, dessa vez para a sede do Unibanco - novamente não construído, devido ao alto preço de venda. Em um terceiro momento, a AES Eletropaulo, então privatizada, enfim liquidou seu ativo para responder à pressão do Banco Nacional do Desenvolvimento (BNDES) para o pagamento de dívidas, vendendo-o para o grupo português Ergi Empreendimentos. Após acordo com o arquiteto Júlio Neves, foi-lhe cedido o projeto de uma área do conjunto, até então ocupada pelo CPD da Eletropaulo, para implantação da Daslu; o restante da gleba, contudo, foi submetido a novo concurso, novamente vencido pelo aflalo/gasperini arquitetos. O programa incluía torres de escritórios, shopping center, hotel e, na torre já construída, foi proposto uso residencial [fig 8.55 e 8.56]. O projeto encontrou dificuldade de viabilização, pois a Ergi Empreendimentos não conseguiu reunir outros investidores. Desse modo, começou o quarto momento do empreendimento, que foi comprado em 2006 pela WTorre, sua atual proprietária. Após outro concurso, o escritório de Edo Rocha fez uma proposta em associação com Pedro Paulo de Melo Saraiva, primeiro apenas para a torre, depois para todo o conjunto [fig 8.57 e 8.58]. Com a obra já em curso, Edo Rocha foi afastado, mas participou ainda do projeto de interiores da Torre São Paulo. Foi, por fim, o projeto seguinte encomendado ao Arquitectonica que foi construído, incorporando decisões de projeto tanto de Júlio Neves, mantendo o esqueleto da Eletropaulo, quanto de Edo Rocha, que havia demolido parte do térreo. A história do complexo é, portanto, longa e disputada.

Diferentemente dos conjuntos na Chucri Zaidan, não há no Complexo WTJK nenhuma 


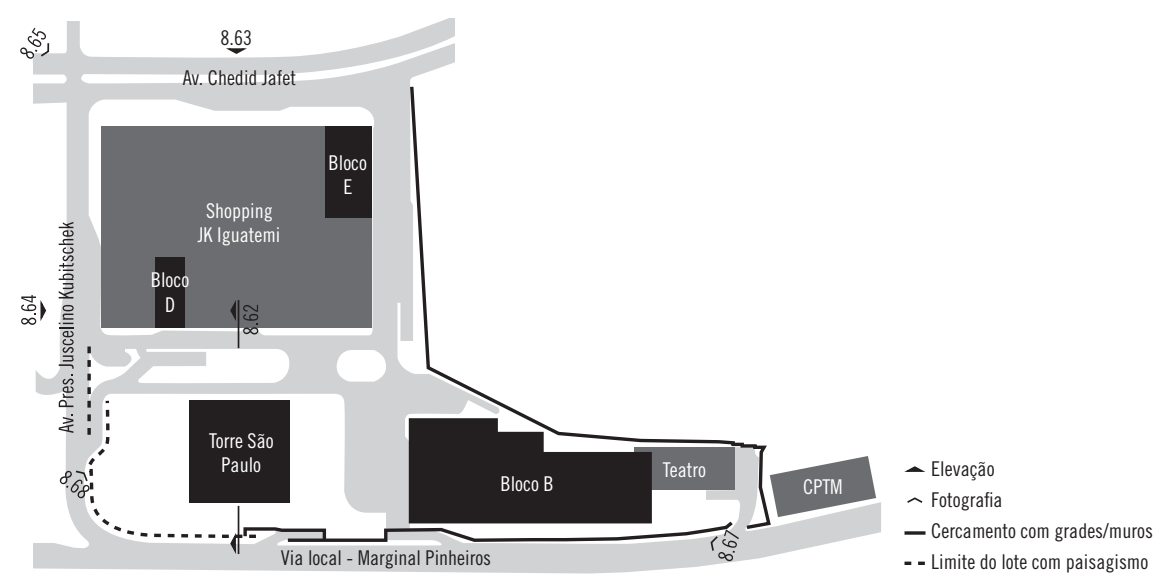

Fig 8.59. Diagrama do complexo WTJK. Elaborado pelo autor.

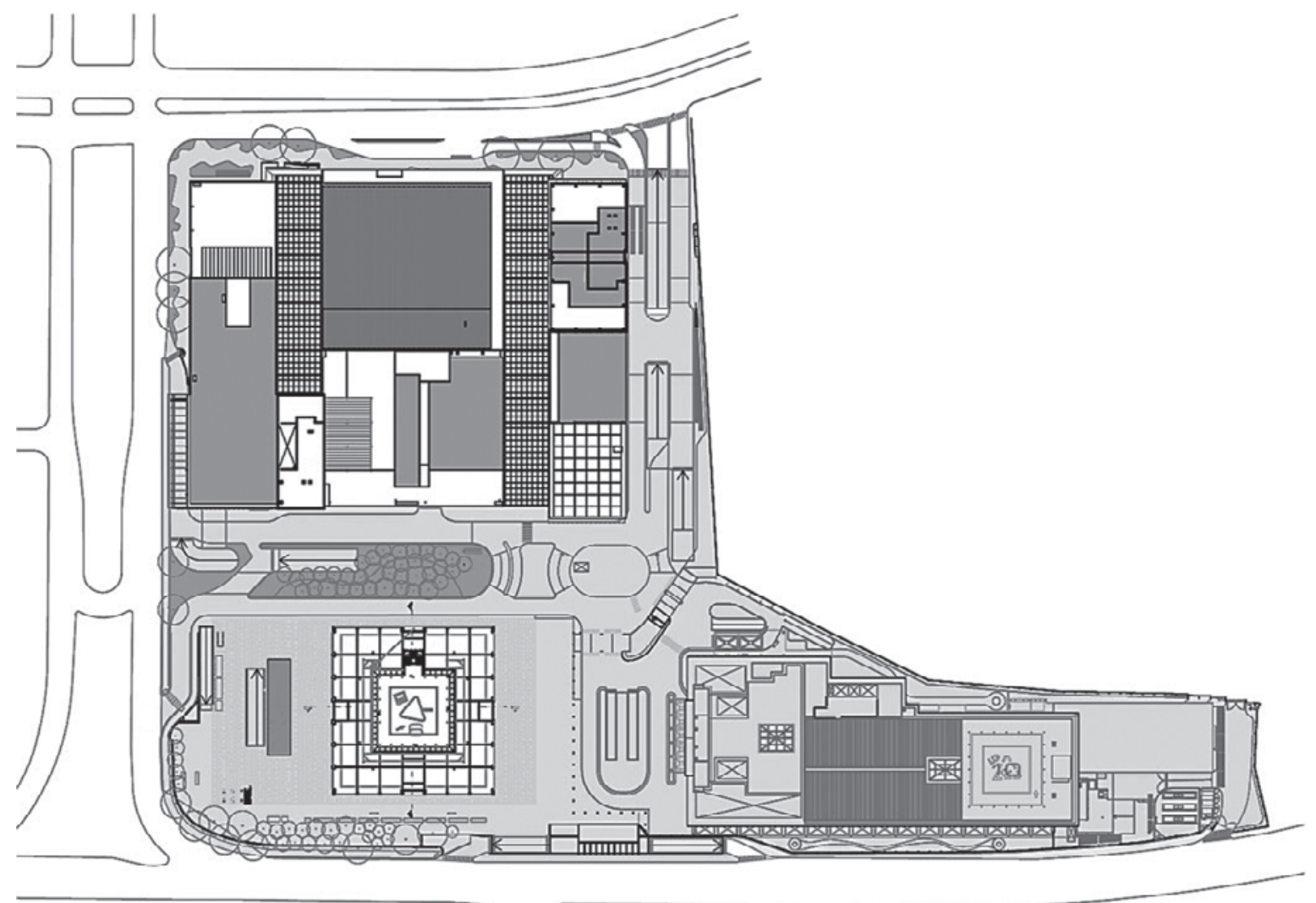

Fig 8.60. Arquitectonica, complexo WTJK (2007-2014).

Implantação. Sem escala. Fonte: Gelinski, "Recortes $50 \mathrm{~m} \quad$ K

suavizam fachada monolítica", Finestra, n. 66. 

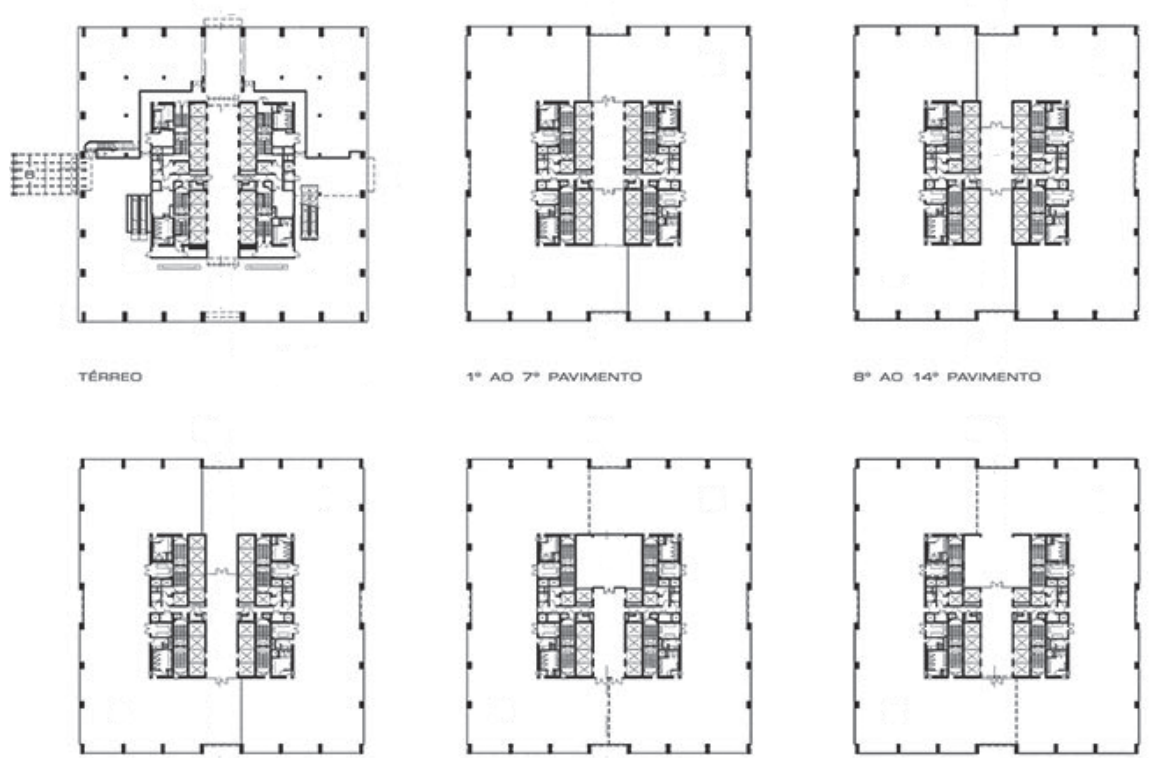

15. PAVIMENTO

10* PAVIMENTO
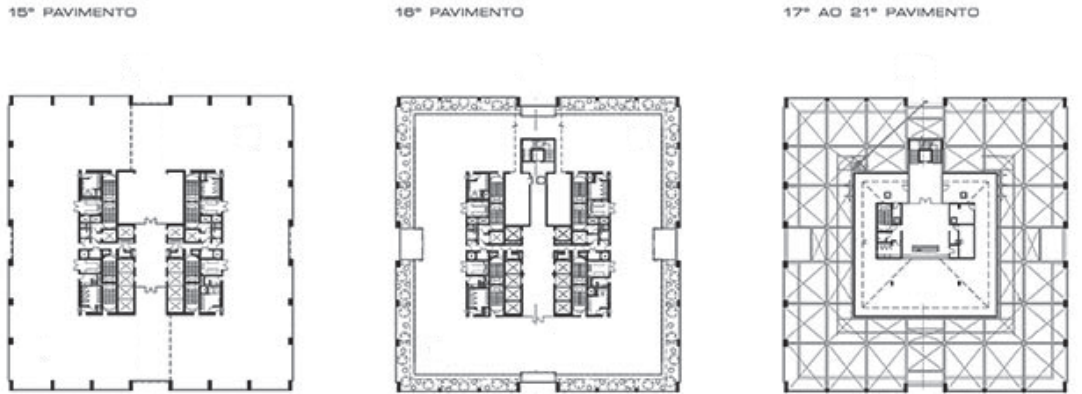

22" AO 27" PAVIMENTO

28: PAVIMENTO

cobertupa e saLA DE EspeaA

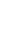

$10 \mathrm{~m} \quad$ K

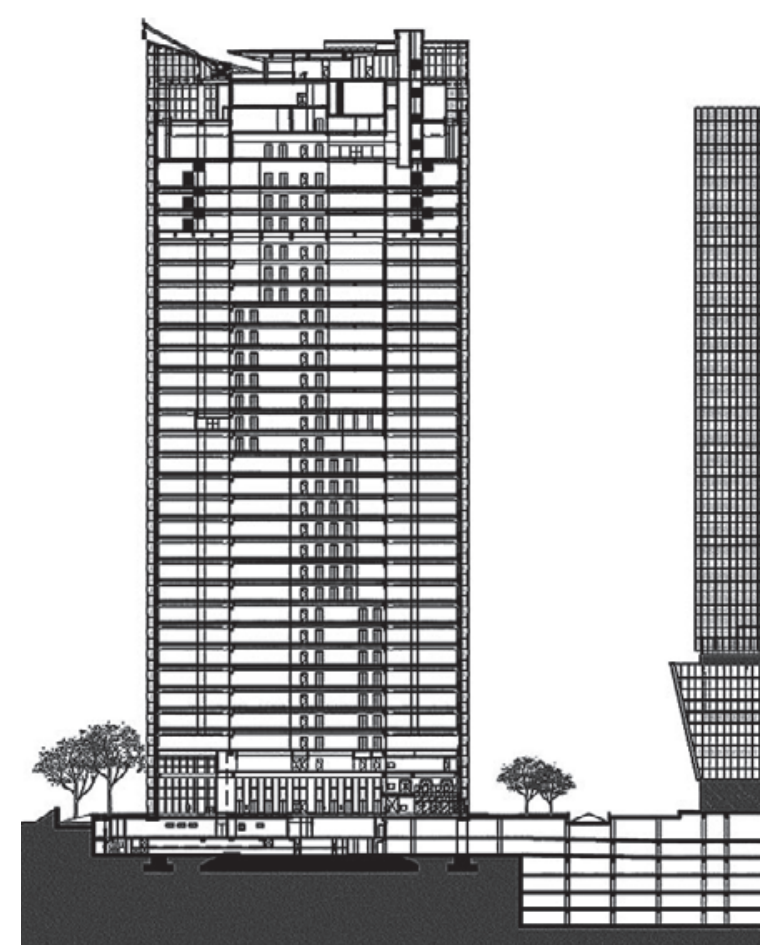

Fig 8.61. Arquitectonica, complexo WTJK (2007-2014).

Pavimentos da torre São Paulo. Sem escala. Fonte: Gelinski,

"Recortes suavizam fachada monolítica", Finestra, n. 66.

Fig 8.62. Arquitectonica, complexo WTJK (2007-2014).

Corte da torre São Paulo. Sem escala. Fonte: Gelinski,

"Recortes suavizam fachada monolítica”, Finestra, n. 66. 


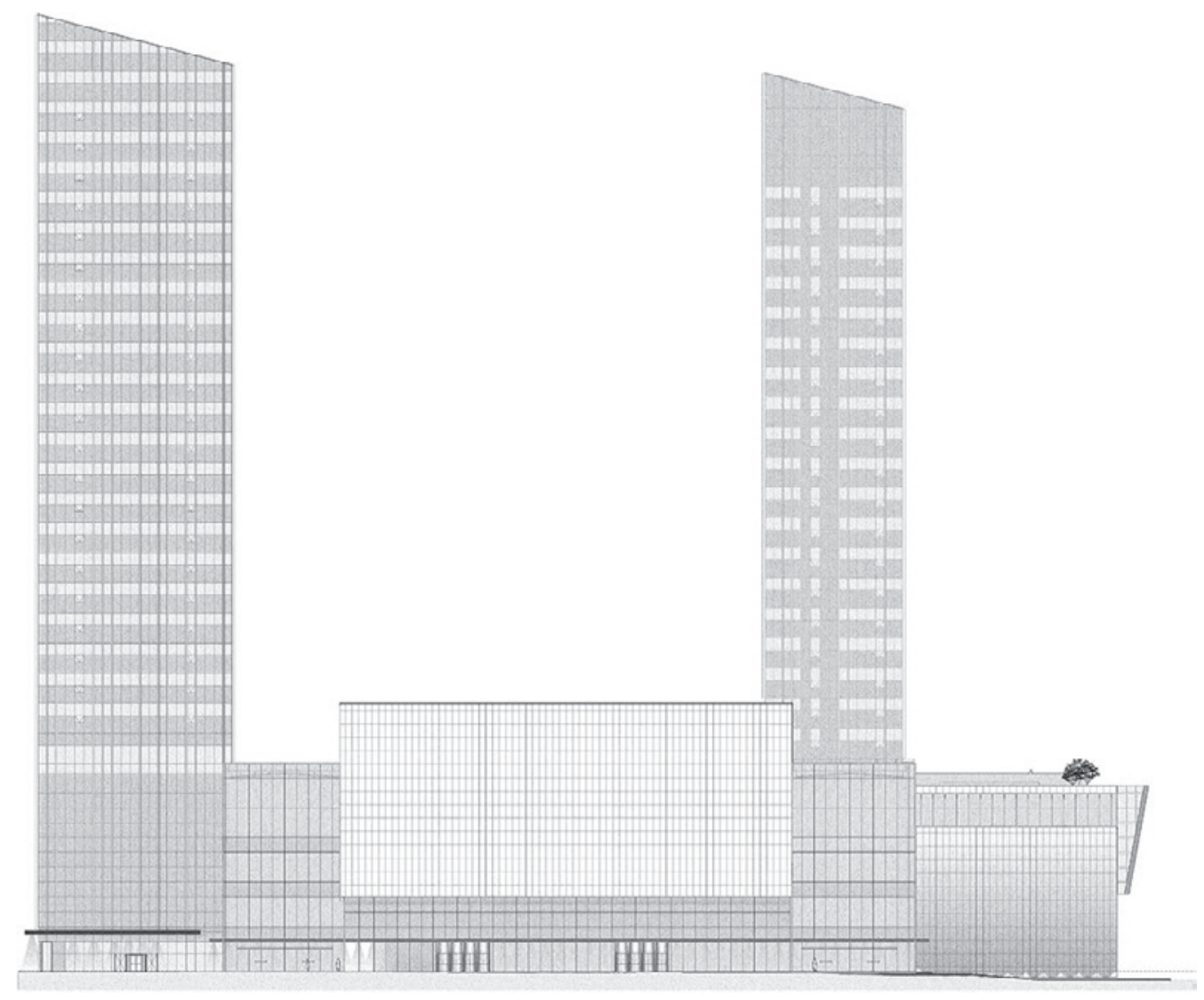

Fig 8.63. Arquitectonica, complexo WTJK (2007-2014). Elevação da rua Chedid Jafet. Sem escala. Fonte: Gelinski, "Megacomplexo abriga torres e shopping", Finestra, n. 79.

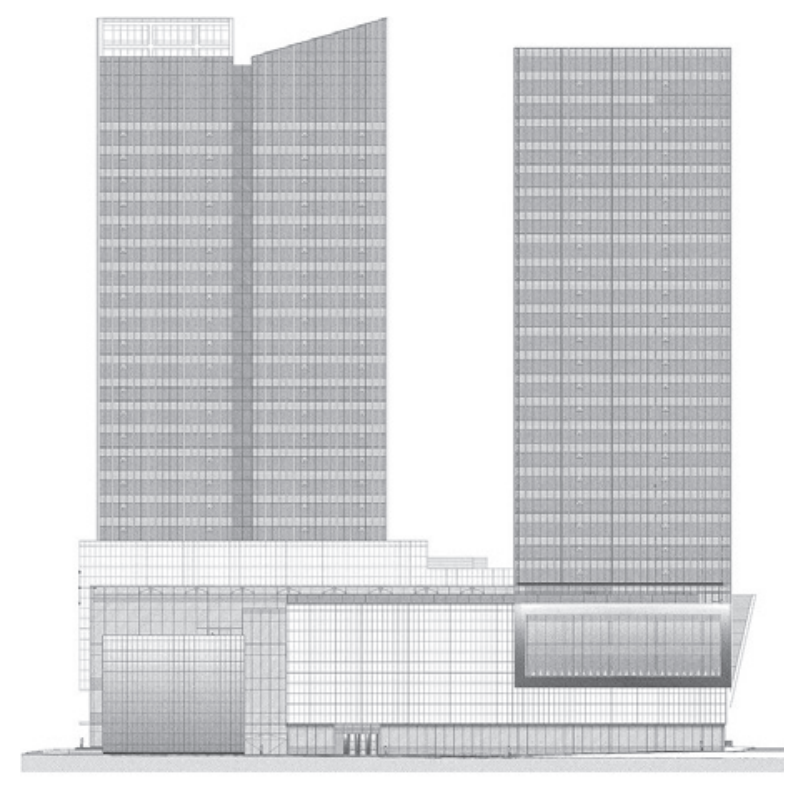

Fig 8.64. Arquitectonica, complexo WTJK (2007-2014). Elevação da avenida Juscelino Kubitschek. Sem escala. Fonte: Gelinski, "Megacomplexo abriga torres e shopping", Finestra, n. 79. 

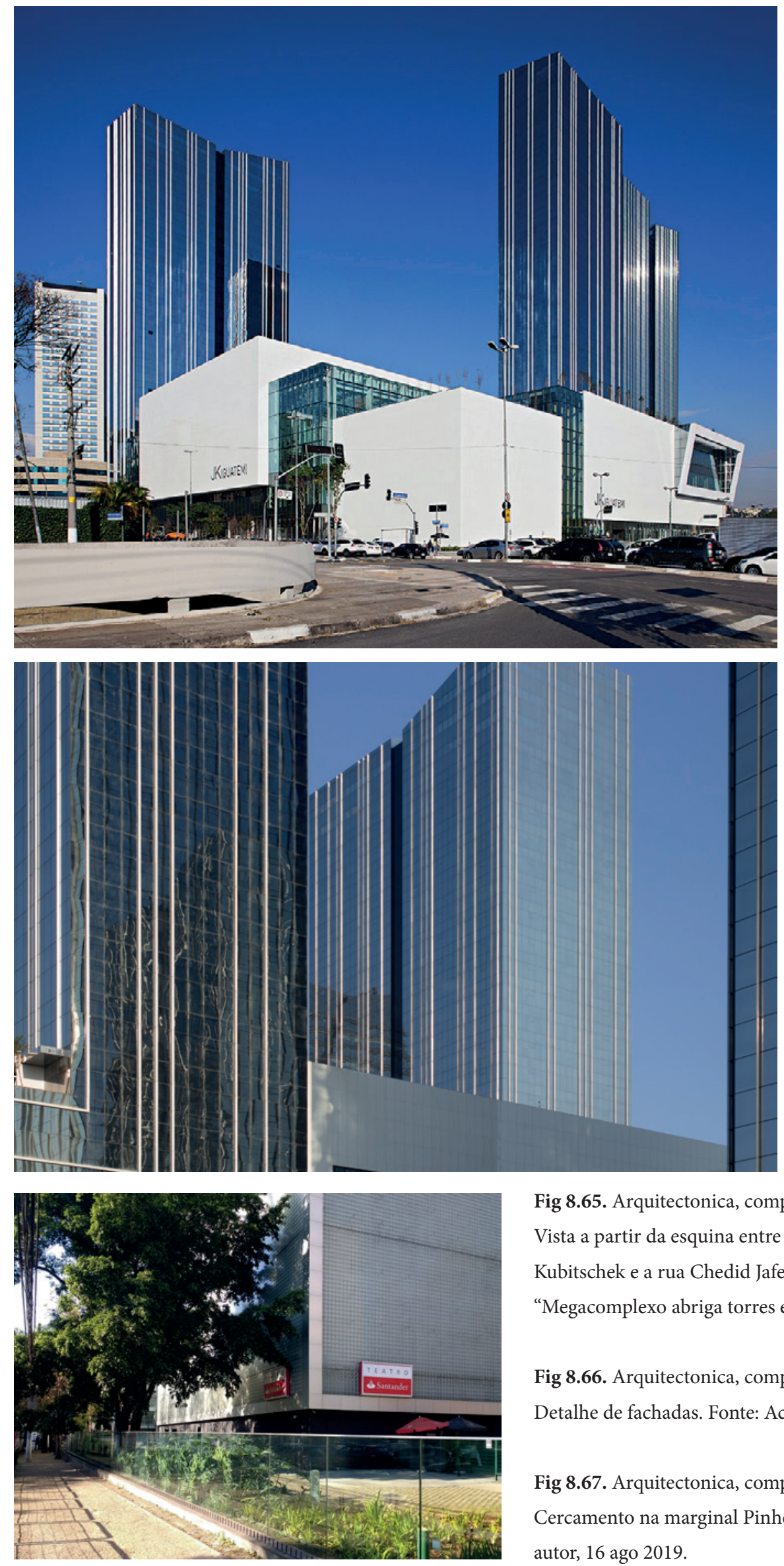

Fig 8.65. Arquitectonica, complexo WTJK (2007-2014). Vista a partir da esquina entre a avenida Juscelino Kubitschek e a rua Chedid Jafet. Fonte: Gelinski,

"Megacomplexo abriga torres e shopping", Finestra, n. 79.

Fig 8.66. Arquitectonica, complexo WTJK (2007-2014).

Detalhe de fachadas. Fonte: Acervo do autor, 27 ago 2016.

Fig 8.67. Arquitectonica, complexo WTJK (2007-2014).

Cercamento na marginal Pinheiros. Fonte: Acervo do autor, 16 ago 2019. 
intenção de constituir um parque [fig 8.59 a 8.67]. O projeto do térreo não se integra propriamente com o Parque do Povo, situado do outro lado da rua, mas as torres estão dispostas isoladamente, de modo que todas usufruem das vistas do parque. Esse foi revitalizado por uma parceria público-privada entre a prefeitura e a incorporadora WTorre e inaugurado em $2008 .^{28} \mathrm{O}$ espaço livre que permeia o complexo é chamado de "boulevard": ${ }^{29}$ um espaço público pouco vegetado, de vias largas no mesmo nível de uma grande área de circulação de pedestres. Entretanto, esse espaço pouco lembra um boulevard. Em primeiro lugar, porque não existe multifuncionalidade das fachadas que compõem o espaço livre, nem mesmo por programas ligados ao consumo, pois os serviços e comércio encontram-se todos confinados no interior do shopping center, conforme à "filosofia indoor" 30 do Grupo Iguatemi. Em segundo lugar, porque, tal como nos conjuntos da Chucri Zaidan, o sistema de vias internas ao conjunto é tão complexo que dificilmente pode ser afirmado que o pedestre pode circular ali despreocupadamente. A flânerie dos boulevards é restrita aos espaços internos do shopping center, que acompanham a atual "tendência mundial" de corredores largos e iluminação natural..$^{31}$

A relação do complexo com o entorno é diferente daquelas dos conjuntos do setor Chucri Zaidan. Por um lado, a permeabilidade com a marginal Pinheiros é claramente negada através de um muro de meia altura complementado por um painel acrílico transparente: um limite que não está presente de modo tão abrupto em nenhum dos conjuntos analisados anteriormente. Por outro lado, nas outras ruas, a relação entre massa edificada e rua é mais próxima: na avenida Chedid Jafet, o acesso ao shopping center se dá diretamente pelo passeio público. Mesmo na Torre São Paulo, que possui um grande recuo em relação à avenida Juscelino Kubitschek, tem seu acesso percebido de forma mais clara - sobretudo quando comparada ao Rochaverá, onde os acessos só são descobertos após certa deambulação pelo parque.

\footnotetext{
28. Fernanda Ikert, “A discussão da certificação LEED na relação edifício-cidade: explorando casos brasileiros" (Dissertação (Mestrado em Urbanismo, História e Arquitetura da Cidade). Orientadora: Lisete Assen de Oliveira, Departamento de Arquitetura e Urbanismo da Universidade Federal de Santa Catarina, 2010).

29. Gilmara Gelinski, “Megacomplexo abriga torres e shopping”, Finestra, nº 79 (março de 2013).

30. Gelinski.

31. Gelinski.
} 
Por fim, o último dos empreendimentos estudados é o São Paulo Corporate Towers. Tal como o Complexo WTJK, sua autoria inicial não era de um escritório internacional, e sim de um local: mais uma vez o aflalo/gasperini arquitetos [fig 8.68 e 8.69]. A importância do terreno para as acionistas e filhas do diretor da Camargo Côrrea, proprietário de longa data do terreno, teria levado à criação de um concurso de arquitetura fechado em meados de 2009, com auxílio do aflalo/gasperini em sua montagem. Nesse sentido, ainda foi procurada a inserção do projeto em um circuito arquitetônico internacional. Segundo a arquiteta Flávia Marcondes:

Nós fizemos um estudo no terreno para esse projeto para a Camargo Côrrea. Fizemos todo o primeiro projeto de prefeitura. Com isso, a gente já estava envolvido no projeto. Foi quando as donas da Camargo [Côrrea], as acionistas, decidiram colocar um escritório de fora. Foi uma decisão delas. Acho que por conta de trazer alguma grife internacional para o projeto. Para elas, esse terreno era do pai, onde elas ajudaram a plantar algumas árvores, [então] tinha ali uma coisa de família ligada ao terreno. Elas queriam que fosse um ícone na cidade. E eu acho até que no mundo. Então por isso que elas tiveram essa vontade de ter um escritório de fora. Elas fizeram um concurso, e o César Pelli [na verdade, Rafael Pelli] ganhou. ${ }^{32}$

Segundo a arquiteta Kristin Hopkins-Klegg, diretora-associada do vitorioso Pelli Clarke Pelli (PCP) e principal fonte do projeto ouvida para a tese, ainda foram convidados para o concurso Norman Foster, SOM e Santiago Calatrava, mas um deles recusou a oferta. ${ }^{33}$ A gleba de projeto incluía uma grande área de vegetação, galpões e um edifício de vinte andares onde funcionava a antiga sede da Camargo Côrrea. O diretor Sebastião Camargo teria trabalhado com a preservação da Mata Atlântica, e, como o projeto abrigaria a nova sede da Camargo Côrrea, as árvores do complexo deveriam ser preservadas. De fato, uma das versões do aflalo/gasperini já havia sido aprovada na prefeitura e assim, para acelerar os trâmites com a prefeitura, o estacionamento no subsolo e as áreas permeáveis especificadas pelos brasileiros não poderiam ser mo-

\footnotetext{
32. Marcondes, (Diretora associada no aflalo/gasperini arquitetos), Entrevista para o autor. O desejo de criar um "ícone na cidade" estava ainda relacionado ao fato de que esse conjunto abrigaria a sede da construtora. Segundo fontes da pesquisa, o nome Camargo Côrrea Corporate Towers chegou a ser sugerido para o empreendimento, mas foi posteriormente abandonado, em razão da perda de valor de marca com a Operação Lava Jato. Entretanto, não foram encontradas evidências decisivas das complicações em torno do nome.

33. Kristin Hopkins-Clegg, (Diretora associada em Pelli Clarke Pelli), Entrevista para o autor, Telefone, 6 de junho de 2018.
} 

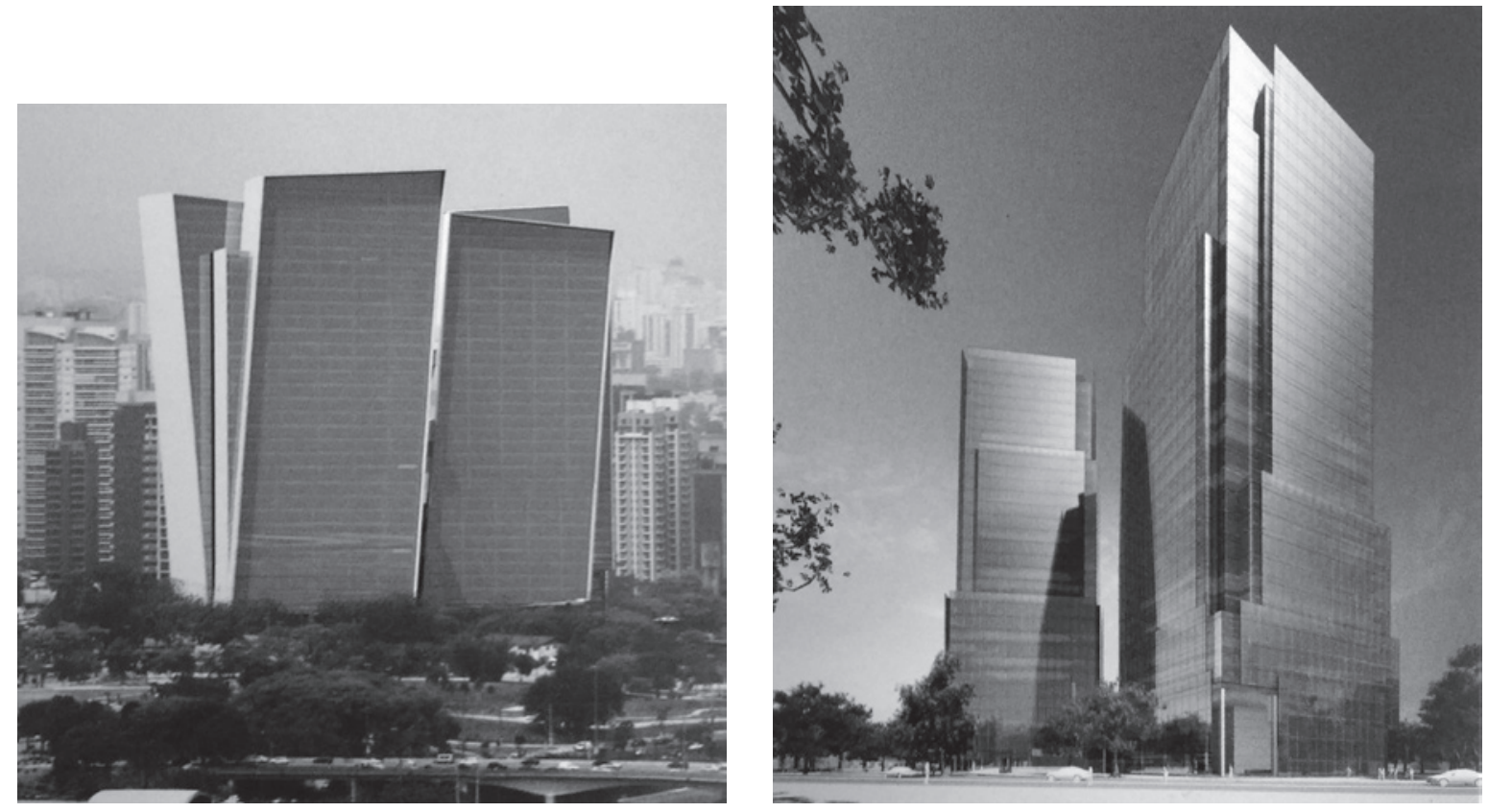

Fig 8.68 e 8.69. aflalo/gasperini arquitetos, São Paulo

Corporate Towers (2008). Versão preliminar. Fonte:

Serapião, A arquitetura de Croce, Aflalo e Gasperini, 295.

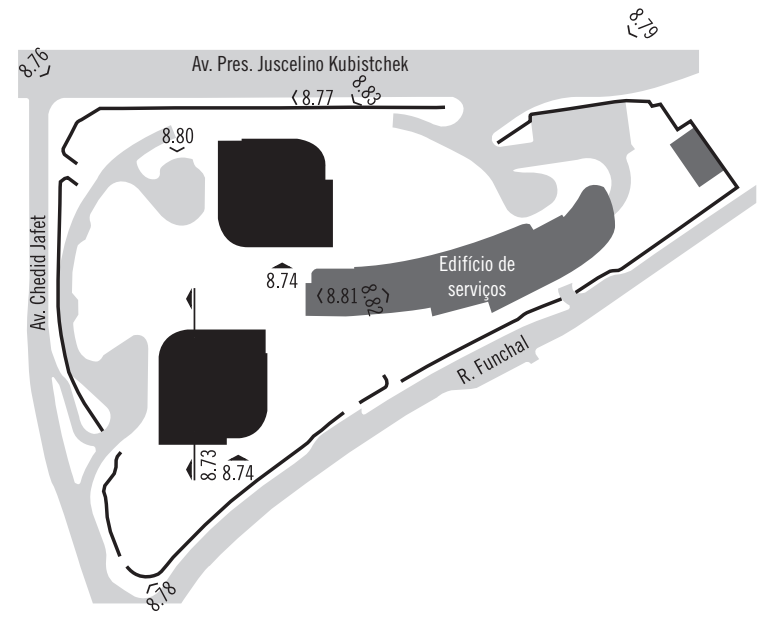

$$
\begin{aligned}
& \text { — Elevação } \\
& \text { — Fotografia } \\
& \text { — Cercamento com grades/muros } \\
& \text { - - Limite do lote com paisagismo }
\end{aligned}
$$

Fig 8.70. Diagrama do São Paulo Corporate Towers.

Elaborado pelo autor. 
dificados pelos competidores do concurso. Havia, portanto, uma área delimitada onde as torres poderiam ser implantadas. Ainda segundo o estipulado pelo concurso, essas torres seriam iguais, mas a arquitetura deveria dissimular essa semelhança.

O PCP tem dois escritórios, um em New Haven e outro em Nova York, o primeiro dirigido por Cesar Pelli e o segundo por seu filho Rafael. A responsabilidade do São Paulo Corporate Towers é da filial nova yorkina, e os autores ainda incluem o paisagismo do Balmori Associates, presidido pela mãe de Rafael Pelli, e consultoria de sustentabilidade do Atelier Ten. O projeto foi selecionado por volta de outubro de 2009 e contratado no fim do mesmo ano. A partir desse momento, passaram a colaborar o aflalo/gasperini - na coordenação com a legislação local - e o $\mathrm{CTE}$ - na certificação. O acompanhamento da obra foi feito pelo próprio $\mathrm{PCP}$, em duas viagens mensais realizadas por Hopkins-Clegg.

A solução no concurso era relativamente simples, com duas torres quadradas de cantos arredondados, permitindo vistas para o rio Pinheiros e um térreo com centro de convenções em posição semelhante à construída. As torres já eram inteiramente envidraçadas, mas possuíam uma grande quantidade de quebra-sóis na tentativa de conter o calor - três vezes mais brises do que projeto construído, segundo Hopkins-Clegg. A Camargo Côrrea reprovou as torres, mas a ênfase no paisagismo garantiu a vitória no concurso. ${ }^{34}$

Face às críticas da Camargo Côrrea, o PCP propôs a remodelação das torres, para que fossem mais esculturais, "como duas mulheres dançando", segundo a metáfora dos arquitetos [fig 8.70 a 8.84$].{ }^{35} \mathrm{O}$ volume das torres é resultado de dois procedimentos: primeiro, duas saliências no pavimento-tipo que sobem em espiral; segundo, uma pequena diminuição da largura do prisma a partir de cerca de metade de sua altura. As torres são iguais, mas os jogos geométricos associados à rotação em $90^{\circ}$ entre elas levaria à aparente diferença. Além disso, o projeto contratado eliminava a maior parte dos quebra-sóis, que conflitavam com a transparência do edifício buscada pelos incorporadores. Como o PCP tinha proposto a obtenção do LEED ${ }^{\circledR}$ Platinum, acima do LEED $^{\circledR}$ Gold exigido no concurso, a perda dos quebra-sóis foi compensada por um parapeito interno e por vidros de melhor performance.

\footnotetext{
34. Marcondes, (Diretora associada no aflalo/gasperini arquitetos), Entrevista para o autor; Hopkins-Clegg, (Diretora associada em Pelli Clarke Pelli), Entrevista para o autor.

35. Hopkins-Clegg, (Diretora associada em Pelli Clarke Pelli), Entrevista para o autor.
} 


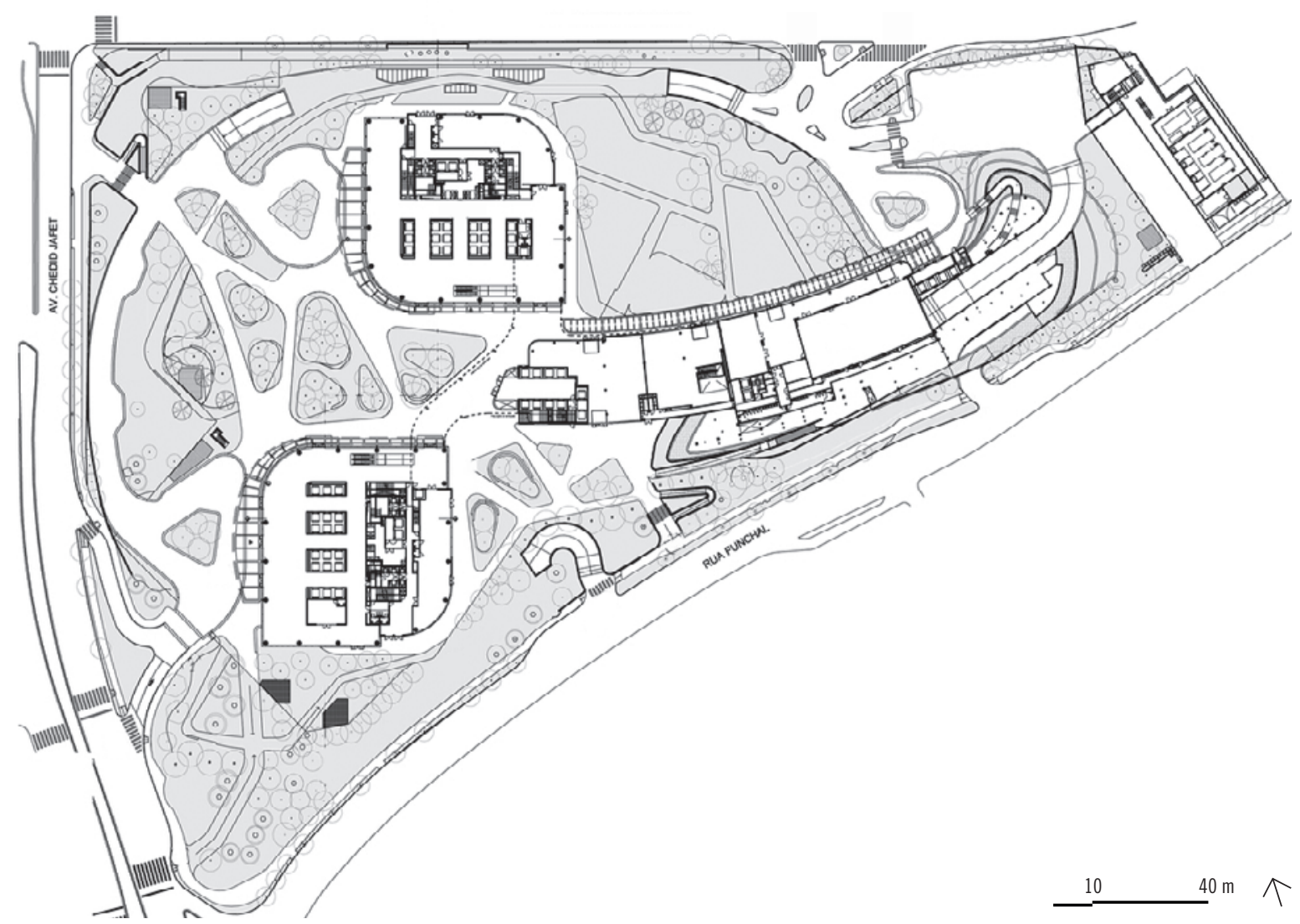

Fig 8.71. Pelli Clarke Pelli e aflalo/gasperini arquitetos, São

Paulo Corporate Towers (2008/2015). Implantação. Sem

escala. Fonte: Archdaily. 


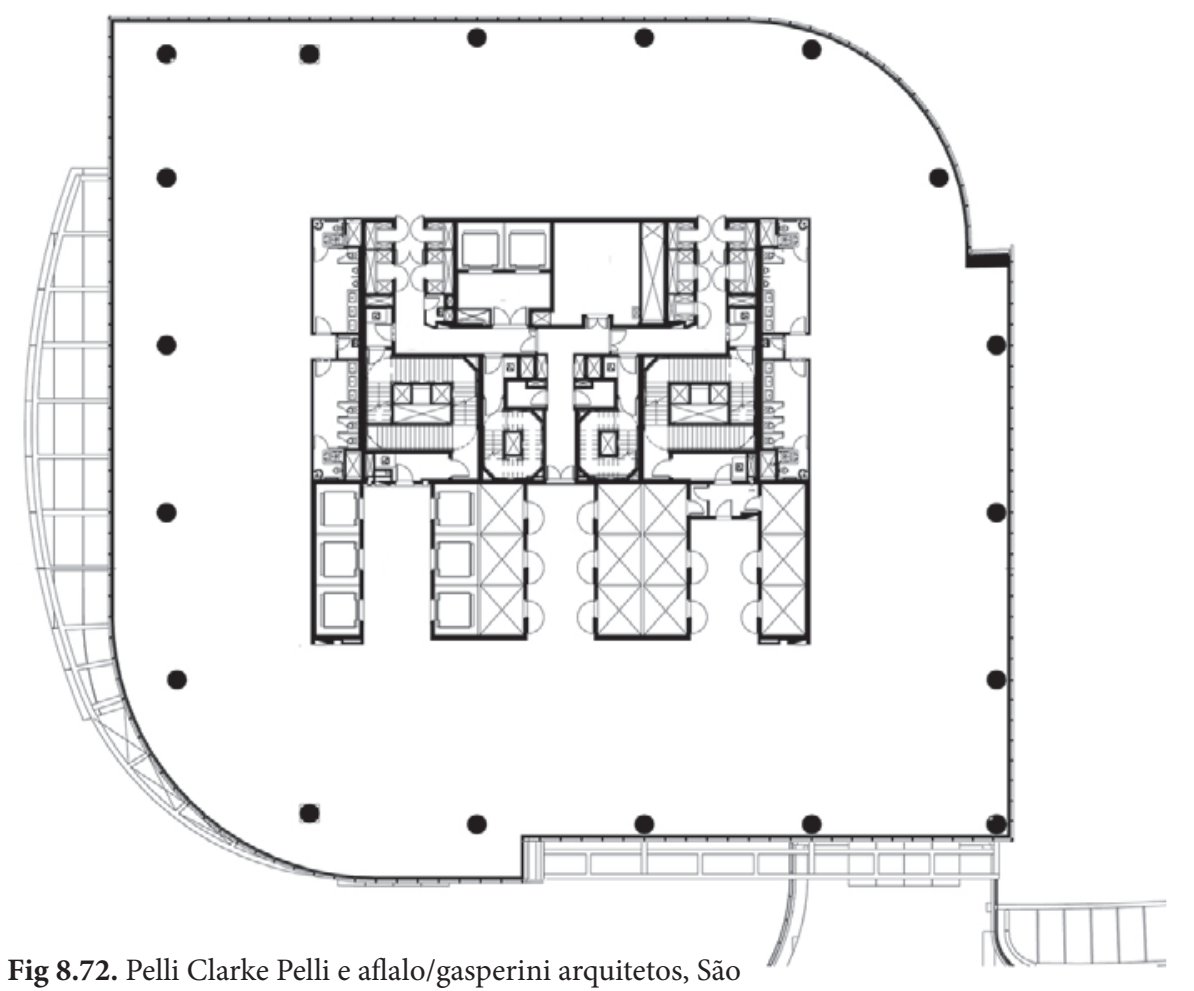

Paulo Corporate Towers (2008/2015). Pavimento-tipo. Sem escala. Fonte: Archdaily.

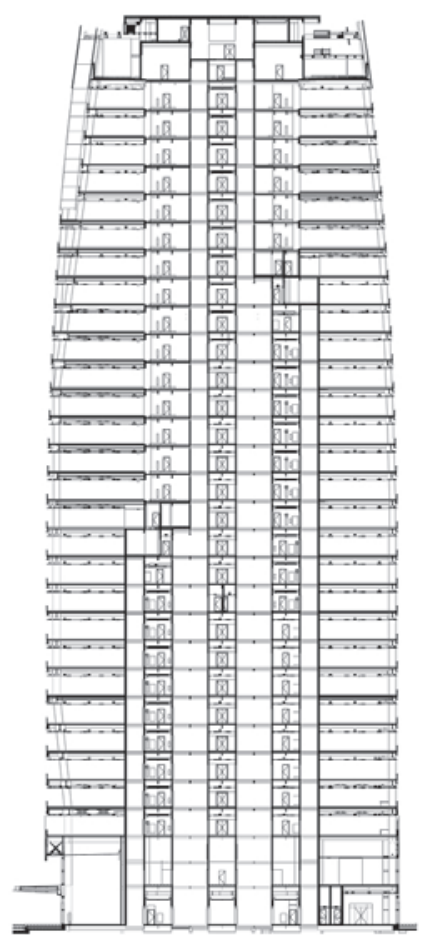

5 $15 \mathrm{~m}$

Fig 8.73. Pelli Clarke Pelli e aflalo/gasperini arquitetos, São Paulo Corporate Towers (2008/2015). Corte. Sem escala. Fonte: Archdaily.
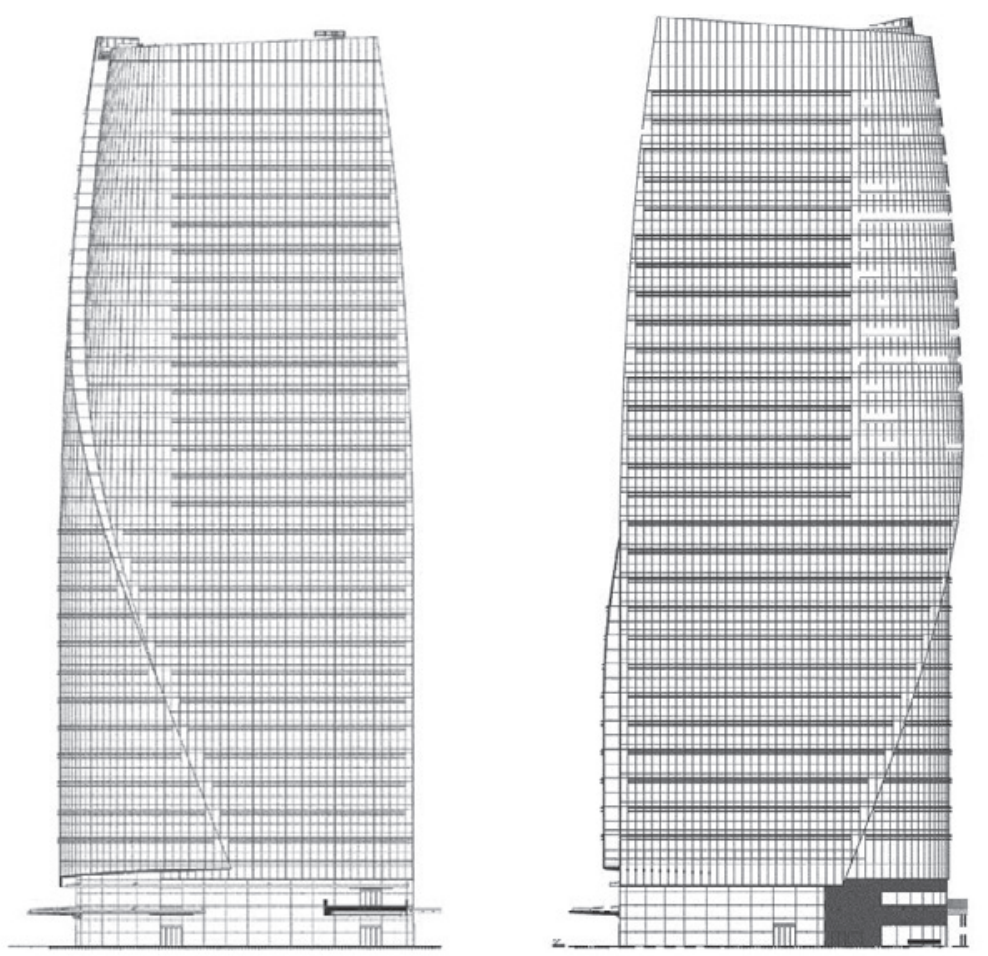

Fig 8.74. Pelli Clarke Pelli e aflalo/gasperini arquitetos, São Paulo Corporate Towers (2008/2015). Elevações. Sem escala. Fonte: Gelinski, “Torres de Cesar Pelli na Vila Olímpia”, Finestra, n. 103. 


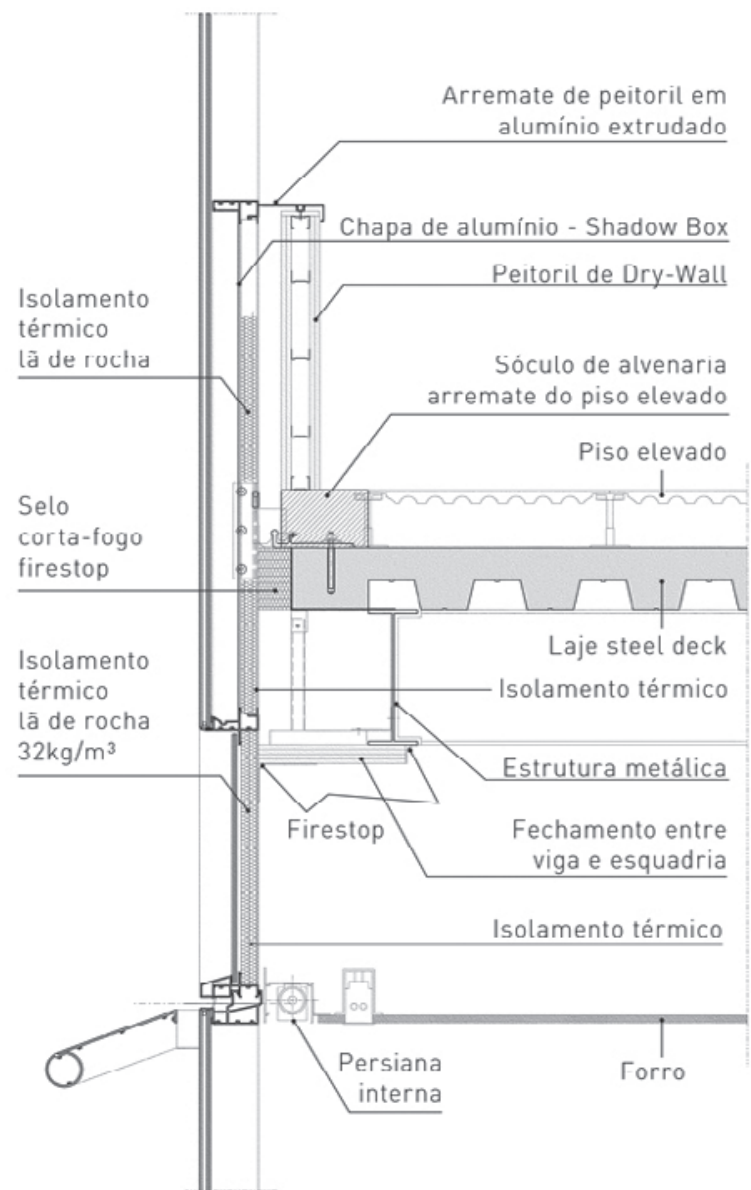

Fig 8.75. Pelli Clarke Pelli e aflalo/gasperini arquitetos, São Paulo Corporate Towers (2008/2015). Detalhe da fachada. Sem escala. Fonte: Gelinski, “Torres de Cesar Pelli na Vila Olímpia”, Finestra, n. 103.

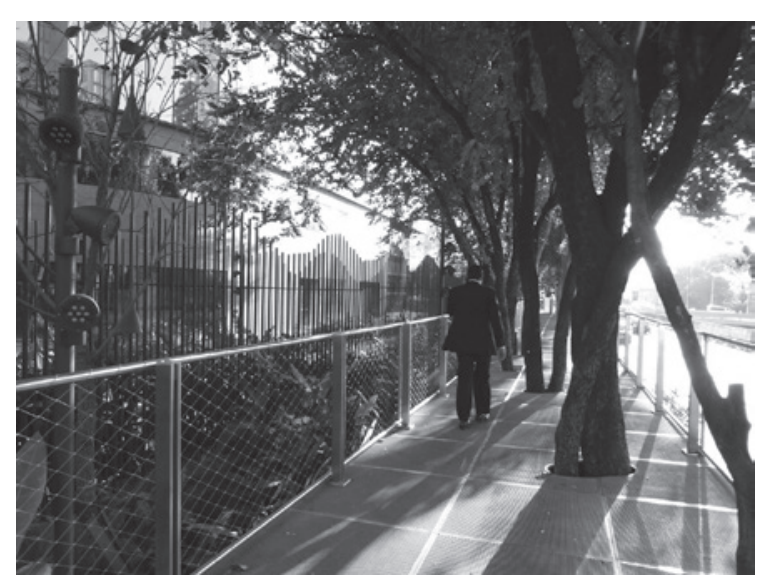

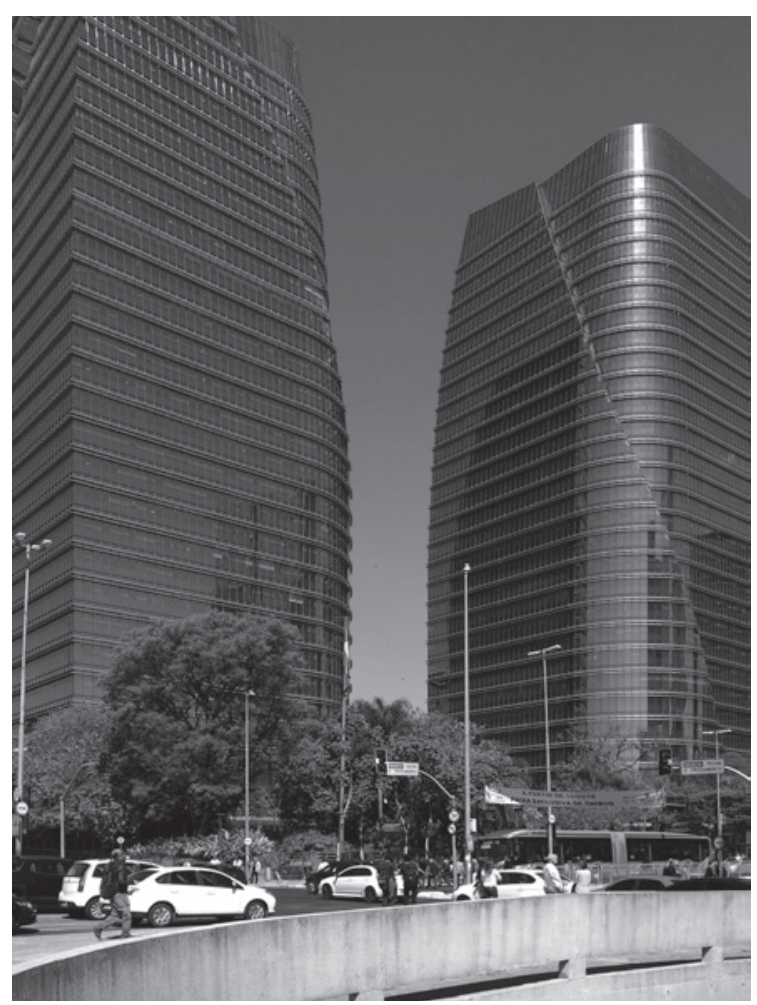

Fig 8.76. Pelli Clarke Pelli e aflalo/gasperini arquitetos, São Paulo Corporate Towers (2008/2015). Vista a partir do cruzamento entre as avenidas Juscelino Kubitschek e Chedid Jafet. Fonte: Acervo do autor, 6 set 2018.

Fig 8.77. Pelli Clarke Pelli e aflalo/gasperini arquitetos, São Paulo Corporate Towers (2008/2015). Vista da calçada elevada da avenida Juscelino Kubitschek e do cercamento do conjunto ao fundo. Fonte: Pelli Clarke Pelli via Balmori Associates, acervo online. 
Fig 8.78. Pelli Clarke Pelli e aflalo/gasperini arquitetos, São Paulo Corporate Towers (2008/2015). Detalhe do

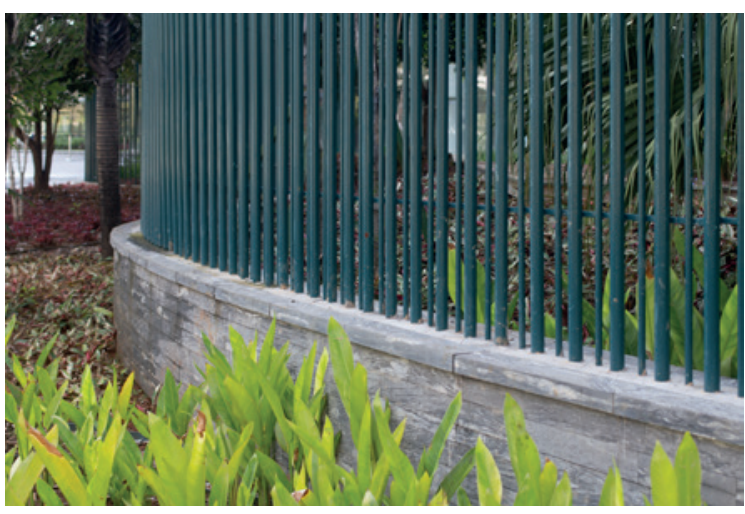

cercamento e do paisagismo. Fonte: Acervo do autor, 27 set 2016.

Fig 8.79. Pelli Clarke Pelli e aflalo/gasperini arquitetos, São Paulo Corporate Towers (2008/2015). Vista dos fundos do empreendimento a partir da passarela Marcelo Fromer. Fonte: Acervo do autor, 16 ago 2019.

Fig 8.80. Pelli Clarke Pelli e aflalo/gasperini arquitetos, São Paulo Corporate Towers (2008/2015). Vista do térreo das torres. Fonte: Pelli Clarke Pelli via Balmori Associates, acervo online.
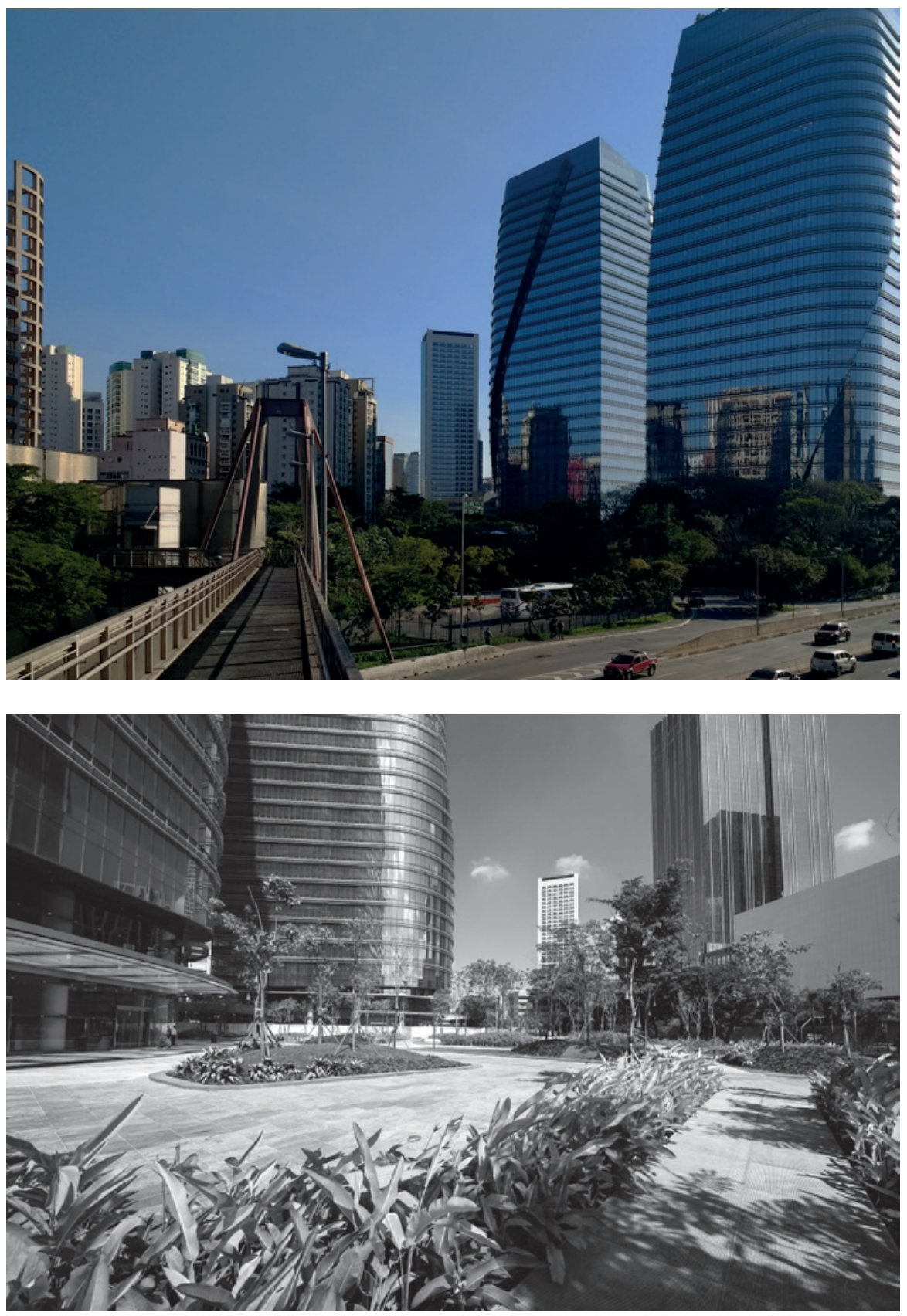


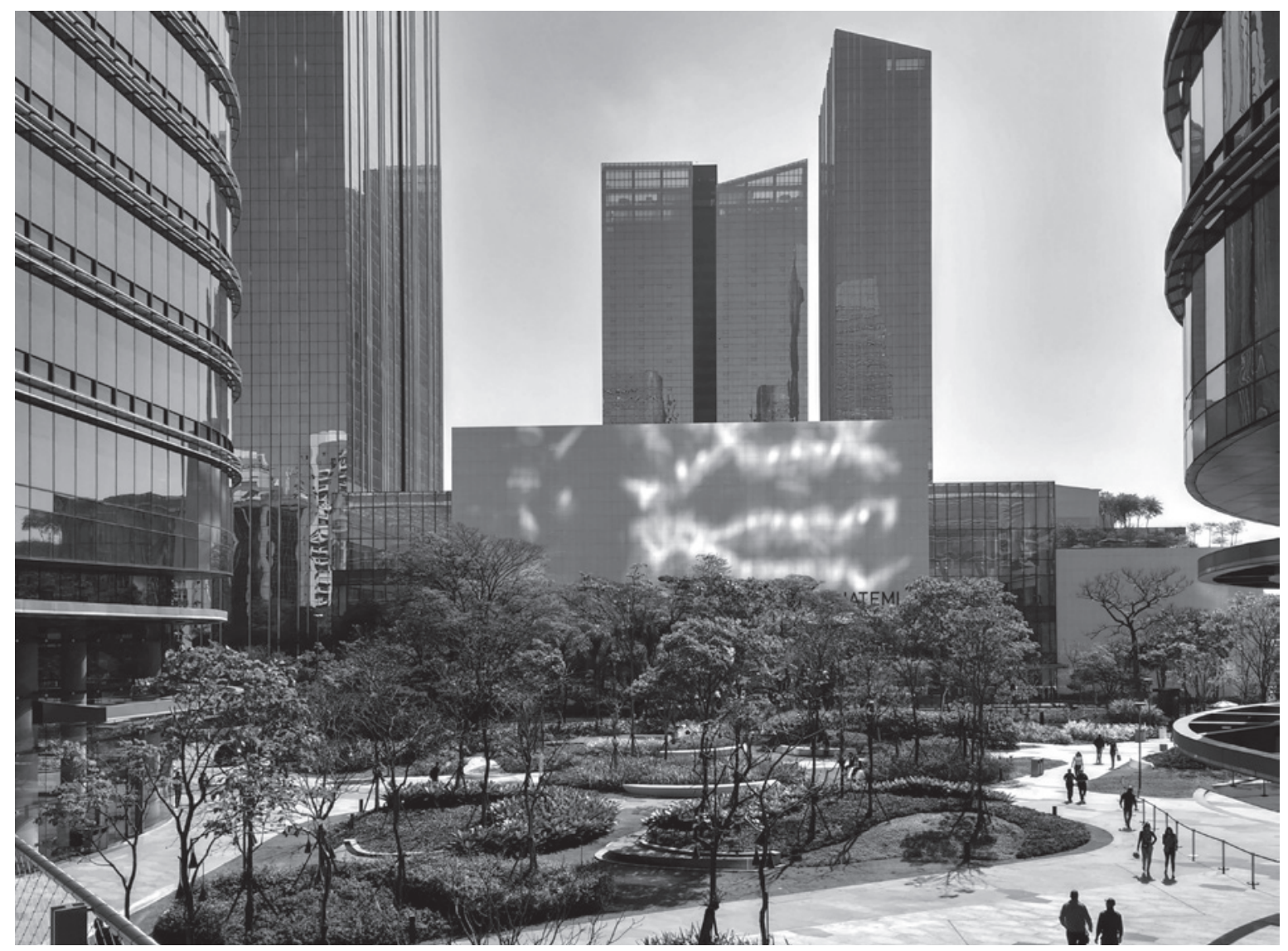

Fig 8.81. Pelli Clarke Pelli e aflalo/gasperini arquitetos,

São Paulo Corporate Towers (2008/2015). Vista a partir

do térreo superior em direção ao complexo WTJK. Fonte:

Acervo do autor, 6 set 2018.

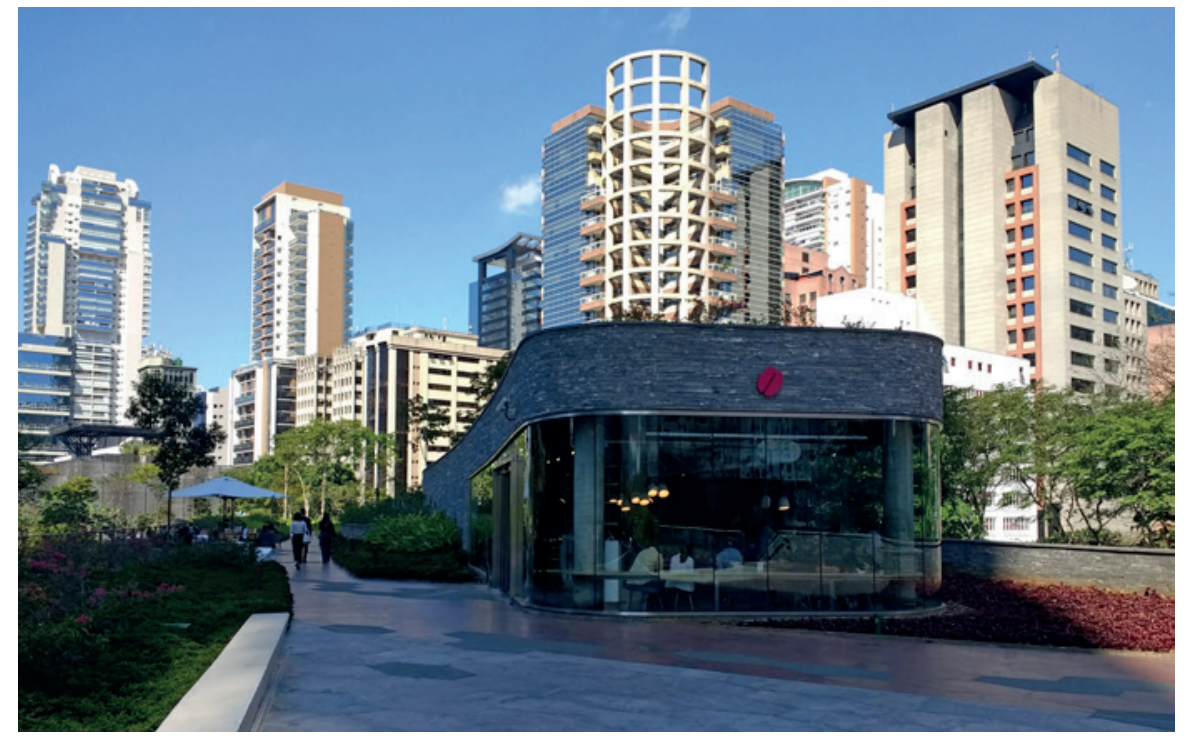

Fig 8.82. Pelli Clarke Pelli e aflalo/gasperini arquitetos,

São Paulo Corporate Towers (2008/2015). Café no térreo

superior. Ao fundo, edifício Atrium VII, de aflalo/gasperini

arquitetos. Fonte: Acervo do autor, 6 set 2018. 


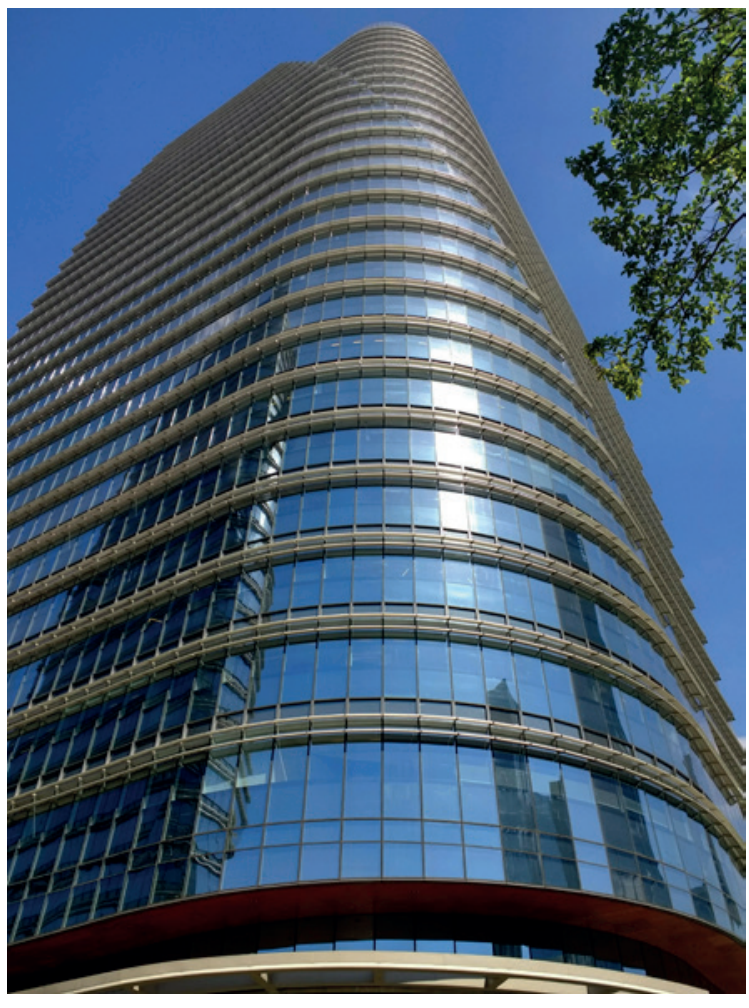

Fig 8.83. Pelli Clarke Pelli e aflalo/gasperini arquitetos, São Paulo Corporate Towers (2008/2015). Detalhe da fachada. Fonte: Acervo do autor, 6 set 2018.

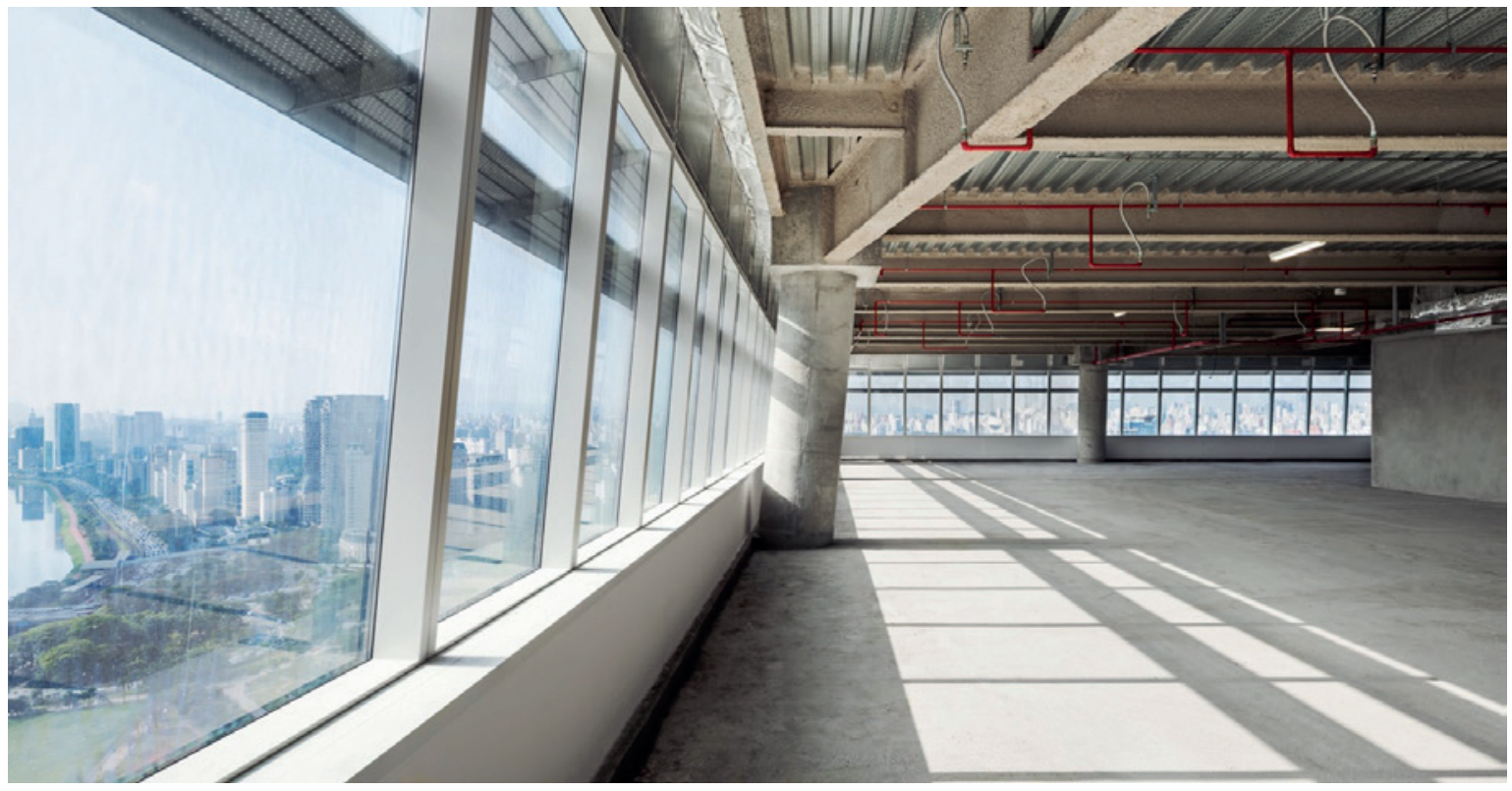

Fig 8.84. Pelli Clarke Pelli e aflalo/gasperini arquitetos, São

Paulo Corporate Towers (2008/2015). Vista do interior do pavimento-tipo. Fonte: Archdaily. 
Em relação à implantação, o projeto começou antes da inauguração do shopping JK Iguatemi, em 2012. Portanto haveria, segundo os arquitetos, pouco contexto para ser usado como referência - apenas a Torre São Paulo tinha volumetria bem delineada naquele momento [fig 8.48]. O principal contexto considerado em projeto era o das calçadas, consideradas estreitas, mas das quais a Camargo Côrrea não autorizou o alargamento ao alegar problemas de regulação com o município. A solução foi, por um lado, o recuo das grades de segurança do empreendimento em alguns pontos, com o paisagismo espraiado para fora do cercamento [fig 8.80]. Por outro lado, o passeio público na avenida Juscelino Kubitschek foi reprojetado para fugir do tráfego intenso, agressivo para o pedestre confinado em espaço estreito. A calçada foi, por isso, elevada para uma cota acima dos veículos, o que criou um deque que funciona como um parque linear próximo à copa das árvores [fig 8.77].

As grades do empreendimento, mencionadas acima, são uma peculiaridade do empreendimento face aos outros estudados. Essas grades têm um desenho sinuoso que remete às curvas das torres e são resultado de "meses" de projeto pelos paisagistas [fig 8.78]. O paisagismo ainda colabora na segurança do projeto por ser feito de forrações e arbustos que impossibilitam o abrigo de moradores de rua. Por outro lado, apesar do cercamento, esse é o projeto com maior redução da área do térreo para a circulação de veículos, dedicado quase exclusiva para pedestres.

\section{USO EMPÍRICO DOS SISTEMAS LEED® NEW CONSTRUCTION E CORE \& SHELL}

A partir das pontuações dos empreendimentos, podem ser notadas duas tendências. Em uma ponta, todos têm desempenho elevado, muitas vezes próximo ao máximo, nas categorias Sustainable Sites, Water Efficiency, Innovation e Regional Priorities - esta última, presente apenas na v3. Na outra ponta, os empreendimentos têm em geral desempenho baixo, por volta de metade dos pontos possíveis, em Energy and Atmosphere, Materials and Resources e Indoor Environmental Quality. A diferença no cumprimento das categorias pode ser explicada por questões de custo. Sistemas elétricos eficientes ou produção local de energia são dispendiosos, mesmo quando pensados desde o início do projeto; a instalação de equipamentos de eficiência hídrica, no entanto, é mais simples. Por outro lado, embora o cumprimento de créditos de baixa emissão de químicos tenha se tornado mais comum na v3, em decorrência da comercialização desses 
materiais no Brasil, há uma tendência permanente de os projetos ignorarem pontos relacionados a materiais recicláveis ou reutilizados, em razão das condições de produção de materiais no Brasil.

Mas a que se deve o baixo desempenho energético, se é esse o centro do LEED ${ }^{\circledR}$ ? Certamente, $\mathrm{o}$ alto custo da produção de energia no próprio empreendimento pode inibir o cumprimento dos créditos específicos desse tema. Mas o principal motivo do baixo desempenho dos edifícios está na sua baixa eficiência, mensurada no crédito EA.1 Optimize Energy Performance. Essa baixa eficiência é resultante não só do alto custo de sistemas mecânicos otimizados, mas também da linguagem arquitetônica: o envelopamento do edifício, que não tem fundamentação funcional. Isso porque poucos projetos cumprem - ao menos na aparência da fachada, como logo se verá o critério de WWR exigido pela norma ASHRAE 90.1: a proporção de 40\% de área transparente para $60 \%$ de áreas opacas. É preferida a solução do envelopamento total dos edifícios com vidro do que a criação de áreas opacas com melhor performance térmica. Reproduz-se aqui, portanto, a mesma lógica analisada anteriormente, da ênfase na linguagem da arquitetura em detrimento de outros aspectos de racionalidade energética.

O desenho usual das fachadas de edifícios corporativos, principalmente aqueles realizados pelo aflalo/gasperini, já teve detalhamento diferente e mesmo mais alinhado ao originalmente privilegiado pelo LEED ${ }^{\circledR}$. Na primeira fase, o Citicorp (1983/1987) [fig 8.87] e a série Atrium (I: 1986, II: 1990, III: 1993, IV a VI: 1995) [fig 8.88] utilizavam grelhas externas, por vezes distanciadas do pano de vidro, por vezes integradas ao plano da fachada. Tal solução revela a tectônica do edifício mesmo em torres de grande altura e, como aponta a arquiteta Flávia Marcondes, sombreia a fachada e reduz a carga térmica recebida. ${ }^{36}$ Dentre os edifícios certificados pelo LEED ${ }^{\curvearrowleft}$ o Eldorado Business Tower (1998-2002/2007, CS v2) [fig 3.15], o primeiro edifício laureado com o nível Platinum na América Latina, é um herdeiro dessa solução e emprega o WWR exato exigido pela ASHRAE $90.1 .^{37}$

Já na segunda fase, a partir da década de 2000, as fachadas perderam a espessura e eventuais jogos de sombra com grelhas e quebra-sóis em prol da planaridade da superfície do volu-

36. Marcondes, (Diretora associada no aflalo/gasperini arquitetos), Entrevista para o autor.

37. Nanci Corbioli, "Projetos levam em conta custo operacional e impacto ambiental”, Projeto Design, outubro de $2007,72$. 


\begin{tabular}{|c|c|c|c|c|c|c|c|c|c|}
\hline \multirow[b]{2}{*}{ \# } & \multirow[b]{2}{*}{ Categorias e créditos } & \multirow[b]{2}{*}{ Máx. } & \multicolumn{4}{|c|}{ Rochaverá Corporate Towers } & \multicolumn{3}{|l|}{ WTJK } \\
\hline & & & Torre A & Torre B & Torre C & Torre D & $\begin{array}{l}\text { Torre S. } \\
\text { Paulo }\end{array}$ & Torre D & Torre E \\
\hline SS & Sustainable Sites & 15 & 11 & 12 & 13 & 13 & 11 & 8 & 8 \\
\hline SS.1 & Site Selection & 1 & 1 & 1 & 1 & 1 & 1 & 1 & 1 \\
\hline SS.2 & Development Density and Community Connectivity & 1 & 1 & 1 & 1 & 1 & 1 & 1 & 1 \\
\hline SS.3 & Brownfield Redevelopment & 1 & 1 & 1 & 1 & 1 & 0 & 0 & 0 \\
\hline SS.4.1 & $\begin{array}{l}\text { Alternative Transportation - Public Transportation } \\
\text { Access }\end{array}$ & 1 & 1 & 1 & 1 & 1 & 1 & 1 & 1 \\
\hline SS.4.2 & $\begin{array}{l}\text { Alternative Transportation - Bicycle Storage and } \\
\text { Changing Rooms }\end{array}$ & 1 & 1 & 1 & 1 & 1 & 0 & 0 & 0 \\
\hline SS.4.3 & $\begin{array}{l}\text { Alternative Transportation - Low-Emitting and Fuel- } \\
\text { Efficient Vehicles }\end{array}$ & 1 & 0 & 0 & 1 & 1 & 1 & 0 & 0 \\
\hline SS.4.4 & Alternative Transportation - Parking Capacity & 1 & 1 & 1 & 1 & 1 & 1 & 0 & 0 \\
\hline SS.5.1 & Site Development - Protect or Restore Habitat & 1 & 0 & 0 & 0 & 0 & 1 & 1 & 1 \\
\hline SS.5.2 & Site Development - Maximize Open Space & 1 & 1 & 1 & 1 & 1 & 1 & 1 & 1 \\
\hline SS.6.1 & Stormwater Design - Quantity Control & 1 & 1 & 1 & 1 & 1 & 1 & 0 & 0 \\
\hline SS.6.2 & Stormwater Design - Quality Control & 1 & 0 & 0 & 0 & 0 & 0 & 0 & 0 \\
\hline SS.7.1 & Heat Island Effect - Nonroof & 1 & 1 & 1 & 1 & 1 & 1 & 1 & 1 \\
\hline SS.7.2 & Heat Island Effect - Roof & 1 & 1 & 1 & 1 & 1 & 1 & 1 & 1 \\
\hline SS.8 & Light Pollution Reduction & 1 & 0 & 1 & 1 & 1 & 0 & 0 & 0 \\
\hline SS.9 & Tenant Design and Construction Guidelines & 1 & 1 & 1 & 1 & 1 & 1 & 1 & 1 \\
\hline WE & Water Efficiency & 5 & 4 & 4 & 4 & 4 & 5 & 5 & 5 \\
\hline WE.1.1 & Water Efficient Landscaping - Reduce by $50 \%$ & 1 & 1 & 1 & 1 & 1 & 1 & 1 & 1 \\
\hline & Water Efficient Landscaping - No Potable Water Use or & & & & & & & & \\
\hline WE.1.2 & No Irrigation & 1 & 1 & 1 & 1 & 1 & 1 & 1 & 1 \\
\hline WE. 2 & Innovative Wastewater Technologies & 1 & 0 & 0 & 0 & 0 & 1 & 1 & 1 \\
\hline WE.3.1 & Water Use Reduction - 20\% Reduction & 1 & 1 & 1 & 1 & 1 & 1 & 1 & 1 \\
\hline WE.3.2 & Water Use Reduction - 30\% Reduction & 1 & 1 & 1 & 1 & 1 & 1 & 1 & 1 \\
\hline EA & Energy and Atmosphere & 14 & 6 & 9 & 9 & 9 & 3 & 4 & 4 \\
\hline EA.1 & Optimize Energy Performance & 8 & 5 & 8 & 8 & 8 & 0 & 2 & 2 \\
\hline EA.2 & On-site Renewable Energy & 1 & 0 & 0 & 0 & 0 & 0 & 0 & 0 \\
\hline EA.3 & Enhanced Commissioning & 1 & 0 & 0 & 0 & 0 & 0 & 0 & 0 \\
\hline EA.4 & Enhanced Refrigerant Management & 1 & 1 & 1 & 1 & 1 & 1 & 0 & 0 \\
\hline EA.5.1 & Measurement and Verification - Base Building & 1 & 0 & 0 & 0 & 0 & 2 & 2 & 2 \\
\hline EA.5 & Measurement and Verification - Tenant Submetering & 1 & 0 & 0 & 0 & 0 & 0 & 0 & 0 \\
\hline EA.6 & Green power & 1 & 0 & 0 & 0 & 0 & 0 & 0 & 0 \\
\hline MR & Materials and Resources & 11 & 7 & 6 & 6 & 6 & 8 & 5 & 5 \\
\hline MR.1.1 & $\begin{array}{l}\text { Building Reuse - Maintain 25\% of Existing Walls, Floors } \\
\text { and Roof }\end{array}$ & 1 & 0 & 0 & 0 & 0 & 1 & 0 & 0 \\
\hline MR.1.2 & $\begin{array}{l}\text { Building Reuse - Maintain } 50 \% \text { of Existing Walls, Floors } \\
\text { and Roof }\end{array}$ & 1 & 0 & 0 & 0 & 0 & 1 & 0 & 0 \\
\hline MR.1.3 & $\begin{array}{l}\text { Building Reuse - Maintain 75\% of Existing Walls, Floors } \\
\text { and Roof }\end{array}$ & 1 & 0 & 0 & 0 & 0 & 1 & 0 & 0 \\
\hline MR.2.1 & $\begin{array}{l}\text { Construction Waste Management - Divert 50\% from } \\
\text { Disposal }\end{array}$ & 1 & 1 & 1 & 1 & 1 & 1 & 1 & 1 \\
\hline MR.2.2 & $\begin{array}{l}\text { Construction Waste Management - Divert 75\% from } \\
\text { Disposal }\end{array}$ & 1 & 1 & 0 & 1 & 0 & 1 & 1 & 1 \\
\hline MR.3 & Materials Reuse - $1 \%$ & 1 & 0 & 0 & 0 & 0 & 0 & 0 & 0 \\
\hline
\end{tabular}




\begin{tabular}{|c|c|c|c|c|c|c|c|c|c|}
\hline \multirow[b]{2}{*}{ \# } & \multirow[b]{2}{*}{ Categorias e créditos } & \multirow[b]{2}{*}{ Máx. } & \multicolumn{4}{|c|}{ Rochaverá Corporate Towers } & \multicolumn{3}{|l|}{ WTJK } \\
\hline & & & Torre A & Torre B & Torre C & Torre D & $\begin{array}{l}\text { Torre S. } \\
\text { Paulo }\end{array}$ & Torre D & Torre E \\
\hline MR.4.1 & $\begin{array}{l}\text { Recycled Content }-10 \% \text { (Post-consumer }+1 / 2 \text { Pre- } \\
\text { consumer) }\end{array}$ & 1 & 1 & 1 & 1 & 1 & 1 & 1 & 1 \\
\hline MR.4.2 & $\begin{array}{l}\text { Recycled Content }-20 \% \text { (Post-consumer }+1 / 2 \text { Pre- } \\
\text { consumer) }\end{array}$ & 1 & 1 & 1 & 0 & 1 & 0 & 0 & 0 \\
\hline MR.5.1 & $\begin{array}{l}\text { Regional Materials - } 10 \% \text { Extracted, Processed and } \\
\text { Manufactured Regionally }\end{array}$ & 1 & 1 & 1 & 1 & 1 & 1 & 1 & 1 \\
\hline MR.5 & $\begin{array}{l}\text { Regional Materials - } 20 \% \text { Extracted, Processed and } \\
\text { Manufactured Regionally }\end{array}$ & 1 & 1 & 1 & 1 & 1 & 1 & 1 & 1 \\
\hline MR.6 & Certified Wood & 1 & 1 & 1 & 1 & 1 & 0 & 0 & 0 \\
\hline EQ & Indoor Environmental Quality & 12 & 5 & 6 & 3 & 4 & 4 & 4 & 3 \\
\hline EQ.1 & Outdoor Air Delivery Monitoring & 1 & 0 & 0 & 0 & 0 & 0 & 0 & 0 \\
\hline EQ.2 & Increased Ventilation & 1 & 1 & 1 & 0 & 0 & 1 & 1 & 0 \\
\hline & Construction Indoor Air Quality Management Plan - & & & & & & & & \\
\hline EQ.3 & During Construction & 1 & 1 & 1 & 1 & 1 & 1 & 1 & 1 \\
\hline EQ.4.1 & Low-Emitting Materials - Adhesives and Sealants & 1 & 0 & 0 & 1 & 1 & 0 & 0 & 0 \\
\hline EQ.4.2 & Low-Emitting Materials - Paints and Coatings & 1 & 0 & 0 & 0 & 0 & 0 & 0 & 0 \\
\hline EQ.4.3 & Low-Emitting Materials - Carpet Systems & 1 & 0 & 0 & 0 & 0 & 0 & 0 & 0 \\
\hline EQ.4.4 & $\begin{array}{l}\text { Low-Emitting Materials - Composite Wood and Agrifiber } \\
\text { Products }\end{array}$ & 1 & 0 & 0 & 0 & 0 & 0 & 0 & 0 \\
\hline EQ.5 & Indoor Chemical and Pollutant Source Control & 1 & 0 & 0 & 0 & 0 & 0 & 0 & 0 \\
\hline EQ.6 & Controllability of Systems - Thermal Comfort & 1 & 0 & 1 & 0 & 0 & 0 & 0 & 0 \\
\hline EQ.7 & Thermal Comfort - Design & 1 & 1 & 1 & 1 & 1 & 1 & 1 & 1 \\
\hline EQ.8.1 & Daylight and Views - Daylight $75 \%$ of Spaces & 1 & 1 & 1 & 0 & 0 & 0 & 0 & 0 \\
\hline EQ.8.2 & Daylight and Views - Views for $90 \%$ of Spaces & 1 & 1 & 1 & 0 & 1 & 1 & 1 & 1 \\
\hline ID & Innovation in Design & 5 & 4 & 5 & 5 & 5 & 5 & 5 & 5 \\
\hline ID.1 & Innovation in Design & 4 & 3 & 4 & 4 & 4 & 4 & 4 & 4 \\
\hline \multirow[t]{5}{*}{ ID. 2} & LEED Accredited Professional & 1 & 1 & 1 & 1 & 1 & 1 & 1 & 1 \\
\hline & Total & 62 & 37 & 42 & 40 & 41 & 36 & 31 & 30 \\
\hline & Nível & & Gold & Gold & Gold & Gold & Gold & Silver & Silver \\
\hline & Registro & & $\mathrm{dez} / 08$ & jul/06 & set/07 & jun/07 & jun/07 & ago/08 & ago/08 \\
\hline & Certificação & & $\mathrm{dez} / 10$ & ago/09 & out $/ 12$ & $\mathrm{mai} / 12$ & $\mathrm{dez} / 10$ & $\operatorname{mar} / 13$ & $\operatorname{mar} / 13$ \\
\hline
\end{tabular}

Tab 8.2. Pontuação dos estudos de caso certificados no LEED ${ }^{\circledR}$ CS v2. Fonte: LEED ${ }^{\circledR}$ Project Directory, 4 jan 2019. Elaborado pelo autor. 


\begin{tabular}{|c|c|c|c|c|}
\hline & & & & $\%$ \\
\hline$\#$ & Categorias e créditos & Máx. & Média & Cumprimento \\
\hline SS & Sustainable Sites & 15 & 10,13 & \\
\hline SS.1 & Site Selection & 1 & 1,00 & $100 \%$ \\
\hline SS.4.1 & Alternative Transportation - Public Transportation Access & 1 & 1,00 & $100 \%$ \\
\hline SS.7.1 & Heat Island Effect - Nonroof & 1 & 1,00 & $100 \%$ \\
\hline SS.9 & Tenant Design and Construction Guidelines & 1 & 1,00 & $100 \%$ \\
\hline SS. 2 & Development Density and Community Connectivity & 1 & 0,93 & $93 \%$ \\
\hline SS.5.2 & Site Development - Maximize Open Space & 1 & 0,86 & $86 \%$ \\
\hline SS.4.3 & Alternative Transportation - Low-Emitting and Fuel-Efficient Vehicles & 1 & 0,79 & $79 \%$ \\
\hline SS.7.2 & Heat Island Effect - Roof & 1 & 0,72 & $72 \%$ \\
\hline SS.4.2 & Alternative Transportation - Bicycle Storage and Changing Rooms & 1 & 0,66 & $66 \%$ \\
\hline SS.6.1 & Stormwater Design - Quantity Control & 1 & 0,66 & $66 \%$ \\
\hline SS.4.4 & Alternative Transportation - Parking Capacity & 1 & 0,59 & $59 \%$ \\
\hline SS.5.1 & Site Development - Protect or Restore Habitat & 1 & 0,52 & $52 \%$ \\
\hline SS.6.2 & Stormwater Design - Quality Control & 1 & 0,28 & $28 \%$ \\
\hline SS. 8 & Light Pollution Reduction & 1 & 0,28 & $28 \%$ \\
\hline SS. 3 & Brownfield Redevelopment & 1 & 0,21 & $21 \%$ \\
\hline WE & Water Efficiency & 5 & 4,24 & \\
\hline WE.3.1 & Water Use Reduction - 20\% Reduction & 1 & 1,00 & $100 \%$ \\
\hline WE.3.2 & Water Use Reduction - 30\% Reduction & 1 & 0,93 & $93 \%$ \\
\hline WE.1.1 & Water Efficient Landscaping - Reduce by $50 \%$ & 1 & 0,93 & $93 \%$ \\
\hline WE.1.2 & Water Efficient Landscaping - No Potable Water Use or No Irrigation & 1 & 0,90 & $90 \%$ \\
\hline WE. 2 & Innovative Wastewater Technologies & 1 & 0,48 & $48 \%$ \\
\hline EA & Energy and Atmosphere & 14 & 5,62 & \\
\hline EA.1 & Optimize Energy Performance & 8 & 2,97 & $79 \%$ \\
\hline EA.4 & Enhanced Refrigerant Management & 1 & 0,66 & $66 \%$ \\
\hline EA.5.1 & Measurement and Verification - Base Building & 1 & 0,79 & $66 \%$ \\
\hline EA.5 & Measurement and Verification - Tenant Submetering & 1 & 0,62 & $62 \%$ \\
\hline EA.3 & Enhanced Commissioning & 1 & 0,31 & $31 \%$ \\
\hline EA.6 & Green power & 1 & 0,28 & $28 \%$ \\
\hline EA.2 & On-Site Renewable Energy & 1 & 0,00 & $0 \%$ \\
\hline MR & Materials and Resources & 11 & 5,93 & \\
\hline MR.5.1 & $\begin{array}{l}\text { Regional Materials - } 10 \% \text { Extracted, Processed and Manufactured } \\
\text { Regionally }\end{array}$ & 1 & 0,97 & $97 \%$ \\
\hline MR.2.1 & Construction Waste Management - Divert 50\% from Disposal & 1 & 0,93 & $93 \%$ \\
\hline MR.4.1 & Recycled Content $-10 \%$ (Post-consumer $+1 / 2$ Pre-consumer) & 1 & 0,93 & $93 \%$ \\
\hline MR.5 & $\begin{array}{l}\text { Regional Materials - } 20 \% \text { Extracted, Processed and Manufactured } \\
\text { Regionally }\end{array}$ & 1 & 0,97 & $97 \%$ \\
\hline MR.2.2 & Construction Waste Management - Divert 75\% from Disposal & 1 & 0,72 & $72 \%$ \\
\hline MR.4.2 & Recycled Content $-20 \%$ (Post-consumer $+1 / 2$ Pre-consumer) & 1 & 0,59 & $59 \%$ \\
\hline MR.6 & Certified Wood & 1 & 0,59 & $59 \%$ \\
\hline MR.1.1 & Building Reuse - Maintain 25\% of Existing Walls, Floors and Roof & 1 & 0,07 & $7 \%$ \\
\hline MR.1.2 & Building Reuse - Maintain 50\% of Existing Walls, Floors and Roof & 1 & 0,07 & $7 \%$ \\
\hline MR.1.3 & Building Reuse - Maintain 75\% of Existing Walls, Floors and Roof & 1 & 0,07 & $7 \%$ \\
\hline MR.3 & Materials Reuse $-1 \%$ & 1 & 0,03 & $3 \%$ \\
\hline
\end{tabular}




\begin{tabular}{lllll}
\hline & & & \multicolumn{2}{c}{$\%$} \\
\hline EQ & Categorias e créditos & Máx. & Média & Cumprimento \\
\hline EQ.7 & Thermal Comfort - Design & $\mathbf{1 2}$ & $\mathbf{4 , 9 3}$ & \\
EQ.8.2 & Daylight and Views - Views for 90\% of Spaces & 1 & 0,90 & $90 \%$ \\
& Construction Indoor Air Quality Management Plan - During & 1 & 0,93 & $93 \%$ \\
EQ.3 & Construction & & & \\
EQ.2 & Increased Ventilation & 1 & 0,83 & $83 \%$ \\
EQ.4.1 & Low-Emitting Materials - Adhesives and Sealants & 1 & 0,79 & $79 \%$ \\
EQ.8.1 & Daylight and Views - Daylight 75\% of Spaces & 1 & 1,00 & $62 \%$ \\
EQ.6 & Controllability of Systems - Thermal Comfort & 1 & 0,21 & $21 \%$ \\
EQ.1 & Outdoor Air Delivery Monitoring & 1 & 0,17 & $17 \%$ \\
EQ.4.2 & Low-Emitting Materials - Paints and Coatings & 1 & 0,10 & $10 \%$ \\
EQ.4.3 & Low-Emitting Materials - Carpet Systems & 1 & 0,00 & $0 \%$ \\
EQ.4.4 & Low-Emitting Materials - Composite Wood and Agrifiber Products & 1 & 0,00 & $0 \%$ \\
EQ.5 & Indoor Chemical and Pollutant Source Control & 1 & 0,00 & $0 \%$ \\
\hline ID & Innovation in Design & $\mathbf{5}$ & $\mathbf{4 , 5 5}$ & \\
\hline ID.1 & Innovation in Design & 4 & 3,55 & $100 \%$ \\
ID.2 & LEED Accredited Professional & 1 & 1,00 & $100 \%$ \\
\hline & Total & $\mathbf{6 2}$ & $\mathbf{3 5 , 7 6}$ & \\
\hline
\end{tabular}

Tab 8.3. Distribuição de pontos no LEED ${ }^{\circ}$ CS v2, projetos corporativos certificados não confidenciais no Brasil. Fonte: LEED $^{\circledR}$ Project Directory, 4 jan 2019. Elaborado pelo autor. Amostra de 29 empreendimentos. Baseado em metodologia de Garde, "Sustainable by design". Cores indicam quartis de cumprimento.

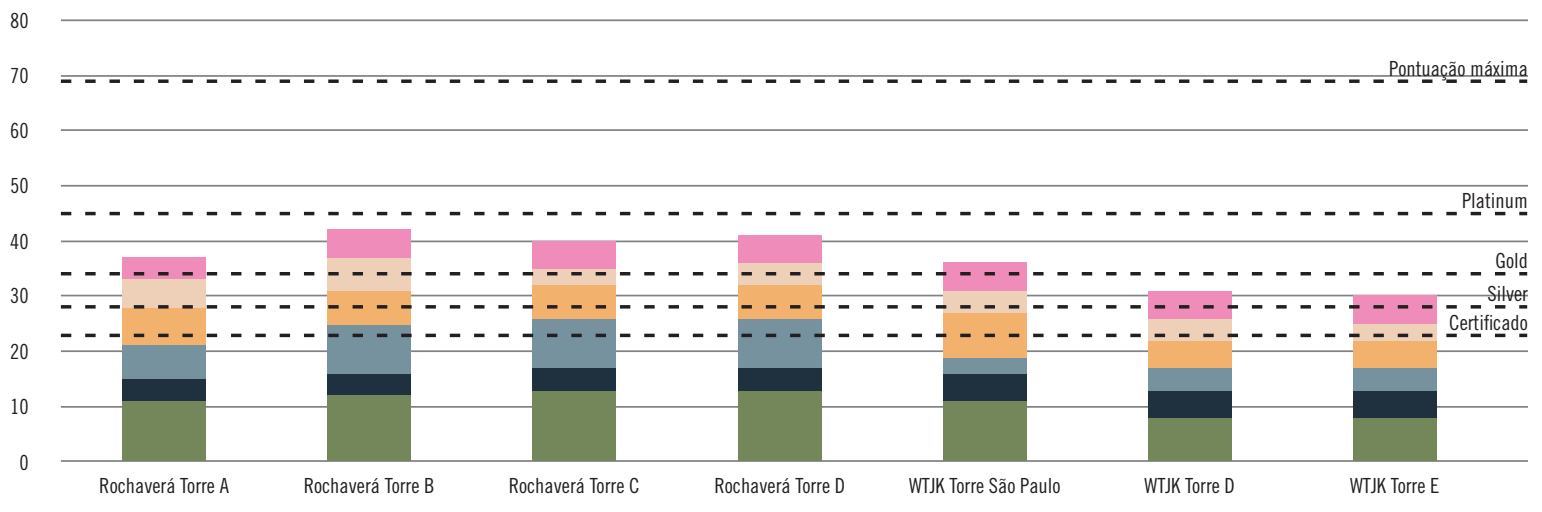

$\square$ SS WE $\square$ EA MR $\square$ EQ $\square$ ID

Fig 8.85. Distribuição de pontos nos estudos de caso certificados pelo LEED ${ }^{\oplus}$ CS v2. Fonte: LEED ${ }^{\circledR}$ Project Directory. 


\begin{tabular}{|c|c|c|c|c|c|c|c|}
\hline \# & Categorias e créditos & Máx. & $\begin{array}{l}\text { Morumbi } \\
\text { Corp }\end{array}$ & $\begin{array}{c}\text { WT } \\
\text { Morumbi }\end{array}$ & $\begin{array}{c}\text { Pq da } \\
\text { Cidade } \\
\text { (Sucupira) }\end{array}$ & $\begin{array}{c}\text { WTJK } \\
\text { Torre B }\end{array}$ & $\begin{array}{c}\text { São Paulo } \\
\text { Corporate } \\
\text { Towers }\end{array}$ \\
\hline SS & Sustainable Sites & 28 & 25 & 25 & 23 & 20 & 27 \\
\hline SS.1 & Site Selection & 1 & 1 & 1 & 1 & 1 & 1 \\
\hline SS.2 2 & Development Density and Community Connectivity & 5 & 5 & 5 & 5 & 5 & 5 \\
\hline SS. 3 & Brownfield Redevelopment & 1 & 1 & 1 & 0 & 0 & 1 \\
\hline SS.4.1 & Alternative Transportation - Public Transportation Access & 6 & 6 & 6 & 6 & 6 & 6 \\
\hline SS.4.2 & $\begin{array}{l}\text { Alternative Transportation - Bicycle Storage and Changing } \\
\text { Rooms }\end{array}$ & 2 & 2 & 2 & 2 & 0 & 2 \\
\hline SS.4.3 & $\begin{array}{l}\text { Alternative Transportation - Low-Emitting and Fuel- } \\
\text { Efficient Vehicles }\end{array}$ & 3 & 3 & 3 & 3 & 3 & 3 \\
\hline SS.4.4 & Alternative Transportation - Parking Capacity & 2 & 2 & 2 & 2 & 2 & 2 \\
\hline SS.5.1 & Site Development - Protect or Restore Habitat & 1 & 0 & 0 & 0 & 0 & 1 \\
\hline SS.5.2 & Site Development - Maximize Open Space & 1 & 1 & 1 & 1 & 0 & 1 \\
\hline SS.6.1 & Stormwater Design - Quantity Control & 1 & 1 & 1 & 0 & 1 & 1 \\
\hline SS.6.2 & Stormwater Design - Quality Control & 1 & 1 & 0 & 1 & 0 & 1 \\
\hline SS.7.1 & Heat Island Effect - Nonroof & 1 & 1 & 1 & 1 & 1 & 1 \\
\hline SS.7.2 & Heat Island Effect - Roof & 1 & 1 & 1 & 0 & 0 & 1 \\
\hline SS.8 & Light Pollution Reduction & 1 & 0 & 0 & 0 & 0 & 0 \\
\hline SS.9 & Tenant Design and Construction Guidelines & 1 & 0 & 1 & 1 & 1 & 1 \\
\hline WE & Water Efficiency & 10 & 10 & 6 & 10 & 6 & 10 \\
\hline WE.1 & Water Efficient Landscaping & 4 & 2 & 2 & 4 & 2 & 4 \\
\hline WE.2 & Innovative Wastewater Technologies & 2 & 2 & 0 & 2 & 0 & 2 \\
\hline WE.3 & Water Use Reduction & 4 & 4 & 4 & 4 & 4 & 4 \\
\hline EA & Energy and Atmosphere & 37 & 13 & 8 & 14 & 13 & 33 \\
\hline EA.1 & Optimize Energy Performance & 21 & 5 & 0 & 6 & 5 & 21 \\
\hline EA. 2 & On-site Renewable Energy & 4 & 0 & 0 & 0 & 0 & 0 \\
\hline EA.3 & Enhanced Commissioning & 2 & 2 & 0 & 2 & 2 & 2 \\
\hline EA.4 & Enhanced Refrigerant Management & 2 & 0 & 2 & 0 & 0 & 2 \\
\hline EA.5.1 & Measurement and Verification - Base Building & 3 & 6 & 3 & 6 & 3 & 3 \\
\hline EA.5 & Measurement and Verification - Tenant Submetering & 3 & 0 & 3 & 0 & 3 & 3 \\
\hline EA.6 & Green power & 2 & 0 & 0 & 0 & 0 & 2 \\
\hline MR & Materials and Resources & 13 & 6 & 6 & 6 & 10 & 7 \\
\hline MR.1 & Building Reuse - Maintain Existing Walls, Floors and Roof & 5 & 0 & 0 & 0 & 4 & 0 \\
\hline MR.2 & Construction Waste Management & 2 & 2 & 2 & 2 & 2 & 2 \\
\hline MR.3 & Materials Reuse & 1 & 0 & 0 & 0 & 0 & 0 \\
\hline MR.4 & Recycled Content & 2 & 1 & 1 & 1 & 1 & 2 \\
\hline MR.5 & Regional Materials & 2 & 2 & 2 & 2 & 2 & 2 \\
\hline MR.6 & Certified Wood & 1 & 1 & 1 & 1 & 1 & 1 \\
\hline
\end{tabular}




\begin{tabular}{|c|c|c|c|c|c|c|c|}
\hline \# & Categorias e créditos & Máx. & $\begin{array}{l}\text { Morumbi } \\
\text { Corp }\end{array}$ & $\begin{array}{c}\text { WT } \\
\text { Morumbi }\end{array}$ & $\begin{array}{c}\text { Pq da } \\
\text { Cidade } \\
\text { (Sucupira) }\end{array}$ & $\begin{array}{c}\text { WTJK } \\
\text { Torre B }\end{array}$ & $\begin{array}{c}\text { São Paulo } \\
\text { Corporate } \\
\text { Towers }\end{array}$ \\
\hline EQ & Indoor Environmental Quality & 12 & 6 & 3 & 5 & 4 & 9 \\
\hline EQ.1 & Outdoor Air Delivery Monitoring & 1 & 0 & 0 & 0 & 0 & 0 \\
\hline EQ.2 & Increased Ventilation & 1 & 1 & 0 & 1 & 1 & 1 \\
\hline EQ.3 & $\begin{array}{l}\text { Construction Indoor Air Quality Management Plan - } \\
\text { During Construction }\end{array}$ & 1 & 1 & 1 & 1 & 1 & 1 \\
\hline EQ.4.1 & Low-Emitting Materials - Adhesives and Sealants & 1 & 1 & 0 & 1 & 1 & 1 \\
\hline EQ.4.2 & Low-Emitting Materials - Paints and Coatings & 1 & 1 & 1 & 1 & 1 & 1 \\
\hline EQ.4.3 & Low-Emitting Materials - Flooring Systems & 1 & 0 & 0 & 0 & 0 & 1 \\
\hline EQ.4.4 & $\begin{array}{l}\text { Low-Emitting Materials - Composite Wood and Agrifiber } \\
\text { Products }\end{array}$ & 1 & 0 & 0 & 0 & 0 & 1 \\
\hline EQ.5 & Indoor Chemical and Pollutant Source Control & 1 & 0 & 0 & 0 & 0 & 1 \\
\hline EQ.6 & Controllability of Systems - Thermal Comfort & 1 & 0 & 0 & 0 & 0 & 0 \\
\hline EQ.7 & Thermal Comfort - Design & 1 & 1 & 0 & 0 & 0 & 0 \\
\hline EQ.8.1 & Daylight and Views - Daylight & 1 & 0 & 0 & 0 & 0 & 1 \\
\hline EQ.8.2 & Daylight and Views - Views & 1 & 1 & 1 & 1 & 0 & 1 \\
\hline ID & Innovation in Design & 6 & 5 & 6 & 5 & 4 & 6 \\
\hline ID.1 & Innovation in Design & 5 & 4 & 5 & 4 & 3 & 5 \\
\hline ID. 2 & LEED Accredited Professional & 1 & 1 & 1 & 1 & 1 & 1 \\
\hline RP & Regional Priority & 4 & 4 & 3 & 4 & 4 & 4 \\
\hline EA.1 & Optimize Energy Performance & 1 & 0 & 0 & 0 & 0 & 1 \\
\hline EA.3 & Enhanced Commissioning & 1 & 1 & 0 & 0 & 1 & 0 \\
\hline EA.5.1 & Measurement and Verification - Base Building & 1 & 0 & 0 & 1 & 0 & 0 \\
\hline EA.5.2 & Measurement and Verification - Tenant Submetering & 1 & 0 & 1 & 0 & 1 & 0 \\
\hline WE.1 & Water Efficient Landscaping & 1 & 1 & 1 & 1 & 1 & 1 \\
\hline WE.2 & Innovative Wastewater Technologies & 1 & 1 & 0 & 1 & 0 & 1 \\
\hline \multirow[t]{5}{*}{ WE.3 } & Water Use Reduction & 1 & 1 & 1 & 1 & 1 & 1 \\
\hline & Total & 110 & 67 & 57 & 67 & 61 & 96 \\
\hline & Nível & & Gold & Silver & Gold & Gold & Platinum \\
\hline & Registro & & out $/ 10$ & $\mathrm{abr} / 12$ & $\mathrm{mai} / 12$ & set/12 & nov/10 \\
\hline & Certificação & & set/14 & fev/17 & $\mathrm{dez} / 16$ & ago/17 & abr/17 \\
\hline
\end{tabular}

Tab 8.4. Pontuação dos estudos de caso certificados no LEED ${ }^{\circledR}$ CS v3. Fonte: LEED ${ }^{\circledR}$ Project Directory, 4 jan 2019. Elaborado pelo autor. 


\begin{tabular}{|c|c|c|c|c|}
\hline & & & & $\%$ \\
\hline \# & Categorias e créditos & Máx. & Média & Cumprimento \\
\hline SS & Sustainable Sites & 28 & 21,81 & \\
\hline SS.1 & Site Selection & 1 & 0,98 & $96 \%$ \\
\hline SS.4.1 & Alternative Transportation - Public Transportation Access & 6 & 5,84 & $96 \%$ \\
\hline SS.7.1 & Heat Island Effect - Nonroof & 1 & 0,97 & $96 \%$ \\
\hline SS.2 & Development Density and Community Connectivity & 5 & 4,82 & $95 \%$ \\
\hline SS.9 & Tenant Design and Construction Guidelines & 1 & 0,96 & $95 \%$ \\
\hline SS.4.3 & Alternative Transportation - Low-Emitting and Fuel-Efficient Vehicles & 3 & 2,73 & $89 \%$ \\
\hline SS.4.2 & Alternative Transportation - Bicycle Storage and Changing Rooms & 2 & 1,72 & $84 \%$ \\
\hline SS.5.2 & Site Development - Maximize Open Space & 1 & 0,81 & $81 \%$ \\
\hline SS.7.2 & Heat Island Effect - Roof & 1 & 0,73 & $73 \%$ \\
\hline SS.4.4 & Alternative Transportation - Parking Capacity & 2 & 1,10 & $54 \%$ \\
\hline SS.6.1 & Stormwater Design - Quantity Control & 1 & 0,53 & $47 \%$ \\
\hline SS.6.2 & Stormwater Design - Quality Control & 1 & 0,26 & $26 \%$ \\
\hline SS.5.1 & Site Development - Protect or Restore Habitat & 1 & 0,24 & $24 \%$ \\
\hline SS.3 & Brownfield Redevelopment & 1 & 0,09 & $9 \%$ \\
\hline SS. 8 & Light Pollution Reduction & 1 & 0,02 & $2 \%$ \\
\hline WE & Water Efficiency & 10 & 9,04 & \\
\hline WE.1 & Water Efficient Landscaping & 4 & 3,73 & $88 \%$ \\
\hline WE.3 & Water Use Reduction & 4 & 3,78 & $85 \%$ \\
\hline WE. 2 & Innovative Wastewater Technologies & 2 & 1,52 & $50 \%$ \\
\hline EA & Energy and Atmosphere & 37 & 16,14 & \\
\hline EA.5.1 & Measurement and Verification - Base Building & 3 & 2,88 & $95 \%$ \\
\hline EA.1 & Optimize Energy Performance & 21 & 6,31 & $90 \%$ \\
\hline EA.5 & Measurement and Verification - Tenant Submetering & 3 & 3,19 & $88 \%$ \\
\hline EA.3 & Enhanced Commissioning & 2 & 1,60 & $62 \%$ \\
\hline EA.6 & Green power & 2 & 1,04 & $50 \%$ \\
\hline EA.4 & Enhanced Refrigerant Management & 2 & 0,73 & $35 \%$ \\
\hline EA.2 & On-Site Renewable Energy & 4 & 0,38 & $9 \%$ \\
\hline MR & Materials and Resources & 13 & 6,46 & \\
\hline MR.5 & Regional Materials & 2 & 1,99 & $98 \%$ \\
\hline MR.2 & Construction Waste Management & 2 & 2,04 & $96 \%$ \\
\hline MR.4 & Recycled Content & 2 & 1,21 & $88 \%$ \\
\hline MR.6 & Certified Wood & 1 & 0,76 & $67 \%$ \\
\hline MR.1 & Building Reuse - Maintain Existing Walls, Floors and Roof & 5 & 0,46 & $10 \%$ \\
\hline MR.3 & Materials Reuse & 1 & 0,00 & $0 \%$ \\
\hline EQ & Indoor Environmental Quality & 12 & 5,03 & \\
\hline EQ.3 & Construction Indoor Air Quality Management Plan - During Construction & 1 & 0,90 & $88 \%$ \\
\hline EQ.4.2 & Low-Emitting Materials - Paints and Coatings & 1 & 0,88 & $88 \%$ \\
\hline EQ.4.1 & Low-Emitting Materials - Adhesives and Sealants & 1 & 0,81 & $80 \%$ \\
\hline EQ.8.2 & Daylight and Views - Views & 1 & 0,78 & $77 \%$ \\
\hline EQ.2 & Increased Ventilation & 1 & 0,76 & $74 \%$ \\
\hline EQ.7 & Thermal Comfort - Design & 1 & 0,42 & $41 \%$ \\
\hline
\end{tabular}




\begin{tabular}{lllll}
\hline & & & \multicolumn{2}{c}{$\%$} \\
\hline EQ.4.3 & Categorias e créditos & Máx. & Média & Cumprimento \\
EQ.8.1 & Daylight and Views - Daylight & 1 & 0,26 & $25 \%$ \\
EQ.1 & Outdoor Air Delivery Monitoring & 1 & 0,07 & $7 \%$ \\
EQ.6 & Controllability of Systems - Thermal Comfort & 1 & 0,05 & $5 \%$ \\
EQ.5 & Indoor Chemical and Pollutant Source Control & 1 & 0,05 & $4 \%$ \\
EQ.4.4 & Low-Emitting Materials - Composite Wood and Agrifiber Products & 1 & 0,03 & $3 \%$ \\
\hline ID & Innovation in Design & 1 & 0,03 & $2 \%$ \\
\hline ID.1 & Innovation in Design & $\mathbf{6}$ & $\mathbf{4 , 8 4}$ & \\
ID.2 & LEED Accredited Professional & 5 & 3,82 & $100 \%$ \\
\hline & Total & 1 & 1,02 & $100 \%$ \\
\hline
\end{tabular}

Tab 8.5. Distribuição de pontos no LEED ${ }^{\circ}$ CS v3, projetos corporativos certificados não confidenciais no Brasil.

Fonte: LEED ${ }^{\circledR}$ Project Directory, 4 jan 2019, com correções e elaboração do autor. Amostra de 113 empreendimentos. Baseado em metodologia de Garde, "Sustainable by design". Cores indicam quartis de cumprimento.
No CS v3, os créditos da categoria Regional Priorities foram incorporadas aos créditos fundamentais, como modo de melhor revelar o peso que cada crédito tem na pontuação final. Por esse motivo, não se deve tomar a média como uma indicação da performance dos empreendimentos, já que as bonificações de Regional Priorities são concedidas quando qualquer pontuação é realizada no crédito, mesmo se baixa.

Comparando as duas tabelas, relativas às versões CS v2 e v3, é possível notar a importância das categorias SS e WE na pontuação. A categoria EA, embora relevante, tem pontuação relativamente baixa se considerada sua centralidade no $\mathrm{LEED}^{\circledR}$, o que também pode ser dito do crédito EA.1: de 21 pontos, a média de cumprimento é 6,31 pontos nav3.

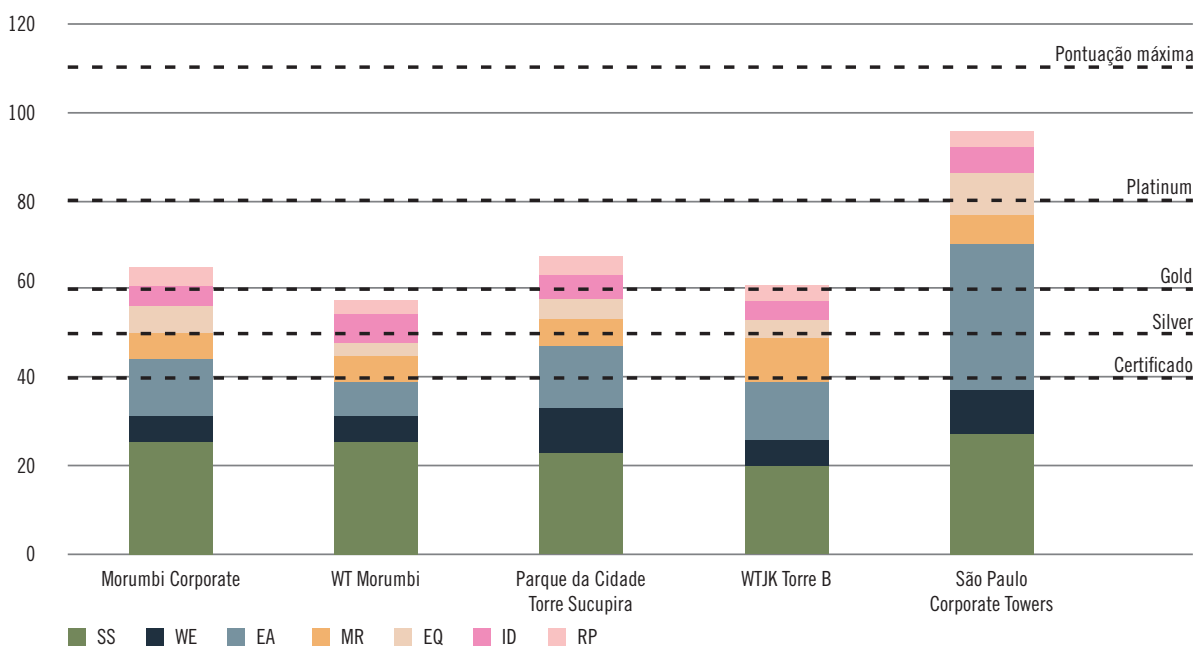

Fig 8.86. Distribuição de pontos nos estudos de caso certificados pelo $\mathrm{LEED}^{\circledR} \mathrm{CS}$ v3. Fonte: LEED ${ }^{\circledR}$ Project Directory. 


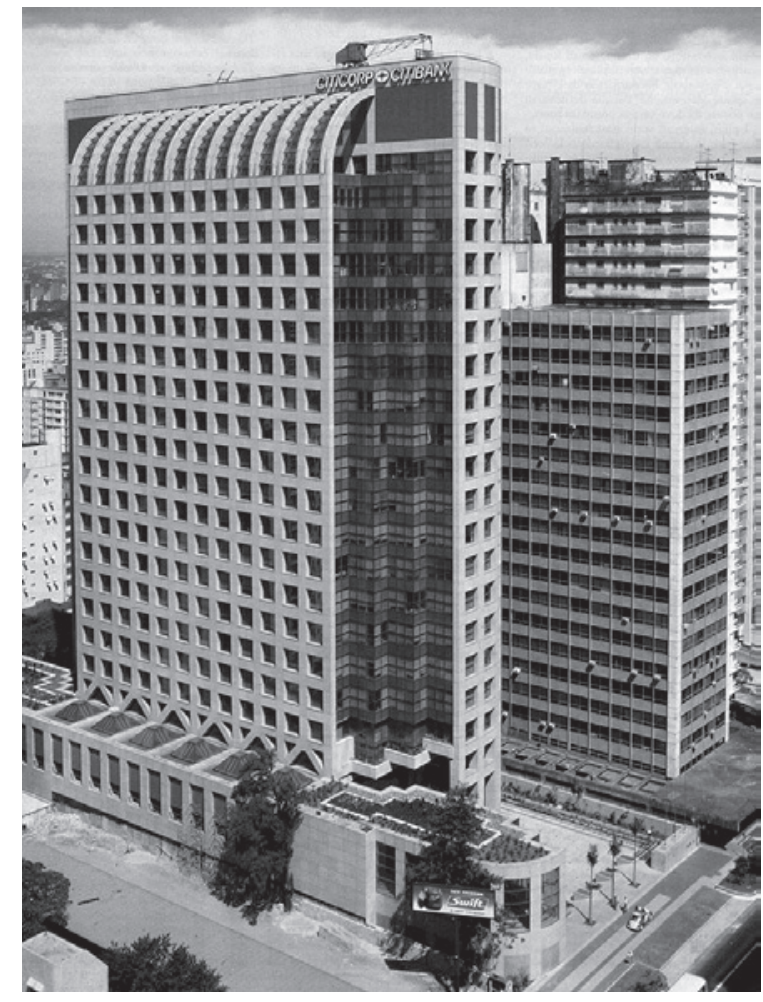

Fig 8.87. aflalo/gasperini arquitetos, Citicorp (1983/1987). Fonte: aflalo/gasperini arquitetos, acervo online.

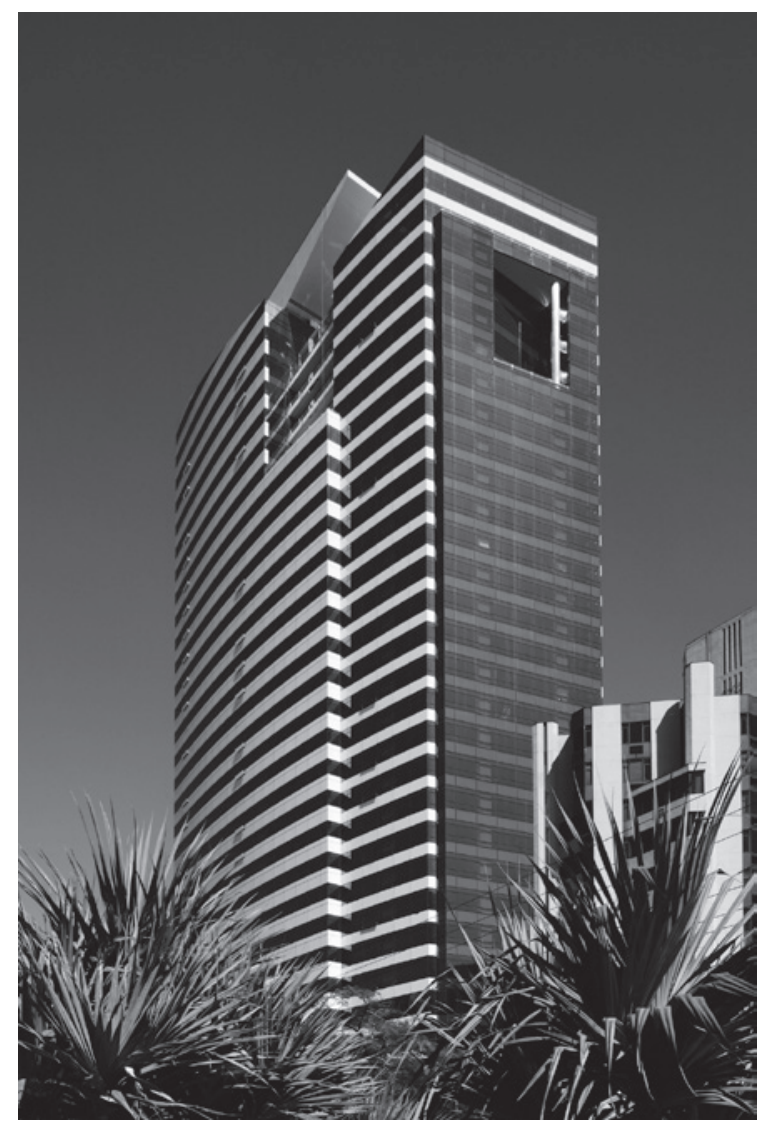

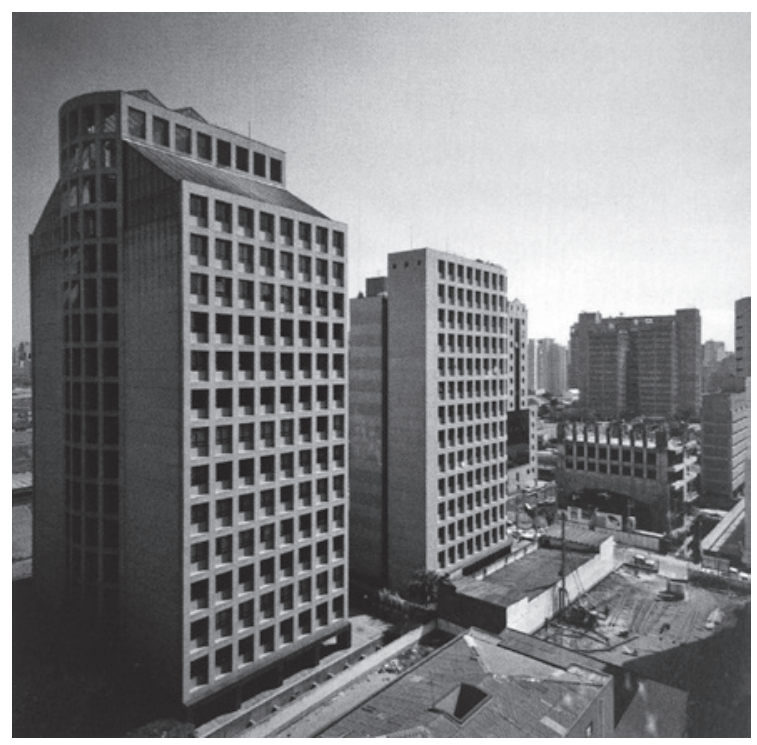

Fig 8.88. aflalo/gasperini arquitetos, Edifícios Atrium I e II (1986/- e 1990/-). Fonte: Serapião, A arquitetura de Croce, Aflalo e Gasperini, 163.

Fig 8.89. aflalo/gasperini arquitetos, Eco Berrini (2007/2011). Fonte: Daniel Ducci via aflalo/gasperini arquitetos, acervo online. 


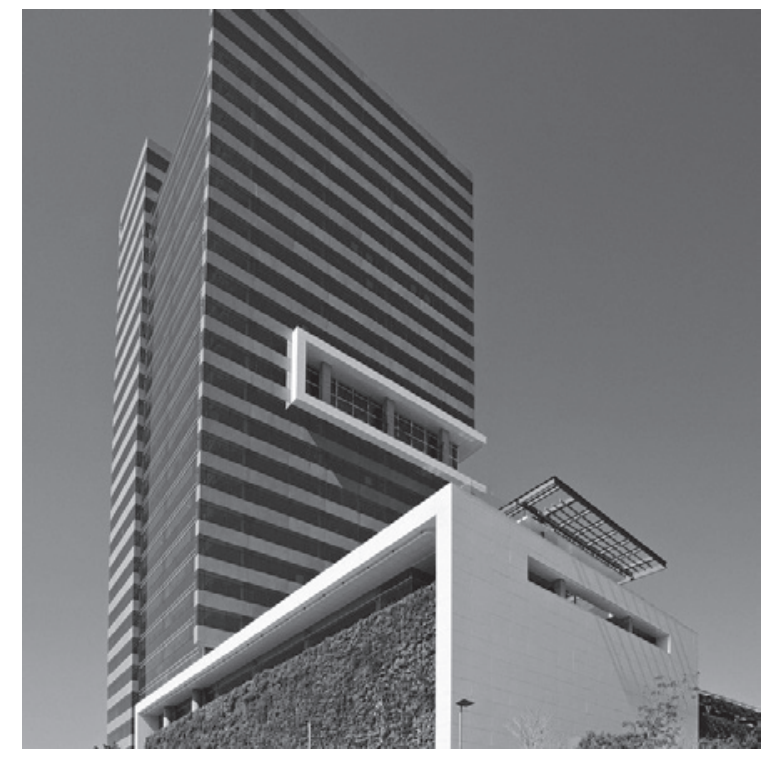

Fig 8.90. aflalo/gasperini arquitetos, edifício Odebrecht (2008/2014). Fonte: Daniel Ducci, acervo online.

Fig 8.91. KPF e aflalo/gasperini arquitetos, Infinity Tower (2008/2012). Fonte: Daniel Ducci, acervo online.

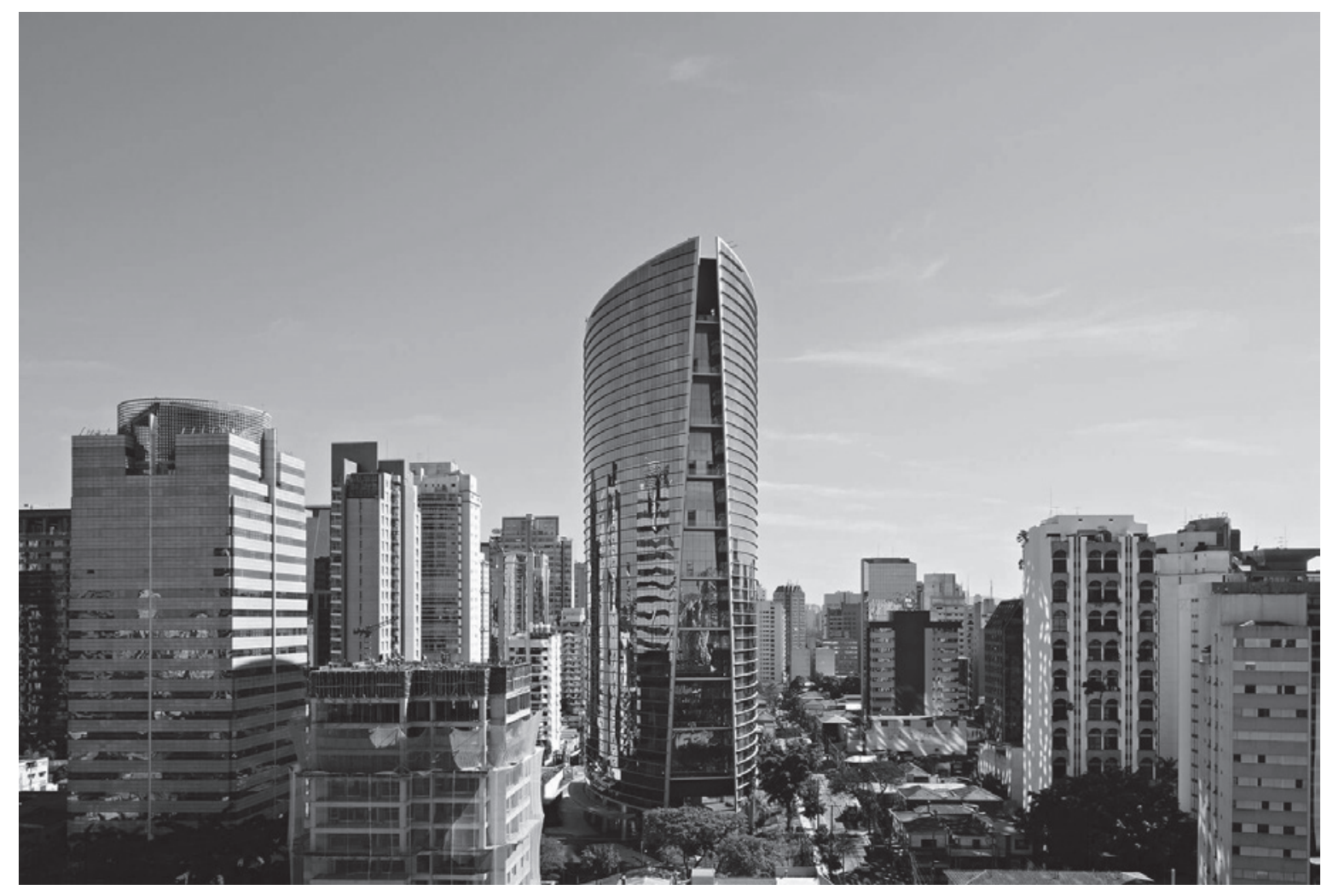



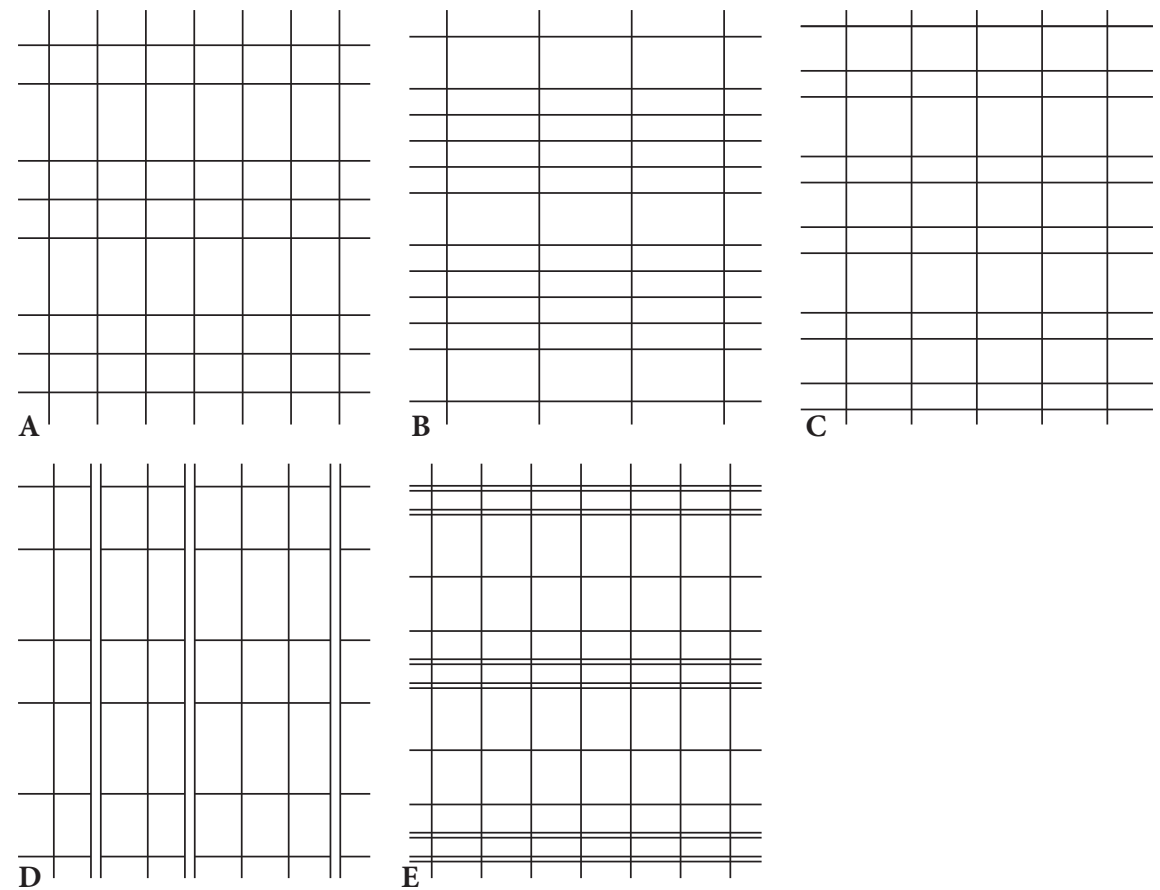

Fig 8.92. Diferentes cortinas de vidro nos estudos de caso. Sem escala. Elaborado pelo autor.
A. Rochaverá Corporate Towers
B. Morumbi Corporate
C. WT Morumbi
D. Complexo WTJK
E. São Paulo Corporate Towers

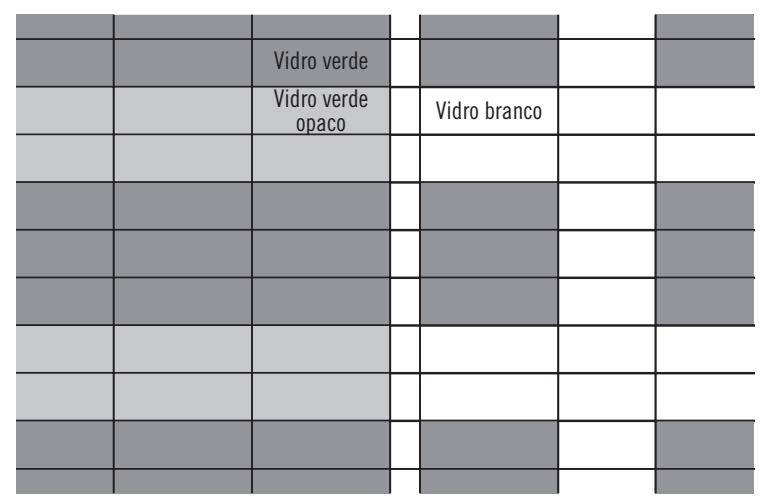

Fig 8.93. Esquema de vidros do Eldorado Business Tower. Fonte: Éride Moura, "Fachada inteligente”, Téchne, 2010. Redesenhado pelo autor. 
me em sua leitura. A superfície resultante integrava vidro e granito polido. As áreas de parapeitos e vigas na fachada passam a ser tratadas com pedra, em contraposição ao vidro empregado no vão-luz, portanto em faixas horizontais que equilibram a altura dos edifícios. De fato, o padrão horizontal em pedra e vidro é um estilema no aflalo/gasperini arquitetos, como no Eco Berrini (2007/2011, CS v2 Platinum) [fig 8.89], no edifício Odebrecht (2008/2014, CS v2 Gold) [fig 8.90], no Rochaverá e no Morumbi Corporate. Ressalte-se, contudo, que a pedra, extremamente polida, muitas vezes é tão refletora quanto o vidro, em nova simplificação dos elementos arquitetônicos.

Por fim, na terceira fase, a partir do fim da década de 2000, há a consolidação da tendência com os edifícios totalmente revestidos de vidro. Edifícios como o Morumbi Corporate, o WT Morumbi, o São Paulo Corporate Towers ou o Complexo WTJK procedem com a ocultação total de indícios construtivos. Os três primeiros são envolvidos inteiramente por uma pele de vidro, que ou marca o ritmo entre vigas e vão-luz, ou sobrepõem-se de modo autônomo em relação ao interior. Já o WTJK marca a verticalidade dos edifícios com adereços que não são de fato montantes das esquadrias, pois seu ritmo irregular revela a ausência de papel estrutural - de modo muito diferente, portanto, dos montantes seriados da fachada miesiana típica.

As cortinas de vidro sem aberturas - janelas que se abrem para o exterior - já inconvenientes no clima nova yorkino do Lever House, a tal ponto de deflagrarem um processo de proibição pela legislação municipal, ${ }^{38}$ são contradições ainda maiores nos trópicos paulistanos. Por essa razão, os edifícios criam recursos para diminuir a carga térmica apesar da sua aparente transparência total. O recurso mais utilizado e fácil é a especificação de vidros de alta performance térmica. Mas há outros recursos mais diretamente relacionados ao projeto. Um deles é a criação de brises de pouca profundidade marcando horizontais sem interferir na leitura uniforme do envelope do edifício, como no São Paulo Corporate Towers ou no Infinity Tower (2008/2012, CS v3 Gold), este último de KPF e aflalo/gasperini [fig 8.91]. Esses brises são aplica-

\footnotetext{
38. Eleanor Gibson, "New York City mayor moves to ban glass skyscrapers as part of Green New Deal”, Dezeen, 24 de abril de 2019, https://www.dezeen.com/2019/04/24/ban-glass-skyscrapers-new-york-green-new-deal-bill-de-blasio-climatechange/?utm_term=RWRpdG9yaWFsX1RoZUNpdHlzY2FwZS0xOTA0Mjg\%3D\&utm_source=esp\&utm_medium=Email\&utm_campaign=TheCityscape\&CMP=cityscape_email; Jeffery C. Mays, "De Blasio’s 'ban' on glass and steel skyscrapers isn't a ban at all", The New York Times, 25 de abril de 2019.
} 
dos sem seus nexos de significado originais, sendo expressos como um padrão homogêneo. Isto é, ao invés de sua função original de sombreamento, que portanto requereria sua diferenciação em cada elevação, os brises dessas torres as circundam homogeneamente, à revelia da orientação solar. Outro recurso é o posicionamento de parapeitos escondidos atrás dos vidros. Seu desempenho é pior do que os parapeitos diretamente posicionados na fachada, devido à criação de pontes térmicas com os vidros, garantindo, no entanto, a aparência de transparência buscada por incorporadores. ${ }^{39} \mathrm{O}$ Rochaverá e o São Paulo Corporate Towers, por exemplo, empregam essa solução em seus panos de vidro contínuos, o que é muitas vezes perceptível pelo ritmo adotado nas esquadrias [fig 8.92].

Além da carga térmica indesejada, o vidro sobreposto a parapeitos tem ainda uma consequência na linguagem da fachada, pois o comportamento do vidro em relação à luz é diferente em vãos-luz ou quando empregado como revestimento. Por esse motivo, a arquitetura precisa responder a essa diferença para manter a aparência de uniformidade. No Eldorado Business Tower, a solução foi aplicar dois vidros verdes diferentes, um opaco como revestimento e outro transparente para o vão-luz, de modo que a tonalidade dos vidros simule homogeneidade quando vistos da rua [fig 8.93]..$^{40}$ Já no São Paulo Corporate Towers, os incorporadores pretendiam a transparência total do empreendimento, com janelas de piso a teto, o que não era possível pela carga térmica: ou eles seriam escuros, ou era necessário um parapeito interno, segundo Hopkins-Clegg. ${ }^{41}$ Como solução, foi adotada a técnica de shadow box, na qual a face onde o vidro é aplicado é pintada de preto, dando a impressão de transparência integral da fachada.$^{42}$ Esses problemas de projeto, ao surgirem como reação a medidas antissustentáveis como o envelopamento do edifício em vidro, são a contraprova da influência do LEED $^{\circledR}$ no projeto.

\footnotetext{
39. Verificar cálculos de desempenho em Cinthia Andreis, Priscila Besen, e Fernando Simon Westphal, "Desempenho energético de fachadas envidraçadas em climas brasileiros", in Anais... (XV Encontro Nacional de Tecnologia do Ambiente Construído, Maceió, 2014), 926-35, https://doi.org/10.17012/entac2014.628.

40. Cida Paiva e Jaime Silva, "Vidros vedam e criam estruturas", Finestra, junho de 2008.

41. Hopkins-Clegg, (Diretora associada em Pelli Clarke Pelli), Entrevista para o autor.

42. Hopkins-Clegg. 
Quatro torres nos estudos de caso cumprem o crédito de iluminação natural, EQ.8.1, do LEED ${ }^{\oplus}$ : as A e B do Rochaverá e as gêmeas do São Paulo Corporate Towers. Já o crédito EQ.8.2, de linhas de visão desimpedidas ao exterior, é cumprido por quase todos os projetos. Isso porque o pano de vidro garante a visão para o exterior por todos os ocupantes se aplicado um layout em meia altura. Porém, isso não é suficiente para garantir luz natural em todo o pavimento - sobretudo se consideradas as grandes dimensões das lajes dos empreendimentos. Esses interiores distantes da caixilharia e da iluminação natural são por excelência os "ambientes bem controlados" discutidos por Banham e referidos no capítulo anterior.

De fato, o critério fundamental para o dimensionamento de lajes comerciais não é a iluminação natural, mas o lease span: a medida do vão locável entre núcleo e casca do empreendimento. ${ }^{43}$ Entre os edifícios estudados, o lease span varia entre 11 e 14 metros, o que torna difícil a iluminação em áreas profundas desses pavimentos. Como referência, na opção prescritiva, mais simples, do EQ.8.1, a medida de profundidade indicada é de duas vezes a altura do ambiente, o que seria cerca de 6 metros. A altura do pé-direito e o tamanho das janelas certamente influem na iluminação do ambiente, mas o aumento de profundidade do pavimento respondendo a demandas de locação é um fator de contradição desse princípio [fig 8.94].

Seguindo o previsto na análise de uma virtualidade do sistema LEED ${ }^{\circledR}$ no capítulo anterior, os edifícios replicam o modelo de torre miesiana para a configuração do pavimento-tipo, já que a geometria em si não é objeto de restrições da norma ASHRAE 90.1. Tal como nos projetos norte-americanos do arquiteto alemão, tanto o núcleo de circulação, com elevadores e escadas, quanto o núcleo servidor, de banheiros e copas, estão centralizados na planta. Já a estrutura de pilares é periférica e disposta atrás da cortina de vidro para manter o acabamento uniforme das faces.

É particular do pavimento-tipo desses empreendimentos, por outro lado, sua grande dimensão. Como apontado por Flávia Marcondes, ${ }^{44}$ para projetos a partir de meados dos anos 2000, as empresas passaram a buscar lajes maiores, de modo que pudessem se alojar em um único andar, e não em vários. De fato, as áreas dos pavimentos-tipo dos primeiros projetos de Carlos

\footnotetext{
43. Marcondes, (Diretora associada no aflalo/gasperini arquitetos), Entrevista para o autor; Maki e Nogueira, (Arquitetos no aflalo/gasperini arquitetos), Entrevista para o autor.

44. Marcondes, (Diretora associada no aflalo/gasperini arquitetos), Entrevista para o autor.
} 


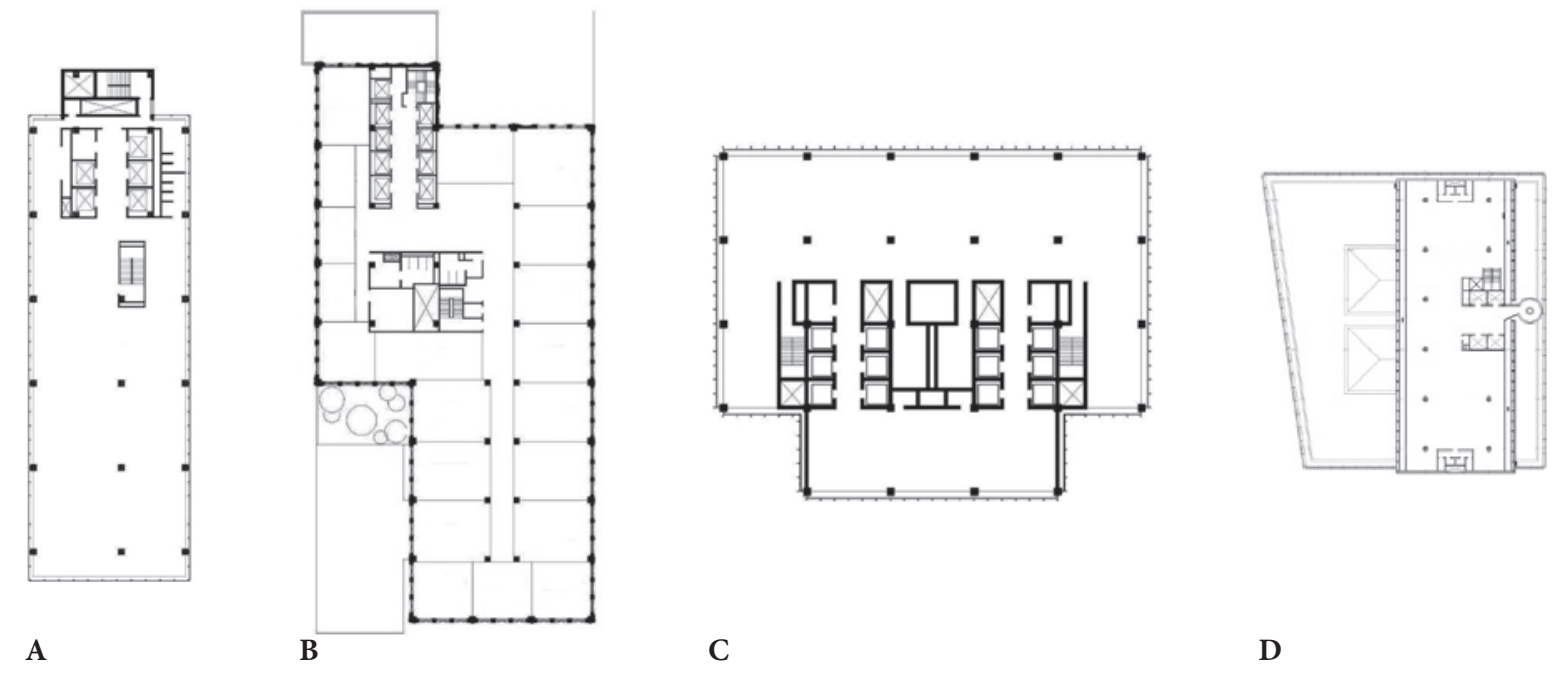

E
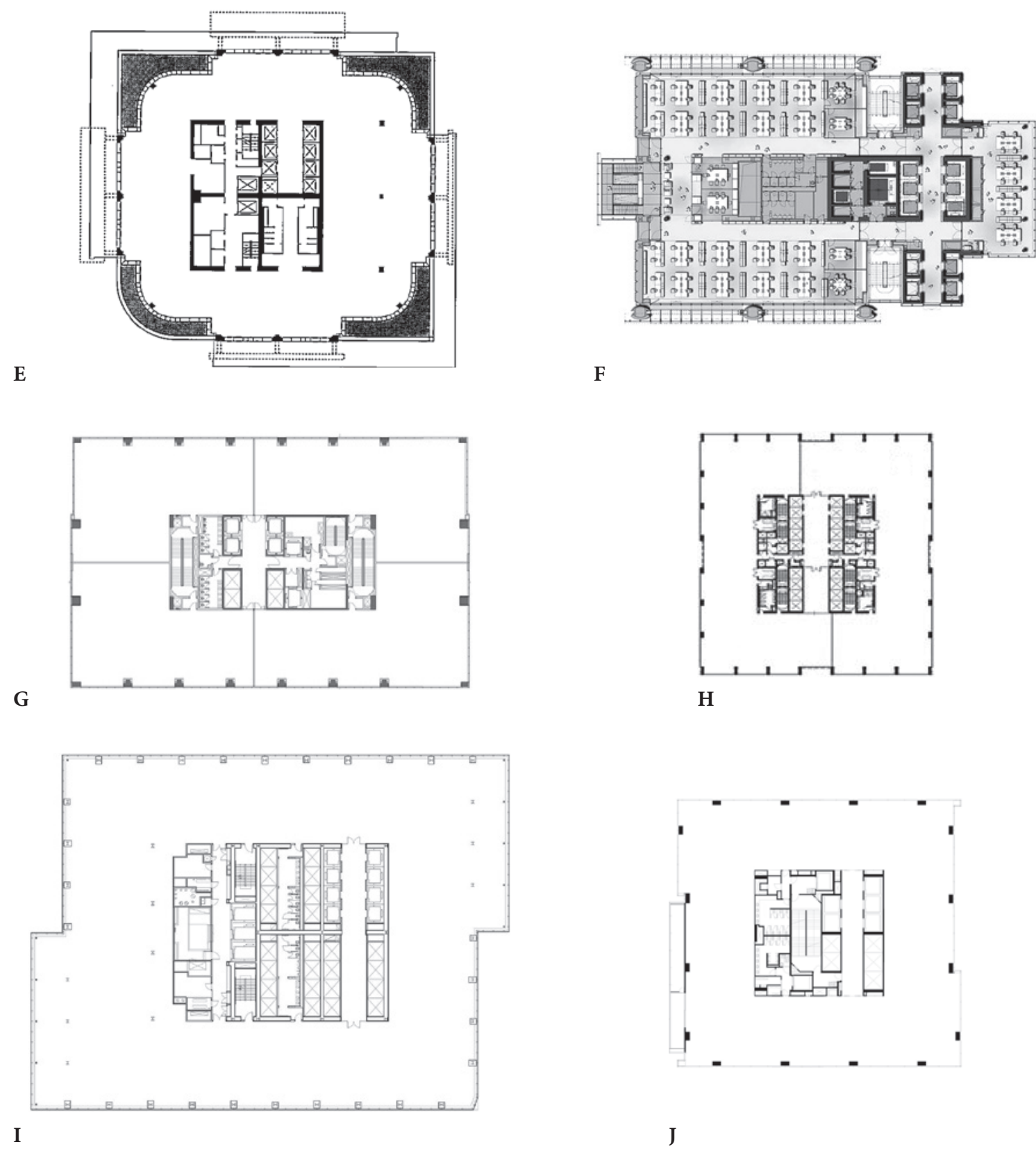


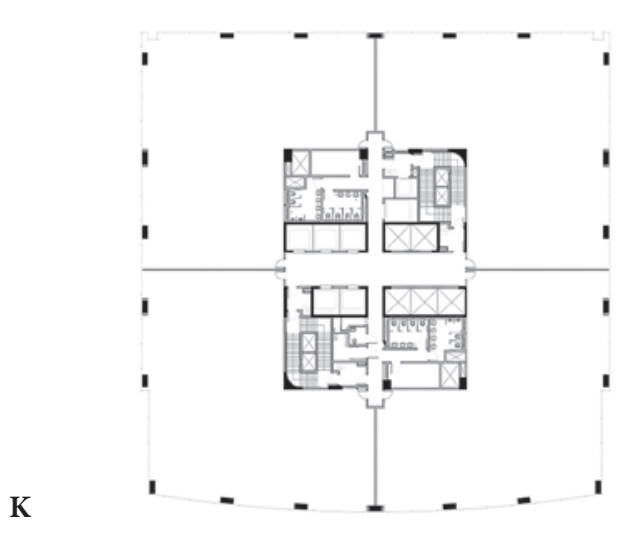

$\mathbf{L}$

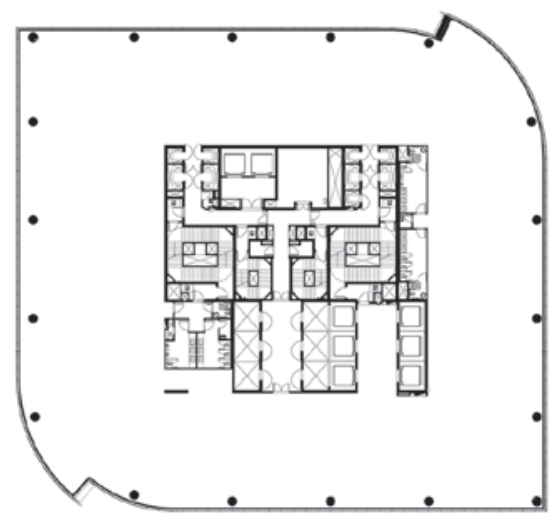

M

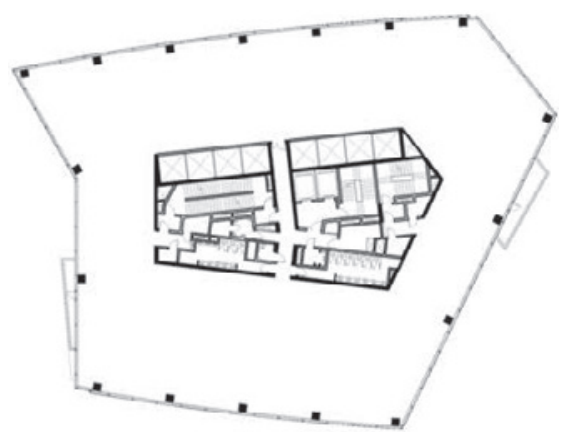

$\mathbf{N}$

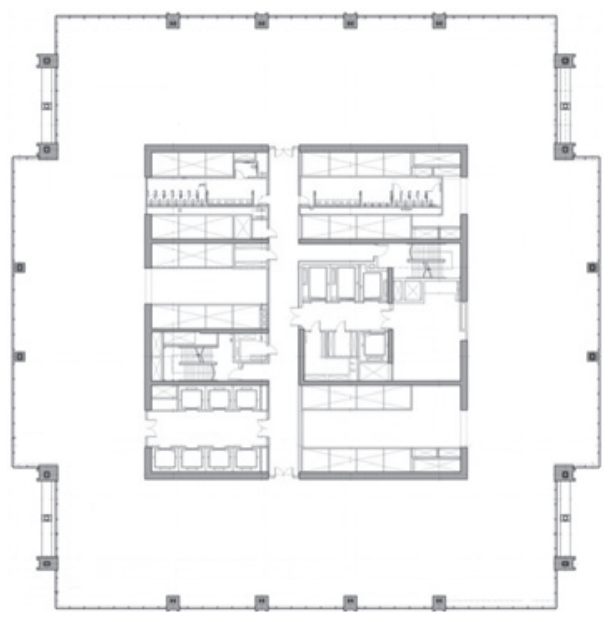

Fig 8.94. Comparativo de pavimentos-tipo de edifícios corporativos, ordenados por ano de inauguração. Escala 1:1000. Fontes entre parênteses:

A. SOM, Lever House, 1952 (Santos, "Entre a transparência e a espessura")

B. Harrison \& Abramovitz, Alcoa, 1953 (Santos, "Entre a transparência e a espessura”)

C. Mies van der Rohe, Seagram, 1958 (Santos, "Entre a transparência e a espessura")

D. Rino Levi, Banco Sul-Americano, 1963 (Archdaily)

E. Fox \& Fowle, 4 Times Square, 1999 (Architectural Record, março 2000)

F. Renzo Piano Building Workshop, New York Times, 2007 (Archdaily)

G. aflalo/gasperini arquitetos, Rochaverá Corporate Towers, 2008 (Pura Arquitetura)

H. Arquitectonica, Torre São Paulo, 2009 (Gelinski,

"Recortes suavizam fachada monolítica", Finestra)

I. Cook Fox, One Bryant Park, 2009 (Cook Fox, via Architecture Week)

J. aflalo/gasperini arquitetos, Edifício Odebrecht, 2012 (Acervo dos arquitetos)

K. aflalo/gasperini arquitetos, Morumbi Corporate -

Diamond Tower, 2013 (Corbioli, "Supremacia do espaço público", Projeto Design)

L. Pelli Clarke Pelli, São Paulo Corporate Towers, 2015 (Archdaily)

M. aflalo/gasperini arquitetos, WT Morumbi, 2016

(Archdaily)

N. Rogers Stirk Harbour, 3 World Trade Center, 2018

(Archdaily)

$1+5 \quad 10 \mathrm{~m}$ 
Bratke para a região da Berrini não ultrapassavam $500 \mathrm{~m}^{2}$, nos maiores casos, enquanto nos edifícios dos anos 2000 na marginal Pinheiros elas são maiores do que $1.500 \mathrm{~m}^{2}$ [fig 8.94].

A dificuldade de projeto decorrente dessas dimensões de pavimento-tipo é a robustez das torres. Com efeito, é recorrente na literatura a menção das estratégias para atribuir maior leveza aos projetos. No Morumbi Corporate:

A fachada do tipo cortina de vidro emprega um material em versão ainda mais transparente e com brilho diferenciado, [...] contribuindo para dar mais leveza e elegância às construções. ${ }^{45}$

O desenho lança mão de vazios que garantem a permeabilidade visual. ${ }^{46}$

Na Torre São Paulo:

O complexo tem um projeto moderno e arrojado que consiste na criatividade de transformar uma laje de mais de 2 mil metros quadrados [...] em um edifício esguio com a ilusão de quatro torres. ${ }^{47}$

Como a ideia era transformar o esqueleto robusto em uma fachada mais dinâmica, a solução foi dividir o volume original com um rasgo central em cada face, assemelhando-o a quatro blocos menores e mais longilíneos. ${ }^{48}$

O aspecto originalmente robusto e monolítico da edificação foi abandonado, e a fachada contínua teve sua verticalidade acentuada pelos recortes centrais em cada uma de suas faces e pelos perfis de aço inoxidável dispostos aleatoriamente. ${ }^{49}$

45. Nanci Corbioli, “Supremacia do espaço público”, Projeto Design, nº 409 (abr de 2014): 64-69.

46. Corbioli.

47. Arquiteta Sheila Zynger, gerente de projetos do Arquitectonica, citada em Gelinski, "Megacomplexo abriga torres e shopping".

48. Arquiteto Washington Fiúza, representante do Arquitectonica no Brasil, citado em Gilmara Gelinski, "Recortes suavizam fachada monolítica", Finestra, no 66 (janeiro de 2011).

49. Gelinski. 
Para criar mais um efeito na fachada, a nova proposta arquitetônica indicou um vidro de cor diferente na área das reentrâncias. ${ }^{50}$

Outra intervenção que o arquiteto determinou foi a inclusão de perfis de aço inox salientes em relação aos montantes e dispostos aleatoriamente, quebrando a monotonia dos planos ${ }^{51}$ [pois] "a área do prédio é muito grande." ${ }^{52}$

[O] vidro não tem cor, e sim aspecto, que muda ao longo do dia, conforme a incidência de luz, com as estações do ano e a orientação das fachadas..$^{53}$

\section{No São Paulo Corporate Towers:}

Peças de vidro com grandes dimensões envolvem em espiral os edifícios [...], o que permitiu pouca interferência visual e, com isso, leveza e movimento... ${ }^{54}$

É que a laje é muito grande. E você tem uma altura limite, que é 140 metros. Então a tendência é que o projeto fosse ficar muito grande, muito pesado, ainda mais duas torres lado a lado. Então essa ideia da torção que eles [os arquitetos do PCP] deram foi para tentar diminuir essa impressão e conseguir manter a mesma área. ${ }^{55}$

\section{No Rochaverá Corporate Towers:}

[O projeto] surpreende por sua leveza, apesar de seu volume maciço - edifícios largos que chegam até o chão, sem provocar no pedestre qualquer sensação de esmagamento... ${ }^{56}$

50. Gelinski.

51. Gelinski.

52. Arquiteto Paulo Duarte, consultor de fachadas do empreendimento, citado em Gelinski.

53. Arquiteto Paulo Duarte, consultor de fachadas do empreendimento, parafraseado em Gelinski.

54. Publieditorial, "Vidros eficientes em fachadas esculturais", Finestra, novembro de 2015.

55. Entrevista com Flávia Marcondes, citada acima.

56. Côrrea, Edifícios sustentáveis: Rochaverá - Aflalo \& Gasperini, 23. 


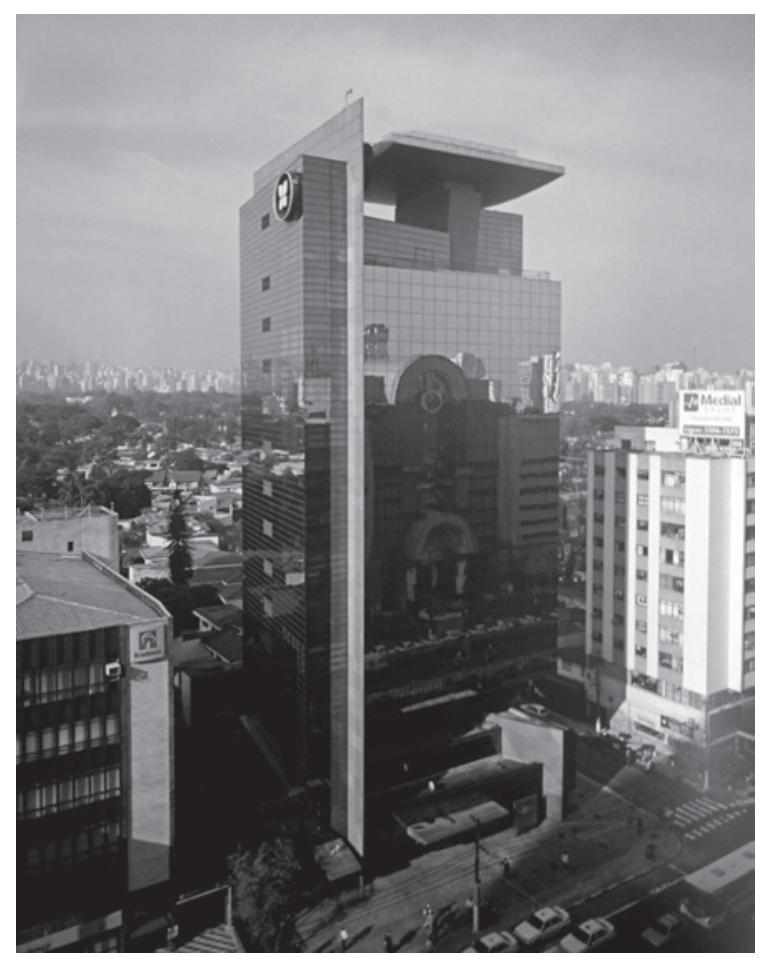

Fig 8.95. aflalo/gasperini arquitetos, Os Bandeirantes (1992/c1995). Fonte: Serapião, A arquitetura de Croce, Aflalo e Gasperini, 308.

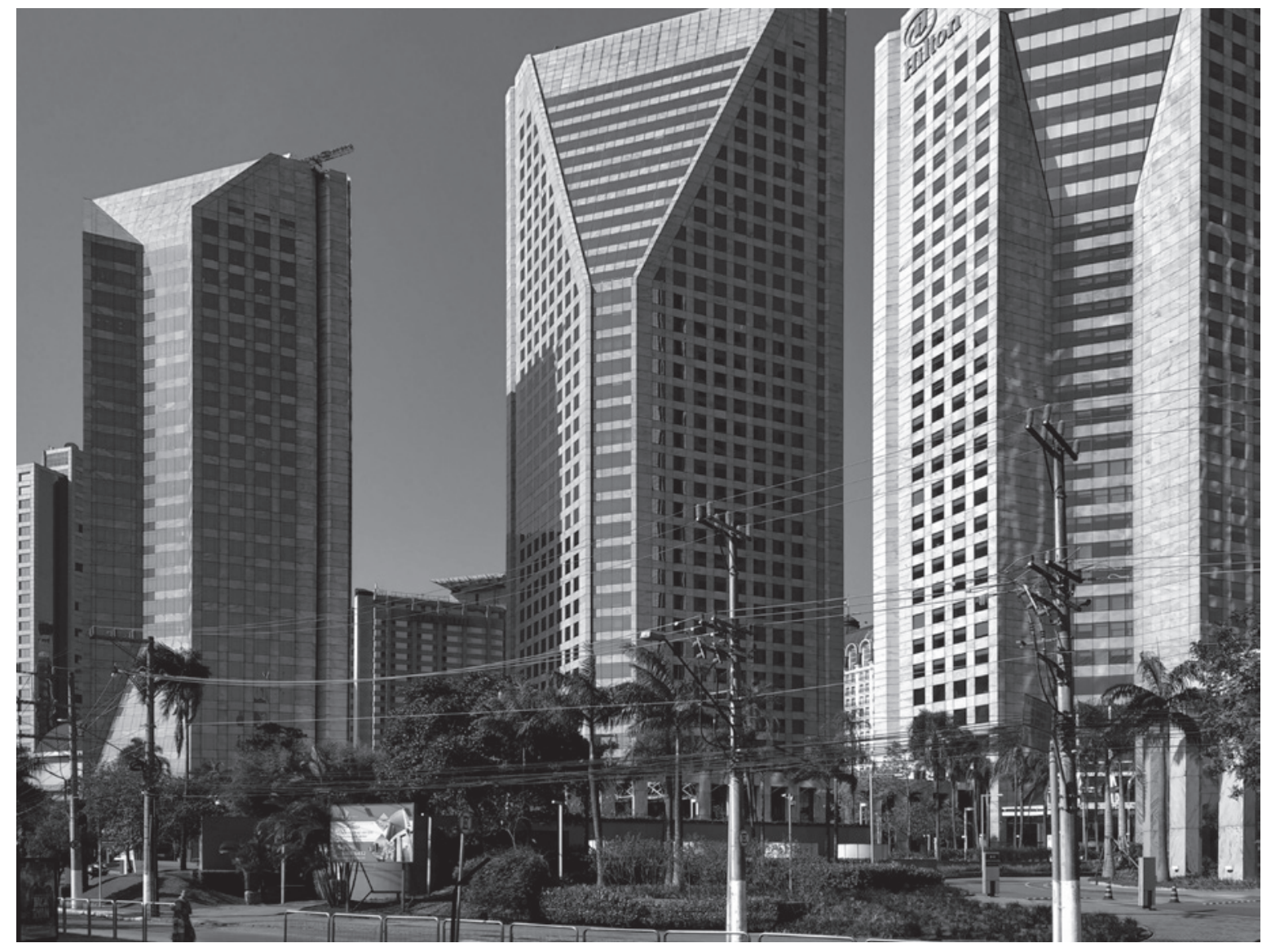

Fig 8.96. Botti Rubin, CENU (1989/2000). Fonte: Acervo do autor, 6 set 2018 . 
A coleção de citações é extensiva, mas não esgota as estratégias projetuais de dinamização das formas robustas resultantes das imposições de mercado. No caso específico do Rochaverá, a dinamização tem ainda um "benefício" suplementar. O incomum desenho trapezoidal de suas torres é regido pelo valor de mercado dos pavimentos, como aponta o memorial: "ao contrário do mais comum, as lajes dos pisos superiores dessas torres possuem $20 \%$ a mais de área que os andares inferiores, resultando em um ganho para o incorporador, uma vez que o preço do metro quadrado dos andares mais altos é mais elevado". ${ }^{57}$ Assim, a singularidade formal do conjunto revela o condicionamento financeiro de seu conteúdo. Isadora Guerreiro aponta a mesma questão:

\footnotetext{
Temos então, na forma mesma do edifício, a combinação entre o retorno direto de renda pelo aumento das áreas mais valorizadas e seu complemento estético, que é a desestabilização - o que não deixa de ser interessante, pois há um conteúdo de verdade bastante forte nesse movimento. No entanto, ele é redirecionado ideologicamente. ${ }^{58}$
}

Acompanhando a autora, essa obra revela então as condicionantes de projeto para o mercado - não fossem essas soluções a própria formalização dessas condicionantes.

As estratégias de dissolução da massa construída já estavam presentes em projetos anteriores do aflalo/gasperini, realizadas pela autonomização dos elementos construtivos. É o que começa a ser realizado com o edifício Os Bandeirantes (1992/c1995) [fig 8.95], pelos planos que cortam o volume da torre, pelo embasamento separado dos escritórios e pelo perfil arqueado do heliponto $^{59}$ - este um recurso formal desde então continuamente replicado por este escritório: novo "conteúdo de verdade redirecionado", se levada em conta a conspícua frota de helicópteros de São Paulo. Entretanto, a dissolução da forma nos projetos dos anos 2000 se dá por intervenções rudimentares (do ponto de vista geométrico) em prismas puros, e não na recomposição dos elementos da arquitetura: saem o desenho de embasamentos e coroamentos, entram as torções e inversões - mesmo que esses procedimentos muitas vezes levem a dificuldades, seja de instalação dos vidros, seja de sua manutenção e limpeza. As formas da arquitetura corporativa buscam,

\footnotetext{
57. Serapião, Monolito, Extra: Aflalo \& Gasperini Arquitetos: 40.

58. Guerreiro, "Arquitetura-capital", 202.

59. Fernando Serapião, A arquitetura de Croce, Aflalo e Gasperini (São Paulo: Editora Paralaxe, 2011), 307.
} 
assim, amenizar suas grandes dimensões, mas também dar conteúdo simbólico e significado a edifícios realizados por signos arquitetônicos dessemantizados, devido à neutralidade necessária para servir ao inquilino incógnito. É esse o processo descrito por Reinhold Martin, a partir de outro exemplo de arquitetura corporativa contemporânea:

Se o edifício IAC de [Frank] Gehry pode servir como um guia, o problema da cidade pós-moderna não é a abundância de estímulos externos mas um tipo de vazio persistente. Atrás de toda a "exuberância irracional" da globalização financeira, o que se torna mais evidente nas tentativas um tanto desesperadas, mesmo dos mais aventurosos empreendedores, de produzir edifícios arquitetonicamente "interessantes" é em quão pouco eles resultam - apenas uma casca vazia com um núcleo ressecado embrulhado em uma pele ansiosa. Em termos estéticos, nós podemos chamar esse fenômeno de forma vazia $^{60}$

Entre prismas atraentes e interiores inacabados, luz solar e lajes profundas, panos de vidro e ar condicionado, o que se nota são as contradições nas quais o programa corporativo se organiza. E ainda uma outra contradição, relevante no caso brasileiro: a tensão entre a permeabilidade do empreendimento e sua segurança.

Começando pelo disposto no LEED $^{\circledR}$ na categoria Sustainable Sites, que trata da relação entre edifício e cidade, há ao menos três tendências principais nos créditos disponíveis e em seu cumprimento. Primeira tendência: empreendimentos de alto padrão, quando optam por localização em área central, de alto preço do solo e boa provisão de infraestrutura, ganham pontos pelas decisões de incorporação, e não de projeto. Os créditos que permitem tal situação (SS.1 e SS.2) provavelmente buscam conter uma tendência de suburbanização, também presente no

\footnotetext{
60. No original: "If Gehry's IAC building can serve as a guide, the problem for the postmodern city is not the abundance of external stimuli but a sort of persistent emptiness. Beneath all of the 'irrational exuberance' of financial globalization, what becomes most evident in the rather desperate attempts of even the most adventurous developers to produce architecturally 'interesting' buildings is how little they amount to - just an empty shell with a dried-up core, wrapped in an anxious skin. In aesthetic terms we can call this phenomenon empty form." Reinhold Martin, "Financial imaginaries: toward a philosophy of the city", Grey Room, no 42 (inverno de 2011): 75, https://doi.org/10.1162/GREY_a_00018, grifo no original, tradução nossa.
} 
Brasil, mas predominante nos Estados Unidos. Entretanto, criam com isso um ciclo de gentrificação que não é enfrentado por nenhum crédito: empreendimentos de alto padrão estão mais aptos a cumprir esses créditos de centralidade e proximidade a transporte de alta capacidade do que concorrentes com menos recursos. ${ }^{61}$ Segunda tendência: ao menos para o caso brasileiro, o LEED ${ }^{\circledR}$ não tensiona suficientemente os requisitos de projeto para além do que já é exigido pelo zoneamento. É o caso do crédito para vagas de estacionamento (SS.4.4), mantidas apenas dentro do esperado pela lei, ao invés de requisitarem valores mais restritos - afinal, como tanto esse crédito quanto o sistema são voluntários, seria adequado beneficiar apenas os empreendedores que atuam acima das exigências legais. Terceira tendência: o LEED ${ }^{\oplus}$ beneficia esquemas de projeto que aumentam a quantidade de áreas livres. Nos sistemas NC e CS, entretanto, não há indicações de como seria o desenho dessas áreas, salvo certos parâmetros de proporção de permeabilidade do solo (SS.5.2). Com isso, garante-se um térreo livre, mas sem necessariamente a multifuncionalidade ou mesmo a apropriação pública dos espaços: em todos os empreendimentos os espaços livres são severamente vigiados, e apenas o São Paulo Corporate Towers e o Morumbi Corporate apresentam outros usos além dos escritórios (os shoppings do Parque da Cidade e JK Iguatemi não podem ser considerados, pois estão fora do perímetro considerado na certificação). De resto, a fórmula composta pela redução da taxa de ocupação, aumento da área construída pela compra de CEPACs e gabarito ilimitado nas operações urbanas beneficia a construção das torres.

A questão não é menor, pois os empreendimentos estudados obtêm cerca de um terço de seus pontos não por questões de eficiência no projeto, mas pelos créditos da categoria SS em que se beneficiam apenas de sua localização urbana. É habitual que as sedes corporativas se situem em áreas urbanas ao menos desde o início da década de 1990, no realinhamento das cidades globais que substituíram os subúrbios do "capitalismo pastoral" das décadas de 1970 e $80 .{ }^{62}$ Por essa razão, a pontuação dos empreendimentos simplesmente por se encontrarem em área urbana,

\footnotetext{
61. Vide matéria segundo a qual o São Paulo Corporate Towers localiza-se em área central para reduzir a pressão da urbanização em mananciais - como se o endereço central do empreendimento não fosse condição mesma para sua construção. Cf. Alexandre Raith, “Tecnologia de baixo impacto”, Revista Infra, nº 181 (14 de dezembro de 2015).

62. Louise A. Mozingo, Pastoral capitalism: a history of suburban corporate landscapes (Cambridge, Massachusetts; Londres: The MIT Press, 2011); ver também Reinhold Martin, Utopia's ghost: architecture and postmodernism, again (Minneapolis, Londres: University of Minnesota Press, 2010), cap. 6, "Subjects: Mass customization”.
} 

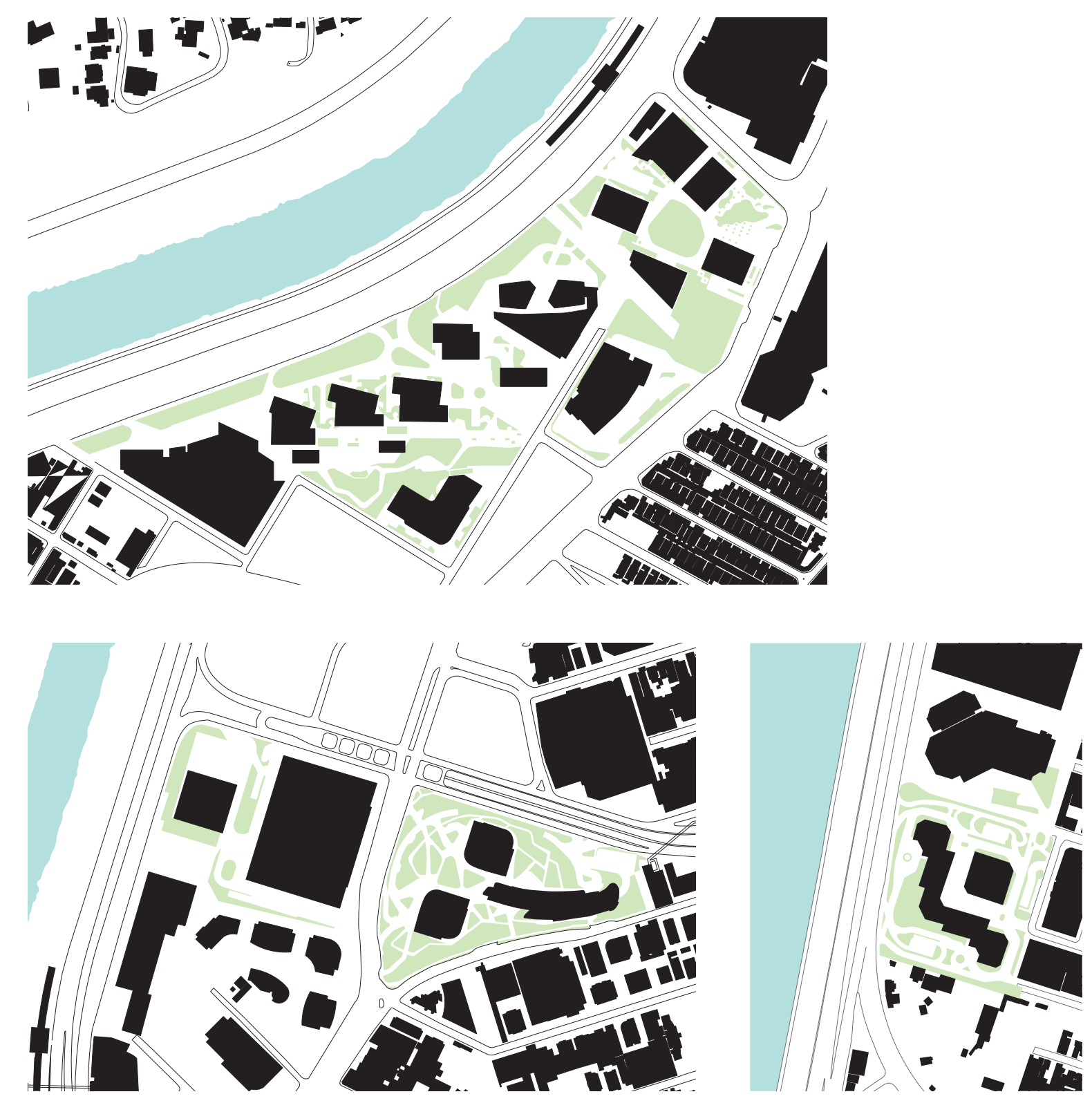

Fig 8.97. Esquemas de áreas verdes em empreendimentos da marginal Pinheiros: setores Chucri Zaidan, Juscelino Kubitschek e CENU e WTC. Escala 1:7500. Elaborado pelo autor. Fontes: Geosampa, Google Earth, implantações dos empreendimentos. 
sem oferecerem novos usos para sua apropriação, parece redundante. De modo tautológico, os edifícios ganham pontos por cumprirem a premissa de sua viabilidade financeira. ${ }^{63}$

Nos dois setores Chucri Zaidan e Juscelino Kubitschek, a virtualidade do LEED ${ }^{\circledR}$ de parques corporativos de grandes dimensões parece se concretizar. Essa tipologia certamente não é uma novidade, já presente desde as praças corporativas nova yorkinas analisadas pelo artista Dan Graham ${ }^{64}$ até os espaços livres privados em São Paulo - como no Centro Empresarial Itaú Conceição (1982/1985) de João de Gennaro na Itauplan, no Citicorp (1983/1986) de aflalo/gasperini [fig 8.87] ou no Brascan Century Plaza (1999/2003) de Königsberger Vannucchi. A soma de grande porte dos empreendimentos e de aumento de área permeável do LEED ${ }^{\circ}$, entretanto, coloca um problema arquitetônico resolvido pela importância dada ao paisagismo, ao mesmo tempo cumprimento dos créditos e aspecto comunicativo do ambientalismo dos projetos. No lugar da solução da geração anterior de projetos corporativos, como o Centro Empresarial de São Paulo (CENESP; 1975/1986), de João Henrique Rocha, ou o Centro Empresarial Nações Unidas (CENU; 1989/2000) de Botti Rubin [fig 8.96], onde as áreas livres se resumiam a gramados indistintos e estrutura viária, a nova geração cria jardins tropicais, ao mesmo tempo área de convívio dos ocupantes do edifícios e imagem local passível de circulação global [fig 8.96].

Há aqui a preocupação com a "fruição" dos espaços livres. O uso do termo é recorrente pelo arquiteto Roberto Aflalo Filho: os terrenos do Morumbi Corporate e do WT Morumbi, adicionados ao do Rochaverá, criariam um "complexo de paisagismo de fruição"65; "a região [da Chucri Zaidan] necessita de grande fruição" "6; o gerenciamento atual dos térreos permite "ao mesmo tempo a segurança e a fruição"67; a "fruição dá um caráter sinérgico com o entorno dos prédios de escritórios" 68 ; os projetos buscam "estender o espaço semipúblico, chegando assim à sensação de maior fruição", o que os empreendedores podem entender que "agregava valor e

63. O argumento é válido para ao menos $10 \%$ dos pontos possíveis no LEED ${ }^{\circledR} \mathrm{NC}$ e CS v3: os doze pontos disponíveis em SS.1 Site Selection, SS.2 Development Density and Community Connectivity e SS.4.1 Alternative Transportation - Public Transportation Access.

64. Dan Graham, Rock my religion: writings and projects 1965-1990, Ed. de Brian Wallis (Cambridge, MA: Massachusetts Institute of Technology, 1993).

65. Serapião, Monolito, Extra: Aflalo \& Gasperini Arquitetos:17.

66. Serapião, Extra: Aflalo \& Gasperini Arquitetos:17.

67. Serapião, Extra: Aflalo \& Gasperini Arquitetos:17.

68. Serapião, Extra: Aflalo \& Gasperini Arquitetos:18. 
criava identidade" ${ }^{69}$; "o principal é isso: o aumento da calçada e a fruição que corta as quadras transversalmente em relação às ruas" ${ }^{\prime 7}$. Donde se induz que fruição seja para os arquitetos a construção de paisagens de contemplação, isoladas do burburinho da rua, em vastos jardins de isolamento e despreocupação tanto com o rush urbano quanto com a insegurança cotidiana. De fato, o paisagismo do Rochaverá (entendido tanto em relação à escolha de vegetação quanto ao espaço concebido), objeto de inúmeras versões antes de agradar aos arquitetos ${ }^{71}$ remete a certo isolamento bucólico, com desenho que incentiva o fruidor a deambular. Como apontado acima, o próprio desenho do jardim, de caminhos com curvas acentuadas, procura desorientar o usuário, que nunca pode atingir retilineamente seu objetivo. Haveria, assim, uma desorientação do desenho paisagístico. Nas palavras da autora Isadora Guerreiro:

O que mais chama a atenção é o caráter bucólico dos jardins projetados, com passeios orgânicos, pequenos montes artificiais e pedras ornamentais. O jardim central, "praça" onde confluem as entradas das quatro torres, é chamado de "Jardim do Éden". A linha absolutamente reta que liga duas das torres viradas uma à frente da outra é quebrada por caminhos tortuosos do "Éden". A alguns metros de uma das maiores vias de circulação da maior cidade do país. A desestabilização das formas dos edifícios - que usa e abusa da tecnologia - é contraposta ao bucolismo do térreo. Assim, o Rochaverá ao mesmo tempo em que cria formas que reclamam a tecnologia, usando elementos "futuristas", tem uma relação urbana contraditória, num espaço cercado de jardins bucólicos. A explicação para esta situação foi dada na negativa de um projeto urbano que beneficiava o uso despretensioso [o café originalmente proposto pelos arquitetos]: falta de rentabilidade. ${ }^{72}$

A mesma proposta de isolamento deve se repetir no Parque da Cidade. A própria disposição do eixo de edifícios, por um lado, e o paisagismo de ligeiros morros vegetados que criam uma mediação com as vias rodoviárias, por outro lado, parece reforçar a criação de um espaço interno

69. Serapião, Extra: Aflalo \& Gasperini Arquitetos:22.

70. Serapião, Extra: Aflalo \& Gasperini Arquitetos:23-24.

71. Côrrea, Edifícios sustentáveis: Rochaverá - Aflalo \& Gasperini, 25; Corbioli, "Fachadas inclinadas atendem à estética e à lógica do mercado", 52. Ver ainda fig 8.9 a 8.14.

72. Guerreiro, "Arquitetura-capital", 204. 
de isolamento em meio à massa construída e à massa vegetada. No Rochaverá, o alheamento é reforçado pela diferença de nível em relação à rua, o que configura um plinto, uma base elevada para todo o conjunto. Esse plinto dá certa autonomia à experiência espacial e afastamento em relação ao espaço público da cidade, o que foi igualmente realizado no São Paulo Corporate Towers.

Mesmo a derrubada proposta dos atuais muros entre os quatro empreendimentos da Chucri Zaidan, ou mesmo a supressão do gradil do São Paulo Corporate Towers, não resolveriam substancialmente o desenho, a não ser na efetiva permeabilidade total do térreo-parque. A derrubada dos muros dos empreendimentos da Chucri Zaidan, ainda que não prevista originalmente, já que os vizinhos ainda não existiam, está implícita na própria solução morfológica do conjunto, de torres isoladas em parque, mas ainda assim não há integração com a implantação dos vizinhos. No São Paulo Corporate Towers, pelo contrário, embora o desenho do espaço intramuros seja muito mais complexo, o gradil é sintomaticamente estetizado, como se fosse um elemento indissociável do conjunto.

Se o plinto busca a autonomia do espaço em relação à cidade, é contraditório que com a marginal, ela sim uma via agressiva para a circulação de pedestres, o térreo do Rochaverá chegue diretamente em nível, apenas com uma suave rampa que ascende à rotatória central. Ali, a mediação entre empreendimento e cidade é feita apenas por um desobstruído paisagismo de forragem. A solução talvez se deva à proximidade com a estação da CPTM, mas ainda assim é incomum na região. No conjunto WTJK, o escritório Arquitectonica criou uma parede de vidro, visualmente permeável, mas fisicamente intransponível, que força o pedestre a sair da via expressa para acessar o conjunto apenas através da rua Funchal, perpendicular à avenida Juscelino Kubitschek. Como também já indicado, o WTorre Morumbi, vizinho ao Rochaverá, criava originalmente não uma parede, mas um guarda-corpo seguido de um fosso paisagístico, embora aqui a sua entrada seja efetivamente pela via expressa, por ser a principal frente do terreno. ${ }^{73}$

O "desenho da cidade" já foi proposto de outro modo pelo escritório. Mesmo projetos mais recentes, como o Eldorado Business Tower e o edifício Odebrecht, trabalham com um embasamento a partir do qual a torre é erguida. Se ambos os projetos foram realizados em áreas

73. A nova solução de integração com o viário, após a intervenção das obras de ampliação da estação da CPTM, não pôde ser encontrada. 


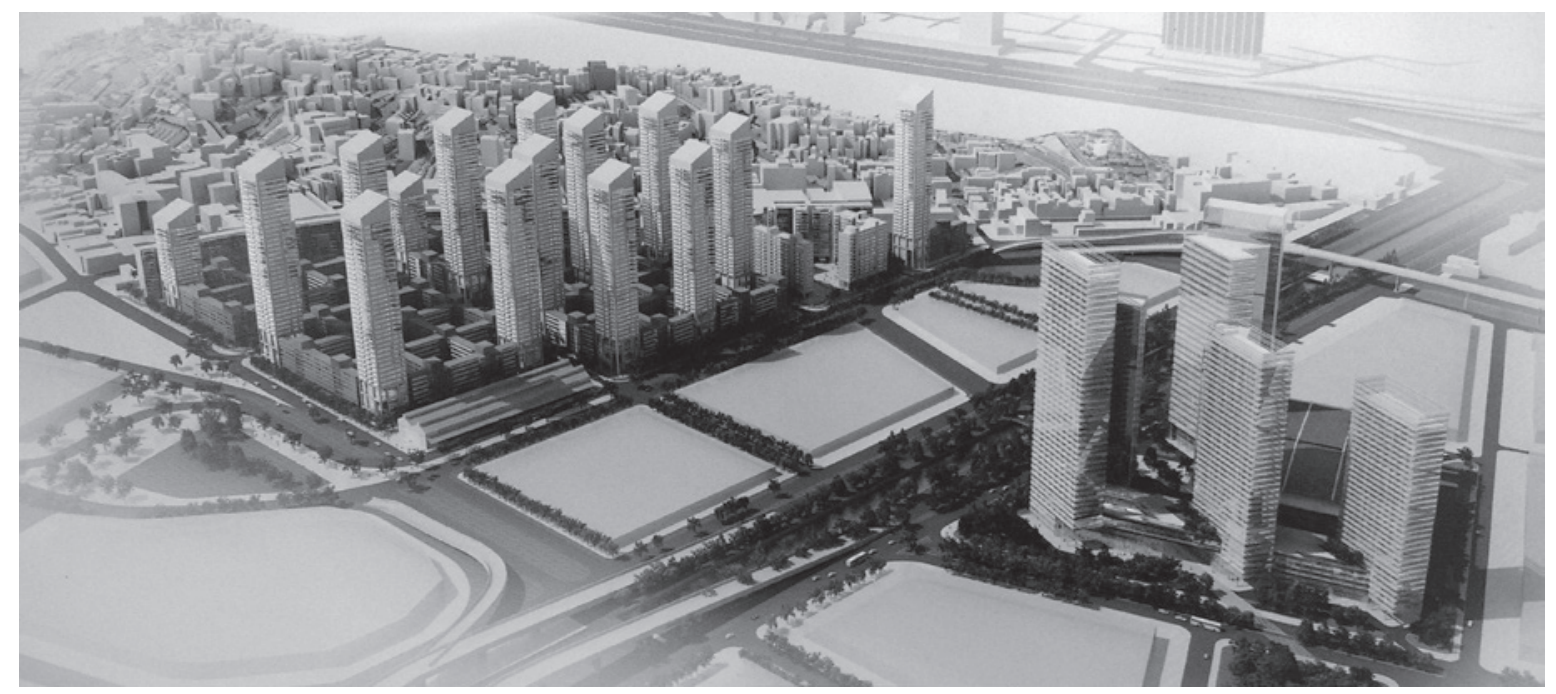

Fig 8.98. aflalo/gasperini arquitetos, Porto Olímpico (2011).

Fonte: Serapião, A arquitetura de Croce, Aflalo e Gasperini, 355. 
consolidadas ou em terrenos menores, donde a dificuldade projetual de criar a configuração da cidade-parque, outros exemplos em grandes glebas podem indicar a particularidade do desenho urbano do Rochaverá. É o caso da proposta para o Porto Maravilha, em que há claro desenho de quadras com um miolo de praça condominial, e em cujas esquinas ascendem torres esbeltas [fig 8.98]. Apesar da proposta ter sido abandonada ainda em estágio preliminar, ela contrasta com os próprios fundamentos da solução do setor Chucri Zaidan, cuja espacialidade, seja uma vez mais salientado, tem no Rochaverá a sua gênese e no Parque da Cidade sua consolidação.

Esses jardins não são os parques modernos, onde não há distinção entre projeto e território. Nos casos analisados, a implantação reafirma sua separação como lote. Por isso, a maior parte dos empreendimentos usa algum tipo de barreira, ainda que amenizada pelo desenho: as grades onduladas do São Paulo Corporate Towers, os muros de acrílico no complexo WTJK, o fosso paisagístico no WT Morumbi, os muros em meia altura para a Chucri Zaidan no Rochaverá, a vegetação cerrada no Parque da Cidade. O paisagismo afunila os percursos para uma quantidade pequena de acessos nos conjuntos, ao mesmo tempo organização dos fluxos e controle de segurança.

Entretanto, apesar dessas semelhanças, os projetos empregam princípios diferentes de desenho urbano. No setor Juscelino Kubitschek, o complexo WTJK reconstitui o viário da região enquanto o São Paulo Corporate Towers o elimina. No setor Chucri Zaidan, o Rochaverá se organiza em torno de uma praça-rotatória, o Parque da Cidade em torno de um eixo-promenade, o Morumbi Corporate orienta-se para a rua e o WT Morumbi orienta-se, como imagem, para a marginal Pinheiros. O espaço livre resultante dos empreendimentos certificados é um amálgama unificado pela lógica de térreo-parque e monofuncionalidade. Mas não há estratégia unificadora de desenho urbano. O que indicaria uma nova fase da heterogeneidade morfológica da marginal Pinheiros identificada por Alexandre Hepner em seu mestrado: em uma área onde se sucedem galpões, casas unifamiliares, condomínios verticais, parques, shoppings e escritórios, a forma urbana é, e continua a ser, o resultado fragmentado de enclaves. ${ }^{74}$

\footnotetext{
74. Alexandre Hepner, "Desenho urbano, capital e ideologia em São Paulo: centralidade e forma urbana na marginal do rio Pinheiros" (Dissertação (Mestrado em Paisagem e Ambiente). Orientador: Silvio Soares Macedo, Faculdade de Arquitetura e Urbanismo da Universidade de São Paulo, 2010).
} 


\section{PARTE IV}

\section{NEW URBANISM NA MARGINAL PINHEIROS}

Entretanto, uma tentativa de fotografar suas ruas internas nos revelou de imediato o rígido monitoramento que impõe aos seus usuários: nossas intenções foram averiguadas por ocupantes de carros de segurança, que alertaram que as ruas eram propriedade privada e não podiam ser fotografadas. Em construções erguidas em diferentes estilos, através de mecanismos visíveis ou ocultos, o empenho de controle persiste.

Philip Gunn ${ }^{1}$

1. Philip Gunn, "O New Urbanism e o revival escapista de mercado", Risco: Revista de Pesquisa em Arquitetura e Urbanismo 2, no 2 (2005): 106. 



\section{CAPÍTULO 9 \\ LEED® E A REVISÃO DO SUBÚRBIO NORTE-AMERICANO}

\section{O SISTEMA LEED® FOR NEIGHBORHOOD DEVELOPMENT}

O LEED ${ }^{\circledR}$ é um “ecossistema de padrões”, mas não é monolítico. Todos os sistemas lançados em uma mesma versão ficam sob a alçada de um comitê diretor, mas há também comitês para cada sistema específico. Assim, apesar da direção geral, há contradições quando outros sistemas são comparados ao LEED ${ }^{\circledR} \mathrm{NC}$ ou CS, apresentados na parte III. Um exemplo é o LEED ${ }^{\circledR}$ Homes, ${ }^{1}$ no qual a pontuação final é ajustada de acordo com o tamanho da construção: residências com menor quantidade de metros quadrados per capita pontuam melhor, em direta oposição ao grande porte das torres corporativas anteriormente analisadas. Outro exemplo é o LEED ${ }^{\circledR}$ for Neighborhood Development (ND), único dos sistemas LEED ${ }^{\circledR}$ que não foi concebido apenas sob a direção do USGBC ${ }^{\circledast}$, mas também do Natural Resources Defense Council (NRDC) e do Congress for the New Urbanism (CNU). O NRDC já colaborava com o USGBC ${ }^{\circledast}$ desde sua fundação, como membro do conselho diretor; ${ }^{2} \mathrm{o}$ New Urbanism era citado por publicações ligadas à modernização ecológica, como o livro Natural capitalism. ${ }^{3}$

O nome do sistema pode levar a erro: não existe especificação de tamanho para o LEED ${ }^{\circledast}$ $\mathrm{ND}$, apenas a sugestão de que o cumprimento é mais fácil quando o projeto possuir entre dois

\footnotetext{
1. USGBC (United States Green Building Council), "LEED for Homes rating system” (USGBC, janeiro de 2008).

2. Ver capítulo 1.

3. Amory B. Lovins, L. Hunter Lovins, e Paul Hawken, Natural capitalism: the next industrial revolution (Washington DC: US Green Building Council, 2000), 106ss. Schlosberg e Rinfret também alertam sobre possíveis componentes de modernização ecológica no New Urbanism. Cf. “Ecological modernisation, American style”, Environmental Politics 17, n’ 2 (2008): 254-75, https://doi.org/10.1080/09644010801936206.
} 
edifícios habitados e meio quilômetro quadrado de área. ${ }^{4}$ Desse modo, ele pode ser aplicado a ruas, condomínios e loteamentos, sem uma escala precisa de intervenção.

Segundo Douglas Farr, um dos membros do comitê específico para o ND, os créditos nele encontrados são, em sua maior parte, novidades para o LEED ${ }^{\oplus}$. Não há em nenhum outro sistema incentivos à diversidade de renda, habitações a preços acessíveis, acessibilidade universal e decisões participativas, ou inibições ao cercamento do empreendimento, presentes no ND. ${ }^{5} \mathrm{~A}$ variedade de créditos está relacionada às novas categorias fundamentais do sistema, onde cada uma responde às exigências de um dos órgãos envolvidos:

A localização de um projeto em uma região - onde ele está - é a principal preocupação do movimento Smart Growth e é tratada na divisão Smart Location and Linkage do LEED for Neighborhood Development. Acessibilidade a pé, usos do solo, desenho urbano e arquitetura do lugar - o que acontece no projeto - é o foco primeiro do Congress for the New Urbanism e é tratado na divisão Neighborhood Pattern and Design. Finalmente, a sustentabilidade da construção e operação de um empreendimento - como ele é construído e gerido - são as principais preocupações do US Green Building Council e são tratadas na divisão Green Construction and Technology [posteriormente Green Infrastructure and Buildings]. ${ }^{6}$

O “movimento Smart Growth" citado por Farr defende cidades compactas, de uso misto, proximidade a transporte coletivo ou sem uso de combustíveis fósseis e preservação de recursos naturais. O Smart Growth é uma corrente de planejamento urbano e não um grupo organizado, portanto não tem representante oficial. É encaminhado no LEED ${ }^{\circledR}$ ND pelo NRDC, uma organização não-governamental e sem fins lucrativos criada na década de 1970 por militantes am-

4. USGBC (United States Green Building Council), Congress for the New Urbanism, e Natural Resources Defense Council, “LEED 2009 for neighborhood development rating system” (USGBC, 2011), xiv.

5. Douglas Farr, Sustainable urbanism: urban design with nature (Hoboken, NJ: John Wiley \& Sons, 2008), 54-55.

6. No original: "The location of a project in a region - where it is - is a principal concern of the Smart Growth movement and is addressed in the Smart Location and Linkage division of LEED for Neighborhood Development. Walkability, land uses, urban design, and architecture of place - what goes on there - is a primary focus of the Congress of New Urbanism and is addressed in the Neighborhood Pattern and Design division. Finally, the greenness of the construction and the operation of a development - how it is built and managed - are principal concerns of the US Green Building Council and are addressed in the Green Construction and Technology division." Farr, 54, grifos no original, tradução nossa. 
bientalistas vindos do meio jurídico. Baseada desde então em Nova York, a organização atua em áreas como preservação ambiental, responsabilização de indústrias poluidoras, energia limpa, mudanças climáticas e saúde comunitária.

Se aceita a divisão de Farr, o NRDC está ligado principalmente à categoria Smart Location and Linkage (SLL), com cerca de um quarto dos pontos possíveis. Como pré-requisitos, a categoria exige a localização dentro ou adjacente à área urbana, em solo não agricultável e não sujeito a enchentes; inexistência ou garantias de preservação de fauna sob risco na área de implantação; e distância de ao menos alguns metros em relação a corpos d'água. Do ponto de vista urbano, seus créditos incentivam a conectividade viária, a multiplicidade de usos e a localização em áreas com oferta de transporte multimodal, com pontos extras para sistema cicloviário. ${ }^{7}$ Já do ponto de vista ambiental, há pontos destinados à eventual descontaminação do solo, à conservação ou restauração de habitats naturais e à não ocupação de áreas com potencial de desabamento. ${ }^{8}$

A segunda categoria, Neighborhood Pattern and Design (NPD), estaria ligada ao CNU, outro defensor do Smart Growth, o que indica certa sobreposição de agendas. A categoria tem a maior concentração de pontos possíveis no $\mathrm{LEED}^{\circledR} \mathrm{ND}$. Ela possui três pré-requisitos: o cumprimento de certas medidas para aumentar a relação dos edifícios com a rua - de modo geral: mínimo de $90 \%$ dos novos edifícios com entradas por um espaço público, mínimo de $15 \%$ das fachadas com uma altura de ao menos um terço da calha da rua, mínimo de $90 \%$ das ruas com calçadas em ambos os lados, no máximo $20 \%$ das fachadas com acessos por meio de estacionamentos -; o respeito a parâmetros de densidade habitacional que variam de acordo com o contexto; e alta conectividade viária, medida pela quantidade de intersecções entre ruas - o empreendimento deve possuir ao menos 140 cruzamentos por milha quadrada, ou situar-se em área que tenha ao menos 90 cruzamentos em uma distância de 0,25 milha a partir dos limites do empreendimento, quando não houverem ruas internas. Quanto aos créditos, de um lado estão aqueles com parâmetros de desenho urbano, com especificações muito precisas do que deve

7. SLL.1 Preferred Locations, SLL.3 Locations with Reduced Automobile Dependence, SLL.4 Bicycle Network and Storage, Housing and Jobs Proximity.

8. SLL.2 Brownfield Development, SLL.6 Steep Slope Protection, SLL.7 Site Design for Habitat or Wetland and Water Body Conservation, SLL.8 Restoration of Habitat or Wetlands and Water Bodies, SLL.9 Long-Term Conservation Management of Habitat or Wetlands and Water Bodies. 
ser seguido, como distância e tamanho de janelas no térreo e recuos; tamanhos de perímetros de quarteirões; sombreamento de ruas com vegetação; densidades de unidades, residenciais ou não; diversidade de usos do bairro; diversidade de unidades residenciais, considerando tanto as características das unidades quanto o seu preço; distâncias ideais a parques e áreas de recreação; projeto de áreas adequadas e confortáveis para espera de transporte público; unidades habitacionais acessíveis para diferentes deficiências e mesmo se há escolas projetadas na gleba. ${ }^{9}$ De outro lado, créditos mais relacionados à gestão do empreendimento, como um plano de transporte para seus usuários que reduza a demanda na área do projeto, mecanismos participativos e produção local de alimentos. ${ }^{10}$

Por fim, a categoria Green Infrastructure and Building (GIB) é a mais diretamente subordinada ao USGBC ${ }^{\circledast}$. São quatro pré-requisitos, relacionados à certificação de ao menos um edifício na área de projeto com $\mathrm{LEED}^{\circledR}$ ou sistema similar e a procedimentos para economia de energia e água, além da redução da poluição gerada pela obra do empreendimento. Seus créditos podem ser divididos entre os referentes à energia, pela eficiência dos sistemas das unidades e do bairro, sua produção renovável no local, à criação de um sistema integrado de resfriamento e aquecimento a partir de uma usina no conjunto, à redução de ilhas de calor e à orientação solar adequada; ${ }^{11}$ os referentes à água, com a eficiência dos equipamentos hidráulicos e gestão de águas das chuvas e da água servida; ${ }^{12}$ e os referentes à redução do impacto do empreendimento pela reutilização de estruturas existentes, à preservação de edifícios históricos, à implantação em áreas já desenvolvidas, ao uso de material reciclado na infraestrutura, ao planejamento da reciclagem dos dejetos na ocupação e à redução de poluição luminosa. ${ }^{13}$ Há ainda um crédito

\footnotetext{
9. NPD.1 Walkable Streets, NPD.2 Compact Development, NPD.3 Mixed-Use Neighborhood Centers, NPD.4 Mixed-Income Diverse Communities, NPD.5 Reduced Parking Footprint, NPD.6 Street Network, NPD.7 Transit Facilities, NPD.9 Access to Civic and Public Spaces, NPD.10 Access to Recreation Facilities, NPD.11 Visitability and Universal Design, NPD.14 Tree-Lined and Shaded Streets e NPD.15 Neighborhood Schools.

10. NPD.8 Transportation Demand Management, NPD.12 Community Outreach and Involvement e NPD.13 Local Food Production.

11. GIB.2 Building Energy Efficiency, GIB.9 Heat Island Reduction, GIB.10 Solar Orientation, GIB.11 On-Site Renewable Energy Sources, GIB.12 District Heating and Cooling e GIB.13 Infrastructure Energy Efficiency.

12. GIB.3 Building Water Efficiency, GIB.4 Water-Efficient Landscaping, GIB.8 Stormwater Management e GIB.14 Wastewater Management.

13. GIB.5 Existing Building Reuse, GIB.6 Historic Resource Preservation and Adaptative Use, GIB.7 Minimized Site Disturbance in Design and Construction, GIB.15 Recycled Content in Infrastructure, GIB.16 Solid Waste Management Infrastructure
} 
com benefícios a edifícios certificados no empreendimento em taxas maiores do que o exigido nos pré-requisitos. ${ }^{14}$

Tal como nos outros sistemas LEED ${ }^{\circledR}$, dez pontos extras estão distribuídos nas categorias Innovation in Design (ID) e Regional Priorities (RP), a última com créditos decididos pelos conselhos locais [tab 9.1].

Diferentemente dos outros sistemas analisados, a certificação pelo ND se dá em fases. Na primeira, a avaliação é realizada quando até metade do empreendimento obteve direito legal de construção; na segunda, é realizada quando todo o empreendimento obteve o direito; na terceira fase, por fim, a avaliação é feita quando a construção estiver concluída.

A versão piloto do $\mathrm{LEED}^{\circledR} \mathrm{ND}^{\mathrm{N}}$ começou a circular em meados de 2007, mas foi efetivamente lançada em 2009, junto com o LEED ${ }^{\circledR}$ v3. Até o fim de 2018, foram certificados 190 empreendimentos, com quase 44 milhões de metros quadrados, sendo apenas dois no Brasil. Mas esses dois projetos são representativos das mudanças na paisagem urbana recente e de seus conflitos: o Ilha Pura, no Rio de Janeiro, construído para abrigar os atletas das Olímpiadas de 2016, e o Parque da Cidade, em São Paulo, ambos incorporados pela Odebrecht Realizações Imobiliárias.

Qual é então o modelo de desenho urbano do LEED $^{\circledR} \mathrm{ND}$ ? Entre os sistemas LEED ${ }^{\oplus}$, esse é o que tem maior intervenção no projeto, com estipulações precisas de distâncias, recuos e desenho de fachadas [fig 9.1]. Se nos sistemas NC e CS o impacto era mais sugerido do que declarado, no $\mathrm{ND}$ as formas de cumprir créditos são menos maleáveis para o projeto. O modelo de tecido urbano do $\mathrm{LEED}^{\oplus}$ pode ser encontrado no ND mais do que no $\mathrm{LEED}^{\circledR}$ for Cities, um sistema mais centrado em políticas públicas e parâmetros de gestão municipal.

\section{NEW URBANISM}

$\mathrm{O}$ aspecto mais relevante para compreender o $\mathrm{LEED}^{\circledR} \mathrm{ND}$ é a autoria compartilhada com o New Urbanism, representado pelo seu congresso. Não só pelo CNU ser o principal desenvolvedor da categoria NPD, mas também por suas relações com o Smart Growth, da categoria SLL. O CNU

e GIB.17 Light Pollution Reduction.

14. GIB.1 Certified Green Buildings. 


\begin{tabular}{|c|c|c|c|}
\hline \# & Categorias e créditos & Pontos & $\%$ \\
\hline SLL & Smart Location and Linkage & 27 & 24,5 \\
\hline SLL.Prereq.1 & Smart Location & - & - \\
\hline SLL.Prereq. 2 & Imperiled Species and Ecological Communities & - & - \\
\hline SLL.Prereq. 3 & Wetland and Water Body Conservation & - & - \\
\hline SLL.Prereq.4 & Agricultural Land Conservation & - & - \\
\hline SLL.Prereq. 5 & Floodplain Avoidance & - & - \\
\hline SLL.1 & Preferred Locations & 10 & 9,1 \\
\hline SLL.2 & Brownfield Redevelopment & 2 & 1,8 \\
\hline SLL.3 & Locations with Reduced Automobile Dependence & 7 & 6,4 \\
\hline SLL.4 & Bicycle Network and Storage & 1 & 0,9 \\
\hline SLL.5 & Housing and Jobs Proximity & 3 & 2,7 \\
\hline SLL.6 & Steep Slope Protection & 1 & 0,9 \\
\hline SLL.7 & Site Design for Habitat or Wetland and Water Body Conservation & 1 & 0,9 \\
\hline SLL.8 & Restoration of Habitat or Wetlands and Water Bodies & 1 & 0,9 \\
\hline SLL.9 & Long-Term Conservation Management of Habitat or Wetlands and Water Bodies & 1 & 0,9 \\
\hline NPD & Neighborhood Pattern and Design & 44 & 40,0 \\
\hline NPD.Prereq.1 & Walkable Streets & - & - \\
\hline NPD.Prereq.2 & Compact Development & - & - \\
\hline NPD.Prereq.3 & Connected and Open Community & - & - \\
\hline NPD.1 & Walkable Streets & 12 & 10,9 \\
\hline NPD. 2 & Compact Development & 6 & 5,5 \\
\hline NPD.3 & Mixed-Use Neighborhood Centers & 4 & 3,6 \\
\hline NPD.4 & Mixed-Income Diverse Communities & 7 & 6,4 \\
\hline NPD. 5 & Reduced Parking Footprint & 1 & 0,9 \\
\hline NPD.6 & Street Network & 2 & 1,8 \\
\hline NPD.7 & Transit Facilities & 1 & 0,9 \\
\hline NPD.8 & Transportation Demand Management & 2 & 1,8 \\
\hline NPD.9 & Access to Civic and Public Spaces & 1 & 0,9 \\
\hline NPD.10 & Access to Recreation Facilities & 1 & 0,9 \\
\hline NPD.11 & Visitability and Universal Design & 1 & 0,9 \\
\hline NPD.12 & Community Outreach and Involvement & 2 & 1,8 \\
\hline NPD.13 & Local Food Production & 1 & 0,9 \\
\hline NPD.14 & Tree-Lined and Shaded Streets & 2 & 1,8 \\
\hline NPD.15 & Neighborhood Schools & 1 & 0,9 \\
\hline
\end{tabular}




\begin{tabular}{|c|c|c|c|}
\hline \# & Categorias e créditos & Pontos & $\%$ \\
\hline GIB & Green Infrastructure and Buildings & 29 & 26,4 \\
\hline GIB.Prereq.1 & Certified Green Building & - & - \\
\hline GIB.Prereq.2 & Minimum Building Energy Efficiency & - & - \\
\hline GIB.Prereq.3 & Minimum Building Water Efficiency & - & - \\
\hline GIB.Prereq. 4 & Construction Activity Pollution Prevention & - & - \\
\hline GIB.1 & Certified Green Buildings & 5 & 4,5 \\
\hline GIB.2 & Building Energy Efficiency & 2 & 1,8 \\
\hline GIB.3 & Building Water Efficiency & 1 & 0,9 \\
\hline GIB.4 & Water-Efficient Landscaping & 1 & 0,9 \\
\hline GIB.5 & Existing Building Reuse & 1 & 0,9 \\
\hline GIB.6 & Historic Resource Preservation and Adaptive Use & 1 & 0,9 \\
\hline GIB.7 & Minimized Site Disturbance in Design and Construction & 1 & 0,9 \\
\hline GIB.8 & Stormwater Management & 4 & 3,6 \\
\hline GIB.9 & Heat Island Reduction & 1 & 0,9 \\
\hline GIB.10 & Solar Orientation & 1 & 0,9 \\
\hline GIB.11 & On-Site Renewable Energy Sources & 3 & 2,7 \\
\hline GIB.12 & District Heating and Cooling & 2 & 1,8 \\
\hline GIB.13 & Infrastructure Energy Efficiency & 1 & 0,9 \\
\hline GIB.14 & Wastewater Management & 2 & 1,8 \\
\hline GIB.15 & Recycled Content in Infrastructure & 1 & 0,9 \\
\hline GIB.16 & Solid Waste Management Infrastructure & 1 & 0,9 \\
\hline GIB.17 & Light Pollution Reduction & 1 & 0,9 \\
\hline ID & Innovation in Design & 6 & 5,5 \\
\hline ID. 1 & Innovation and Exemplary Performance & 5 & 4,5 \\
\hline ID. 2 & LEED Accredited Professional & 1 & 0,9 \\
\hline $\mathbf{R P}$ & Regional Priority & 4 & 3,6 \\
\hline RP.1 & Regional Priority & 4 & 3,6 \\
\hline
\end{tabular}

Tab 9.1. Créditos do LEED ${ }^{\circ}$ for Neighborhood Development, versão 2009. Porcentagens pelo autor. 

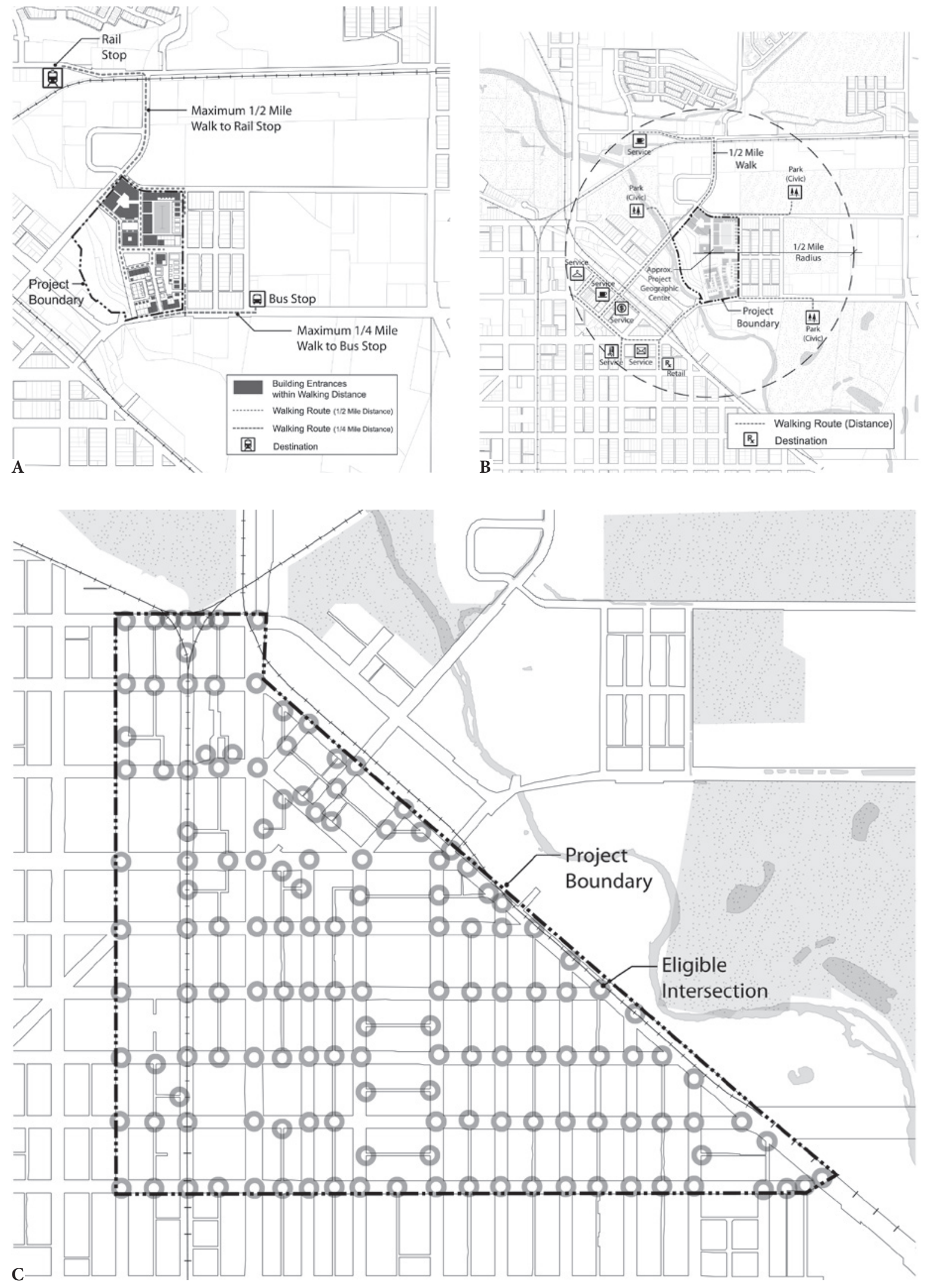

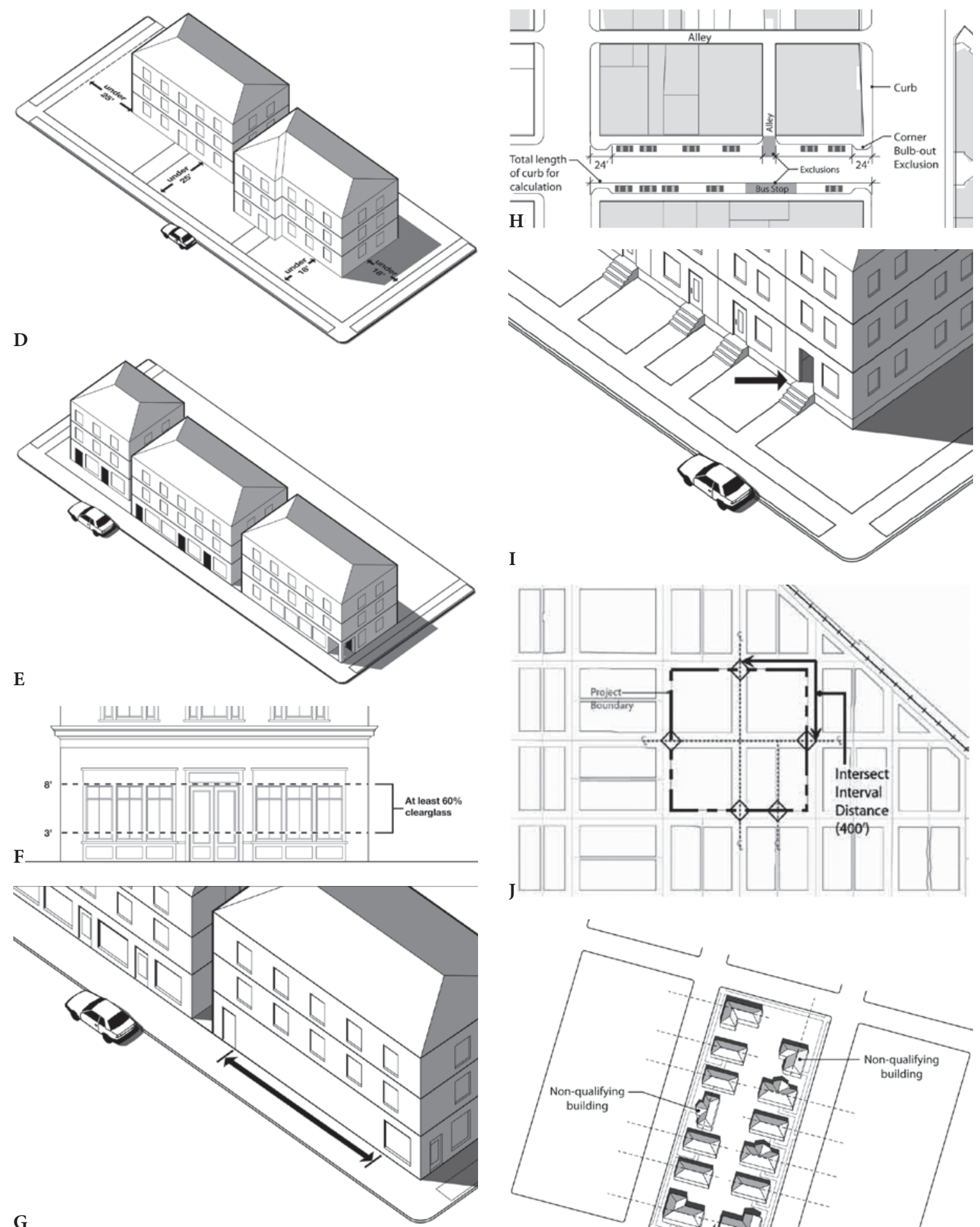

Fig 9.1. Seleção de esquemas de projeto publicados no LEED ${ }^{\circledR} \mathrm{ND}$, versão 2009.
A. Distância até ponto de ônibus (SS.Prereq.1)
B. Distância até usos não residenciais (SS.Prereq.1)
C. Intersecções de ruas públicas (NPD.Prereq.3)
D. Recuos máximos de edifícos (NPD.1)
E. Distância máxima de entradas na fachada frontal (NPD.1)
F. Desenho e proporção de vitrines comerciais (NPD.1)

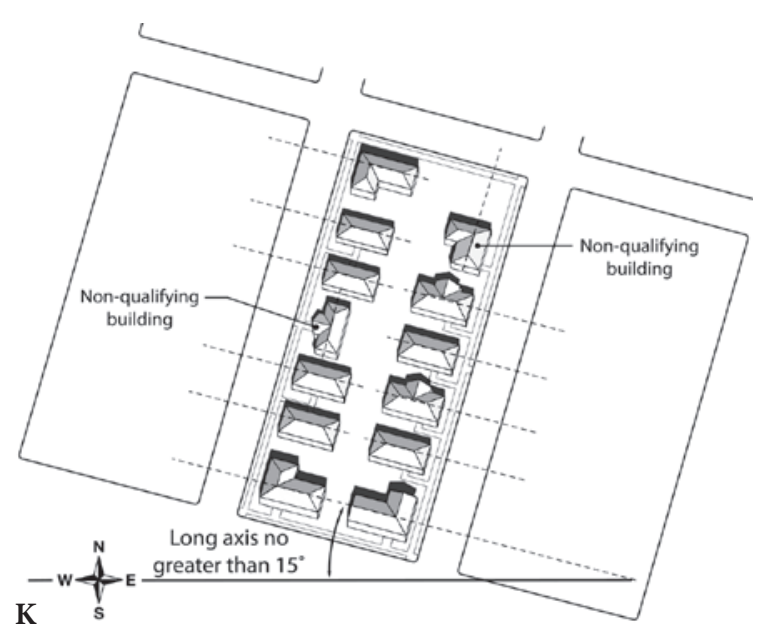

G. Distância máxima de fachada frontal térrea cega (NPD.1) H. Especificações para estacionamento a meio-fio (NPD.1) I. Elevação mínima de unidades residenciais térreas (NPD.1)

J. Intersecções no limite do empreendimento (NPD.6)

K. Orientação solar majoritária dos edifícios (GIB.10) 


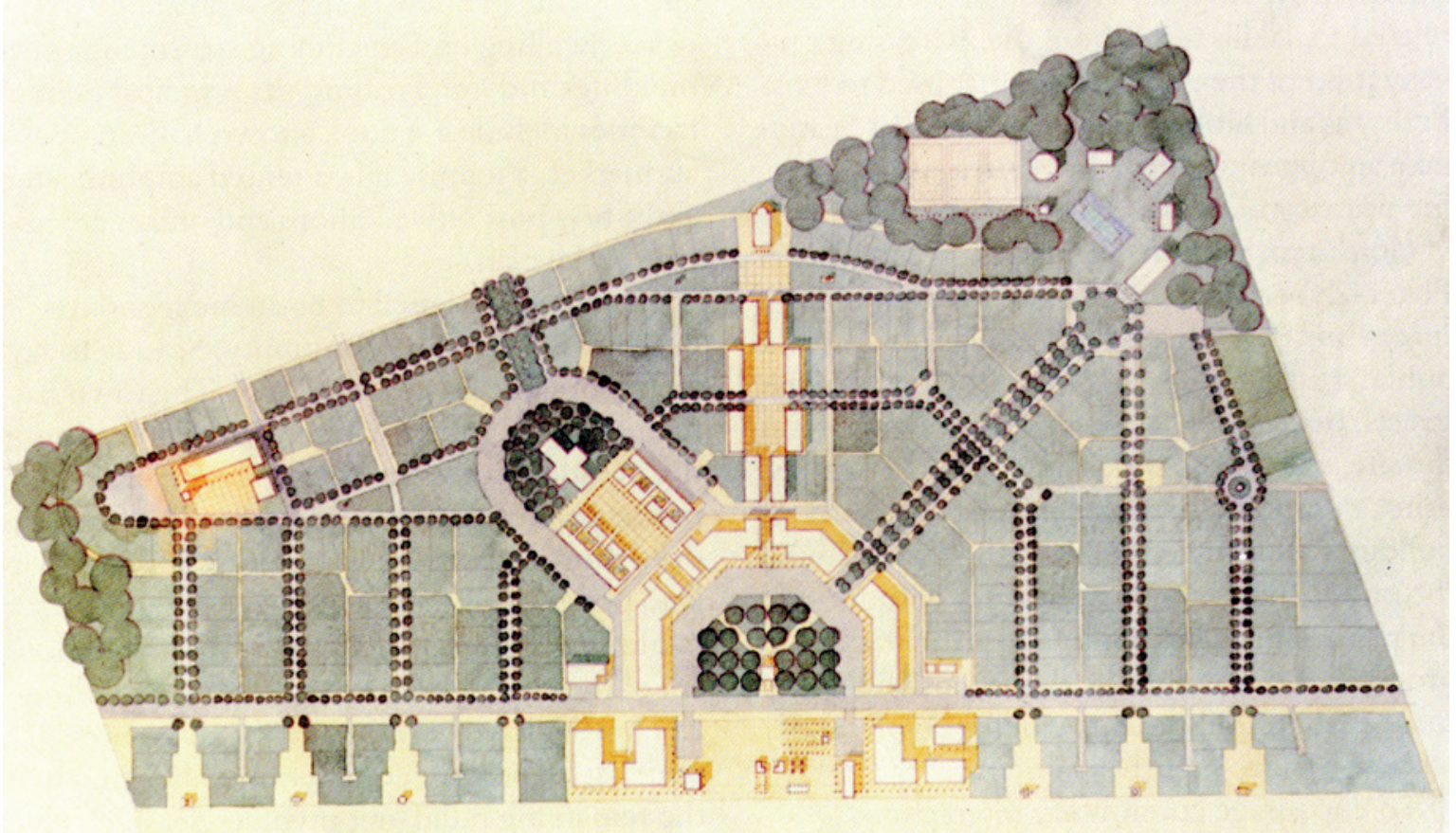

Fig 9.2. DPZ, Seaside (1978/1985). Fonte: Katz, The New

Urbanism.

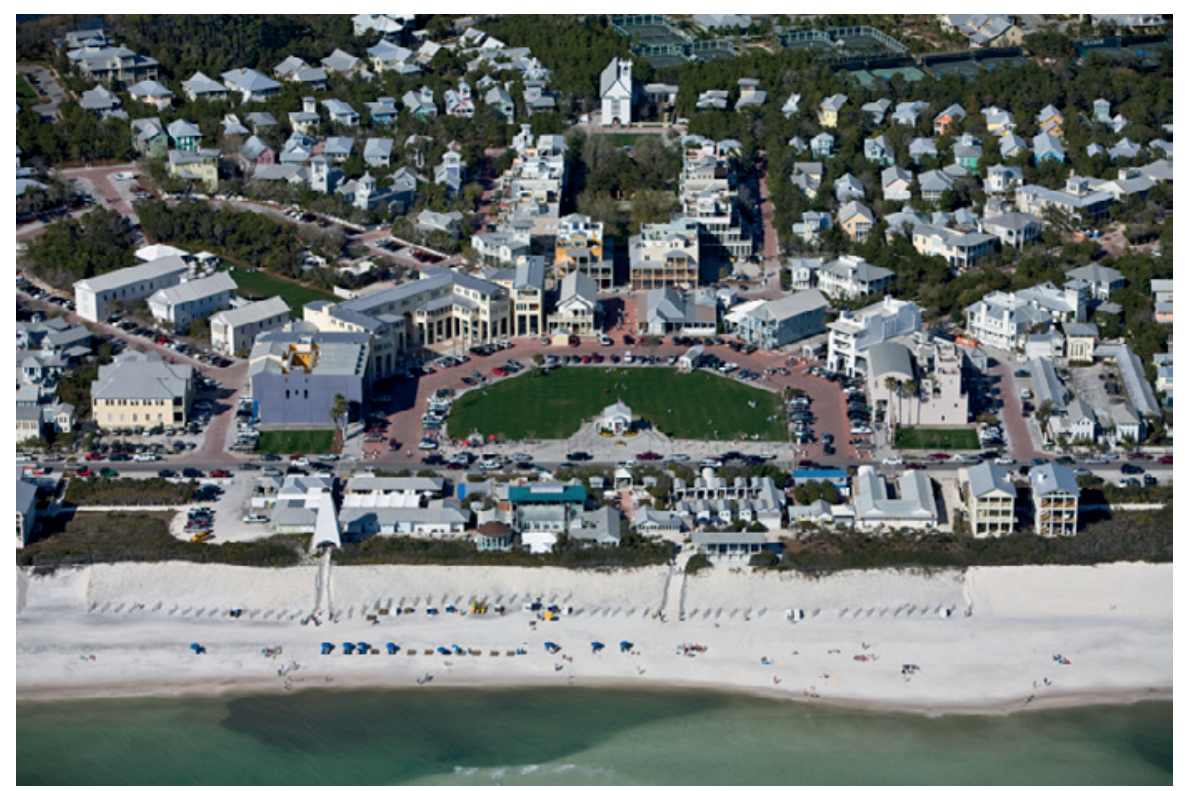

Fig 9.3. DPZ, Seaside (1978/1985). Fonte: DPZ, acervo online. 
teve sua primeira edição em 1993, mesmo ano de fundação do USGBC ${ }^{\oplus}$, formado por alumni vindos sobretudo das faculdades de arquitetura de Princeton e Yale: Peter Calthorpe, Robert Davis, Andrés Duany, Elizabeth Moule, Elizabeth Plater-Zyberk, Stefanos Polyzoides e Daniel Solomon. Na carta aprovada na quarta edição, em 1996, os new urbanists afirmaram que

os bairros devem ter populações e usos diversificados; as comunidades devem ser concebidas não só para o automóvel, como também para o pedestre e o transporte coletivo; as cidades pequenas e médias devem ser moldadas por instituições comunitárias e espaços públicos fisicamente definidos e universalmente acessíveis; os espaços urbanos devem ser definidos por um projeto paisagístico e arquitetônico que celebre a prática edilícia, a ecologia, o clima e a história locais. ${ }^{15}$

Para isso, os new urbanists estabeleciam em sua carta diretrizes gerais de projeto para atuar desde a escala da metrópole até a do edifício. Embora as ênfases variem entre cada membro, o CNU consolidava estratégias de desenho urbano que já vinham sendo elaboradas pelo menos desde o fim da década de 1970.

A literatura do New Urbanism critica três fenômenos urbanísticos. O primeiro fenômeno criticado é o urbanismo moderno, predominante no planejamento urbano de Estado especialmente a partir do pós-guerra. Embora inicialmente o urbanismo moderno combatesse os problemas sanitários da cidade tradicional e sua dificuldade em absorver a industrialização e o automóvel, o New Urbanism vê nele a construção de uma cidade de setores monofuncionais, baixa capacidade de apropriação cívica e favorecimento do automóvel sobre a escala do pedestre. O segundo fenômeno é o subúrbio norte-americano, também surgido no pós-guerra. A tipologia estava ligada ao sonho da classe média de fuga da cidade tradicional rumo a uma paisagem natural, mas o grupo vê ali o surgimento de inúmeras patologias sociais: a hiperdependência do carro, pois as baixas densidades requeriam viagens motorizadas para qualquer atividade; o aumento da obesidade em crescimento indiretamente proporcional às viagens a pé; e a ineficiência da infraestrutura urbana ao conectar atividades e usos distantes entre si. Por fim, o terceiro fenômeno

15. Congresso para o novo urbanismo, "Carta do novo urbanismo", in O campo ampliado da arquitetura: antologia teórica 1993-2009, org. A. Krista Sykes, trad. Denise Bottmann e Roberto Grey, [Ed. orig. 2010], , (São Paulo: CosacNaify, 2013 ), 53. 


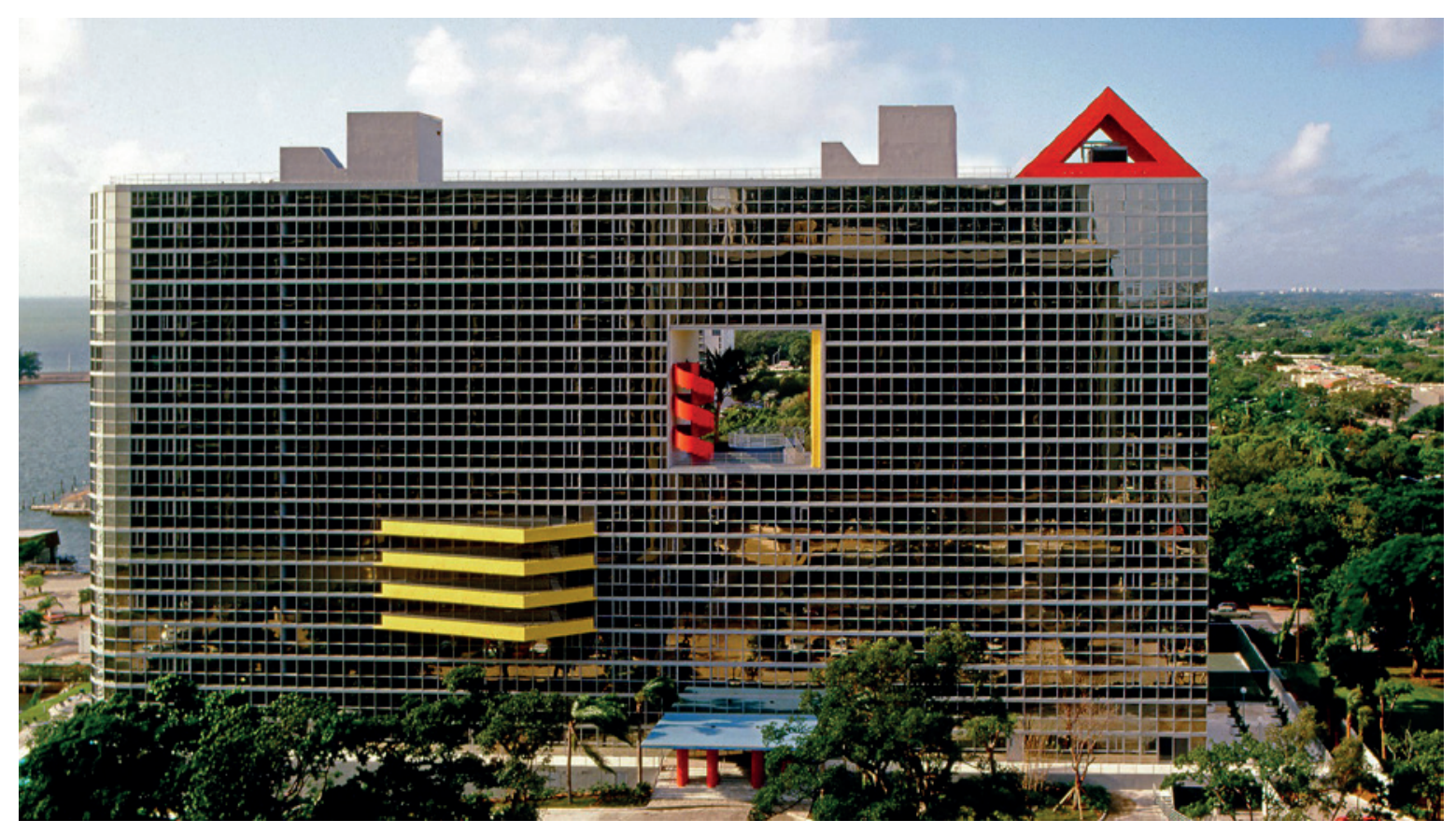

Fig 9.4. Arquitectonica, Atlantis (1980/1982). Fonte:

Arquitectonica, acervo online.

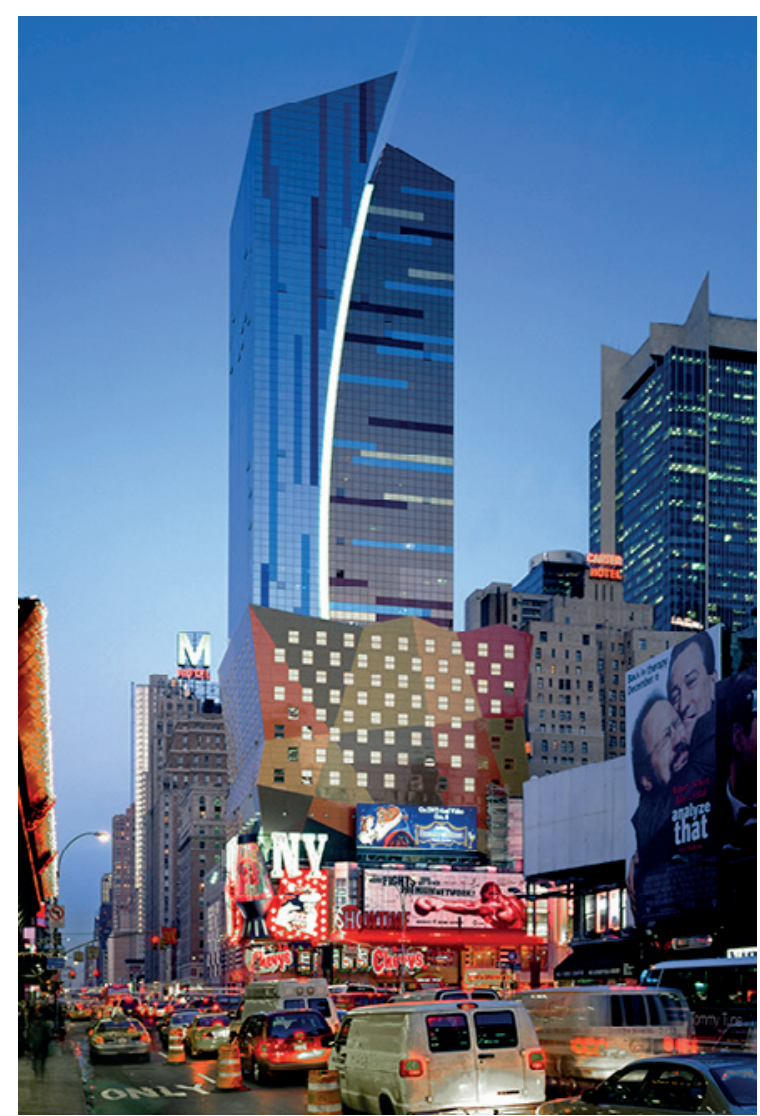

Fig 9.5. Arquitectonica, Westin New York (1995/2002). Fonte: Arquitectonica, acervo online.

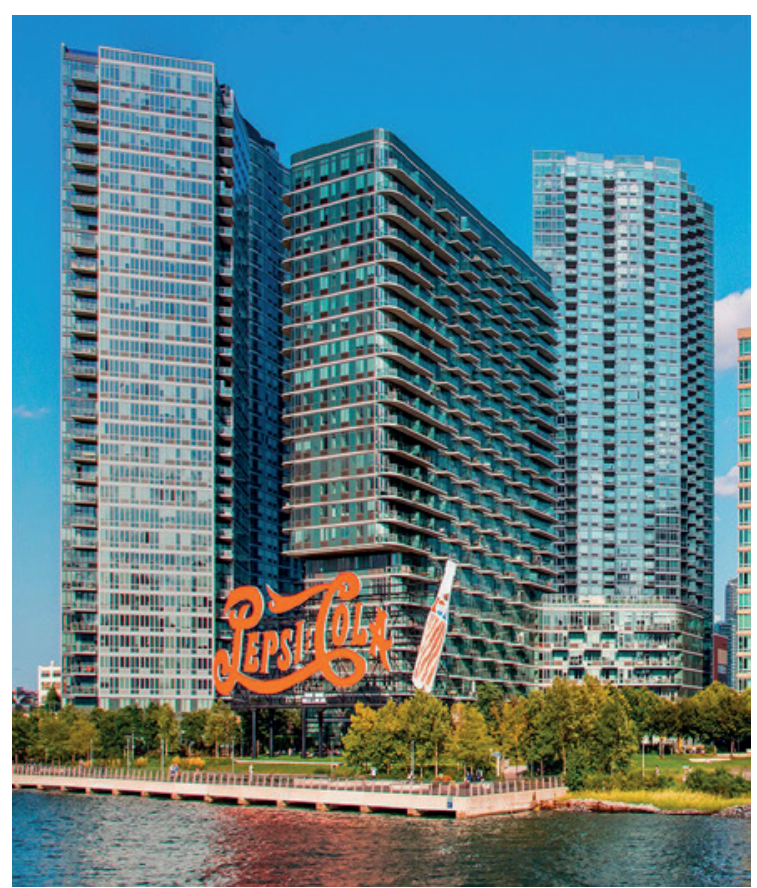

Fig 9.6. Arquitectonica, Queens West (c2001/2014). Fonte: Arquitectonica, acervo online. 
combatido pelo New Urbanism é o crescimento descontrolado dos centros urbanos, nos quais a falta de planejamento teria anulado a possibilidade de apropriação pela população. ${ }^{16}$

Esses três fenômenos são combatidos pela redescoberta das tipologias da cidade tradicional negada pelos modernos. O New Urbanism revê a particularidade do local em oposição à abstração universalizante do modernismo e revisa o papel do repertório histórico nas estratégias de projeto. Os arquitetos pretendem retomar a organicidade do crescimento da cidade tradicional, onde encontram qualidades como seu amadurecimento ao longo do tempo, a conectividade de espaços e o pluralismo de atividades e usuários. ${ }^{17}$

Os experimentos do New Urbanism remontam ao Seaside, um condomínio de veraneio na Flórida projetado entre 1978 e 1985 [fig 9.2 e 9.3]. Os arquitetos Andrés Duany e Elizabeth Plater-Zyberk propuseram um pequeno vilarejo cujos edifícios não seriam necessariamente por eles projetados, mas por arquitetos convidados que deveriam seguir parâmetros de proporções e linguagem arquitetônica referentes à arquitetura popular norte-americana. O resultado era, para Kurt Andersen, uma tensão entre um projeto democrático, pela inexistência de cercamento e ostentação, e um conservador, pela nostalgia estilística e pelo fato de os moradores serem homogeneamente de classe média. ${ }^{18}$

Além de arquitetos como Léon Krier e Steven Holl, participou do projeto das unidades desse condomínio o Arquitectonica, o escritório responsável pelo complexo WTJK discutido na parte III. Na época do Seaside, os arquitetos Duany e Plater-Zyberk haviam recentemente co-fundado o Arquitectonica, uma sociedade desfeita poucos anos depois quando ficaram claras as diferenças de projeto em relação a Bernardo Fort-Brescia e Laurinda H. Spear, o outro casal de fundadores. Os primeiros criaram, em seguida, o escritório de arquitetura DPZ. A cisão entre os dois casais coincide com a tensão interna ao pós-modernismo: para os primeiros, o pós-modernismo era o contextualismo e a linguagem da tradição; para os últimos, ele era a arquitetura como

16. Philip Langdon, A better place to live: reshaping the American suburb (Amherst: The University of Massachusetts Press, 1994); David Harvey, "The New Urbanism and the communitarian trap", Harvard Design Magazine, n 1 (inverno-primavera de 1997); Farr, Sustainable urbanism.

17. Sonia A. Hirt, "Premodern, modern, postmodern? Placing New Urbanism into a historical perspective”, Journal of Planning History 8, $\mathrm{n}^{\circ} 3$ (agosto de 2009): 248-73, https://doi.org/10.1177/1538513209338902.

18. In David Mohney e Keller Easterling, Seaside: making a town in America (New York: Princeton Architectural Press, 1991). 


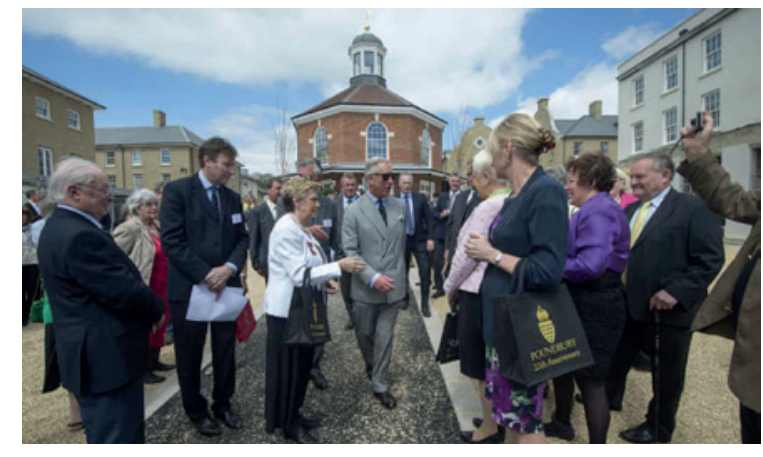

Fig 9.7. Príncipe Charles, defensor do New Urbanism, visita Poundbury, projeto de Léon Krier (1988/1993). Fonte: Paul Grover/REX via Oliver Wainwright, "A royal revolution: is Prince Charles's model village having the last laugh?", The Guardian, 27 out 2016.

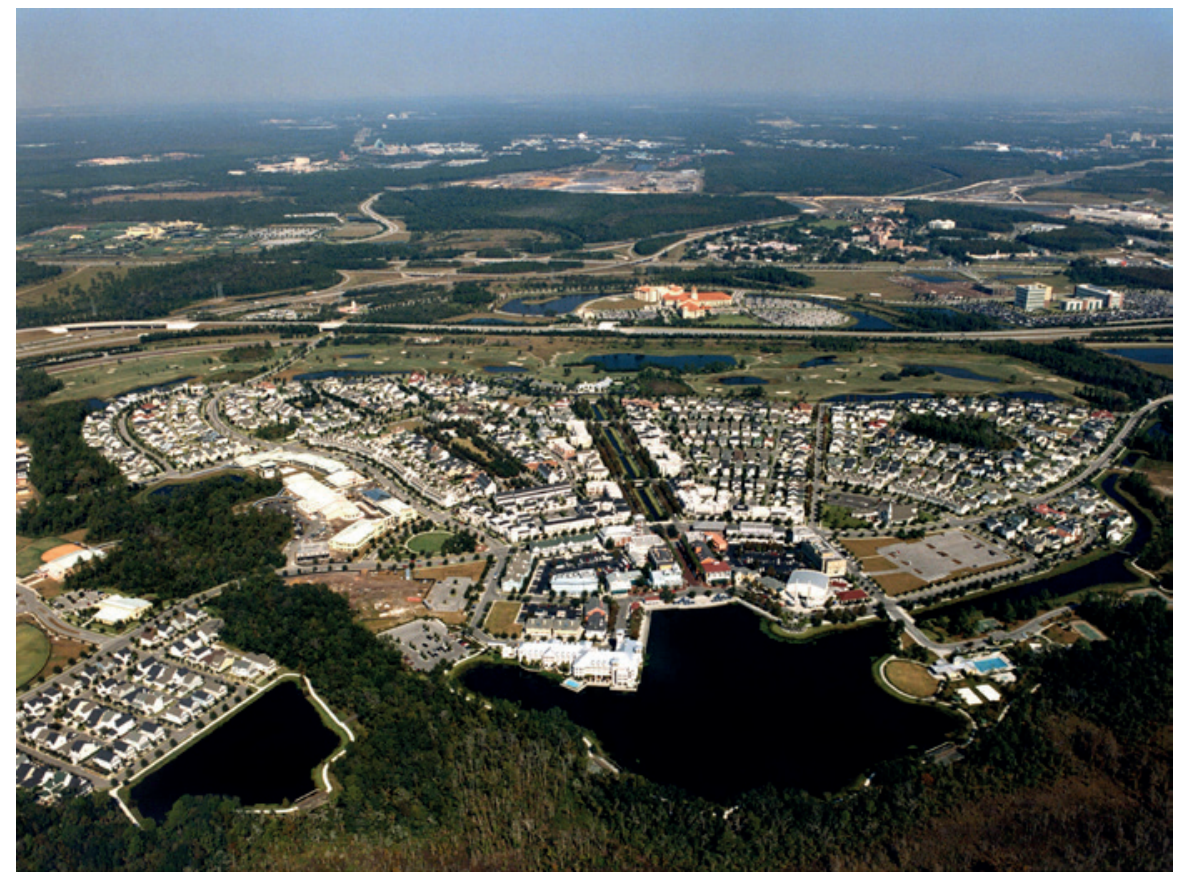

Fig 9.8. Robert A.M. Stern Architects, Celebration

(1994/1997). Fonte: RAMSA, acervo online.

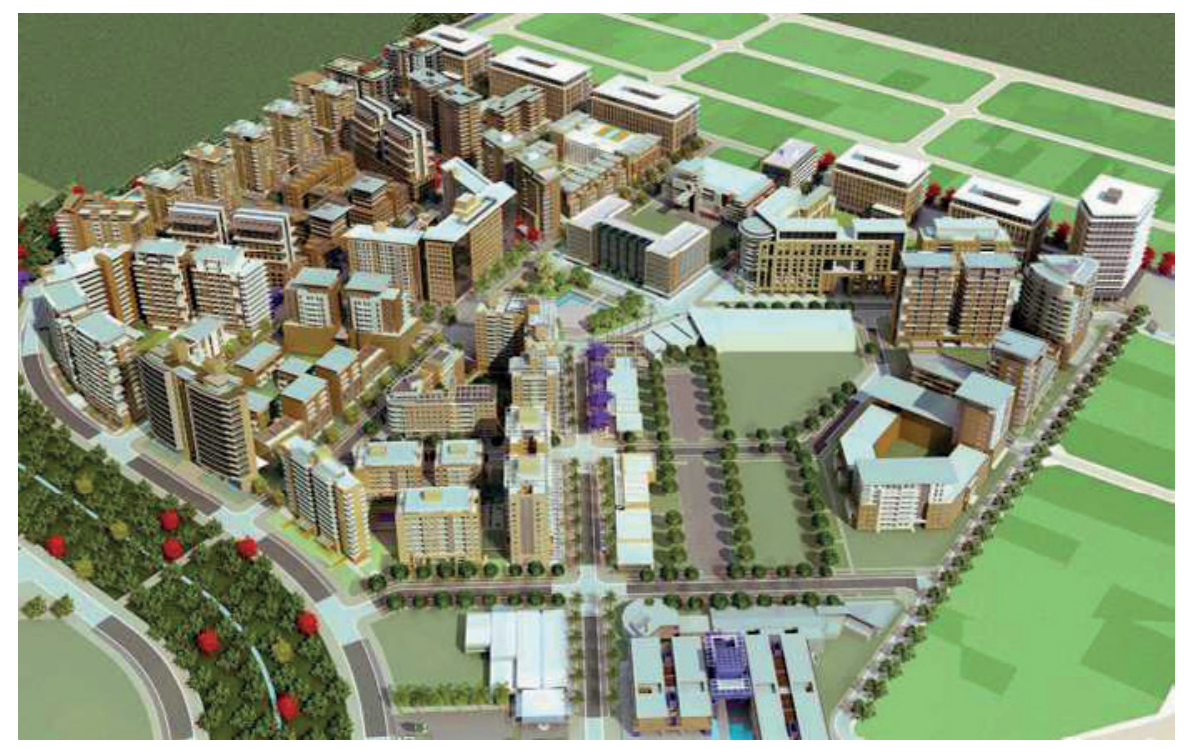

Fig 9.9. DPZ, Pedra Branca (2005). Fonte: Pedra Branca, acervo online. 
comunicação. Segundo o crítico Herbet Muschamp, Duany e Plater-Zyberk teriam acusado “o Arquitectonica de criar edifícios que parecem bons a partir de carros em movimento." ${ }^{19}$ De fato, a comunicação pop do Arquitectonica está presente tanto em fatores relativamente contingenciais, como seu edifício Atlantis (1980/1982) [fig 9.4] usado como pano de fundo para a série televisiva Miami Vice ${ }^{20}$ quanto nas dobras coloridas do edifício Westin New York (1995/2002) [fig 9.5], e também o Queens West, construído no terreno de uma antiga fábrica da Pepsi, da qual preservou o letreiro (c2001/2014) [fig 9.6]. ${ }^{21}$ De modo aparentemente contraditório, essa comunicação pop se transformou vinte e cinco anos depois no novo estágio do estilo internacional do WTJK. Mas só aparentemente contraditório: Hal Foster já discutiu como o pop, passadas suas formas venturianas iniciais, desviou seu aparato comunicativo para o skyline de torres de vidro do "estilo global" atual, nas quais o pastiche deu lugar à planaridade e à construção de uma imagem transnacional. ${ }^{22}$

O projeto do Seaside antecipa outros casos célebres do New Urbanism, como o bairro de Poundbury de Léon Krier (1988/1993) [fig 9.7], que tomava como referência a cidade tradicional inglesa, ou a Celebration da Disney, de Robert A.M. Stern (1994/1997) [fig 9.8], significativamente mais estrita em termos de código de linguagem construtiva pela sua minuciosa coordenação de diretrizes para projeto e uso dos edifícios. No Brasil, o maior exemplo de New Urbanism é o Pedra Branca, em Palhoça, Santa Catarina, do DPZ e consultorias de Jaime Lerner, Jan Gehl e Arup (2005) [fig 9.9].

Embora busquem a pluralidade de renda e etnias, os projetos do New Urbanism tendem a se restringir a empreendimentos de classes média ou alta, o que pode ser notado tanto pelos exemplos privilegiados pela literatura quanto pelos dados empíricos disponíveis. Do ponto de vista téorico, David Harvey nota como existe uma agenda de transformação do subúrbio norte-americano, mas sem adentrar as contradições dos centros de cidade, ${ }^{23}$ o que Vincent Scully chamou de "New Suburbanism" em um posfácio de um insuspeito livro de apresentação do mo-

19. No original: "have accused Arquitectonica of creating buildings that look good from moving cars." Herbert Muschamp, "Miami virtue: Arquitectonica’s low-rent housing", The New York Times, 11 de julho de 1993, tradução nossa.

20. O fato de o próprio Seaside de Duany e Plater-Zyberk tornar-se cenário para o filme O show de Truman (1998), ou de a Disney encomendar a cidade de Celebration para Robert A.M. Stern no começo dos anos 1990, apenas reforça o caráter pop do pós-modernismo, mesmo naquele de viés comunitário e conservador.

21. David W. Dunlap, "Saving a spot for Pepsi-Cola as a tower goes up", The New York Times, 10 de julho de 2013.

22. Hal Foster, O complexo arte-arquitetura, [Ed. orig. 2013] (São Paulo: CosacNaify, 2015).

23. Harvey, "The New Urbanism and the communitarian trap". 
vimento. ${ }^{24}$ Mesmo apologistas como Philip Langdon evidenciam o dilema, como no subtítulo de seu livro: "remodelando o subúrbio norte-americano". ${ }^{25}$ A conclusão é a mesma do ponto de vista empírico: um estudo analisou 642 empreendimentos do New Urbanism nos primeiros vinte anos de sua existência e observou a tendência desses projetos se localizarem em áreas de maior valor de propriedade e melhores condições socioeconômicas dos moradores. ${ }^{26}$

Além da homogeneidade, a principal crítica sofrida pelo New Urbanism diz respeito ao que seria um determinismo espacial, pelo qual os new urbanists pregariam que a mudança da forma urbana acarretaria o restabelecimento dos laços comunitários. Para os opositores, a solução evitaria o enfrentamento de questões relativas à economia política: na sua ênfase na forma comunitária, mas suburbana e de população homogênea, o New Urbanism manteria as contradições e desigualdades dos esquemas urbanos anteriores. ${ }^{27}$ Cuthbert chega a argumentar que o movimento é "uma reação de classe aos problemas percebidos na vida pós-moderna das cidades; em outras palavras é ideológico": ${ }^{28}$ sua restrição aos aspectos formais do urbanismo não daria conta de responder aos problemas urbanos, a não ser por essa limitação inerente a suas propostas. ${ }^{29}$

Retornando ainda mais no tempo, a crítica se ramifica até o debate do pós-modernismo contextualista: a retomada de ideais comunitários seria não só conservadora, como dizia Lefebvre, mas também impossível de ser realizada em um estágio de capitalismo avançado e suas lógicas de organização econômica e espacial. ${ }^{30}$ Ademais, equipamentos de grande porte como óperas, grandes hospitais e museus não são possíveis em aglomerações de pequeno porte. ${ }^{31} \mathrm{Em}$ sentido si-

24. In Peter Katz, The new urbanism: toward an architecture of community, Posfácio de Vincent Scully. Ensaios de Todd W. Bressi, Andres Duany, Elizabeth Moule, Stefanos Polyzoides e Elizabeth Plater-Zyberk (Nova York: McGraw-Hill, 1994); ver também Peter Marcuse, "The New Urbanism: the dangers so far", disP - The Planning Review 36, n 140 (2000): 4-6, https:// doi.org/10.1080/02513625.2000.10556727.

25. Langdon, A better place to live.

26. Yan Song et al., "An examination of early New Urbanist developments in the United States: where are they located and why?", Cities, no 61 (2017): 128-35, https://doi.org/10.1016/j.cities.2016.08.013.

27. Harvey, "The New Urbanism and the communitarian trap".

28. No original: "a class-based reaction to perceived problems of postmodern life in cities; in other words it is ideological" Alexander Cuthbert, The form of cities: political economy and urban design (Malden, EUA; Oxford, Inglaterra; Victoria, Austrália: Blackwell Publishing, 2006), 123, tradução nossa.

29. Alexander Cuthbert, Understanding cities: method in urban design (Oxford: Routledge, 2011), 126ss.

30. Henri Lefebvre, Le droit à la ville, 3a ed (Paris: Economica, 2009), 21.

31. Lefebvre fazia essa advertência em relação ao "tamanho ótimo de cidade" buscado por urbanistas soviéticos em meados da década de 1920. Se a cidade soviética ideal de 300.000 habitantes logo revelava suas limitações a Lefebvre, a contradição 
milar, Otília Arantes vê nesse pós-modernismo uma "ideologia comunitária", em que a reativação urbana passa pela retomada dos princípios da cidade tradicional a despeito do desaparecimento da vida social que ali se desenrolava. ${ }^{32}$ A estratégia dos new urbanists, desse modo, não é suburbana por uma contingência empírica, mas pelo próprio esquema projetual empregado. Certamente, uma cidade orientada para a experiência do pedestre é um avanço em relação às agendas urbanas hegemônicas, mas a falta de instrumentos para lidar com o espaço metropolitano impede a superação de mecanismos de segregação socioespacial. Se o New Urbanism assim trabalha, ele o faz por meio de procedimentos liberais, ao enfatizar a intervenção local destituída de preceitos diretores na escala da cidade. No entanto, apesar de seus problemas, o New Urbanism ainda atua em terreno relativamente consensual hoje, de valorização da experiência da rua e do adensamento das cidades - em contraposição a alguns desurbanistas que continuam a fazer apologia ao subúrbio. ${ }^{33}$

\section{TECIDO URBANO PARA 0 LEED@ FOR NEIGHBORHOOD DEVELOPMENT}

Tal como nos sistemas NC e CS, o LEED ${ }^{\circledR}$ ND também premia empreendimentos localizados em áreas urbanizadas e bem providas de infraestrutura, em concordância com sua filiação ao Smart Growth. O SLL.1 Preferred Locations, o segundo crédito com maior concentração de pontos no $\mathrm{ND}$, estabelece parâmetros para beneficiar não só empreendimentos em áreas urbanizadas, mas também para medir o grau de impacto do empreendimento. Bairros adjacentes a áreas urbanas ganham menos pontos do que outros nelas inseridos, assim como a implantação em um terreno já ocupado pontua menos do que outra realizada em um terreno baldio. Dificuldades também são impostas nos pré-requisitos da categoria SLL para empreendimentos em áreas agricultáveis, reservas naturais e outras situações de isolamento do tecido urbano. Essas características do LEED $^{\circledR} \mathrm{ND}$, além de serem mais detalhadas do que as dos sistemas NC e CS, têm impacto notadamente maior. Isso porque, se nos edifícios corporativos a localização em área central pode ser

\footnotetext{
é tanto maior na estratégia de projeto pelo fragmento, mesmo se comunitário, dos new urbanists. Cf. Henri Lefebvre, $L a$ révolution urbaine (Paris: Gallimard, 1970), 126.

32. Otília Beatriz Fiori Arantes, “A ideologia do 'lugar público’ na arquitetura contemporânea (um roteiro)”, in O lugar da arquitetura depois dos modernos, 3a [Ed. orig. 1993] (São Paulo: Edusp, 2000), 95-155.

33. Cf. debate nas seções iniciais de Cuthbert, Understanding cities, cap. 7.
} 
tomada como certa na configuração contemporânea das cidades, o mesmo não pode ser dito dos empreendimentos do $\mathrm{LEED}^{\circledR} \mathrm{ND}$, que podem ser condomínios residenciais, cidades universitárias, vilas militares, entre outros. Os obstáculos impostos à suburbanização pelo LEED ${ }^{\circledR} \mathrm{ND}$ contradizem fenômenos de isolamento radical de empreendimentos. Além disso, enquanto o New Urbanism trata sobretudo de núcleos suburbanos, o LEED ${ }^{\circledR} \mathrm{ND}$ foi aplicado em uma gama maior de empreendimentos, como galpões industriais abandonados, terrenos vazios em área urbana, campi universitários, pequenas ruas residenciais e bairros inteiros. ${ }^{34}$

$\mathrm{O} \mathrm{LEED}^{\circ} \mathrm{ND}$ incentiva a "conectividade", termo que se refere à quantidade de intersecções viárias por milha quadrada. Se ele não impede necessariamente o cercamento total ou parcial do empreendimento, o sistema inclui índices mínimos de conectividade interior ou exterior a serem atingidos que podem inviabilizar esse tipo de prática em exigências de pré-requisitos. ${ }^{35}$ Também de modo diferente dos sistemas NC e CS, há créditos pontuando a densidade de ocupação, a multiplicidade de atividades e a variedade de tipologias residenciais e de estratos de renda, em cerca de 24 pontos, o que vale não só para o entorno, mas sobretudo para o empreendimento implantado. ${ }^{36}$

Além desses critérios relacionados à localização do empreendimento na malha urbana e da sua oferta de usos, o $\mathrm{LEED}^{\oplus} \mathrm{ND}^{\mathrm{e}}$ exigente em relação às proporções dos edifícios, sobretudo na sua relação com a rua e de seu impacto no desenho urbano. Se o EA.1 Optimize Energy Performance era o principal crédito dos sistemas NC e CS, no ND o mesmo pode ser dito sobre o NPD. 1 Walkable Streets, com quase 11\% dos pontos possíveis. O crédito estipula características para o embasamento: 1) ao menos $80 \%$ das fachadas do projeto viradas para a rua devem estar a até $7,6 \mathrm{~m}$ da divisa da propriedade; 2 ) ao menos $50 \%$ das fachadas do projeto viradas para a rua devem estar a até 5,5 $\mathrm{m}$ da divisa da propriedade; 3 ) ao menos $50 \%$ das fachadas viradas para a rua de edifícios não-residenciais ou mistos estão a até $30 \mathrm{~cm}$ da divisa da propriedade; 4) as entradas principais (em oposição às de serviço) devem estar distantes em média e no mínimo a 22,8 m entre si; 5) as entradas principais de edifícios não residenciais ou mistos devem estar distantes

\footnotetext{
34. Katie Weeks e Sophie Lambert, “A deeper look at LEED-ND”, Architect, 3 de junho de 2010, https://www.architectmagazine.com/technology/a-deeper-look-at-leed-nd_o.

35. NPD.Prereq.3 Connected and Open Community.

36. Podem ser considerados nessa listagem os seguintes créditos: SLL.5 Housing and Jobs Proximity, NPD.2 Compact Development, NPD.3 Mixed-Use Neighborhood Centers, NPD.4 Mixed-Income Diverse Communities, NPD.9 Access to Civic and Public Space, NPD.10 Access to Recreation Facilities, NPD.13 Local Food Production e NPD.15 Neighborhood Schools.
} 
em média e no mínimo a 9,1 m entre si; 6) o comércio no térreo deve ter ao menos $60 \%$ de área envidraçada entre os limites de 0,9 e 2,4 m acima do nível da rua; 7) não pode existir mais de 15 $m$ de fachada cega no nível da rua; 8) o comércio no térreo não pode ser fechado com venezianas ou portas de ferro durante a noite; 9) deve haver estacionamento em ao menos $70 \%$ das ruas, em ambos os lados; 10) devem existir calçadas em todas as ruas do projeto, em ambos os lados; 11) as unidades residenciais do térreo não podem estar elevadas a mais de $60 \mathrm{~cm}$ do nível da rua; 12) ao menos 50\% do edifícios de escritório devem ter comércio no térreo; 13) ao menos $40 \%$ dos edifícios virados para a rua devem ter uma proporção mínima de 1:3 entre sua altura e a distância para a rua; 14) 75\% das ruas exclusivamente residenciais do projeto devem ter velocidade máxima de $30 \mathrm{~km} / \mathrm{h}$; 15) 70\% da ruas não residenciais do projeto devem ter velocidade máxima de $40 \mathrm{~km} / \mathrm{h}$; 16) cruzamentos em nível com a rua não podem superar $10 \%$ da largura das calçadas no projeto. Os pontos são concedidos a depender da quantidade de especificações cumpridas: pelo menos duas especificações conferem um ponto; pelo menos quinze conferem o máximo de doze pontos.

Ao contrário do New Urbanism, o LEED ${ }^{\circledR}$ ND não apresenta diretrizes de linguagem arquitetônica: um edifício não precisa remeter a uma cidade tradicional e vernacular idealizada para atingir os pontos. Mas o sistema retoma a ideia de quadra já prevista nesse movimento, com o estabelecimento de um perímetro totalmente ocupado - ao menos em seu embasamento -, um térreo com vitrines e janelas para os passantes e a reconstituição do tecido urbano. ${ }^{37} \mathrm{O}$ LEED ${ }^{\circ} \mathrm{ND}$ elimina os obstáculos entre edifícios e pedestres, seja os presentes em recuos, desníveis, cercamentos, estacionamentos ou muros. Ele contradiz, assim, o esquema projetual de figura e fundo implícito nos sistemas NC e CS.

Pela sua relação com o New Urbanism, um movimento há décadas em atuação, e também pela própria consolidação do USGBC ${ }^{\oplus}$, já mais estruturado após quinze anos de atuação, não

\footnotetext{
37. Phillipe Panerai et al., Urban forms: the death and life of the urban block (Oxford: Architectural Press; Elsevier, 2004). Para os propósitos desta tese, a versão inglesa é mais relevante do que a francesa, em razão de seu epílogo com análise do New Urbanism. O livro demonstra, com isso, como o quarteirão se desintegrou progressivamente ao longo do século XX, para ser retomado por arquitetos anglo-saxães no fim do período.
} 


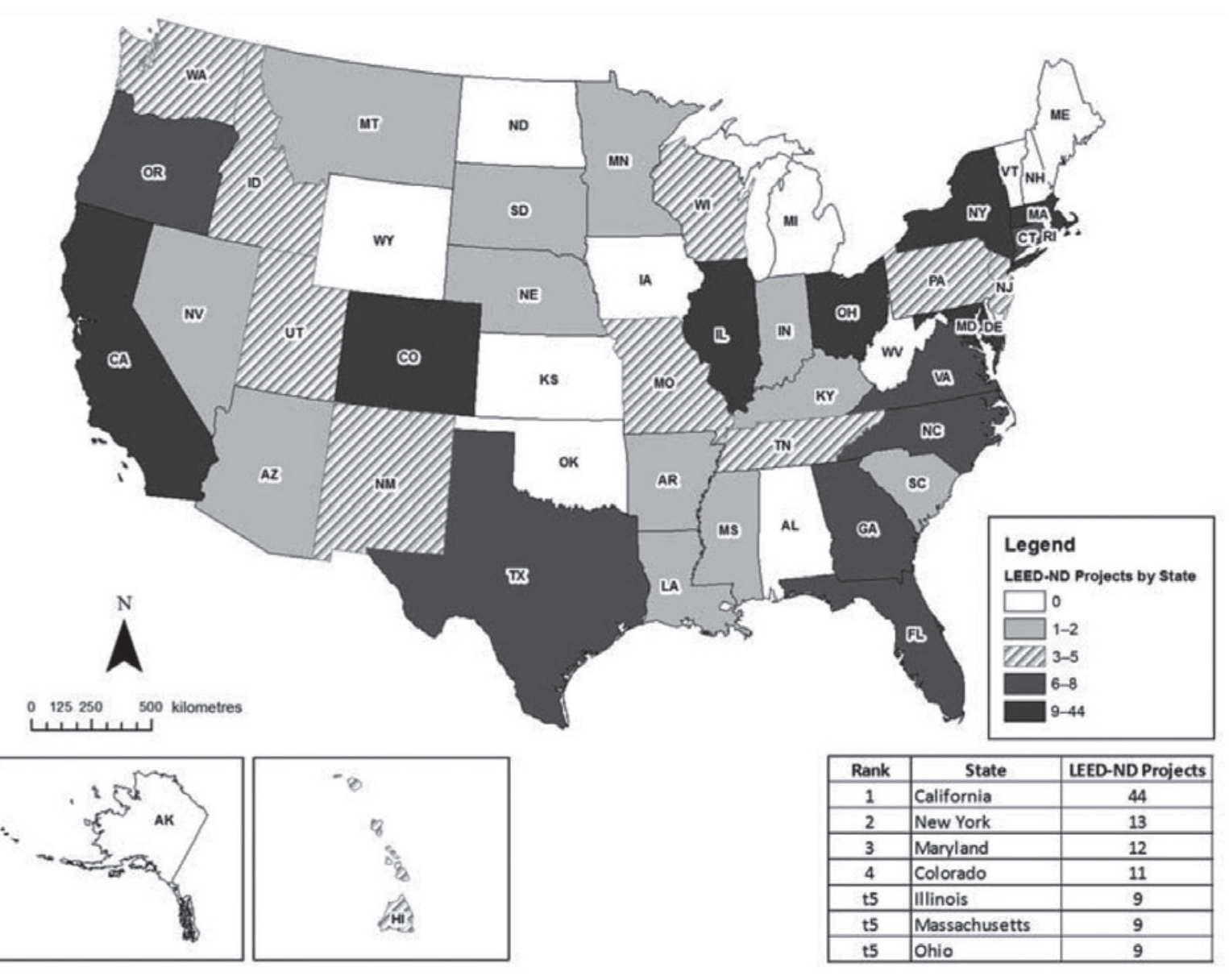

Fig 9.10. Distribuição de empreendimentos certificados LEED $^{\circ}$ ND nos Estados Unidos. Fonte: Smith, "Planning for urban sustainability". 
existe propriamente um protótipo do LEED ${ }^{\circledR}$ ND tal como havia no NC. Seus protótipos são, de certo modo, os condomínios do New Urbanism feitos nas décadas anteriores, ou ao menos os 140 empreendimentos inscritos na versão piloto, que contribuíram para algumas correções na versão posteriormente comercializada. Os empreendimentos certificados tendem, tal como visto anteriormente em outros casos, a se concentrar em alguns locais dos Estados Unidos [fig 9.10]. Após a primeira rodada de empreendimentos piloto, ajustes foram feitos, como a permissão para pequenas construções em áreas de várzea, ou tentativas de consenso entre os três órgãos fundadores: na impossibilidade de acordo entre eles, os créditos ou passaram a oferecer alternativas em seu cumprimento, ou transformaram o que era imaginado como pré-requisito para cumprimento apenas facultativo. ${ }^{38}$ Foi o caso da provisão de habitação a baixo custo, inicialmente um pré-requisito, mas inserida apenas como crédito opcional após discordâncias entre os órgãos. ${ }^{39}$ Foi o caso também da exigência de parâmetros mínimos de eficiência energética e hídrica, que estavam ausentes da versão piloto, o que permitia empreendimentos "sustentáveis" sem nenhuma melhoria no consumo de recursos naturais. ${ }^{40}$

A partir de 73 empreendimentos piloto, Ajay Garde nota a preferência pelo cumprimento de créditos das categorias SLL e NPD. Os projetos privilegiam sua localização e desenho urbano, portanto, antes das inovações tecnológicas e eficiências que podem ser alcançadas pela categoria GIB, de maior custo. ${ }^{41}$ Com a adoção da mesma metodologia, tendência ainda mais acentuada é vista quando detalhada a pontuação dos empreendimentos norte-americanos certificados na versão de 2009 [tab 9.2 e 9.3, fig 9.11]. E o mesmo pode ser visto em estudos de caso norte-americanos: tomando como base aqueles considerados excepcionais por Douglas Farr, são encontrados os mesmos padrões de constituição de quarteirões mencionados anteriormente [fig 9.12 a 9.14]. ${ }^{42}$ Essas tendências são diferentes em contexto brasileiro, como se verá no próximo capítulo.

\footnotetext{
38. Weeks e Lambert, "A deeper look at LEED-ND".

39. Weeks e Lambert.

40. Ayay Garde, "Sustainable by design?: insights from US LEED-ND pilot projects", Journal of the American Planning Association 75, no 4 (2009): 424-40, https://doi.org/10.1080/01944360903148174.

41. Garde.

42. Douglas Farr, Sustainable nation: urban design patterns for the future, Prefácio de Janette Sadik-Khan (Hoboken, NJ: John Wiley \& Sons, 2018). Nos estudos elencados nas imagens, não foi inserido o empreendimento de Paseo Verde, na Philadelphia, que Farr afirma ser o primeiro LEED ND Platinum. Comparando-o com os dados do LEED Project Directory, tem-se que o projeto foi certificado na verdade pelo LEED Homes.
} 


\begin{tabular}{|c|c|c|c|c|}
\hline \# & Categorias e créditos & Máx. & Média & \% Cumprimento \\
\hline SLL & Smart Location and Linkage & 30 & 17,6 & \\
\hline SLL.3 & Preferred Location & 10 & 6,9 & $95,9 \%$ \\
\hline SLL.4 & Reduced Automobile Dependence & 8 & 4 & $91,8 \%$ \\
\hline SLL.6 & Housing and Jobs Proximity & 3 & 2,3 & $84,9 \%$ \\
\hline SLL. 5 & Bicycle Network & 1 & 0,8 & $76,7 \%$ \\
\hline SLL.7 & School Proximity & 1 & 0,7 & $72,6 \%$ \\
\hline SLL.8 & Steep Slope Protection & 1 & 0,7 & $65,8 \%$ \\
\hline SLL.9 & Site Design for Habitat or Wetlands Conservation & 1 & 0,6 & $56,2 \%$ \\
\hline SLL.1 & Brownfield Redevelopment & 2 & 0,9 & $45,2 \%$ \\
\hline SLL.11 & Conservation Management of Habitat or Wetlands & 1 & 0,3 & $35,6 \%$ \\
\hline SLL.10 & Restoration of Habitat or Wetlands & 1 & 0,3 & $34,2 \%$ \\
\hline SLL. 2 & High Priority Brownfields Redevelopment & 1 & 0,1 & $13,7 \%$ \\
\hline NPD & Neighborhood Pattern and Design & 39 & 24,2 & \\
\hline NPD.2 & Diversity of Uses & 4 & 3,3 & $98,6 \%$ \\
\hline NPD.7 & Walkable Streets & 8 & 6,1 & $95,9 \%$ \\
\hline NPD.13 & Access to Active Public Spaces & 1 & 0,9 & $91,8 \%$ \\
\hline NPD.15 & Community Outreach and Involvement & 1 & 0,9 & $90,4 \%$ \\
\hline NPD.12 & Access to Public Spaces & 1 & 0,9 & $89,0 \%$ \\
\hline NPD.11 & Access to Surrounding Vicinity & 1 & 0,9 & $87,7 \%$ \\
\hline NPD.1 & Compact Development & 7 & 2,9 & $86,3 \%$ \\
\hline NPD.3 & Diversity of Housing Types & 3 & 1,7 & $80,8 \%$ \\
\hline NPD. 8 & Street Network & 2 & 1,3 & $79,5 \%$ \\
\hline NPD.6 & Reduced Parking Footprint & 2 & 1,3 & $69,9 \%$ \\
\hline NPD.9 & Transit Facilities & 1 & 0,6 & $63,0 \%$ \\
\hline NPD.14 & Universal Accessibility & 1 & 0,6 & $63,0 \%$ \\
\hline NPD.5 & Affordable For-Sale Housing & 2 & 0,9 & $57,5 \%$ \\
\hline NPD.10 & Transportation Demand Management & 2 & 0,8 & $54,8 \%$ \\
\hline NPD.4 & Affordable Rental Housing & 2 & 0,8 & $47,9 \%$ \\
\hline NPD.16 & Local Food Production & 1 & 0,3 & $27,4 \%$ \\
\hline
\end{tabular}




\begin{tabular}{|c|c|c|c|c|}
\hline$\#$ & Categorias e créditos & Máx. & Média & \% Cumprimento \\
\hline GIB & Green Infrastructure and Buildings & 31 & 15,1 & \\
\hline GIB.9 & Stormwater Management & 5 & 2,9 & $86,3 \%$ \\
\hline GIB.6 & Minimize Site Disturbance through Site Design & 1 & 0,8 & $82,2 \%$ \\
\hline GIB.7 & Minimize Site Disturbance during Construction & 1 & 0,8 & $82,2 \%$ \\
\hline GIB.3 & Reduced Water Use & 3 & 1,6 & $79,5 \%$ \\
\hline GIB.10 & Heat Island Reduction & 1 & 0,8 & $75,3 \%$ \\
\hline GIB.19 & Comprehensive Waste Management & 1 & 0,7 & $74,0 \%$ \\
\hline GIB.2 & Energy Efficiency in Buildings & 3 & 1,5 & $72,6 \%$ \\
\hline GIB.18 & Construction Waste Management & 1 & 0,7 & $71,2 \%$ \\
\hline GIB.20 & Light Pollution Reduction & 1 & 0,6 & $64,4 \%$ \\
\hline GIB.1 & LEED Certified Green Buildings & 3 & 1,5 & $63,0 \%$ \\
\hline GIB.15 & Infrastructure Energy Efficiency & 1 & 0,6 & $63,0 \%$ \\
\hline GIB.17 & Recycled Content for Infrastructure & 1 & 0,5 & $53,4 \%$ \\
\hline GIB.4 & Building Reuse and Adaptative Reuse & 2 & 0,5 & $32,9 \%$ \\
\hline GIB.11 & Solar Orientation & 1 & 0,3 & $31,5 \%$ \\
\hline GIB.13 & On-Site Renewable Energy Sources & 1 & 0,3 & $30,1 \%$ \\
\hline GIB.12 & On-Site Energy Generation & 1 & 0,2 & $23,3 \%$ \\
\hline GIB.16 & Wastewater Management & 1 & 0,2 & $21,9 \%$ \\
\hline GIB.8 & Contaminant Reduction in Brownfields Remediation & 1 & 0,2 & $20,5 \%$ \\
\hline GIB.5 & Reuse of Historic Buildings & 1 & 0,2 & $17,8 \%$ \\
\hline GIB.14 & District Heating and Cooling & 1 & 0,2 & $15,1 \%$ \\
\hline ID & Innovation in Design & 6 & 2,7 & \\
\hline ID. 2 & LEED Accredited Professional & 1 & 0,9 & $91,8 \%$ \\
\hline \multirow[t]{2}{*}{ ID. 1} & Innovation and Exemplary Performance & 5 & 1,8 & $57,5 \%$ \\
\hline & Total & 110 & 59,6 & \\
\hline
\end{tabular}

Tab 9.2. Distribuição de pontos no LEED ND Piloto. Amostra de 73 empreendimentos nos Estados Unidos. Cores e listagem dos créditos organizados segundo o grau de cumprimento. Fonte: Garde, "Sustainable by design?”. Redesenhado pelo autor. Cores indicam quartis de cumprimento. 


\begin{tabular}{|c|c|c|c|c|}
\hline \# & Categorias e créditos & Máx. & Média & \% Cumprimento \\
\hline SLL & Smart Location and Linkage & 27 & 18,41 & \\
\hline SLL.1 & Preferred Locations & 10 & 7,31 & $97 \%$ \\
\hline SLL.3 & Locations with Reduced Automobile Dependence & 7 & 6,27 & $97 \%$ \\
\hline SLL.7 & Site Design for Habitat or Wetland and Water Body Conservation & 1 & 0,93 & $90 \%$ \\
\hline SLL.5 & Housing and Jobs Proximity & 3 & 2 & $72 \%$ \\
\hline SLL.6 & Steep Slope Protection & 1 & 0,62 & $62 \%$ \\
\hline SLL. 2 & Brownfield Redevelopment & 2 & 0,96 & $55 \%$ \\
\hline SLL.4 & Bicycle Network and Storage & 1 & 0,27 & $21 \%$ \\
\hline SLL.9 & $\begin{array}{l}\text { Long-Term Conservation Management of Habitat or Wetlands and } \\
\text { Water Bodies }\end{array}$ & 1 & 0,03 & $3 \%$ \\
\hline SLL.8 & Restoration of Habitat or Wetlands and Water Bodies & 1 & 0 & $0 \%$ \\
\hline NPD & Neighborhood Pattern and Design & 44 & 26,69 & \\
\hline NPD.1 & Walkable Streets & 12 & 7,13 & $100 \%$ \\
\hline NPD.2 & Compact Development & 6 & 4,68 & $100 \%$ \\
\hline NPD.3 & Mixed-Use Neighborhood Centers & 4 & 2,62 & $86 \%$ \\
\hline NPD.4 & Mixed-Income Diverse Communities & 7 & 5,20 & $86 \%$ \\
\hline NPD.9 & Access to Civic and Public Spaces & 1 & 0,96 & $86 \%$ \\
\hline NPD.10 & Access to Recreation Facilities & 1 & 0,82 & $83 \%$ \\
\hline NPD.14 & Tree-Lined and Shaded Streets & 2 & 1,55 & $79 \%$ \\
\hline NPD.15 & Neighborhood Schools & 1 & 0,68 & $66 \%$ \\
\hline NPD. 12 & Community Outreach and Involvement & 2 & 1,06 & $62 \%$ \\
\hline NPD.11 & Visitability and Universal Design & 1 & 0,55 & $55 \%$ \\
\hline NPD.7 & Transit Facilities & 1 & 0,51 & $48 \%$ \\
\hline NPD.6 & Street Network & 2 & 0,44 & $28 \%$ \\
\hline NPD.13 & Local Food Production & 1 & 0,31 & $28 \%$ \\
\hline NPD.8 & Transportation Demand Management & 2 & 0,06 & $7 \%$ \\
\hline NPD.5 & Reduced Parking Footprint & 1 & 0,03 & $3 \%$ \\
\hline
\end{tabular}




\begin{tabular}{|c|c|c|c|c|}
\hline \# & Categorias e créditos & Máx. & Média & \% Cumprimento \\
\hline GIB & Green Infrastructure and Buildings & 29 & 9,03 & \\
\hline GIB.9 & Heat Island Reduction & 1 & 0,82 & $76 \%$ \\
\hline GIB.1 & Certified Green Buildings & 5 & 2,65 & $62 \%$ \\
\hline GIB.4 & Water-Efficient Landscaping & 1 & 0,72 & $62 \%$ \\
\hline GIB.13 & Infrastructure Energy Efficiency & 1 & 0,51 & $52 \%$ \\
\hline GIB.16 & Solid Waste Management Infrastructure & 1 & 0,55 & $52 \%$ \\
\hline GIB. 2 & Building Energy Efficiency & 2 & 0,89 & $48 \%$ \\
\hline GIB.15 & Recycled Content in Infrastructure & 1 & 0,41 & $41 \%$ \\
\hline GIB.3 & Building Water Efficiency & 1 & 0,34 & $34 \%$ \\
\hline GIB.8 & Stormwater Management & 4 & 1,13 & $28 \%$ \\
\hline GIB.5 & Existing Building Reuse & 1 & 0,24 & $21 \%$ \\
\hline GIB.7 & Minimized Site Disturbance in Design and Construction & 1 & 0,20 & $21 \%$ \\
\hline GIB.17 & Light Pollution Reduction & 1 & 0,10 & $10 \%$ \\
\hline GIB.6 & Historic Resource Preservation and Adaptive Use & 1 & 0,06 & $7 \%$ \\
\hline GIB.10 & Solar Orientation & 1 & 0,06 & $7 \%$ \\
\hline GIB.11 & On-Site Renewable Energy Sources & 3 & 0,13 & $7 \%$ \\
\hline GIB.12 & District Heating and Cooling & 2 & 0,13 & $7 \%$ \\
\hline GIB.14 & Wastewater Management & 2 & 0 & $0 \%$ \\
\hline ID & Innovation in Design & 6 & 4,10 & \\
\hline ID. 1 & Innovation and Exemplary Performance & 5 & 3,10 & $100 \%$ \\
\hline \multirow[t]{2}{*}{ ID. 2} & LEED Accredited Professional & 1 & 1 & $100 \%$ \\
\hline & Total & 110 & 58,24 & \\
\hline
\end{tabular}

Tab 9.3. Distribuição de pontos no LEED ${ }^{\circledR}$ ND 2009, projetos não confidenciais. Amostra de 29 empreendimentos nos Estados Unidos. Cores e listagem dos créditos organizados segundo o grau de cumprimento. Fonte: LEED ${ }^{\circledR}$ Project Directory, 4 jan 2019. Elaborado pelo autor a partir de metodologia de Garde, “Sustainable by design?". Cores indicam quartis de cumprimento.

As duas tabelas são apenas parcialmente comparáveis, pois as versões piloto e 2009 possuem muitas diferenças. Note-se sobretudo como a categoria Green Infrastructure and Buildings tem cumprimento ainda menor na versão de 2009. 


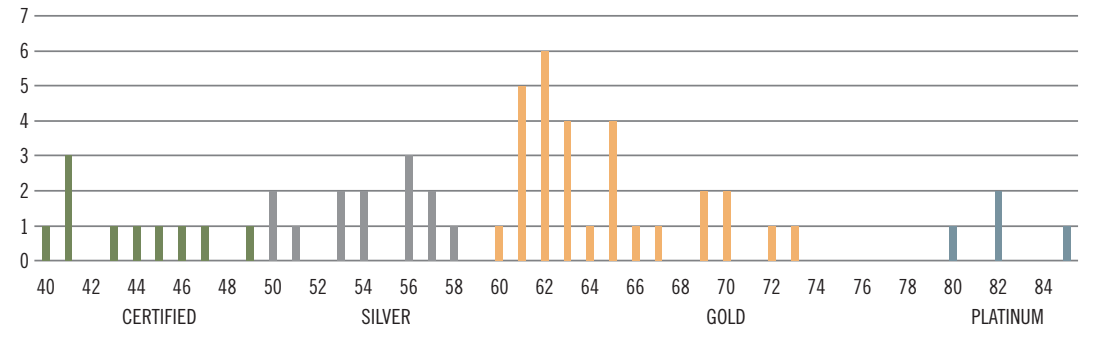

Fig 9.11. Distribuição de edifícios certificados com

LEED $^{\circledR}$ ND v3, Estágio 2, no mundo, de acordo com sua pontuação. Amostra de 56 projetos. Fonte: LEED Project Directory, 4 jan 2019. Elaborado pelo autor.

Os empreendimentos ND apresentam igual tendência de concentração nos limites inferiores de cada nível e de preferência pelo nível Gold. Cf. os gráficos correspondentes aos sistemas NC e CS [fig 5.12 a 5.15].

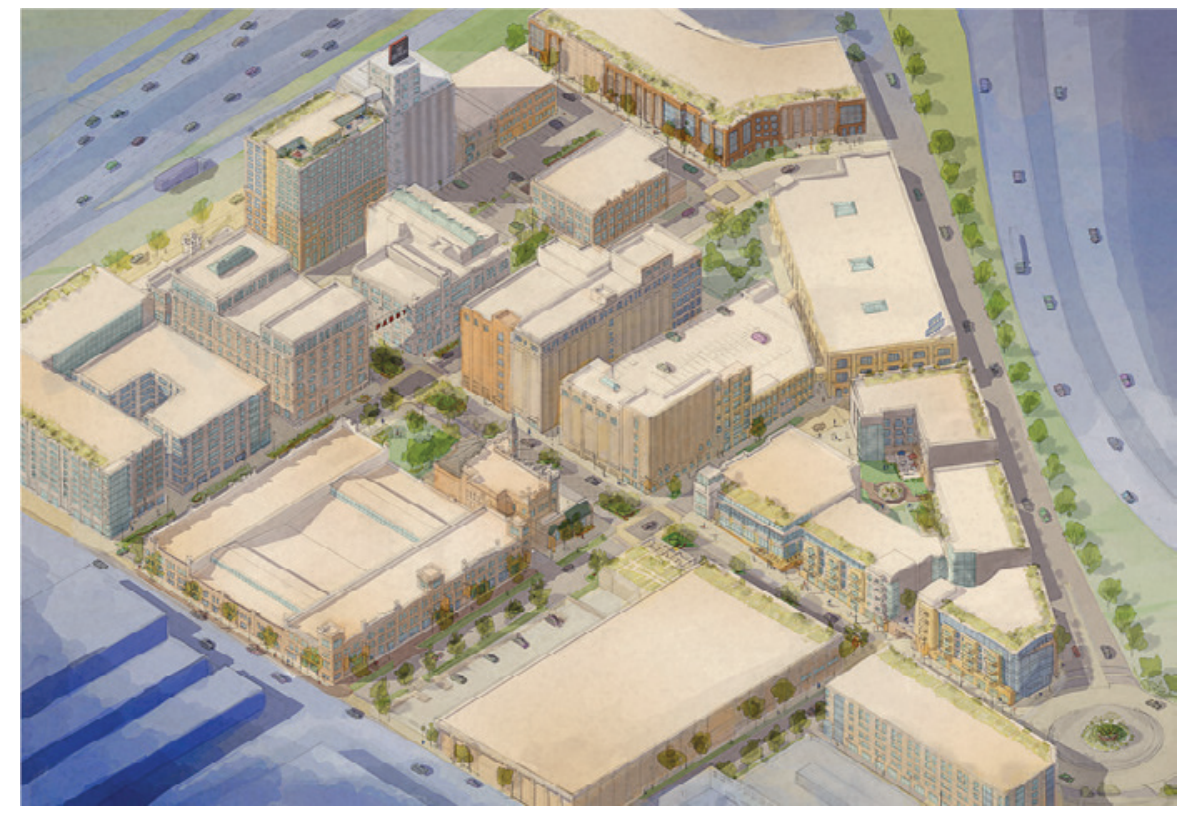

Fig 9.12. Plano do The Brewery. Fonte: Farr, Sustainable nation, 56. 


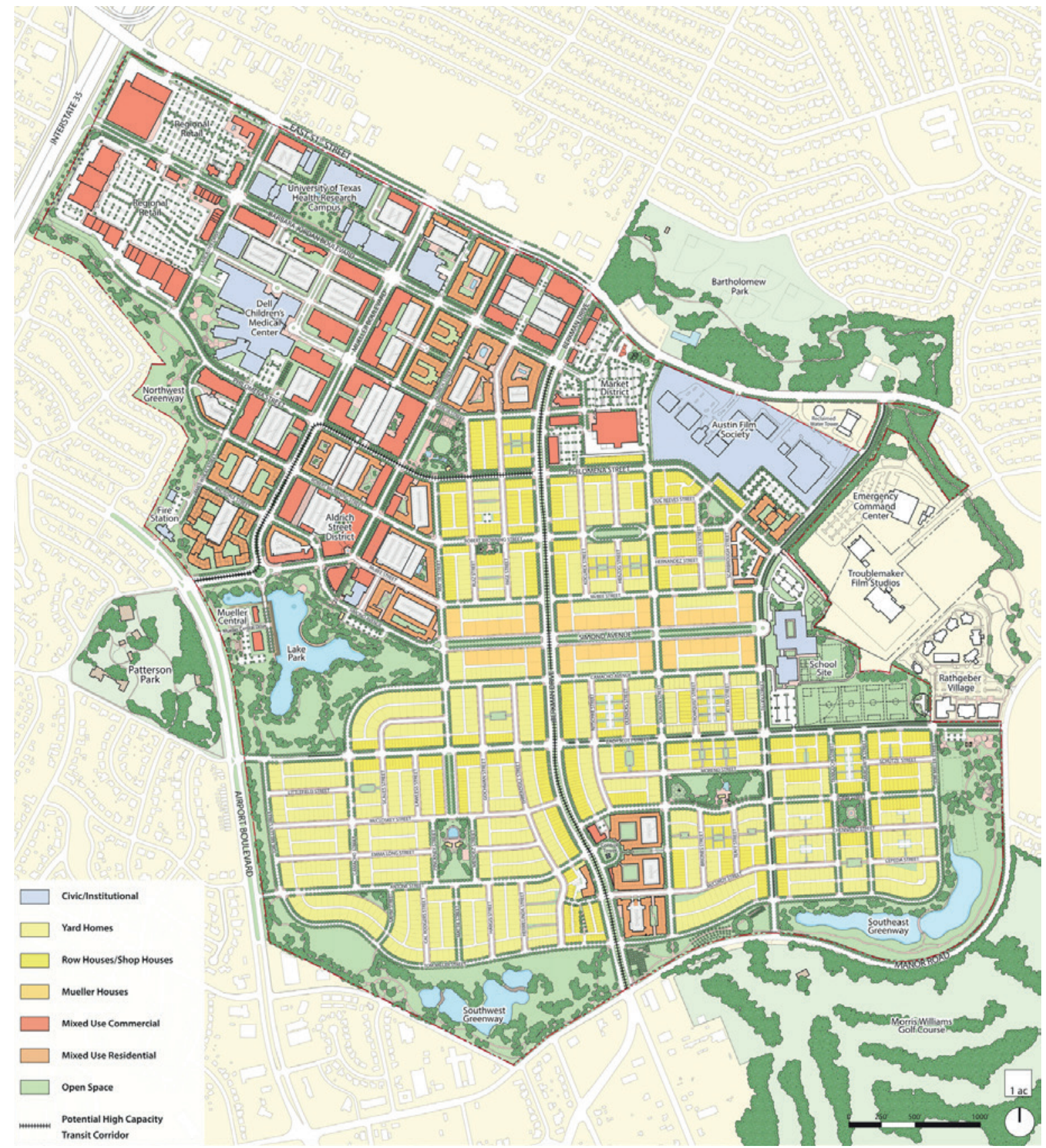

Fig 9.13. Plano de redesenvolvimento da cidade de

Mueller. Fonte: Farr, Sustainable nation, 52. 


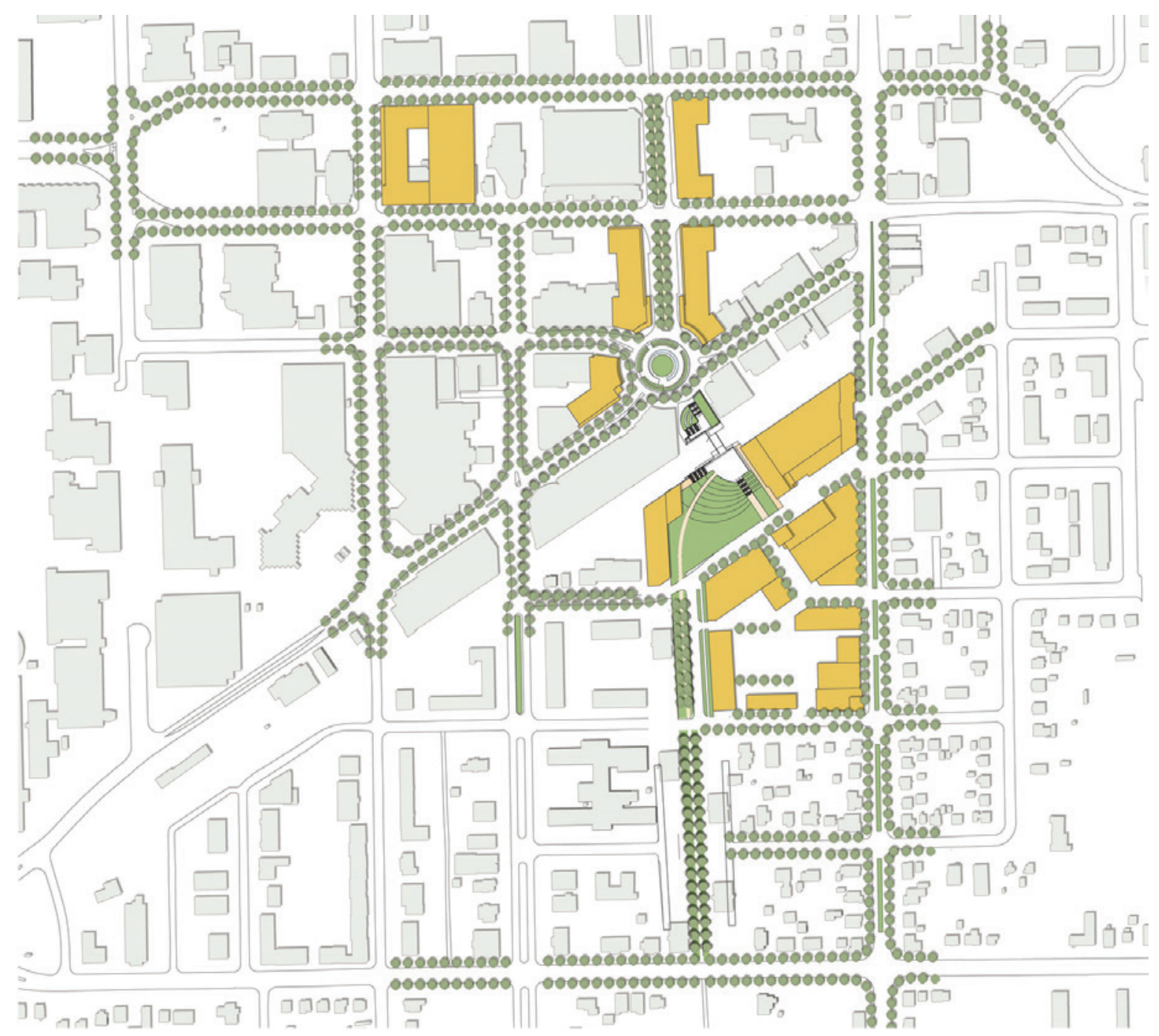

Fig 9.14. Plano de redesenvolvimento da cidade de

Normal. Fonte: Farr, Sustainable nation, 60.

As diferentes implantações de empreendimentos ND nos Estados Unidos, em diferentes escalas mas sempre com ocupação perimetral e clara separação entre ruas e edifícios, contrasta com a solução do Parque da Cidade e do Ilha Pura, empreendimentos brasileiros tratados no capítulo 10. 


\section{CAPÍTULO 10 OBSTÁCULOS DO PACTO DISCIPLINAR BRASILEIRO}

Entre o contexto urbano norte-americano e o brasileiro, há certamente semelhanças. Os prejuízos da suburbanização, os grandes conjuntos habitacionais modernos degradados e os centros urbanos abandonados repelidos pelos new urbanists e pelo LEED ${ }^{\circledR}$ for Neighborhood Development (ND) também podem ser encontrados nas cidades brasileiras. Mas como o sistema é usado no Brasil? A amostragem agora é menor do que aquela da parte III, referente à certificação de edifícios de escritório. Com apenas dois empreendimentos certificados no país, o LEED ${ }^{\circledR}$ ND ainda não é empregado de modo tão generalizado na produção de condomínios e loteamentos quanto o New Construction (NC) e o Core \& Shell (CS) são no setor corporativo - ou ao menos em seu estrato premium. ${ }^{1}$

Ambos empreendimentos certificados pelo LEED ${ }^{\circledR}$ ND concentram grande investimento: o Ilha Pura, em parte construído para abrigar os atletas dos Jogos Olímpicos no Rio de Janeiro, e o Parque da Cidade, concebido como um produto singular pela ausência de muros e multiplicidade de usos e como nova paisagem para a Chucri Zaidan.

\section{MARGINAL PINHEIROS, CENTRO FINANCEIRO DE UMA CIDADE GLOBAL PERIFÉRICA}

Os empreendimentos dos setores Chucri Zaidan e Juscelino Kubitschek não só formam aglomerações de certificados, mas, em uma escala um pouco mais abrangente, também se situam nos ende-

\footnotetext{
1. A pesquisadora Marta Eliza de Oliveira sugere que o empreendimento Pedra Branca em Palhoça (SC) e o desenvolvimento do Setor Noroeste de Brasília visariam a certificação pelo LEED ${ }^{\circledR} \mathrm{ND}$, mas nenhum dos casos está registrado nos dados oficiais do USGBC", cf. "Grandes empreendimentos, Novo Urbanismo e imagem ambiental no Setor Noroeste, em Brasília" (Tese (Doutorado em Gestão Territorial e Urbana). Orientadora: Lúcia Cony Faria Cidade, Departamento de Geografia Instituto de Ciências Humanas da Universidade de Brasília, 2016).
} 


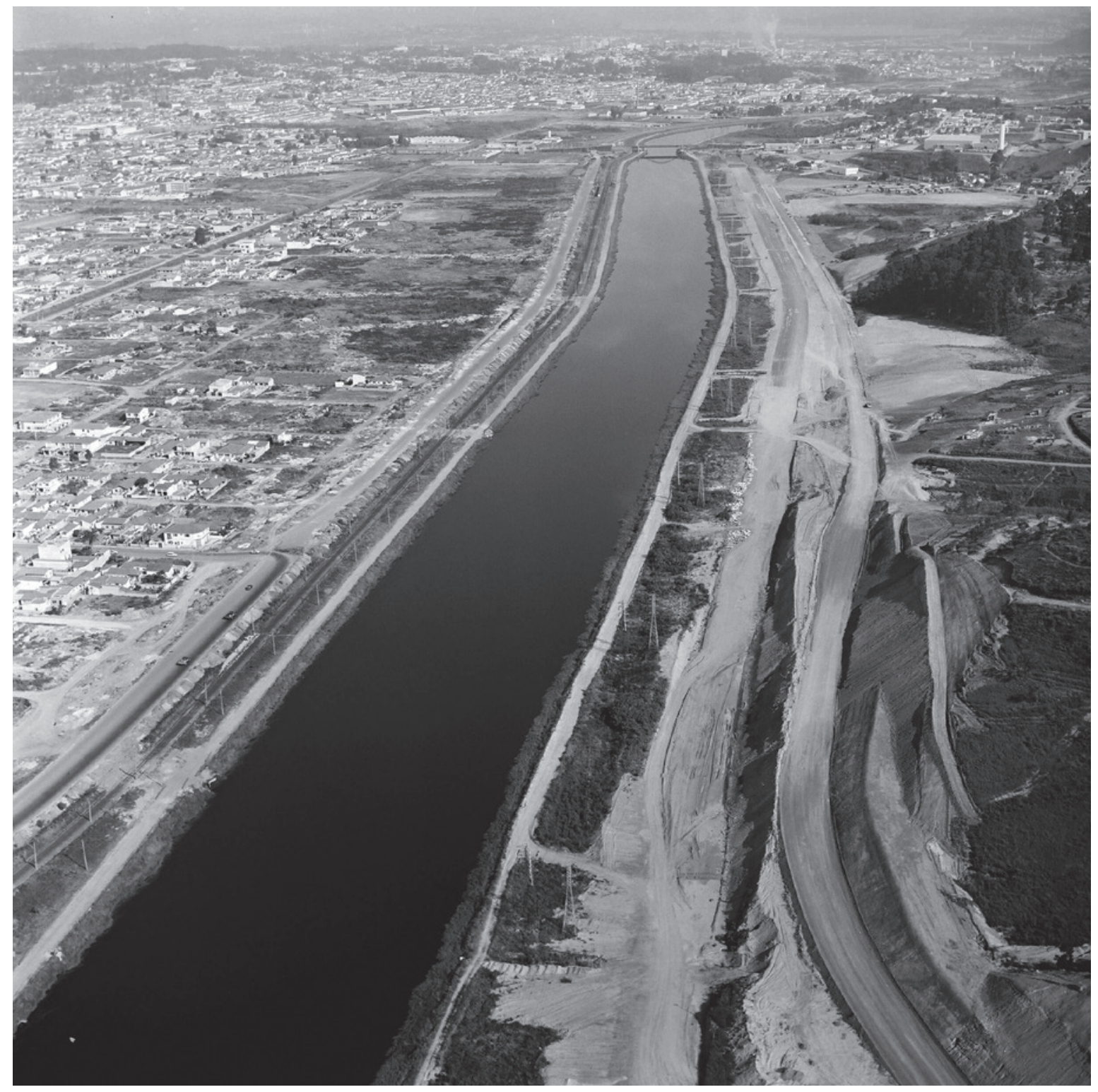

Fig 10.1. Vista da região do rio Pinheiros (1968). Fonte:

Ivo Justino via Mariana Rosario, "Os desafios da Berrini para dar a volta por cima”, Veja SP, 21 jan 2019. 
reços de altíssimo preço de solo e concentração de certificados, vistos no capítulo 5 [fig 5.20 a 5.21]. Uma área de alta transformação nas últimas décadas, na qual o LEED $^{\circledR}$ esteve presente em sua fase mais recente. Essa transformação foi facilitada pela promulgação de duas operações urbanas, a da Faria Lima e a da Água Espraiada, aquelas de maior participação do mercado entre as operações urbanas. ${ }^{2}$ Ambas são ainda os alicerces da consolidação da "virada global" da cidade de São Paulo.

Os arredores do rio Pinheiros eram ocupados por chácaras remotas do núcleo urbano até serem substituídos, entre as décadas de 1920 e 1940, primeiro por residências unifamiliares de classe média e baixa e em seguida por galpões industriais em alguns focos de concentração [fig 10.1 a 10.3]. A partir de meados dos anos 1970, diversos empreendimentos corporativos começam a surgir na região. É o caso de edifícios isolados, como o Wilson Mendes Caldeira (-/1973), o primeiro a ser construído; de grandes conjuntos, como o CENESP; e também dos diversos empreendimentos realizados pela construtora Bratke-Collet ao longo da avenida Engenheiro Luís Carlos Berrini, paralela à marginal Pinheiros. Esses edifícios compartilhavam o método de projeto e a sobreposição de funções da empresa, ao mesmo tempo projetista, construtora e incorporadora. Os arquitetos-incorporadores notaram a ausência de oferta de edifícios corporativos na região, os custos baixos dos terrenos, a alta conectividade viária e o alto potencial de valorização de seus projetos e viram ali uma oportunidade. Embora de radical impacto no tecido urbano da região, ainda se tratava de edifícios pequenos: a Bratke-Collet oferecia unidades de escritórios para profissionais liberais, direcionadas aos residentes nos bairros circundantes [fig 10.4 e 10.5]. ${ }^{3}$

Uma experiência contemporânea à da Bratke-Collet foi a do São Paulo Office Park (SPOP). Como na primeira, ele não é um empreendimento localizado em uma grande gleba, mas disperso em diversos lotes, nesse caso quatorze, distribuídos no entorno da avenida Verbo Divino. Os edifícios são baixos, no mais das vezes de três a cinco pavimentos, com grandes recuos para vegetação e estacionamento seguindo um modelo norte-americano de "office park". As lajes, por sua vez, são maiores: enquanto a Bratke-Collet se orientou por padrões entre 300 e $500 \mathrm{~m}^{2}$, no

2. Camila Maleronka e Jason Hobbs, "Operações Urbanas: o que podemos aprender com a experiência de São Paulo? Notas técnicas n. IDB-TN-1355” (Banco Interamericano de Desenvolvimento, dezembro de 2017).

3. Nelson Akio Fujimoto, "Produção monopolista do espaço urbano e a desconcentração do terciário de gestão na cidade de São Paulo" (Dissertação (Mestrado em Geografia Humana). Orientador: Manoel Seabra, Faculdade de Filosofia, Letras e Ciências Humanas da Universidade de São Paulo, 1994). 


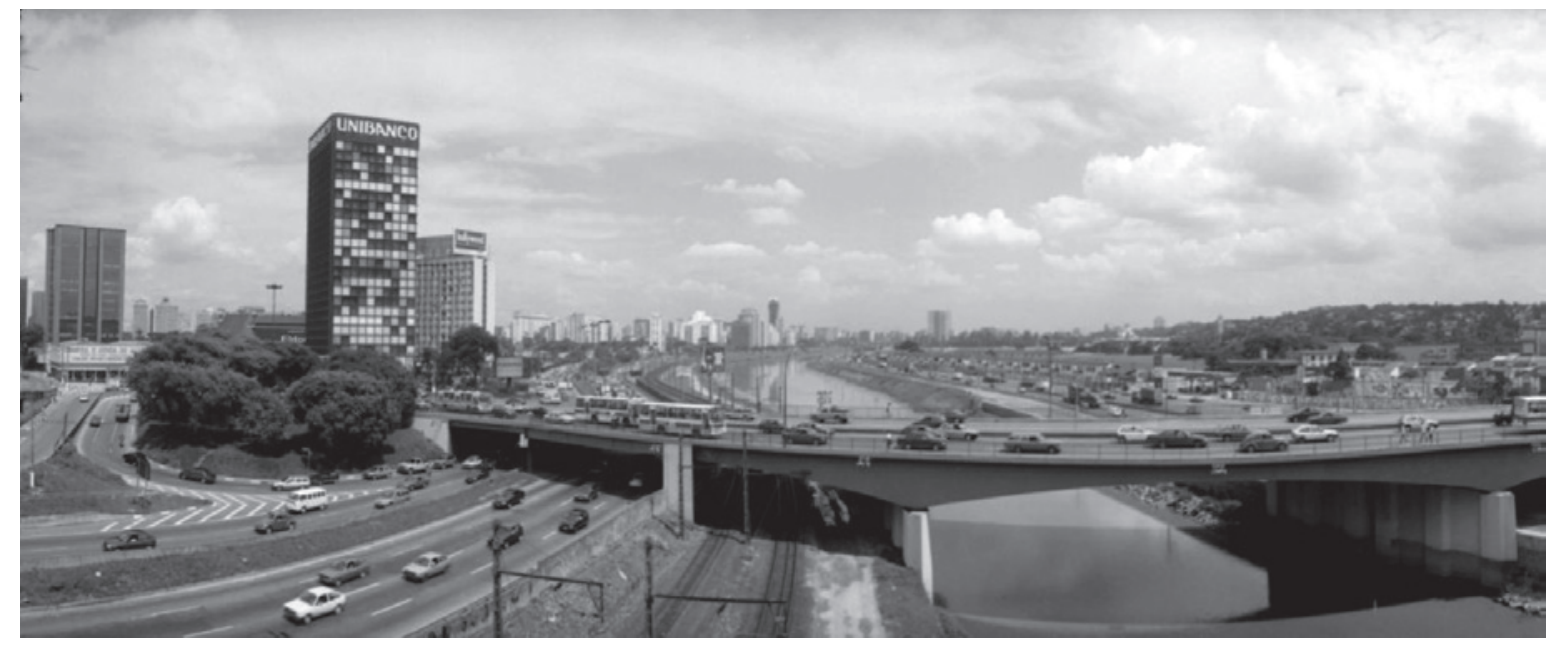

Fig 10.2. Vista da região do rio Pinheiros, na altura da ponte Eusébio Matoso (29 jan 1997). Fonte: Juca Martins/ Acervo IMS.

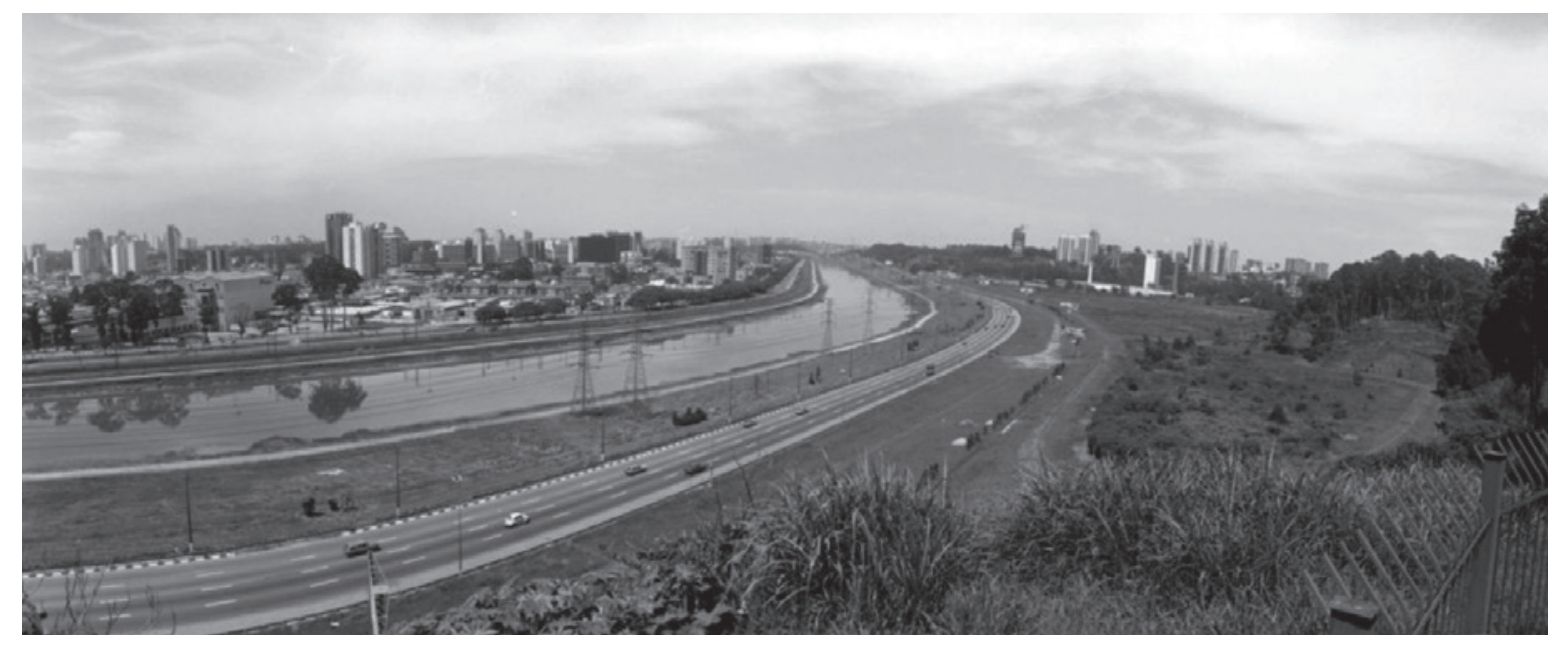

Fig 10.3. Vista da região do rio Pinheiros (10 fev 1997).

Fonte: Juca Martins/Acervo IMS. 
SPOP elas variavam em torno de $1000 \mathrm{~m}^{2}$. Além da tipologia contrastante, o empreendimento teve incorporação da Richard Ellis, com modelos mais sofisticados de financiamento e marketing do que aqueles realizados pela Bratke-Collet. Assim, os edifícios do SPOP já foram concebidos desde o princípio para locação, como forma de renda para fundos de pensão integrantes de sua carteira de investidores. ${ }^{4}$

Essa vinculação com fundos de pensão foi decisiva para os empreendimentos posteriores na região, esses de escala muito maior do que os analisados até aqui. O World Trade Center (WTC; -/1995), do aflalo/gasperini arquitetos, e o CENU têm áreas muito superiores aos edifícios incorporados pela Bratke-Collet ou do São Paulo Office Park. Isso porque sua lógica é outra: não se trata mais de um edifício autônomo no lote, mas de grandes complexos corporativos multiuso, mais próximos da tipologia do CENESP, ou, fora de nossa região primordial de estudo, do Centro Empresarial Itaú Conceição. Não há mais a monofuncionalidade do SPOP e dos primeiros edifícios da Bratke-Collet, de térreo restrito a estacionamento e acessos aos escritórios. Além da torre para locação, o WTC possui hotel, shopping especializado em mobiliário e centro de convenções; seu vizinho, o CENU, também possui shopping no embasamento.

Ainda que a área fosse provida de viário de alta capacidade, a escala dos empreendimentos e a quantidade de ocupantes pressionou o poder público por mais melhorias na região. Esse já era o caso, ainda no início da ocupação da área, da extensão da marginal Pinheiros por conta da construção do CENESP. ${ }^{5}$ Mas muitas outras melhorias foram realizadas pelo Estado para o desenvolvimento da região: a linha da CPTM, atual Esmeralda (Osasco-Grajaú), uma das primeiras a oferecer ar condicionado nos trens e escadas rolantes nas estações, reproduzindo o padrão do Metrô; ${ }^{6}$ a linha de monotrilho Ouro (São Paulo/Morumbi-Jabaquara), atualmente em construção; a ponte estaiada Octávio Frias de Oliveira, logo alçada a cartão-postal da ci-

\footnotetext{
4. Eduardo Alberto Cusce Nobre, "Reestruturação econômica e território: expansão recente do terciário na marginal do rio Pinheiros" (Tese (Doutorado). Orientadora: Gilda Collet Bruna, Faculdade de Arquitetura e Urbanismo da Universidade de São Paulo, 2000).

5. Editora Flex, "Estudo de caso - centro empresarial", Ofício: Imobiliário, 3 de abril de 1994; apud Nobre, "Reestruturação econômica e território: expansão recente do terciário na marginal do rio Pinheiros”, 168.

6. O argumento hoje parece irrelevante, já que muitas linhas de transporte sobre trilhos compartilham essas características de atendimento, mas é interessante notar como a qualidade do serviço era excepcional na época de sua implantação. Cf. Flávio Villaça, "Prefácio" in Mariana Fix, São Paulo cidade global: fundamentos financeiros de uma miragem (São Paulo: Boitempo, 2007), 10.
} 


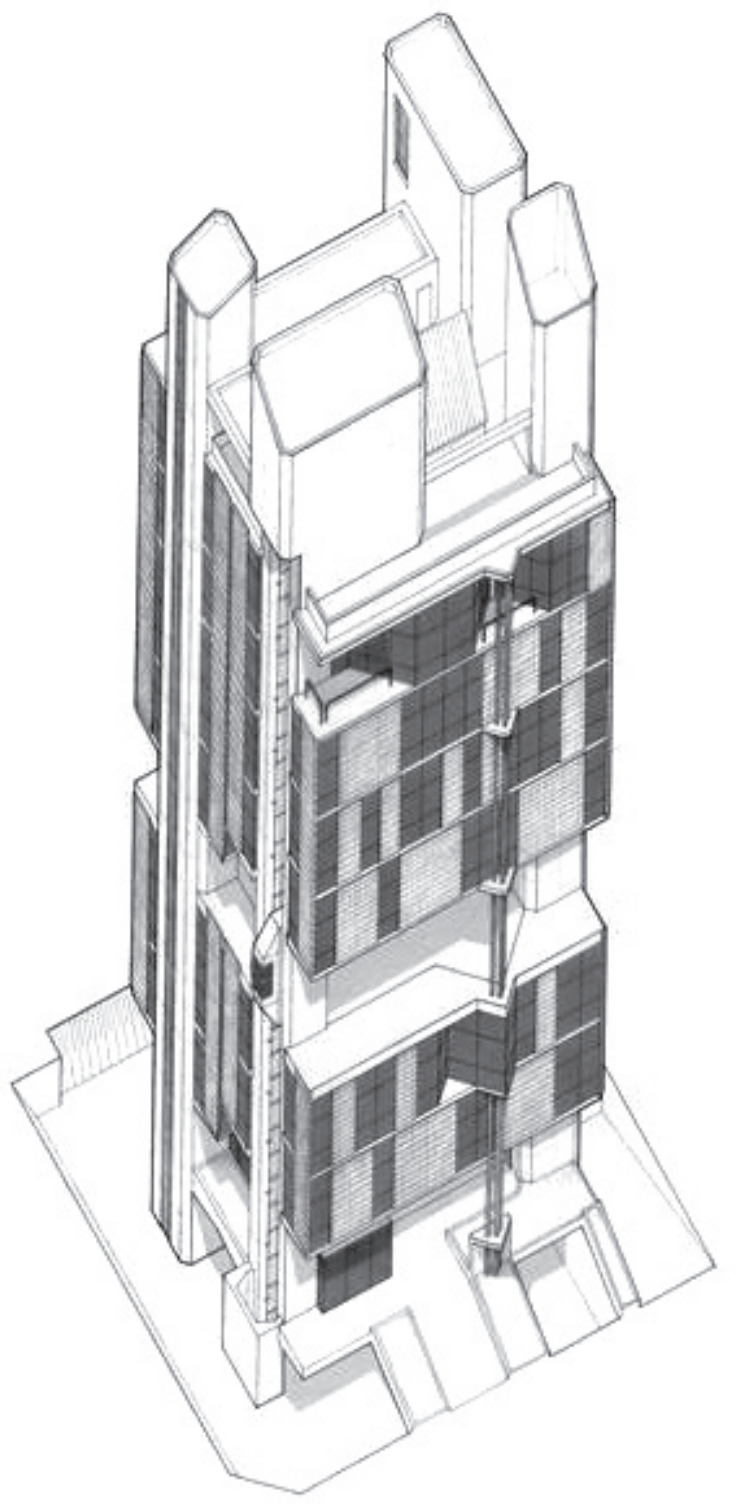

Fig 10.4. Carlos Bratke, Edifício Oswaldo Bratke (-/1982). Fonte: Centre Pompidou.

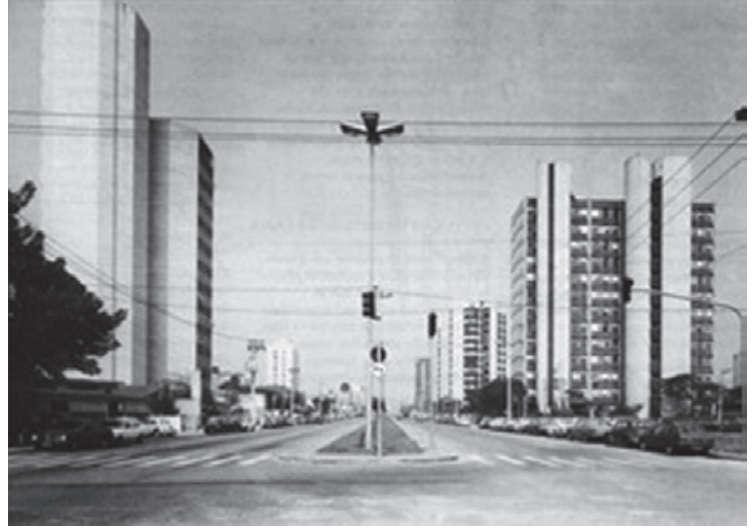

Fig 10.5. Avenida Engenheiro Luís Carlos Berrini (1975). Fonte: Bratke-Collet, acervo online. 
dade; o túnel de ligação, por ora cancelado, entre a avenida Jornalista Roberto Marinho - ela própria mais um item da lista de melhorias - e a Rodovia dos Imigrantes; a criação da Águas Espraiadas; a extensão da avenida Chucri Zaidan até a avenida João Dias, ainda em execução, dentre outras. Houve ainda estratégias diretamente gentrificadoras, como a retirada da favela que se localizava no Parque do Povo, da favela na Águas Espraiadas e a relocação dos moradores da favela Jardim Edite, ${ }^{7}$ parcialmente realojados em um conjunto habitacional de mesmo nome ao lado da ponte Octávio Frias, projetado pelos escritórios MMBB e H+F (2010/2013). Parte dessas melhorias está associada à OUCAE, criada pela Lei Municipal n. 13.260, de 28 de dezembro de 2001, no início do mandato da prefeita Marta Suplicy (2001-2004), então filiada ao Partido dos Trabalhadores (PT). ${ }^{8}$ Para a OUCFL também há melhorias, como as estações da linha amarela do metrô, a extensão sul da avenida Faria Lima e as renovações do Largo da Batata e do Parque do Povo.

Certamente, essas benfeitorias, aqui apenas esquematizadas, não só desafogam espaços urbanos com taxas crescentes de ocupação, mas também induzem e viabilizam novos empreendimentos. Isso porque, além das vantagens garantidas por essas obras, as operações urbanas ainda incentivam remembramentos de lotes e permitem a participação em leilões de CEPACs, em que sua compra autoriza o incremento no coeficiente de aproveitamento do terreno e a mudança do uso previsto no zoneamento. Pela combinação entre benfeitorias públicas e facilidades construtivas, surgiu a nova paisagem urbana da avenida Faria Lima e da marginal Pinheiros, onde os empreendimentos certificados têm alta propensão de se localizar [fig 10.6].

\footnotetext{
7. Descrita em Mariana Fix, Parceiros da exclusão: duas histórias da construção de uma "nova cidade" em São Paulo: Faria Lima e Água Espraiada (São Paulo: Boitempo, 2001), seç. “A remoção das favelas em Água Espraiada”. Como demonstrado por Paulo Emílio Buarque Ferreira, a remoção das favelas não foi acompanhada pela devida relocação, que não só foi continuamente postergada, como também inviabilizada tanto por impossibilidades orçamentárias quanto pela recessão econômica dos últimos anos. Estabelece-se, assim, o procedimento para a gentrificação da área. Cf. "Operação Urbana Consorciada Água Espraiada: um novo discurso sobre remoções”, Óculum Ensaios 16, no 2 (2019): 277-90, http://dx.doi. org/10.24220/2318-09 19v16n2a4190.

8. Dados e análises da OUCAE acompanham aqui a tese de Álvaro Luís dos Santos Pereira, "Intervenções em centros urbanos e conflitos distributivos: modelos regulatórios, circuitos de valorização e estratégias discursivas" (Tese (Doutorado), Faculdade de Direito da Universidade de São Paulo, 2015), cap. 3.
} 


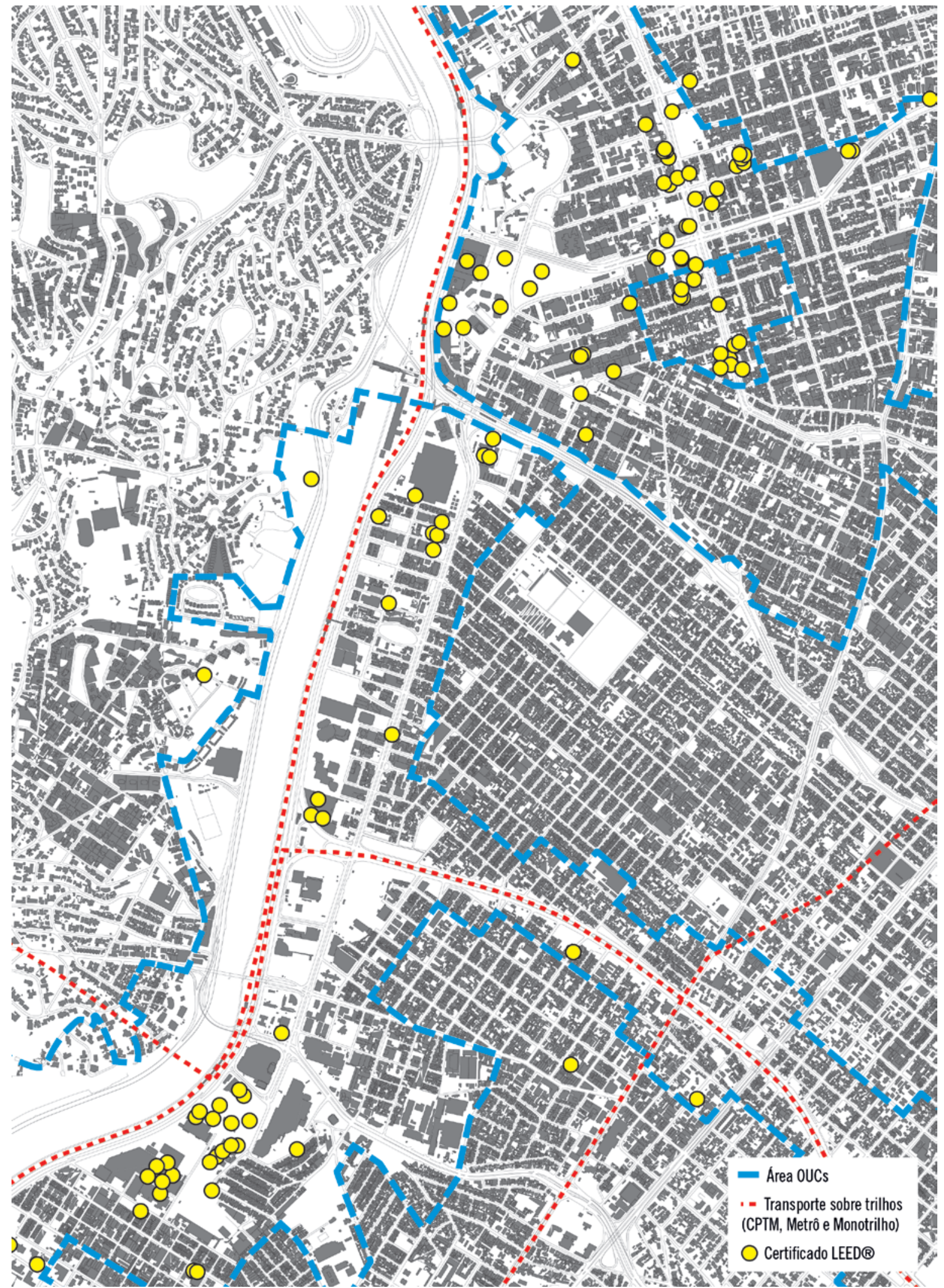

Fig 10.6. Certificados LEED ${ }^{\circledR}$ e sua localização nas operações urbanas Água Espraiada e Faria Lima. Elaborado pelo autor. Fontes: LEED Project Directory (4 jan 2019), SMDU, Geosampa. 
Todo esse processo resulta da combinação de fenômenos locais e globais. Do ponto de vista local, a OUCFL e a OUCAE estão na direção de deslocamento da população de mais alta renda para o vetor sudoeste, e a concomitante mudança nos polos de negócios e serviços, tal como analisado por Flávio Villaça em seu Espaço intra-urbano no Brasil. ${ }^{9}$ Mas o processo também ocorre em meio a fenômenos de maior abrangência, notadamente o das "cidades globais", pelo qual cidades em processo de desindustrialização tornaram-se centros de gestão de negócios.

Evidentemente, há as cidades desindustrializadas que simplesmente perderam sua atividade econômica principal e foram abandonadas pela parcela da população com meios para buscar empregos de alta remuneração em outros locais. Mas há aquelas cidades que, por já terem relevância como centros econômicos, se realinharam como centros ou subcentros de gestão e serviços. Na primeira geração analisada por Saskia Sassen, ${ }^{10}$ as cidades globais eram Nova York, Londres e Tóquio, que ocupavam papeis específicos no sistema de gestão global. Concentravam-se nessas cidades as sedes das empresas, enquanto a produção efetiva de mercadorias era enviada para onde quer que os custos fossem menores. Esse distanciamento entre gestão e produção só foi possível em razão da flexibilização dos instrumentos financeiros e pelo aperfeiçoamento das tecnologias de comunicação a partir da década de 1980.

O conceito de Sassen revelava idiossincrasias desses novos espaços urbanos e suas atividades socioeconômicas. À crescente dispersão das atividades das empresas pelo mundo correspondiam funções administrativas cada vez mais complexas em suas sedes, o que requeria serviços especializados de terceiros, como em consultorias legais, financeiras e de comunicação. A dispersão levaria ainda ao aumento de transações financeiras e comunicacionais entre os diversos centros da produção da empresa ao redor do globo, já que as sedes precisavam supervisionar as filiais. Do ponto de vista do trabalho, as cidades globais, em razão dos serviços especializados, concentram funcionários de colarinho branco de alta capacitação e remuneração e, inversamente, também levam à informalização e precarização daqueles trabalhadores que não podem competir com as atividades de alta lucratividade. ${ }^{11} \mathrm{O}$ que se deve reter para os propósitos desta tese não é só

9. Flávio Villaça, Espaço intra-urbano no Brasil, 2a (São Paulo: Studio Nobel; Fapesp; Lincoln Institute, 2001).

10. Saskia Sassen, The global city: New York, London, Tokyo (Princeton, EUA; Oxford, Reino Unido: Princeton University Press, 1991).

11. Saskia Sassen, “The global city: introducing a concept”, The Brown Journal of World Affairs XI, n 2 (2005): 27-43. 

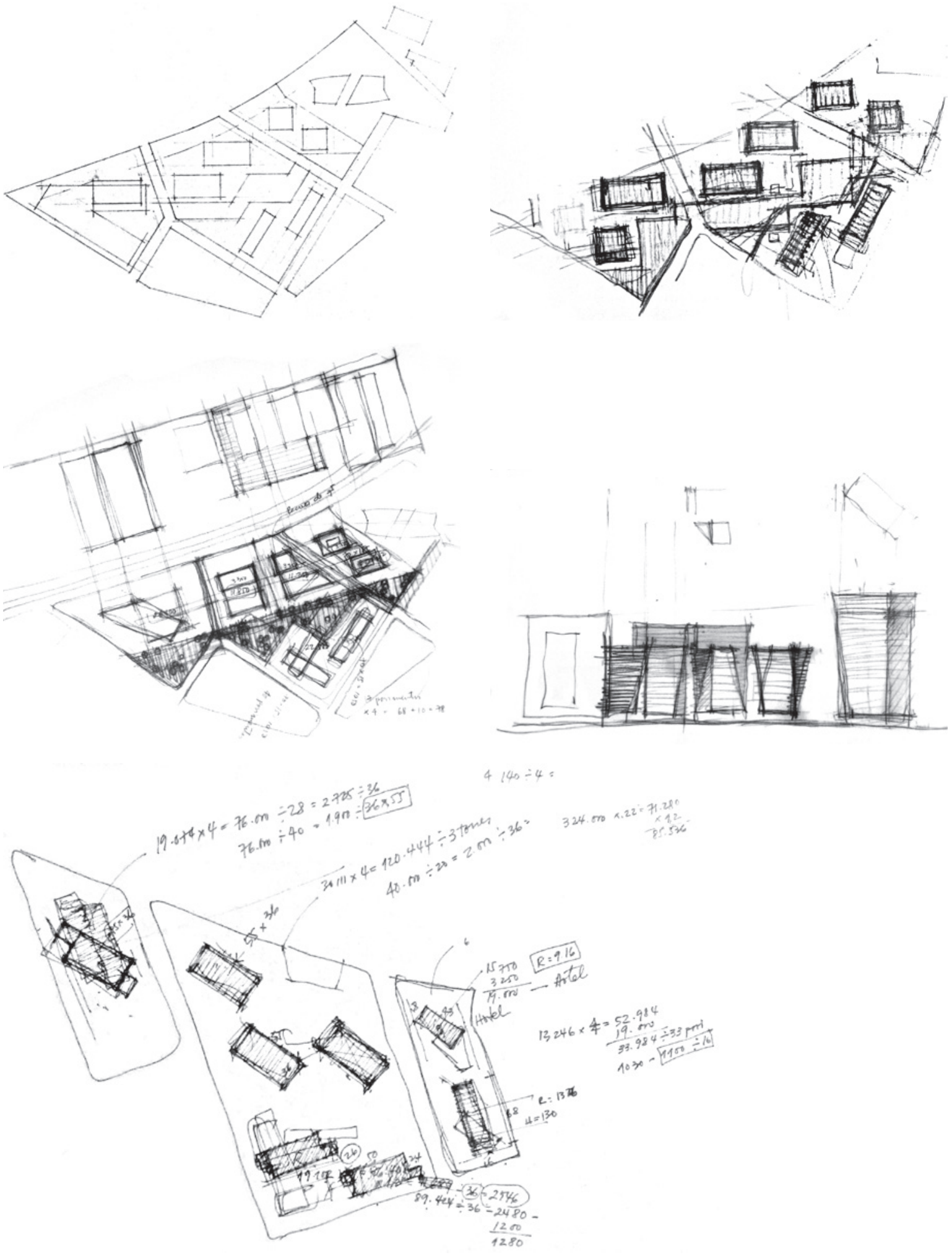

Fig 10.7 a 10.11. aflalo/gasperini arquitetos, Parque da

Cidade. Implantação, versões preliminares (s/d).

Fonte: Serapião, Monolito, 18, 20, 21, 24, 29. 
as raízes financeiras e comunicacionais das cidades globais, mas também como seus diferentes aspectos estão conectados em um quadro dinâmico de criação de novos setores econômicos e novos mecanismos de segregação. É, assim, no mesmo período de ascensão das cidades globais que se multiplica a pobreza urbana e as favelas. ${ }^{12}$ Além disso, o que é central na tese de Sassen é a importância das cidades nesse processo: Sassen ainda dá valor à categoria de "espaço" face à de comunicação, em contraposição à leitura que era realizada por muitos de seus contemporâneos. ${ }^{13}$

Conforme a estratégia se disseminava para outros contextos, a cidade global tornou-se uma nova categoria de publicidade urbana, em que cada grande metrópole competia para ser o próximo centro global ou regional. São Paulo passava a ser uma daquelas identificadas como membros de um circuito secundário de cidades globais. O conceito de cidade global, originalmente um instrumento crítico, tornava-se assim uma agenda positiva perseguida por planejadores urbanos. ${ }^{14}$ Com isso, mesmo se essa virada possa ter sido inicialmente ideológica, tal como proposto por comentadores brasileiros, ${ }^{15}$ fato é que ela transformou a paisagem urbana da marginal Pinheiros e foi motor de sua produção imobiliária. Nesse processo, as OUC são centrais para facilitar a alteração desses espaços pelo mercado. É por sua dualidade, pela junção de produtos financeiros complexos e acumulação primitiva por desapropriações, de elites e populações destituídas, de torres de vidro e favelas, que a cidade global paulistana se caracteriza. ${ }^{16}$ Também é nesses espaços e nesses edifícios criados para abrigar as filiais de multinacionais que o LEED ${ }^{\circledR}$ floresce como um instrumento para alavancar investimento e justificar relatórios de responsabilidade corporativa o sistema não tinha serventia na paisagem da marginal anterior à sua virada global.

12. Para outra perspectiva da reorganização urbana global a partir da década de 1980, do ponto de vista dos mecanismos de financiamento mais do que da transformação da produção, e da favela mais do que do distrito financeiro, ver Mike Davis, Planeta favela, Posfácio de Ermínia Maricato. Tradução de Beatriz Medina. (São Paulo: Boitempo Editorial, 2006).

13. Sassen, The global city.

14. Joshua K. Leon, "Global cities at any cost", City: analysis of urban trends, culture, theory, policy, action 21, $\mathrm{n}^{\circ} 1$ (2017): 6-24, http://dx.doi.org/10.1080/13604813.2016.1263491.

15. João Sette Whitaker Ferreira, O mito da cidade-global: o papel da ideologia na produção do espaço urbano, Prefácio de Ermínia Maricato e apresentação de Flávio Villaça (Petrópolis, RJ; São Paulo; Salvador: Vozes; Editora UNESP; ANPUR, 2007).

16. Mariana Fix, "Uma ponte para a especulação - ou a arte da renda na montagem de uma 'cidade global"', Caderno CRH 22, no 55 (janeiro de 2009): 41-64; Álvaro Luís dos Santos Pereira, "A montagem de enclaves financeiros numa metrópole periférica: verso e reverso do planejamento urbano" (Dissertação (Mestrado). Orientadora: Ana Maria de Oliveira Nusdeo, Faculdade de Direito da Universidade de São Paulo, 2011). 


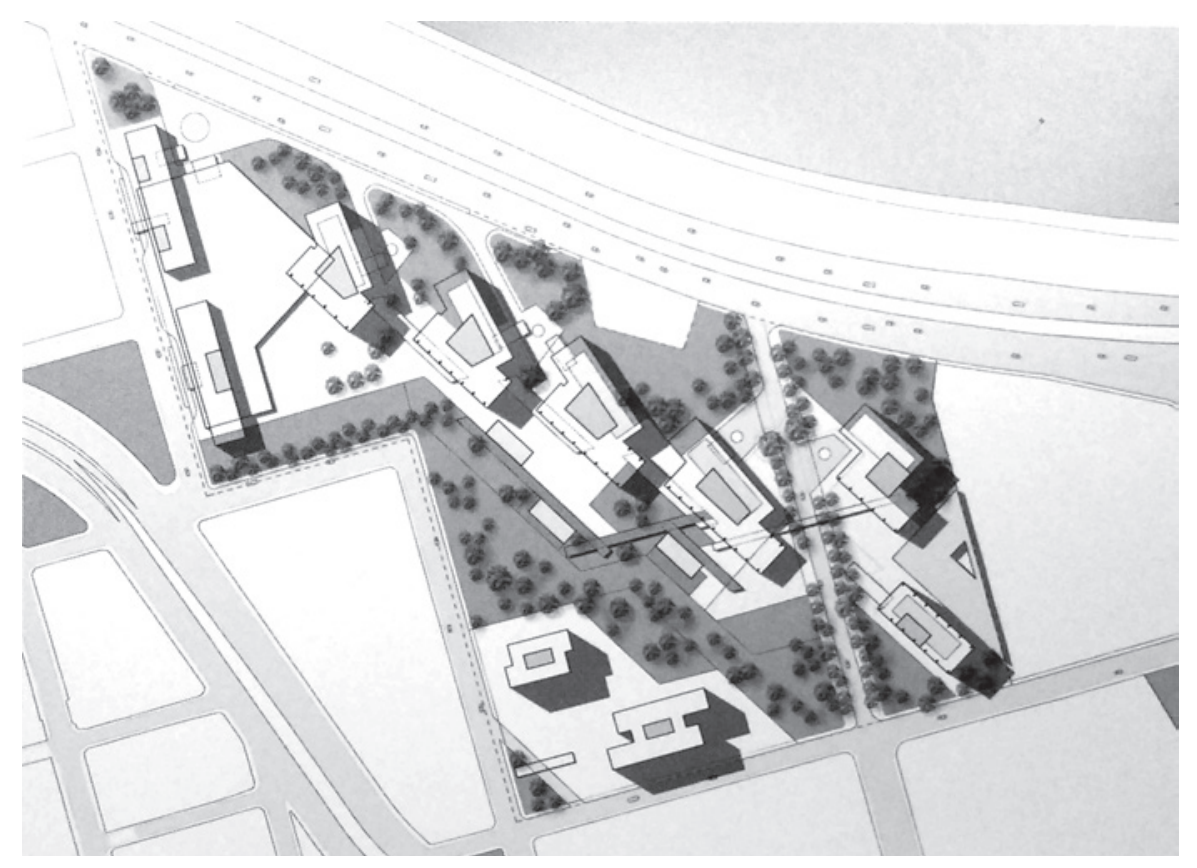

Fig 10.12. aflalo/gasperini arquitetos, Parque da Cidade.

Implantação, versão preliminar (2011). Fonte: Serapião, A arquitetura de Croce, Aflalo e Gasperini, 299.

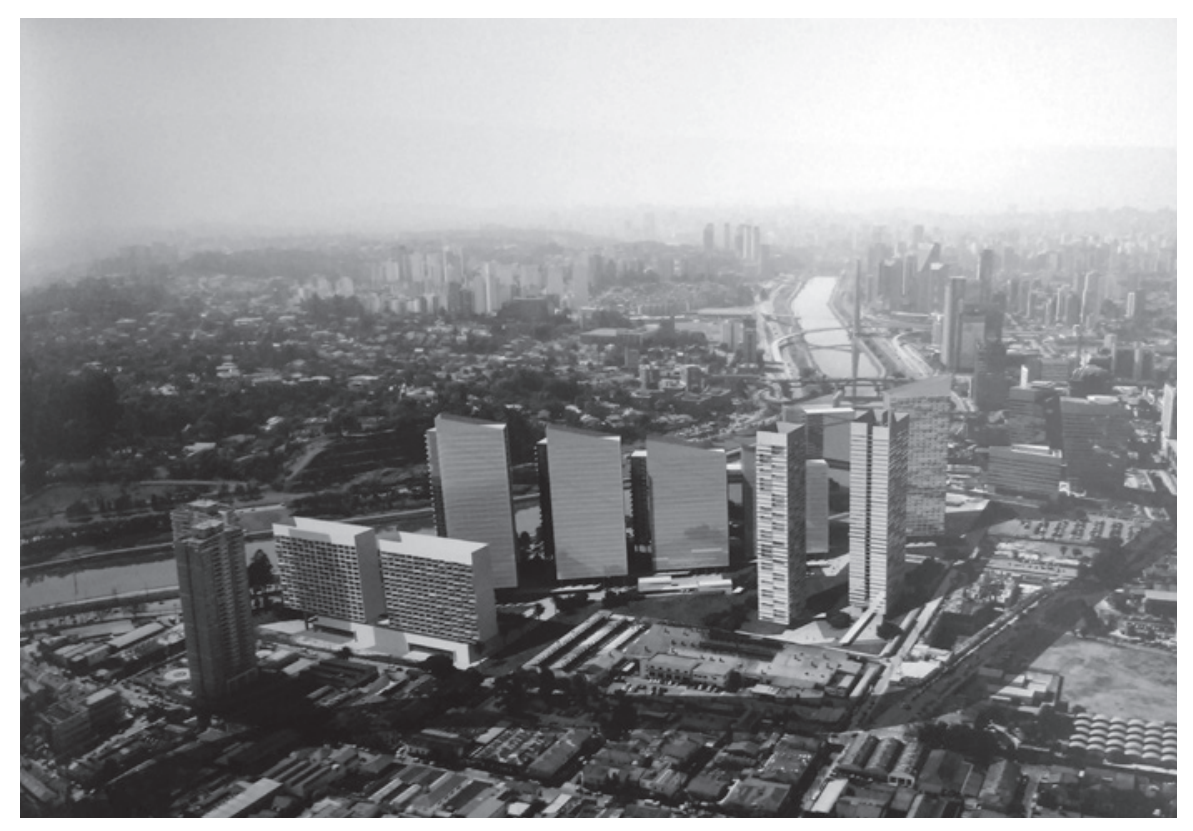

Fig 10.13. aflalo/gasperini arquitetos, Parque da Cidade.

Vista, versão preliminar (2011). Fonte: Serapião,

A arquitetura de Croce, Aflalo e Gasperini, 299. 


\section{PARQUE DA CIDADE}

$\mathrm{O} \mathrm{LEED}^{\circledR}$ se desenvolve, portanto, em mais uma etapa do alinhamento global de São Paulo. Após o surgimento dos primeiros grandes empreendimentos imobiliários na região, aqueles inaugurados desde meados da década de 2000 utilizam o certificado e seus preceitos como elemento de distinção em relação à produção anterior. É o caso do Parque da Cidade, um dos poucos produtos imobiliários brasileiros certificados com o LEED $^{\circledR}$ ND [fig 10.7 a 10.22].

Como mencionado no capítulo 8, a conformação de torres em um jardim do Parque da Cidade tem gênese no Rochaverá, segundo a intenção declarada pelos próprios arquitetos, embora aqui o projeto tenha dimensões muito maiores. Contrariamente à implantação do modelo original, entretanto, o Parque da Cidade não se organiza ao redor de uma praça central em uma grade de cheios e vazios, mas segundo um eixo em torno do qual distribui-se a maior parte dos edifícios. Esse eixo parte da ponta mais extrema da gleba e divide-a em duas partes: a sul, onde se situam o shopping e o hotel, na ponta oeste do eixo, e os edifícios residenciais, na ponta leste; e a norte, onde se situam os edifícios corporativos e de salas comerciais. Estão previstos ainda restaurantes e comércio nos térreos das torres e em blocos independentes ao longo do eixo.

Como o complexo ainda se encontra em construção, e os desenhos divulgados apresentam poucos detalhes, não é clara a futura relação entre empreendimento e entorno. Pelas informações e desenhos disponíveis, sugere-se, por um lado, que a relação com a Chucri Zaidan será mais imediata do que no Rochaverá, mas, em contrapartida, haverá maior distanciamento em relação à marginal Pinheiros do que nesse modelo original, com uma faixa arborizada funcionando como barreira visual. Tal como no Rochaverá, por outro lado, o térreo, entendido como parque, também precisar organizar um complexo sistema de vias auxiliares que garantem o desembarque junto ao lobby de cada edifício devido à grande circulação promovida pelo empreendimento. $\mathrm{O}$ exame da implantação permite notar que a área vegetada, ao menos aquela em superfície contínua, restringe-se à área residencial. A área vegetada do restante do empreendimento ou está fragmentada entre os edifícios e as vias auxiliares, mediando a relação entre os dois, ou se concentra na fronteira com a marginal. Quando pronto, pela grande dimensão, provavelmente essa fragmentação e área restrita da massa de vegetação não serão percebidas como tal pelo usuário. Mas como procedimento de projeto, o paisagismo tem primordialmente um papel de delimitação do espaço de pedestres e automóveis. 


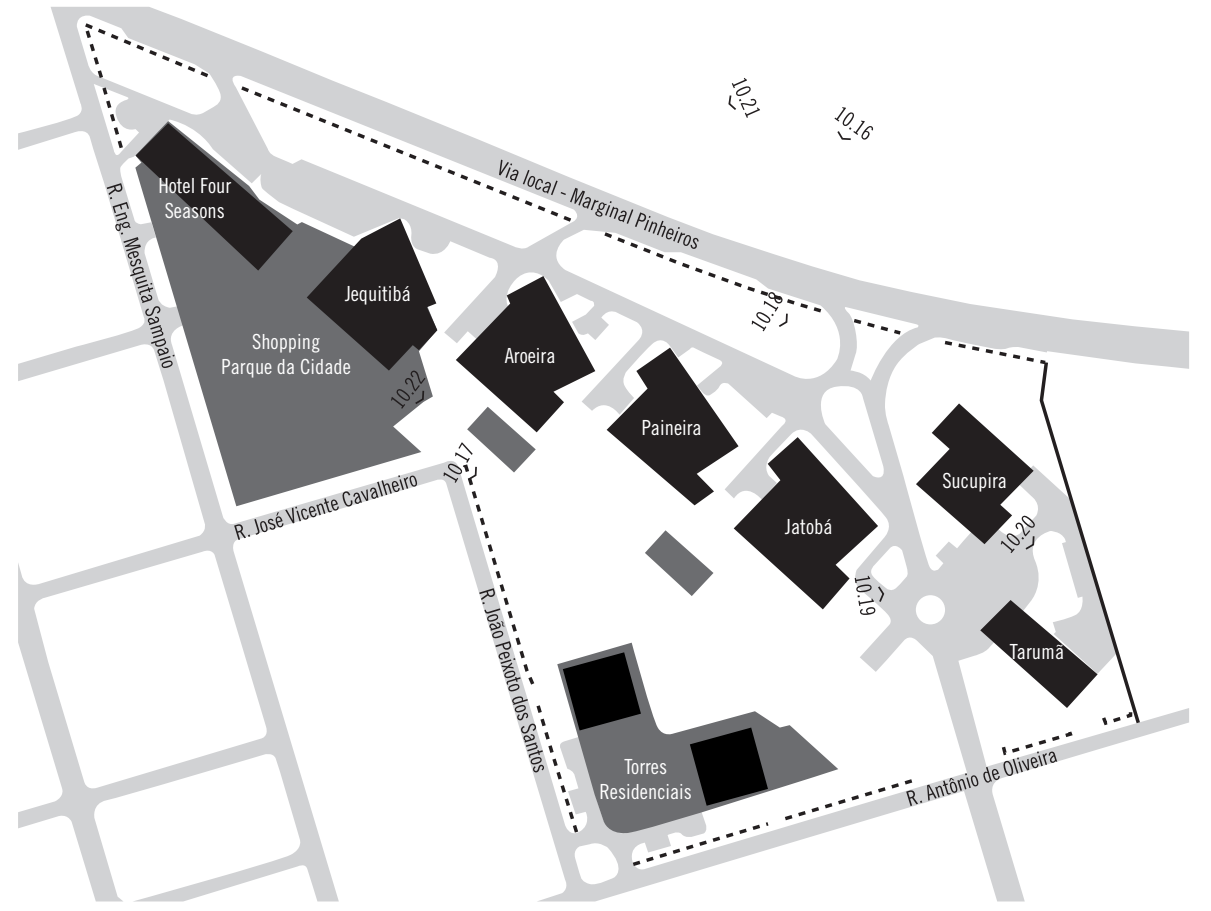

- Elevação

- Fotografia

— Cercamento com grades/muros

- - Limite do lote com paisagismo

Fig 10.14. Diagrama do Parque da Cidade. Elaborado pelo

autor.

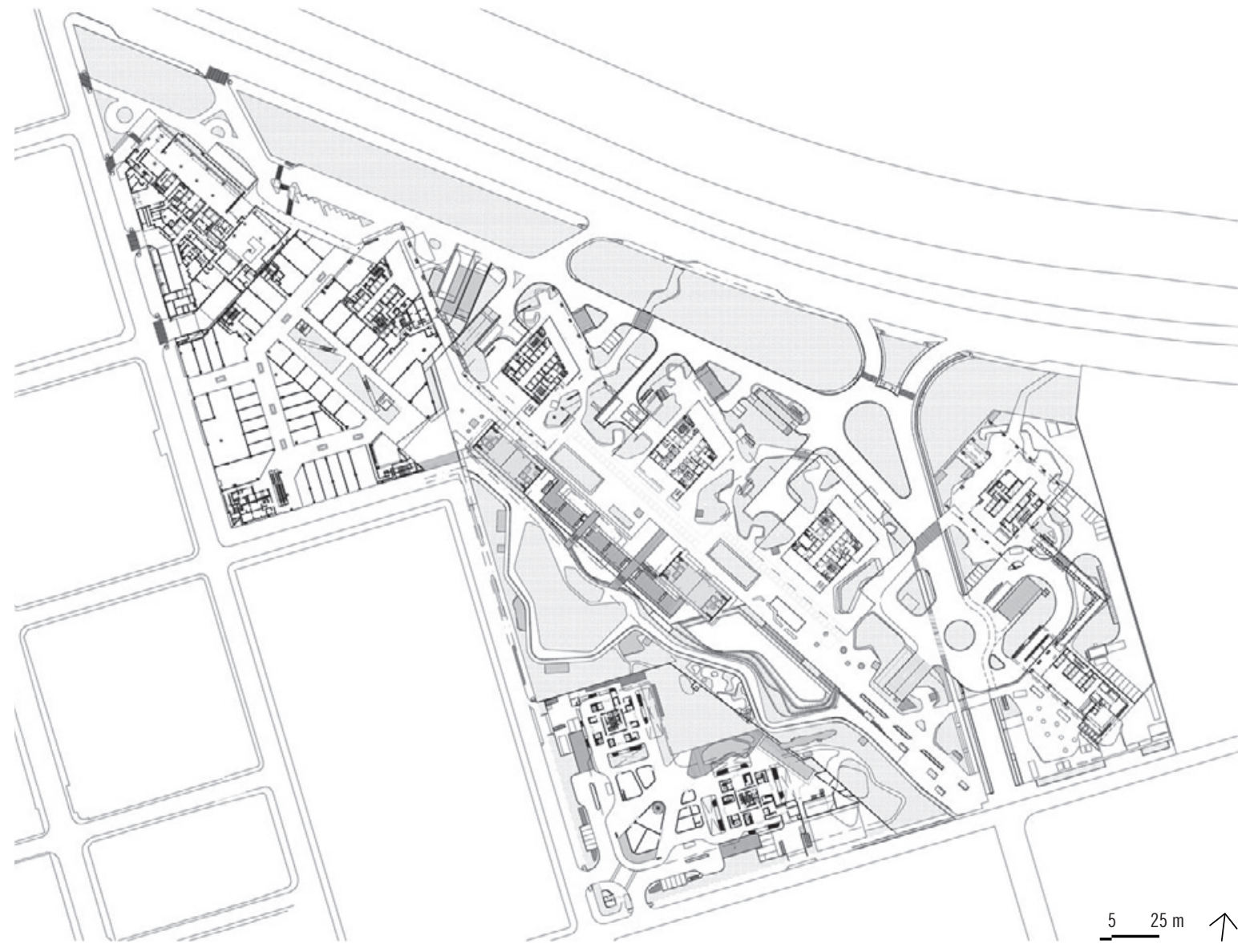

Fig 10.15. aflalo/gasperini arquitetos, Parque da Cidade

(2010/-). Implantação. Sem escala. Fonte: aflalo/gasperini arquitetos, acervo online. 
Como o LEED ${ }^{\circledR}$ ND não permite que o empreendimento seja todo murado, o paisagismo foi utilizado como modo de aumentar o controle na gleba. Há, assim, poucas entradas possíveis no conjunto. Segundo uma das arquitetas, o paisagismo das áreas residenciais, por sua vez, cria obstáculos com cercas vivas largas, mas não altas, mantendo as perspectivas. ${ }^{17}$

Para assegurar a distinção do empreendimento, foram aplicadas diversas certificações: são

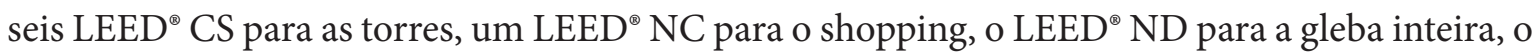
certificado Aqua para as torres residenciais e o Climate Development Program para o empreendimento. Esse último é conferido a projetos com significativa redução nas emissões de carbono, com incentivos à eficiência em energia, água e transporte. Esse certificado foi aplicado a um ainda restrito grupo de cerca de vinte empreendimentos, incluindo o próprio Parque da Cidade e o campus Pedra Branca, em Santa Catarina. Mas, diferentemente do LEED ${ }^{\circledR}$ e do Aqua, essa certificação, criada pelo programa C40 Cities em parceria com a Fundação Clinton e o USGBC ${ }^{\oplus}$, não tem propriamente parâmetros e requisitos - ao menos não com acesso público -, mas um curto manual de boas práticas. São quatro categorias principais: objetivos ambiciosos e planejamento holístico, estrutura regulatória que estimule projetos regenerativos, transformação de áreas industriais e maximização de parcerias público-privadas. ${ }^{18}$

Entre o Parque da Cidade e o Ilha Pura [fig 3.16], este apresentado aqui apenas para contraste, o comportamento na certificação é muito semelhante, salvo em uma categoria: a dedicada ao Smart Growth, a Smart Location and Linkage (SLL) [tab 10.1 e fig 10.23]. A localização suburbana do Ilha Pura, em uma extremidade da Barra da Tijuca, faz com que o empreendimento tenha metade dos pontos na SLL obtidos pelo Parque da Cidade. De fato, o último recebe oito pontos apenas por ser implantado em área com alta oferta de transporte público. ${ }^{19}$ No mesmo sentido, o Parque da Cidade se beneficia do uso misto do entorno, mas ao mesmo tempo oferece também novos usos. ${ }^{20} \mathrm{O}$ Parque da Cidade apresenta ainda densidade adequada ao previsto no LEED ${ }^{\circledR} \mathrm{ND}$

\footnotetext{
17. Tânia Yang, (Arquiteta no aflalo/gasperini arquitetos), Entrevista para o autor, Telefone, 27 de fevereiro de 2019. 18. C40 Cities, Fundação Clinton, e USGBC (United States Green Building Council), “Good practice guide: Climate Positive Development" (C40 Cities, fevereiro de 2016).

19. SLL.3 Locations with Reduced Automobile Dependence e um ponto extra em RP. Há razoável pontuação ainda em SLL.1 Preferred Locations.

20. NPD.3 Mixed-Use Neighborhood Centers.
} 


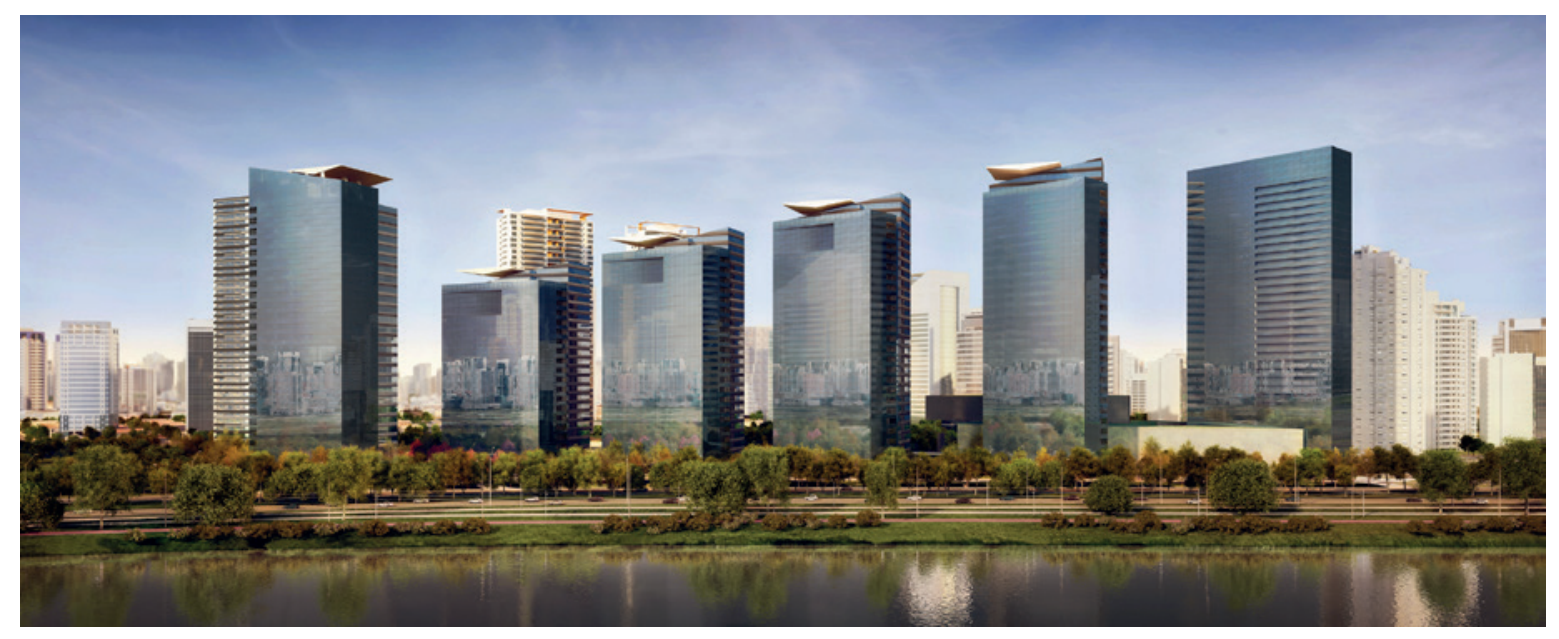

Fig 10.16. aflalo/gasperini arquitetos, Parque da Cidade (2010/-). Simulação vista a partir da marginal Pinheiros. Fonte: aflalo/gasperini arquitetos, acervo online.

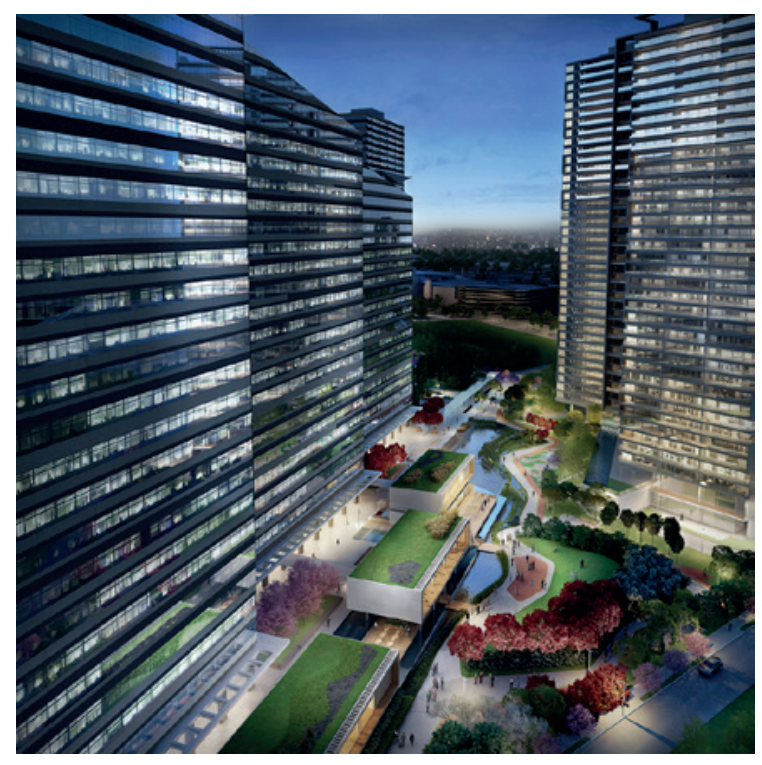

Fig 10.17. aflalo/gasperini arquitetos, Parque da Cidade (2010/-). Simulação do parque interno. Fonte: aflalo/ gasperini arquitetos, acervo online.

Fig 10.18. aflalo/gasperini arquitetos, Parque da Cidade (2010/-). Vista do conjunto, com obra em andamento. Fonte: Ana Mello via Fernanda Strazzacappa, "Parque da Cidade: complexo multiuso", Galeria da Arquitetura.

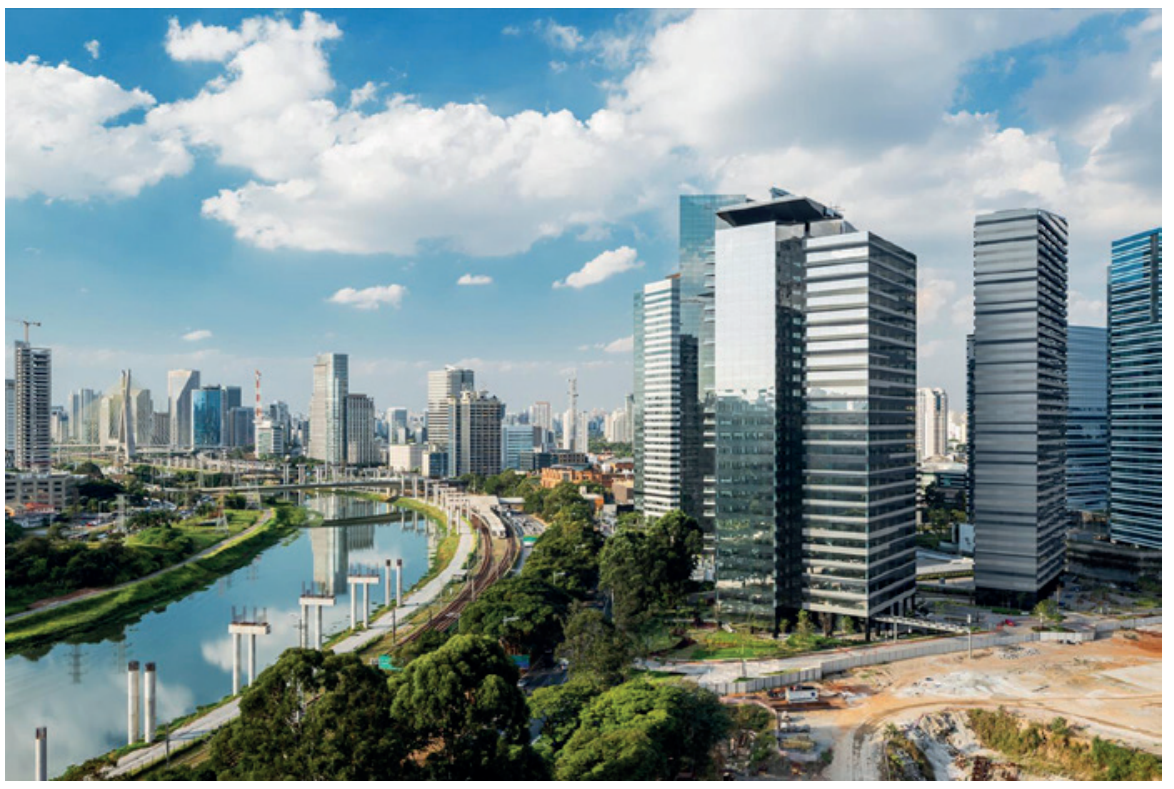


e cumpre o exigido para a certificação dos edifícios dentro do próprio empreendimento ${ }^{21}$ - de fato, há diversas certificações participando, como visto logo acima. Esses créditos são importantes para a análise, porque são aqueles, entre os cumpridos pelo Parque da Cidade, com a maior quantidade de pontos: mais de metade daqueles obtidos encontram-se dentro dessas poucas estratégias. ${ }^{22}$

Há ainda outro conjunto de pontos cujo cumprimento é relativamente simples: a criação de ruas sombreadas por árvores, a provisão de áreas verdes, o fato do empreendimento não se localizar em área sujeita a deslizamentos ou junto a um corpo d'água, a conversão de uma área industrial em um empreendimento de uso misto. ${ }^{23}$ Por um lado, são procedimentos simples; por outro lado, são recorrentes em empreendimentos de alto padrão, sobretudo na marginal Pinheiros - novamente, os projetos recebem pontos por realizar estratégias imobiliárias que lhe seriam habituais. Essas estratégias garantem quase um quinto dos pontos obtidos pelo Parque da Cidade.

Mas tão importante quanto os créditos cumpridos são os evitados. Isso porque é baixa a pontuação do Parque da Cidade, em contradição ao peso que a certificação ocupa em seu marketing, um argumento que pode ser realizado pela própria medida do LEED ${ }^{\circledR}$. Além disso, considerando-se que a certificação ainda está no estágio 2, do plano, pode-se prever perda de pontos no estágio 3, da obra concluída, a exemplo do Ilha Pura: no novo estágio, o empreendimento carioca perdeu quatro pontos em seu já fraco desempenho. Em sua concepção e operação, o Ilha Pura distancia-se cada vez mais dos preceitos incluídos no LEED ${ }^{\circledR}$ ND: o incorporador Carlos Carvalho declarou não ter nenhum interesse na diversificação de renda dos moradores, o parque público foi cercado e escolas previstas em projeto não foram construídas - contrariando tanto o certificado quanto a lei carioca, já que os dois últimos itens foram requisitados como contrapartida à implantação. ${ }^{24}$

\section{GIB.1 Certified Green Buildings.}

22. Não são considerados aqui os pontos na categoria ID, de alto cumprimento, mas cujos parâmetros de avaliação nunca são transparentes.

23. NPD.14 Tree-Lined and Shaded Streets e um ponto extra em RP, NPD.9 Access to Civic and Public Spaces e um ponto extra em RP, NPD.10 Access to Recreational Facilities, SLL.6 Steep Slope Protection, SLL.7 Site Design for Habitat or Wetland and Water Body Conservation e SLL.2 Brownfield Redevelopment.

24. Jefferson Puff, “'Como é que você vai botar o pobre ali?', diz bilionário 'dono da Barra da Tijuca”, BBC Brasil, ago de 2015, https://www.bbc.com/portuguese/noticias/2015/08/150809_construtora_olimpiada_jp; Ruben Berta, “Construtoras de condomínio da Rio 2016 trocaram escolas públicas por parque onde ninguém entra”, The Intercept Brasil, 8 de fevereiro de 2018, https://theintercept.com/2018/02/08/construtoras-de-condominio-da-rio-2016-trocaram-escolas-publicas-por- 


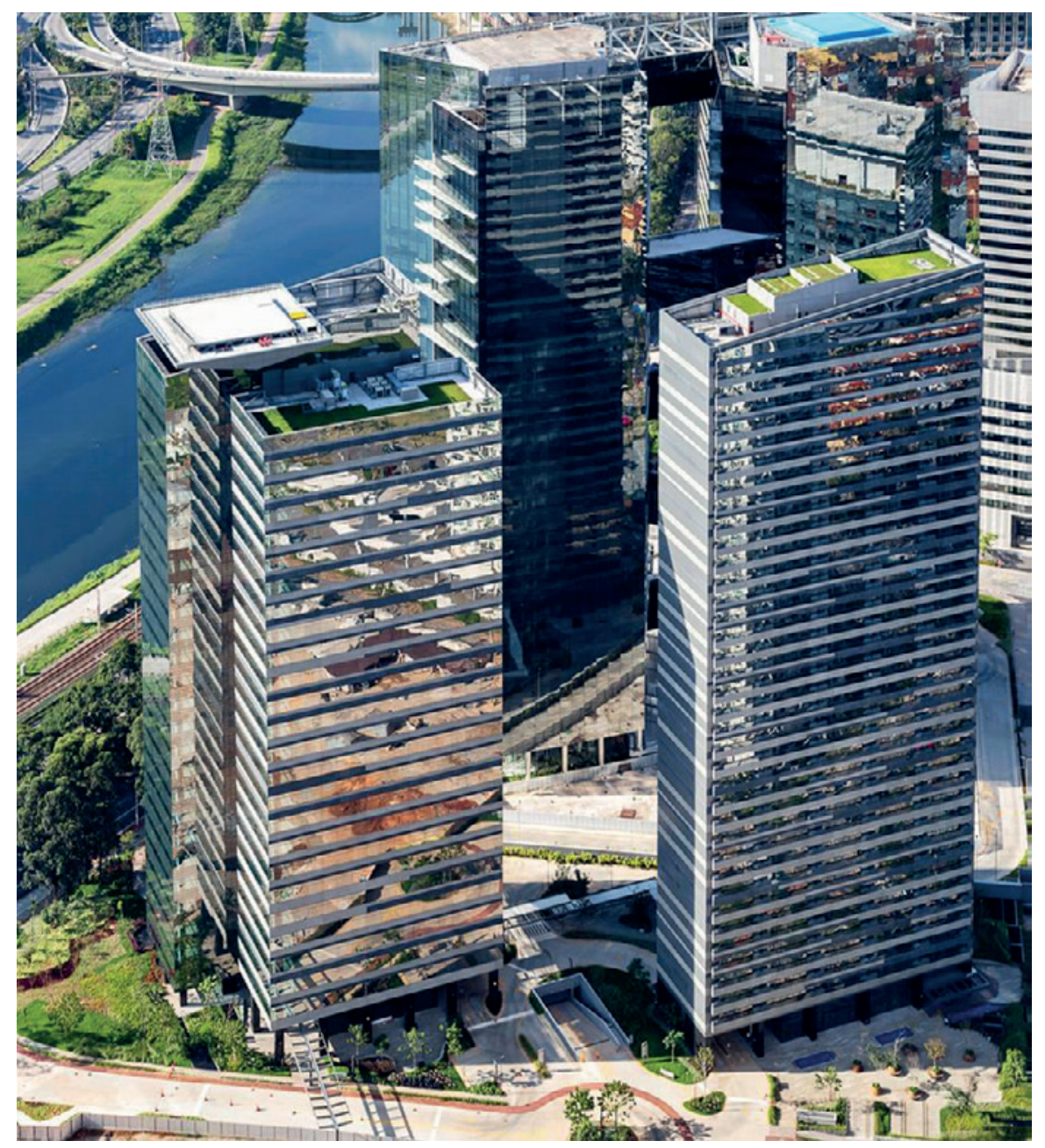

Fig 10.19. aflalo/gasperini arquitetos, Parque da Cidade (2010/-). Vista da primeira etapa de torres inauguradas.

Fonte: Ana Mello via Fernanda Strazzacappa, "Parque da

Cidade: complexo multiuso", Galeria da Arquitetura.

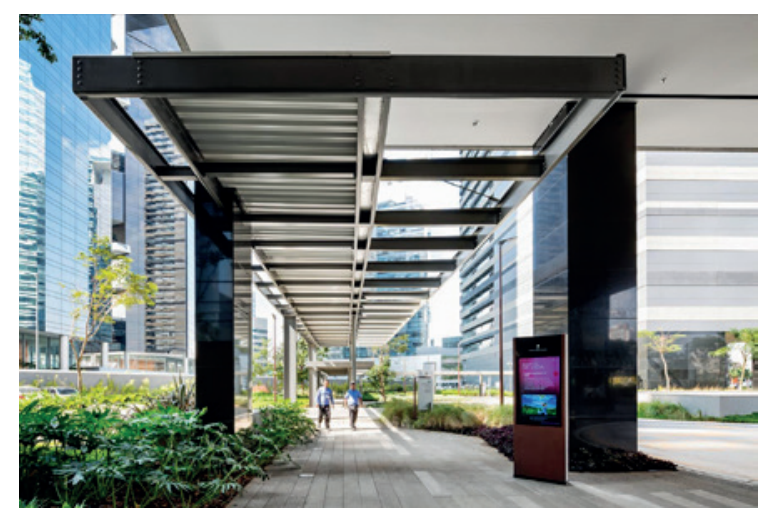

Fig 10.20. aflalo/gasperini arquitetos, Parque da Cidade (2010/-). Vista do eixo de circulação. Fonte: Ana Mello via Fernanda Strazzacappa, "Parque da Cidade: complexo multiuso", Galeria da Arquitetura. 
Nesse sentido, destaque-se apenas os créditos evitados com impacto direto na forma urbana. De fato, o que se nota é que muitos deles foram desconsiderados no projeto. Ele não cria nenhum recurso para conectividade urbana - a contagem de intersecções entre ruas a partir dos limites do empreendimento, variando de modo geral entre 400 e 800 metros a depender do crédito - como os indicados no item 2 de SSL.1, no item 1 de NPD.Prereq.3 ou no crédito NPD.6. Assim, ao invés de criar intersecções entre ruas na área interna à gleba, o projeto atinge os pontos a partir das intersecções nos arredores, preferindo manter a gleba intacta e evitando o desenho de ruas internas que aumentariam a permeabilidade de espaço. Desse modo, o Parque da Cidade reproduz exatamente a mesma estratégia dos outros empreendimentos do entorno caracterizados por suas grandes glebas. O Parque da Cidade dribla as características de alta conectividade urbana defendida no New Urbanism e no LEED ${ }^{\circledR} \mathrm{ND}$; este, por sua vez, não cria nenhum mecanismo para exigir essa conectividade, o que permite essa configuração urbana, mesmo se mal pontuada.

O crédito NPD.1 Walkable Streets, referente ao desenho do embasamento e o de maior quantidade de pontos possíveis, que poderia ter alto impacto no projeto, apresenta por sua vez pontuação mínima no Parque da Cidade. Os quinze parâmetros de avaliação tratam de soluções de fachada, em que a face para a rua não pode ser obstruída por carros e deve apresentar aberturas e proximidade ao pedestre. Assim, embora sejam muitas as possibilidades de cumprir o crédito, apenas um ponto é obtido, em um total de doze. Isso porque a própria lógica do empreendimento contraria o desenho urbano previsto no LEED ${ }^{\circledR}$ ND: enquanto o certificado prevê uma cidade altamente conectada e com fachada ativa ininterrupta, o projeto proposto é um conjunto de torres de escritório em um parque, cuja principal área comercial é um shopping center segregado.

Créditos como o NPD.4 Mixed-Income Diverse Communities, que garantiriam a diversidade de moradores a partir do fornecimento de unidades de valor mais baixo do que o da região, ou ao menos com a criação de diferentes tipologias de unidades residenciais, tampouco é obtido. Como comum em empreendimentos de alto padrão, tampouco foram obtidos pontos pelo NPD.12 Community Outreach and Involvement, relacionado a mecanismos de participação para residentes e moradores do entorno. Por outro lado, se essas são características que talvez ultra-

-parque-onde-ninguem-entra/. 


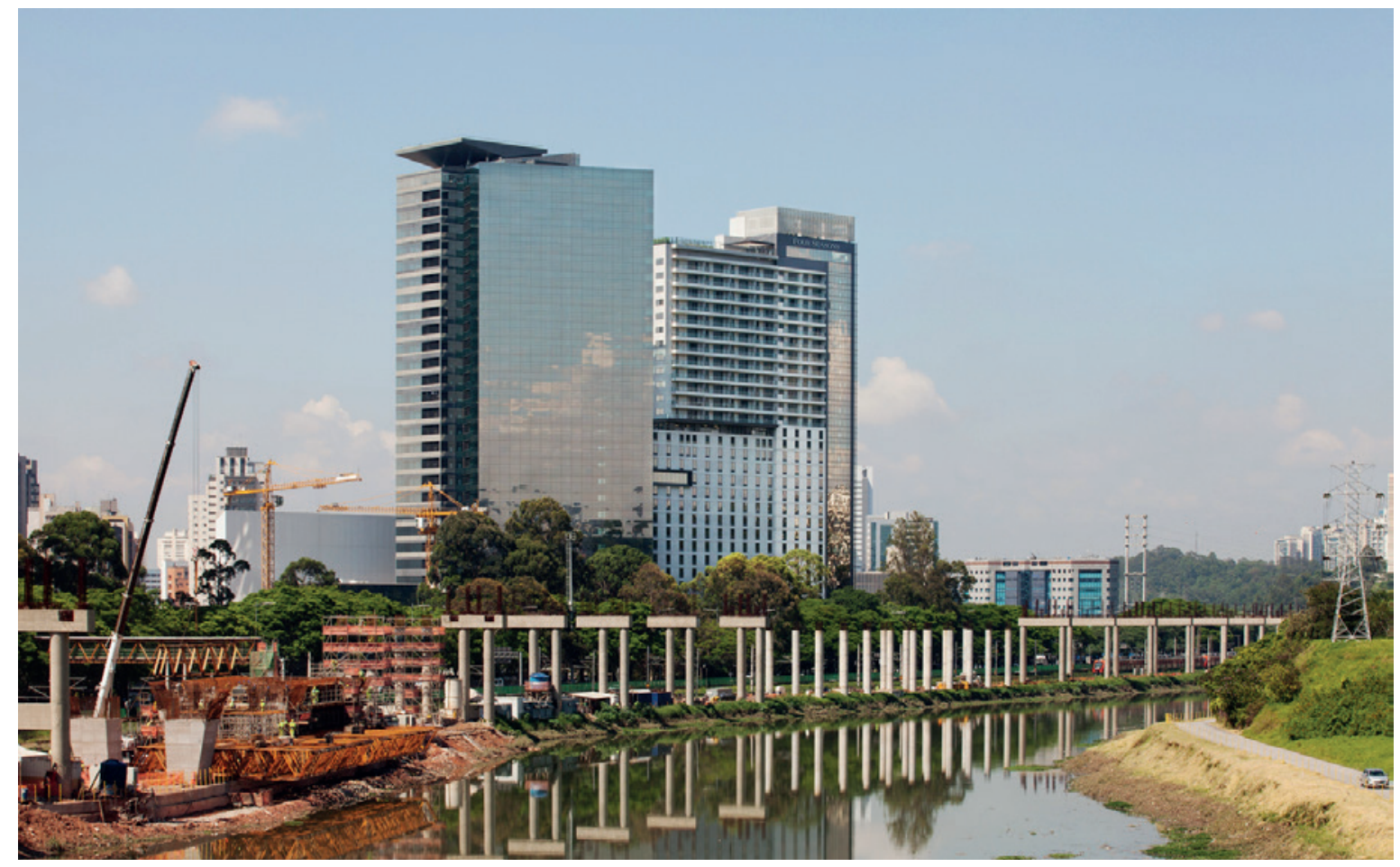

Fig 10.21. aflalo/gasperini arquitetos, Parque da Cidade (2010/-). Vista da segunda etapa, a partir da marginal Pinheiros, com torre Jequitibá e hotel Four Seasons. Fonte: Daniel Ducci via Archdaily.

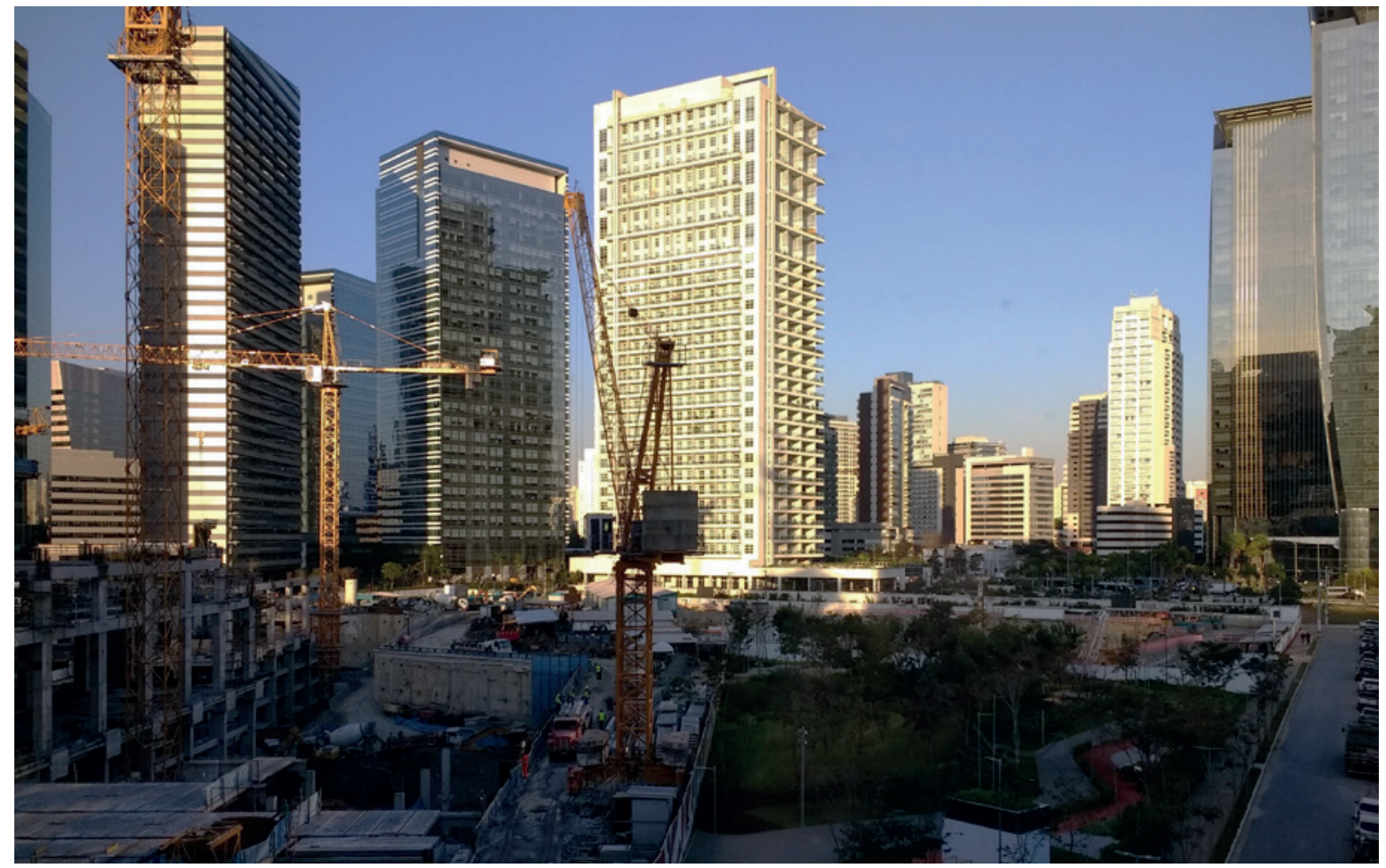

Fig 10.22. Vista da construção do Parque da Cidade, a partir do shopping. Fonte: Acervo do autor, 16 ago 2019.
Ao fundo, da esquerda para a direita: Rochaverá Corporate Towers, Tarumã, Morumbi Corporate, Capital Corporate Office. À direita, EZ Towers. 
passassem demasiadamente o padrão de mercado, nem mesmo o uso de bicicleta, que já estava presente desde os primeiros edifícios certificados e tem ganhado força nos últimos anos em São Paulo, é pontuado. ${ }^{25}$

\section{LIMITES DISCIPLINARES}

A partir do exposto, não se pode afirmar que o Parque da Cidade se relaciona, seja como linguagem simbólica, seja como desenho urbano, à agenda do New Urbanism. De fato, o empreendimento parece negar não só as estratégias desse movimento, como também a própria orientação estritamente solar dos edifícios preconizada pelo LEED $^{\oplus},{ }^{26}$ cujos autores, vinculados ao tradicional escritório de arquitetura aflalo/gasperini arquitetos, afirmam como prática habitual de seus projetos. ${ }^{27} \mathrm{O}$ "New Urbanism na marginal Pinheiros", título desta parte IV, é portanto uma formulação não consumada.

Diferentemente da experiência norte-americana, onde a pontuação do LEED ${ }^{\oplus}$ ND costuma se concentrar nas categorias de localização e desenho urbano, deixando a custosa obtenção de pontos vinculados à construção e tecnologia para aqueles projetos que busquem melhor performance, ${ }^{28}$ no caso brasileiro a solução é outra. O Parque da Cidade - e também o Ilha Pura, saliente-se - abre mão da maior parte dos pontos de desenho urbano ao manter o esquema moderno de figura-fundo, à custa de seu desempenho na certificação. A implantação do empreendimento é primordialmente visual. O eixo de organização dos edifícios não é a rua, como sugere o LEED ${ }^{\circledR}$ ND, mas uma marquise diagonal no centro da gleba, desalinhada de toda a estrutura viária. Desse modo, o vetor é próprio do projeto e interno a ele, evitando a relação com as pré-existências - as quais, não se pode esquecer, são na maior parte projeto do mesmo escritório, aflalo/gasperini arquitetos. Se um dos princípios do New Urbanism é a característica de comunidade e a vincu-

\section{SLL.4 Bicycle Network and Storage.}

26. GIB.10 Solar Orientation.

27. Flávia Marcondes, (Diretora associada no aflalo/gasperini arquitetos), Entrevista para o autor, Presencial, 27 de setembro de 2016.

28. Ayay Garde, "Sustainable by design?: insights from US LEED-ND pilot projects", Journal of the American Planning Association 75, no 4 (2009): 424-40, https://doi.org/10.1080/01944360903148174. Ver também conclusões no capítulo 9 e nas tabelas 9.2 e 9.3 . 


\begin{tabular}{|c|c|c|c|c|}
\hline \# & Categorias e créditos & Máx. & $\begin{array}{c}\text { Pq. da } \\
\text { Cidade } \\
\text { (Estágio 2) }\end{array}$ & $\begin{array}{l}\text { Ilha Pura } \\
\text { (Estágio 2) }\end{array}$ \\
\hline SLL & Smart Location and Linkage & 27 & 15 & 8 \\
\hline SLL.1 & Preferred Locations & 10 & 5 & 5 \\
\hline SLL.2 & Brownfield Redevelopment & 2 & 1 & 0 \\
\hline SLL.3 & Locations with Reduced Automobile Dependence & 7 & 7 & 0 \\
\hline SLL.4 & Bicycle Network and Storage & 1 & 0 & 1 \\
\hline SLL.5 & Housing and Jobs Proximity & 3 & 0 & 0 \\
\hline SLL.6 & Steep Slope Protection & 1 & 1 & 1 \\
\hline SLL.7 & Site Design for Habitat or Wetland and Water Body Conservation & 1 & 1 & 1 \\
\hline SLL.8 & Restoration of Habitat or Wetlands and Water Bodies & 1 & 0 & 0 \\
\hline \multirow[t]{2}{*}{ SLL.9 } & Long-Term Conservation Management of Habitat or Wetlands and & 1 & 0 & 0 \\
\hline & Water Bodies & & & \\
\hline NPD & Neighborhood Pattern and Design & 44 & 16 & 17 \\
\hline NPD.1 & Walkable Streets & 12 & 1 & 4 \\
\hline NPD.2 & Compact Development & 6 & 6 & 6 \\
\hline NPD.3 & Mixed-Use Neighborhood Centers & 4 & 4 & 0 \\
\hline NPD.4 & Mixed-Income Diverse Communities & 7 & 0 & 0 \\
\hline NPD.5 & Reduced Parking Footprint & 1 & 0 & 0 \\
\hline NPD.6 & Street Network & 2 & 0 & 0 \\
\hline NPD.7 & Transit Facilities & 1 & 0 & 1 \\
\hline NPD.8 & Transportation Demand Management & 2 & 0 & 0 \\
\hline NPD.9 & Access to Civic and Public Spaces & 1 & 1 & 1 \\
\hline NPD.10 & Access to Recreation Facilities & 1 & 1 & 1 \\
\hline NPD.11 & Visitability and Universal Design & 1 & 0 & 1 \\
\hline NPD.12 & Community Outreach and Involvement & 2 & 0 & 0 \\
\hline NPD.13 & Local Food Production & 1 & 1 & 1 \\
\hline NPD.14 & Tree-Lined and Shaded Streets & 2 & 2 & 2 \\
\hline NPD.15 & Neighborhood Schools & 1 & 0 & 0 \\
\hline GIB & Green Infrastructure and Buildings & 29 & 11 & 12 \\
\hline GIB.1 & Certified Green Buildings & 5 & 5 & 5 \\
\hline GIB.2 & Building Energy Efficiency & 2 & 0 & 0 \\
\hline GIB.3 & Building Water Efficiency & 1 & 1 & 1 \\
\hline GIB.4 & Water-Efficient Landscaping & 1 & 1 & 1 \\
\hline GIB.5 & Existing Building Reuse & 1 & 0 & 0 \\
\hline GIB.6 & Historic Resource Preservation and Adaptive Use & 1 & 0 & 0 \\
\hline GIB.7 & Minimized Site Disturbance in Design and Construction & 1 & 0 & 0 \\
\hline GIB.8 & Stormwater Management & 4 & 0 & 0 \\
\hline GIB.9 & Heat Island Reduction & 1 & 1 & 1 \\
\hline GIB.10 & Solar Orientation & 1 & 0 & 0 \\
\hline GIB.11 & On-Site Renewable Energy Sources & 3 & 0 & 0 \\
\hline GIB.12 & District Heating and Cooling & 2 & 0 & 0 \\
\hline GIB.13 & Infrastructure Energy Efficiency & 1 & 0 & 1 \\
\hline GIB.14 & Wastewater Management & 2 & 1 & 0 \\
\hline GIB.15 & Recycled Content in Infrastructure & 1 & 1 & 1 \\
\hline
\end{tabular}




\begin{tabular}{|c|c|c|c|c|}
\hline$\#$ & Categorias e créditos & Máx. & $\begin{array}{c}\text { Pq. da } \\
\text { Cidade } \\
\text { (Estágio 2) }\end{array}$ & $\begin{array}{l}\text { Ilha Pura } \\
\text { (Estágio 2) }\end{array}$ \\
\hline GIB.16 & Solid Waste Management Infrastructure & 1 & 1 & 1 \\
\hline GIB.17 & Light Pollution Reduction & 1 & 0 & 1 \\
\hline ID & Innovation in Design & 6 & 5 & 6 \\
\hline ID.1 & Innovation and Exemplary Performance & 5 & 4 & 5 \\
\hline ID. 2 & LEED Accredited Professional & 1 & 1 & 1 \\
\hline $\mathbf{R P}$ & Regional Priority & 4 & 4 & 4 \\
\hline SLL.3 & Locations with Reduced Automobile Dependence & 1 & 1 & 0 \\
\hline SLL.9 & $\begin{array}{l}\text { Long-Term Conservation Management of Habitat or Wetlands and } \\
\text { Water Bodies }\end{array}$ & 1 & - & 0 \\
\hline NPD.4 & Mixed-Income Diverse Communities & 1 & 0 & - \\
\hline NPD.9 & Access to Civic and Public Spaces & 1 & 1 & 1 \\
\hline NPD.14 & Tree-Lined and Shaded Streets & 1 & 1 & 1 \\
\hline GIB.8 & Stormwater Management & 1 & - & 0 \\
\hline GIB.14 & Wastewater Management & 1 & 1 & 1 \\
\hline \multirow[t]{5}{*}{ GIB.16 } & Solid Waste Management Infrastructure & 1 & 0 & 1 \\
\hline & Total & 110 & 51 & 47 \\
\hline & Nível & & Silver & Certificado \\
\hline & Registro & & $\mathrm{abr} / 13$ & mai/12 \\
\hline & Certificação & & $\mathrm{dez} / 14$ & $\mathrm{abr} / 14$ \\
\hline
\end{tabular}

Tab 10.1. Pontuação dos empreendimentos brasileiros certificados no LEED ${ }^{\circledR}$ ND v3. O Ilha Pura já foi certificado no Estágio 3, com 43 pontos, mas o detalhamento do desempenho ainda não está disponível publicamente. Fonte: LEED ${ }^{\circ}$ Project Directory, 4 jan 2019. Elaborado pelo autor.
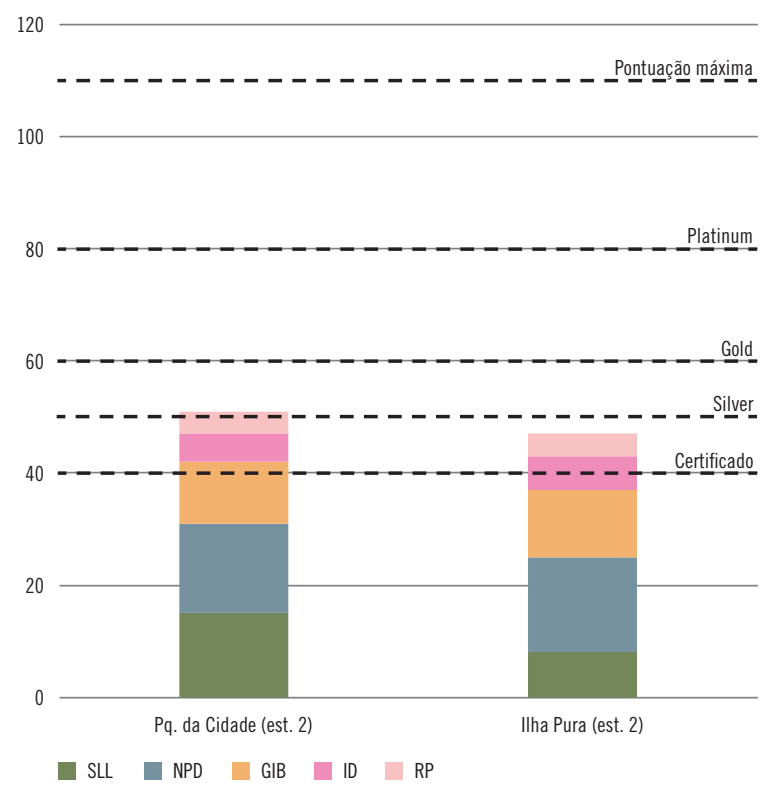

Quando comparados aos empreendimentos norteamericanos, os casos brasileiros têm cumprimento significativamente mais baixo nas categorias SLL e NPD, mas ligeiramente mais alto na categoria GIB [tab $9.2 \mathrm{e}$ 9.3]. Desse modo, custosas estratégias tecnológicas são utilizadas para obterem pontos não alcançados pela escolha de terrenos localizados em áreas consolidadas das cidades e, sobretudo, por renunciarem alterações morfológicas nos projetos.

Fig 10.23. Distribuição de pontos nos empreendimentos brasileiros certificados no LEED ${ }^{\circ} \mathrm{ND}$ v3. Fonte: LEED ${ }^{\oplus}$ Project Directory, 4 jan 2019. Elaborado pelo autor. 
lação com o lugar, então a estratégia de projeto em questão nega seus próprios fundamentos, e, por esse motivo, não consegue melhor pontuação. As diversas torres do conjunto, implantadas de modo a manter a independência de sua visualidade quando vistas da marginal Pinheiros, ainda se organizam em torno de uma grande área verde. A julgar pelas outras experiências na Chucri Zaidan realizadas pelo mesmo escritório, a área verde não será pública, ou mesmo "cívica", como sugere o LEED ND no crédito NPD.9: a "fruição" é aqui a de um espaço aparentemente público, mas na verdade severamente vigiado, como o usuário pode constatar visitando outros empreendimentos da região. ${ }^{29} \mathrm{O}$ sistema permite, portanto, práticas de segregação espacial, mesmo se criticadas em alguns de seus créditos, pois ainda são possíveis em razão da flexibilidade de cumprimento. Além disso, não se deve atribuir a morfologia desses conjuntos a limites impostos por leis de zoneamento e códigos de obras. Em primeiro lugar, porque tanto o Ilha Pura quanto o Parque da Cidade foram concebidos como empreendimentos de exceção e em direto diálogo com o poder público, de modo que se distinguissem como produtos imobiliários excepcionais. Em segundo lugar, porque o LEED ${ }^{\circledR}$ ND também encontrou resistência legal nos Estados Unidos, que foi resolvida por negociação com as municipalidades e eventos participativos de projeto. ${ }^{30}$

Em certo sentido, não há novidade aqui: a criação de espaços públicos vigiados, de cunho meramente contemplativo, é antiga no urbanismo corporativo, e há muito tempo analisada na literatura. Mas há também diferenças: a primeira, de escala, em que as novas áreas inseridas na cidade são significativamente maiores do que as de ciclos anteriores. Enquanto o Parque da Cidade tem $600.000 \mathrm{~m}^{2}$ de área construída em região em rápida consolidação, o CENESP tem dois terços disso em região mais distante, e o CENU, exemplo recorrente na literatura sobre a OUCAE pela sua escala, tem metade da área construída do Parque da Cidade. Em segundo lugar, está o papel da certificação, que legitima esse novo urbanismo por uma organização do terceiro setor reconhecida pelo mercado. Assim, a certificação garante a legitimidade do empreendimento, enquanto ele se esquiva de medidas mais inabituais do contexto arquitetônico local.

Os impedimentos colocados ao New Urbanism na marginal Pinheiros são certamente de

\footnotetext{
29. A rua e a praça certamente deixaram de ser palco do cotidiano, tal como eram em Lefebvre, para se tornarem espaços de "vigilância microfísica". Cf. Reinhold Martin, "Financial imaginaries: toward a philosophy of the city", Grey Room, n 42 (inverno de 2011): 62, https://doi.org/10.1162/GREY_a_00018.

30. Douglas Farr, Sustainable urbanism: urban design with nature (Hoboken, NJ: John Wiley \& Sons, 2008), 32-33.
} 
incorporação: as exigências não se adequam ao recorrente dos produtos imobiliários de risco conhecido de comercialização. Mas são também disciplinares, pois é à arquitetura e ao urbanismo que cabem a construção espacial e simbólica dos novos produtos almejados pelos incorporadores.

\section{EVASIVAS AO LEED@ FOR NEIGHBORHOOD DEVELOPMENT}

$\mathrm{O}_{\text {LEED }}{ }^{\circledR} \mathrm{ND}$ certamente não favorece suficientemente medidas que poderiam tensionar o mercado, como pelo aporte de mais pontos para habitação de baixo custo, o que já é notado desde sua versão piloto. ${ }^{31}$ Entretanto, é capaz de estabelecer algumas tensões, tanto em contexto norte-americano quanto brasileiro. Nos Estados Unidos, incorporadores expressaram resistência a exigências como distâncias mínimas a corpos d'água e várzeas. ${ }^{32}$ Alguns parâmetros de recuo e densidade são ilegais em determinadas partes do país, o que exigiu negociação por parte de projetistas e incorporadores para viabilizar projetos. ${ }^{33}$ Já no Brasil, as dificuldades relacionadas à abertura e uso misto do empreendimento podem explicar a baixa quantidade de interessados. Certificados concorrentes, como os concedidos pelo Processo Aqua - Bairros e Loteamentos, da Fundação Vanzolini, são pouco usados, mas em taxa superior ao LEED ${ }^{\oplus}{ }^{34}$ Isso se dá em razão de sua baixa exigência: o Processo Aqua não se opõe a problemas básicos de segregação dos loteamentos brasileiros mesmo tendo sido concebido exclusivamente para o mercado nacional. Isso permitiu a certificação de enclaves rigorosamente alinhados à produção corrente do mercado imobiliário e que não cumpririam nem mesmo os pré-requisitos do LEED ${ }^{\circledR} \mathrm{ND}^{35}$

31. Garde, "Sustainable by design?: insights from US LEED-ND pilot projects"; ver também Ayyoob Sharifi e Akito Murayama, "A critical review of seven selected neighborhood sustainability assessment tools", Environmental Impact Assessment Review 38 (2013): 73-87, https://doi.org/10.1016/j.eiar.2012.06.006.

32. Garde, "Sustainable by design?: insights from US LEED-ND pilot projects", 427.

33. Farr, Sustainable urbanism, 59.

34. Pelos dados disponibilizados pela Fundação Vanzolini para a pesquisa, são dez loteamentos certificados no Brasil, com levantamento em 7 mai 2019. Ao contrário do USGBC ${ }^{\oplus}$, a Fundação Vanzolini não publica ou fornece as notas e pontuações em cada crédito.

35. Luciana Márcia Gonçalves et al., "Contradições acerca da sustentabilidade em condomínios horizontais - Certificação ambiental e segregação sócio-espacial”, in Anais... (IV Simpósio de Pós-Graduação em Engenharia Urbana, Passo Fundo, RS, 2015). Os autores demonstram como um condomínio fechado em São Carlos obteve avaliação "Excelente", a mais alta possível, em seis de quinze categorias. Nessas categorias, o projeto não se opõe a questões triviais de fragmentação urbana e segregação: dista $8 \mathrm{~km}$ do núcleo urbano, dispõe de pouco transporte público, é cercado, não oferece empregos além dos 
O mesmo pode ser dito dos Referenciais Casa (piloto em 2012) e Condomínio (v1 em 2017), criados pelo GBC Brasil para disputar o mercado residencial com o Aqua. Os referenciais são versões brasileiras dos sistemas LEED ${ }^{\circledR}$ Homes e ND, simplificados e destituídos de créditos contrários às práticas locais. Não se pode afirmar que sejam versões para exatamente o mesmo tipo de projeto do que os norte-americanos: embora o Referencial Casa seja realmente direcionado a residências unifamiliares, como o LEED $^{\circledR}$ Homes, o Referencial Condomínio trata de edifícios residenciais - uma escala inexistente no LEED $^{\circledR} \mathrm{ND}$ - mas é também utilizado por conjuntos com mais torres. Os referenciais são mais simples de serem cumpridos, exigem menos consultorias e eliminam instrumentos de maior ruptura com o mercado. Assim, no caso do Referencial Casa, não há mais compensações da pontuação de acordo com a área per capita como no LEED ${ }^{\circledR}$ Homes. Já no caso do Referencial Condomínio, o sistema é simplificado com o objetivo de otimizar a produção imobiliária, mais do que se contrapor às configurações estabelecidas. Não há mais, por exemplo, o pré-requisito de se localizar em área interna ou adjacente a uma aglomeração urbana, mas apenas que haja infraestrutura de esgoto e água, ou que ela seja criada. ${ }^{36}$ Muros e controles de acesso são impedidos em relação ao bairro em que o condomínio ou casa se localizam, mas apenas caso seja buscada pontuação pelo projeto se localizar em bairro sustentável, e esse ponto não é mais um pré-requisito como no LEED $^{\circledR}$ ND. ${ }^{37}$ Em qualquer caso, os condomínios e as casas podem ser individualmente murados.

Os referenciais tiveram resposta melhor do que o LEED ${ }^{\circledR}$ até o fim de 2018, eram 41 registros no Casa, com oito certificados (contra apenas um certificado no LEED ${ }^{\odot}$ Homes), e 19 registros no Condomínio, com um certificado.

O exame dos dois Referenciais e mesmo do Aqua excedem o objetivo da tese, mas são aqui citados pelo que revelam: a dificuldade de entrada do $\mathrm{LEED}^{\circledR} \mathrm{ND}$ no Brasil por conta dos critérios de projeto acima mencionados gerou um hiato no mercado, agora ocupado por esses sistemas mais transigentes com as práticas locais de desenho urbano.

poucos relacionados a afazeres domésticos, localiza-se em antiga área de cultivo, possui baixíssima densidade construtiva e populacional e entorno com baixa oferta de comércio e serviços.

36. Na categoria Implantação dos Referenciais, no Pré-requisito 4 - Seleção do Terreno.

37. Na categoria Implantação dos Referenciais, Crédito 1 - Desenvolvimento Urbano Certificado. 


\section{PARTE V}

\section{O ESPAÇO SOB PADRÕES GLOBAIS}

A sociedade global é um mundo racionalizado, mas não exatamente um que alguém poderia chamar racional. Gili Drori, John Meyer e Hokyu Hwang ${ }^{1}$

\footnotetext{
1. No original: "Global society is a rationalized world, but not exactly what one could call a rational one." Gili S. Drori, John W. Meyer, e Hokyu Hwang, orgs., Globalization and organization: world society and organizational change (Oxford: Oxford University Press, 2006), 269, tradução nossa.
} 



\section{CAPÍTULO 11 \\ O LASTRO DOS PRODUTOS ESPACIAIS NA CERTIFICAÇÃO}

Os resultados obtidos ao longo deste trabalho têm como ponto de partida diferentes aspectos do sistema LEED ${ }^{\oplus}$ : seu desenvolvimento histórico-espacial, indicado na parte I; seus fundamentos teóricos induzidos pela exegese de textos de seus partidários, presente na parte II; e seu horizonte arquitetônico-urbanístico intrínseco e empírico, discutido nas partes III e IV. Esses indícios e as conclusões ali tiradas podem agora ser empregados em um novo nível de argumentação, cujas considerações são apresentadas a seguir em três frentes. A primeira é o impacto dos sistemas LEED", e do "ecossistema" de padrões associados ou em competição, nas estratégias disciplinares da arquitetura e do urbanismo. A segunda frente é a de como esse modo específico de operação da disciplina conduz a produtos espaciais, nos quais a padronização de soluções arquitetônico-urbanísticas azeita a circulação global de investimentos e práticas espaciais. A terceira, por fim, é da interpretação dos padrões como tecnologias do neoliberalismo.

\section{DISPOSIÇÃO}

As práticas espaciais inscritas no $\mathrm{LEED}^{\circledR}$ não são geograficamente restritas, mas globais. O sistema foi pensado desde o início para aplicação internacional, e essa concepção foi de fato acompanhada pela utilização do sistema, desde a versão piloto, além das fronteiras dos Estados Unidos. A adequação geográfica está prevista no alinhamento a normas locais e nas bonificações da categoria Regional Priorities, mas nada mais do que isso: o sistema mantém-se fundamentalmente uniforme em contextos variados. Por um lado, essa uniformidade permite entrever as estratégias projetuais do LEED ${ }^{\circledR}$. Por outro lado, ela é a baliza pela qual podem ser comparados os empreendimentos e o modo como eles cumprem as demandas do sistema. Esses foram os temas das partes III e IV. 
As imposições projetuais são claras no LEED ${ }^{\circledR}$ for Neighborhood Development (ND). A projeção do embasamento do edifício, a relação dos elementos arquitetônicos com a rua e características do passeio público são especificados com proporções, sugestões e esquemas projetuais. Já as estratégias dos sistemas New Construction (NC) e Core \& Shell (CS) são menos nítidas. O que se tem neles não são tipologias, mesmo em sentido vago, pois eles não estabelecem recuos, alturas, distâncias ou hierarquias entre os espaços. Mas, isso sim, há neles disposições da forma arquitetônica e urbana, pois são previstas determinadas relações de projeto e de espaço. Os projetos NC e CS são mais dispostos à regulação ambiental por sistemas mecânicos, ao envelope contínuo e estanque, ao perímetro de planta reduzido, a esquemas figura-fundo e à grande escala. Os projetos ND são mais dispostos à multifuncionalidade, à abertura pública, à ocupação perimetral e à permeabilidade de acesso ao pedestre.

O termo "disposição", tal como aqui empregado, tem origem em análise realizada por Keller Easterling para tratar dos novos fenômenos espaciais introduzidos na arquitetura por meio de aparatos normativos. Em seu livro Extrastatecraft, Easterling elabora a "disposição" a partir do estudo dos padrões técnicos, em especial aqueles relativos à série ISO 9000, que tratam da gestão de projetos. Para a autora, a disposição é como um jogo geométrico onde uma bola é posta no topo de um plano inclinado. Disposição é a relação potencial entre os dois elementos, bola e plano, pela qual se "descreve uma tendência, atividade, faculdade ou propriedade tanto em seres quanto em objetos - uma propensão dentro de um contexto."1 Portanto, a bola não precisa necessariamente deslizar para que a disposição se realize: ela se dá pela relação entre os elementos, mesmo quando a ação é apenas potencial. O termo deve-se, indica Easterling, a diversas referências, uma delas o "dispositivo" de Michel Foucault, que seria "um conjunto completamente heterogêneo de discursos, instituições, formas arquitetônicas, decisões regulatórias, leis, medidas administrativas, declarações científicas, proposições filosóficas, morais e filantrópicas - em resumo, o dito tanto quanto o não dito."2 Para Giorgio Agamben, em uma outra interpretação do

\footnotetext{
1. No original: "describes a tendency, activity, faculty, or property in either beings or objects- a propensity with in a context." Keller Easterling, Extrastatecraft: the power of infrastructure space (Londres, Nova York: Verso, 2014), 72, tradução nossa.

2. No original: "is... a thoroughly heterogeneous ensemble consisting of discourses, institutions, architectural forms, regulatory decisions, laws, administrative measures, scientific statements, philosophical, moral and philanthropic propositions - in short, the said as much as the unsaid." Michel Foucault, “The confession of the flesh", in Power/knowledge: selected interviews and other writings, 1972-1977, org. Colin Gordon (Nova York: Pantheon Books, 1980), 194, tradução nossa.
} 
pensamento de Foucault, "o dispositivo é, antes de tudo, uma máquina que produz subjetivações e somente enquanto tal é também uma máquina de governo"3 e "Não seria provavelmente errado definir a fase extrema do desenvolvimento capitalista que estamos vivendo como uma gigantesca proliferação de dispositivos."

Logo, a disposição dos padrões analisados por Easterling estabelece relações entre sujeitos e formas. A autora persegue a disposição por meio de formas espaciais do capitalismo contemporâneo, nesse sentido compartilhando o diagnóstico de Agamben, ainda que não o mencione, ainda que ambos recorram ao mesmo esquema foucaultiano. Nessas formas, como zonas de interesse econômico e padrões normativos, Easterling vê atributos latentes de novas atuações do arquiteto no mundo contemporâneo: seu trabalho se daria pelo estabelecimento das regras e fundamentos a partir dos quais a forma arquitetônica é gerada, mais do que do edifício em si. Contra o projeto tradicional, que ela chama de "forma-objeto", deveria ser feito o projeto da "infraestrutura do espaço", a "forma-ativa". Easterling vê, portanto, nessas formas avançadas do capitalismo tardio uma possibilidade de reformulação disciplinar.

Os exemplos colhidos por Easterling vão de resorts e campos de golfe a campi de TI, ${ }^{5}$ mas o caso mais relevante para o argumento deste trabalho é o dos padrões ISO, aplicados desde as dimensões de um cartão de crédito até a avaliação do planejamento urbano, no recente ISO 37120. A International Organization for Standardization (ISO) é uma ONG relativamente pequena em termos de funcionários, mas com grande número de colaboradores voluntários e amplo impacto no setor produtivo, da indústria aos serviços. O USGBC ${ }^{\circledast}$ reflete em grande medida o ISO nesses aspectos de estrutura organizacional. Interessa a Easterling essa combinação entre um pequeno porte, do ponto de vista do capital da empresa e seu quadro de funcionários, contraposto à ubiquidade de seus parâmetros.

O principal padrão analisado por Easterling é o da série ISO 9000, o mais popular entre os publicados pela organização. Criado em 1987, o padrão ainda serviu de modelo para o ISO

3. Giorgio Agamben, “O que é um dispositivo?”, in O que é o contemporâneo? e outros ensaios, [Orig. de 2005] (Chapecó: Argos, 2009), 46.

4. Agamben, 42.

5. Keller Easterling, Enduring innocence: global architecture and its political masquerades (Cambridge, EUA; Londres, Inglaterra: The MIT Press, 2007); Easterling, Extrastatecraft. 
14000, dedicado ao meio ambiente. O ISO 9000 avalia a gestão, e não o produto final: ele estabelece modos de documentação do processo de produção, e assim pode ser aplicado desde o fluxo de trabalho em um escritório de arquitetura até uma cadeia produtiva industrial. ${ }^{6}$ Veja-se o exemplo de James Lamprecht em um manual de utilização do padrão:

A interpretação seria a mesma para um gerente de hotel, um dentista, um diretor de hospital ou uma companhia de software? Obviamente não, mas há semelhanças. Em um restaurante, a revisão do contrato é realizada na interação entre cliente e garçom. Os clientes pedem um catálogo (mais conhecido como cardápio). Requisições diferentes da "oferta" são resolvidas no local com a total confiança de que a cozinha será capaz de cumprir a requisição contratual modificada... Na rara situação de que a cozinha (onde o parágrafo 4.9 do Controle de Processo teria efeito) não pode entregar o que foi prometido pelo garçom/garçonete, uma refeição não conforme (parágrafos 4.13 do Controle de Produtos Não Conformes e 4.13.1 da Revisão e Disposição de Não Conformidade) será o produto final. Entretanto, como é o caso em muitas indústrias manufatureiras, refeições não conformes apenas podem ser resolvidas após a entrega do produto. Muitos restaurantes aceitarão de bom grado a aplicação de uma ação corretiva (4.14), seja pela troca, seja pela mudança do pedido sem custo extra ao cliente.

Quanto à requisição de manter registros de qualidade, os registros de todas revisões de contrato são inseridos no cupom do pedido que provavelmente é guardado (ver 4.16) apenas por alguns dias, no máximo. Consequentemente, vemos como organizações de serviço podem de fato encontrar relevância na maior parte, senão em todos os vinte parágrafos do ISO $9001 .^{7}$

\footnotetext{
6. Peter Mendel, "The making and expansion of international management standards: the global diffusion of ISO 9000 quality management certificates", in Globalization and organization: world society and organizational change, org. Gili S. Drori, John W. Meyer, e Hokyu Hwang (Oxford: Oxford University Press, 2006), 137-66.

7. No original: "Would the interpretation be the same for a hotel manager, a dentist, a hospital director, or a software company? Obviously not, and yet there are similarities. In a restaurant, the contract review is performed at the customer/waiter interface. Customers order from a catalogue (better known as a menu). Requirements differing from the 'tender' are resolved on the spot with the full confidence that the kitchen will be able to meet the modified contractual requirement ... In the rare event that the kitchen (where paragraph 4.9 Process Control would take effect) cannot deliver what was promised by the waiter(ess), a nonconforming meal (paragraphs 4.13 Control of Nonconforming Products and 4.13.1 Nonconformity Review and Disposition) will be the end product. However, as is the case with some manufacturing industries, meal nonconformities can only be resolved after the product is delivered. Most restaurants will gladly apply corrective action (4.14) by either replacing or otherwise adjusting the order at no extra cost to the customer. As for the requirement to keep quality records, records of all contract reviews are written on the ordering ticket which is probably retained (see 4.16) for no more
} 
O que se nota, portanto, é a regulação da produção pelos padrões, mas de modo suficientemente genérico para serem aplicados nos mais diversos processos e sem demasiada interferência na empresa. Além disso, o ISO 9000 não se pronuncia sobre o produto final: o resultado pode ser irrelevante ou socialmente daninho, mas o padrão apenas afere a qualidade do processo a partir do cumprimento de etapas e sua documentação. ${ }^{8}$ Esse padrão ISO é neutro quanto ao âmbito de atuação da empresa, assim como o LEED ${ }^{\circledR}$ o é a respeito dos ocupantes dos edifícios certificados.

Além da proximidade entre ISO e USGBC ${ }^{\circledR}$ em relação a sua estrutura organizacional, essa prevalência da documentação referida por Lamprecht na citação acima também pode ser notada nos dois padrões promovidos por essas organizações. Julie Cidell já indicava como os trâmites burocráticos da documentação exigida pelo LEED ${ }^{\circledR}$ eram uma das maiores características do sistema, e mesmo análises mais recentes como as de Jerry Yudelson ainda enfatizam a dificuldade de manter os registros e comprovações atualizados para o envio ao Green Business Certification Inc. (GBCI). ${ }^{9}$ Os créditos vinculados ao comissionamento do projeto, ${ }^{10}$ por exemplo, são a verificação de que os equipamentos projetados foram instalados, e a comprovação de que essa verificação foi realizada, mas o desempenho real não era aferido até ao menos a introdução da plataforma Arc. Os créditos vinculados a materiais, do mesmo modo, são comprovados pelo cumprimento de ainda outro grupo de certificados, na mesma linha de documentação extensiva. ${ }^{11}$ Por fim, ao

than a few days at the most. Consequently, we see that service organizations can indeed bring relevance to most if not all of the twenty ISO 9001 paragraphs." James L. Lamprecht, Implementing the ISO 9000 series (Nova York: Marcel Dekker, 1993), 42-44; apud Mendel, "The making and expansion of international management standards: the global diffusion of ISO 9000 quality management certificates", 139, tradução nossa. Os itálicos são de Mendel e foram inseridos nas expressões referentes à terminologia típica da série ISO 9000.

8. Mendel, "The making and expansion of international management standards: the global diffusion of ISO 9000 quality management certificates", 142

9. Julie Cidell, "A political ecology of the built environment: LEED certification for green buildings", Local Environment 14, n. 7 (ago de 2009): 621-33, https://doi.org/10.1080/13549830903089275; Jerry Yudelson, Reinventing green building: why certification systems aren't working and what we can do about it, Prefácio de Pamela Lippe (Gabriola Land, Canada: New Society Publishers, 2016).

10. Nos sistemas NC e CS v3, trata-se dos créditos EA.Prereq.1 Fundamental Commissioning of Building Energy Systems e EA.3 Enhanced Commissioning.

11. Ainda nos sistemas NC e CS v3, seria o caso dos seguintes créditos: WE.Prereq.1 Water Use Reduction e WE.3 Water Use Reduction. com o certificado WaterSense como uma das formas de cumprimento; EA.4 Enhanced Refrigerant Management, com o Eurovent; EA.6 Green Power, que se referencia pelo Green-e Energy; MR.6 Certified Wood, referenciado ao Forest Stewardship Council (FSC), com impacto ainda em MR.3 Materials Reuse, MR.4 Recycled Content e MR.5 Regional Materials; EQ.4.3 Low-Emitting Materials - Flooring Systems, cumprido por meio do Green Label Plus ou do FloorScore. 
modo do ISO, tal como tratado por Easterling, as práticas certificadas pelo LEED ${ }^{\circledR}$ por vezes revelam pouco do produto final, como nos créditos de proibição do ato de fumar ou de criação de vagas de automóveis apenas até o exigido por lei: nesses casos, o sistema somente requer o já obrigatório. ${ }^{12}$ Um pré-requisito exigindo o cumprimento integral das leis locais poderia ser suficiente, mas o LEED ${ }^{\oplus}$ acaba por enfatizar algumas leis, mas não outras - como, por exemplo, a ausência na maior parte de seus sistemas de critérios exigindo a formalidade do trabalho. Nesse mesmo aspecto, de o $\mathrm{LEED}^{\circledR}$ pouco revelar sobre o produto certificado, é notável que sua flexibilidade permita o não cumprimento de categorias inteiras de avaliação. ${ }^{13}$ Edifícios analisados na parte III, como a Torre São Paulo e o WT Morumbi, por exemplo, têm desempenhos muitos baixos na categoria Energy and Atmosphere, e não conquistam nenhum ponto nos créditos diretamente relacionados a menor custo energético. Entretanto, isso não os impediu de alcançar o nível Gold de certificação: a prescrição flexível permite aos empreendimentos serem certificados mesmo se não cumprirem as intenções do sistema.

O uso do termo "disposição" permite, portanto, abarcar a gestão de projeto em suas estratégias contemporâneas, cuja flexibilidade dificulta a compreensão de seu conteúdo arquitetônico e urbanístico. Não se trata mais da análise de um objeto fixo, da forma-objeto, mas da organização das relações por ele produzidas, a forma-ativa. Esse diagnóstico certamente não é novo: Manfredo Tafuri, em seu Projeto e utopia, já analisava a "crise do objeto" na obra de Ludwig Hilberseimer e a transformação do projeto moderno em uma ferramenta de organização. ${ }^{14} \mathrm{O}$ que muda entre as duas situações é o significado de organização: não mais a distribuição ordenada dos espaços, ao modo da cadeia produtiva industrial, mas a gestão das relações espaciais, ao modo do capitalismo tardio. E contudo, apesar do argumento acompanhar até aqui o proposto por Easterling a respeito da forma-ativa das normas, há diferenças entre os fenômenos analisados pela autora e por este trabalho.

12. Como em EQ.Prereq.2 Environmental Tobacco Smoke (ETS) Control e SS.4.4 Alternative Transportation - Parking Capacity.

13. O que é diferente do Processo Aqua, um sistema brasileiro baseado no francês $\mathrm{HQE}^{\circledR}$.

14. Manfredo Tafuri, Projecto e utopia: arquitetura e desenvolvimento do capitalismo, [Ed. orig. 1973] (Lisboa: Editorial Presença, 1985), cap. "Arquitetura 'radical' e cidade". 
A partir desse ponto, são necessárias ao menos duas precisões a respeito da teoria arquitetônica da "disposição". Primeira: o exposto nesta pesquisa permite concluir que os padrões só são válidos, em termos de fundamentação social, em economias centrais. Assim, partindo do estudo de caso do ISO 9000, Peter Mendel nota que seus dados

sugerem que nossas tipologias institucionais usuais geradas em países desenvolvidos podem não ser diretamente aplicadas em políticas não-ocidentais ou menos modernizadas. Pode ser que as estruturas institucionais estatais em países em desenvolvimento são mais um reflexo de regimes externamente impostos do que de orientações culturais mais amplas. Ou talvez as normas institucionais e culturais representem filtros mais fracos para modelos globalmente legitimados em comparação com países centrais, especialmente se os setores econômicos são menos integrados na sociedade civil dentro de nações em desenvolvimento. ${ }^{15}$

Assim, do ponto de vista das economias periféricas, a formalidade exigida pelos padrões não teria organicidade social. Por um lado, o padrão se imporia a despeito das práticas locais. Por outro lado, no caso específico do sistema $\mathrm{LEED}^{\circledR}$, ele pretende auxiliar a construção de torres verdes com base em condições sociais que o negam: do trabalho e moradia informais aos rios transformados em esgoto, o cenário dos projetos brasileiros nega os avanços de performance neles obtidos. O LEED ${ }^{\circledR}$ tem como pressuposto um determinado grau de formalidade social. Por isso, em terreno impróprio, sua aplicação tensiona as contradições, como no contraste entre torres futurísticas e assentamentos primitivos sentido en passant por Rick Fedrizzi, como mencionado no capítulo 6. Além disso, o GBC Brasil, como conselho de sustentabilidade, não tem programas específicos para o contexto do país. Sua atuação se concentra na promoção do

\footnotetext{
15. No original: "suggest that our usual institutional typologies generated from developed countries may not be directly applicable to non-Western or less modernized polities. It may be that state institutional structures in developing countries are more a reflection of externally imposed regimes than of broader cultural orientations. Or perhaps, cultural and institutional norms represent weaker filters for globally legitimated models compared to core countries, especially if economic sectors are less integrated into civic society within developing nations." Mendel, "The making and expansion of international management standards: the global diffusion of ISO 9000 quality management certificates", 159-60, tradução nossa.
} 
LEED $^{\oplus}$, o recorrente produto de sustentabilidade financeira dos conselhos verdes vinculados ao World GBC. Descontada a malsucedida Lei do Teto Branco, a atuação do GBC Brasil está amparada no LEED $^{\oplus}$ mesmo quando o conselho entra no debate de políticas públicas, como quando defendeu cláusulas de incentivo ao sistema na Quota Ambiental e no IPTU Verde paulistanos. O conselho brasileiro precisaria, portanto, se posicionar frente aos problemas ambientais próprios do país que não são resolvidos pelas eficiências internas ao lote avaliadas por seu produto LEED ${ }^{\circledR}$.

Segunda precisão: o conceito de disposição tal como elaborado por Keller Easterling trata sobretudo de instrumentos não-espaciais:

Com a sua grande quantidade de padrões, o ISO fala muitas linguagens técnicas, mas ele não tem padrões de gestão que empregam diretamente variáveis espaciais, embora o espaço em si seja uma tecnologia e um meio de informação. A matriz de produtos espaciais repetíveis como shoppings, resorts, campos de golfe e subúrbios, assim como fórmulas urbanas para zonas econômicas ou redes de banda larga, contribuem para um sistema operacional global. Alterar a infraestrutura do espaço é frequentemente uma questão de interesse global, superando o alcance de nações e negócios e requerendo a escala e a alavancagem de uma habilidade operacional fora do Estado [extrastatecraft], mas ela é ordinariamente manipulada com ferramentas não espaciais. ${ }^{16}$

Essa "capacidade extra-estatal" já foi tratada na parte II. Naquele ponto do argumento, foi indicado como a modernização ecológica atua de modo "paraestatal" ou "paraempresarial", seguindo a terminologia do urbanista Henri Acselrad. ${ }^{17}$ Embora existam sutis diferenças entre os termos - o paralelismo ao Estado e ao mercado em Acselrad, o caráter sub-reptício em Easter-

16. No original: "With its multitude of standards ISO speaks many technical languages, but it has no management standards that directly deploy spatial variables even though space itself is a technology and a medium of information. The matrix of repeatable spatial products like malls, resorts, golf courses, and suburbs, as well the urban formulas for zones or broadband networks, contributes to a global spatial operating system. Altering infrastructure space is often a matter of global concern, exceeding the reach of nations and businesses and requiring the scale and leverage of extrastatecraft, but it is ordinarily manipulated with non-spatial tools.” Easterling, Extrastatecraft, 173-74, tradução nossa.

17. Henri Acselrad, "Ambientalização das lutas sociais - o caso do movimento por justiça ambiental", Estudos avançados 24, no 68 (2010): 103-19, http://dx.doi.org/10.1590/S0103-40142010000100010. 
ling -, está em análise nos dois autores a operação da sociedade civil por instrumentos distintos daqueles presentes no par Estado e mercado. Mas, se o ISO tem uma potencial implicação espacial sem, contudo, manipular variáveis espaciais, por outro lado o objeto desta pesquisa é mais nítido. Por mais que o LEED $^{\circledR}$ nem sempre se pretenda como tal, ele é uma ferramenta espacial, pois trata de projeto e construção de empreendimentos. Portanto, suas "estratégias potenciais", para usar uma expressão presente nos sistemas em sugestões para o cumprimento dos créditos [fig 1.1], têm implicações formais. O LEED ${ }^{\circledR}$ se encontra, assim, entre a "forma-ativa" e a "forma-objeto": seus efeitos podem ser mais do que meramente disposições e, como visto no LEED ${ }^{\circledR}$ $\mathrm{ND}$, chegam no limite de sugerir um esquema tipológico. O estudo do LEED ${ }^{\circledR}$ permite um passo não realizado por Keller Easterling, embora sugerido em versões preliminares de seu trabalho: o da interferência da forma-ativa na forma-objeto, do aparato normativo sobre a forma arquitetônico-urbanística. ${ }^{18}$

Pela objetividade de seu esquema normativo, o $\mathrm{LEED}^{\circledR}$ ainda é relevante não só pelas suas consequências na forma arquitetônico-urbanística, mas também pelo contraste existente entre seus parâmetros e as características de projeto que respondem unicamente a decisões de linguagem arquitetônica. Por exemplo: os sistemas LEED $^{\circledR}$ NC e CS não só estabelecem virtualmente um envelope uniforme e de perímetro relativo ao edifício, como também revelam as contradições resultantes do seu não cumprimento. Os projetos que escondem parapeitos atrás do pano de vidro e a este sobrepõem delicados quebra-sóis, como no São Paulo Corporate Towers, demonstram como ainda não é possível alcançar com o vidro os mesmos índices de desempenho térmico presentes em materiais opacos, por mais que arquitetos e incorporadores insistam retoricamente na alta performance dos vidros contemporâneos. ${ }^{19} \mathrm{~A}$ incongruência projetual presente na sobreposição do vidro ao parapeito, ou do quebra-sol sutil ao pano de vidro ubíquo, revela as demandas contraditórias na elaboração da forma arquitetônico-urbanística.

\footnotetext{
18. Como sugerido em Keller Easterling, "We will be making active form", Architectural design 82 (2012): 58-63.

19. Por exemplo, os depoimentos em Regiane Teixeira e Vanessa Correa, “Pele de vidro’ se torna padrão para edifícios corporativos em SP”, Folha de São Paulo, 11 de maio de 2013, seç. São Paulo; verificar ainda os cálculos de Cinthia Andreis, Priscila Besen, e Fernando Simon Westphal, "Desempenho energético de fachadas envidraçadas em climas brasileiros", in Anais... (XV Encontro Nacional de Tecnologia do Ambiente Construído, Maceió, 2014), 926-35, https://doi.org/10.17012/ entac2014.628.
} 
Além disso, seguindo a sugestão de Easterling sobre a disposição, ${ }^{20}$ é possível verificar o que o LEED $^{\circledast}$ não faz, ou mesmo obstrui. $\mathrm{O}^{2 E E D}{ }^{\circledR}$ não incentiva estratégias vernaculares, embora o faça para soluções high tech; ele reforça determinadas leis, mas não outras; ele beneficia performances excepcionais em edifícios de linguagem ordinária, ao invés de soluções simples e generalizáveis ou da renovação tipológica; seus parâmetros, sobretudo nos sistemas NC e CS, não combatem a monofuncionalidade e a segregação. Ademais, a simples aferição de performance é insuficiente face aos problemas ambientais atuais. A centralidade de parâmetros quantitativos no $\mathrm{LEED}^{\circledR}$ esvaziou, por um lado, a arquitetura ambiental da elaboração tipológica que lhe era habitual, uniformizando as estratégias entre os empreendimentos certificados. ${ }^{21}$ Por outro lado, os sistemas LEED ${ }^{\circledR}$ NC e CS não extrapolam sua atuação para processos sociais exteriores ao edifício, como mencionado a respeito da regulação do trabalho de construção no capítulo 5 .

\section{PRODUTOS ESPACIAIS}

Em antítese a manuais de empreendedorismo, a estratégia dos padrões não é a da inovação, que pode representar um ganho excepcional por monopólio ou efeitos colaterais se planejada equivocadamente, mas a de uma racionalização que nivela as práticas das empresas. ${ }^{22}$ Uma empresa que utilize um padrão age, logo, não pela recompensa face ao risco, mas pela segurança face à conformação. Se esses termos forem aplicados à arquitetura, o 30 St Mary Axe de Foster + Part-

20. Easterling, Extrastatecraft, 173.

21. O que certamente não é exclusividade do LEED ${ }^{\oplus}$. Em entrevista para pesquisadores, um consultor espanhol do sistema britânico BREEAM ${ }^{\circledast}$ nota como a linguagem arquitetônica é padronizada em detrimento de soluções locais, como forma de adequação para certificação. Segundo ele, "What is used in construction varies internationally, but BREEAM demands products with very particular specifications, which may not be appropriate or available in other non-UK contexts. Globally recognized contemporary design styles have been replacing local material usage and traditional building techniques, in other words vernacular architecture, since the twentieth century in the interests of constructing a 'modern looking building'. Such global certifications have replaced the main considerations of design.” James Faulconbridge e Sercan Yalciner, "Local variants of mobile sustainable building assessment models: the marketization and constrained mutation of BREEAM ES”, Global networks 15 (2015): 374, https://doi.org/10.1111/glob.12083.

22. Mendel, "The making and expansion of international management standards: the global diffusion of ISO 9000 quality management certificates", 142 . 
ners arrisca a originalidade tipológica com o objetivo de ganhos por uma "renda da forma"; ${ }^{23}$ o 4 Times Square é o produto espacial de retorno previsível. Como notado por Jerry Yudelson, o LEED ${ }^{\circledR}$ não só permite comparar diferentes projetos, por serem emparelhados a um mesmo sistema de pontos, como também os ranqueia em razão de seu desempenho. ${ }^{24}$ Assim, o LEED ${ }^{\circ}$ oferece distinções aos empreendimentos, mas sempre a partir de um conjunto fixo de parâmetros e "boas práticas" que inibe a inovação tipológica e formal.

Os padrões são, desse modo, um aspecto de homogeneização de soluções arquitetônicas, por reduzirem o escopo de projeto ao que está neles previsto. Eles se somam a outras práticas de uniformidade espacial. Otília Arantes já notava como é possível encontrar

a mesma paisagem por toda a parte, ou melhor, sem contar os simulacros na periferia, as mesmas landscapes of power descritas por Sharon Zukin em cidades globais como Nova York e Londres: não há nada de surpreendente nisto, pois o redesenvolvimento das áreas centrais nas duas cidades não por acaso caíram nas mãos das mesmas instituições financeiras, das mesmas megaincorporadoras, dos mesmos escritórios do star system, que por seu turno preparam o terreno por encomenda das matrizes multinacionais de sempre..$^{25}$

As semelhanças entre as paisagens globais notadas por Arantes também estão presentes na transformação urbana da marginal Pinheiros, inclusive por conta de seus agentes. Ainda que aqui as incorporadoras fossem brasileiras, escritórios como o Pelli Clarke Pelli e o Arquitectonica são recorrentemente requisitados para o projeto de distritos financeiros, e as corporações visadas como potenciais inquilinas dos empreendimentos são igualmente frequentes na ocupação desses espaços. Tem-se com isso a combinação entre a reestruturação econômica das cidades globais e a internacionalização dos escritórios de arquitetura, dos proprietários de edifícios, dos

23. O termo é de Pedro Fiori Arantes, Arquitetura na era digital-financeira: desenho, canteiro e renda da forma (São Paulo: Editora 34, 2012).

24. Jerry Yudelson, The green building revolution, Prefácio de Rick Fedrizzi (Washington, DC; Covelo, CA; Londres: Island Press, 2008), 14.

25. Otília Beatriz Fiori Arantes, Berlim e Barcelona: duas imagens estratégicas (São Paulo: Annablume, 2012), 24; Arantes menciona Sharon Zukin, Landscapes of power: from Detroit to Disney World (Berkeley, CA: University of California Press, 1991). 
investidores e dos instrumentos financeiros imobiliários. ${ }^{26}$ Donde a ubiquidade dessas formas arquitetônico-urbanísticas, que levaram o crítico Reinhold Martin a caracterizar as torres corporativas como o correlato, no capitalismo tardio, das formas da circulação do capital examinadas nas arcadas de Paris por Walter Benjamin. ${ }^{27}$ Os padrões seriam um novo estágio nesse processo de alinhamento internacional.

Essas práticas espaciais da "cidade global” são históricas e, portanto, tiveram início e terão um fim. A cidade global, como forma específica de produção urbana, começou na reestruturação econômico-espacial dos anos 1980. Mas, como nota Simon Curtis, ela pode ter encontrado seu termo no começo dos anos 2010, com o recrudescimento das fronteiras nacionais e as guerras comerciais, mas também por motivos intrínsecos a sua própria lógica, como a combinação de crescimento acelerado e aumento de desigualdade social. ${ }^{28} \mathrm{Ou}$, como argumenta Saskia Sassen, uma das precursoras do estudo das cidades globais: as formas recentes de globalização atuam com um nível de violência existente apenas nos primórdios do capitalismo, como pode ser visto nas expulsões de populações na crise de refugiados, o extrativismo predatório de recursos naturais, a propriedade de grandes extensões de terra por investidores estrangeiros e os instrumentos financeiros de aguda concentração de capital. ${ }^{29}$ Pode ser induzido de seu argumento que essa violência é incompatível com os modos de operação do Consenso de Washington nos anos 1990, no que pode ser vislumbrado um novo estágio de organização socioeconômica. A sustentabilidade e a economia verde emergiram no mesmo período da globalização, e também têm sofrido revezes com a ascensão de grupos políticos de negacionismo ambiental ${ }^{30}$ - de resto, organizados ao me-

\footnotetext{
26. James Faulconbridge e Monika Grubbauer, “Transnational building practices: knowledge mobility and the inescapable market", Global networks 15 (2015): 276.

27. Reinhold Martin, "Financial imaginaries: toward a philosophy of the city", Grey Room, nº 42 (inverno de 2011): 60-79, https://doi.org/10.1162/GREY_a_00018.

28. Simon Curtis, “Global Cities and the Ends of Globalism”, New Global Studies 12, nº 1 (25 de abril de 2018): 75-90, https:// doi.org/10.1515/ngs-2018-0007.

29. Saskia Sassen, Expulsions: Brutality and complexity in the global economy (Cambridge, USA: The Belknap Press of Harvard University Press, 2014).

30. Stephen Zehr, "The sociology of global climate change", WIREs Climate Change 6 (março de 2015): 137-38, https://doi. org/10.1002/wcc.328. O texto, de 2015, não aborda os desenvolvimentos mais recentes do negacionismo ambiental, mas sua revisão bibliográfica interessa a esta pesquisa em mais de um ponto. Zehr identifica as diferentes posições do "contramovimento conservador" e a sua especificidade geográfica no momento da redação do artigo.
} 
nos desde a presidência de George W. Bush (2001-2009). ${ }^{31}$ Certamente, os processos sociais em curso não permitem estimar um fim próximo das cidades globais. Mas os abalos a esses modelos revelam como o $\mathrm{LEED}^{\circledR}$ - como um padrão global de fundamentos financeiros, espaciais e ambientais - faz parte de um conjunto de instrumentos particulares a esse tipo de produção urbana e política ambiental internacional.

O sistema LEED ${ }^{\circledR}$ prospera no cenário das cidades globais onde se encontra um "fetichismo da liquidez". A expressão de François Chesnais refere-se à preferência do capital financeiro por ativos facilmente transacionados, em busca das melhores oportunidades de retorno. ${ }^{32}$ Para Mariana Fix, disso decorreriam dois conjuntos de consequências para a produção imobiliária. De um lado, mudanças organizacionais, em que as empresas deixam de ser proprietárias de seus locais de trabalho: com o intuito de imobilização mínima de capital, elas passaram a locar seus escritórios, ao invés de comprá-los. De outro lado, a propriedade dos edifícios corporativos por fundos imobiliários, e não pelas empresas inquilinas, insere os edifícios em um circuito de imperativos financeiros distintos do modelo precedente. Os edifícios, mercadorias por sua própria natureza ilíquidas, passam a também se submeter a lógicas de aumento de liquidez. Donde a padronização de soluções arquitetônicas, de organização do programa, de detalhamentos construtivos, de localizações no tecido urbano. ${ }^{33}$ Isto é: a predominância das torres inteiramente envelopadas em vidro, os esquemas de pavimento-tipo com núcleo de serviços e circulação centralizado, o respeito a normas de bombeiros novaiorquinas, a adequação a expectativas de pé direito e área útil por pavimento-tipo, a aparência de uniformidade do envelope, a proximidade a vias expressas, eixos de transporte de massa e aeroportos, entre tantos outros aspectos avaliados por

31. Quando presidente, Bush regrediu as políticas ambientais em curso e iniciou uma mudança de comunicação ao trocar a expressão "aquecimento global" por "mudança climática”. Pesquisas de opinião pública mostravam que a nova expressão trazia menor urgência ao problema. Thassanee Wanick, fundadora do GBC Brasil, coloca, contudo, que Bush teria um grande impacto no USGBC ${ }^{\oplus}$, pois teria assinado uma lei obrigando os edifícios públicos a serem certificados pelo LEED ${ }^{\circ}$. Desse modo, vantagens para o LEED ${ }^{\circledR}$ não significam necessariamente melhores políticas ambientas. Cf. Thassanee Wanick, (Fundadora do GBC Brasil), Entrevista para o autor, 24 de janeiro de 2017; Oliver Burkeman, “Memo exposes Bush's new green strategy", The Guardian, 4 de março de 2003, seç. Environment, https://www.theguardian.com/environment/2003/ mar/04/usnews.climatechange; Paul Harris, "Bush covers up climate change”, The Guardian, 21 de setembro de 2003, seç. Environment, https://www.theguardian.com/environment/2003/sep/21/usnews.georgewbush.

32. François Chesnais, A mundialização do capital, [Ed. orig. 1994] (São Paulo: Xamã, 1996).

33. Mariana Fix, São Paulo cidade global: fundamentos financeiros de uma miragem (São Paulo: Boitempo, 2007), 15, 154, 156 , entre outras. 
gestores de fundos. Tais características são todas mensuradas e avaliadas pelos administradores de edifícios corporativos, o que permite a classificação dos empreendimentos segundo sua distinção no mercado.

Nesse contexto, instrumentos são criados para facilitar não só as transações de capital maneiras de os investimentos atravessarem fronteiras com maior fluidez -, como também a adequação dos espaços locados no estrangeiro às expectativas das matrizes. As zonas de interesse econômico e os padrões normativos são, para Easterling, indicadores de azeitamento dessas duas características. Os padrões, o LEED ${ }^{\circledR}$ entre eles, permitem ao investidor e ao inquilino calibrarem suas expectativas em relação ao ambiente construído. Eles são um lastro para o investimento: não mais uma conjectura incerta, mas um título com credibilidade assegurada; eles são uma imagem espectral do edifício, de seus espaços e ocupação possíveis.

A segurança de investimento é essencial nesses casos, pois, como coloca Reinhold Martin, "Ao invés de trocarem bens ou mesmo dinheiro, as pessoas estão aqui trocando crédito. Como resultado, elas devem confiar umas nas outras mais intimamente do que se elas estivessem trocando coisas mais tangíveis." ${ }^{4}$ É em razão dessas preocupações que François Chesnais identifica "comportamentos patologicamente nervosos" nos investidores, em busca de segurança face ao risco e de liquidez para mudar de trajetória aos primeiros sinais de infortúnio. ${ }^{35}$

Desses aspectos decorre o "isomorfismo" das "boas práticas" globais de negócios. ${ }^{36}$ Esse isomorfismo permite a cooperação internacional, entre sedes e filiais, ou, para a arquitetura, entre arquitetos internacionais e empreendedores locais. Segundo a teoria organizacional de Nils Brunsson e Bengt Jacobsson, “Os padrões facilitam a coordenação e cooperação em escala global. Eles criam similaridade e homogeneidade mesmo entre pessoas e organizações distantes entre si. Eles são instrumentos de controle." ${ }^{37}$

\footnotetext{
34. No original: “'"Rather than exchanging goods or even cash, people here are exchanging credit. As a result, they must trust one another more intimately than if they had exchanged more tangible things." Martin, "Financial imaginaries: toward a philosophy of the city", 68, tradução nossa.

35. Chesnais, A mundialização do capital, 15.

36. John Boli e George M. Thomas, Constructing world culture: international nongovernmental organizations since 1875 (Stanford, CA: Stanford University Press, 1999).

37. No original: "Standards facilitate co-ordination and co-operation on a global scale. They create similarity and homogeneity even among people and organizations far apart from one another. They are instruments of control." Nils Brunsson e Bengt Jacobsson, "The contemporary expansion of standardization”, in A world of standards (Londres: Oxford University 
A comparabilidade e comensurabilidade entre projetos locais e contexto internacional é essencial para o sucesso dos padrões. São essas características que levaram a fundadora do GBC Brasil, Thassanee Wanick, a defender a adoção do LEED ${ }^{\circ}$ tanto dentro do conselho quanto no contato com políticos. Para ela, o fato de o LEED $^{\circledR}$ ser uma marca internacionalmente reconhecida permitiria que os investidores logo compreendessem os edifícios com que estavam lidando, em oposição a um certificado autóctone, como defendia a organização opositora CBCS seguindo o iiSBE, que apesar do ajuste local, não permitiria o diálogo global. ${ }^{38} \mathrm{Ou}$ seja: as relações espaciais e financeiras só são desimpedidas se o isomorfismo for garantido globalmente.

Entretanto, a lógica de operação desses instrumentos não é exclusivamente global. A iniciativa para sua implantação, e isso pode ser visto na própria história de fundação do GBC Brasil, é local. ${ }^{39}$ As atividades visadas por essa iniciativa, apesar de uniformizadas em relação às economias centrais, ainda requerem algum nível de ajuste local, pois, como afirma Sassen, a "globalização homogeneíza padrões - para administrar, para contabilizar, para construir distritos de escritórios modernos e assim por diante, mas ainda requer diversificação das capacidades econômicas", em que cada cidade tem uma função na rede global. ${ }^{40} \mathrm{~A}$ isso corresponde, ainda, a própria imagem do espaço construído: alinhado às diretrizes globais, mas com uma imagem local suficientemente idiossincrática para operar em livre circulação. É o que Hal Foster identifica no "cosmopolitismo banal", de como o tênue regionalismo do Ninho de Pássaro do estádio olímpico chinês, projetado por Herzog \& De Meuron, se alinha à produção arquitetônica global. ${ }^{41}$ É o que pode ser visto nos empreendimentos certificados pelo LEED ${ }^{\circledR}$ no Brasil, com sua singular exuberância de jardins tropicais em meio à rigidez das torres corporativas.

\footnotetext{
Press, 2002), 1, tradução nossa.

38. Wanick, (Fundadora do GBC Brasil), Entrevista para o autor. Ver capítulo 3. Sobre esse mesmo tema de comparabilidade internacional, verificar ainda o uso do BREEAM $^{\circledR}$ na Espanha, tal como narrado em Faulconbridge e Yalciner, "Local variants of mobile sustainable building assessment models: the marketization and constrained mutation of BREEAM ES". 39. Luciana Melchert Saguas Presas e Arthur P.J. Mol, "Ecologizando edifícios transnacionais: entre fluxos globais e espaços locais", Ambiente \& Sociedade VII, n 1 (junho de 2004): 22, http://dx.doi.org/10.1590/S1414-753X2004000100002.

40. Saskia Sassen, "As diferentes especializações das cidades globais", in Cidades sul-americanas: assegurando um futuro urbano (São Paulo: Imprensa Oficial, 2008), 4-6.

41. Hal Foster, O complexo arte-arquitetura, [Ed. orig. 2013] (São Paulo: CosacNaify, 2015), 11.
} 


\section{ARQUITETURA AUDITADA}

A profusão de padrões, o LEED $^{\circledR}$ entre eles, faz parte da ascensão das práticas de auditoria iniciada no fim dos anos 1980. Pelo termo "sociedade da auditoria", o contador e sociólogo Michael Power identifica uma tendência de promoção da atividade, antes um aspecto marginal da profissão contábil, à centralidade da organização administrativa das corporações. Os "rituais de verificação" deixavam de se restringir ao campo financeiro e atingiam os mais diversos setores, como o ambiental, tecnológico e organizacional. O elemento unificador é a ratificação, por vezes de departamentos internos às corporações, por vezes de terceiros especializados, de que o plano foi implementado. Essa ascensão da auditoria buscaria resolver uma ansiedade crescente no meio corporativo, embora ataque seus efeitos no lugar de resolver suas causas. Para Power, a origem do problema estaria no aumento de conhecimento de negócios pelos acionistas, por um lado, e por outro, à perda de confiança no trabalho dos diretores corporativos, contra o que a auditoria nada tem a manifestar. ${ }^{42} \mathrm{O}$ período histórico desse desalinhamento entre expectativa e confiança não é mencionado por Power, mas se trata precisamente do momento de globalização econômica em que houve o maior crescimento relativo e absoluto na remuneração dos diretores corporativos. ${ }^{43}$

O processo narrado por Power foi extrapolado por intérpretes vindos da sociologia, como as "culturas de auditoria" de Andrew Kipnis e as "burocracias da virtude" de Marie-Andrée Jacob e Annelise Riles. ${ }^{44}$ Nesse ponto, o próprio LEED ${ }^{\circledR}$ é um caso citado pela literatura, como um sistema alinhado à "nova economia moral", nas palavras do etnólogo Michael Brown. ${ }^{45}$ Para ele, "O resultado desse sistema é que ele transforma virtude, consciência cívica e confiança em mercadorias" e "Essa comodificação é evidente nos métodos quantitativos usados para medir o cumprimento [do sistema] ${ }^{\prime 46}$ Desse modo, o LEED ${ }^{\circledR}$ permite instrumentalizar qualidades intan-

42. Michael Power, The audit society: rituals of verification (Oxford: Oxford University Press, 1997), 122.

43. David Harvey, A brief history of neoliberalism (Nova York: Oxford University Press, 2005), 18.

44. Andrew P. Kipnis, "Audit cultures: neoliberal governmentality, socialist legacy, or technologies of governing?", American Ethnologist 35, nº 2 (2008): 275-89, https://doi.org/10.1111/j.2008.1548-1425.00034.x; Marie-Andrée Jacob e Annelise Riles,

"The new bureaucracies of virtue: introduction", PoLAR: Political and Legal Anthropology Review 30, n 2 (2007): 181-91, https://doi.org/10.1525/pol.2007.30.2.181.

45. Michael F. Brown, "A tale of three buildings: certifying virtue in the new moral economy", American Ethnologist 37, $\mathrm{n}^{\circ} 4$ (novembro de 2010): 741-52, https://doi.org/10.1111/j.1548-1425.2010.01282.x.

46. No original: "The result of this system is that it transforms virtue, civic-mindedness, and trust into commodities. Such 
gíveis da arquitetura, desde sua relação com a comunidade do entorno até o seu grau de respeito ao meio ambiente, e com isso adicionar uma camada de valorização financeira antes inexistente. O empreendimento deixa de ser valorizado apenas pelas suas qualidades intrínsecas de espaço e detalhamento construtivo e adquire um novo conjunto de atributos financeiros vinculados à certificação.

As consequências da comodificação das "virtudes" arquitetônicas não são apenas ontológicas. Isso porque uma certificação LEED $^{\oplus}$ é menos objetiva do que seus parâmetros racionais podem levar a crer. A grande quantidade de créditos e a flexibilidade de cumprimento permitem um nível alto de certificação sem o atendimento das expectativas de qualidade ambiental. É o caso do baixo desempenho energético de algumas das torres analisadas, como mencionado acima. É o caso também do processo de certificação analisado por Brown, em que foram implantados vestiários para ciclistas em um campus universitário a despeito da ausência de ciclovias no entorno e de sua localização rural em terreno montanhoso. Entretanto, esses vestiários eram uma alternativa relativamente fácil para obter pontos no LEED ${ }^{\circledast}$ face a créditos mais onerosos, e por isso sua execução foi mantida. ${ }^{47}$

Desse modo, o método racional da certificação revela a irracionalidade de seus resultados. Power, em seu livro sobre a ascensão da auditoria, alertava contra a excessiva preocupação com "rituais rasos de verificação no lugar de outras formas de inteligência organizacional". ${ }^{8}$ Para ele, a auditoria de processos ganhava uma preponderância que desconsiderava investimentos mais produtivos, tomando aqui o termo em seu sentido literal: no lugar dos esforços de verificação, seria mais racional e rentável o investimento em aumentos de eficiência e melhorias organizacionais nas empresas. Afinal, a certificação resultante do processo de auditoria é mera produção de conforto: a certeza ao investidor, ao acionista, ao cliente e ao projetista da qualidade do processo. ${ }^{49}$ Os padrões, e especialmente aqueles ligados ao ambientalismo como o LEED ${ }^{\circledR}$, operam pelo tensionamento entre a urgência de liquidez dos títulos financeiros - "da qual," diz Chesnais,

commodification is evident in the quantitative methods used to measure compliance...”. Brown, 748, tradução nossa.

47. Brown, 747.

48. No original: "shallow rituals of verification at the expense of other forms of organizational intelligence." Power, The audit society, 123, tradução nossa.

49. Power, 126. 


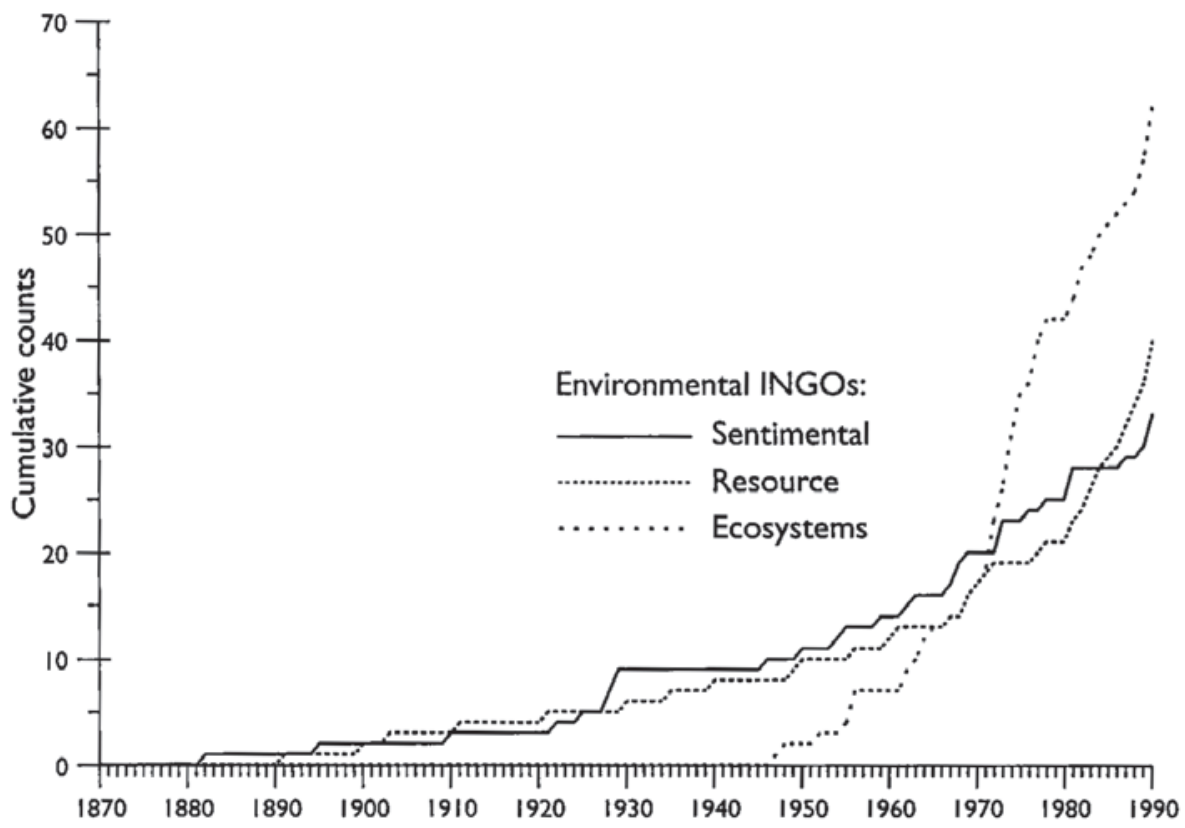

Fig 11.1. ONGs internacionais ambientalistas segundo sua classificação em agendas "sentimentais", de preservação de recursos e de ecossistemas. Fonte: Frank et al., "The rationalization and organization of nature in world culture", 93.

A inflexão das agendas ambientalistas na direção de pautas de recursos e sobretudo de ecossistemas indica uma racionalização nas estratégias de atuação dos movimentos.

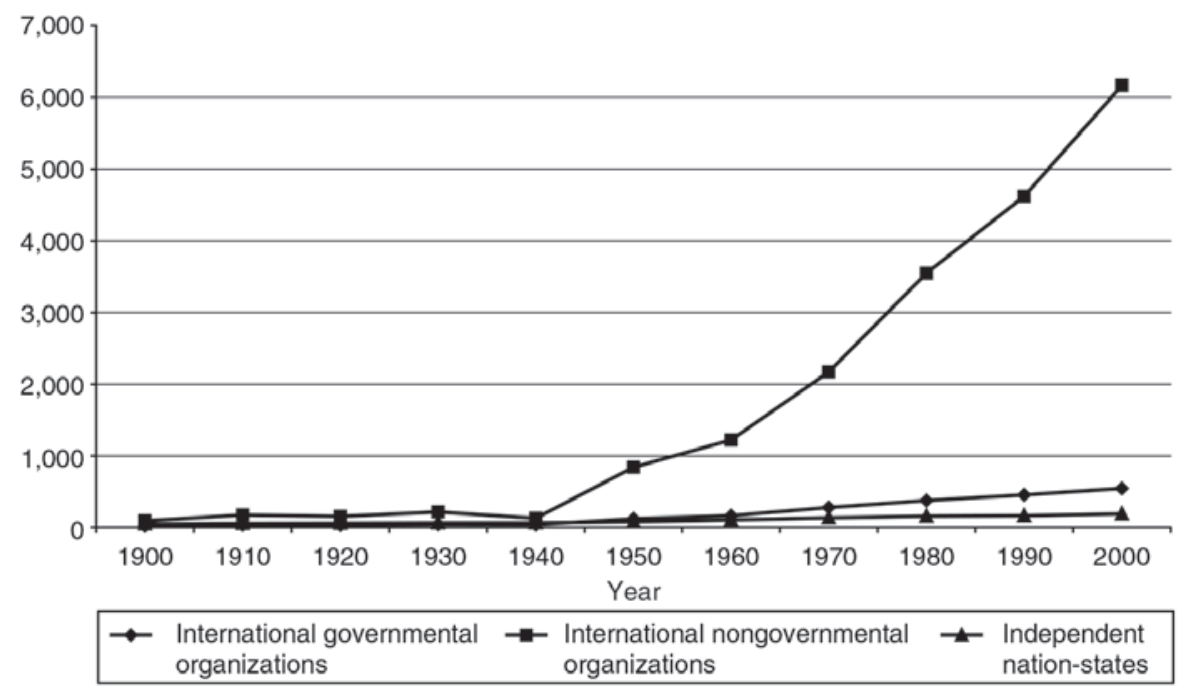

Fig 11.2. Expansão global de organizações no século XX. Fonte: Drori, Meyer e Hwang, Globalization and organization, 5. 
"Keynes denunciara o caráter 'anti-social', isto é, antitético ao investimento de longo prazo" ${ }^{50}-\mathrm{e}$ o longo prazo da "sustentabilidade" ambiental, financeira e social. Mas nem sempre essa certeza tem lastro, como nos casos indicados acima, afinal a certificação apenas define o desempenho de um empreendimento em função da metodologia de avaliação de um sistema específico.

Esses esquemas de auditoria e certificação não são exclusivos do neoliberalismo das últimas décadas, embora tenham nele prosperado. Kipnis enfatiza que eles estariam mais ligados a um "cientismo" [scientism] em que qualquer processo administrativo deve ser corroborado por um discurso científico. ${ }^{51}$ Nesse sentido, tanto a burocracia comunista chinesa quanto o neoliberalismo ocidental utilizariam os processos de auditoria e certificação. Mas, ainda seguindo Kipnis, o interesse não é propriamente de identificar procedimentos exclusivos ao neoliberalismo, nem de dele fazer uma teoria geral, mas de examinar em detalhe as tecnologias com que ele é posto em prática $^{52}$ - e o LEED $^{\circledR}$ certamente é uma delas.

Paralelamente à globalização e seus efeitos urbanos, analisados neste trabalho em mais de uma passagem, podem ser encontrados diversos fenômenos ligados ao campo da gestão. Nesse período, a agenda do movimento ambientalista passa por uma gradual racionalização, em que pautas de conservação ambiental por razões éticas - comumente apelidada na literatura como de cunho "sentimental" - foram substituídas por outras de preservação quantificável de recursos [fig 11.1]; ${ }^{53}$ organizações ambientalistas e de atuação internacional passam a ser mais numerosas [fig 11.2 e 11.3]; ${ }^{54}$ há enorme ascensão de cursos e periódicos especializados em gestão e negócios [fig 11.4 e 11.5], ${ }^{55}$ e é nesse período que são criados todos os sistemas de avaliação de construção

\footnotetext{
50. Chesnais, A mundialização do capital, 15.
}

51. Kipnis, “Audit cultures: neoliberal governmentality, socialist legacy, or technologies of governing?”; sobre o cientismo, também Gili S. Drori e John W. Meyer, “Global scientization: an environment for expanded organization”, in Globalization and organization: world society and organizational change, org. Gili S. Drori, John W. Meyer, e Hokyu Hwang (Oxford: Oxford University Press, 2006), 50-68.

52. Kipnis, “Audit cultures: neoliberal governmentality, socialist legacy, or technologies of governing?”, 285.

53. David John Frank et al., "The rationalization and organization of nature in world culture”, in Constructing world culture: international nongovernmental organizations since 1875, org. John Boli e George M. Thomas (Stanford, CA: Stanford University Press, 1999), 92-93.

54. Gili S. Drori, John W. Meyer, e Hokyu Hwang, orgs., Globalization and organization: world society and organizational change (Oxford: Oxford University Press, 2006); Boli e Thomas, Constructing world culture.

55. Hyeyoung Moon e Christine Min Wotipka, “The worldwide diffusion of business education, 1881-1999: historical trajectory and mechanisms of expansion”, in Globalization and organization: world society and organizational change, org. Gili 


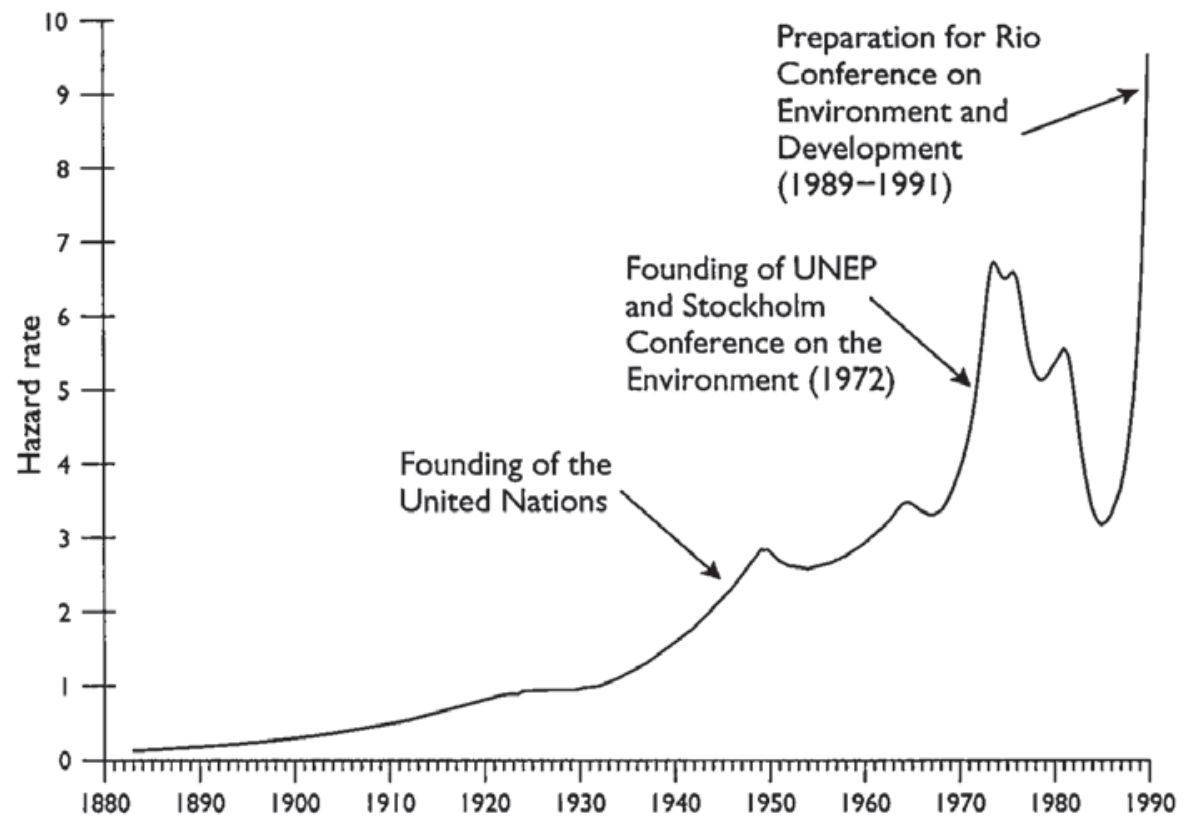

Fig 11.3. Taxa de risco suavizada de formação de ONGs internacionais ambientalistas de 1880 a 1990. Fonte: Frank et al., "The rationalization and organization of nature in world culture", 85 .

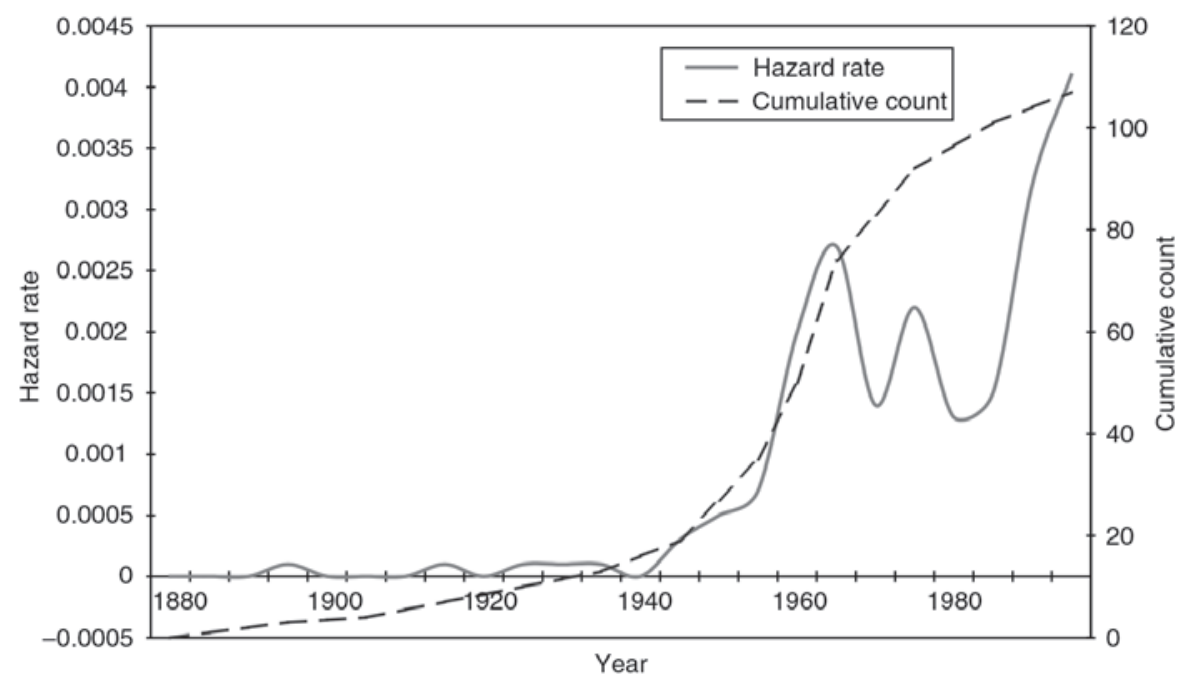

Fig 11.4. Contagem cumulativa de adoção e taxa de risco de fundação de cursos de negócios, 1880-1999. Fonte: Moon e Wotipka, “The worldwide diffusion of business education, 1881-1999: historical trajectory and mechanisms of expansion", 123. 
sustentável [fig 11.6]. Assim, o LEED ${ }^{\oplus}$ não é um caso isolado, mas acompanha tendências mais gerais do campo da gestão, desde o comportamento das ONGs ambientalistas até a consolidação da administração de empresas como um ramo acadêmico e profissional.

A criação de tantos padrões pelo terceiro setor coloca-os em competição. Afinal, esses padrões nem têm a legitimidade própria do Estado, nem a sua compulsoriedade. Por esse motivo, os padrões são voluntários, e como tal "os padronizadores frequentemente têm que gastar um esforço considerável convencendo os outros que é de seu interesse, seja agora ou a longo prazo, aceitar os padrões. ${ }^{\prime 56}$ Como argumentos para tal, o LEED ${ }^{\circledR}$ e o USGBC ${ }^{\circledR}$ apresentam as inúmeras vantagens descritas no capítulo 5, que resultam não só em mais competitividade para as empresas, mas também em pontos de referência [benchmark] contra os quais elas podem se comparar. Nesse sentido, os padrões, ou ao menos os mais bem-sucedidos em termos de quantidade de usuários, sempre são alinhados ao mercado [market-friendly]: ${ }^{57}$ na ausência da estrutura estatal, a legitimidade é alcançada por sua preferência nos negócios. Essas características têm impacto mesmo em questões menores, como o design das placas promocionais instaladas nos empreendimentos certificados. Um profissional espanhol ligado à construção verde notou, em entrevista para pesquisadores, que as "placas do BREEAM são simples e feias. As placas do LEED são mais chamativas e é isso que os clientes querem." ${ }^{58}$ Assim, mesmo elementos triviais como essas placas têm impacto na decisão de qual sistema o empreendedor vai aplicar.

O impasse em torno das placas de certificação é talvez o aspecto mais banal da centralidade da dimensão simbólica das certificações na produção urbana. ${ }^{59}$ Outro aspecto que pode ser destacado é o deslizamento conceitual entre a transparência arquitetônica dos edifícios corporativos e a transparência política das corporações neles abrigadas, como argumentado pelo crítico

\footnotetext{
S. Drori, John W. Meyer, e Hokyu Hwang (Oxford: Oxford University Press, 2006), 121-36.

56. No original: "standardizers often have to expend considerable effort convincing other people that it in their interest, either now or in the long term, to accept the standards." Brunsson e Jacobsson, "The contemporary expansion of standardization", 2, tradução nossa.

57. Faulconbridge e Yalciner, "Local variants of mobile sustainable building assessment models: the marketization and constrained mutation of BREEAM ES", 363.

58. No original: "BREEAM plaques are simple and ugly. LEED plaques are more showy and that is what clients want." Faulconbridge e Yalciner, 370, tradução nossa.

59. Cf. Martin, "Financial imaginaries: toward a philosophy of the city", 66, entre outros.
} 


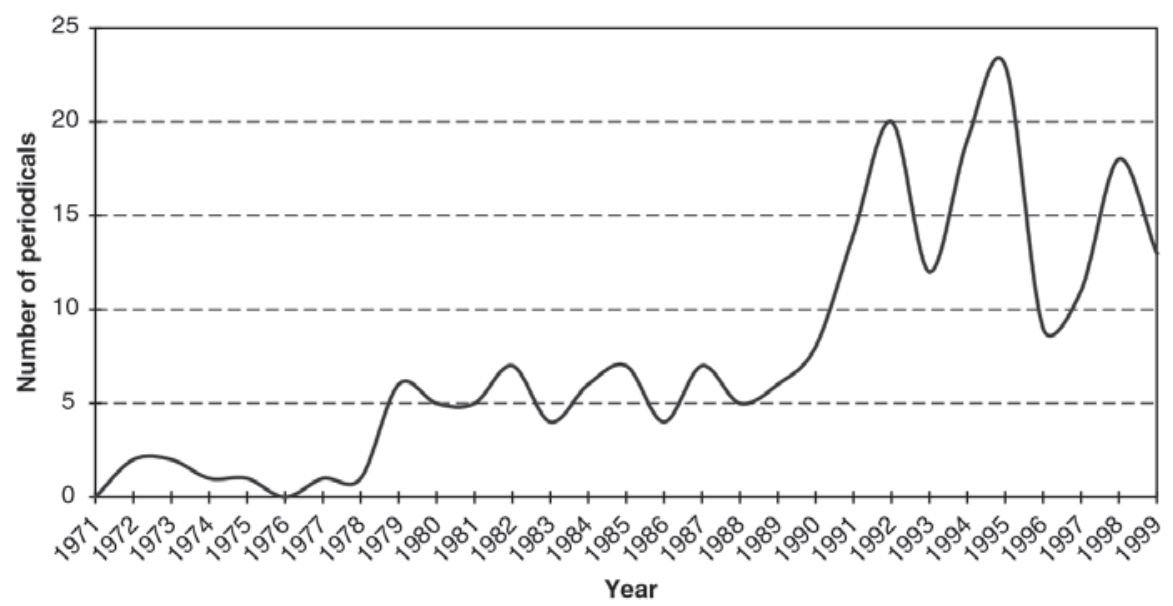

Fig 11.5. Número de periódicos com artigos sobre negócios e administração de empresas. Amostra de 217 periódicos. Fonte: Moon e Wotipka, “The worldwide diffusion of business education, 1881-1999: historical trajectory and mechanisms of expansion", 126.

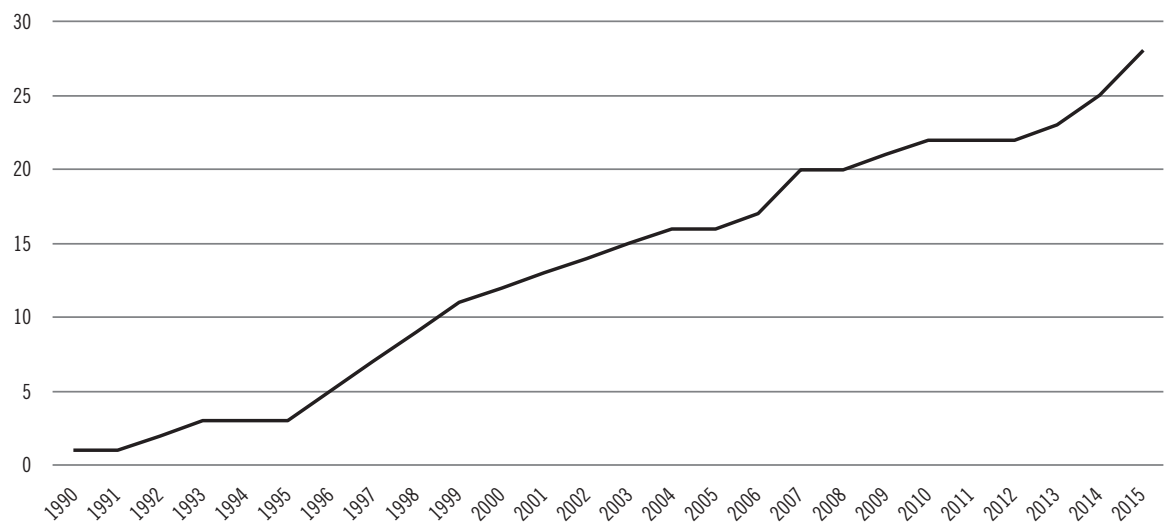

Fig 11.6. Quantidade cumulativa de sistemas de avaliação ambiental. Elaborado pelo autor. Dados: ATHENA ${ }^{\circ}$ (2002), BEAT $^{\oplus}$ (2000), BREEAM ${ }^{\oplus}$ (1990), CASBEE ${ }^{\oplus}$ (2001), DGNB (2009), EcoEffect ${ }^{\oplus}$ (1999), Ecoprofile (1999), Eco-Quantum (1997), EDGE ${ }^{\circledast}$ (2015), Energy Star ${ }^{\circledR}$ (1992), Miljøstatus (1997), Green Globes ${ }^{\oplus}$ (2007), Green Star ${ }^{\circledast}$ (2003), HQE (2004), ISO 14000 (1996), LBC ${ }^{\oplus}$ (2006), LEED ${ }^{\circledR}$ (1998), MINERGIE (1998), Parksmart ${ }^{\bullet}$ (2014), Passivhaus (1996), PEER ${ }^{\circledast}$ (2015), Procel Edifica (2003), SBTool (2007), Selo Azul (2010), SITES ${ }^{\oplus}$ (2007), TRUE ${ }^{\oplus}$ (2013), Well ${ }^{\oplus}$ (2014), What Works Cities (2015). 
Hal Foster a respeito das torres de vidro dos "estilos globais"60 - ao que poderia certamente ser adicionada a aparência de transparência das auditorias e certificações. Que os vidros desses edifícios corporativos sejam na verdade reflexivos - e isso mesmo naqueles mais recentes, nos quais diversos arquitetos entrevistados durante a pesquisa enfatizaram o uso de vidro transparente por imposição dos empreendedores - parece um efeito colateral imprevisto mas esclarecedor sobre a persistência da reflexividade da linguagem arquitetônica, tema comum na crítica da arquitetura pós-moderna.$^{61}$ Não por acaso, quando o vidro se torna excessivamente caro, ou não é buscado na totalidade no envelope, a solução arquitetônica de uso de pedra polida uniformiza o envelope pela reflexividade dos materiais.

Esse elemento cultural pode ser visto como origem não só da arquitetura certificada, mas dos próprios sistemas de avaliação. De fato, a literatura a respeito dos padrões indica que nem a multiplicação das ONGs ambientalistas é resultado de maior degeneração do ambiente, nem que o aumento de padrões técnicos é resultado da maior complexidade das atividades contemporâneas de gestão. Em oposição a essa interpretação "funcionalista", os autores enfatizam o aspecto cultural desse processo - e as "culturas da auditoria" mencionadas acima certamente se alinham a essa interpretação. Drori, Meyer e Hwang notam como não existe correlação entre maior complexidade e a modernização de um grupo social: o que haveria, isso sim, é uma nova cultura organizacional. A proliferação dos padrões no fim da década de 1980, inclusive em sua passagem de critérios exclusivamente técnicos para gerenciais como no ISO 9000, seria um indício da reorganização global do trabalho. ${ }^{62}$ Ao que se soma o ambientalismo arquitetônico: em sua recente profissionalização - como mencionado em citação do crítico Luis Fernández-Galiano na parte III $^{63}$ - presente em congressos, periódicos especializados, um setor estabelecido de consultorias e certificados, o ambientalismo se consolida, mas também perde seu apelo de contra-agenda na

60. Foster, O complexo arte-arquitetura, 49.

61. Cf. Reinhold Martin, Utopia's ghost: architecture and postmodernism, again (Minneapolis, Londres: University of Minnesota Press, 2010), cap. "Mirrors"; Fredric Jameson, Pós-modernismo: a lógica cultural do capitalismo tardio, 2a (São Paulo: Editora Ática, 2007); Fredric Jameson, “The brick and the balloon: architecture, idealism and land speculation”, in The cultural turn: selected writings on the postmodern, 1983-1998 (Londres, Nova York: Verso, 1998), 162-89.

62. Drori, Meyer, e Hwang, Globalization and organization, 7-10. Ver também Boli e Thomas, Constructing world culture, em especial o capítulo de David John Frank et al., "The rationalization and organization of nature in world nature”.

63. Luis Fernández-Galiano, “¡La economía, ecologistas!: la construcción sostenible ante la crisis del petróleo”, Arquitectura viva, $\mathrm{n}^{\circ}$ 105: Etiquetas verdes (2005): 23-25. 
concepção tipológica da arquitetura e do urbanismo. Desse modo, o ambientalismo faz parte de uma certa estratégia e cultura de gestão que o coloca dentro de um espectro de fenômenos analisado por autores como Fredric Jameson e Reinhold Martin: a construção simbólica do urbano como uma questão central da produção, e não mais secundária. ${ }^{64} \mathrm{~A}$ dimensão cultural da economia, e a econômica da cultura, sobrepõem-se sem possibilidade de separação.

64. Jameson, Pós-modernismo; Martin, "Financial imaginaries: toward a philosophy of the city”; Martin, Utopia’s ghost, cap. Mirrors. 


\section{CONSIDERAÇÕES FINAIS}

O USGBC ${ }^{\circledast}$ foi fundado quando iniciava o ciclo histórico de reorganização global em torno dos consensos da economia liberal, no início dos anos 1990. Esse conselho norte-americano, os diversos conselhos nacionais e o LEED ${ }^{\circledR}$ encontravam no mercado o agente de superação dos impasses ambientais. Entre teorias mais ou menos radicais das potencialidades emancipatórias do capitalismo liberal, reproposto em novo estágio de capitalismo natural ou ecocapitalismo, as entidades e ferramentas analisadas aqui agem prioritariamente por meio do setor corporativo, mais do que entram em conflito com ele.

A pesquisa da tese iniciou-se em 2013, momento ainda de crescimento econômico, tanto nacional quanto global. O modelo de sustentabilidade corporativa era então uma bem-sucedida variante dos esquemas de negócios. Parecia mesmo seu mais provável futuro, pois a "sustentabilidade" ambiental e econômica poderia ser um modo mais seguro de negócios após a crise de 2008. Do ponto de vista arquitetônico, seria o contraponto aos excessos do star system nas duas décadas anteriores. ${ }^{1}$ A pesquisa encerra-se em meados de 2019, quando o espectro político hegemônico é outro. A agenda ambiental marginalizou-se na medida em que importantes líderes políticos e seus diversos quadros são agora negacionistas do aquecimento global e das diversas catástrofes ambientais em curso. Além disso, estão organizadas as forças políticas contrárias à globalização e sua livre circulação de capital, vista como uma causa do arrefecimento econômico e da diminuição de empregos industriais nas economias centrais. Esses dois processos podem ter impacto sobre o LEED ${ }^{\oplus}$. Por um lado, a organização corporativa negacionista ganha espaço

1. Pedro Fiori Arantes, Arquitetura na era digital-financeira: desenho, canteiro e renda da forma (São Paulo: Editora 34, 2012), cap. "A próxima fronteira". 
político, reduzindo o poder de atuação dos conselhos vinculados ao WGBC ${ }^{\circledast}$. Por outro lado, o recrudescimento das fronteiras nacionais pode desidratar as motivações financeiras do emprego do LEED ${ }^{\oplus}$, como é o caso da incorporação do sistema em relatórios corporativos de subsidiárias, ou do elemento de comparabilidade à distância utilizado em fundos imobiliários a fim de atrair investidores estrangeiros. Não será o fim do LEED $^{\circledR}$ e de sistemas similares, mas provavelmente sua estabilização, como os dados já vêm sugerindo.

O LEED ${ }^{\circledR}$ é uma tecnologia do neoliberalismo, pois sua premissa é de que os agentes de mercado livremente organizados possam construir uma ferramenta que premie seus utilizadores e condene ao ostracismo seus detratores. O mercado, então, se autorregularia. O sistema faz parte de um conjunto de padrões de surgimento especialmente numeroso a partir do início dos anos 1990, cuja função é auxiliar a gestão global de transações: o certificado estabelece uma pedra de toque contra a qual empreendimentos podem ser comparados. Como foi demonstrado na parte $\mathrm{V}$, o certificado oferece, por um lado, um lastro para investimentos realizados remotamente: a um determinado nível de certificação corresponde um determinado edifício virtual, com suas características de qualidade de acabamento, de estratégia de implantação e de modo de operação cotidiano. Por outro lado, o certificado precisa fazê-lo garantindo certa flexibilidade de aplicação, sem a qual um modelo ambiental seria imposto, contrariando práticas espaciais locais dos mercados. Desse modo, os padrões operam na tensão entre um lastro estável de comparabilidade e a flexibilidade para uma aplicação consensual e de larga escala.

Essa tensão ainda ocorre em um segundo nível, aquele do conteúdo ambientalista do sistema LEED ${ }^{\circledR}$. A circularidade dos argumentos na parte II reproduziu como o alinhamento entre mercado e ecologia impõe seguidos impasses ao sistema, levando a modos de incentivar o mercado a adotá-lo sem com isso contradizer as práticas habituais de negócios. Na verdade, o oxímoro entre mercado e ecologia nunca é inteiramente superado. Se isso pode ser dito dos modos de produção industrial alinhados à modernização ecológica, tanto mais válido o é para a produção de edifícios e cidades, na qual "soluções tecnológicas (potencialmente comercializáveis)" encontram "limites inerentes", conforme define de modo insuspeito um de seus apologistas, Martin Jänicke. ${ }^{2}$ A história do urbanismo nos últimos trinta anos exprime a medida com

\footnotetext{
2. Martin Jänicke, “Ecological modernisation: new perspectives”, Journal of Cleaner Production 16 (2008): 562.
} 
que esses limites são constantemente expandidos, mas certamente ao custo de novas contradições na produção urbana. Mais do que pelas suas características ambientalistas, a expansão do LEED $^{\circledR}$ pode ser mais bem explicada pelo fato de ter se transformado em um instrumento de transações internacionais.

A relação tensa do LEED $^{\circledR}$ entre negócios e ambientalismo foi aparentemente superada pelas decisões tomadas na fundação do $\mathrm{USGBC}^{\circledast}$ e dos diversos conselhos verdes nacionais. $\mathrm{Na}$ formação de cada um deles é possível notar como foram geridas as contradições entre uma ferramenta de uso local e a incorporação de tendências internacionais, entre a regulação e o incentivo ao mercado, entre a velocidade de expansão e as alianças com representantes locais dos estados. O alinhamento dos agentes efetuou-se, como visto na parte I, pelo afastamento de certas ideias e membros em favor de outros, e assim a decantação de quais seriam as práticas privilegiadas pelos conselhos.

Por essas razões, os certificados de destaque fora dos Estados Unidos são os aplicados a torres de escritórios, mais diretamente relacionadas tanto ao espaço de trabalho de subsidiárias de corporações quanto aos títulos de fundos imobiliários. Embora nos Estados Unidos o US$\mathrm{GBC}^{\circledast}$ tenha maior inserção social, o que pode ser visto pela grande quantidade de casas e escolas certificadas, esses programas têm pouca relevância internacional. A pouca produção residencial internacional certificada restringe-se ao Oriente Médio e parece alinhar-se aos mesmos mecanismos de financeirização e comparabilidade internacional presentes nas torres corporativas. Desse modo, uma história dos edifícios com certificação LEED ${ }^{\circledR}$ não deve se restringir à identificação de projetos primogênitos, como a agência do Banco Real-ABN AMRO no Brasil ou o EPICenter nos Estados Unidos. Essa história deve, isso sim, revelar quais são os casos que melhor articularam as diferentes tensões presentes no LEED ${ }^{\circledR}$, criando assim modelos reproduzidos por projetos posteriores. O 4 Times Square, com seu aparato tecnológico sobreposto a uma torre core \& shell convencional, ou o Rochaverá Corporate Towers, com seu parque ao mesmo tempo símbolo da sustentabilidade e espaço monofuncional contemplativo, foram destacados na parte III como casos centrais para a organização das estratégias projetuais de edifícios certificados. Por mais que o sistema tenha sido incorporado ao Rochaverá com o projeto em estágio avançado, a replicação de seu modelo em empreendimentos como o Parque da Cidade e o São Paulo Corporate Towers indica a acomodação do certificado em determinadas práticas espaciais. 
O estudo do LEED $^{\circledR}$ não trata de determinismos espaciais, mas de disposições, em que certas características do espaço são recorrentes, mesmo se resolvidas nos projetos de modos variados. Também não trata de determinismos porque as indicações do LEED $^{\circledR}$ são avaliadas pelo incorporador e pelos projetistas e cumpridas apenas parcialmente. As disposições, entretanto, continuam a atuar potencialmente no sistema, motivo pelo qual podem ser encontradas contradições entre a forma construída e a forma virtual do LEED ${ }^{\oplus}$. Os casos mais evidentes são os diversos artifícios projetuais necessários para viabilizar ambientalmente torres de vidro, ou a simples inobservância dos requisitos de forma que poderiam alinhar os empreendimentos ao New Urbanism, no caso do LEED $^{\circledR}$ ND. A racionalidade intrínseca ao sistema LEED $^{\circledR}$, com seu conjunto de pontos e de parâmetros técnicos, revela quais decisões não tomam o ambiente como pressuposto. E, pela incongruência formal entre o projeto e suas demandas, revelam também como nem mesmo o custo é um dado imperioso, pois caso contrário o vidro, elemento oneroso nos projetos, não enveloparia completamente os edifícios para em seguida ser protegido contra cargas térmicas por meio de numerosos subterfúgios.

Embora o LEED ${ }^{\circledast}$ ND possua pré-requisitos impeditivos de cercamento ou segregação espacial do empreendimento, os diversos sistemas $\mathrm{LEED}^{\circledR}$ relegam ao incorporador essas decisões. Se alguns contextos espaciais e temporais foram mais favoráveis a empreendimentos com maior integração espacial com seu entorno, não coube ao LEED $^{\circledR}$ a criação de instrumentos que pudessem garanti-la. A flexibilidade do sistema lhe permite adequar-se não só ao que o empreendedor considera mais relevante em sua interpretação de sustentabilidade, mas também a práticas locais regressivas. O sistema se adapta à segregação por não estabelecer valores mínimos em cada categoria.

$\mathrm{O} \mathrm{LEED}^{\circledR}$ atua, entretanto, de modo mais efetivo na contenção dessas práticas locais regressivas do que sistemas autóctones, como é o caso dos diversos condomínios fechados certificados pelo Aqua. Mas deve-se inquirir se os sistemas LEED $^{\circledR}$ continuarão a ter esse caráter de mediação entre tendências de incorporação e projeto, forçando ganhos incrementais na produção urbana. Isso porque os padrões globais estabelecem instâncias de negociação entre os diversos campos sociais que talvez não sejam mais usados nos processos de mercado. Estudos como os de Saskia Sassen têm enfatizado a brutalidade da produção espacial recente, em que os mecanismos de acumulação capitalista não recorrem mais ao respeito de direitos sociais, mesmo quando consi- 
derados apenas formalmente. ${ }^{3}$ Certamente, e sobretudo em contexto brasileiro, a violência sempre esteve presente nos processos de produção urbana. Mas agora o papel mediador das normas pode ter perdido relevância.

Com isso, o LEED ${ }^{\oplus}$, em conjunto com outros padrões incidentes no espaço construído, adquire aspectos tanto estéticos quanto históricos. Estéticos, pois ele privilegia determinadas estratégias de projeto da forma arquitetônica e urbanística, e o faz estabelecendo disposições ao invés de tipologias. Históricos, pois apesar da neutralidade aparente das normas e padrões técnicos, o sistema está circunscrito a um determinado tipo de prática espacial surgido com as cidades globais dos anos 1990, cuja utilização está sujeita a transformações ao longo do tempo.

3. Saskia Sassen, Expulsions: Brutality and complexity in the global economy (Cambridge, USA: The Belknap Press of Harvard University Press, 2014). Trabalhos não publicados de Keller Easterling a respeito da crise de refugiados também apontam nessa direção. 



\section{REFERÊNCIAS}

10 anos de história. Revista GBC Brasil, v. 4, n. 14, Anuário 2017, p. 54-62, ago 2017.

ÁBALOS, Iñaki; HERREROS, Juan. Tower and office: from modernist theory to contemporary practice. [Ed. orig. 1992]. Cambridge, Massachusetts; Londres: The MIT Press, 2003.

ACSELRAD, Henri. Sentidos da sustentabilidade urbana. In: A duração das cidades: sustentabilidade e risco nas políticas urbanas. $2^{\mathrm{a}}$ ed. Rio de Janeiro: Lamparina, 2009. p. 43-70.

ACSELRAD, Henri. Ambientalização das lutas sociais - o caso do movimento por justiça ambiental. Estudos avançados, v. 24, n. 68, p. 103-119, 2010. Doi: 10.1590/S0103-40142010000100010.

AGAMBEN, Giorgio. O que é um dispositivo? In: O que é o contemporâneo? e outros ensaios. [Ed. orig. 2005]. Chapecó: Argos, 2009. p. 25-51.

AKBARI, Hashem; MENON, Surabi; ROSENFELD, Arthur. Global cooling: effect of urban albedo on global temperature. $2^{\text {nd }}$ PALENC \& AIVC Conference. Proceedings... Creta, 2007.

AKBARI, Hashem; MENON, Surabi; ROSENFELD, Arthur. Global cooling: increasing world-wide urban albedos to offset CO2. Climatic Change, v. 94, n. 3-4, p. 275-286, jun. 2009. Doi: 10.1007/s10584-008-9515-9.

ALCHAPAR, Noelia Liliana; PEZZUTO, Cláudia Cotrim; CORREA, Erica Norma. Parámetros urbanos morfo-materiales y su correlación con las temperaturas de aire en verano. Ambiente Construído, v. 18, n. 4, p. 199-213, out. 2018. Doi: $10.1590 / \mathrm{s} 1678-86212018000400301$

ALCOTT, Blake. Historical overview of the Jevons Paradox in the literature. In: POLIMENI, John M.; MAYUMI, Kozo; GIAMPIETRO, Mario; ALCOTT, Blake. The Jevons paradox and the myth of resource efficiency improvements. Londres: Earthscan, 2008. p. 7-78.

ALVAREZ, Isabel Pinto. A produção de espaços financeirizados na metrópole de São Paulo. In: FERREIRA, Alvaro; RUA, João; MATTOS, Regina Célia de (eds.). O espaço e a metropolização: cotidiano e ação. Rio de Janeiro: Consequência, 2017. p. 241-266.

AMARAL, Marco Antônio Teixeira de. Green building: análise das dificuldades (ainda) enfrentadas durante o processo de certificação LEED no Brasil. Dissertação (Mestrado Executivo em Gestão Empresarial). Orientação de Hélio Arthur Reis Irigaray—Rio de Janeiro: Escola Brasileira de Administração Pública e de Empresas da Fundação Getúlio Vargas, 2013.

ANDREIS, Cinthia; BESEN, Priscila; WESTPHAL, Fernando Simon. Desempenho energético de fachadas envidraçadas em climas brasileiros. In: XV ENCONTRO NACIONAL DE TECNOLOGIA DO AMBIENTE CONSTRUÍDO. Anais... Maceió: 2014, p. 926-935.

ARANTES, Otília Beatriz Fiori. A ideologia do "lugar público" na arquitetura contemporânea (um roteiro). In: O lugar da arquitetura depois dos modernos. 3a ed. [Ed. orig. 1993]. São Paulo: Edusp, 2000. p. 95-155.

ARANTES, Otília Beatriz Fiori. Berlim e Barcelona: duas imagens estratégicas. São Paulo: Annablume, 2012a.

ARANTES, Pedro Fiori. Arquitetura na era digital-financeira: desenho, canteiro e renda da forma. São Paulo: Editora 34, 2012b. 
ARNOLD, D. Air conditioning in office buildings after World War II. ASHRAE Journal, p. 33-41, jul. 1999.

BANHAM, Reyner. The architecture of the well-tempered environment. Londres, Reino Unido; Chicago, EUA: The Architectural Press; The University of Chicago Press, 1969.

BARAN, Katna. Não pretendo jamais disputar uma eleição, diz Moro. Folha de São Paulo, 5 nov. 2018, seç. Poder. Disponível em: https://www1.folha.uol.com.br/poder/2018/11/nao-pretendo-jamais-disputar-uma-eleicao-diz-moro. shtml. Acesso em 25 ago 2019.

BARRINGER, Felicity. White roofs catch on as energy cost cutters. The New York Times, p. A1, 29 jul. 2009, seç. Environment. Disponível em https://www.nytimes.com/2009/07/30/science/earth/30degrees.html. Acesso em 25 ago 2019.

BARROS, Ana Dorys Muñoz. A adoção de sistemas de avaliação ambiental de edifícios (LEED e Processo Aqua) no Brasil: motivações, benefícios e dificuldades. Dissertação (Mestrado em Arquitetura, Urbanismo e Tecnologia). Orientador: Marcio Minto Fabrício-São Carlos, SP: Instituto de Arquitetura e Urbanismo da Escola de Engenharia de São Carlos, Universidade de São Paulo, 2012.

BARTH, Brian. Is LEED tough enough for the climate-change era?. Citylab, 5 jun 2018. Disponível em: https://www.citylab. com/environment/2018/06/is-leed-tough-enough-for-the-climate-change-era/559478/. Acesso em 25 ago 2019.

BATISTA, Norma do Nascimento; ROVERE, Emilio Lèbre La; AGUIAR, João Carlos Rodrigues. Energy efficiency labeling of buildings: An assessment of the Brazilian case. Energy and Buildings, v. 43, n. 6, p. 1179-1188, jun. 2011. Doi: 10.1016/j.enbuild.2010.11.010.

BECK, Ulrich. Sociedade de risco: rumo a uma outra modernidade. Trad. de Sebastião Nascimento. 2a ed. [Ed. orig. 1986]. São Paulo: Editora 34, 2011.

BERKEBILE, Robert. (Diretor em BNIM), Entrevista para o autor, Telefone, 29 jun. 2018, c. 50min.

BERTA, Ruben. Construtoras de condomínio da Rio 2016 trocaram escolas públicas por parque onde ninguém entra. The Intercept Brasil, 8 fev 2018. Disponível em: https://theintercept.com/2018/02/08/construtoras-de-condominio-da-rio-2016-trocaram-escolas-publicas-por-parque-onde-ninguem-entra/. Acesso em 25 ago 2019.

BEYEA, Jan. (Representante da National Audubon Society no primeiro conselho diretor do USGBC), Entrevista para o autor, Email, 7 a 24 jun. 2018.

BLOWERS, Andrew. Environmental policy: ecological modernisation or the risk society? Urban Studies, v. 34, n. 5-6, p. 845-871, 1997. Doi: 10.1080/0042098975853.

BOLI, John; THOMAS, George M. (org.). Constructing world culture: international nongovernmental organizations since 1875. Stanford, CA: Stanford University Press, 1999.

BOSCHMANN, E. Eric; GABRIEL, Jessica N. Urban sustainability and the LEED rating system: case studies on the role of regional characteristics and adaptive reuse in green building in Denver and Boulder, Colorado. The Geographical Journal, v. 179, n. 3, p. 221-233, set. 2013. Doi: 10.1111/j.1475-4959.2012.00493.x.

BRE (BUILDING RESEARCH ESTABLISHMENT). BREEAM International New Construction. Technical Manual. Watford: BRE, 2014.

BROWN, Michael F. A tale of three buildings: certifying virtue in the new moral economy. American Ethnologist, v. 37, n. 4, p. 741-752, nov. 2010. Doi: 10.1111/j.1548-1425.2010.01282.x

BRUNSSON, Nils; JACOBSSON, Bengt. The contemporary expansion of standardization. In: A world of standards. Londres: Oxford University Press, 2002. p. 1-17.

BURKEMAN, Oliver. Memo exposes Bush's new green strategy. The Guardian, Londres, 4 mar. 2003, seç. Environment. Disponível em https://www.theguardian.com/environment/2003/mar/04/usnews.climatechange. Acesso em 25 ago 2019.

BURNETT, John. City buildings - Eco-labels and shades of green! Landscape and Urban Planning, n. 83, p. 27-38, 2007. Doi: 10.1016/j.landurbplan.2007.09.003.

BUTTEL, Frederick H. Ecological modernization as social theory. Geoforum, n. 31, p. 57-65, 2000. 
C40 CITIES; FUNDAÇÃO CLINTON; USGBC (UNITED STATES GREEN BUILDING COUNCIL). Good practice guide: Climate Positive Development. C40 Cities, fev. 2016.

CAHN, Matthew Alan. Environmental deceptions: the tension between liberalism and environmental policymaking in the United States. Albany: State University of New York Press, 1995.

CÂMARA MUNICIPAL DE SÃO PAULO. Lei n. 16402, de 22 de março de 2016. Disciplina o parcelamento, o uso e a ocupação do solo no Município de São Paulo, de acordo com a Lei n. 16050, de 31 de julho de 2014 - Plano Diretor Estratégico, 22 mar. 2016.

CARDOSO, Fernando Henrique; GBC BRASIL. Entrevista: Fernando Henrique Cardoso. Revista GBC Brasil, v. 1, n. 2, p. 8-11, dez. 2014.

CASADO, Marcos. (Engenheiro do $1^{\circ}$ edifício certificado no Brasil; Diretor educacional e de comitês técnicos no GBC Brasil, 2007-2013), Entrevista para o autor, Presencial, 18 set. 2017, c. 1 h.

CASSIDY, Robert; WRIGHT, Gordon; FLYNN, Larry; BARISTA, David; ZISSMAN, Mindi; RICHARDS, Martha; POPP, Dee; NIGH, Larry; JAMES, Bonnie. White paper on sustainability: A report on the green building movement. Supplement to Building Design \& Construction. Building Design \& Construction, p. 1-48, nov. 2013.

CASTELLS, Manuel. O “verdejar” do ser: o movimento ambientalista. In: A era da informação. Trad. de Klauss Brandini Gerhardt. [Ed. orig. 1996]. São Paulo: Paz e Terra, 1999. v. 2, O poder da identidade. p. 141-168.

CAVALCANTE, Rodrigo de Castro Dantas. Simulação energética para análise da arquitetura de edifícios de escritório além da comprovação de conformidade com códigos de desempenho. Dissertação (Mestrado em Tecnologia da Arquitetura). Orientador: Ualfrido Del Carlo—São Paulo: Faculdade de Arquitetura e Urbanismo da Universidade de São Paulo, 2010.

CHATTO, Chris F. (Diretor no ZGF Architects), Entrevista para o autor, Telefone, 23 mar. 2018, c. 40min.

CHEGUT, Andrea; EICHHOLTZ, Piet; KOK, Nils. Supply, demand and the value of green buildings. Urban Studies, v. 51, n. 1, p. 22-43, jan. 2014. Doi: 10.1177/0042098013484526.

CHESNAIS, François. A mundialização do capital. [Ed. orig. 1994]. São Paulo: Xamã, 1996.

CIDELL, Julie. A political ecology of the built environment: LEED certification for green buildings. Local Environment, v. 14, n. 7, p. 621-633, ago 2009. Doi: 10.1080/13549830903089275.

CIDELL, Julie. Building green: the emerging geography of LEED-certified buildings and professionals. The Professional Geographer, v. 61, n. 2, p. 200-215, abr 2009. Doi: 10.1080/00330120902735932.

CIDELL, Julie; COPE, Miriam A. Factors explaining the adoption and impact of LEED-based green building policies at the municipal level. Journal of Environmental Planning and Management, v. 57, n. 12, p. 1763-1781, 2014. Doi: 10.1080/09640568.2013.835714.

COMITÊ TEMÁTICO DE MATERIAIS. Posicionamento sobre tetos frios. CBCS, set. 2011. Disponível em: http://www. cbcs.org.br/website/posicionamentos/show.asp?ppsCode=23E36908-D91D-4B00-BB52-33B805469A73. Acesso em 25 ago 2019.

CONGRESSO PARA O NOVO URBANISMO. Carta do novo urbanismo. In: SYKES, A. K. (org.). O campo ampliado da arquitetura: antologia teórica 1993-2009. Tradução de Denise Bottmann e Roberto Grey. [Ed. orig. 2010]. São Paulo: CosacNaify, 2013. p. 53-57.

CORBIOLI, Nanci. Projetos levam em conta custo operacional e impacto ambiental. Projeto Design, n. 332, p. 72-89, out. 2007.

CORBIOLI, Nanci. Fachadas inclinadas atendem à estética e à lógica do mercado. Projeto Design, v. 350, p. 46-57, abr 2009.

CORBIOLI, Nanci. Supremacia do espaço público. Projeto Design, n. 409, p. 64-69, abr 2014.

CORPORAÇÃO FINANCEIRA INTERNACIONAL. EDGE. User guide for offices. Version 2.0, 18 jul. 2017.

CÔRREA, Cristiane. Edifícios sustentáveis: Rochaverá - Aflalo \& Gasperini. São Paulo: C4, 2008. 
COURTNEY, Roger. Building Research Establishment - past, present and future. Building Research \& Information, v. 25, n. 5, p. 285-291, 1997. Doi: 10.1080/096132197370264.

CURTIS, Simon. Global Cities and the Ends of Globalism. New Global Studies, v. 12, n. 1, p. 75-90, 25 abr. 2018. Doi: 10.1515/ngs-2018-0007.

CUTHBERT, Alexander. The form of cities: political economy and urban design. Malden, EUA; Oxford, Inglaterra; Victoria, Austrália: Blackwell Publishing, 2006.

CUTHBERT, Alexander. Understanding cities: method in urban design. Oxford: Routledge, 2011.

DAVIS, Mike. Planeta favela. Posfácio de Ermínia Maricato. Tradução de Beatriz Medina. São Paulo: Boitempo Editorial, 2006.

DELISLE, James; GRISSOM, Terry; HÖGBERG, Lovisa. Sustainable real estate: an empirical study of the behavioural response of developers and investors to the LEED rating system. Journal of Property Investment \& Finance, v. 31, n. 1, p. 10-40, 2013. Doi: 10.1108/14635781311292953.

Desempenho LEED. Anuário GBC 2016, v. 3, n. 9, p. 56-58, jul. 2016.

DGNB (DEUTSCHE GESELLSCHAFT FÜR NACHHALTIGES BAUEN). DGNB - Core and scheme sheet. Offices, version 2014. DGNB, 2014.

DOMINGOS, Roney. Projeto que prevê telhados brancos provoca polêmica na Câmara de SP. G1, 10 out. 2011. Disponível em: http:/g1.globo.com/sao-paulo/noticia/2011/10/projeto-que-preve-telhados-brancos-provoca-polemica-na-camara-de-sp.html. Acesso em 25 ago 2019.

DÓRIA JR., João; WOHNRATH, Ivo. [Programa Show Business] - Caito Maia e Ivo Wohnrath. YouTube, 14 out 2013. Disponível em: https://www.youtube.com/watch?v=jA0PfZ2mAMA. Acesso em 25 ago 2019.

DRORI, Gili S.; MEYER, John W. Global scientization: an environment for expanded organization. In: DRORI, Gili S.; MEYER, John W.; HWANG, Hokyu (org.). Globalization and organization: world society and organizational change. Oxford: Oxford University Press, 2006. p. 50-68.

DRORI, Gili S.; MEYER, John W.; HWANG, Hokyu (org.). Globalization and organization: world society and organizational change. Oxford: Oxford University Press, 2006.

DUNLAP, David W. Saving a spot for Pepsi-Cola as a tower goes up. The New York Times, p. A21, 10 jul. 2013.

DWAIKAT, Luay N.; ALI, Kherun N. Green buildings cost premium: a review of empirical evidence. Energy and Buildings, n. 110, p. 396-403, 2015. Doi: 10.1016/j.enbuild.2015.11.021.

EASTERLING, Keller. Enduring innocence: global architecture and its political masquerades. Cambridge, EUA; Londres, Inglaterra: The MIT Press, 2007.

EASTERLING, Keller. We will be making active form. Architectural design, v. 82, p. 58-63, 2012.

EASTERLING, Keller. Extrastatecraft: the power of infrastructure space. Londres, Nova York: Verso, 2014.

EDITORA FLEX. Estudo de caso - centro empresarial. Ofício: Imobiliário, n. 29, p. 6-10, 3 abr. 1994.

EDWARDS, Brian; PLESSIS, Chrisna du. Snakes in utopia: a brief history of sustainability. Architectural Design, v. 71, n. 4, p. 9-19, jul. 2001.

EHRENFELD, John R. Eco-efficiency: philosophy, theory, and tools. Journal of Industrial Ecology, v. 9, n. 4, p. 6-8, 2005.

EICHHOLTZ, Piet; KOK, Nils; QUIGLEY, Jon. The economics of green building. The Review of Economics and Statistics, v. 95, n. 1, p. 50-63, mar. 2013. Doi: 10.1162/REST_a_00291.

EICHHOLTZ, Piet; KOK, Nils; QUIGLEY, Jon. Doing well by doing good? Green office buildings. The American Economic Review, v. 100, n. 5, p. 2492-2509, dez 2010. Doi: 10.1257/aer.100.5.2492.

ELKINGTON, John. Accounting for the triple bottom line. Measuring Business Excellence, v. 2, n. 3, p. 18-22, 1998.

Emergency housing in Peru. Architectural Design, v. 41, p. 264-265, maio 1971. 
ÉPOCA NEGÓCIOS ONLINE. Empreendimento no Brooklin será o maior de São Paulo. Disponível em: https://epocanegocios.globo.com/Informacao/Acao/noticia/2012/08/empreendimento-no-brooklin-sera-o-maior-de-sao-paulo. html. Acesso em 25 ago 2019.

FARIA, Felipe. MVS - Fórum Março 2016 - Palestra Felipe Faria - GBC Brasil (na íntegra). YouTube, mar 2016. Disponível em: https://www.youtube.com/watch?v=qo53qUqPXdk. Acesso em 25 ago 2019.

FARIA, Felipe. A certificação LEED e os benefícios econômicos dos edifícios verdes - palestrante Felipe Faria. YouTube, 24 mai 2017. Disponível em: https://www.youtube.com/watch?v=iVg0RvUjetw. Acesso em 25 ago 2019.

FARIA, Felipe. (Diretor executivo do GBC Brasil, 2012-atual), Entrevista para o autor, Presencial, 18 dez. 2017, c. $1 \mathrm{~h}$.

FARR, Douglas. Sustainable urbanism: urban design with nature. Hoboken, NJ: John Wiley \& Sons, 2008.

FARR, Douglas. Sustainable nation: urban design patterns for the future. Prefácio de Janette Sadik-Khan ed. Hoboken, NJ: John Wiley \& Sons, 2018.

FAULCONBRIDGE, James; GRUBBAUER, Monika. Transnational building practices: knowledge mobility and the inescapable market. Global networks, v. 15, p. 275-287, 2015.

FAULCONBRIDGE, James; YALCINER, Sercan. Local variants of mobile sustainable building assessment models: the marketization and constrained mutation of BREEAM ES. Global networks, v. 15, p. 360-378, 2015. Doi: 10.1111/ glob.12083.

FEDRIZZI, Rick. Greenthink: how profit can save the planet. Prefácio de Leonardo DiCaprio. Charleston, SC: Disruption Books, 2015.

FEDRIZZI, Rick. Rick Fedrizzi to join the International WELL Building Institute as Chairman. USGBC, 7 jul 2016. Disponível em: https://www.usgbc.org/articles/rick-fedrizzi-join-international-well-building-institute-chairman. Acesso em 25 ago 2019.

FERNANDES, Gabriel de Andrade. Entre ambientes, (contra)culturas e naturezas: o emergente discurso ambiental na literatura dos anos 1960 e 1970 a partir de Buckminster Fuller, Ian McHarg e Murray Bookchin. Dissertação (Mestrado em Paisagem e Ambiente). Orientador: Euler Sandeville Jr.-São Paulo: Faculdade de Arquitetura e Urbanismo da Universidade de São Paulo, 2017.

FERNÁNDEZ-GALIANO, Luis. ¡La economía, ecologistas!: la construcción sostenible ante la crisis del petróleo. Arquitectura viva, n. 105: Etiquetas verdes, p. 23-25, 2005.

FERREIRA, João Sette Whitaker. O mito da cidade-global: o papel da ideologia na produção do espaço urbano. Prefácio de Ermínia Maricato e apresentação de Flávio Villaça ed. Petrópolis, RJ; São Paulo; Salvador: Vozes; Editora UNESP; ANPUR, 2007.

FERREIRA, Paulo Emílio Buarque. Operação Urbana Consorciada Água Espraiada: um novo discurso sobre remoções. Óculum Ensaios, v. 16, n. 2, p. 277-290, 2019. Doi: 10.24220/2318-09 19v16n2a4190.

FIX, Mariana. Parceiros da exclusão: duas histórias da construção de uma "nova cidade" em São Paulo: Faria Lima e Água Espraiada. São Paulo: Boitempo, 2001.

FIX, Mariana. São Paulo cidade global: fundamentos financeiros de uma miragem. São Paulo: Boitempo, 2007.

FIX, Mariana. Uma ponte para a especulação - ou a arte da renda na montagem de uma "cidade global". Caderno CRH, v. 22, n. 55, p. 41-64, jan. 2009.

FORBES, Linda C.; JERMIER, John M. The new corporate environmentalism and The ecology of commerce. Organization \& Environment, v. 23, n. 4, p. 465-481, 2010. Doi: 10.1177/1086026610394639

FOSTER, Hal. O complexo arte-arquitetura. [Ed. orig. 2013]. São Paulo: CosacNaify, 2015.

FOSTER, John Bellamy; CLARK, Brett; YORK, Richard. Capitalism and the curse of energy efficiency: the return of the Jevons Paradox. Monthly Review, v. 62, n. 6, 1 nov. 2010.

FOUCAULT, Michel. The confession of the flesh. In: GORDON, Colin (org.). Power/knowledge: selected interviews and other writings, 1972-1977. Nova York: Pantheon Books, 1980. p. 194-228. 
FRANK, David John; HIRONAKA, Ann; MEYER, John W; SCHOFER, Evan; TUMA, Nancy Brandon. The rationalization and organization of nature in world culture. In: BOLI, John; THOMAS, George M. (org.). Constructing world culture: international nongovernmental organizations since 1875. Stanford, CA: Stanford University Press, 1999. p. 81-99.

FUERST, Franz; MCALLISTER, Patrick. Green noise or green value? Measuring the effects of environmental certification on office values. Real Estate Economics, v. 39, n. 1, p. 45-69, 2011. Doi: 10.1111/j.1540-6229.2010.00286.x.

FUJIHARA, Maria Carolina. (Diretora de comitês técnicos do GBC Brasil, 2013-2016), Entrevista para o autor, Email, 23 nov. 2018.

FUJIMOTO, Nelson Akio. Produção monopolista do espaço urbano e a desconcentração do terciário de gestão na cidade de São Paulo. Dissertação (Mestrado em Geografia Humana). Orientador: Manoel Seabra—São Paulo: Faculdade de Filosofia, Letras e Ciências Humanas da Universidade de São Paulo, 1994.

FUKUYAMA, Francis. The end of history and the last man. Nova York: The Free Press, 1992.

FULLER, Richard Buckminster. Operating manual for spaceship Earth. [s. 1.]: Lars Müller Publishers, 1969.

GABINETE DO PREFEITO. Decreto n. 57.565, de 27 de dezembro de 2016. Regulamenta procedimentos para a aplicação da Quota Ambiental, nos termos da Lei n. 16.402, de 22 de março de 2016. 27 dez. 2016.

GARDE, Ayay. Sustainable by design?: insights from US LEED-ND pilot projects. Journal of the American Planning Association, v. 75, n. 4, p. 424-440, 2009. Doi: 10.1080/01944360903148174.

GAZZONI, Marina. Lei do telhado branco custará cerca de R\$ 380 milhões a São Paulo. IG, 7 jun 2011. Disponível em: https://economia.ig.com.br/lei-do-telhado-branco-custara-cerca-de-r-380-milhoes-a-sao-paulo/n1597009588177. html. Acesso em 25 ago 2019.

GBC BRASIL. Política - Conflito de interesse. GBC Brasil, [s.d.]. Disponível em: http://gbcbrasil.org.br/sistema/pdf/PoliticaConflitoInteresse.pdf. Acesso em: 10 out 2017.

GBC BRASIL. GBC Brasil - Institucional, 6 abr. 2009. Disponível em: https://www.youtube.com/watch?v=S9vaF2NT4Lg. Acesso em 25 ago 2019.

GELINSKI, Gilmara. Recortes suavizam fachada monolítica. Finestra, n. 66, jan. 2011.

GELINSKI, Gilmara. Megacomplexo abriga torres e shopping. Finestra, n. 79, mar. 2013.

GIBSON, Eleanor. New York City mayor moves to ban glass skyscrapers as part of Green New Deal. Dezeen, 24 abr 2019. Disponível em: https://www.dezeen.com/2019/04/24/ban-glass-skyscrapers-new-york-green-new-deal-bill-de-blasio-climate-change/. Acesso em 25 ago 2019.

GLENN, Deborah Snoonian. Green grows up... and up and up and up. Architectural Record, 1 out. 2003.

GOLDEMBERG, José. (Fundador honorário do GBC Brasil), Entrevista para o autor, Presencial, 12 set. 2016, c. 15min.

GONÇALVES, Joana Carla Soares; BODE, Klaus (orgs.). Edifício ambiental. São Paulo: Oficina de Textos, 2015.

GONÇALVES, Joana Carla Soares; UMAKOSHI, Érica M. The environmental performance of tall buildings. Londres; Washington, DC: Earthscan, 2010.

GONÇALVES, Luciana Márcia; RIBEIRO, Rochele Amorim; REZEK, Sarah Finotti; LIMA, Bruno Joaquim. Contradições acerca da sustentabilidade em condomínios horizontais - Certificação ambiental e segregação sócio-espacial. In: IV SIMPÓSIO DE PÓS-GRADUAÇÃO EM ENGENHARIA URBANA. Anais... Passo Fundo, RS: 2015.

GORZ, André. Ecológica. Trad. Celso Azzan Jr. [Ed. orig. 2008]. São Paulo: Annablume, 2010.

GOTTFRIED, David. Greed to green: the transformation of an industry and a life. Prefácio de Paul Hawken. Berkeley, CA: WorldBuild Publishing, 2004.

GOTTFRIED, David. Greening my life: a green building pioneer takes on his most challenging project. Berkeley, CA: Regenerative Publishing, 2010.

GOTTFRIED, David. Explosion green: one man's journey to green the world's largest industry. Prefácio de Paul Hawken. Introdução de Rick Fedrizzi. Nova York: Morgan James, 2014. 
GOTTFRIED, David. (Fundador do USGBC e do World GBC), Entrevista para o autor, Email, 7 jun. 2018.

GOULART, Antonio. Projeto de Lei 01-0615/2009 do Vereador Goulart (PMDB), set. 2009.

GOWDA, Arathi. (Diretora associada no SOM), Entrevista para o autor, Telefone, 24 ago. 2018, c. 30 min.

GRAHAM, Dan; WALLIS, Brian (org.). Rock my religion: writings and projects 1965-1990. Cambridge, MA: Massachusetts Institute of Technology, 1993.

GRAZZIANO, Raphael. A perspectiva tecnológica da sustentabilidade ambiental: Buckminster Fuller e a arquitetura dos anos 2000. Óculum Ensaios, v. 15, n. 1, p. 111-128, 2018. Doi: 10.24220/2318-0919v15n1a3374.

GREEN BUILDING COUNCIL BRASIL (GBC BRASIL). Estatuto do Green Building Council - Brasil, s/d. GBC Brasil. Disponível em: http://www.gbcbrasil.org.br/pdf/Modelo_publicacao_site_05_07_2016.pdf. Acesso em: 17 abr 2018.

GRUNOW, Evelise; HERMAN, Luiz Felipe Aflalo; LEMOS NETO, José Luiz; AFLALO FILHO, Roberto; ROCHA, Grazzielli Gomes. Entrevista: “Sabíamos que não dependíamos de uma pessoa apenas”. Projeto Design, v. 424, agosto 2015.

GUERREIRO, Isadora de Andrade. Arquitetura-capital: a funcionalidade dos edifícios corporativos paulistas. Dissertação (Mestrado em Projeto, Espaço e Cultura). Orientadora: Vera Maria Pallamin_São Paulo: Faculdade de Arquitetura e Urbanismo da Universidade de São Paulo, 2010.

GUILES JR., Ellis G. Building professional accreditation, construction quality control and better buildings. ASHRAE Transactions, v. 117, n. 1, p. 170-177, 2011.

GUNN, Philip. O New Urbanism e o revival escapista de mercado. Risco: Revista de Pesquisa em Arquitetura e Urbanismo, v. 2, n. 2, p. 105-107, 2005.

HARRIS, Paul. Bush covers up climate change. The Guardian, 21 set. 2003, seç. Environment. Disponível em: https://www. theguardian.com/environment/2003/sep/21/usnews.georgewbush. Acesso em 25 ago 2019.

HART, David M. Don't worry about the government? LEED Green Building Rating System and Energy Efficiency in US Commercial Buildings. MIT Industrial Performance Center. Energy Innovation Working Paper, n. 09-001, p. 1-23, mar. 2009.

HARVEY, David. Justice, nature and the geography of difference. Cambridge, Massachusetts; Oxford, UK: Blackwell Publishers, 1996.

HARVEY, David. The New Urbanism and the communitarian trap. Harvard Design Magazine, n. 1, inverno-primavera 1997.

HARVEY, David. What's green and makes the environment go round? In: JAMESON, Fredric; MIYOSHI, Masao (orgs.). The cultures of globalization. Durnham; Londres: Duke University Press, 1998. p. 327-355.

HARVEY, David. A brief history of neoliberalism. Nova York: Oxford University Press, 2005.

HAWKEN, Paul. The ecology of commerce: a declaration of sustainability. Nova York: HarperCollins Publishers, 1993.

HEPNER, Alexandre. Desenho urbano, capital e ideologia em São Paulo: centralidade e forma urbana na marginal do rio Pinheiros. Dissertação (Mestrado em Paisagem e Ambiente). Orientador: Silvio Soares Macedo-São Paulo: Faculdade de Arquitetura e Urbanismo da Universidade de São Paulo, 2010.

HEPNER, Christina M.; BOSER, Richard A. Architect's perceptions of LEED Indoor Environmental Quality checklist items on employee productivity. International Journal of Construction Education and Research, v. 2, n. 3, p. 193-208, 2006. Doi: 10.1080/15578770600907156.

HIRT, Sonia A. Premodern, modern, postmodern? Placing New Urbanism into a historical perspective. Journal of Planning History, v. 8, n. 3, p. 248-273, ago. 2009. Doi: 10.1177/1538513209338902.

HITCHCOCK, Henry-Russell; DANZ, Ernst. SOM: Architecture of Skidmore, Owings \& Merrill, 1950-1962. Introdução de 1961. New York: The Monacelli Press, 2009.

HOLUSHA, John. Technology in the front seat at 4 Times Square. The New York Times, 30 mar. 1997. Disponível em: https://www.nytimes.com/1997/03/30/realestate/technology-in-the-front-seat-at-4-times-square.html. Acesso em 25 ago 2019. 
HONDA, Wilson Saburo. Certificação da sustentabilidade de edifícios de escritórios corporativos no Brasil. Tese (Doutorado em Engenharia da Construção Civil e Urbana). Orientador: João da Rocha Lima Jr.-São Paulo: Escola Politécnica da Universidade de São Paulo, 2016.

HOPKINS-CLEGG, Kristin. (Diretora associada em Pelli Clarke Pelli), Entrevista para o autor, Telefone, 6 jun. 2018, c. 40min.

HUI, Eddie Chi-Man; CHAN, Eric Wing-Fai; YU, Ka-Hung. The effect of LEED certification on Shanghai's pime office rental value. Journal of Facilities Management, v. 13, n. 3, p. 297-310, 2015. Doi: 10.1108/JFM-10-2014-0033.

IG SÃO PAULO. Maria Clara Coracini deixa DuPont e vai para a ONG GBC Brasil. Disponível em: https://economia.ig.com. $\mathrm{br} /$ carreiras/maria-clara-coracini-deixa-dupont-e-vai-para-a-ong-gbc-brasil/n1238080990703.html. Acesso em 25 ago 2019.

IKERT, Fernanda. A discussão da certificação LEED na relação edifício-cidade: explorando casos brasileiros. Dissertação (Mestrado em Urbanismo, História e Arquitetura da Cidade). Orientadora: Lisete Assen de Oliveira-Florianópolis: Departamento de Arquitetura e Urbanismo da Universidade Federal de Santa Catarina, 2010.

ILLICH, Ivan. A convivencialidade. Trad. de Arsênio Mota [Ed. orig. 1973]. Lisboa: Publicações Europa-América, 1976.

INTERNATIONAL ENERGY AGENCY. The future of cooling: opportunities for energy-efficient air conditioning. [s.l.] IEA Publications, 2018.

INTERNATIONAL LIVING FUTURE INSTITUTE. Living Building Challenge 3.1. International Living Future Institute, 2016.

INTERNATIONAL WELL BUILDING INSTITUTE. The WELL building standard v1 with Q4 2017 addenda. Delos Living, 2017.

JACOB, Marie-Andrée; RILES, Annelise. The new bureaucracies of virtue: introduction. PoLAR: Political and Legal Anthropology Review, v. 30, n. 2, p. 181-191, 2007. Doi: 10.1525/pol.2007.30.2.181.

JAMESON, Fredric. The brick and the balloon: architecture, idealism and land speculation. In: The cultural turn: selected writings on the postmodern, 1983-1998. Londres, Nova York: Verso, 1998. p. 162-189.

JAMESON, Fredric. Pós-modernismo: a lógica cultural do capitalismo tardio. $2^{\mathrm{a}}$ ed. São Paulo: Editora Ática, 2007.

JÄNICKE, Martin; BLAZEJCZAK, Jürgen; EDLER, Dietmanr; HEMMELSKAMP, Jens. Environmental policy and innovation: an international comparison of policy frameworks and innovation effects. In: HEMMELSKAMP, Jens; RENNINGS, Klaus; LEONE, Fabio (orgs.). Innovation-oriented environmental regulation. Theoretical Approaches and Empirical Analysis. Heidelberg: Springer, 2000. p. 125-152.

JÄNICKE, Martin. Ecological modernisation: new perspectives. Journal of Cleaner Production, v. 16, p. 557-565, 2008. Doi: 10.1016/j.jclepro.2007.02.011.

JENCKS, Charles. The language of post-modern architecture. $2^{\mathrm{a}}$ ed. Londres: Academy Editions, 1978.

JENCKS, Charles. Skyscrapers-Skyprickers-Skycities. Londres: Academy Editions, 1980.

JEVONS, William Stanley. The coal question: an inquiry concerning the progress of the nation, and the probable exhaustion of our coal-mines. [Ed. orig. 1865]. Londres: Macmillan, 1906.

JONES, Geoffrey. Profits and sustainability: a history of green entrepreneurship. Oxford: Oxford University Press, 2017.

KATZ, Peter. The new urbanism: toward an architecture of community. Posfácio de Vincent Scully. Ensaios de Todd W. Bressi, Andres Duany, Elizabeth Moule, Stefanos Polyzoides e Elizabeth Plater-Zyberk ed. Nova York: McGraw-Hill, 1994.

KEYNES, John Maynard. The general theory of employment, interest and money. Introdução de Paul Krugman. Posfácio de Robert Skidelksy. [Ed. orig. 1935]. Cambridge, UK: Palgrave Macmillan, 2018.

KIPNIS, Andrew P. Audit cultures: neoliberal governmentality, socialist legacy, or technologies of governing? American Ethnologist, v. 35, n. 2, p. 275-289, 2008. Doi: 10.1111/j.2008.1548-1425.00034.x. 
KONAK, Nahide. Ecological modernization and eco-marxist perspectives: globalization and gold mining development in Turkey. Capitalism Nature Socialism, v. 19, n. 4, dez 2008. Doi: 10.1080/10455750802571264.

LAMPRECHT, James L. Implementing the ISO 9000 series. Nova York: Marcel Dekker, 1993.

LANGDON, Philip. A better place to live: reshaping the American suburb. Amherst: The University of Massachusetts Press, 1994.

LAYRARGUES, Philippe Pomier. A cortina de fumaça: o discurso empresarial verde e a ideologia da racionalidade econômica. São Paulo: Annablume, 1998.

LEAL, Ledy Valporto. Inclinação para o verde. aU - Arquitetura \& Urbanismo, p. 36-45, ago 2008.

LEFEBVRE, Henri. La révolution urbaine. Paris: Gallimard, 1970.

LEFEBVRE, Henri. Le droit à la ville. 3a. ed. Paris: Economica, 2009.

LEME, Alvaro. Thassanee Wanick contra o aquecimento global. Veja São Paulo, 18 set 2009. Disponível em: http://vejasp. abril.com.br/materia/thassanee-wanick-contra-aquecimento-global. Acesso em 25 ago 2019.

LEON, Joshua K. Global cities at any cost. City: analysis of urban trends, culture, theory, policy, action, v. 21, n. 1, p. 6-24, 2017. Doi: $10.1080 / 13604813.2016 .1263491$.

LONG, Marisa. GBCI joins forces with GRESB. USGBC, 15 out 2014. Disponível em: https://www.usgbc.org/articles/gbci-joins-forces-gresb. Acesso em 25 ago 2019.

LORENZ, David; LÜTZKENDORF, Thomas. Sustainability in property valuation: theory and practice. Journal of Property Investment \& Finance, v. 26, n. 6, p. 482-521, 2008. Doi: 10.1108/14635780810908361.

LOVINS, Amory B.; LOVINS, L. Hunter; HAWKEN, Paul. Natural capitalism: the next industrial revolution. Washington DC: US Green Building Council, 2000.

MAKI, Luciana; NOGUEIRA, Luiz. (Arquitetos no aflalo/gasperini arquitetos), Entrevista para o autor, Presencial, 5 fev. 2019, c. 1 h.

MALERONKA, Camila; HOBBS, Jason. Operações Urbanas: o que podemos aprender com a experiência de São Paulo? Notas técnicas n. IDB-TN-1355. Banco Interamericano de Desenvolvimento, dez. 2017.

MARCONDES, Flávia. (Diretora associada no aflalo/gasperini arquitetos), Entrevista para o autor, Presencial, 27 set. 2016, c. $45 \mathrm{~min}$.

MARCUSE, Peter. The New Urbanism: the dangers so far. disP - The Planning Review, v. 36, n. 140, p. 4-6, 2000. Doi: 10.1080/02513625.2000.10556727.

MARINS, Luiz; WOHNRATH, Ivo. Programa Show Business - Ivo Wohnrath. YouTube, 27 set 2016. Disponível em: https:// www.youtube.com/watch?v=hJICnnTQs48\&list=PLb_X8C8ocZw8cQVFpeiHJNpnmSJzD47Y4\&index=16. Acesso em 25 ago 2019.

MARTIN, Reinhold. The organizational complex: architecture, media, and corporate space. Cambridge, Massachusetts: The MIT Press, 2005.

MARTIN, Reinhold. Utopia's ghost: architecture and postmodernism, again. Minneapolis, Londres: University of Minnesota Press, 2010.

MARTIN, Reinhold. Financial imaginaries: toward a philosophy of the city. Grey Room, n. 42, p. 60-79, inverno 2011. Doi: 10.1162/GREY_a_00018.

MARTINEZ, Victor. CDHU adere à campanha One Degree Less para diminuir a temperatura do entorno. Piniweb, 4 nov 2009. Disponível em: <http://piniweb17.pini.com.br/construcao/sustentabilidade/cdhu-adere-a-campanha-para-diminuir-a-temperatura-do-entorno-151013-1.aspx>. Acesso em: 27 nov. 2018.

MAYS, Jeffrey C. De Blasio’s “ban” on glass and steel skyscrapers isn’t a ban at all. The New York Times, p. A23, 25 abr. 2019.

MCDONOUGH, William; BRAUNGART, Michael. Cradle to cradle: remaking the way we make things. Nova York: North Point Press, 2002. 
MCHARG, Ian L. Design with nature. $2^{\mathrm{a}}$ ed. [1ª ed. 1969]. [s.l.] John Wiley \& Sons, 1992.

MEADOWS, D. H. et al. Limites do crescimento. [Ed. orig. 1972]. São Paulo: Perspectiva, 1978.

MEDEIROS, Heloísa. Fachada ajustável. Téchne, n. 197, p. 40-44, ago 2013.

MENDEL, Peter. The making and expansion of international management standards: the global diffusion of ISO 9000 quality management certificates. In: DRORI, Gili S.; MEYER, John W.; HWANG, Hokyu (org.). Globalization and organization: world society and organizational change. Oxford: Oxford University Press, 2006. p. 137-166.

MOHNEY, David; EASTERLING, Keller. Seaside: making a town in America. New York: Princeton Architectural Press, 1991.

MOL, Arthur P. J. The environmental movement in an era of ecological modernisation. Geoforum, n. 31, p. 45-56, 2000. Doi: 10.1016/S0016-7185(99)00043-3.

MONTANER, Josep Maria. Belleza de las arquitecturas tecnológicas. In: La modernidad superada: arquitectura, arte y pensamiento del siglo XX. $2^{\text {a }}$ ed. Barcelona: Editorial Gustavo Gili, 1998. p. 207-222.

MOON, Hyeyoung; WOTIPKA, Christine Min. The worldwide diffusion of business education, 1881-1999: historical trajectory and mechanisms of expansion. In: DRORI, Gili S.; MEYER, John W.; HWANG, Hokyu (org.). Globalization and organization: world society and organizational change. Oxford: Oxford University Press, 2006. p. $121-136$.

Most expensive buildings in South America. Emporis. Disponível em: https://www.emporis.com/statistics/most-expensive-buildings/continent/100003/south-america. Acesso em 25 ago 2019.

MOSTAFAVI, Mohsen; DOHERTY, Gareth. Ecological urbanism. Londres: Lars Müller Publishers, 2010.

MOULIN NETTO, José. (Co-fundador do GBC Brasil), Entrevista para o autor, Presencial, 4 dez. 2017, c. 30min.

MOZINGO, Louise A. Pastoral capitalism: a history of suburban corporate landscapes. Cambridge, Massachusetts; Londres: The MIT Press, 2011.

MUSCHAMP, Herbert. Miami virtue: Arquitectonica’s low-rent housing. The New York Times, p. 2002028, 11 jul. 1993.

MUSCHAMP, Herbert. Smaller is better: Conde Nast in Times Sq. The New York Times, p. 1001021, 18 maio 1996.

NAKASHIMA, Takuji. (Arquiteto no aflalo/gasperini arquitetos, 2000-2016), Entrevista para o autor, Telefone, 29 jan. 2019 , c. $50 \mathrm{~min}$.

NEWSHAM, Guy R.; MANCINI, Sandra; BIRT, Benjamin J. Do LEED-certified buildings save energy? Yes, but... Energy and Buildings, n. 41, p. 897-905, 2009. Doi: 10.1016/j.enbuild.2009.03.014.

NOBRE, Eduardo Alberto Cusce. Reestruturação econômica e território: expansão recente do terciário na marginal do rio Pinheiros. Tese (Doutorado). Orientadora: Gilda Collet Bruna-São Paulo: Faculdade de Arquitetura e Urbanismo da Universidade de São Paulo, 2000.

NOMURA, Maria Carolina. Especialistas divergem sobre selo. Folha de São Paulo, 8 jul. 2007, seç. Construção.

OLIVEIRA, Marta Eliza de. Grandes empreendimentos, Novo Urbanismo e imagem ambiental no Setor Noroeste, em Brasília. Tese (Doutorado em Gestão Territorial e Urbana). Orientadora: Lúcia Cony Faria Cidade-Brasília: Departamento de Geografia - Instituto de Ciências Humanas da Universidade de Brasília, 2016.

OLIVEIRA, Thiago. Sustentável desde o canteiro. Téchne, n. 125, ago. 2007.

ORGANIZAÇÃO DAS NAÇÕES UNIDAS. Montreal Protocol on Substances that Deplete the Ozone Layer, 1987. Disponível em: http://www.un-documents.net/mpsdol.htm. Acesso em 25 ago 2019.

Our story. World GBC. Disponível em: https://www.worldgbc.org/our-story. Acesso em 20 nov. 2018.

OUROUSSOFF, Nicolai. Pride and nostalgia mix in The Times's new home. The New York Times, p. E1, 20 nov. 2007.

PAEHLKE, Robert. Environmentalism and the future of progressive politics. New Haven, Londres: Yale University Press, 1989.

PAIVA, Cida; SILVA, Jaime. Vidros vedam e criam estruturas. Finestra, p. 26-41, jun. 2008. 
PANERAI, Philippe; CASTEX, Jean; DEPAULE, Jean Charles; SAMUELS, Ivor. Urban forms: the death and life of the urban block. Oxford: Architectural Press; Elsevier, 2004.

PAPANEK, Victor. Design for the real world: human ecology and social change. 2a. ed. Londres: Thames \& Hudson, 1984.

PERCIO, Stephen T. Del. The skyscraper, green design, \& the LEED green building rating system: the creation of uniform sustainable standards for the 21st century or the perpetuation of an architectural fiction? Environs: Environmental Law and Policy Journal, v. 28, n. 1, p. 117-154, 2004.

PEREIRA, Álvaro Luís dos Santos. A montagem de enclaves financeiros numa metrópole periférica: verso e reverso do planejamento urbano. Dissertação (Mestrado). Orientadora: Ana Maria de Oliveira Nusdeo-São Paulo: Faculdade de Direito da Universidade de São Paulo, 2011.

PEREIRA, Álvaro Luís dos Santos. Intervenções em centros urbanos e conflitos distributivos: modelos regulatórios, circuitos de valorização e estratégias discursivas. Tese (Doutorado)—São Paulo: Faculdade de Direito da Universidade de São Paulo, 2015.

PETINELLI, Guido. (Rector of Council Development no World GBC, 2006-2008; Co-fundador do GBC Brasil), Entrevista para o autor, Telefone, 1 maio 2018, $1 \mathrm{~h} 15 \mathrm{~min}$.

PISELLO, Anna Laura. State of the art on the development of cool coatings for buildings and cities. Solar Energy, v. 144, p. 660-680, mar. 2017. Doi: 10.1016/j.solener.2017.01.068.

POLIMENI, John M.; MAYUMI, Kozo; GIAMPIETRO, Mario; ALCOTT, Blake. The Jevons paradox and the myth of resource efficiency improvements. Londres: Earthscan, 2008.

PORTO, Paola Torneri. Método para gestão de portfólios de investimentos em edifícios de escritórios para locação no Brasil. Tese (Doutorado em Engenharia de Construção Civil e Urbana). Orientador: João da Rocha Lima Jr.-São Paulo: Escola Politécnica da Universidade de São Paulo, 2010.

POWER, Michael. The audit society: rituals of verification. Oxford: Oxford University Press, 1997.

Prêmio AsBEA 2008: Prêmio Roberto Cláudio dos Santos Aflalo - Aflalo \& Gasperini Arquitetos. Projeto Design, n. 346, dez. 2008.

PRESAS, Luciana Melchert Saguas; MOL, Arthur P. J. Ecologizando edifícios transnacionais: entre fluxos globais e espaços locais. Ambiente \& Sociedade, v. VII, n. 1, p. 9-25, jun. 2004. Doi: 10.1590/S1414-753X2004000100002.

Projeto de Lei 01-00568/2015 do Executivo. 28 out. 2015.

Prospecto definitivo de oferta pública de distribuição de cotas do Fundo de Investimento Imobiliário - FII BTG Pactual Corporate Office Fund. Merril Lynch Brasil, 8 jan. 2013. Disponível em: http://www.merrilllynch-brasil.com.br/pdf/ FII\%20BTG\%20PACTUAL/prospecto\%20definitivo\%2020130107.pdf. Acesso em: 8 jan. 2017.

Prospecto definitivo de oferta pública de distribuição primária e secundária de ações ordinárias de emissão da BR Properties. Safra, 4 mar. 2010. Disponível em: http://www.safranet.com.br/ADS/Download/15_2-2-2012_8-41-03_ PM.pdf. Acesso em: 5 nov. 2016.

PRZYCHODZEN, Justyna; PRZYCHODZEN, Wojciech. Corporate sustainability and shareholder wealth. Journal of Environmental Planning and Management, v. 56, n. 4, p. 474-493, mai 2013. Doi: 10.1080/09640568.2012.685927.

PUBLIEDITORIAL. Vidros eficientes em fachadas esculturais. Finestra, v. 20, n. 95, nov. 2015.

PUFF, Jefferson. 'Como é que você vai botar o pobre ali?', diz bilionário 'dono da Barra da Tijuca'. BBC Brasil, 10 ago 2015. Disponível em: https://www.bbc.com/portuguese/noticias/2015/08/150809_construtora_olimpiada_jp. Acesso em 25 ago 2019.

RAITH, Alexandre. Tecnologia de baixo impacto. Revista Infra, n. 181, 14 dez. 2015.

RAMOS, Murilo. Mantega pressionou fundo de pensão a investir em empreendimento da Odebrecht. Época, 23 set. 2016.

REICHARDT, Alexander; FUERST, Franz; ROTTKE, Nico B.; ZIETZ, Joachim. Sustainable building certification and the rent premium: a panel data approach. Journal of Real Estate Research, v. 34, n. 1, p. 99-126, 2012. 
REOLOM, Mônica. Evento festeja o Elephant's Day na capital paulista. O Estado de S. Paulo, ago 2015, seç. Sustentabilidade. Disponível em: https:/sustentabilidade.estadao.com.br/noticias/geral,evento-festeja-o-elephants-day-na-capital-paulista,1743039. Acesso em 25 ago 2019.

ROSATO, Donald V.; DIMATTIA, David P.; ROSATO, Dominick V. Designing with plastics and composites: a handbook. Nova York: Springer Science+Business Media, 1991

SANDOVAL, Pavel; PRAKASH, Aseem. The Gold Rush: the popularity of the Gold tier in LEED certification. Environmental Policy and Governance, v. 26, p. 543-555, 2016. Doi: 10.1002/eet.1724.

SANFELICI, Daniel de Mello. A metrópole sob o ritmo das finanças: implicações socioespaciais da expansão imobiliária no Brasil. Tese (Doutorado em Geografia Humana). Orientadora: Amélia Luísa Damiani-São Paulo: Departamento de Geografia - Faculdade de Filosofia, Letras e Ciências Humanas da Universidade de São Paulo, 2013.

SANTOS, Michelle Schneider. Entre a transparência e a espessura: a moderna fachada do edifício comercial americano 19451975. Tese (Doutorado em Arquitetura e Urbanismo). Orientação de Ruth Verde Zein—São Paulo: Universidade Presbiteriana Mackenzie, 2016.

SARTORI, Adriano. (Vice-presidente CBRE Brasil), Entrevista para o autor, Email, 31 nov. 2017.

SASSEN, Saskia. The global city: New York, London, Tokyo. Princeton, EUA; Oxford, Reino Unido: Princeton University Press, 1991.

SASSEN, Saskia. The global city: introducing a concept. The Brown Journal of World Affairs, v. XI, n. 2, p. 27-43, 2005.

SASSEN, Saskia. As diferentes especializações das cidades globais. In: Cidades sul-americanas: assegurando um futuro urbano. São Paulo: Imprensa Oficial, 2008. p. 4-6.

SASSEN, Saskia. Expulsions: Brutality and complexity in the global economy. Cambridge, USA: The Belknap Press of Harvard University Press, 2014.

SCHLOSBERG, David; RINFRET, Sata. Ecological modernisation, American style. Environmental Politics, v. 17, n. 2, p. 254-275, 2008. Doi: 10.1080/09644010801936206.

SCHUMACHER, Ernst F. Small is beautiful: economics as if people mattered. Londres: Blond \& Briggs, 1973.

SCOTT, Felicity D. Architecture and techno-utopia: politics after modernism. Cambridge, Massachusetts; Londres: The MIT Press, 2007.

SERAPIÃO, Fernando. Esqueletos no armário. Projeto Design, n. 368, p. 74-81, out 2010.

SERAPIÃO, Fernando. A arquitetura de Croce, Aflalo e Gasperini. São Paulo: Editora Paralaxe, 2011.

SERAPIÃO, Fernando (ed.). Monolito, v. Extra: Aflalo \& Gasperini Arquitetos. São Paulo: Editora Monolito, 2012.

SHARIFI, Ayyoob; MURAYAMA, Akito. A critical review of seven selected neighborhood sustainability assessment tools. Environmental Impact Assessment Review, v. 38, p. 73-87, 2013. Doi: 10.1016/j.eiar.2012.06.006.

SHELLENBERGER, Michael; NORDHAUS, Ted. The death of environmentalism: global warming politics in a post-environmental world. Social Policy, p. 19-30, 2005.

SIMCOE, Timothy; TOFFEL, Michael W. Government green procurement spillovers: evidence from municipal building policies in California. Journal of Environmental Economics and Management, n. 68, p. 411-434, 2014. Doi: 10.1016/j. jeem.2014.09.001.

SKAER, Mark. The 1990s: the decade of refrigerant chaos - and change. ACHR News, 25 abr. 2001. Disponível em: https:// www.achrnews.com/articles/84856-the-1990s-the-decade-of-refrigerant-chaos-8212-and-change. Acesso em 25 ago 2018 .

SMITH, Russell M. Planning for urban sustainability: the geography of LEED ${ }^{\circledR}$ - Neighborhood Development ${ }^{\mathrm{TM}}\left(\mathrm{LEED}^{\circ}-\right.$ $\mathrm{ND}^{\mathrm{TM}}$ ) projects in the United States. International Journal of Urban Sustainable Development, v. 7, n. 1, p. 15-32, 2 jan. 2015. Doi: 10.1080/19463138.2014.971802.

SONG, Yan; STEVENS, Mark R.; GAO, Jie; BERKE, Philip R.; CHEN, Yanping. An examination of early New Urbanist 
developments in the United States: where are they located and why? Cities, n. 61, p. 128-135, 2017. Doi: 10.1016/j. cities.2016.08.013.

SPAARGAREN, Gert. Ecological modernization theory and the changing discourse on environment and modernity. In: SPAARGAREN, Gert; MOL, Arthur P. J.; BUTTEL, Frederick H. (orgs.). Environment and global modernity. Londres, Reino Unido; Thousand Oaks, EUA; Nova Delhi, Índia: SAGE Publications, 2000. p. 41-71.

STEPHENS, Suzanne. Fox \& Fowle creates a collage in Four Times Square, using skyscrapers past and present and a touch of "green". Architectural Record, p. 90-97, mar. 2000.

STEPHENS, Suzanne. The New York Times Building. Architectural Record, 19 fev. 2008. Disponível em: https://www.architecturalrecord.com/articles/8081-the-new-york-times-building. Acesso em 25 ago 2019.

Sustainability standards. ASTM. Disponível em: https://www.astm.org/Standards/sustainability-standards.html. Acesso em: 11 set. 2018.

TABB, Phillip James; DEVIREN, A. Senem. The greening of architecture: a critical history and survey of contemporary sustainable architecture and urban design. Surrey, Inglaterra; Burlington, EUA: Ashgate Publishing, 2013.

TAFURI, Manfredo. Theories and history if architecture. [4a ed. orig. 1976; $1^{\mathrm{a}}$ ed orig. 1968]. Nova York: Harper \& Row Publishers, 1980.

TAFURI, Manfredo. Projecto e utopia: arquitetura e desenvolvimento do capitalismo. [Ed. orig. 1973]. Lisboa: Editorial Presença, 1985.

TAKAOKA, Marcelo V. Diretrizes de ação (revisão 1, em junho de 2013). CBCS, maio 2013. Disponível em: http://www. cbcs.org.br/website/institucional/show.asp?ppgCode=CA4D48EC-82E0-4FED-BAF7-11E3DACBE63B. Acesso em 25 ago 2019.

TEIXEIRA, Regiane; CORREA, Vanessa. "Pele de vidro" se torna padrão para edifícios corporativos em SP. Folha de São Paulo, 11 maio 2013.

TEMPLETON, Peter. (Vice-diretor de Desenvolvimento de Mercado Global do USGBC), Entrevista para o autor, Telefone, 20 abr. 2018, c. 1 h15min

TODD, Joel Ann; PYKE, Chris; TUFTS, Robert. Implications of trends in LEED usage: rating system design and market transformation. Building Research \& Information, v. 41, n. 4, p. 384-400, 2013. Doi: 10.1080/09613218.2013.775565.

TURNER, Fred. A technocrat for the counterculture. AV Monografías, n. 143: Buckminster Fuller 1895-1983, p. 102-115, jun. 2010.

Um panorama do LEED e sua internacionalização. Anuário GBC 2015, n. 4, p. 18-22, jul. 2015.

USGBC (UNITED STATES GREEN BUILDING COUNCIL). LEED certification deadlines. Disponível em: <https://new. usgbc.org/cert-guide/deadlines>. Acesso em 25 ago 2019.

USGBC (UNITED STATES GREEN BUILDING COUNCIL). LEED green building rating system 1.0. Washington, DC: USGBC, 1999.

USGBC (UNITED STATES GREEN BUILDING COUNCIL). Green building rating system for new construction \& major renovations (LEED NC). Version 2.1. Washington, DC: USGBC, 2003.

USGBC (UNITED STATES GREEN BUILDING COUNCIL). LEED for Homes rating system. Washington, DC: USGBC, jan. 2008.

USGBC (UNITED STATES GREEN BUILDING COUNCIL). LEED 2009 for new construction and major renovations with alternative compliance paths for projects outside the US; v. 3 reference guide. Washington, DC: USGBC, 2011a.

USGBC (UNITED STATES GREEN BUILDING COUNCIL). LEED 2009 for core and shell development. Washington, DC: USGBC, ago. 2011b.

USGBC (UNITED STATES GREEN BUILDING COUNCIL). LEED $v 4$ for building design and construction. Washington, DC: USGBC, 5 abr. 2016. 
USGBC (UNITED STATES GREEN BUILDING COUNCIL). LEED $v 4$ for interior design and construction. Washington, DC: USGBC, 2 jul. 2018.

USGBC (UNITED STATES GREEN BUILDING COUNCIL); CONGRESS FOR THE NEW URBANISM; NATURAL RESOURCES DEFENSE COUNCIL. LEED 2009 for neighborhood development rating system. Washington, DC: USGBC, 2011.

VILLAÇA, Flávio. Espaço intra-urbano no Brasil. 2a ed. São Paulo: Studio Nobel; Fapesp; Lincoln Institute, 2001.

WAIB, Sergio; WOHNRATH, Ivo. Giro Business com Ivo Wohnrath - História e tendências da arquitetura corporativa Parte 03/04. YouTube, 3 abr 2017. Disponível em: https://www.youtube.com/watch?v=4EtxltIYx70. Acesso em 25 ago 2019.

WALlHAGEN, Marita; GLAUMANN, Mauritz. Design consequences of differences in building assessment tools: a case study. Building Research \& Information, v. 39, n. 1, p. 16-33, 2011. Doi: 10.1080/09613218.2010.513210.

WANICK, Thassanee. (Fundadora do GBC Brasil), Entrevista para o autor, Telefone, 24 jan. 2017, c. 1h15min.

WEEKS, Katie; LAMBERT, Sophie. A deeper look at LEED-ND. Architect, 3 jun 2010. Disponível em: https://www.architectmagazine.com/technology/a-deeper-look-at-leed-nd_o. Acesso em 25 ago 2019.

WEHBA, Cristina. Novas relaçães de produção imobiliária na metrópole do século XXI: Odebrecht, Água Espraiada e o Parque da Cidade em São Paulo. Dissertação (Mestrado em Planejamento Urbano e Regional). Orientadora: Maria Beatriz Cruz Rufino-São Paulo: Faculdade de Arquitetura e Urbanismo da Universidade de São Paulo, 2018.

WINES, James. Green architecture. Colônia: Taschen, 2000.

WORLD COMISSION ON ENVIRONMENT AND DEVELOPMENT. Our common future. Organização das Nações Unidas, 1987. Disponível em: http://www.un-documents.net/our-common-future.pdf. Acesso em 25 ago 2019.

WTorre S.A. Demonstrações financeiras em 31 de dezembro de 2014. WTorre, dez 2014. Disponível em: http://www.wtorre. com.br/_docs/WTorreSA/Demonstracoes_Financeiras_4T14.pdf. Acesso em 25 ago 2019.

YANG, Tânia. (Arquiteta no aflalo/gasperini arquitetos), Entrevista para o autor, Telefone, 27 fev. 2019, c. 1h.

YORK, Richard. Ecological paradoxes: William Stanley Jevons and the paperless office. Human Ecology Review, v. 13, n. 2, p. 143-147, 2006.

YUDELSON, Jerry. The green building revolution. Prefácio de Rick Fedrizzi ed. Washington, DC; Covelo, CA; Londres: Island Press, 2008.

YUDELSON, Jerry. Reinventing green building: why certification systems aren't working and what we can do about it. Prefácio de Pamela Lippe. Gabriola Land, Canada: New Society Publishers, 2016.

ZANETTINI, Siegbert. (Fundador honorário do GBC Brasil), Entrevista para o autor, Telefone, 1 nov. 2016, c. 40min.

ZEHR, Stephen. The sociology of global climate change. WIREs Climate Change, v. 6, p. 129-150, mar. 2015. Doi: 10.1002/ wcc.328.

ZUKIN, Sharon. Landscapes of power: from Detroit to Disney World. Berkeley, CA: University of California Press, 1991. 


\section{VERSÕES PRELIMINARES}

Versões preliminares de partes da tese e mesmo materiais dela suprimidos foram publicados em periódicos e anais de eventos. O artigo "A perspectiva tecnológica da sustentabilidade ambiental: Buckminster Fuller e a arquitetura dos anos 2000", que seria inicialmente parte de um dos capítulos, foi publicado na revista Óculum Ensaios, v. 15, n. 1, em 2018, páginas 111 a 128. O conteúdo desse artigo terminou por ficar quase ausente da tese, salvo em algumas passagens do capítulo 7. A conferência "Urbanismo corporativo com certificação internacional: uso e contradição do LEED ${ }^{\circledast}$ ND no Parque da Cidade" foi apresentada no V Encontro da Associação Nacional de Pesquisa e Pós-Graduação em Arquitetura e Urbanismo, ocorrido na Universidade Federal da Bahia em 2018, posteriormente publicada no primeiro volume de seus anais, páginas 1444 a 1459. Naquela versão, pode ser encontrada a primeira redação do que seria depois o capítulo 10. Já a conferência “Recent transformations in the 'global city' concept: analysing green buildings in São Paulo", apresentada na conferência Through Local Eyes: Place-based approaches to emerging architectural, urban design and planning challenges in Africa and the Global South, ocorrida em Adis Abeba, Etiópia, teve apenas o resumo publicado. A conferência vinculou estudos preparatórios de materiais que constam nos capítulos 8 e 11. 